Prepared for the U.S. Department of Energy

under Contract DE-AC05-76RL01830

\title{
Assessment of the LV-C2 Stack Sampling Probe Location for Compliance with ANSI/HPS N13.1-1999
}
JA Glissmeyer
EJ Antonio
JE Flaherty

September 2015

Pacific Northwest

NATIONAL LABORATORY

Proudly Operated by Battelle Since 1965 


\title{
DISCLAIMER
}

This report was prepared as an account of work sponsored by an agency of the United States Government. Neither the United States Government nor any agency thereof, nor Battelle Memorial Institute, nor any of their employees, makes any warranty, express or implied, or assumes any legal liability or responsibility for the accuracy, completeness, or usefulness of any information, apparatus, product, or process disclosed, or represents that its use would not infringe privately owned rights. Reference herein to any specific commercial product, process, or service by trade name, trademark, manufacturer, or otherwise does not necessarily constitute or imply its endorsement, recommendation, or favoring by the United States Government or any agency thereof, or Battelle Memorial Institute. The views and opinions of authors expressed herein do not necessarily state or reflect those of the United States Government or any agency thereof.

\author{
PACIFIC NORTHWEST NATIONAL LABORATORY \\ operated by \\ BATTELLE \\ for the \\ UNITED STATES DEPARTMENT OF ENERGY \\ under Contract DE-AC05-76RL01830
}

Printed in the United States of America

Available to DOE and DOE contractors from the

Office of Scientific and Technical Information,

P.O. Box 62, Oak Ridge, TN 37831-0062;

ph: (865) 576-8401

fax: $(865) 576-5728$

email: reports@adonis.osti.gov

Available to the public from the National Technical Information Service

5301 Shawnee Rd., Alexandria, VA 22312

ph: (800) 553-NTIS (6847)

email: orders@ntis.gov <http://www.ntis.gov/about/form.aspx>

Online ordering: http://www.ntis.gov

(x)

This document was printed on recycled paper.

(8/2010) 


\section{Assessment of the LV-C2 Stack Sampling Probe Location for Compliance with ANSI/HPS N13.1-1999}

JA Glissmeyer

EJ Antonio

JE Flaherty

September 2015

Test Specification:

$\mathrm{N} / \mathrm{A}$

Statement of Work

24590-QL-SRA-W000-00101

Work Authorization:

WA\# 009

Test Plan:

TP-WTPSP-130, Rev 1

Test Exceptions:

$\mathrm{N} / \mathrm{A}$

Test Scoping Statement(s): NA

QA Technology Level:

Developmental Work

Prepared for

the U.S. Department of Energy

under Contract DE-AC05-76RL01830 and

subcontract number MOA:24590-QL-HC9-WA49-00001

Pacific Northwest National Laboratory

Richland, Washington 99352 

WTP-RPT-236, Rev. 0

Completeness of Testing

This report describes the results of work and testing specified by test plan TP-WTPSP-130. The work and any associated testing followed the quality assurance requirements outlined in the test plan. The descriptions provided in this test report are an accurate account of both the conduct of the work and the data collected. Test plan results are reported. Also reported are any unusual or anomalous occurrences that are different from expected results. The test results and this report have been reviewed and verified.

Approved:

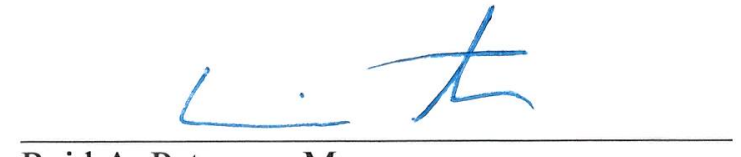

Reid A. Peterson, Manager WTP Support Project

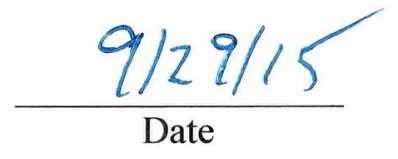

Date 



\section{Summary}

This document reports on a series of tests conducted to assess the proposed air sampling location for the Hanford Tank Waste Treatment and Immobilization Plant (WTP) Low-Activity Waste (LAW) C2V (LV-C2) exhaust stack with respect to the applicable criteria regarding the placement of an air sampling probe. Federal regulations ${ }^{1}$ require that a sampling probe be located in the exhaust stack according to the criteria established by the American National Standards Institute/Health Physics Society (ANSI/HPS) N13.1-1999, Sampling and Monitoring Releases of Airborne Radioactive Substances from the Stack and Ducts of Nuclear Facilities. ${ }^{2}$ These criteria address the capability of the sampling probe to extract a sample that represents the effluent stream.

The testing on the scale model stack conducted for this project was part of the River Protection Project-Waste Treatment Plant Support Program under Contract No. DE-AC05-76RL01830 according to the statement of work issued by Bechtel National, Inc. (BNI, 24590-QL-SRA-W000-00101, N13.1-1999 Stack Monitor Scale Model Testing and Qualification, Revision 1, 9/12/2007) and Work Authorization 09 of Memorandum of Agreement 24590-QL-HC9-WA49-00001. The internal Pacific Northwest National Laboratory (PNNL) project for this task is 53024, Work for Hanford Contractors Stack Monitoring. The testing described in this document was further guided by the Test Plan Air Sampling Probe Location Remedial Tests for Waste Treatment Plant LAW LV-C2 Air Exhaust System (TP-WTPSP-130).

The tests conducted by PNNL during 2013, 2014 and 2015 on the LV-C2 scale model system are described in this report. The series of tests consists of various measurements taken over a grid of points in the duct cross section at the designed sampling probe locations. The ANSI/HPS N13.1-1999 qualification criteria concern the following properties of the air flowing through the ducts where the air sampling probes are to be located:

1. Uniform Air Velocity-The gas momentum across the stack cross section where the sample is extracted should be well-mixed or uniform. The uniformity is expressed as the variability of the measurements about the mean, expressed as the percent coefficient of variance $(\% \mathrm{COV})$. It is calculated as the standard deviation divided by the mean and expressed as a percentage - the lower the $\% \mathrm{COV}$ value, the more uniform the velocity.

2. Angular Flow-The purpose of this test is to determine whether the air velocity vector is aligned with the sampling nozzle.

3. Uniform Concentration of Tracer Gases-A uniform contaminant concentration in the sampling plane enables the extraction of gas samples that represent the true concentration.

4. Uniform Concentration of Tracer Particles- A uniform contaminant concentration at the sampling probe enables the extraction of particle samples (with particles that are large enough to exhibit inertial effect) that represent the true concentration. Particles of $10-\mu \mathrm{m}$ aerodynamic diameter were used.

\footnotetext{
${ }^{1}$ Title 40 of the Code of Federal Regulations (CFR), Part 61, National Emissions Standards for Hazardous Air Pollutants (NESHAP), Subpart H, National Emission Standard for Emissions of Radionuclides Other Than Radon From Department of Energy Facilities.

${ }^{2}$ Health Physics Society, McLean, VA 22101. The standard has been reaffirmed in 2011 and is identical to the 1999 version. The regulations have not been updated yet, so the 1999 version is still referenced.
} 
The LV-C2 stack will have a single sampling location. The test results for the successfully-tested configuration are summarized in Table S.1. The details of the successful configuration are given in the report.

Table S.1. Summary of Sampling Probe Location Results for the LV-C2 Scale Model Stack

\begin{tabular}{lclc}
\hline & $\begin{array}{c}\text { Acceptance } \\
\text { Criteria }\end{array}$ & Units & Test Port 1 \\
\hline $\begin{array}{l}\text { Velocity } \\
\text { Uniformity }\end{array}$ & $\leq 20$ & \%COV & $2.1-5.1$ \\
\hline Flow Angle & $\leq 20$ & Degrees & $1.9-5.5$ \\
\hline Gas Tracer & $\leq 20$ & \%COV & $0.3-11.9$ \\
\cline { 2 - 4 } Uniformity & $\leq 30$ & $\begin{array}{l}\text { Maximum \% } \\
\text { Deviation from Mean }\end{array}$ & $0.5-27.6$ \\
\hline $\begin{array}{l}\text { Particle Tracer } \\
\text { Uniformity }\end{array}$ & $\leq 20$ & Normalized \%COV & $2.5-12.8$ \\
\hline
\end{tabular}

Based on the scale model tests, the location proposed for the air sampling probe in the scale model stack meet the requirements of the ANSI/HPS N13.1-1999 standard for velocity uniformity, flow angle, gas tracer and particle tracer uniformity. Additional velocity uniformity and flow angle tests on the actual stack will be necessary during cold startup to confirm the validity of the scale model results in representing the actual stack. In particular, the velocity uniformity test results for the actual stack must be within $5 \% \mathrm{COV}$ of the range of results listed for the scale model for the scale model results to be representative of the stack. If the velocity uniformity results on the actual stack fall within these bounds, and flow angle test results fall within qualification criteria (mean angle $\leq 20^{\circ}$ ) the scale model results may be used as a substitute for results from the actual stack.

The Waste Treatment Plant Support Program (WTPSP) implements an NQA-1-2000 quality assurance (QA) program, using a graded approach as presented in NQA-1-2000, Part IV, Subpart 4.2. The WTPSP Quality Assurance manual (QA-WTPSP-0002) describes the technology life cycle stages under the WTPSP QA plan (QA-WTPSP-0001). The technology life cycle includes the progression of technology development, commercialization, and retirement in process phases of basic and applied research and development (R\&D), engineering and production, and operation until process completion. The life cycle is characterized by flexible and informal QA activities in basic research, which becomes more structured and formalized through the applied R\&D stages. The work described in this report has been completed under the QA Technology level of Developmental Work as the data will be used to apply for air discharge permits.

WTPSP addresses internal verification and validation activities by conducting an Independent Technical Review of the final data report in accordance with WTPSP's procedure QA-WTPSP-0601, Document Preparation and Change. This review verifies that the reported results are traceable, that inferences and conclusions are soundly based, and the reported work satisfies the test plan objectives. Appendix A lists the reviewed test plan, test instructions, and calculation packages used for the tests documented in this report. 


\section{Acronyms}

\begin{tabular}{|c|c|}
\hline acfm & actual cubic feet per minute \\
\hline $\mathrm{AD}$ & aerodynamic diameter \\
\hline afpm & actual feet per minute \\
\hline ANSI & American National Standards Institute \\
\hline ASME & American Society of Mechanical Engineers \\
\hline $\mathrm{BNI}$ & Bechtel National, Inc. \\
\hline $\mathrm{CCP}$ & computer-assisted calculation package \\
\hline CFR & Code of Federal Regulations \\
\hline DOE & U.S. Department of Energy \\
\hline DV & hydraulic diameter $\times$ mean velocity \\
\hline EPA & U.S. Environmental Protection Agency \\
\hline FA & flow angle test \\
\hline GT & gaseous tracer test \\
\hline HDI & "How Do I...?" \\
\hline HPS & Health Physics Society \\
\hline LAW & low-activity waste \\
\hline LV-C2 & low-activity waste non-process area ventilation exhaust \\
\hline $\mathrm{N}_{2} \mathrm{O}$ & nitrous oxide \\
\hline NCR & Non-Conformance Report \\
\hline NESHAP & National Emissions Standards for Hazardous Air Pollutants \\
\hline $\mathrm{OPC}$ & optical particle counter \\
\hline$\% \mathrm{COV}$ & percent coefficient of variation \\
\hline PNNL & Pacific Northwest National Laboratory \\
\hline PT & particle tracer test \\
\hline QA & quality assurance \\
\hline scfm & standard cubic feet per minute \\
\hline TI & test instruction \\
\hline VT & velocity uniformity test \\
\hline WTP & Hanford Tank Waste Treatment and Immobilization Plant \\
\hline WTPSP & Waste Treatment Plant Support Program \\
\hline
\end{tabular}





\section{Acknowledgments}

Preparing, executing, and post-processing these scale model measurements involved a number of Pacific Northwest National Laboratory staff. We would like to particularly acknowledge the support of our quality engineer, Kirsten Meier, and the administrative support from Chrissy Charron and Mona Champion. We would also like to express our appreciation to scientific staff members Carmen Arimescu and Yin-Fong Su, who conducted measurements under a variety of weather conditions. Additionally, Matthew Barnett, and Carmen Arimescu, provided technical reviews. Megan Peters provided editorial support for this report.

Funding for this effort was provided by the Department of Energy's Waste Treatment and Immobilization Plant Project through a subcontract with Bechtel National, Inc. Pacific Northwest National Laboratory is operated for the U.S. Department of Energy by Battelle under Contract DE-AC05-76RL01830. 



\section{Contents}

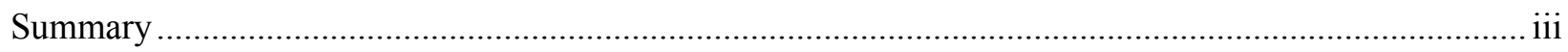

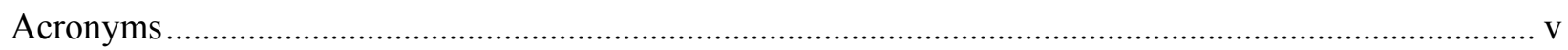

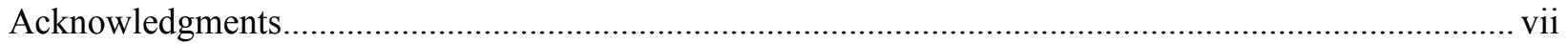

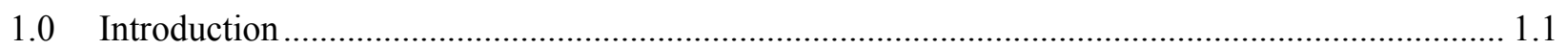

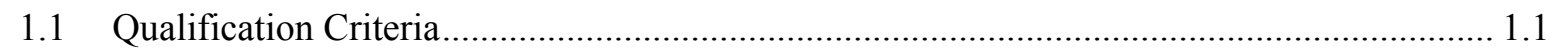

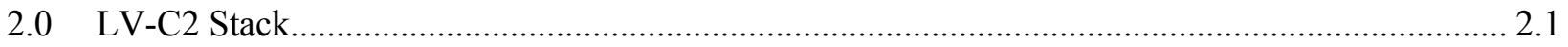

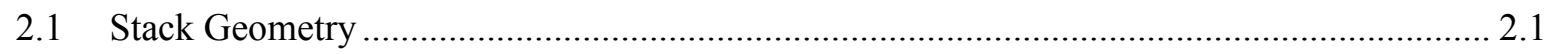

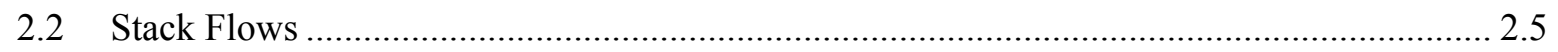

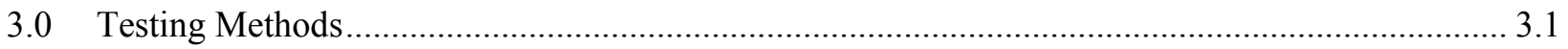

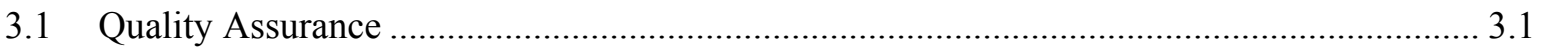

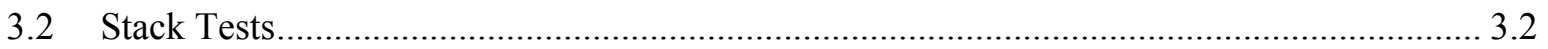

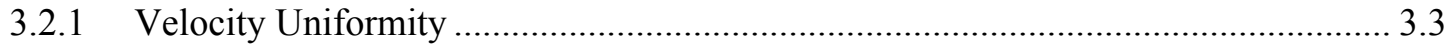

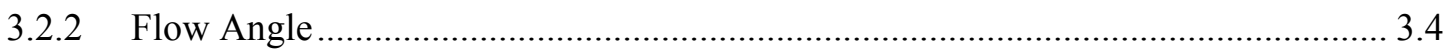

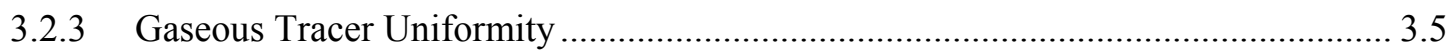

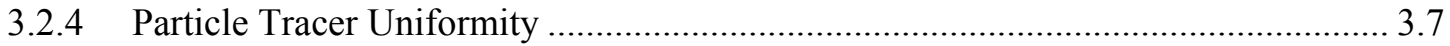

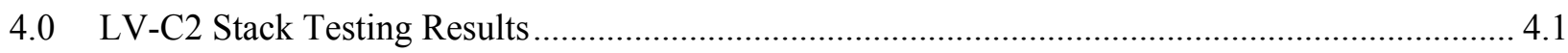

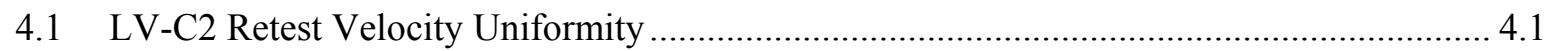

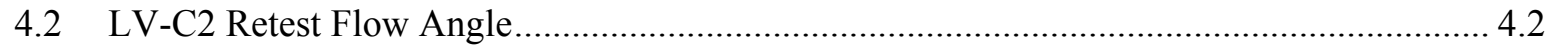

4.3 LV-C2 Retest Gaseous Tracer Uniformity ................................................................... 4.3

4.4 LV-C2 Particle Tracer Uniformity ….................................................................................... 4.5

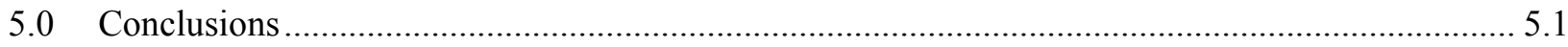

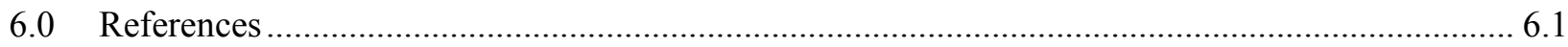

Appendix A LV-C2 Scale Model Testing Supporting Documents List................................................ A.1

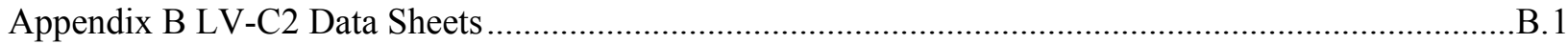

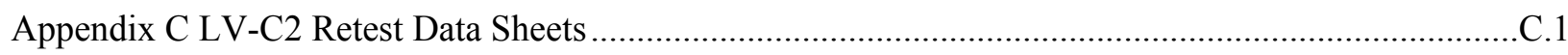




\section{Figures}

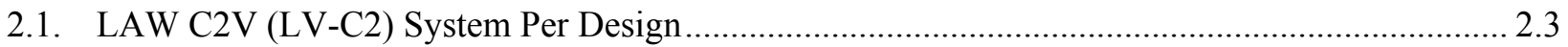

2.2. Layout of LAW C2V (LV-C2) Scale Model Test System ......................................................... 2.4

2.3. Photographs of: a) Oversized Backdraft Damper; b) Scale Model Backdraft Damper; and

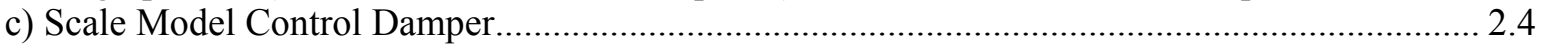

3.1. Cross Section of the Duct at the Testing Ports with Measurement Points ....................................... 3.3

3.2. Equipment Used for the Velocity Uniformity Test ...................................................................... 3.4

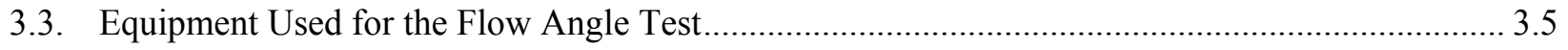

3.4. Equipment Used for the Gaseous Tracer Injection. ................................................................ 3.6

3.5. Illustration of Five Injection Points in a Circular Duct ............................................................... 3.6

3.6. Equipment Used for the Gaseous Tracer Sampling ................................................................. 3.7

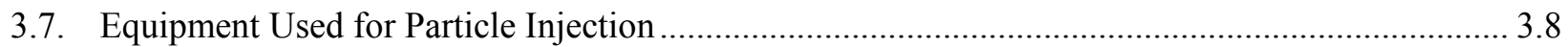

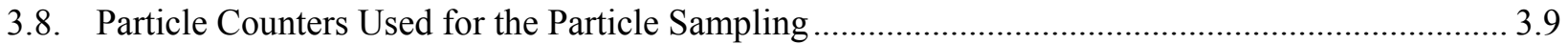

4.1. Modified Section of Scale Model Stack with Additional Tests Ports at 1-ft Intervals ................... 4.6

4.2. Injection Probes Fabricated to Accommodate Tight Space at Injection Port 5............................. 4.7

\section{Tables}

2.1. Provided Flow Rate and Temperature Converted to Actual Flow Rates ...................................... 2.5

2.2. Summary of Flow Parameters for LV-C2 Scale Model Stack .................................................... 2.6

2.3. Summary of DV Values for Scale Model Stacks ............................................................................ 2.6

4.1. Summary of LV-C2 Retest Velocity Uniformity Tests............................................................. 4.2

4.2. Summary of LV-C2 Retest Flow Angle Tests …....................................................................... 4.3

4.3. Summary of LV-C2 Retest Gas Tracer Uniformity Tests............................................................ 4.4

4.4. Summary of LV-C2 Retest Preliminary Particle Tracer Uniformity Tests Using Injection

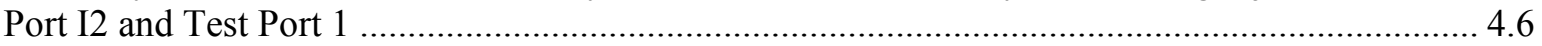

4.5. Summary of LV-C2 Retest Preliminary Particle Tracer Uniformity Tests Investigating Injection Ports and Test Ports at Revised Maximum Flow Rates, with Fan B ............................. 4.8

4.6. Summary of Final LV-C2 Retest Particle Tracer Uniformity Tests ............................................ 4.9

5.1. Summary of Sampling Probe Location Results for the LV-C2 Scale Model Stack....................... 5.1 


\subsection{Introduction}

This set of scale model tests was performed to document whether the current design for the air monitoring location at one air exhaust stack in the Hanford Tank Waste Treatment and Immobilization Plant (WTP) meets the applicable regulatory criteria governing effluent monitoring systems. A group (Test Group 1-2A) tested together, originally consisted of three Low-Activity Waste (LAW) facility stacks: LV-C2, LV-S2, and LV-S3 (i.e., the emission units for the LAW C2V, LAW C5V, and the LAW secondary offgas / vessel vent process system [LVP], respectively). The LV-C2 stack, however, required further testing due to deficiencies in the original test results, and are therefore reported separately here.

The emissions from this low-activity waste facility air exhaust stack may exceed the 0.1-millirem per year threshold limit given in Title 40 of the Code of Federal Regulations (CFR), Part 61, National Emissions Standards for Hazardous Air Pollutants (NESHAP), Subpart H, National Emission Standard for Emissions of Radionuclides Other Than Radon From Department of Energy Facilities. The NESHAP rule requires that a sampling probe be located in the exhaust stack according to criteria established by the American National Standards Institute/Health Physics Society (ANSI/HPS) N13.1-1999, Sampling and Monitoring Releases of Airborne Radioactive Substances from the Stack and Ducts of Nuclear Facilities. ${ }^{1}$ The capability of the sampling probe location in the LV-C2 stack to meet this standard has been demonstrated with a series of tests on a scale model of the stack. These data will be used by Bechtel National, Inc. (BNI) as input to the air discharge permitting process.

This work is performed as part of the River Protection Project-Waste Treatment Plant Support Program under Contract No. DE-AC05-76RL01830 according to the statement of work issued by BNI, 24590-QL-SRA-W000-00101, N13.1-1999 Stack Monitor Scale Model Testing and Qualification, Revision 1, 09/12/2007 and Work Authorization 09 of Memorandum of Agreement 24590-QL-HC9-WA49-00001. The internal Pacific Northwest National Laboratory (PNNL) project for this task is 53024, Work for Hanford Contractors Stack Monitoring.

PNNL personnel conducted the original scale model tests during 2013 and the remedial tests in 2014 and 2015. No BNI personnel were directly involved in the tests. The BNI WTP point of contact and facility engineers provided the most current engineering input to support PNNL's tests. BNI retains responsibility for the technical design of the stack discharge and air monitoring systems.

\subsection{Qualification Criteria}

The qualification criteria for the location of a stack air monitoring probe are taken from ANSI/HPS N13.1-1999, Section 5.2.2 and are paraphrased as follows:

1. Uniform Air Velocity-It is required that the air velocity be fairly uniform across the stack cross section where the sample is extracted. Consequently, the velocity is measured at several discrete points in the duct cross section at the proposed location of the sampling nozzle. The uniformity is expressed as the variability of the measurements about the mean. This is expressed using the percent

\footnotetext{
${ }^{1}$ Health Physics Society, McLean, VA 22101. The standard has been reaffirmed in 2011 and is identical to the 1999 version. The regulations have not been updated yet, so the 1999 version is still referenced.
} 
coefficient of variation $(\% \mathrm{COV}),{ }^{1}$ which is the standard deviation divided by the mean and expressed as a percentage - the lower the \% COV value, the more uniform the velocity. The qualification criterion is that the $\% \mathrm{COV}$ of the air velocity must be $\leq 20 \%$ in the center two-thirds of the duct cross section where the sampling probe is to be located.

2. Angular Flow-Sampling nozzles are typically aligned with the axis of the stack. If the air travels through the stack in cyclonic fashion, the air velocity vector approaching a sampling nozzle could be sufficiently misaligned with the nozzle to impair extraction of particles. Consequently, the flow angle is measured at the proposed location of the sampling probe. The average of the flow angle measurements (made at the same grid of points as the velocity measurements) should not exceed $20^{\circ}$ relative to the sampling nozzle axis.

3. Uniform Concentration of Tracer Gases-A uniform contaminant concentration in the sampling plane enables the extraction of samples that represent the true concentration within the duct. The uniformity of the concentration is first tested with a tracer gas to represent gaseous effluents. The fan is a good mixer, so injecting the tracer downstream of the fan provides worst-case results. The qualification criteria are that 1 ) the $\% \mathrm{COV}$ of the measured tracer gas concentration is $\leq 20 \%$ across the center two-thirds of the duct cross section at the sampling location, and that 2) the concentrations at any of the measurement points cannot deviate from the mean by $>30 \%$.

4. Uniform Concentration of Tracer Particles - The second set of tests addressing contaminant concentration uniformity at the sampling position uses tracer particles large enough to exhibit inertial effects. Tracer particles of $10-\mu \mathrm{m}$ aerodynamic diameter (AD) are used by default unless it is known that larger contaminant particles will be present in the airstream. The qualification criterion is that the $\% \mathrm{COV}$ of particle concentration is $\leq 20 \%$ across the center two-thirds of the duct at the sampling location.

Tests to determine if criteria 1 through 4 were met were conducted on the LV-C2 scale model at the proposed sampling location along the exhaust duct. By conducting tests on a scale model of the exhaust system, the designed air sampling locations can be qualified before cold commissioning, and compensatory measures could be made in the design if testing results were not satisfactory. All of the tracer concentration, velocity, and flow angle measurements were made using the same grid of points in a given cross section of the duct. The ANSI/HPS N13.1-1999 standard sets additional qualification criteria for the use of a scale model as a substitute for the actual stack:

- The scale model and its sampling location must be geometrically similar to the actual stack.

- The product of the hydraulic diameter and the mean velocity (DV) for the scale model must be within a factor of six of the DV for the actual stack.

- The Reynolds number for the actual and model stacks must be $>10,000$.

- The scale model results are considered valid if it is further shown that:

- The velocity profile in the actual stack meets the uniformity criterion ( $\% \mathrm{COV} \leq 20 \%)$.

- The velocity uniformity COV values for the actual and model stacks agree within $5 \% \mathrm{COV}$.

- The flow angle criterion (with a mean value less than or equal to $20^{\circ}$ ) is met.

${ }^{1}$ Coefficient of variation is considered "dated" terminology. The modern terminology is percent relative standard deviation. However, because the standard uses the older terminology, it will likewise be used here. 
The tests to determine the validity of the scale model testing will be performed during cold startup testing on the actual WTP stacks under a separate test plan. The scale model testing conducted, as well as the results of these tests, are described in subsequent sections of this report. 



\subsection{LV-C2 Stack}

\subsection{Stack Geometry}

The scale model design is based on assumptions about the necessary simulation detail. These assumptions are listed below.

- Flows induced by natural convection due to temperature gradients are negligible compared to flows driven by forced currents from the fans. Therefore, gravitational impacts are negligible and the vertical orientation of the full-scale stack can be modeled in a horizontal configuration.

- Sampling at the sample port location from two test ports 90 degrees apart provides representative characterization of stack flow. It is unnecessary to mimic the angular orientation of test ports relative to upstream elbows (or bends).

- WTP design injection port locations will initially be assumed to be adequate on account of the high Reynolds number and sufficient length of straight duct from the last elbow to the sampling location. If data analysis indicates that the WTP injection location does not provide representative sampling WTP will be notified and testing from other injection locations (farther upstream) may be conducted to achieve data representative of a well-mixed system.

- Temperature has negligible effect on the mixing given that the temperature from either fan would be the same. Model testing will not seek to match temperature conditions of the WTP system.

- Backdraft dampers and control dampers on the standby fan are assumed to be fully closed such that there is no leakage back to the LAW ventilation system. During model testing, the operating fan(s) will be utilized for testing and the standby fan will be isolated.

- The measurement uncertainty for each test type (e.g., velocity, flow angle, tracer) depends only upon the measurement (instruments and procedures) and not upon the fan configuration or flow condition. The air velocity and tracer uniformity downstream of the dampers would not be greatly influenced by equipment upstream of the dampers.

- Backdraft damper blades do not usually open fully, so the partially open blades direct the air velocity vector toward one side of the duct, significantly disrupting the air flow and possibly washing out the effect of upstream disturbances.

In the LV-C2 stack, the designed sampling probes will be located in vertical sections of duct. Figure 2.1 shows the layout for the stack design, from the fan outlet to the outlet of the vertical duct. Figure 2.2 shows the scale model layout for the stack design. Test Port 1 represents the planned location for the record sampling system sample port Figure 2.1. The scale model system had an additional port located five duct diameters downstream of Test Port 1, used to monitor the output of the aerosol generator during particle tracer uniformity testing.

The scale model was constructed with a primary duct diameter of $12 \mathrm{in}$. for convenience and to maintain the ability to re-use the duct sections for subsequent stack designs. The diameter of the actual stack is 60 inches yielding a scaling factor of one-fifth for the 12 -in. scale model diameter. The calculations of the key scale model dimensions were performed in spreadsheets and then verified and validated in accordance with appropriate quality assurance (QA) procedures. ANSI/HPS N13.1-1999 
requires that the models be geometrically similar to the actual stacks. Acceptable deviations in key dimensions of the scale model arising from scaling and fabrication errors are within about $\pm 5 \%$ for cross-sectional dimensions and about $25 \%$ of a duct diameter in overall length between the sampling point and the flow disturbances. These deviations would have less impact on the test results than the normal standard deviation of repeat tests. The key scale model dimensions for the as-built scale models were measured and recorded by testing staff.

The LV-C2 stack was originally tested as part of a group of three LAW stacks referred to as Test Group 1-2A. However, the LV-C2 model required additional testing because the particle tracer tests failed to meet the acceptance criteria when one of the fans was operating at its maximum flow condition. Also, BNI designers re-estimated the system flowrates and the new estimates were significantly lower than for the previous tests.

A visit to the Vitrification Plant was made to compare the scale model to the constructed stack. The comparison showed that the backdraft dampers used on the model (used from a previous model, to save costs), were oversized and had damper blades that were oriented incorrectly relative to the axis of flow. Scale model tests performed in the past did not indicate that backdraft dampers would significantly influence the test results. However, the LV-C2 stack is fairly simple (just a single bend), and short (only ten duct diameters between the bend and sampling location), so it is reasonable to expect that the initial geometry would have a greater influence on the test results.

Several potential remedial actions were considered for the LV-C2 scale model tests:

- Relocate the sampling point farther downstream,

- Correctly orient the oversized dampers,

- Install correctly scaled dampers,

- Locate tracer injection ports further upstream,

- Install a static mixer between the fans and the base of the stack.

Additional scale model tests were performed to investigate the effect of implementing the first four of these remedies.

First, additional particle tracer tests were performed to compare the oversized dampers in the correct orientation with those that were offset by $90^{\circ}$ at both the original flow conditions and at the revised, lower flowrate conditions. Subsequently, scaled control and backdraft dampers were fabricated and particle tracer tests were performed with sampling performed at Test Port 1 (the planned sampling port for the stack) and at test ports inserted at one duct diameter and two duct diameters downstream of Test Port 1. For these tests, the tracer material was injected at Injection Ports I2, I3 and I5, which, given their upstream locations, maximizes mixing. The oversized and scale model dampers are shown in Figure 2.3. 


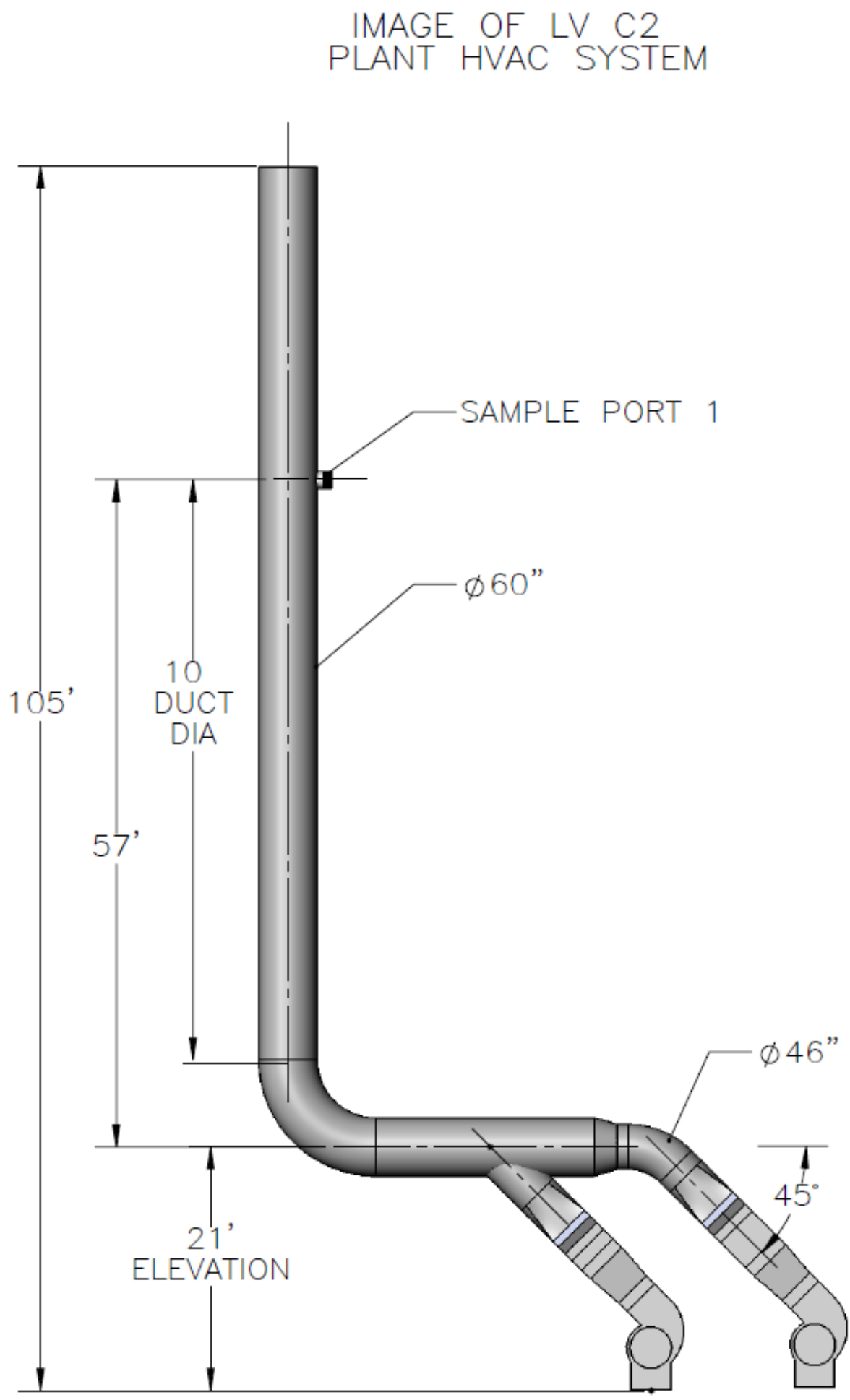

2 WORKING FANS

Figure 2.1. LAW C2V (LV-C2) System Per Design 


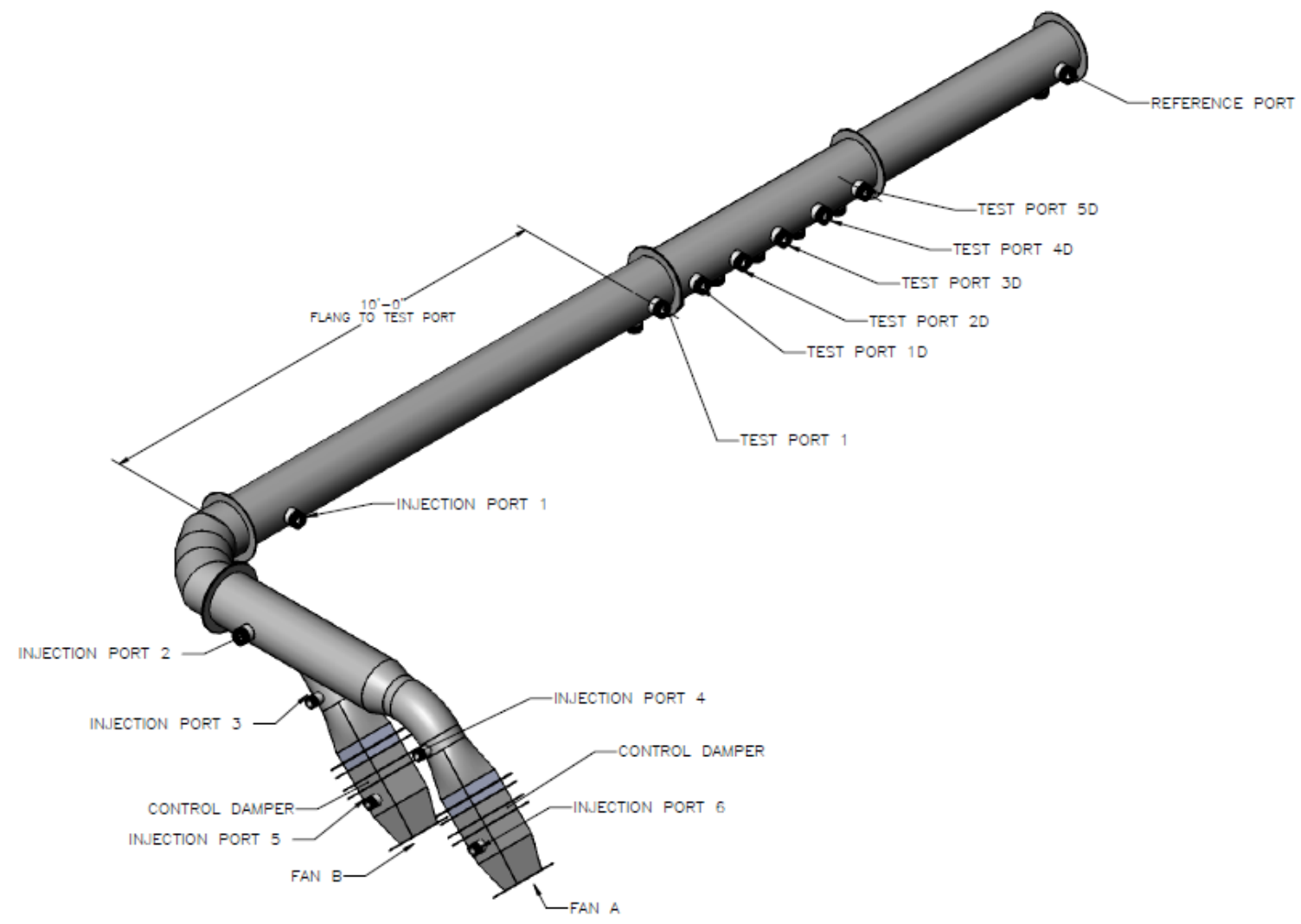

Figure 2.2. Layout of LAW C2V (LV-C2) Scale Model Test System

a

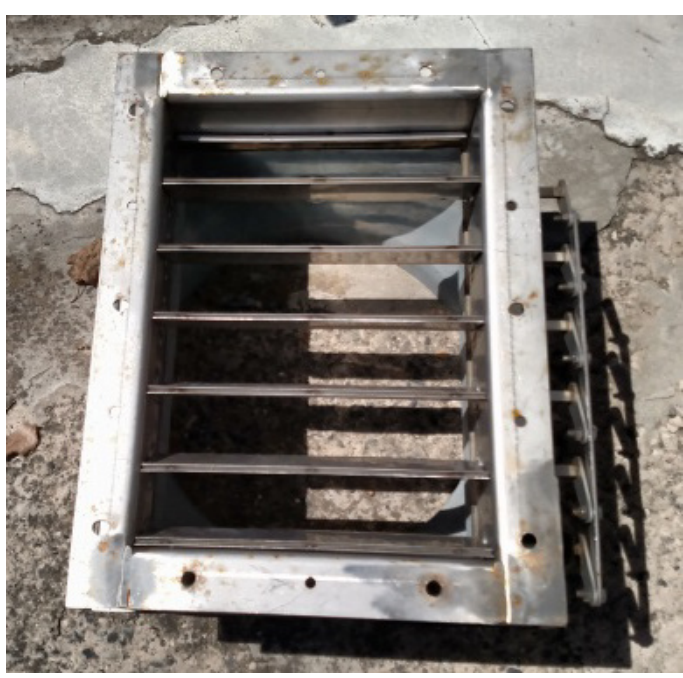

b

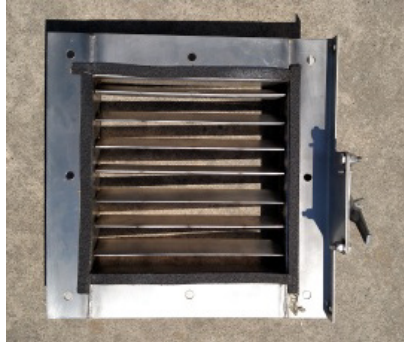

$\mathrm{c}$

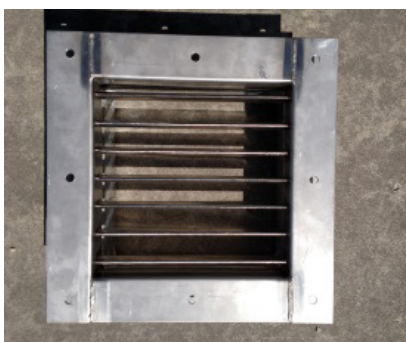

Figure 2.3. Photographs of: a) Oversized Backdraft Damper; b) Scale Model Backdraft Damper; and c) Scale Model Control Damper 


\subsection{Stack Flows}

Tests of the scale model stack were conducted at flow rates that bracket the range of expected normal and accident flow rates and operating configurations. Various combinations of flow rates and operating fans were tested. BNI provided normal, minimum, and maximum flow rates.

Additional considerations come from the ANSI/HPS N13.1-1999 standard. The standard requires that the DV of the scale model be within a factor of six of the actual stack. For stacks with a circular cross section, this is equivalent to requiring that the ratio of flow rate to stack diameter be within a factor of six of the actual stack. The standard also requires that the Reynolds number for the prototype and model stacks must both exceed 10,000.

There are two fans available to power the LAW C2V (LV-C2) exhaust system, which exhausts the air from the $\mathrm{C} 2$ ventilation system of the low-activity waste facility. One fan will be operated at a time, and one will be on standby. Each fan is capable of providing the design maximum flow rate, and is equipped with an adjustable-speed drive to compensate for filter loading and pressure variations.

BNI provided estimated flow rates, in standard cubic feet per minute ( $\mathrm{scfm}$ ), and temperatures for the operation of LV-C2 as shown in Table 2.1. The previous and updated flow rates (CCN 270918) are both given in the table. The table also shows the calculated volumetric flowrate, actual cubic feet per minute $(\mathrm{acfm})$, taking the temperature and updated flow rates into account. BNI uses $14.7 \mathrm{psia}$ and $68^{\circ} \mathrm{F}$ as standard gas conditions for ventilation. Flow parameters used in subsequent sections will be at the estimated conditions.

Table 2.1. Provided Flow Rate and Temperature Converted to Actual Flow Rates

\begin{tabular}{|c|c|c|c|c|c|c|c|}
\hline \multirow[b]{2}{*}{$\begin{array}{c}\text { Emission } \\
\text { Unit }\end{array}$} & \multirow[b]{2}{*}{$\begin{array}{c}\text { Duct } \\
\text { Diameter } \\
\text { in. }\end{array}$} & \multirow[b]{2}{*}{$\begin{array}{l}\text { Operating } \\
\text { Condition }\end{array}$} & \multirow[b]{2}{*}{$\begin{array}{l}\text { Previous } \\
\text { scfm }\end{array}$} & \multicolumn{2}{|c|}{ BNI Provided Data } & \multicolumn{2}{|c|}{ Calculated } \\
\hline & & & & $\begin{array}{l}\text { Updated } \\
\text { scfm }\end{array}$ & $\begin{array}{c}\text { Updated } \\
\text { Temperature } \\
{ }^{\circ} \mathrm{F} \\
\end{array}$ & $\begin{array}{c}\text { Previous } \\
\text { acfm }\end{array}$ & $\begin{array}{c}\text { Updated } \\
\text { acfm }\end{array}$ \\
\hline LV-C2 & 60 & Maximum & 68,000 & 55,550 & 140 & 76,981 & 63,130 \\
\hline LV-C2 & 60 & Normal & 54,000 & 50,500 & 95 & 56,547 & 53,084 \\
\hline LV-C2 & 60 & Minimum & 37,800 & 33,800 & 59 & 36,374 & 33,224 \\
\hline
\end{tabular}

Table 2.2 summarizes the flow conditions for the actual and scale model stacks. The minimum air flow (in acfm) and air velocity (in actual feet per minute [afpm]) to achieve the assumed minimum and maximum actual stack flow are listed. The tabulated values of flow and velocity in the "Scale Model Minimum" columns are the minimum scaled values that will meet the criterion listed in Section 1.1 that the DV product be within a factor of six of the prototype. The scale model Reynolds numbers are calculated for those minima. One of the qualification criteria listed in Section 1.1 is that the Reynolds number for both the actual and scale model stack must be greater than 10,000. Therefore, the Reynolds numbers for the actual and scale model stacks at the minimum and maximum flow rates are included in Table 2.2. The conditions prescribed for these scale model tests fulfill the criterion of a Reynolds number greater than 10,000 . 
Table 2.2. Summary of Flow Parameters for LV-C2 Scale Model Stack

\begin{tabular}{lcccccc}
\hline & \multicolumn{2}{c}{ Air Flow (acfm) } & \multicolumn{2}{c}{ Air Velocity (afpm) } & \multicolumn{2}{c}{ Reynolds Number } \\
\cline { 2 - 7 } Flow & \multicolumn{3}{c}{ Scale Model } & \multicolumn{3}{c}{ Scale Model } \\
Actual Stack & Minimum & Actual Stack & Minimum & Actual Stack & Minimum \\
\hline Max flow & 63,130 & 2,104 & 3,215 & 2,679 & $1.3 \mathrm{E}+06$ & $2.2 \mathrm{E}+05$ \\
Normal flow & 53,084 & 1,769 & 2,704 & 2,253 & $1.3 \mathrm{E}+06$ & $2.1 \mathrm{E}+05$ \\
Min flow & 33,224 & 1,107 & 1,692 & 1,410 & $9.0 \mathrm{E}+05$ & $1.5 \mathrm{E}+05$ \\
\hline
\end{tabular}

As listed in Section 1.1, the qualification criteria include a constraint on the DV value of the scale model relative to the actual stack. For comparison between the tests on the scale models and the acceptable DV range, DV values are tabulated in Table 2.3. They are calculated for each of the three flow conditions for each stack. The acceptable DV range (1/6 to $6 \times$ that of the actual stack) is quite large, and the upper end of the range is impractical with real-world blowers. Usually, during testing, an upper velocity approximately equal to that of the actual stack is selected for use. With the use of variable frequency drives to control the blowers, the velocity corresponding to the lower end of the DV range is practical, and this velocity (or a slightly higher velocity) is typically used.

Note that because the scale model stack diameter is one foot, that the DV values in Table 2.3 are equal to the velocity values for the scale model. For example, the LV-C2 minimum DV, which is $1410 \mathrm{ft}^{2} / \mathrm{min}$, corresponds to a velocity of $1410 \mathrm{ft} / \mathrm{min}$ for the 1 - $\mathrm{ft}$-diameter scale model.

Table 2.3. Summary of DV Values for Scale Model Stacks

\begin{tabular}{llccc}
\hline Stack & DV, $\mathbf{f t}^{2} /$ min & Min & Norm & Max \\
\hline \multirow{4}{*}{ LV-C2 } & Actual Stack & 8,460 & 13,520 & 16,075 \\
& Min. for Model & 1,410 & 2,253 & 2,679 \\
& Max. for Model & 50,760 & 81,120 & 96,450 \\
\hline
\end{tabular}




\subsection{Testing Methods}

The testing methods were based on the requirements of ANSI/HPS N13.1-1999. A test plan, TP-WTPSP-130, Air Sampling Probe Location Tests for Waste Treatment Plant LAW LV-C2 Air Exhaust System, was prepared by PNNL and approved by BNI. This plan referenced the use of PNNL procedures, which define how the test should be conducted in general. A test instruction (TI) was prepared for each test type and for the scale model stack. These TIs contain specific instructions pertaining to the tests that are not addressed in the general procedures. Such information includes the following:

- Layout of measurement points

- Locations of tracer injection points

- List of equipment and instrumentation

- Safety requirements

- List of minimum test runs

- Test description and measurement data sheets with hand entries

- Table of preliminary results.

Because the final data sheets and a description of the test methods are included in this report, the TIs are not included here. The QA program that is implemented for this project is described in Section 3.1 and a summary of the stack testing methods used for each of the four test types is presented in Section 3.2.

\subsection{Quality Assurance}

The PNNL QA program is based on the requirements defined in the U.S. Department of Energy Order 414.1D, Quality Assurance, and 10 CFR 830, Energy/Nuclear Safety Management, and Subpart AQuality Assurance Requirements (a.k.a. the Quality Rule). PNNL has chosen to implement the following consensus standards in a graded approach:

- ASME NQA-1-2000, Quality Assurance Requirements for Nuclear Facility Applications, Part I, "Requirements for Quality Assurance Programs for Nuclear Facilities".

- ASME NQA-1-2000, Part II, Subpart 2.7, Quality Assurance Requirements for Computer Software for Nuclear Facility Applications.

- ASME NQA-1-2000, Part IV, Subpart 4.2, Guidance on Graded Approach Application of Quality Assurance (QA) Requirements for Nuclear-Related Research and Development.

The procedures necessary to implement the requirements are documented through PNNL's "How Do I...?" (HDI), which is a system for managing the delivery of laboratory-level policies, requirements, and procedures.

The Waste Treatment Plant Support Program (WTPSP) implements an NQA-1-2000 QA program, using a graded approach as presented in NQA-1-2000, Part IV, Subpart 4.2. The WTPSP Quality Assurance manual (QA-WTPSP-0002) describes the technology life cycle stages under the WTPSP QA 
plan (QA-WTPSP-0001). The technology life cycle includes the progression of technology development, commercialization, and retirement in process phases of basic and applied research and development $(R \& D)$, engineering and production, and operation until process completion. The life cycle is characterized by flexible and informal QA activities in basic research, which becomes more structured and formalized through the applied R\&D stages. The work described in this report has been completed under the QA Technology level of Developmental Work as the data will be used for applying for air discharge permits.

- DEVELOPMENTAL WORK-Developmental work consists of research tasks moving toward technology commercialization. These tasks still require a degree of flexibility, and there is still a degree of uncertainty that exists in many cases. The role of quality on developmental work is to make sure that adequate controls exist to support movement into commercialization.

WTPSP addresses internal verification and validation activities by conducting an Independent Technical Review of the final data report in accordance with WTPSP's procedure QA-WTPSP-0601, Document Preparation and Change. This review verifies that the reported results are traceable, that inferences and conclusions are soundly based, and the reported work satisfies the test plan objectives. Appendix A lists the reviewed test plan, test instructions, and calculation packages used for the tests documented in this report.

\subsection{Stack Tests}

The tests described in the following subsections were conducted under scale flow conditions designed for the LV-C2 stack, which were listed in Table 2.2. The test matrix included with the test plan described the minimum number of tests that were planned for each stack. The actual number of tests typically exceeded the planned number because tests were added to confirm results.

Before conducting the tests to determine whether the four qualification criteria described in Section 1.1 were met for each stack, two other measurement sets were made. First, the major features of the stack were measured. The longitudinal distances from the fans to the bends, duct reducers, and ports were determined, in addition to the duct diameter at each measurement port. The second set of measurements determined the fan frequency settings needed to achieve the desired flow rates. For these measurements, the location within the duct cross section that had velocity measurements closest to the mean velocity was determined for the test port. Then, velocity measurements were made at this single measurement point at 5-Hz increments in the fan frequency setting. By developing a frequency-vs.-velocity relationship for the scale model stack, the frequency setting needed to achieve the flow conditions could be pre-determined. The data sheets from these velocity calibration tests are included in Appendices B.1 and C.1.

A common grid of measurement points in the duct cross section was used for each of the qualification criteria tests described in the following subsections. The number and distance between measurement points were based on the U.S. Environmental Protection Agency (EPA) procedure 40 CFR 60, Appendix A, Method 1, for circular stacks. For a 12-in. duct diameter, eight traverse points are required at the relative positions shown in Figure 3.1. Measurements also were made at the centerpoint. In lieu of making the two measurement points nearest to the walls at $3.2 \%$ of the duct diameter from the duct walls, the minimum distance from the wall was set to 0.5 in., as prescribed by EPA Method 1 . The measurement point closest to the port was Point 1, while the point farthest from the port was Point 8. 


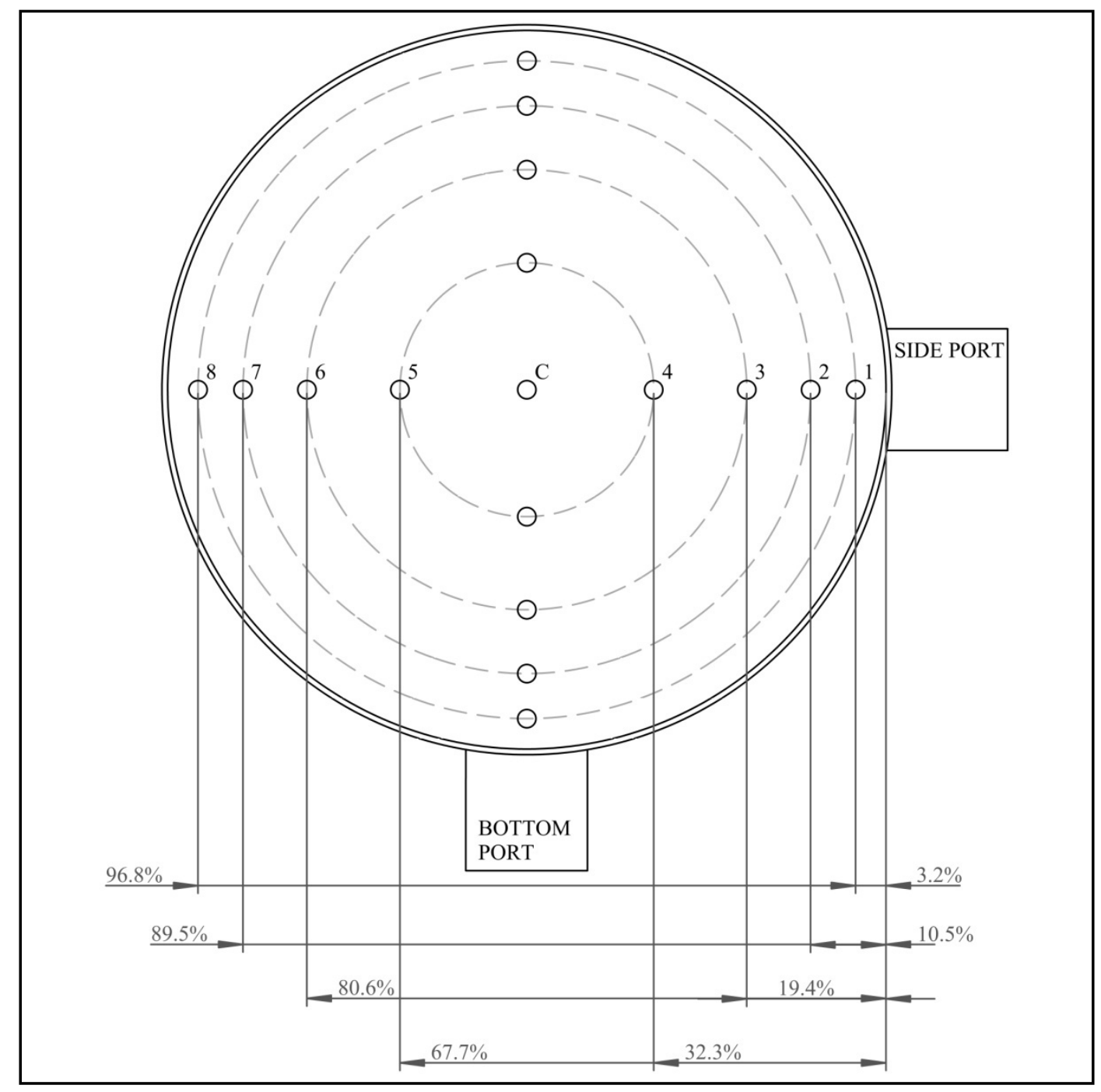

Figure 3.1. Cross Section of the Duct at the Testing Ports with Measurement Points

\subsubsection{Velocity Uniformity}

The uniformity of air velocity at the stack monitoring location indicates whether the momentum in the stack is well-mixed. The method used to conduct the velocity uniformity tests was based on 40 CFR 60 , Appendix A, Method 1. The velocity uniformity criterion is that the $\%$ COV should be less than $20 \%$ in the center two-thirds of the duct (measurement points 2-7).

For each test run, three air velocity readings were obtained at each measurement point in the cross section of the duct. The measured velocity was the average of the three readings. The measured velocity for each point was used to determine the mean and standard deviation of the velocity across the crosssectional plane. The \%COV (a.k.a. the percent relative standard deviation) was calculated as 100 times the standard deviation divided by the mean.

Air velocity measurements were made using a handheld thermal anemometer (TSI, Model 9545, Shoreview, MN). Duct air temperature measurements also were made with the same handheld thermal 
anemometer. The thermal anemometer is capable of reporting velocity in standard feet per minute, with standard conditions defined as $1 \mathrm{~atm}$ and $70^{\circ} \mathrm{F}$, or in actual feet per minute using the actual air temperature measured by the thermal anemometer and the actual barometric pressure measured with another instrument and input to the anemometer. Figure 3.2 shows the thermal anemometer used for this test. The procedure EMS-JAG-04 and test instructions TI-WTPSP-114 and TI-WTPSP-120 were followed to conduct this test for the scale models.
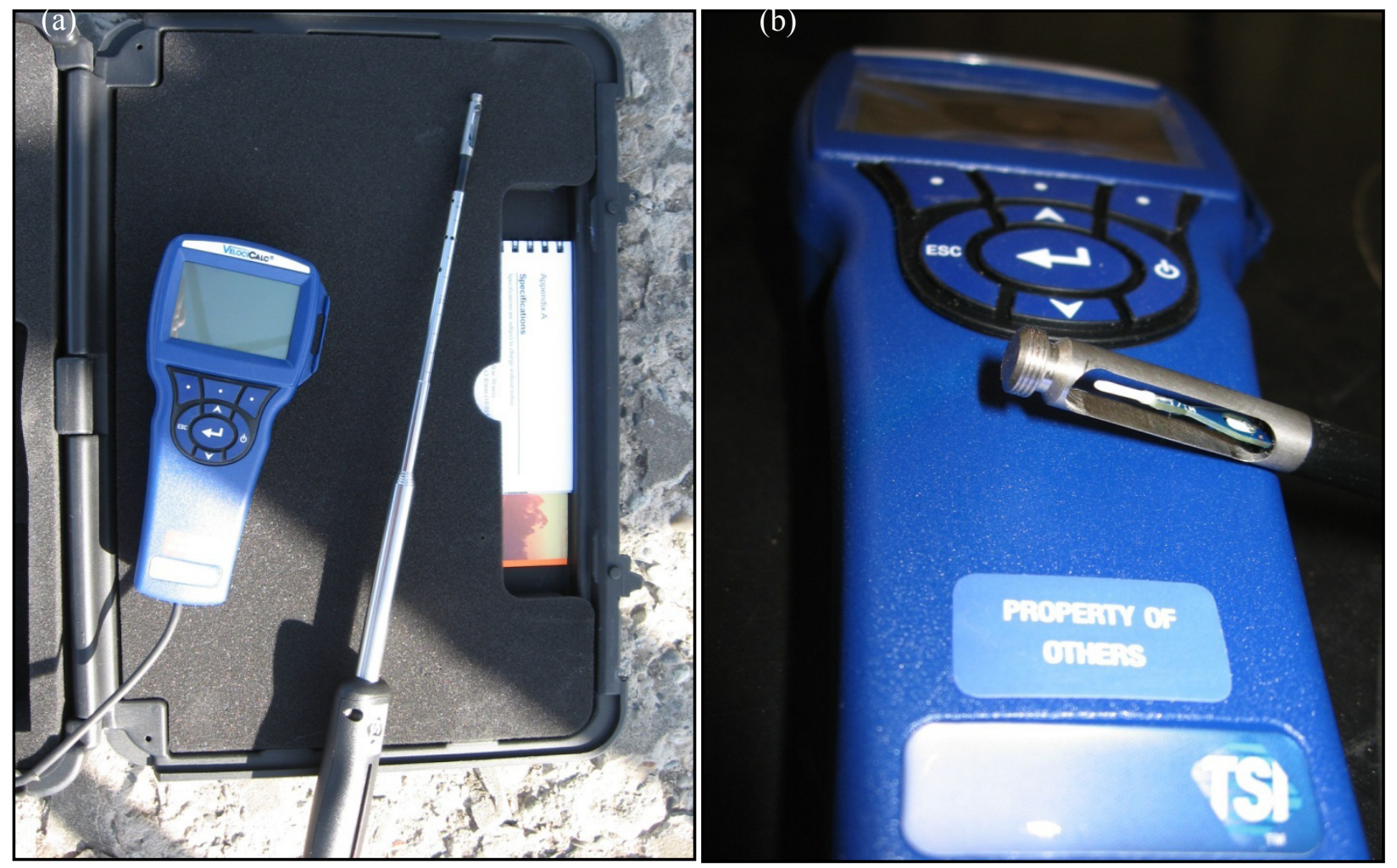

Figure 3.2. Equipment Used for the Velocity Uniformity Test (a) Thermal Anemometer, and (b) Close-Up View of Thermal Anemometer Probe Tip

\subsubsection{Flow Angle}

The air velocity vector approaching the sample nozzle should be aligned with the axis of the nozzle within an acceptable range so that the sample extraction performance is not degraded. The test method is based on 40 CFR 60, Appendix A, Method 1, Section 11.4, "Verification of the Absence of Cyclonic Flow." The term "flow angle" refers to the angle between the velocity vector of the flow in the duct and the axis of the sampling nozzle. For the stack testing activities, the flow angle was measured at a grid of nine points across two axes in a cross section of the duct (see Figure 3.1). The qualification criterion for the flow angle test is that the average angle should not exceed $20^{\circ}$.

The flow angle measurements were made using an S-type Pitot tube (Dwyer Instruments, 160S-36, Michigan City, IN) attached by flexible tubing to a slant-tube manometer (Dwyer Instruments, 400-5, Michigan City, Indiana) and an angle-indicating device attached to the sampling port as shown in Figure 3.3. For this test, the S-type Pitot tube is rotated so that the planes of the two open ends of the two tubes are parallel to the long axis of the duct. The pitot tube is then rotated about its long axis until the 
differential pressure across the open ends of the tubes reads zero on the manometer. The rotation angle is read from the angle-indicating device. The measured flow angle for each point is the average of three readings. These measured values are used to calculate the mean absolute value of the flow angle across the duct. The procedure EMS-JAG-05 and test instructions TI-WTPSP-115 and TI-WTPSP-121 were used to conduct this test for each of the scale models.
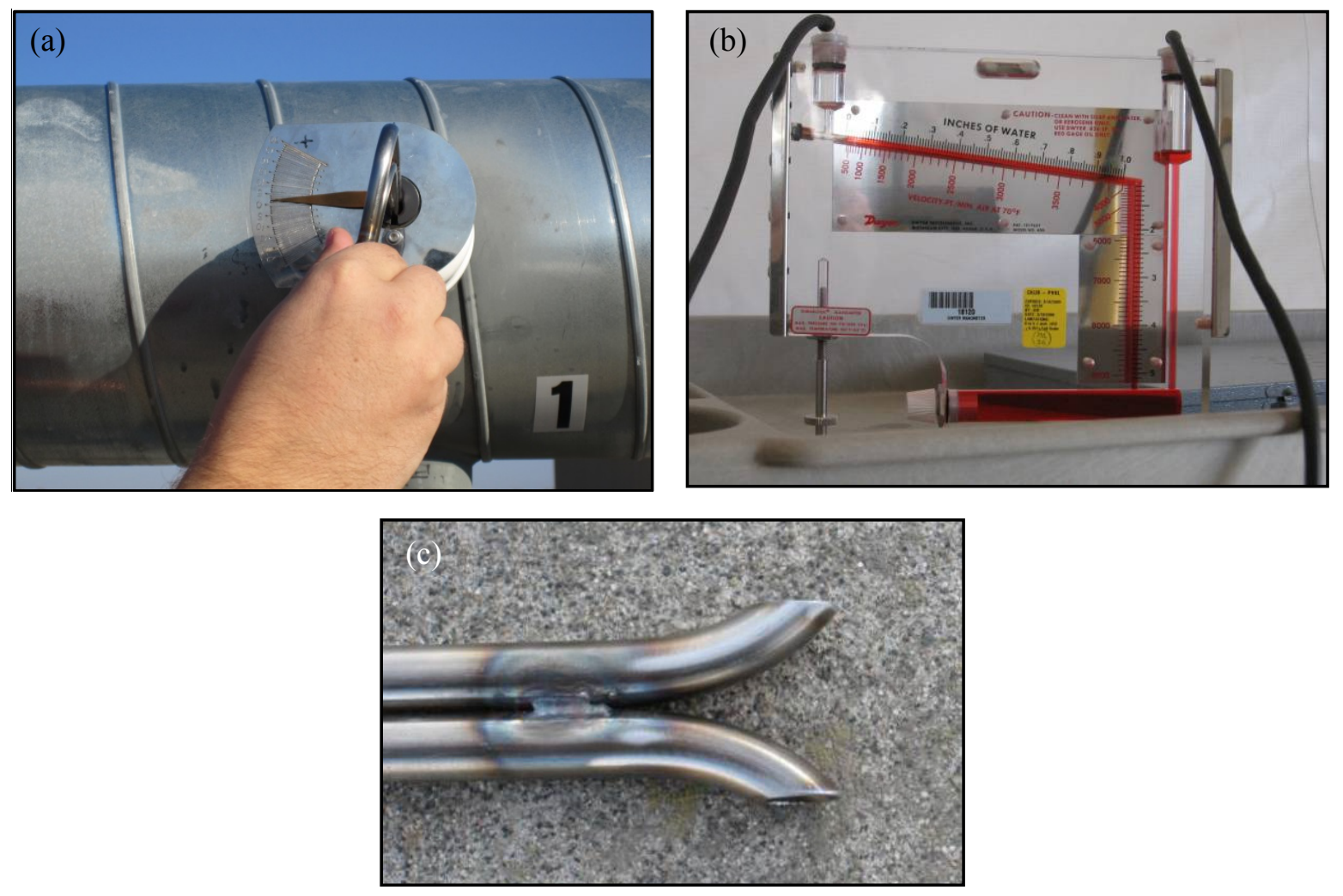

Figure 3.3. Equipment Used for the Flow Angle Test: (a) S-type Pitot Tube Inserted in a Test Port with the Angle-Indicating Device, (b) Slant-Tube Manometer, and (c) Openings at Tip of S-Type Pitot Tube

\subsubsection{Gaseous Tracer Uniformity}

The gaseous contaminant concentration uniformity was demonstrated using the tracer gas nitrous oxide $\left(\mathrm{N}_{2} \mathrm{O}\right)$. A compressed gas cylinder and a flow controller were used to deliver a constant stream of $\mathrm{N}_{2} \mathrm{O}$ into the duct. The gaseous tracer was typically injected into the duct at a point downstream of the fans. Figure 3.4 shows the injection locations with an injection probe positioned in the port. For separate test runs, the injection probe is positioned at one of five different locations in the duct cross section as illustrated in Figure 3.5 for circular ducts. The remaining four injection locations are within a specified distance of the duct wall. For a nominally 12-in.-diameter duct, the four "wall" injection locations were located within 2.4 in. of the wall. 


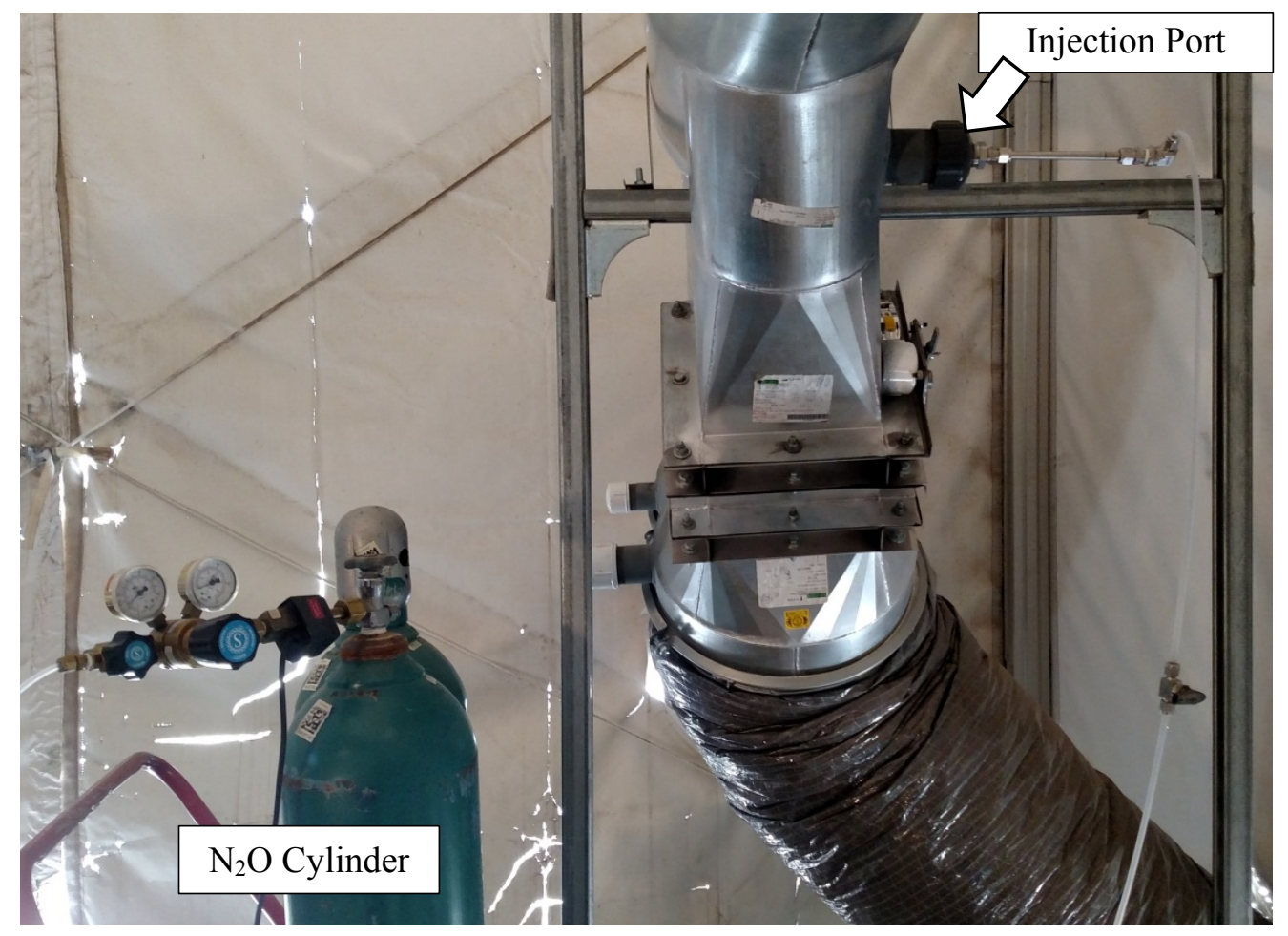

Figure 3.4. Equipment Used for the Gaseous Tracer Injection. Injection Probe Installed in the Scale Model and Cylinder of Pure $\mathrm{N}_{2} \mathrm{O}$ with Heater and Regulator.

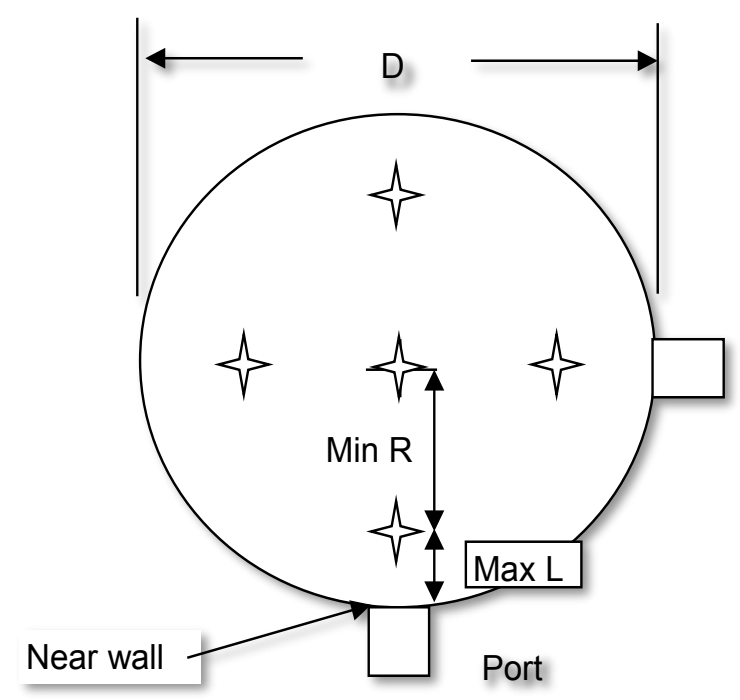

Figure 3.5. Illustration of Five Injection Points in a Circular Duct. Note: Max L is the maximum distance from the wall, which is $20 \%$ of the hydraulic diameter. Therefore, Min R, the minimum radius from the duct center, is $80 \%$ of the hydraulic diameter. In the case of a circular duct, the hydraulic diameter is equal to the physical diameter (D).

For each test run, the tracer concentration was read three times at each of the measurement points across the duct. The measured concentration for each point is the average of the three readings. These measured concentrations are used to calculate the overall mean, standard deviation, and \%COV. These 
calculations also are performed just for the measurement points in the center two-thirds of the duct. The qualification criteria for the gaseous tracer test are that 1) the $\% \mathrm{COV}$ should be $\leq 20 \%$ within the center two-thirds of the duct, and 2) the concentration at any measurement point should not deviate from the overall mean by more than $30 \%$.

A photoacoustic gas analyzer (Brüel \& Kjær, Model 1302, Ballerup, Denmark) was used to measure tracer gas concentrations. The concentration variation is the important result for this test, so calibration bias is not important in the test results. However, the analyzer response was checked with calibration standards before and after conducting the test series (as well as weekly during the test series) to verify an adequate instrument response. The response was considered acceptable if the concentration from the instrument was within $10 \%$ of the calibration standard.

A simple probe was used to extract the sample and deliver it to the gas analyzer. A small pump drew air from within the stack through the probe. The gas analyzers then sampled the air from the sample line for analysis (Figure 3.6). The procedure EMS-JAG-01, Rev 4 and test instructions TI-WTPSP-117 and TI-WTPSP-122 were used to conduct this test for each scale model.

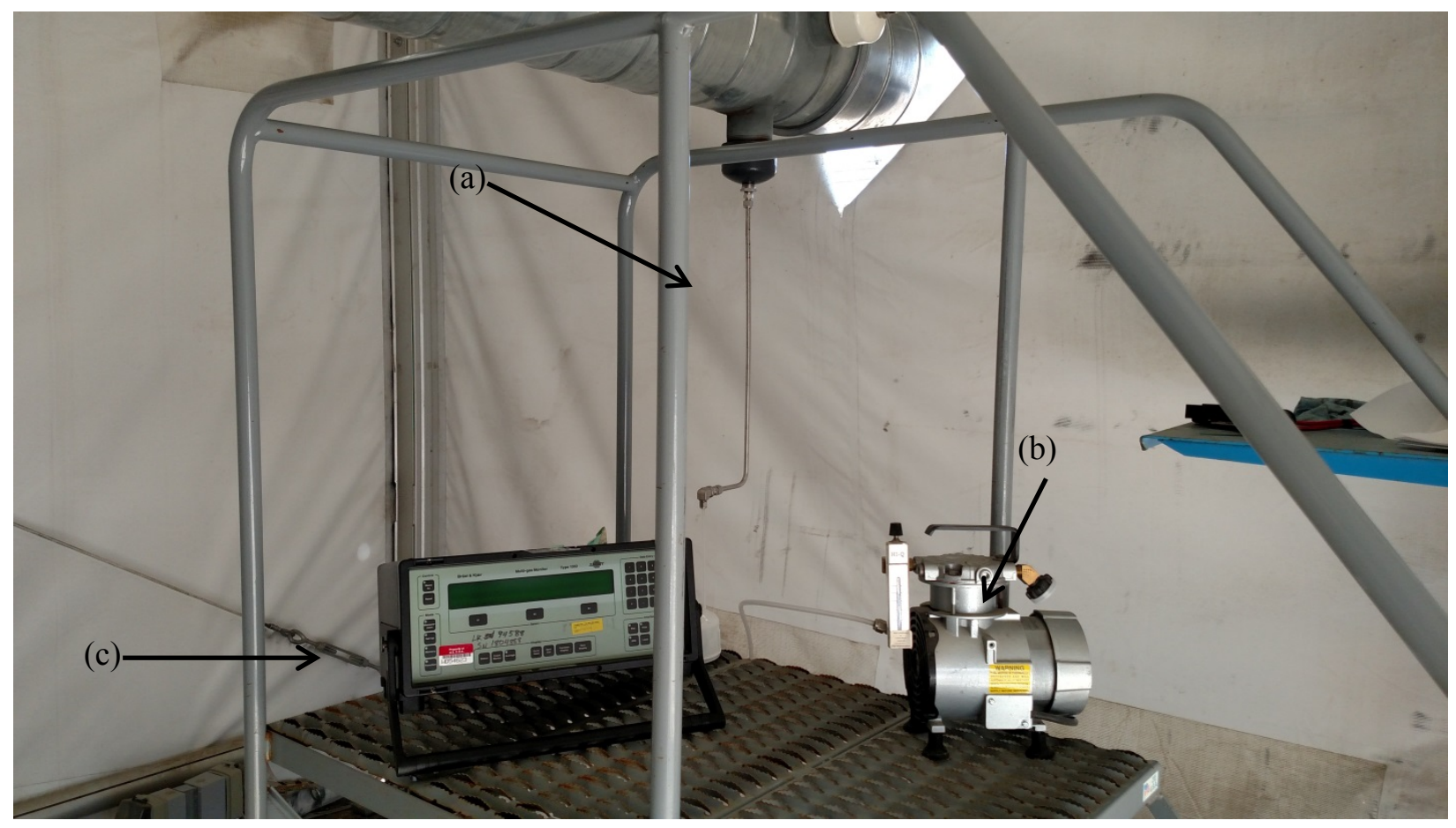

Figure 3.6. Equipment Used for the Gaseous Tracer Sampling: (a) Sampling Probe Installed in a Port, (b) Sampling Pump, and (c) Gas Analyzer

\subsubsection{Particle Tracer Uniformity}

The uniformity of the particulate contaminant concentration was demonstrated using polydisperse vacuum pump oil particles as a particle tracer. The oil was drawn into a spray nozzle (driven by compressed air) housed in a stainless steel chamber. These aerosol particles were injected into the duct air at an injection point downstream of the fans as shown in Figure 3.7. Figure 3.7 shows the equipment setup for an aerosol injection in the LV-C scale model stack. The stainless steel chamber and spray 
nozzle assembly is also referred to as the aerosol generator. In previous tests, an aerosol generator of similar design, except constructed out of PVC, was used. The aerosol was injected at the centerline of the duct, and this test was repeated to gain some sense of the variability of the results.

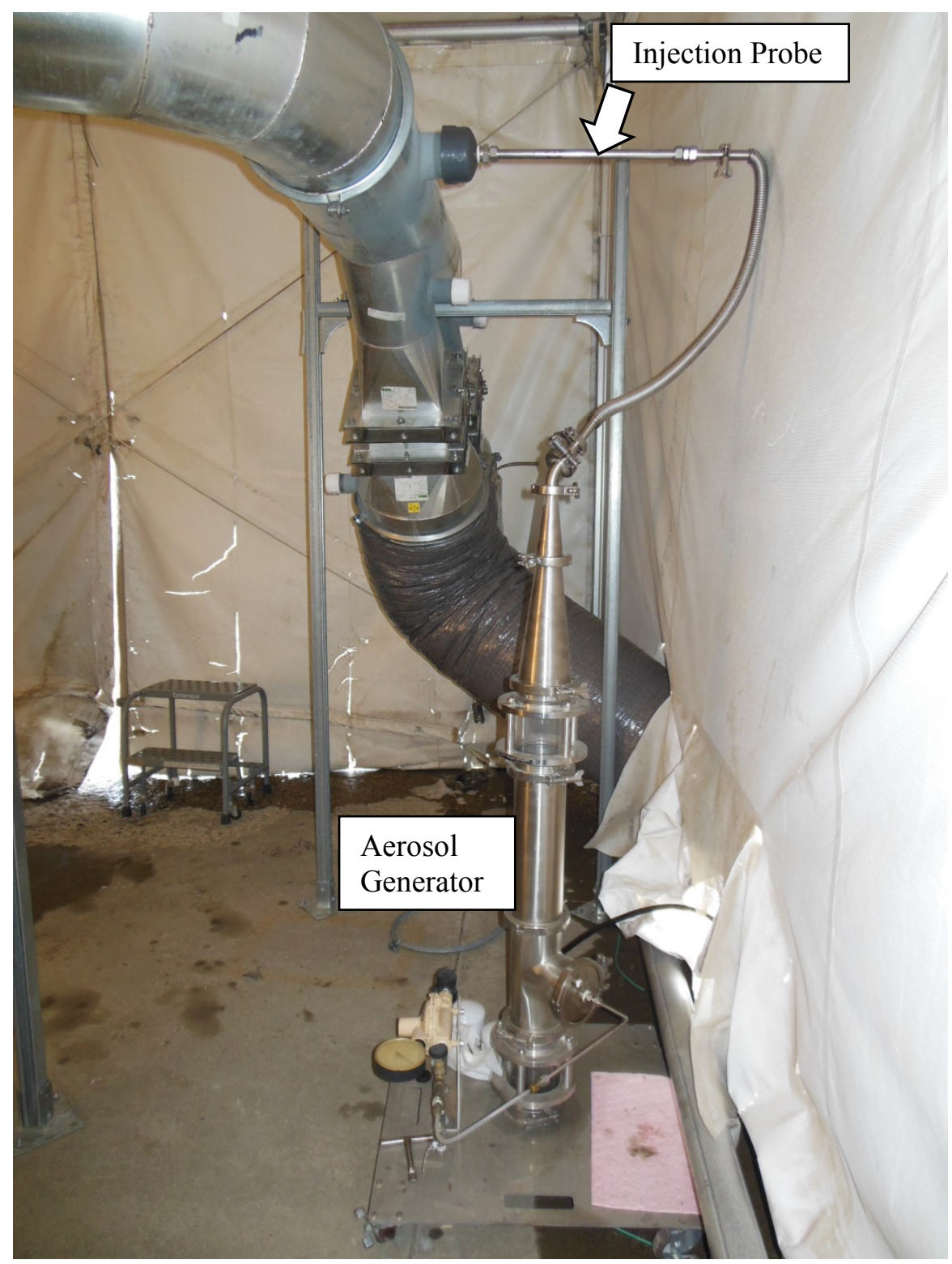

Figure 3.7. Equipment Used for Particle Injection

The concentration of the particles is measured at the sampling grid points with a calibrated optical particle counter (OPC) (Hach, Met-One Model 3415, Loveland, CO). A simple probe was used to extract the sample and deliver it to the OPC. Figure 3.8 shows the sampling setup with the simple probe connected to the OPC. To identify potential inconsistencies in the aerosol output, tests were conducted with a reference instrument measuring the particle concentration at a location downstream of the test port. The OPC sorts the particles into eight size channels. As mentioned in Section 1.1, the particles of interest have an $\mathrm{AD}$ of $10 \mu \mathrm{m}$. Therefore, only data in the 9- to $11-\mu \mathrm{m}$ channel of the OPC were used. 
The particle concentration was read three times at each of the measurement points across the cross section of the duct. The measured concentration for each point is the average of the three readings. From these measurements, the overall mean, standard deviation, and \%COV were calculated for all of the points and also just for those within the center two-thirds of the duct. The qualification criterion for the particle tracer test is that the \%COV should be less than or equal to $20 \%$ within the center two-thirds of the duct. The procedure EMS-JAG-02 and test instructions TI-WTPSP-116 and TI-WTPSP-123 were used to conduct this test.
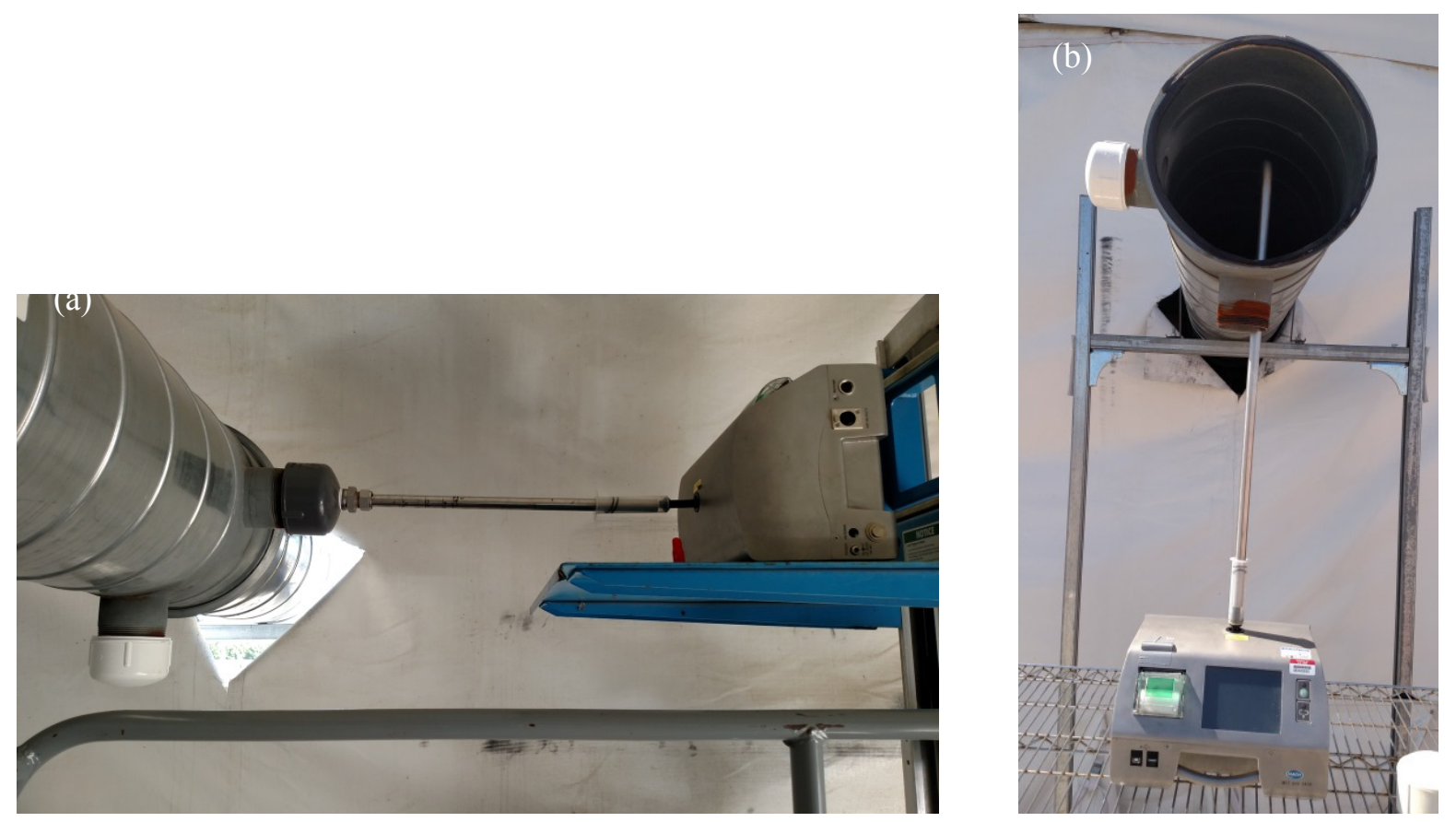

Figure 3.8. Particle Counters Used for the Particle Sampling. (a) Optical Particle Counter for Measurement Data in Side Port of LV-C2 Scale Model System; (b) Fixed Position Reference Optical Particle Counter in Bottom of LV-C2 Reference Port. 



\subsection{LV-C2 Stack Testing Results}

This section summarizes the results of the stack testing activities for the retest of the LV-C2 scale model stack. The primary, reportable results are the data and data calculations to confirm that the requirements of the ANSI/HPS N13.1-1999 standard have been met. Independent reviews were performed to verify the data transcription and calculations. These calculations were performed using Excel (2010) and documented in computer-assisted calculation packages (CCPs) in accordance with WTPSP procedures. The final data sheets for the LV-C2 tests are included in Appendices B and C, respectively. Appendix A contains a list of supporting documentation (such as the test plan and test instructions) used with this scale model Test Group.

The scale model stack underwent a series of velocity uniformity tests (designated VT), flow angle tests (designated FA), gas tracer tests (designated GT) and particle tracer tests (designated PT). Tables summarizing the results of tests for the scale model are presented in subsections of this section. It is possible that during some tests the scale model velocity values were higher than the actual stack flow for the conditions the test was meant to represent. This is acceptable because the DV value was still within a factor of six of the stack design values, and the facility flow conditions are estimates and may vary significantly from the design conditions at times for a variety of reasons.

The LV-C2 stack was originally tested as part of a group of three LAW stacks referred to as Test Group 1-2A. The original test results are not summarized in this section of the report, but summary tables and the datasheets are included as Appendix B for completeness.

Summary tables of the data for Test Port 1 for LV-C2 retest flow angle, velocity, gas tracer, and particle tracer test results are presented in the following subsections. Some test combinations were repeated (i.e., performed more than once at different times) to quantify the testing and response measurement uncertainty.

\subsection{LV-C2 Retest Velocity Uniformity}

Table 4.1 lists the results for the velocity uniformity tests performed on the retest of the scale model LV-C2 stack. In all cases, the results were well within the criterion of $\% \mathrm{COV}$ values $\leq 20 \%$. Velocity uniformity results were typically below 5\%. The velocity in the stack ranged from 1437 to 3235 afpm (1114 to $2508 \mathrm{acfm}$ ). Table 2.2. lists the desired range of minimum scale model flow rates as 1410 to $1692 \mathrm{afpm}$ (1105 to $2137 \mathrm{acfm}$ ). The desired testing conditions were between the minimum scale model flow rate and the actual stack velocity. With these flow conditions, the scale model meets both the Reynolds number and DV criteria required to represent the actual stack. The completed data sheets from these tests are available in Appendix C, Subsection C.1. 
Table 4.1. Summary of LV-C2 Retest Velocity Uniformity Tests

\begin{tabular}{|c|c|c|c|c|c|}
\hline Operating Fan & $\begin{array}{c}\text { Flow } \\
\text { Condition }\end{array}$ & Run No. & $\begin{array}{l}\text { Flow } \\
(\mathrm{acfm})\end{array}$ & $\begin{array}{c}\text { Approx. Air } \\
\text { Velocity (afpm) }\end{array}$ & $\% \mathrm{COV}$ \\
\hline \multirow{5}{*}{ A } & Max & VT-12 & 2414 & 3115 & 2.1 \\
\hline & Norm & VT-16 & 1973 & 2545 & 2.5 \\
\hline & \multirow{3}{*}{ Min } & VT-13 & 1217 & 1570 & 2.7 \\
\hline & & VT-14 & 1212 & 1563 & 2.6 \\
\hline & & VT-15 & 1214 & 1565 & 2.7 \\
\hline \multirow{7}{*}{ B } & \multirow{3}{*}{ Max } & VT-1 & 2508 & 3235 & 3.4 \\
\hline & & VT-2 & 2471 & 3188 & 4.4 \\
\hline & & VT-3 & 2461 & 3174 & 4.2 \\
\hline & \multirow{3}{*}{ Norm } & VT-5 & 1982 & 2556 & 2.8 \\
\hline & & VT-6 & 2158 & 2783 & 4.9 \\
\hline & & VT-7 & 1814 & 2340 & 5.2 \\
\hline & Min & VT-4 & 1114 & 1437 & 5.1 \\
\hline \multirow{4}{*}{$A \& B$} & \multirow{3}{*}{ Max } & VT-8 & 2261 & 2917 & 3.7 \\
\hline & & VT-9 & 2263 & 2920 & 3.2 \\
\hline & & VT-10 & 2255 & 2908 & 3.3 \\
\hline & Min & VT-11 & 1202 & 1551 & 3.7 \\
\hline
\end{tabular}

Note: Individual and replicate sets of tests are alternately shaded and unshaded.

\subsection{LV-C2 Retest Flow Angle}

Table 4.2 lists the results for the flow angle tests performed on the retest of the LV-C2 scale model stack. The results for all tests were well within the criterion of flow angle values $\leq 20^{\circ}$. Fan A flow angles ranged from $1.9^{\circ}$ to $3.4^{\circ}$, while Fan B flow angles range from $3.2^{\circ}$ to $6.4^{\circ}$, and with both Fans A and $\mathrm{B}$ operating, the flow angles ranged from $2.7^{\circ}$ to $3.1^{\circ}$. The completed data sheets from these tests are available in Appendix C, Subsection C.2. 
Table 4.2. Summary of LV-C2 Retest Flow Angle Tests

\begin{tabular}{|c|c|c|c|c|}
\hline Operating Fan & $\begin{array}{c}\text { Flow } \\
\text { Condition }\end{array}$ & Run No. & $\begin{array}{c}\text { Approx. Air } \\
\text { Velocity (afpm) }\end{array}$ & $\begin{array}{c}\text { Flow Angle } \\
\text { (Degrees) }\end{array}$ \\
\hline \multirow{7}{*}{ A } & \multirow{3}{*}{$\operatorname{Max}$} & FA-1 & 3266 & 3.4 \\
\hline & & FA-2 & 3253 & 2.7 \\
\hline & & FA-3 & 3144 & 2.4 \\
\hline & \multirow{3}{*}{ Norm } & FA-4 & 2797 & 2.4 \\
\hline & & FA-5 & 2530 & 2.3 \\
\hline & & FA-6 & 2496 & 2.3 \\
\hline & Min & FA-7 & 1647 & 1.9 \\
\hline \multirow{6}{*}{ B } & \multirow{2}{*}{$\operatorname{Max}$} & FA-8 & 3156 & 6.4 \\
\hline & & FA-9 & 3177 & 4.6 \\
\hline & Norm & FA-10 & 2567 & 4.4 \\
\hline & \multirow{3}{*}{ Min } & FA-11 & 1547 & 3.2 \\
\hline & & FA-12 & 1586 & 5.5 \\
\hline & & FA-13 & 1556 & 5.2 \\
\hline \multirow{4}{*}{$A \& B$} & Max & FA-14 & 3041 & 3.4 \\
\hline & \multirow{3}{*}{ Min } & FA-15 & 1582 & 2.7 \\
\hline & & FA-16 & 1577 & 2.6 \\
\hline & & FA-17 & 1569 & 3.1 \\
\hline
\end{tabular}

\subsection{LV-C2 Retest Gaseous Tracer Uniformity}

During the gas tracer testing, the responses of the gas analyzers were checked against calibration standards of appropriate concentrations, and the results met the requirements of the procedure. The data sheets from these calibration checks can be found in the first portion of Appendix C, Subsection C.3.

The LV-C2 scale model had six injection ports, however, only three were employed during testing. They are Injection Port 2 (I2), Injection Port 3 (I3), and Injection Port 4 (I4), as shown in Figure 2.2. All three injection ports are in circular sections of duct and the five injection points within the circular duct are shown in Figure 3.5.

Table 4.3 lists the results for all of the gaseous tracer uniformity tests performed on the scale model LV-C2 stack. No contingency sampling port was tested for this scale model; all tests were performed at the proposed test port location. Gas tracer test conditions for GT-1 through GT-4 were repeated at the end of the end of testing, as GT-32 through GT-35, because the calibration gas standard used to check the performance of the gas analyzer was past its expiration date and was discovered in an internal audit which generated a Non-Conformance Report (NCR-OTS-0787). These test results (GT-1 - GT-4) are not to be used. However, they are reported here for completeness and are considered For Information Only.

Gaseous uniformity tests using Fan A ranged from 0.3 to $2.6 \% \mathrm{COV}$ for gas injection at I4. Gas uniformity tests using Fan B ranged from 1.2 to $6.1 \% \mathrm{COV}$ with gas injection occurring at I3. Gas uniformity tests using both fans ranged from 1.9 to $11.9 \% \mathrm{COV}$ for gas injection at I2. In all cases, the gas tracer was well-mixed, with results well within the qualification criteria of $\% \mathrm{COV}$ values less than or equal to $20 \%$ and absolute value of maximum deviation less than or equal to $30 \%$. COV values were typically less than $10 \%$, with maximum deviation values typically less than $20 \%$. The completed data sheets are available in Appendix C, Subsection C.3. 
Table 4.3. Summary of LV-C2 Retest Gas Tracer Uniformity Tests

\begin{tabular}{|c|c|c|c|c|c|c|}
\hline $\begin{array}{c}\text { Operating } \\
\text { Fan }\end{array}$ & $\begin{array}{c}\text { Flow } \\
\text { Condition } \\
\end{array}$ & $\begin{array}{c}\text { Injection Port \& } \\
\text { Location }\end{array}$ & Run No. & $\begin{array}{c}\text { Approx. } \\
\text { Air } \\
\text { Velocity } \\
\text { (afpm) }\end{array}$ & $\% \mathrm{COV}$ & $\begin{array}{l}\text { Absolute \% } \\
\text { Max. Dev. } \\
\text { from Mean }\end{array}$ \\
\hline \multirow{11}{*}{ A } & \multirow{7}{*}{ Min } & I4, Center & GT-12 & 1616 & 0.3 & 0.5 \\
\hline & & I4, Top & GT-13 & 1632 & 1.2 & 1.6 \\
\hline & & I4, Bottom & GT-14 & 1611 & 0.6 & 1.4 \\
\hline & & I4, Far Wall & GT-15 & 1612 & 2.6 & 6.8 \\
\hline & & I4, Near Wall & GT-16 & 1663 & 1.4 & 2.9 \\
\hline & & I4, Far Wall & GT-17 & 1602 & 2.1 & 4.4 \\
\hline & & I4, Far Wall & GT-18 & 1596 & 1.5 & 2.7 \\
\hline & \multirow{2}{*}{ Norm } & I4, Far Wall & GT-19 & 2617 & 1.9 & 3.5 \\
\hline & & I4, Far Wall & GT-20 & 2652 & 1.9 & 3.7 \\
\hline & \multirow{2}{*}{ Max } & I4, Far Wall & GT-21 & 3178 & 2.3 & 5.0 \\
\hline & & I4, Far Wall & GT-22 & 3117 & 2.1 & 3.7 \\
\hline \multirow{15}{*}{ B } & \multirow{11}{*}{ Max } & 13, Center & GT 1 & 3191 & 4.4 & 7.2 \\
\hline & & I3, Center & GT-32 & 3106 & 6.1 & 11.6 \\
\hline & & I3, Far Wall & GT-2 & 3105 & 1.7 & 5.2 \\
\hline & & I3, Far Wall & GT-33 & 3088 & 2.5 & 6.0 \\
\hline & & 13, Near Wall & GT-3 & 3145 & 3.2 & 5.0 \\
\hline & & I3, Near Wall & GT-34 & 3145 & 4.0 & 7.2 \\
\hline & & I3, Top & GT-4 & 3116 & 2.1 & 3.8 \\
\hline & & I3, Top & GT-35 & 3171 & 1.3 & 4.0 \\
\hline & & I3, Bottom & GT-5 & 3066 & 1.2 & 3.0 \\
\hline & & I3, Center & GT-6 & 3053 & 1.7 & 3.5 \\
\hline & & I3, Center & GT-7 & 3109 & 1.8 & 3.4 \\
\hline & \multirow{2}{*}{ Norm } & I3, Center & GT-8 & 2616 & 1.7 & 3.7 \\
\hline & & I3, Center & GT-9 & 2651 & 2.1 & 4.9 \\
\hline & \multirow{2}{*}{ Min } & I3, Center & GT-10 & 1608 & 2.6 & 4.7 \\
\hline & & I3, Center & GT-11 & 1624 & 3.2 & 7.6 \\
\hline \multirow{9}{*}{$\mathrm{A} \& \mathrm{~B}$} & \multirow{7}{*}{ Min } & I2, Center & GT-23 & 1637 & 10.5 & 27.6 \\
\hline & & I2, Far Wall & GT-24 & 1609 & 9.4 & 19.4 \\
\hline & & I2, Near Wall & GT-25 & 1639 & 11.9 & 27.4 \\
\hline & & I2, Bottom & GT-26 & 1636 & 1.9 & 5.5 \\
\hline & & I2, Top & GT-27 & 1648 & 8.3 & 16.3 \\
\hline & & I2, Near Wall & GT-28 & 1589 & 9.4 & 18.7 \\
\hline & & I2, Near Wall & GT-29 & 1604 & 9.8 & 21.2 \\
\hline & \multirow{2}{*}{ Max } & I2, Near Wall & GT-30 & 3136 & 9.5 & 20.1 \\
\hline & & I2, Near Wall & GT-31 & 3160 & 9.0 & 20.0 \\
\hline
\end{tabular}

Note 1: Individual and replicate sets of tests are alternately shaded and unshaded.

Note 2: The test results GT-1 to GT-4 are not to be used, but are reported here for completeness. 


\subsection{LV-C2 Particle Tracer Uniformity}

Results of the particle tracer uniformity tests include the non-normalized \%COV and normalized $\% \mathrm{COV}$ for each run. The non-normalized \%COV utilizes the particulate concentration data directly, while the normalized \%COV results from a data adjustment that has been performed for this and previous tests based on previous test experience. Typically, a concentration bias is encountered between the two traverse directions because the probe orientation is vertical through the bottom port and horizontal through the side port. The bias is removed by adjusting the data from the traverse with the lower concentration upward by a factor to match the concentrations at the center of the duct (the common point between the two traverses). These results were then termed "normalized." In interpreting the table of particle tracer uniformity results, the normalized data are considered the pertinent result. The non-normalized data are used in comparison to the normalized result as an indication of the concentration bias.

In the original LV-C2 testing, conducted in 2014, the particle tracer uniformity test criteria were not met in the maximum flow condition. Those tests utilized not-to-scale backdraft dampers which were installed $90^{\circ}$ offset compared with the actual system. After the original tests, BNI notified PNNL of reduced system flow rates. As part of the retest effort, a set of preliminary tests were performed to relate the original test results with the not-to-scale backdraft damper installed in correct orientation and to scaled control and backdraft dampers installed in proper orientation with the updated flow conditions. All preliminary tests were done in the same configuration that failed during initial testing, i.e., Fan B at maximum flow rate, and the results are shown in Table 4.4.

The results of these preliminary tests still indicated that even with the reduced flow conditions, the installation of the scaled dampers did not pass the test criterion with particle injection at Injection Port 2 (normalized \% COV $=23.4$ ).

A second set of preliminary tests was conducted to find a sampling port and injection port combination that would allow the system to pass. To simulate relocating the sampling location farther downstream on the stack, a five foot section of duct with new test ports was installed (see Figure 4.1). The new section was inserted between the section of duct with the Test Port 1 and the section of duct with the Reference Port. An Injection Port 5 was added upstream of the Fan B control damper. Because of the tight space the standard injection probe could not be used at I5, so two other injection probes were fabricated. Based on flow patterns the probe with the right angle was used to inject particles at I5 (see Figure 4.2). The aerosol from the probe with the $90^{\circ}$ angle flowed more directly downstream as opposed to the probe with the $90^{\circ}$ sweeping bend where the aerosol drifted out of the probe end at an obtuse angle. 
Table 4.4. Summary of LV-C2 Retest Preliminary Particle Tracer Uniformity Tests Using Injection Port I2 and Test Port 1

\begin{tabular}{|c|c|c|c|c|c|}
\hline $\begin{array}{c}\text { Damper } \\
\text { Configuration } \\
\end{array}$ & Fan & $\begin{array}{l}\text { Run } \\
\text { Nos. }\end{array}$ & $\begin{array}{l}\text { Approx. } \\
\text { Air } \\
\text { Velocity } \\
\text { (afpm) }\end{array}$ & $\begin{array}{c}\text { Non- } \\
\text { Normalized \% } \\
\text { COV }\end{array}$ & $\begin{array}{c}\text { Normalized \% } \\
\text { COV }\end{array}$ \\
\hline \multirow{6}{*}{$\begin{array}{l}\text { Oversized, } \\
\text { correct } \\
\text { alignment }\end{array}$} & \multirow{3}{*}{$\begin{array}{c}\text { B } \\
\text { Previous } \\
\text { Max }\end{array}$} & PT-1 & 3958 & 29.9 & 21.5 \\
\hline & & PT-2 & 3953 & 29.4 & 29.6 \\
\hline & & PT-3 & 3984 & 23.5 & 23.5 \\
\hline & \multirow{3}{*}{$\begin{array}{l}\text { B Retest } \\
\text { Max }\end{array}$} & PT-4 & 3262 & 33.5 & 33.5 \\
\hline & & PT-5 & 3229 & 41.0 & 33.5 \\
\hline & & PT-6 & 3319 & 16.6 & 16.0 \\
\hline \multirow{6}{*}{$\begin{array}{l}\text { Oversized } 90^{\circ} \\
\text { off alignment }\end{array}$} & \multirow{3}{*}{$\begin{array}{c}\text { B } \\
\text { Previous } \\
\text { Max }\end{array}$} & PT-7 & 3762 & 21.3 & 22.6 \\
\hline & & PT-8 & 3859 & 22.5 & 23.4 \\
\hline & & PT-9 & 3873 & 12.1 & 14.7 \\
\hline & \multirow{3}{*}{$\begin{array}{l}\text { B Retest } \\
\text { Max }\end{array}$} & PT-10 & 3250 & 25.6 & 25.8 \\
\hline & & PT-11 & 3172 & 20.0 & 19.3 \\
\hline & & PT-12 & 3141 & 15.2 & 15.2 \\
\hline \multirow{4}{*}{ Scale } & \multirow{3}{*}{$\begin{array}{c}\text { B } \\
\text { Previous } \\
\text { Max }\end{array}$} & PT-13 & 3161 & 54.6 & 17.5 \\
\hline & & PT-14 & 3190 & 22.1 & 22.1 \\
\hline & & PT-15 & 3173 & 24.7 & 24.7 \\
\hline & $\begin{array}{l}\text { B Retest } \\
\text { Max }\end{array}$ & PT-16 & 2746 & 23.4 & 23.4 \\
\hline
\end{tabular}

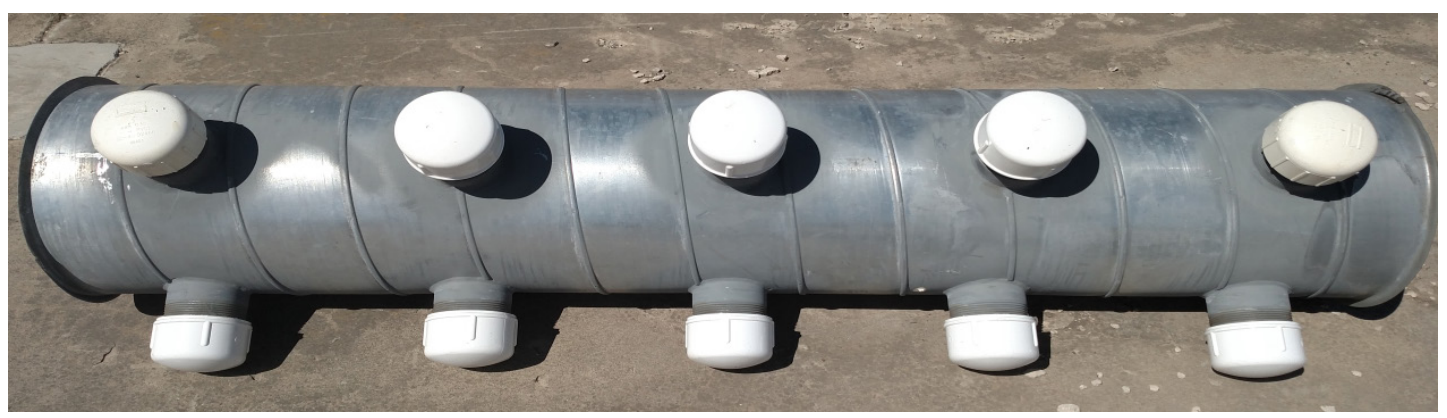

Figure 4.1. Modified Section of Scale Model Stack with Additional Tests Ports at 1-ft Intervals 

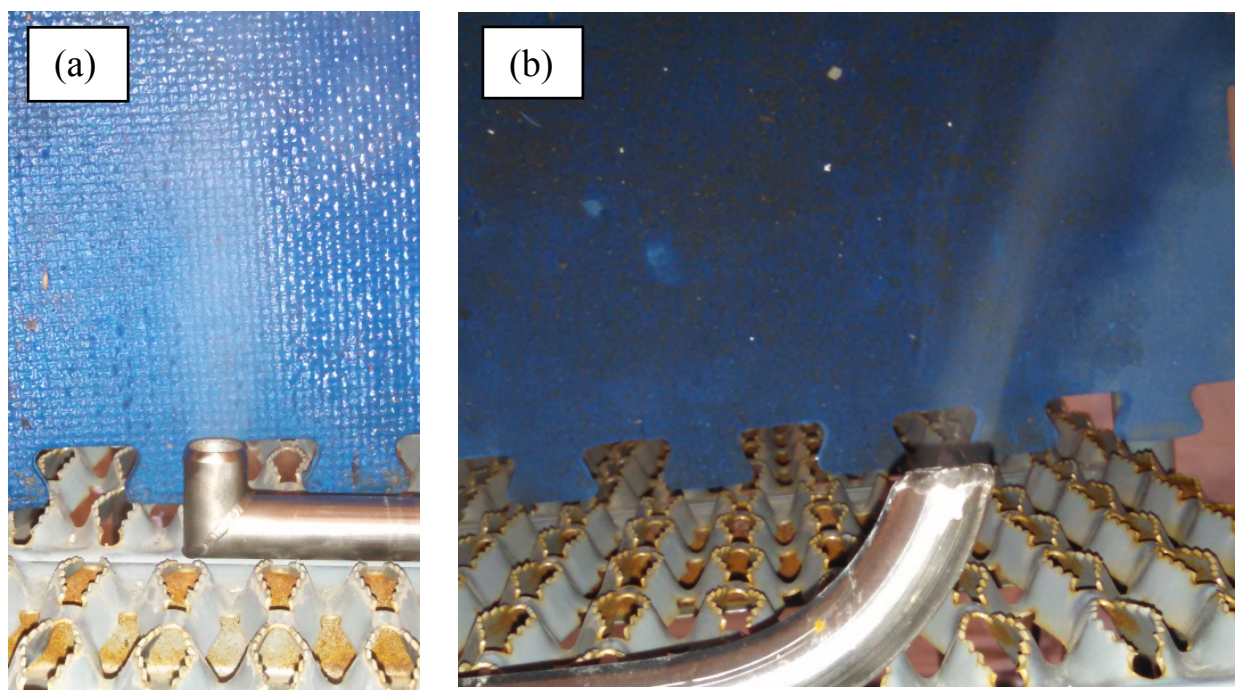

Figure 4.2. Injection Probes Fabricated to Accommodate Tight Space at Injection Port 5: a) $90^{\circ}$ Angle and b) $90^{\circ}$ Bend

Results of this second set of preliminary tests are shown in Table 4.5. With tests for each set of injection port / test port combination done in triplicate, it was clear that if the Injection Port was to remain at the I 2 location, the Test Port would have to be relocated at least one duct diameter further downstream than the current location of Test Port 1 . This situation was undesirable due to cost associated with modifying the existing stack to move the sampling port. Particle injection before the control damper (Injection Port 5) was the least preferred injection location regardless of where sampling was done.

Injection port 3 seemed to have mixed results, so another set of triplicate test were completed for all test port locations and on average, particle injection at I3 with sampling taking place at the preferred location (Test Port 1) appeared to be the best combination of injection and test ports. After this combination was identified for the Fan B maximum flow conditions it was determined that when a single fan was operating tracer injection would be performed on the individual fan leg (Injection Port 3 or 4 ). When both fans were operated at same time, particle injection would be done at Injection Port 2. Then the test matrix laid out in the Test Plan (TP-WTPSP-130 Rev. 1) was performed as the final tests. These results are shown in Table 4.6.

The results from the final particle uniformity tests using Fan A ranged from 2.50 to $8.86 \% \mathrm{COV}$ for particle injection at I4, while particle uniformity tests using Fan B ranged from 4.96 to $12.77 \% \mathrm{COV}$ with particle injection occurring at I3. Particle uniformity tests using both fans ranged from 4.96 to $11.16 \% \mathrm{COV}$ for particle injection at I2. In all cases, the particle tracer was well-mixed, with results well within the qualification criteria of \%COV values less than or equal to $20 \%$. COV values were typically less than 10\%. The entire set of completed data sheets are available in Appendix C, Subsection C.4. 
Table 4.5. Summary of LV-C2 Retest Preliminary Particle Tracer Uniformity Tests Investigating Injection Ports and Test Ports at Revised Maximum Flow Rates, with Fan B

\begin{tabular}{|c|c|c|c|c|c|}
\hline $\begin{array}{l}\text { Injection } \\
\text { Port }\end{array}$ & $\begin{array}{l}\text { Test } \\
\text { Port }^{1} \\
\end{array}$ & $\begin{array}{l}\text { Run } \\
\text { Nos. }\end{array}$ & $\begin{array}{l}\text { Approx. } \\
\text { Air } \\
\text { Velocity } \\
\text { (afpm) }\end{array}$ & $\begin{array}{c}\text { Non-Normalized } \\
\% \mathrm{COV}\end{array}$ & $\begin{array}{c}\text { Normalized \% } \\
\text { COV }\end{array}$ \\
\hline \multirow{6}{*}{$\mathrm{I} 2$} & \multirow{3}{*}{$1 \mathrm{D}$} & PT-17 & 3007 & 12.5 & 11.1 \\
\hline & & PT-18 & 3237 & 12.6 & 11.9 \\
\hline & & PT-19 & 3093 & 19.9 & 19.3 \\
\hline & \multirow{3}{*}{$2 \mathrm{D}$} & PT-29 & 3080 & 18.4 & 17.4 \\
\hline & & PT-30 & 3087 & 13.6 & 13.5 \\
\hline & & PT-31 & 3104 & 12.5 & 12.4 \\
\hline \multirow{18}{*}{ I3 } & \multirow{6}{*}{1} & PT-20 & 3049 & 35.8 & 18.3 \\
\hline & & PT-21 & 2929 & 16.0 & 15.1 \\
\hline & & PT-22 & 2993 & 19.7 & 19.7 \\
\hline & & PT-41 & 3086 & 18.5 & 7.1 \\
\hline & & PT-42 & 3071 & 8.8 & 8.8 \\
\hline & & PT-43 & 3074 & 22.7 & 10.2 \\
\hline & \multirow{6}{*}{ 1D } & PT-23 & 2978 & 21.4 & 22.0 \\
\hline & & PT-24 & 3035 & 11.1 & 11.2 \\
\hline & & PT-25 & 3100 & 13.4 & 14.0 \\
\hline & & PT-38 & 3036 & 14.5 & 13.9 \\
\hline & & PT-39 & 3061 & 14.4 & 14.1 \\
\hline & & PT-40 & 3080 & 19.5 & 13.4 \\
\hline & \multirow{6}{*}{$2 \mathrm{D}$} & PT-26 & 3233 & 11.2 & 11.6 \\
\hline & & PT-27 & 3177 & 13.2 & 13.9 \\
\hline & & PT-28 & 3071 & 12.7 & 12.6 \\
\hline & & PT-44 & 3087 & 16.1 & 16.5 \\
\hline & & PT-45 & 3107 & 14.5 & 14.0 \\
\hline & & PT-46 & 3035 & 21.0 & 17.1 \\
\hline \multirow{6}{*}{ I5 } & \multirow{3}{*}{1} & PT-32 & 3071 & 17.4 & 17.4 \\
\hline & & PT-35 & 3134 & 13.5 & 13.3 \\
\hline & & PT-37 & 3058 & 16.7 & 16.5 \\
\hline & \multirow{3}{*}{$1 \mathrm{D}$} & PT-33 & 3025 & 23.2 & 23.4 \\
\hline & & PT-34 & 3161 & 21.0 & 21.2 \\
\hline & & PT-36 & 3069 & 19.3 & 16.8 \\
\hline
\end{tabular}

Note 1: $\mathrm{D}$ is used in Test Port column to indicate the location of the sampling port, i.e., either 1 or 2 Duct Diameter(s) Downstream of Test Port 1. 
Table 4.6. Summary of Final LV-C2 Retest Particle Tracer Uniformity Tests

\begin{tabular}{|c|c|c|c|c|c|c|}
\hline $\begin{array}{c}\text { Operating } \\
\text { Fan }\end{array}$ & $\begin{array}{l}\text { Injection } \\
\text { Port }\end{array}$ & $\begin{array}{c}\text { Flow } \\
\text { Condition }\end{array}$ & $\begin{array}{l}\text { Run } \\
\text { Nos. }\end{array}$ & $\begin{array}{c}\text { Measured } \\
\text { AFPM }\end{array}$ & $\begin{array}{c}\text { Non- } \\
\text { Normalized } \\
\% \mathrm{COV}\end{array}$ & $\begin{array}{c}\text { Normalized } \\
\% \mathrm{COV}\end{array}$ \\
\hline \multirow{9}{*}{ A } & \multirow{9}{*}{ I4 } & \multirow{3}{*}{ Min } & PT-53 & 1551 & 3.5 & 3.4 \\
\hline & & & PT-54 & 1522 & 8.9 & 2.5 \\
\hline & & & PT-55 & 1528 & 4.8 & 3.5 \\
\hline & & \multirow{3}{*}{ Norm } & PT-59 & 2621 & 6.7 & 6.1 \\
\hline & & & PT-60 & 2737 & 9.9 & 4.3 \\
\hline & & & PT-61 & 2676 & 5.9 & 6.8 \\
\hline & & \multirow{3}{*}{ Max } & PT-56 & 3141 & 8.3 & 7.4 \\
\hline & & & PT-57 & 3156 & 9.6 & 7.1 \\
\hline & & & PT-58 & 3100 & 11.0 & 8.9 \\
\hline \multirow{13}{*}{ B } & \multirow{13}{*}{$\mathrm{I} 3$} & \multirow{3}{*}{ Min } & PT-50 & 1477 & 9.5 & 5.0 \\
\hline & & & PT-51 & 1595 & 8.4 & 8.6 \\
\hline & & & PT-52 & 1625 & 10.1 & 9.4 \\
\hline & & \multirow{3}{*}{ Norm } & PT-47 & 2364 & 12.3 & 8.4 \\
\hline & & & PT-48 & 2595 & 11.5 & 11.0 \\
\hline & & & PT-49 & 2626 & 9.4 & 9.2 \\
\hline & & \multirow{7}{*}{ Max } & PT-41 & 3086 & 18.5 & 7.1 \\
\hline & & & PT-42 & 3071 & 8.8 & 8.8 \\
\hline & & & PT-43 & 3074 & 22.7 & 10.2 \\
\hline & & & PT-68 & 3041 & 7.9 & 7.5 \\
\hline & & & PT-69 & 3098 & 10.5 & 8.6 \\
\hline & & & PT-70 & 3153 & 12.9 & 12.8 \\
\hline & & & PT-71 & 3145 & 16.1 & 9.4 \\
\hline \multirow{6}{*}{$A \& B$} & \multirow{6}{*}{$\mathrm{I} 2$} & \multirow{3}{*}{ Min } & PT-65 & 1626 & 6.3 & 6.2 \\
\hline & & & PT-66 & 1643 & 9.9 & 5.0 \\
\hline & & & PT-67 & 1624 & 8.7 & 8.0 \\
\hline & & \multirow{3}{*}{ Max } & PT-62 & 3029 & 13.6 & 11.2 \\
\hline & & & PT-63 & 3050 & 13.9 & 9.6 \\
\hline & & & PT-64 & 3066 & 11.6 & 9.9 \\
\hline
\end{tabular}





\subsection{Conclusions}

The results of the stack qualification tests performed with the LV-C2 scale model stack are summarized in Table 5.1. The criteria for sampling probe locations given in ANSI/HPS N13.1-1999, Sampling and Monitoring Releases of Airborne Radioactive Substances from the Stack and Ducts of Nuclear Facilities, were met in all cases. These criteria address the capability of the sampling probe to extract a sample that represents the effluent stream. The range of results presented in Table 5.1 for the LV-C2 stack covers the designed location for the air sampling probe, Test Port 1.

Table 5.1. Summary of Sampling Probe Location Results for the LV-C2 Scale Model Stack

\begin{tabular}{lclcc}
\hline & $\begin{array}{c}\text { Acceptance } \\
\text { Criteria }\end{array}$ & Units & $\begin{array}{c}\text { Original } \\
\text { LV-C2 }\end{array}$ & $\begin{array}{c}\text { Final } \\
\text { LV-C2 }\end{array}$ \\
\cline { 2 - 5 } & $\leq 20$ & \%COV & $2.2-5.4$ & $2.1-5.1$ \\
\hline $\begin{array}{l}\text { Velocity } \\
\text { Uniformity }\end{array}$ & $\leq 20$ & Degrees & $2.9-8.0$ & $1.9-5.5$ \\
\hline Flow Angle & $\leq 20$ & $\%$ COV & $0.8-14.7$ & $0.3-11.9$ \\
\hline $\begin{array}{l}\text { Gas Tracer } \\
\text { Uniformity }\end{array}$ & $\leq 30$ & $\begin{array}{l}\text { Maximum \% } \\
\text { Deviation from Mean }\end{array}$ & $1.3-18.6$ & $0.5-27.6$ \\
\hline $\begin{array}{l}\text { Particle Tracer } \\
\text { Uniformity }\end{array}$ & $\leq 20$ & Normalized \%COV & $6.0-31.1$ & $2.5-12.8$ \\
\hline Nest Port 1
\end{tabular}

Note: The test failure in the original results was for the particle tracer uniformity tests when Fan B was operated at the maximum flow condition.

Based on these scale model tests, the location proposed for the air sampling probe in the LV-C2 stack meet the requirements of the ANSI/HPS N13.1-1999 standard. Additional velocity uniformity and flow angle tests on the actual stacks will be necessary during cold startup to confirm the validity of the scale model results in representing the actual stacks. In particular, the velocity uniformity test results for the actual stacks must be within $5 \% \mathrm{COV}$ of the range of results listed above for the scale model so that scale model results can be said to be representative of the stack. For example, if the actual LV-C2 stack sampling probe is located in a position corresponding to Test Port 1 , the measured velocity uniformity $\% \mathrm{COV}$ should be between 0.0 and $10.1 \% \mathrm{COV}$ (non-negative value for $2.1-5=0.0$, and $5.1+5=10.1$ ). The velocity uniformity test results summarized in Table 5.1 cover a range of flow conditions that are expected to bracket the conditions of the actual stack. For cold startup tests, the DV value and Reynolds number should meet the criteria listed in Section 1.1 (i.e., DV within a factor of six and Reynolds number $>10,000)$. The velocity uniformity acceptance range would be constructed using the scale model results that correspond to the probe location and fan operating conditions present during the test on the actual stack.

If in-plant qualification testing becomes necessary, results comparable to this report are more likely when the tracer injection locations are comparable to those used for these tests. For the LV-C2 system either Injection Port I2 (when both fans are operating), I3 (only Fan B operating) or I4 (only Fan A operating) would be acceptable (see Figure 2.2). 



\subsection{References}

10 CFR 830, Subpart A. “Quality Assurance Requirements.” Code of Federal Regulations, U.S. Department of Energy.

40 CFR 60, Appendix A, Method 1. "Method 1-Sample and Velocity Traverses for Stationary Sources." Code of Federal Regulations, U.S. Environmental Protection Agency.

40 CFR 61, Subpart H. "National Emission Standard for Emissions of Radionuclides Other Than Radon From Department of Energy Facilities." Code of Federal Regulations, U.S. Environmental Protection Agency.

ANSI/HPS N13.1-1999. Sampling and Monitoring Releases of Airborne Radioactive Substances from the Stacks and ducts of Nuclear Facilities. American National Standards Institute and the Health Physics Society, McLean, VA (reaffirmed in 2011 as ANSI/HPS N13.1-2011).

American Society of Mechanical Engineers (ASME). Quality Assurance Requirements for Nuclear Facility Applications. NQA-1-2000, New York, NY.

DOE Order 414.1D. “Quality Assurance.” U.S. Department of Energy, Washington, D.C. 



\section{Appendix A}

\section{LV-C2 Scale Model Testing Supporting Documents List}





\section{Appendix A: Document List}

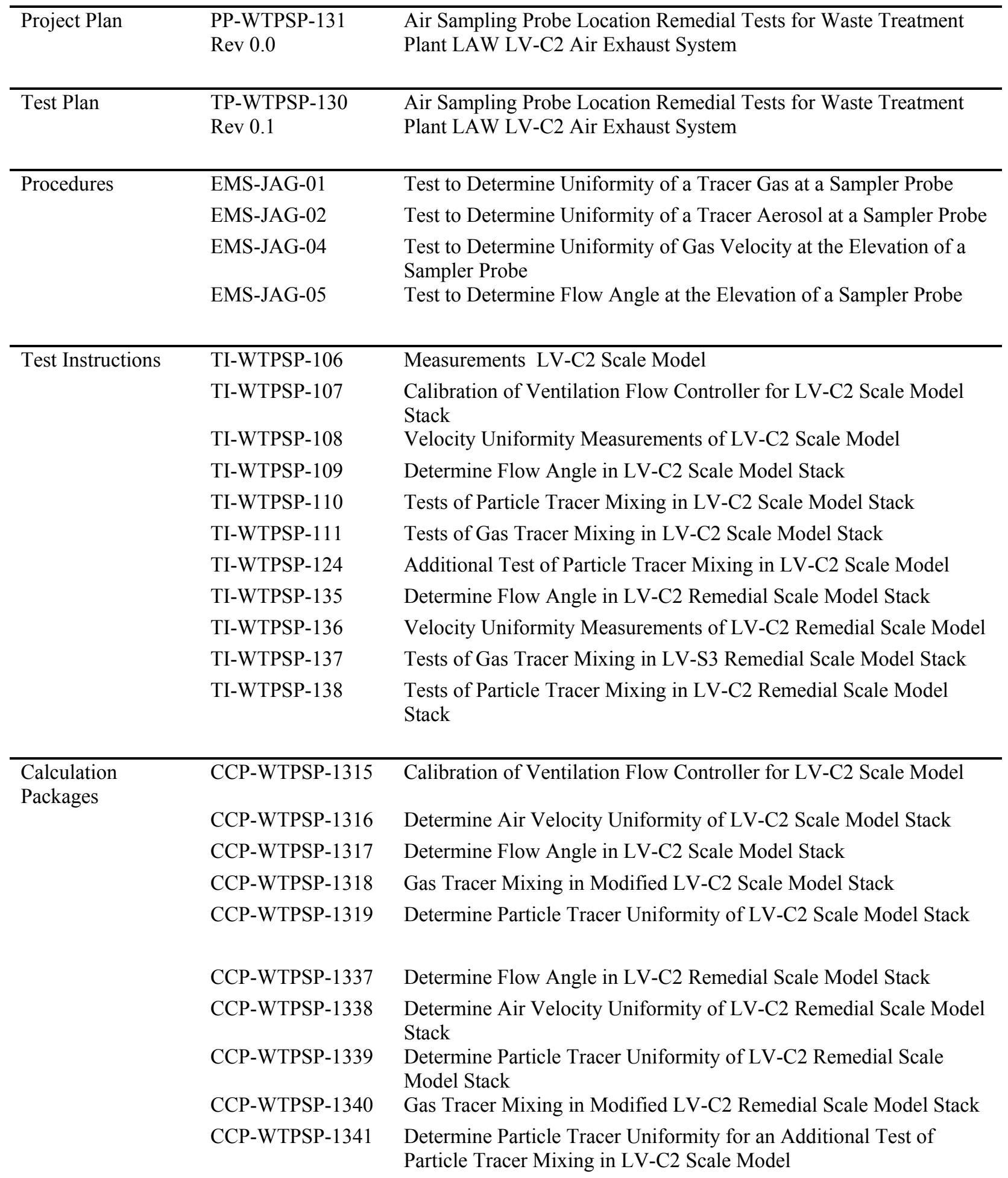



Appendix B

LV-C2 Data Sheets 



\section{B.1 LV-C2 Summary Tables}

Table B.1. Summary of LV-C2 Velocity Uniformity Tests

\begin{tabular}{|c|c|c|c|c|c|c|}
\hline Operating Fan & $\begin{array}{c}\text { Flow } \\
\text { Condition } \\
\end{array}$ & Run No. & $\begin{array}{c}\begin{array}{c}\text { Flow } \\
(\mathrm{acfm})\end{array} \\
\end{array}$ & $\begin{array}{l}\text { Approx. Ai } \\
\text { Velocity } \\
\text { (afpm) }\end{array}$ & $\% \mathrm{COV}$ & $\begin{array}{c}\text { ABS Max } \\
\text { Dev. }\end{array}$ \\
\hline \multirow{4}{*}{ A } & Max & VT-1 & 3022 & 3332 & 5.4 & 17.2 \\
\hline & \multirow{3}{*}{ Min } & VT-5 & 1430 & 1863 & 2.8 & 33.0 \\
\hline & & VT-7 & 1455 & 1877 & 3.7 & 34.0 \\
\hline & & VT-8 & 1443 & 1862 & 3.7 & 38.3 \\
\hline \multirow{4}{*}{ B } & \multirow{3}{*}{ Max } & VT-2 & 2996 & 3898 & 4.1 & 19.9 \\
\hline & & VT-3 & 2924 & 3864 & 3.8 & 21.3 \\
\hline & & VT-4 & 2583 & 3771 & 2.2 & 92.7 \\
\hline & Min & VT-6 & 1288 & 1662 & 2.3 & 82.2 \\
\hline \multirow{2}{*}{$\mathrm{AB}$} & Max & VT-9 & 1359 & 1754 & 2.9 & 29.6 \\
\hline & Min & VT-10 & 3858 & 3838 & 4.1 & 27.0 \\
\hline
\end{tabular}

Table B.2. Summary of LV-C2 Flow Angle Tests

\begin{tabular}{llccc}
\hline Operating Fan & Condition & Run No. & $\begin{array}{c}\text { Approx. Air } \\
\text { Velocity }(\mathrm{afpm})\end{array}$ & $\begin{array}{c}\text { Flow Angle } \\
\text { (Degrees) }\end{array}$ \\
\hline \multirow{4}{*}{ A } & \multirow{3}{*}{ Max } & FA-1 & 3804 & 4.1 \\
& & FA-2 & 3904 & 3.2 \\
& Min & FA-3 & 3707 & 3.7 \\
\hline \multirow{3}{*}{ B } & Max & FA-10 & 1850 & 2.9 \\
\cline { 2 - 5 } & \multirow{3}{*}{ Min } & FA-4 & 3722 & 8.0 \\
\hline A \& B & & FA-5 & 1743 & 5.8 \\
\hline & Max & FA-6 & 1772 & 6.1 \\
\hline & Min & FA-8 & 1768 & 6.4 \\
\hline
\end{tabular}


Table B.3. Summary of LV-C2 Gas Tracer Uniformity Tests

\begin{tabular}{|c|c|c|c|c|c|c|}
\hline $\begin{array}{c}\text { Operating } \\
\text { Fan }\end{array}$ & $\begin{array}{c}\text { Flow } \\
\text { Condition }\end{array}$ & $\begin{array}{c}\text { Injection Port \& } \\
\text { Location }\end{array}$ & Run No. & $\begin{array}{l}\text { Average } \\
\text { Velocity } \\
\text { (afpm) }\end{array}$ & $\% \mathrm{COV}$ & $\begin{array}{l}\text { Absolute \% } \\
\text { Max. Dev. } \\
\text { from Mean }\end{array}$ \\
\hline \multirow{7}{*}{ Fan A } & \multirow{6}{*}{ Max } & I2, Center & GT-11 & 3825 & 0.8 & 1.3 \\
\hline & & I2, Near & GT-18 & 3871 & 3.6 & 7.7 \\
\hline & & I2, Far & GT-21 & 3809 & 2.9 & 4.3 \\
\hline & & I2, Top & GT-14 & 3850 & 2.4 & 4.8 \\
\hline & & I2, Center & GT-12 & 3875 & 2.0 & 2.7 \\
\hline & & I2, Bottom & GT-13 & 3965 & 2.9 & 6.3 \\
\hline & Min & I2, Near & GT-25 & 1803 & 5.3 & 13.2 \\
\hline \multirow{9}{*}{ Fan B } & \multirow{4}{*}{ Max } & I2, Center & GT-4 & 3918 & 14.7 & 18.6 \\
\hline & & I2, Center & GT-5 & 3838 & 0.3 & 0.4 \\
\hline & & I2, Center & GT-10 & 3838 & 3.0 & 9.1 \\
\hline & & I2, Center & GT-22 & 3963 & 2.0 & 3.9 \\
\hline & \multirow{5}{*}{ Min } & I2, Center & GT-1 & 1827 & 1.7 & 3.3 \\
\hline & & I2, Near & GT-19 & 1873 & 6.1 & 11.5 \\
\hline & & I2, Far & GT-20 & 1826 & 1.1 & 2.2 \\
\hline & & I2, Top & GT-3 & 1805 & 5.2 & 13.6 \\
\hline & & I2, Bottom & GT-2 & 1826 & 1.9 & 3.3 \\
\hline \multirow{9}{*}{$\begin{array}{l}\text { Fans } \\
\text { A\&B }\end{array}$} & \multirow{8}{*}{ Max } & I2, Center & GT-6 & 3925 & 1.7 & 2.6 \\
\hline & & I2, Center & GT-9 & 3965 & 10.7 & 23.7 \\
\hline & & I2, Near & GT-17 & 4023 & 5.9 & 11.8 \\
\hline & & I2, Far & GT-16 & 3931 & 8.9 & 15.2 \\
\hline & & I2, Top & GT-15 & 3839 & 8.2 & 13.0 \\
\hline & & I2, Bottom & GT-7 & 3835 & 1.3 & 1.4 \\
\hline & & I2, Bottom & GT-8 & 3906 & 4.5 & 8.9 \\
\hline & & I2, Far & GT-24 & 3859 & 4.4 & 9.7 \\
\hline & Min & I2, Center & GT-23 & 1815 & 7.8 & 12.9 \\
\hline
\end{tabular}


Table B.4. Summary of LV-C2 Particle Tracer Uniformity Tests

\begin{tabular}{|c|c|c|c|c|c|c|c|}
\hline $\begin{array}{c}\text { Operating } \\
\text { Fan }\end{array}$ & $\begin{array}{c}\text { Flow } \\
\text { Condition } \\
\end{array}$ & Test Port & $\begin{array}{c}\text { Injection } \\
\text { Port } \\
\end{array}$ & Run No. & $\begin{array}{c}\text { Avg Velocity } \\
\text { (afpm) }\end{array}$ & $\begin{array}{c}\text { Normalized } \\
\% \mathrm{COV}\end{array}$ & $\begin{array}{l}\text { Absolute \% } \\
\text { Max. Dev. } \\
\text { from Mean }\end{array}$ \\
\hline \multirow{5}{*}{ Fan A } & \multirow{4}{*}{ Max } & \multirow{4}{*}{1} & \multirow{3}{*}{$\mathrm{I} 2$} & PT-1 & 3958 & 11.9 & 46.7 \\
\hline & & & & PT-2 & 3948 & 11.9 & 46.6 \\
\hline & & & & PT-3 & 3882 & 7.7 & 52.4 \\
\hline & & & I4 & PT-15 & 3751 & 13.4 & 30.6 \\
\hline & Min & 1 & $\mathrm{I} 2$ & PT-4 & 1853 & 2.4 & 20.3 \\
\hline \multirow{21}{*}{ Fan B } & \multirow{18}{*}{ Max } & \multirow{14}{*}{1} & \multirow{3}{*}{$\mathrm{I} 2$} & PT-5 & 3946 & 22.9 & 72.0 \\
\hline & & & & PT-9 & 3871 & 31.1 & 87.7 \\
\hline & & & & PT-26 & 3867 & 22.1 & 59.1 \\
\hline & & & \multirow{5}{*}{$\begin{array}{l}\text { I2, BDD } \\
65^{\circ} \text { Open }\end{array}$} & РT-29 & 3462 & 8.47 & 33.3 \\
\hline & & & & PT-30 & 3826 & 19.7 & 61.0 \\
\hline & & & & PT-31 & 3709 & 24.7 & 68.3 \\
\hline & & & & PT-33 & 3600 & 17.5 & 49.1 \\
\hline & & & & PT-34 & 3506 & 16.5 & 45.1 \\
\hline & & & \multirow{5}{*}{ I3 } & PT-14 & 3763 & 27.9 & 77.3 \\
\hline & & & & PT-18 & 3820 & 14.1 & 60.2 \\
\hline & & & & PT-24 & 3868 & 25.4 & 67.2 \\
\hline & & & & PT-27 & 3638 & 23.5 & 50.7 \\
\hline & & & & PT-28 & 3605 & 22.8 & 50.1 \\
\hline & & & I5 & PT-33 & 3703 & 21.6 & 53.3 \\
\hline & & \multirow{3}{*}{ Ref Port } & I3 & PT-19 & 3860 & 18.4 & 64.4 \\
\hline & & & \multirow{2}{*}{ I2 } & PT-20 & 3847 & 18.5 & 38.1 \\
\hline & & & & PT-21 & 3844 & 14.4 & 42.9 \\
\hline & & 1D & I2 & PT-25 & 3893 & 26.2 & 99.5 \\
\hline & \multirow{3}{*}{ Min } & \multirow{3}{*}{1} & \multirow{3}{*}{ I2 } & PT-6 & 1811 & 13.3 & 29.5 \\
\hline & & & & PT-7 & 1803 & 8.7 & 19.4 \\
\hline & & & & PT-8 & 1798 & 14.8 & 41.0 \\
\hline \multirow{8}{*}{$\begin{array}{l}\text { Fans } \\
\text { A\&B }\end{array}$} & \multirow{3}{*}{ Max } & \multirow{3}{*}{1} & I2 & PT-10 & 3745 & 17.6 & 37.5 \\
\hline & & & I3 & PT-17 & 3794 & 14.9 & 53.7 \\
\hline & & & I4 & PT-16 & 3595 & 12.4 & 49.5 \\
\hline & \multirow{5}{*}{ Min } & \multirow{4}{*}{1} & \multirow{4}{*}{ I2 } & PT-11 & 1734 & 12.8 & 31.6 \\
\hline & & & & PT-12 & 1760 & 20.2 & 41.0 \\
\hline & & & & PT-13 & 1831 & 19.7 & 32.5 \\
\hline & & & & PT-23 & 1785 & 14.3 & 30.0 \\
\hline & & Ref Port & I2 & PT-22 & 1808 & 6.0 & 34.4 \\
\hline
\end{tabular}




\section{B.2 LV-C2 Calibration of Ventilation Flow Controller \\ VELOCITY TRAVERSE DATA FORM}

Site LV-C2 Model

Date 4/22/13

Testers EA, CA

Stack Dia.

Stack X-Area

Test Port

Distance to disturbance

Velocity units aft/min

11.922 in

111.6 in. 2

1$$
\text { in }
$$

Order -->

Traverse-->

Trial ---->

\begin{tabular}{|c|c|}
\hline Point & Depth, in. \\
\hline 1 & 0.50 \\
\hline 2 & 1.25 \\
\hline 3 & 2.31 \\
\hline 4 & 3.85 \\
\hline Center & 5.9 \\
\hline 5 & 8.0 \\
\hline 6 & 9.6 \\
\hline 7 & 10.6 \\
\hline 8 & 11. \\
\hline
\end{tabular}

119.88 inches

2nd

Run No. FC-1

Fan Configuration Fan A

Fan Setting $\mathbf{3 0}$

Stack Temp

Start/End Time 930/958

Center 2/3 from

Points in Center 2/3

Data Files: NA

\begin{tabular}{|c|c|c|}
\hline \multicolumn{3}{|c|}{$\mathrm{Hz}$} \\
\hline 57.2 & $\operatorname{deg} F$ & \\
\hline & & \\
\hline 1.09 & to: & 10.83 \\
\hline 2 & to: & 7 \\
\hline
\end{tabular}

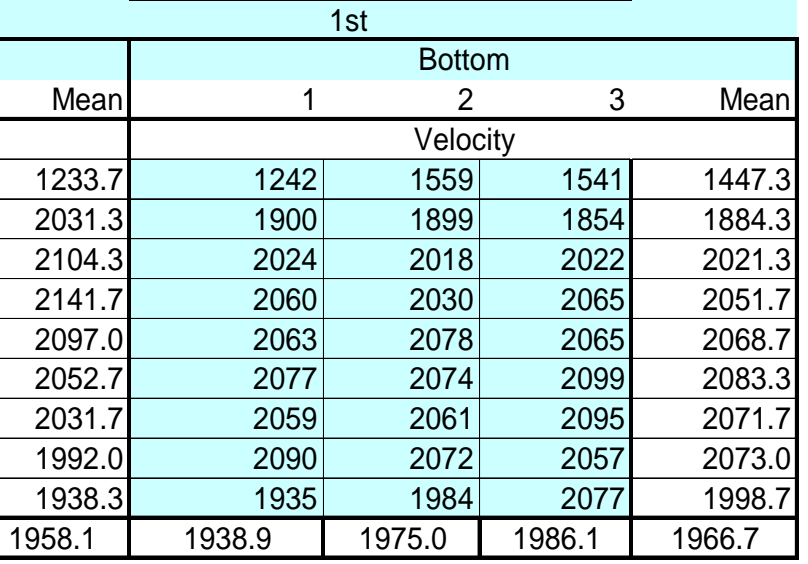

\begin{tabular}{|c|c|c|c|c|c|c|}
\hline$A I I$ & $\mathrm{ft} / \mathrm{min}$ & Dev. from mean & Center $2 / 3$ & Side & Bottom & All \\
\hline Mean & $\overline{1962.4}$ & & Mean & $20 \overline{64.4}$ & $\overline{2036.3}$ & 2050.3 \\
\hline Min Point & 1233.7 & $-37.1 \%$ & Std. Dev. & 51.9 & 70.0 & 61.0 \\
\hline Max Point & 2141.7 & $9.1 \%$ & cov as $\%$ & 2.5 & 3.4[ & 3.0 \\
\hline
\end{tabular}

Flow w/o C-Pt $\quad 1510 \mathrm{acfm}$

Vel Avg w/o C-Pt 1947 afpm

Stack temp

Equipment temp

Ambient temp

Stack static

Ambient pressure

Total Stack pressure

Ambient humidity

\begin{tabular}{|c|c|}
\hline Start & Finish \\
\hline 57.4 & 57 \\
\hline $\mathrm{NA}$ & $N A$ \\
\hline 55.4 & 57.2 \\
\hline$N A$ & NA \\
\hline 30.09 & 30.09 \\
\hline NA & NA \\
\hline $32 \%$ & $29 \%$ \\
\hline
\end{tabular}

Notes:

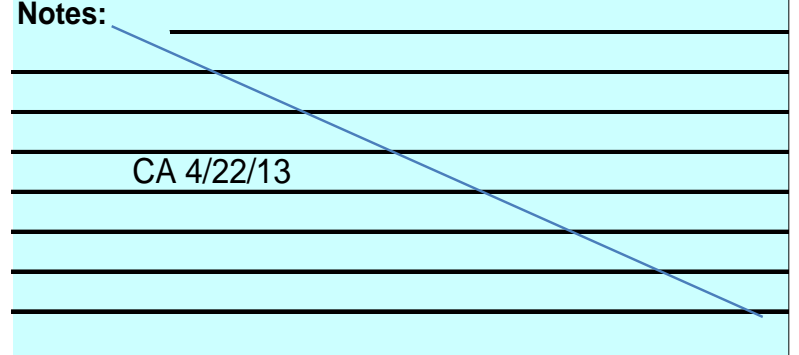

Entries made by:

Signature/date
Instuments Used:

TSI VelociCalc T95351203001

Cal Due

Fisher Scientific Barometer

$90936818 \quad 12 / 11 / 2013$

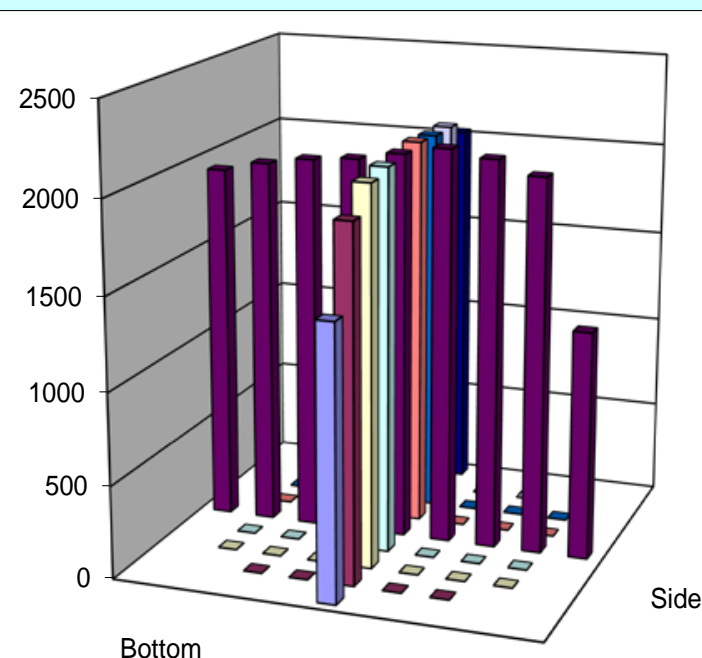

Bottom

Technical Data Review performed by: EG

Signature/date 6/11/2013

Signature on file with original TI-WTPSP-107 


\section{VELOCITY TRAVERSE DATA FORM}

Site LV-C2 Model

Date $4 / 22 / 13$

Testers EA, CA

Stack Dia.

Stack X-Area

Test Port

Distance to disturbance

Velocity units $\underline{\mathrm{aft} / \mathrm{min}}$

Order -->

Traverse-->

Trial --.->

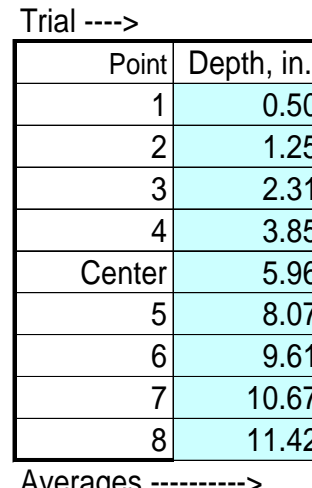

Averages --------->

$\frac{\frac{11.922 \text { in. }}{111.6 \text { in.2 }}}{\frac{1}{119.88 \text { inches }}}$

1 st
Run No. FC-2

Fan Configuration Fan B

Fan Setting 30

Stack Temp

Start/End Time 1000/1025

Center $2 / 3$ from

Points in Center 2/3

Data Files: NA
$59.2 \quad \operatorname{deg} \mathrm{F}$

$\frac{1.09}{2}$ to: $\quad$ to: $\underline{10.83}$

\begin{tabular}{|r|r|r|r|r|r|}
\cline { 3 - 6 } & \multicolumn{5}{|c|}{ 2nd } \\
\hline & & \multicolumn{5}{|c|}{ Bottom } \\
\hline 1472 & 1488.3 & 1769 & 1836 & 1907 & 1837.3 \\
\hline 2039 & 2069.0 & 2131 & 2123 & 2124 & 2126.0 \\
\hline 2093 & 2077.3 & 2123 & 2104 & 2089 & 2105.3 \\
\hline 2038 & 2011.3 & 2055 & 2029 & 2033 & 2039.0 \\
\hline 2012 & 2010.7 & 2034 & 2011 & 2002 & 2015.7 \\
\hline 2040 & 2033.0 & 2041 & 1983 & 2011 & 2011.7 \\
\hline 2111 & 2109.7 & 2017 & 1984 & 1994 & 1998.3 \\
\hline 2190 & 2193.3 & 1961 & 1934 & 1970 & 1955.0 \\
\hline 2188 & 2186.7 & 1927 & 1886 & 1919 & 1910.7 \\
\hline 2020.3 & 2019.9 & 2006.4 & 1987.8 & 2005.4 & 1999.9 \\
\hline
\end{tabular}

\begin{tabular}{|l|l|l|}
\hline 2012.1 & 2027.3 & 2020.3 \\
\hline
\end{tabular}

\begin{tabular}{l|l}
2019.9 & 2006.4 \\
\hline
\end{tabular}

\begin{tabular}{|lrr|lrrr|}
\hline All & $\underline{\mathrm{ft} / \mathrm{min}}$ & Dev. from mean & Center 2/3 & $\underline{\text { Side }}$ & $\underline{\text { Bottom }}$ & All \\
Mean & 2009.9 & & Mean & 2072.0 & 2035.9 & 2054.0 \\
Min Point & 1488.3 & $-26.0 \%$ & Std. Dev. & 64.7 & 60.4 & 63.0 \\
Max Point & 2193.3 & $9.1 \%$ & COV as \% & 3.1 & 3.0 & $\mathbf{3 . 1}$ \\
\hline
\end{tabular}

Flow w/o C-Pt $1558 \mathrm{acfm}$

Vel Avg w/o C-Pt 2010 afpm

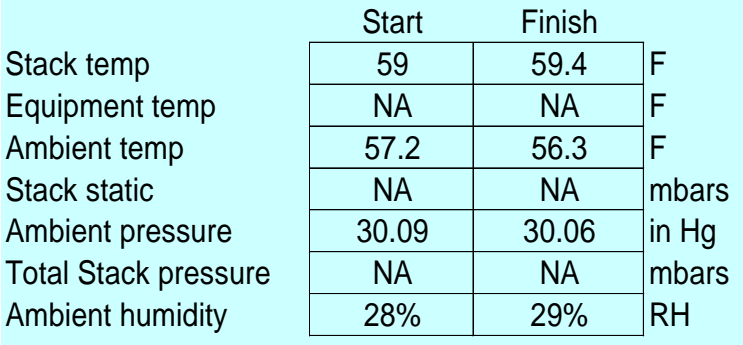

Instuments Used:

Cal Due

TSI VelociCalc

T95351203001

$12 / 10 / 13$

Fisher Scientific Barometer

$90936818 \quad 12 / 11 / 2013$

Notes:
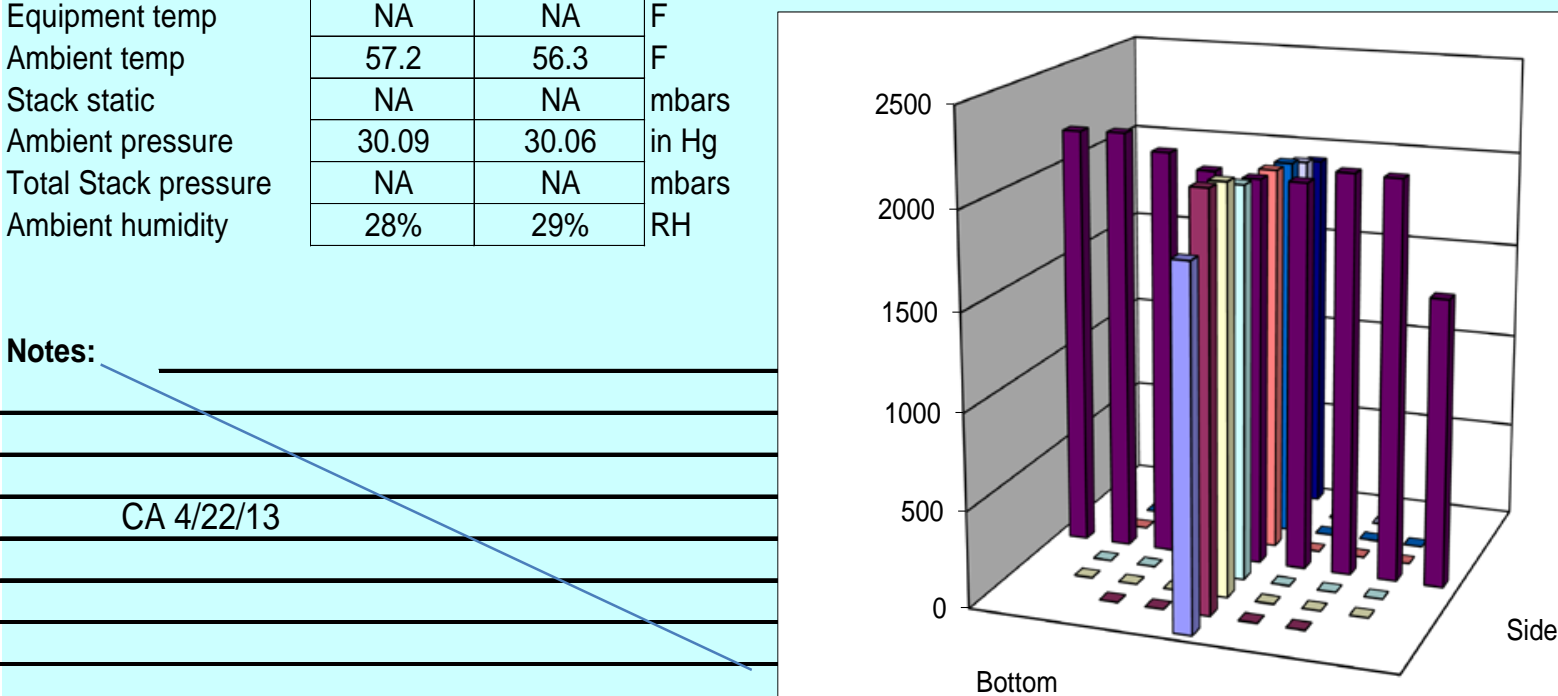

Bottom

\begin{tabular}{|lc}
\hline Entries made by: & Carmen Arimescu \\
Signature/date & $4 / 22 / 2013$
\end{tabular}

Technical Data Review performed by: EG

Signature/date 6/3/2013

Signature on file with original TI-WTPSP-107 


\section{VELOCITY TRAVERSE DATA FORM}

Site LV-C2 Model

Date $4 / 22 / 13$

Testers EA, CA

Stack Dia.

Stack X-Area

Test Port

Distance to disturbance

Velocity units aft/min

Order -->

Traverse-->

Trial --.->

\begin{tabular}{|r|r|} 
Trial ----> \\
\hline Point & Depth, in. \\
\hline 1 & 0.50 \\
\hline 2 & 1.25 \\
\hline 3 & 2.31 \\
\hline 4 & 3.85 \\
\hline Center & 5.96 \\
\hline 5 & 8.07 \\
\hline 6 & 9.61 \\
\hline 7 & 10.67 \\
\hline 8 & 11.42 \\
\hline Averages -------->
\end{tabular}

Averages --------->

2823.3

1

2nd
Run No. FC-3

Fan Configuration FAN AB

Fan Setting 30

Stack Temp

Start/End Time 1030/1045

Center $2 / 3$ from

Points in Center $2 / 3$

Data Files: NA

$59.5 \quad \operatorname{deg} \mathrm{F}$

2 to: $\underline{7}$

$1 \mathrm{st}$

\begin{tabular}{|r|r|r|r|r|r|}
\hline & & \multicolumn{5}{|c|}{ Bottom } \\
\hline 3 & Mean & \multicolumn{5}{|c|}{$\begin{array}{c}\text { Velocity } \\
3\end{array}$} \\
\hline 1757 & 1863.3 & 2096 & 2204 & 2321 & 2207.0 \\
\hline 3019 & 3002.3 & 2984 & 2955 & 2945 & 2961.3 \\
\hline 3106 & 3126.7 & 3183 & 3135 & 3101 & 3139.7 \\
\hline 3140 & 3160.7 & 3215 & 3181 & 3126 & 3174.0 \\
\hline 3058 & 3061.7 & 3085 & 3069 & 3031 & 3061.7 \\
\hline 2997 & 3001.3 & 3013 & 3018 & 2965 & 2998.7 \\
\hline 2933 & 2944.0 & 2992 & 2993 & 2968 & 2984.3 \\
\hline 2808 & 2832.7 & 2961 & 2927 & 2932 & 2940.0 \\
\hline 2728 & 2744.3 & 2892 & 2836 & 2882 & 2870.0 \\
\hline 2838.4 & 2859.7 & 2935.7 & 2924.2 & 2919.0 & 2926.3 \\
\hline
\end{tabular}

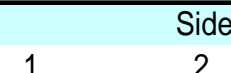

Velocity

\begin{tabular}{|r|r|r|}
\hline 1628 & 2205 & 1757 \\
\hline 3007 & 2981 & 3019 \\
\hline 3128 & 3146 & 3106 \\
\hline 3157 & 3185 & 3140 \\
\hline 3037 & 3090 & 3058 \\
\hline 2989 & 3018 & 2997 \\
\hline 2940 & 2959 & 2933 \\
\hline 2822 & 2868 & 2808 \\
\hline 2702 & 2803 & 2728 \\
\hline 823.3 & 2917.2 & 2838.4 \\
\hline
\end{tabular}

2859.7

2935.7

\begin{tabular}{|lr}
\hline All & $\underline{\mathrm{ft} / \mathrm{min}}$ \\
Mean & 2893.0 \\
Min Point & 1863.3 \\
Max Point & 3174.0 \\
\hline
\end{tabular}

Flow w/o C-Pt

$2226 \mathrm{acfm}$

Vel Avg w/o C-Pt

2872 afpm

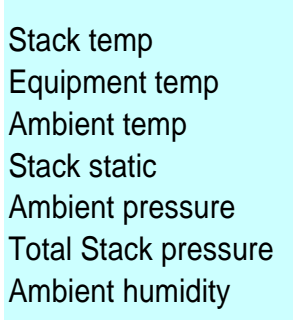

\begin{tabular}{|c|c|c|}
\hline Start & Finish & \\
\hline 59 & 60 & $F$ \\
\hline NA & NA & $F$ \\
\hline 55.4 & 57.2 & $F$ \\
\hline NA & NA & mbar \\
\hline 30.06 & 30.06 & in $\mathrm{Hg}$ \\
\hline NA & NA & mbar \\
\hline $28 \%$ & $26 \%$ & $\mathrm{RH}$ \\
\hline
\end{tabular}

Notes:

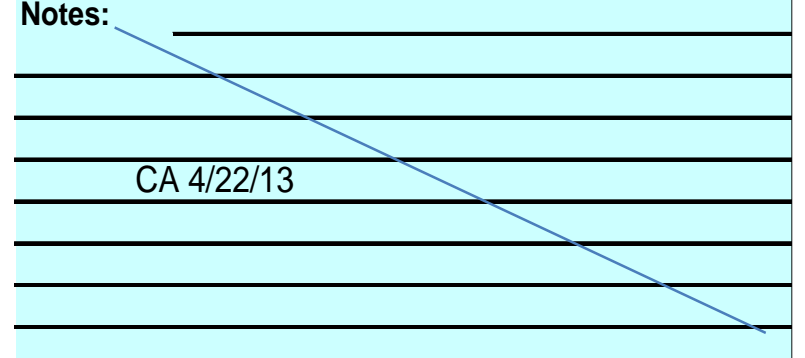
Dev. from mean Center 2/3
Mean
$-35.6 \%$ Std. Dev.
9.7\% COV as \%

Side
3018.5
111.4
3.7

\begin{tabular}{rr|}
\hline Bottom & All \\
\hline 3037.1 & 3027.8 \\
90.6 & 98.0 \\
3.0 & 3.2 \\
\hline
\end{tabular}

Instuments Used:

Cal Due

TSI VelociCalc

T95351203001

$12 / 10 / 13$

Fisher Scientific Barometer

$90936818 \quad 12 / 11 / 2013$

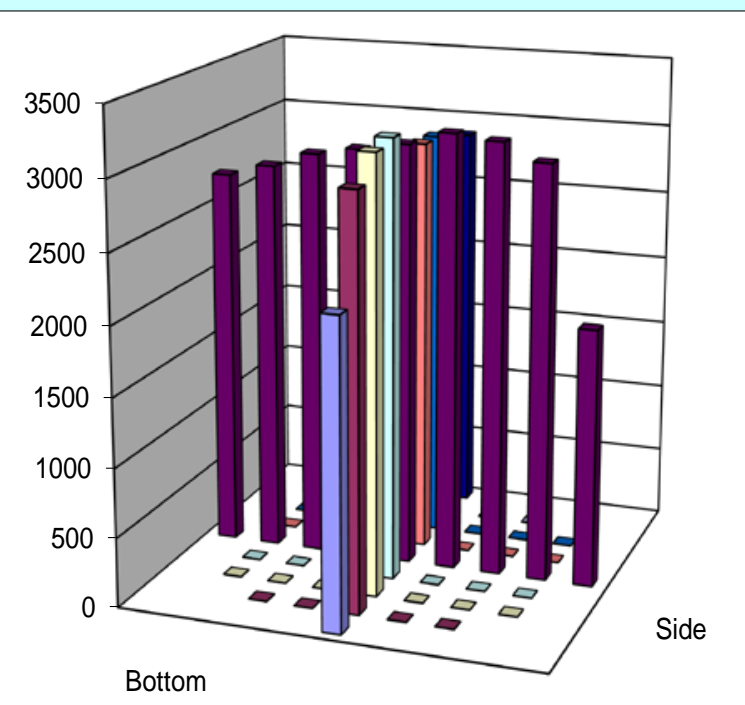

Entries made by:

Carmen Arimescu

Signature/date

4/22/2013

Technical Data Review performed by:

EG

Signature/date

$6 / 3 / 2013$

Signature on file with original TI-WTPSP-107 


\begin{tabular}{|c|c|c|c|c|c|}
\hline \multicolumn{5}{|c|}{ VELOCITY vs. FREQUENCY DATA FORM } & \\
\hline Site & \multicolumn{2}{|c|}{ LV-C2 model } & \multicolumn{2}{|c|}{ Run No. VF-1 } & \\
\hline Date & \multicolumn{2}{|c|}{$4 / 22 / 2013$} & Stack Temp & 66.5 & \\
\hline Tester & \multicolumn{2}{|c|}{$\mathrm{EA}, \mathrm{CA}$} & Stack RH\% & NA & \\
\hline Stack Dia. & 11.922 & in. & Baro Press & 30.12 & \\
\hline Stack X-Area & 111.6 & in2 & Fan Configuration & Fan $A B$ & \\
\hline Test Port & 1 & & Start/End Time & $114 / 200$ & \\
\hline disturbance & 119.88 & inches & Reference point from & velocity test VC & Bottom 8 \\
\hline
\end{tabular}

Dist. from disturbance 119.88 inches

Velocity Readings, units

\begin{tabular}{|c|c|c|c|c|}
\hline & $\begin{array}{r}\text { Target } \\
\text { acfm }\end{array}$ & $\begin{array}{r}\text { Target } \\
\text { afpm }\end{array}$ & $\begin{array}{r}\text { Estmtd } \\
\mathrm{Hz}\end{array}$ \\
\hline & & 2566 & 3921 & 39 \\
\hline & & 1885 & 2880 & 29.5 \\
\hline \multicolumn{2}{|l|}{$\mathrm{m}$} & 1212 & 1853 & 20 \\
\hline 3 & Mean & StDev & 2 StDev & $\mathrm{cfm}$ \\
\hline 288 & 220.00 & 85.51 & 171.02 & 170.55 \\
\hline 758 & 769.67 & 12.01 & 24.03 & 596.66 \\
\hline 1246 & 1224.67 & 24.44 & 48.88 & 949.39 \\
\hline 1752 & 1767.33 & 28.31 & 56.62 & 1370.07 \\
\hline 2359 & 2359.00 & 31.00 & 62.00 & 1828.75 \\
\hline 2768 & 2907.67 & 121.33 & 242.65 & 2254.08 \\
\hline 3497 & 3536.00 & 182.65 & 365.30 & 2741.18 \\
\hline 3992 & 4108.00 & 111.34 & 222.67 & 3184.61 \\
\hline 4535 & 4551.67 & 82.28 & 164.55 & 3528.55 \\
\hline 5094 & 5134.33 & 49.80 & 99.61 & 3980.24 \\
\hline 5649 & 5645.67 & 158.03 & 316.05 & 4376.64 \\
\hline
\end{tabular}

\section{Instuments Used:}

TSI VelociCalc T95351203001

Cal Exp. Date:

Fisher Scientific Barometı 90936818

Velocity vs. Frequency $\quad y=109.87 x-366.53$ $12 / 11 / 2013$

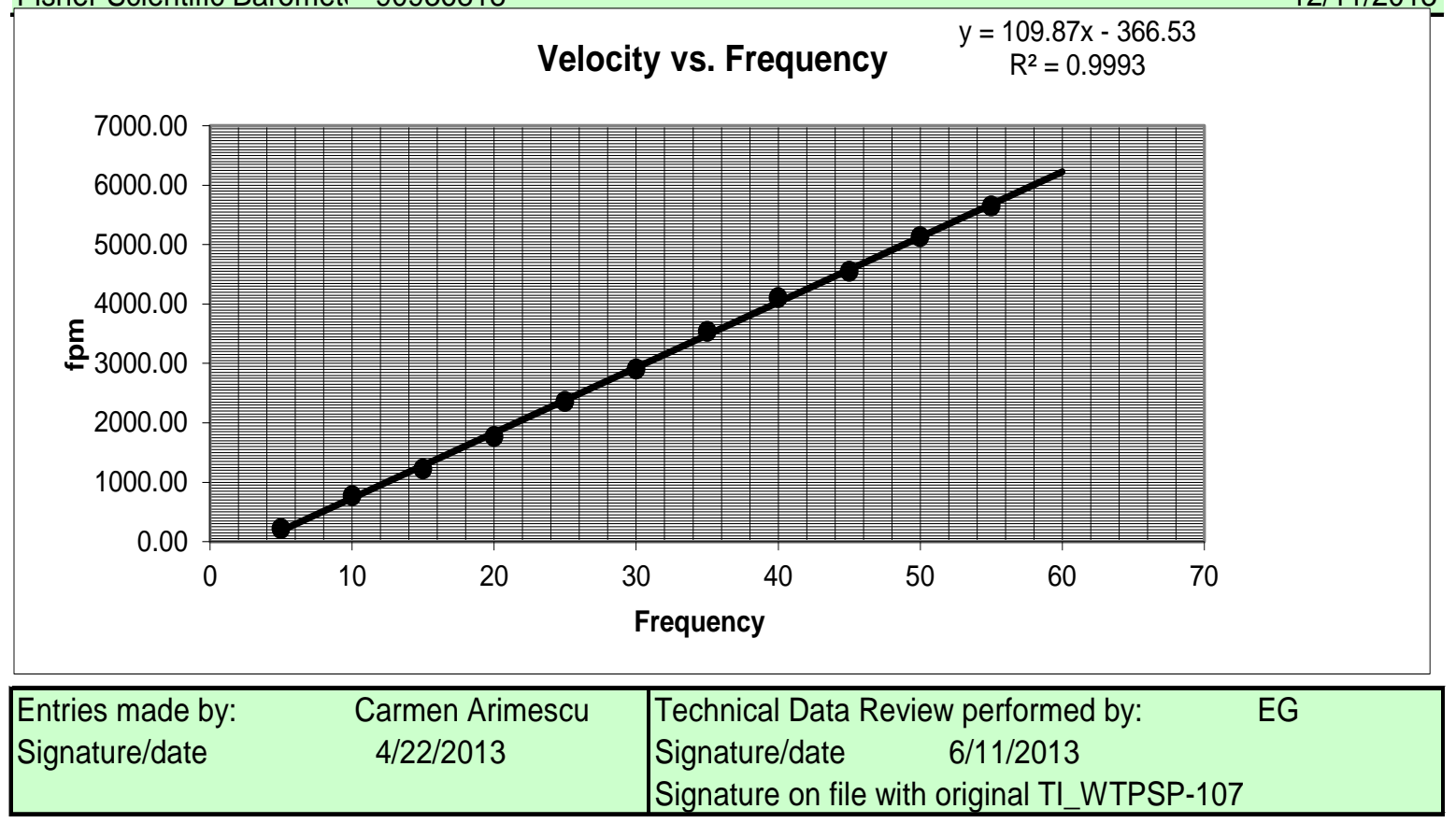




\section{VELOCITY vS. FREQUENCY DATA FORM}

\begin{tabular}{rlr} 
Site & \multicolumn{2}{c}{ LV-C2 model } \\
\cline { 2 - 2 } Date & \multicolumn{2}{c}{$4 / 22 / 2013$} \\
Tester & \multicolumn{2}{c}{ EA, CA } \\
\cline { 2 - 3 } Stack Dia. & 11.922 & in. \\
Stack X-Area & 111.6 & in2 \\
Test Port & 1 & \\
\cline { 2 - 3 } disturbance & 119.88 & inches \\
Readings, units & $=$ & afpm \\
\end{tabular}

\begin{tabular}{|c|c|}
\hline \multicolumn{2}{|c|}{ Run No. VF-2 } \\
\hline Stack Temp & 69 \\
\hline Stack RH\% & $\mathrm{NA}$ \\
\hline Baro Press & 30.12 \\
\hline an Configuration & Fan A \\
\hline Start/End Time & $205 / 223$ \\
\hline
\end{tabular}

Dist. from disturbance 119.88

Velocity Readings, units $=$ 205/223

Reference point from velocity test VC : Side 8

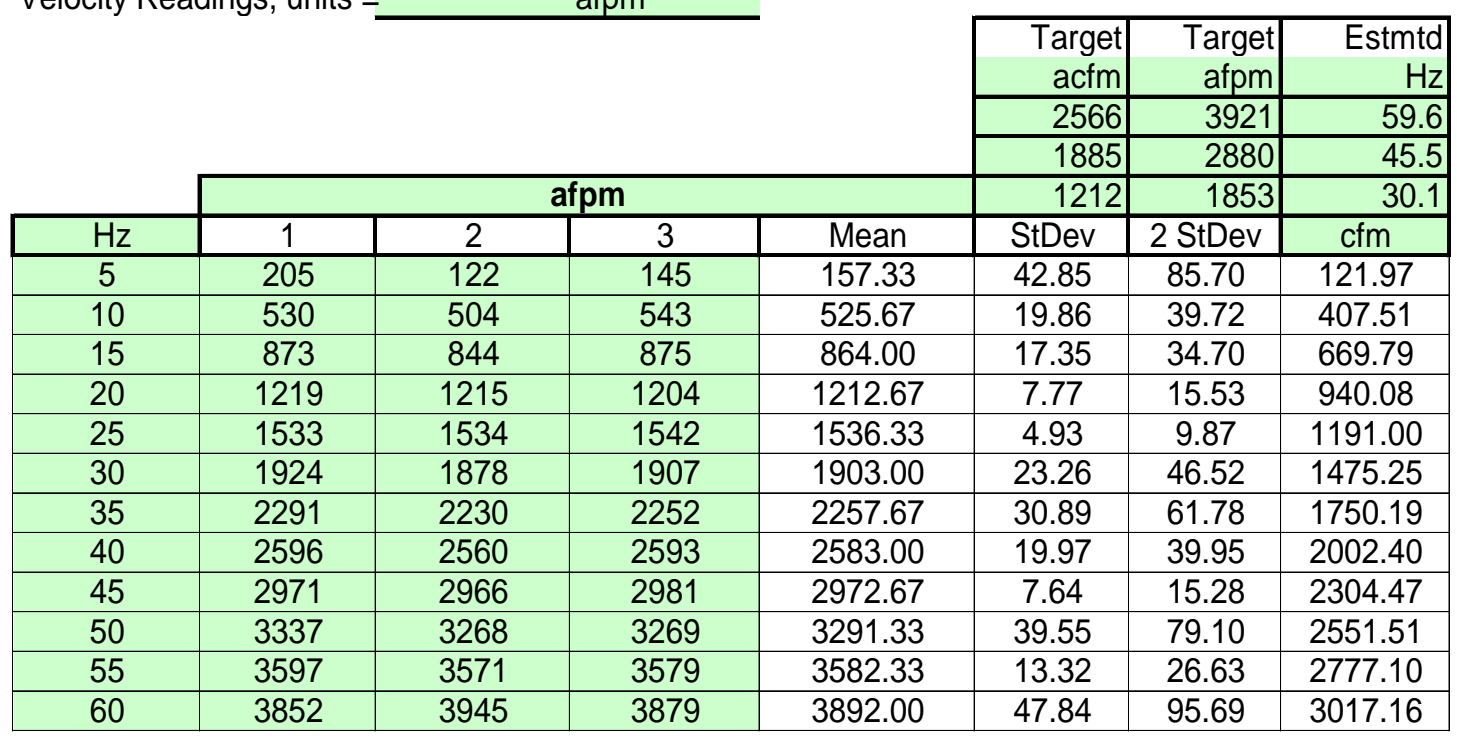

Instuments Used:

TSI VelociCalc

Fisher Scientific Barometı 90936818
Cal Exp. Date:

$12 / 10 / 2013$ $12 / 11 / 2013$

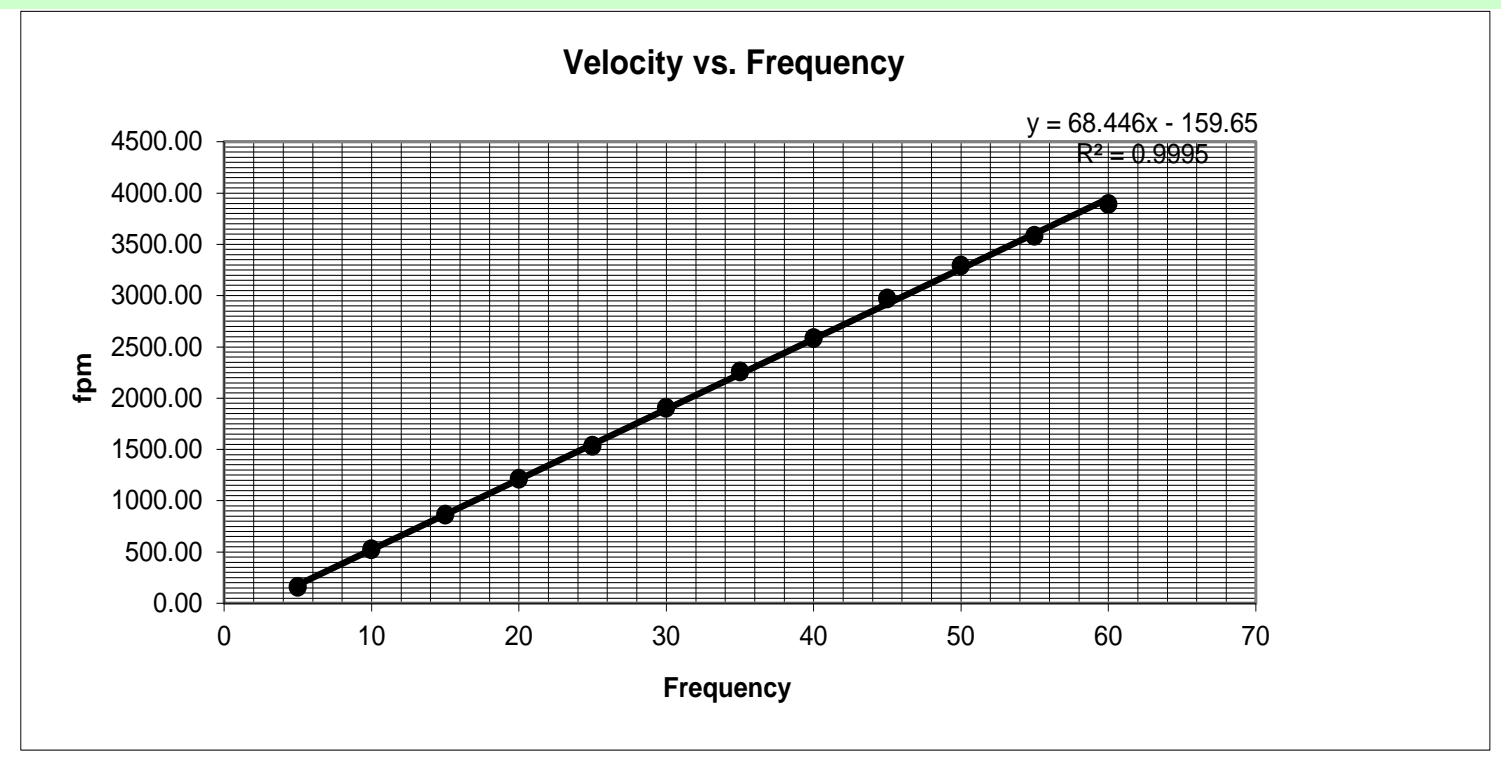

Entries made by: Signature/date
Carmen Arimescu $4 / 22 / 2013$
Technical Data Review performed by:

Signature/date

6/3/2013

Signature on file with original TI WTPSP-107
EG 


\section{VELOCITY vS. FREQUENCY DATA FORM}

\begin{tabular}{|c|c|c|}
\hline Site & \multicolumn{2}{|c|}{ LV-C2 model } \\
\hline Date & & \\
\hline Tester & & \\
\hline Stack Dia. & 11.922 & in. \\
\hline Stack X-Area & 111.6 & in2 \\
\hline
\end{tabular}

\begin{tabular}{rc} 
Run No. VF-3 \\
\cline { 2 - 2 } Stack Temp & 73 \\
\cline { 2 - 2 } Stack RH\% & $\mathrm{NA}$ \\
Baro Press & 30.15 \\
\cline { 2 - 2 } Fan Configuration & Fan B \\
${ } }$ & $230 / 330$
\end{tabular}

Dist. from disturbance $\overline{119.88 \quad \text { inches }}$ Reference point from velocity test VC : Side Center Velocity Readings, units $=\quad$ afpm

\begin{tabular}{|c|c|c|c|c|c|c|c|c|}
\hline & & & & \\
\hline & & & & & Target & Target & Estmtd & \\
\hline & & & & & acfm & afpm & $\mathrm{Hz}$ & \\
\hline & & & & & 2566 & 3921 & 58 & $\max$ \\
\hline & & & & & 1885 & 2880 & 43.1 & normal \\
\hline & \multicolumn{4}{|c|}{ afpm } & 1212 & 1853 & 28.4 & $\min$ \\
\hline $\mathrm{Hz}$ & 1 & 2 & 3 & Mean & StDev & $2 \mathrm{StDev}$ & cfm & \\
\hline 5 & 235 & 255 & 231 & 240.33 & 12.86 & 25.72 & 186.31 & \\
\hline 10 & 577 & 554 & 565 & 565.33 & 11.50 & 23.01 & 438.26 & \\
\hline 15 & 930 & 908 & 921 & 919.67 & 11.06 & 22.12 & 712.95 & \\
\hline 20 & 1265 & 1232 & 1220 & 1239.00 & 23.30 & 46.60 & 960.50 & \\
\hline 25 & 1629 & 1583 & 1583 & 1598.33 & 26.56 & 53.12 & 1239.06 & \\
\hline 30 & 1977 & 1930 & 1971 & 1959.33 & 25.58 & 51.16 & 1518.92 & \\
\hline 35 & 2349 & 2318 & 2318 & 2328.33 & 17.90 & 35.80 & 1804.97 & \\
\hline 40 & 2719 & 2650 & 2657 & 2675.33 & 37.98 & 75.96 & 2073.98 & \\
\hline 45 & 3088 & 3022 & 2998 & 3036.00 & 46.60 & 93.21 & 2353.57 & \\
\hline 50 & 3410 & 3339 & 3365 & 3371.33 & 35.92 & 71.84 & 2613.53 & \\
\hline 55 & 3738 & 3646 & 3714 & 3699.33 & 47.72 & 95.44 & 2867.80 & \\
\hline 60 & 4082 & 4046 & 4008 & 4045.33 & 37.00 & 74.01 & 3136.03 & \\
\hline
\end{tabular}

\section{Instuments Used:}

\section{TSI VelociCalc}

T95351203001
Cal Exp. Date: $12 / 10 / 2013$ $12 / 11 / 2013$

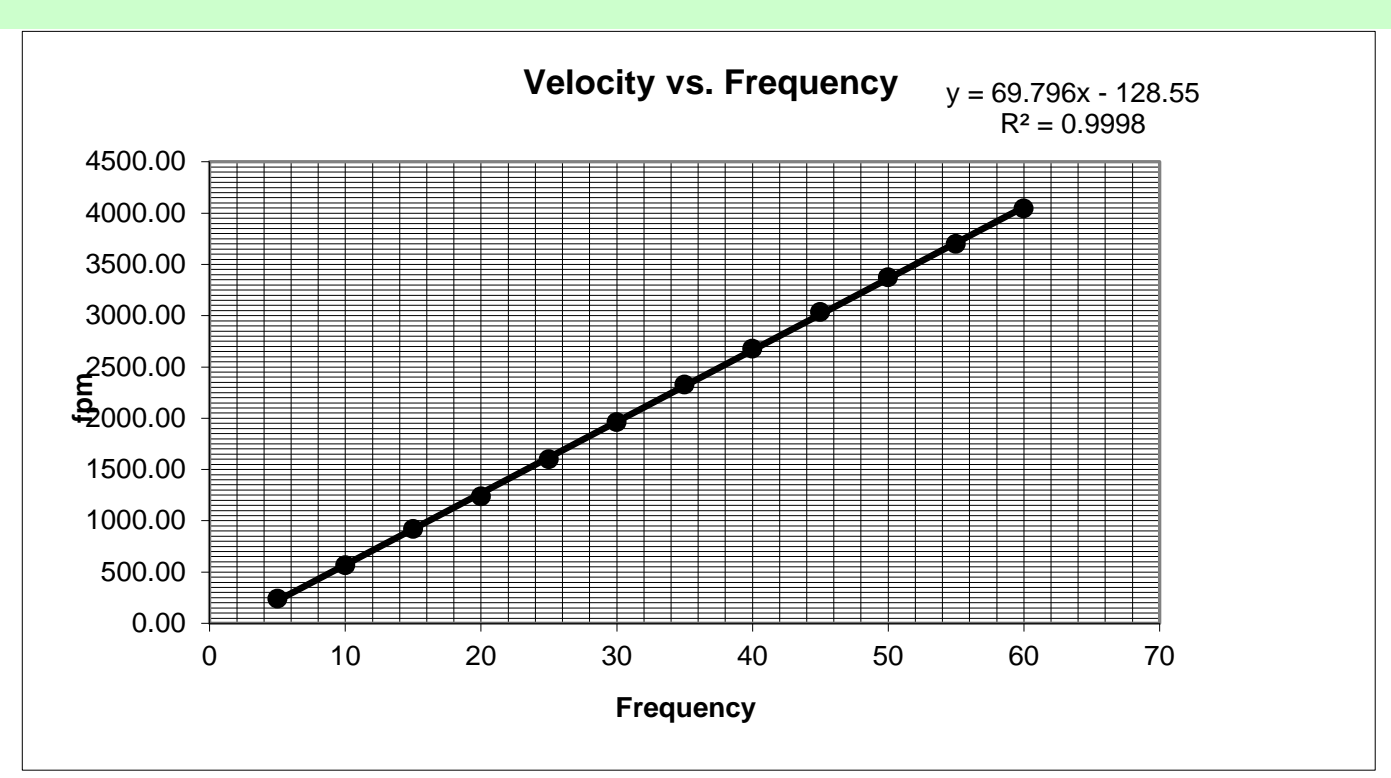

Entries made by: Signature/date

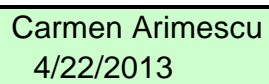

Technical Data Review performed by: $6 / 3 / 2013$

Signature on file with original TI_WTPSP-107 


\section{B.3 LV-C2 Velocity Uniformity Data Sheets}

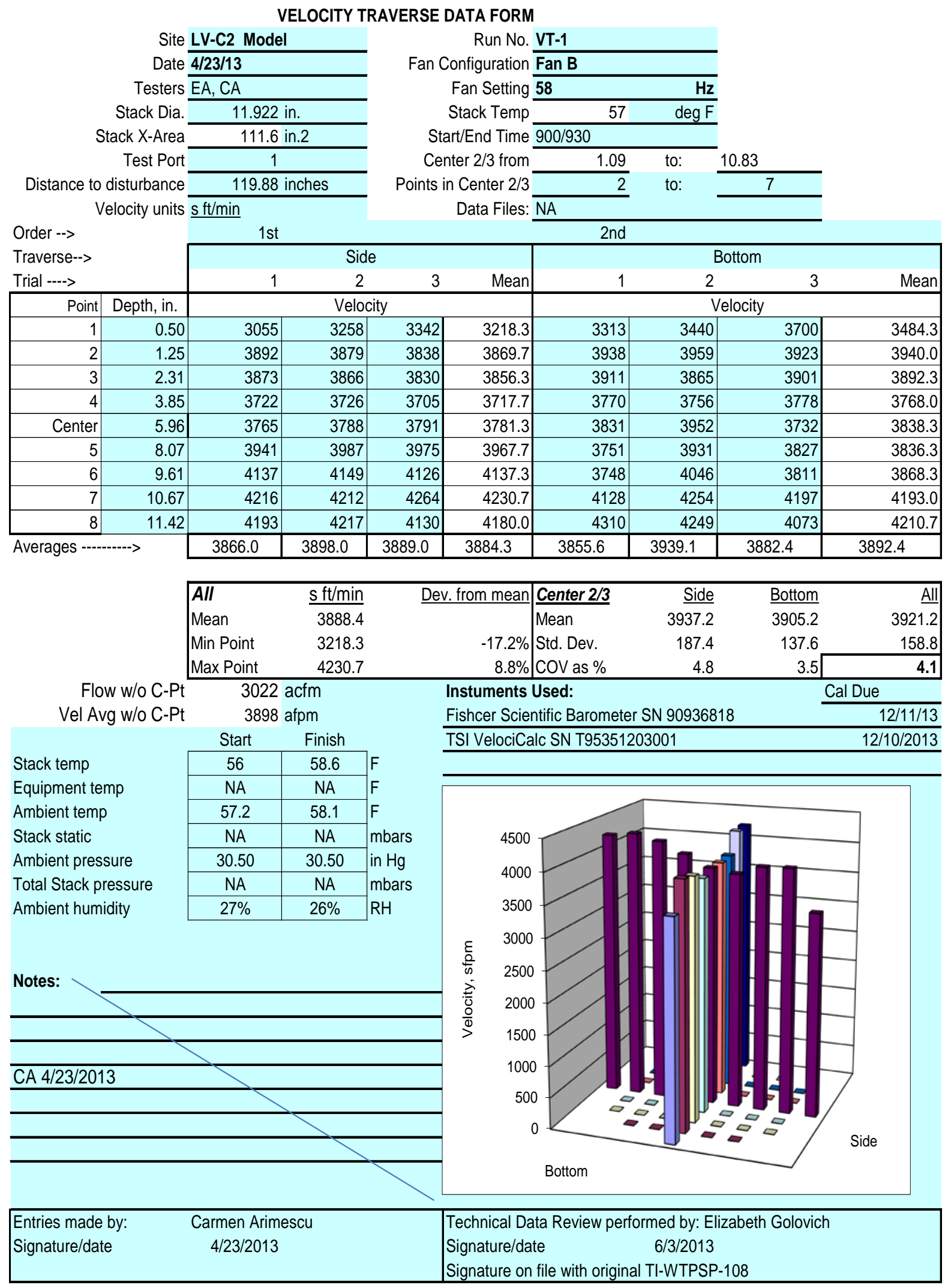




\section{VELOCITY TRAVERSE DATA FORM}

Site LV-C2 Model

Date 4/23/13

Testers EA, CA

Stack Dia.

Stack X-Area

Test Port

Distance to disturbance

Velocity units $\underline{\mathrm{ft} / \mathrm{min}}$

Order -->

Traverse-->

Trial ---->
Run No. VT-2

Fan Configuration Fan B

Fan Setting 58

Stack Temp

Start/End Time 930/1000

Center $2 / 3$ from

Points in Center 2/3

Data Files: NA

2nd

$59.7 \quad \operatorname{deg} \mathrm{F}$

1.09 to:

2 to:

1st

\begin{tabular}{|c|c|c|c|c|c|c|c|c|c|}
\hline \multicolumn{2}{|l|}{ Trial ----> } & 1 & 2 & 3 & Mean & 1 & 2 & 3 & Mean \\
\hline Point & Depth, in. & \multicolumn{4}{|c|}{ Velocity } & \multicolumn{4}{|c|}{ Velocity } \\
\hline 1 & 0.50 & 3075 & 3007 & 3174 & 3085.3 & 3690 & 3650 & 3673 & 3671.0 \\
\hline 2 & 1.25 & 3834 & 3795 & 3806 & 3811.7 & 3966 & 3897 & 3894 & 3919.0 \\
\hline 3 & 2.31 & 3779 & 3755 & 3773 & 3769.0 & 3908 & 3872 & 3842 & 3874.0 \\
\hline 4 & 3.85 & 3693 & 3679 & 3685 & 3685.7 & 3766 & 3743 & 3769 & 3759.3 \\
\hline Center & 5.96 & 3772 & 3677 & 3675 & 3708.0 & 3805 & 3717 & 3942 & 3821.3 \\
\hline 5 & 8.07 & 3889 & 3818 & 3807 & 3838.0 & 3878 & 3884 & 3953 & 3905.0 \\
\hline 6 & 9.61 & 4016 & 3961 & 3912 & 3963.0 & 4110 & 3930 & 4233 & 4091.0 \\
\hline 7 & 10.67 & 4096 & 4050 & 4024 & 4056.7 & 4206 & 4116 & 4234 & 4185.3 \\
\hline 8 & 11.42 & 4078 & 4057 & 3937 & 4024.0 & 4240 & 4152 & 4179 & 4190.3 \\
\hline Averages ---- & $\cdots$ & 3803.6 & 3755.4 & 3754.8 & 3771.3 & 3952.1 & 3884.6 & 3968.8 & 3935.1 \\
\hline
\end{tabular}

\begin{tabular}{|lrr|lrrr|}
\hline All & $\underline{\mathrm{ft} / \mathrm{min}}$ & Dev. from mean & Center 2/3 & $\underline{\text { Side }}$ & $\underline{\text { Bottom }}$ & $\underline{\text { All }}$ \\
Mean & 3853.2 & & Mean & 3833.1 & 3936.4 & 3884.8 \\
Min Point & 3085.3 & $-19.9 \%$ & Std. Dev. & 134.7 & 150.4 & 147.2 \\
Max Point & 4190.3 & $8.7 \%$ & Cov as $\%$ & 3.5 & 3.8 & 3.8 \\
\hline
\end{tabular}

Flow w/o C-Pt 2996 acfm

Vel Avg w/o C-Pt

Stack temp

Equipment temp

Ambient temp

Stack static

Ambient pressure

Total Stack pressure

Ambient humidity

3864 fpm

\begin{tabular}{|c|c|}
\hline Start & Finish \\
\hline 58.7 & 60.7 \\
\hline NA & NA \\
\hline 58.1 & 59 \\
\hline NA & $N A$ \\
\hline 30.50 & 30.50 \\
\hline NA & $\mathrm{NA}$ \\
\hline $26 \%$ & $26 \%$ \\
\hline
\end{tabular}

Notes:

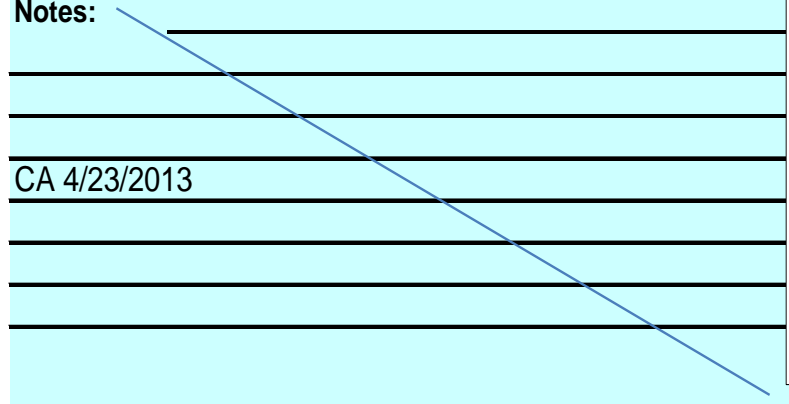

Entries made by:

Signature/date

\section{Instuments Used:}

Fishcer Scientific Barometer SN 90936818

TSI VelociCalc SN T95351203001

Cal Due

12/10/2013

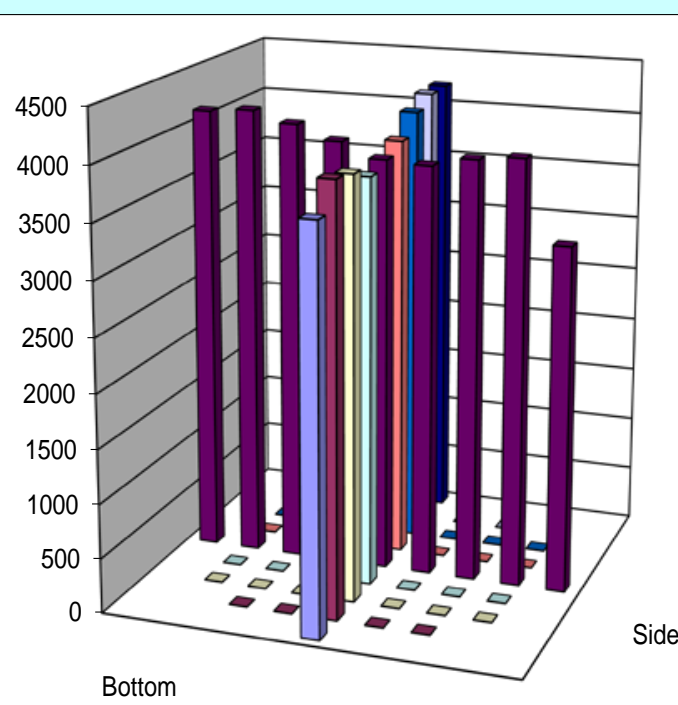

Bottom

Technical Data Review performed by: Elizabeth Golovich

Signature/date

$6 / 3 / 2013$

Signature on file with original TI-WTPSP-108 


\section{VELOCITY TRAVERSE DATA FORM}

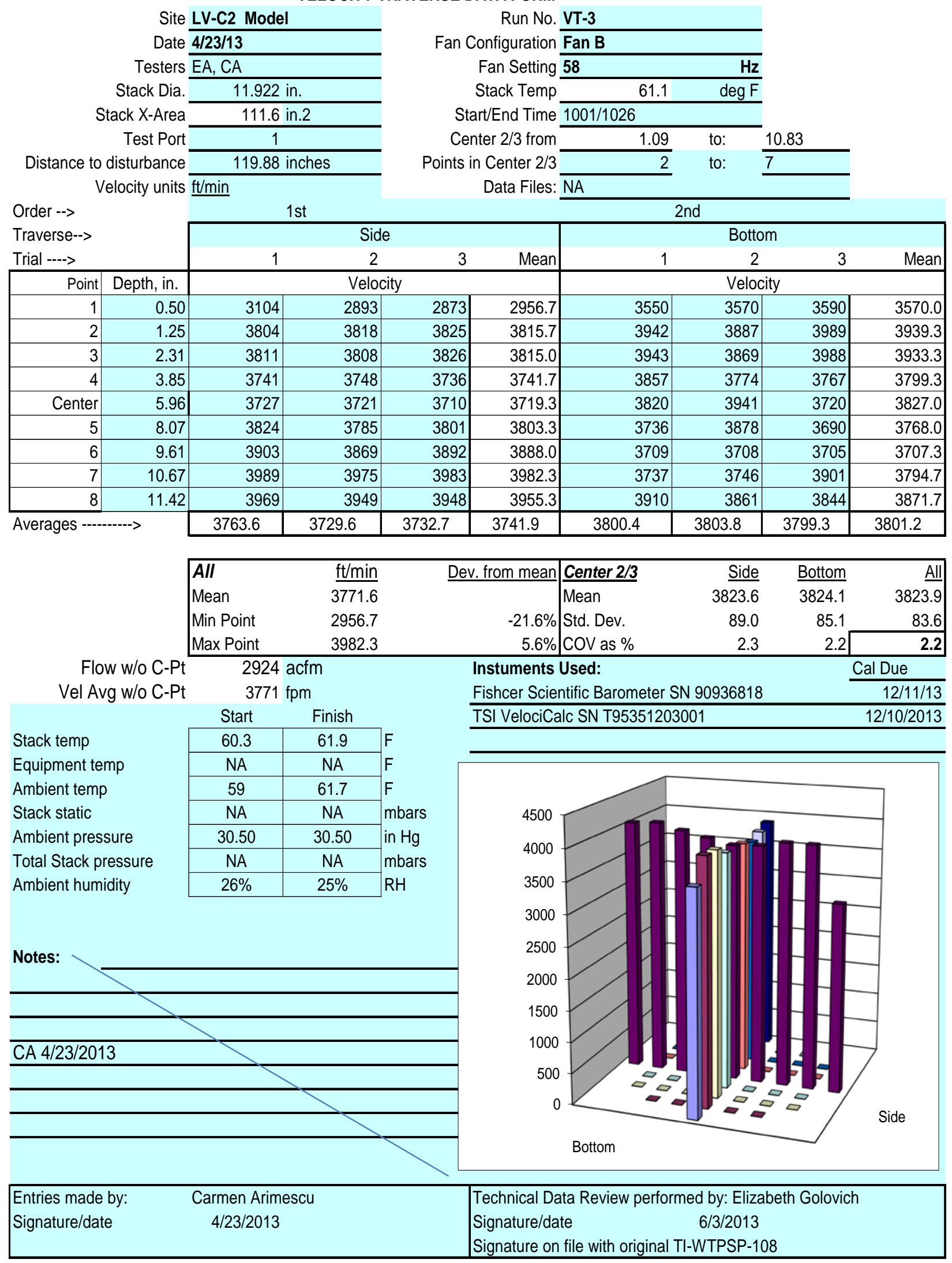




\section{VELOCITY TRAVERSE DATA FORM}

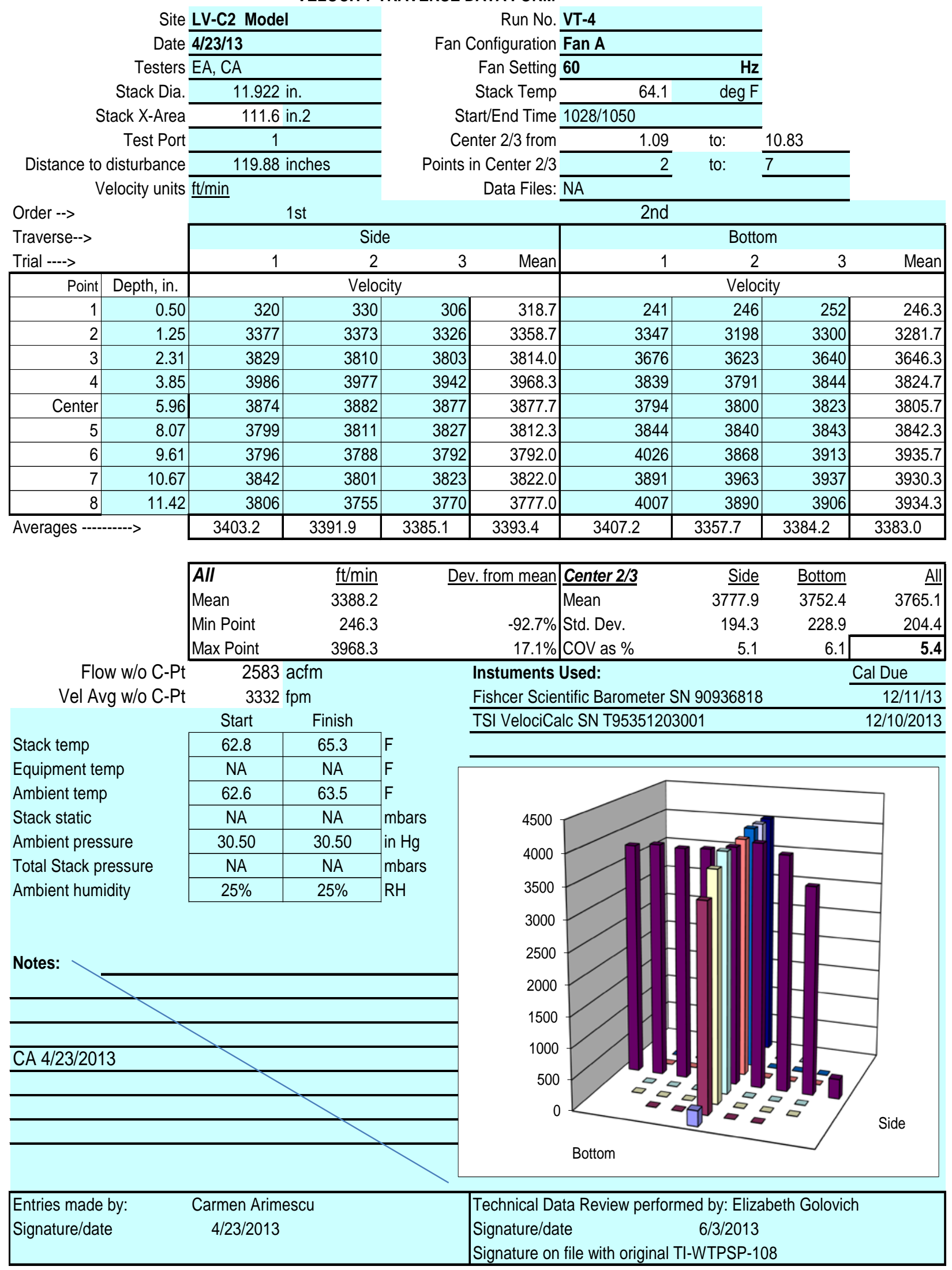




\section{VELOCITY TRAVERSE DATA FORM}

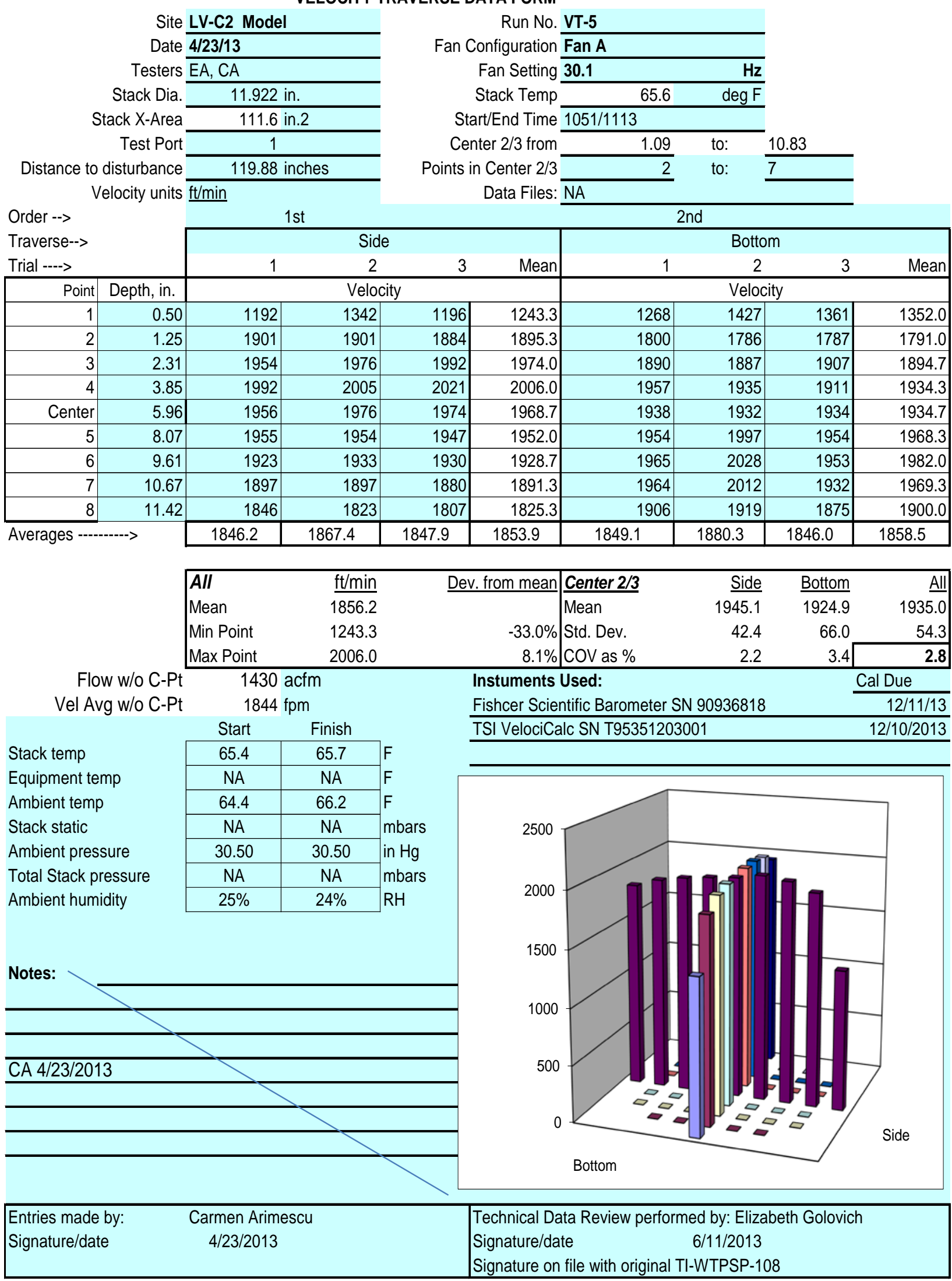




\section{VELOCITY TRAVERSE DATA FORM}

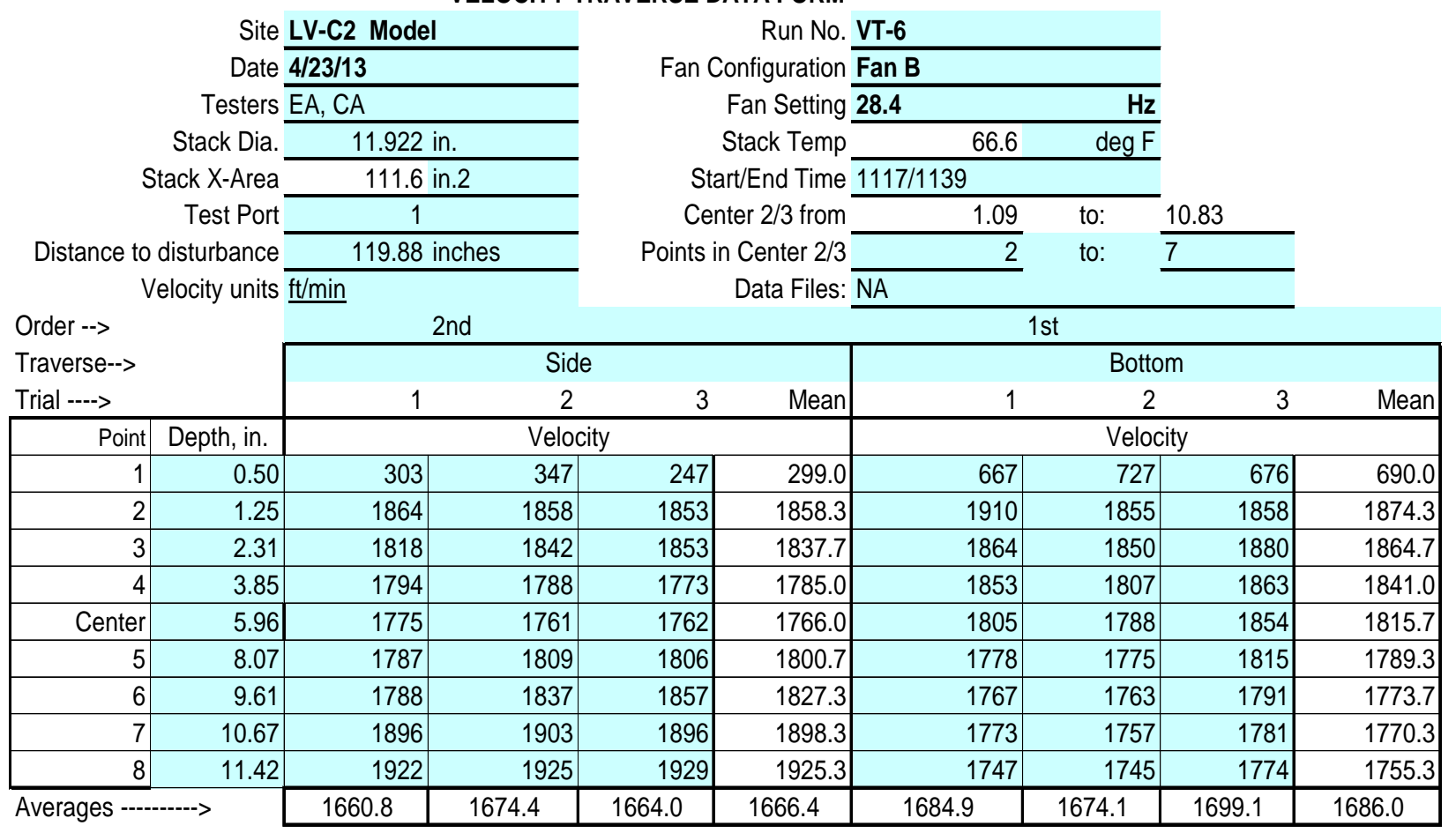

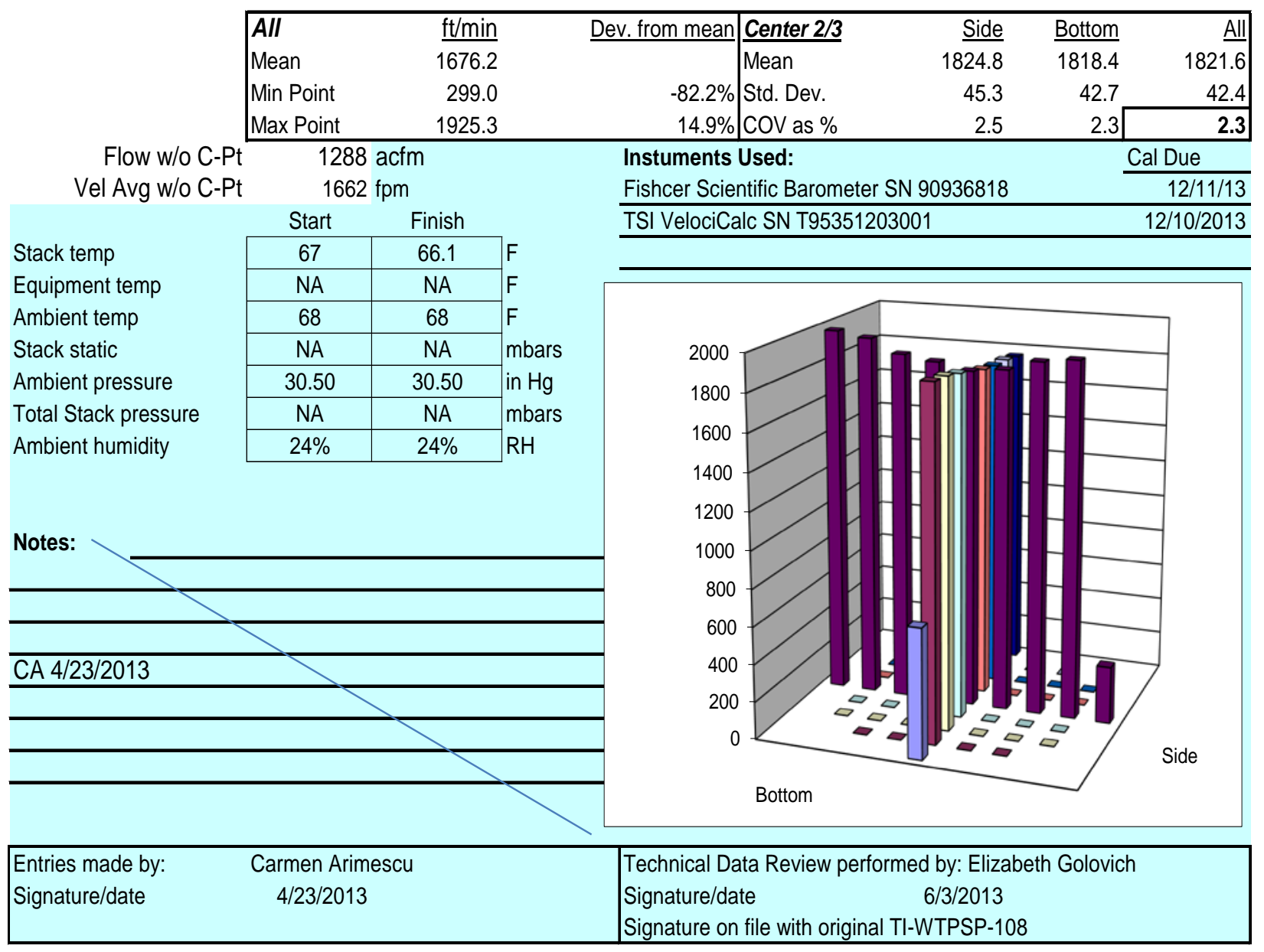




\section{VELOCITY TRAVERSE DATA FORM}

Site LV-C2 Model

Date 4/23/13

Testers EA, CA

Stack Dia.

Stack X-Area

Test Port

$\frac{11.922 \text { in. }}{\frac{111.6 \text { in. } 2}{1}}$

Distance to disturbance

Velocity units $\underline{\mathrm{ft} / \mathrm{min}}$

Order -->

Traverse-->

Trial ---->

Trial --->
\begin{tabular}{|r|r|}
\hline Point & Depth, in. \\
\hline 1 & 0.50 \\
2 & 1.25 \\
\hline 3 & 2.31 \\
\hline 4 & 3.85 \\
\hline Center & 5.96 \\
\hline 5 & 8.07 \\
\hline 6 & 9.61 \\
\hline 7 & 10.67 \\
\hline 8 & 11.42 \\
\hline
\end{tabular}

Averages --------->
1 st
Fan Configuration Fan A

Fan Setting 30.1

Stack Temp

Start/End Time 1141/1209

Center $2 / 3$ from

Points in Center $2 / 3$

Data Files: NA

\begin{tabular}{lr} 
& $\mathrm{Hz}$ \\
$68.5 \quad \operatorname{deg} \mathrm{F}$ \\
\hline
\end{tabular}

1.0

1.09

2 to:

$\quad 10.83$

: 7

\section{2nd 2nd}

\begin{tabular}{|r|r|r|r|r|}
\hline & \multicolumn{5}{|c|}{$\begin{array}{c}\text { Bottom } \\
\text { Mean }\end{array}$} & 1 & \multicolumn{3}{c|}{3} & Mean \\
\hline & 1443 & 1344 & 1381 & 1389.3 \\
\hline 1245.7 & 1770 & 1804 & 1744 & 1772.7 \\
\hline 1903.7 & 1927 & 1916 & 1913 & 1918.7 \\
\hline 2043.3 & 1931 & 1976 & 2004 & 1970.3 \\
\hline 2017.7 & 1919 & 1958 & 1972 & 1949.7 \\
\hline 1974.3 & 1995 & 1959 & 2035 & 1996.3 \\
\hline 1940.7 & 2005 & 2002 & 2073 & 2026.7 \\
\hline 1952.7 & 2019 & 2124 & 2049 & 2064.0 \\
\hline 1947.3 & 1959 & 2008 & 1939 & 1968.7 \\
\hline 1881.3 & 1885.3 & 1899.0 & 1901.1 & 1895.1 \\
\hline 1878.5 & & & & \\
\hline & & \multicolumn{5}{|c|}{} \\
\hline
\end{tabular}

\begin{tabular}{|lrr|lrrr|}
\hline All & $\underline{\mathrm{ft} / \mathrm{min}}$ & Dev. from mean & Center 2/3 & $\underline{\text { Side }}$ & $\underline{\text { Bottom }}$ & All \\
Mean & 1886.8 & & Mean & 1968.5 & 1956.9 & 1962.7 \\
Min Point & 1245.7 & $-34.0 \%$ & Std. Dev. & 47.8 & 94.5 & 72.2 \\
Max Point & 2064.0 & $9.4 \%$ & COV as $\%$ & 2.4 & 4.8 & $\mathbf{3 . 7}$ \\
\hline
\end{tabular}

Flow w/o C-Pt $\quad 1455$ acfm

Vel Avg w/o C-Pt

Stack temp

Equipment temp

Ambient temp

Stack static

Ambient pressure

Total Stack pressure

Ambient humidity

$1877 \mathrm{fpm}$

\begin{tabular}{|c|c|}
\hline Start & Finish \\
\hline 68 & 69 \\
\hline NA & NA \\
\hline 68.9 & 74.3 \\
\hline NA & NA \\
\hline 30.50 & 30.50 \\
\hline NA & NA \\
\hline $24 \%$ & $22 \%$ \\
\hline
\end{tabular}

Notes:

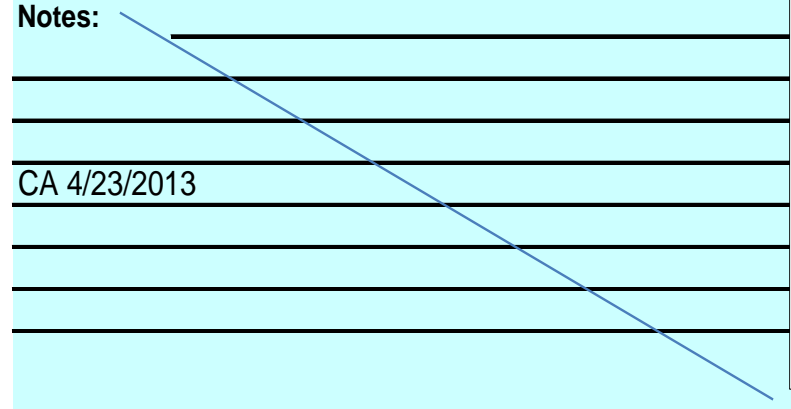

Entries made by:

Signature/date
Instuments Used:

Fishcer Scientific Barometer SN 90936818

TSI VelociCalc SN T95351203001
Cal Due

$12 / 11 / 13$

$12 / 10 / 2013$

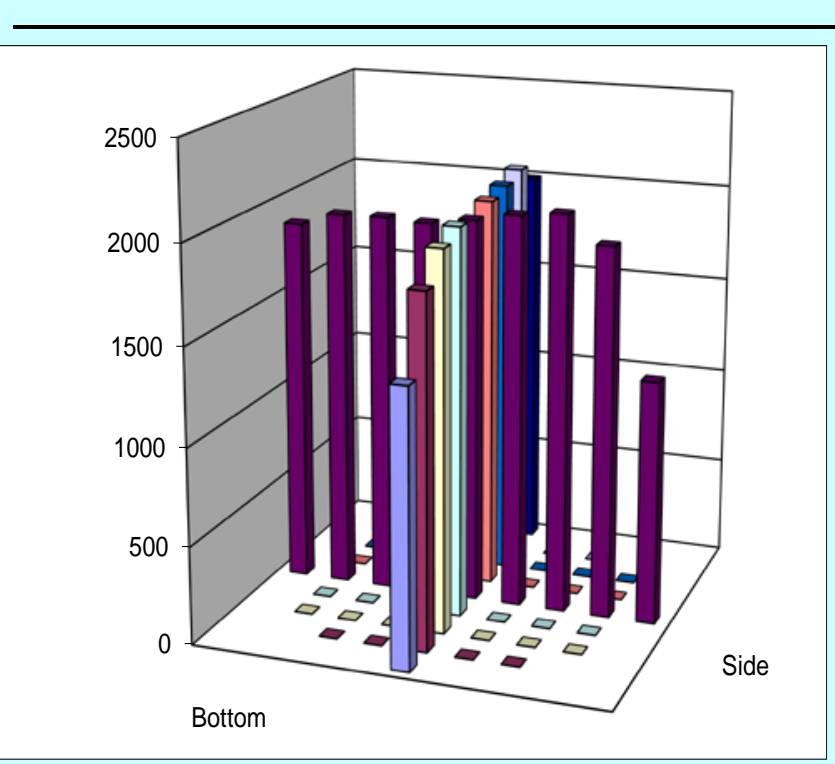

Technical Data Review performed by: Elizabeth Golovich

Signature/date 6/3/2013

Signature on file with original TI-WTPSP-108 


\section{VELOCITY TRAVERSE DATA FORM}

Site LV-C2 Model

\section{Date 4/23/13}

Testers EA, CA

Stack Dia

Stack X-Area

Test Port

\begin{tabular}{|c|}
\hline 11.922 in. \\
\hline 111.6 in. 2 \\
\hline 1 \\
\hline
\end{tabular}

Distance to disturbance

Velocity units $\underline{\mathrm{ft} / \mathrm{min}}$

Order -->

Traverse-->

Trial ---->

2nd
Run No. VT-8

Fan Configuration Fan A

Fan Setting $\mathbf{3 0 . 1}$

Stack Temp

Start/End Time 1212/1239

Center 2/3 from

Points in Center 2/3

Data Files: NA

\begin{tabular}{llll}
$\frac{1.09}{2}$ & to: & 10.83 \\
\hline & to: & \\
\hline
\end{tabular}

$1 \mathrm{st}$

\begin{tabular}{|c|c|c|c|c|c|c|c|c|c|}
\hline Point & Depth, in. & \multicolumn{4}{|c|}{ Velocity } & \multicolumn{4}{|c|}{ Velocity } \\
\hline 1 & 0.50 & 1089 & 1171 & 1211 & 1157.0 & 1176 & 1307 & 1348 & 1277.0 \\
\hline 2 & 1.25 & 1852 & 1870 & 1833 & 1851.7 & 1773 & 1787 & 1791 & 1783.7 \\
\hline 3 & 2.31 & 1993 & 1993 & 1978 & 1988.0 & 1874 & 1917 & 1896 & 1895.7 \\
\hline 4 & 3.85 & 2021 & 2019 & 1998 & 2012.7 & 1931 & 1936 & 1980 & 1949.0 \\
\hline Center & 5.96 & 1987 & 1969 & 1975 & 1977.0 & 1950 & 1940 & 1985 & 1958.3 \\
\hline 5 & 8.07 & 1968 & 1973 & 1958 & 1966.3 & 2187 & 1970 & 1975 & 2044.0 \\
\hline 6 & 9.61 & 2006 & 1988 & 1981 & 1991.7 & 2021 & 2065 & 1974 & 2020.0 \\
\hline 7 & 10.67 & 1962 & 1961 & 1995 & 1972.7 & 2057 & 2040 & 2006 & 2034.3 \\
\hline 8 & 11.42 & 1910 & 1915 & 1896 & 1907.0 & 1969 & 1932 & 1924 & 1941.7 \\
\hline Averages --- & $-\cdots-->$ & 1865.3 & 1873.2 & 1869.4 & 1869.3 & 1882.0 & 1877.1 & 1875.4 & 1878.2 \\
\hline
\end{tabular}

\begin{tabular}{|lrr|lrrr|}
\hline All & $\underline{\mathrm{ft} / \mathrm{min}}$ & Dev. from mean & Center 2/3 & $\underline{\text { Side }}$ & $\underline{\text { Bottom }}$ & $\underline{\text { All }}$ \\
Mean & 1873.8 & & Mean & 1965.7 & 1955.0 & 1960.4 \\
Min Point & 1157.0 & $-38.3 \%$ & Std. Dev. & 52.5 & 92.5 & 72.5 \\
Max Point & 2044.0 & $9.1 \%$ & COV as \% & 2.7 & 4.7 & 3.7 \\
\hline
\end{tabular}

Flow w/o C-Pt Vel Avg w/o C-Pt

Stack temp

Equipment temp

Ambient temp

Stack static

Ambient pressure

Total Stack pressure

Ambient humidity

$1443 \mathrm{acfm}$

1862 fpm

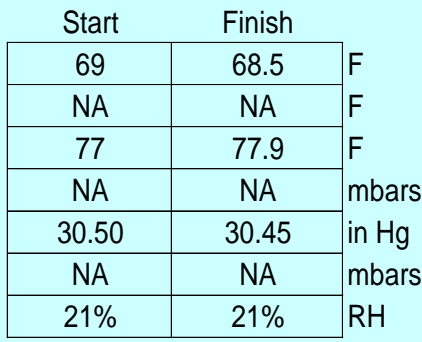

Notes:

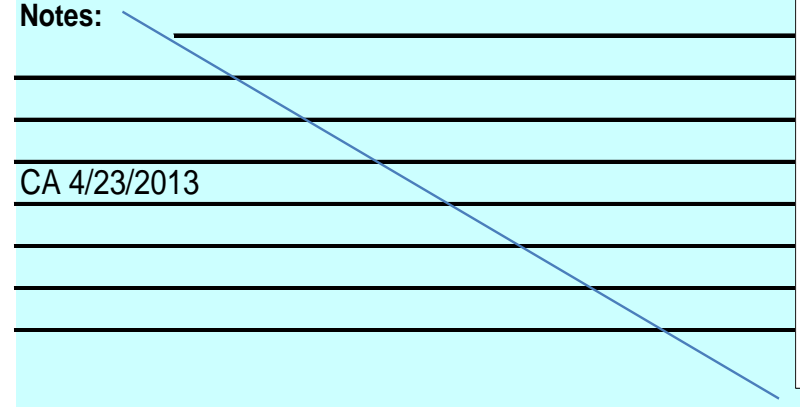

Entries made by:

Signature/date
Instuments Used:

Fishcer Scientific Barometer SN 90936818

TSI VelociCalc SN T95351203001

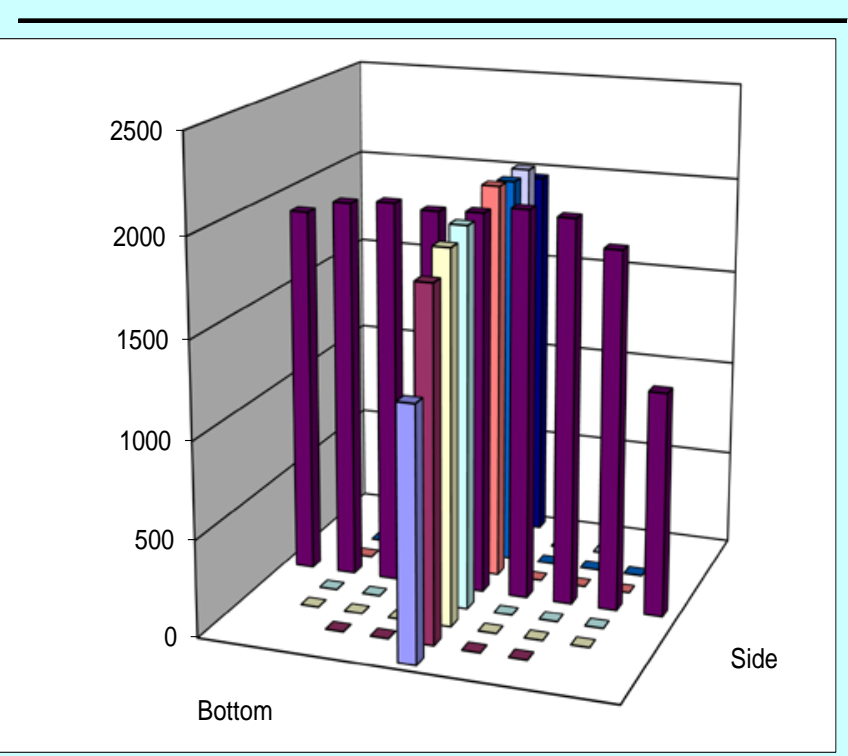

Technical Data Review performed by: Elizabeth Golovich

Signature/date

Signature on file with original TI-WTPSP-108 


\section{VELOCITY TRAVERSE DATA FORM}

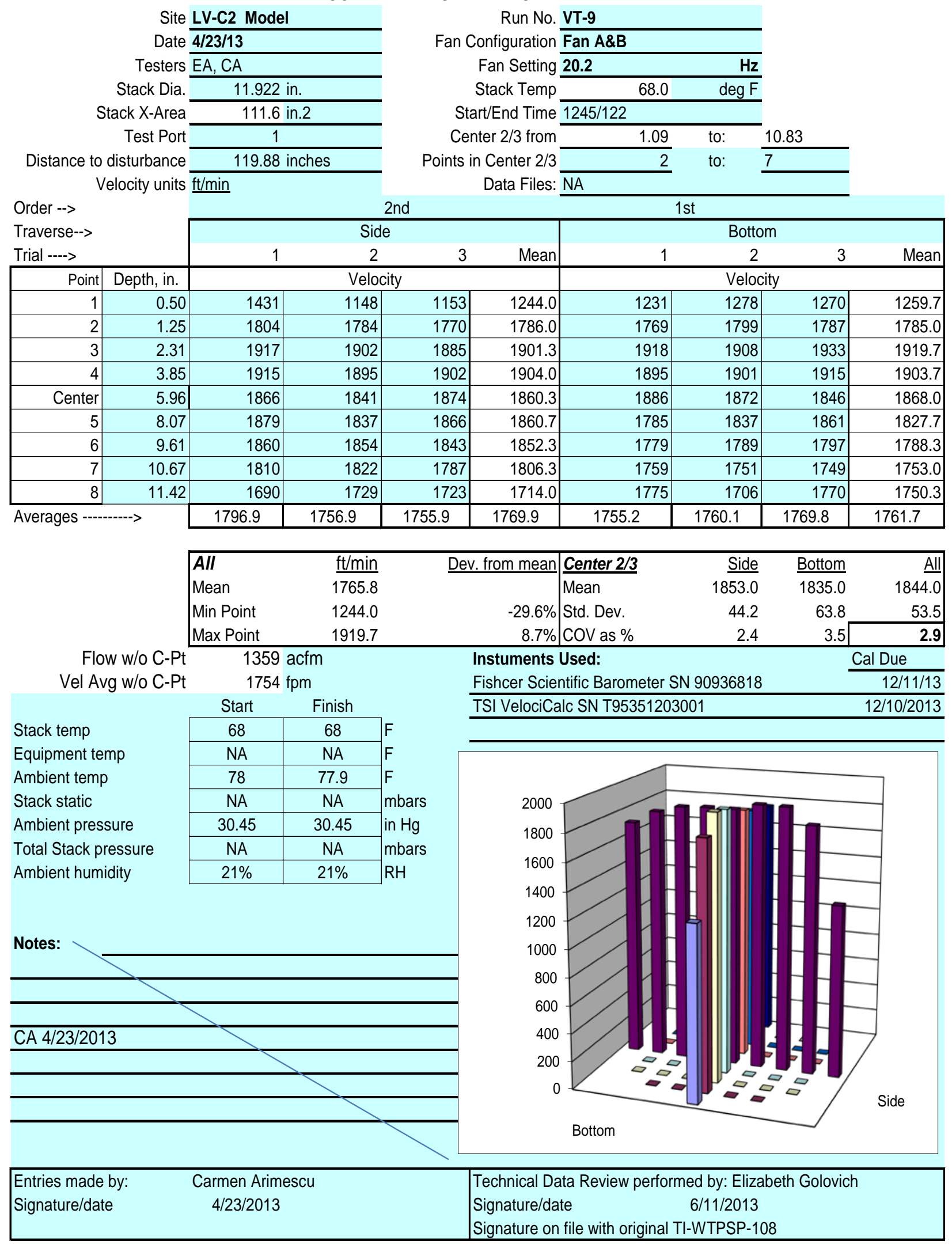




\section{VELOCITY TRAVERSE DATA FORM}

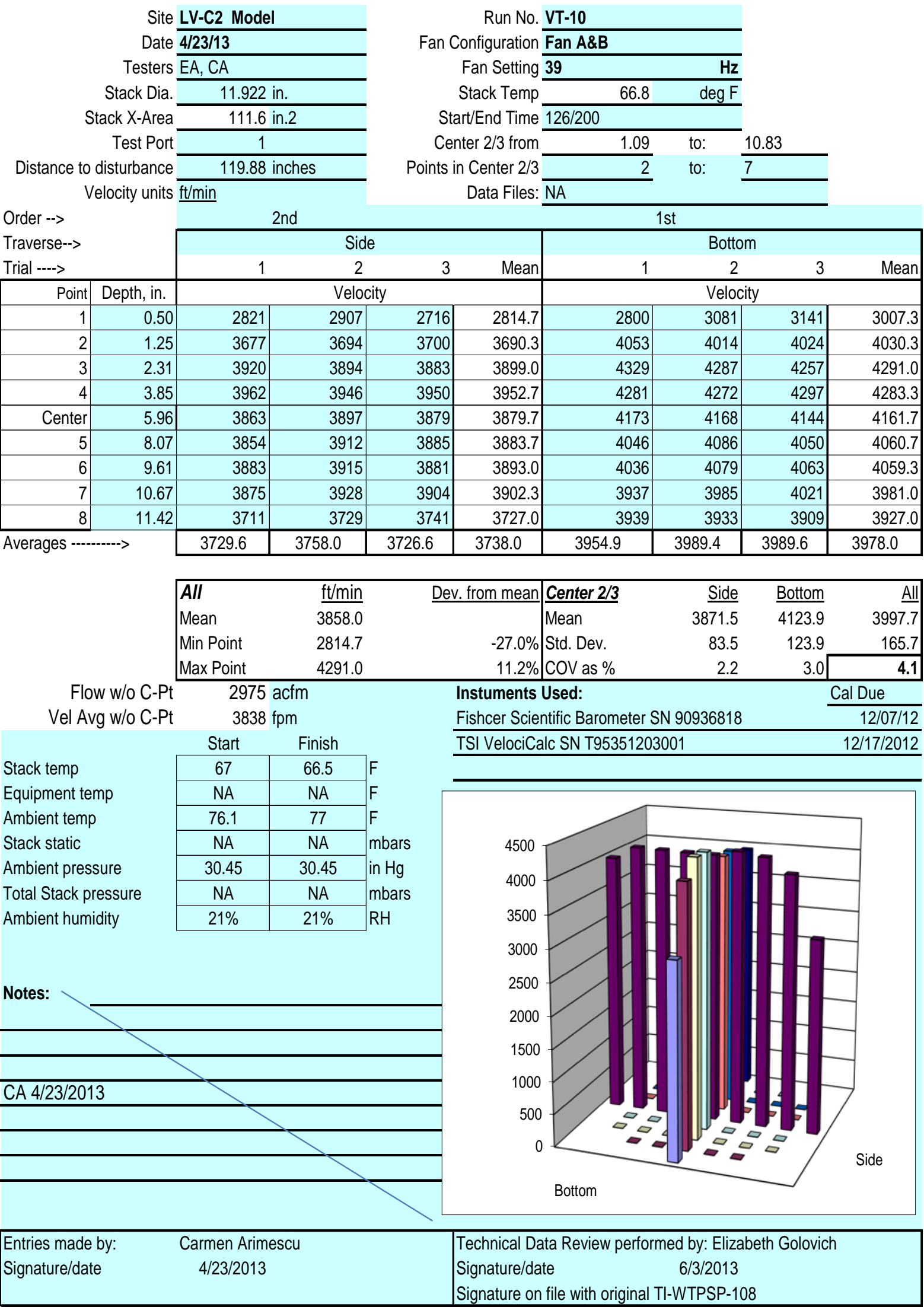




\section{B.4 LV-C2 Flow Angle Data Sheets}

\section{FLOW ANGLE DATA FORM}

\begin{tabular}{|c|c|c|}
\hline \multicolumn{3}{|c|}{ Site LV-C2 Scale Mod } \\
\hline \multicolumn{3}{|c|}{ Date $\overline{4 / 24 / 2013}$} \\
\hline \multicolumn{3}{|c|}{ Tester $\mathrm{EA}, \mathrm{CA}$} \\
\hline Stack Dia. & 11.922 & in \\
\hline Stack X-Area & 111.6 & in2 \\
\hline Elevation & N.A. & $\mathrm{tt}$ \\
\hline Distance to disturbance & 119.88 & in \\
\hline Start/End Time & $\overline{00 / 945}$ & \\
\hline
\end{tabular}

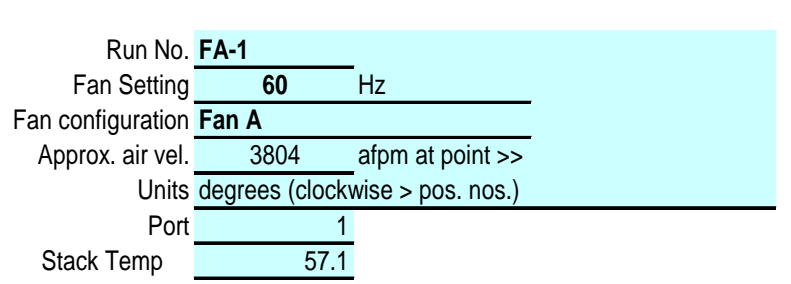

\begin{tabular}{|c|c|c|c|c|c|c|c|c|c|}
\hline \multirow{4}{*}{$\begin{array}{l}\text { Order --> } \\
\text { Traverse--> } \\
\text { Trial ----> }\end{array}$} & & & & & & \multirow[b]{2}{*}{$1 \mathrm{st}$} & & \\
\hline & & 2nd & & & & & & & \\
\hline & & \multicolumn{4}{|c|}{ Side } & \multicolumn{4}{|c|}{ Bottom } \\
\hline & & 1 & 2 & 3 & & 1 & 2 & 3 & \\
\hline Point & Depth, in. & deg. CW & deg. CW & deg. CW & Avg. & deg. $\mathrm{cw}$ & deg. CW & deg. CW & Avg. \\
\hline 1 & 0.50 & -10 & -11 & -13 & -11.3 & -10 & -11 & -10 & -10.3 \\
\hline 2 & 1.25 & 1 & 2 & 3 & 2.0 & 6 & 6 & 4 & 5.3 \\
\hline 3 & 2.31 & -1 & 0 & 0 & -0.3 & 4 & 5 & 2 & 3.7 \\
\hline 4 & 3.85 & -6 & -3 & -2 & -3.7 & 0 & 0 & 1 & 0.3 \\
\hline Center & 5.96 & -8 & -7 & -9 & -8.0 & -2 & -4 & -2 & -2.7 \\
\hline 5 & 8.07 & -4 & -5 & -6 & -5.0 & 1 & 0 & 1 & 0.7 \\
\hline 6 & 9.61 & -1 & -1 & 0 & -0.7 & 3 & 3 & 1 & 2.3 \\
\hline 7 & 10.67 & 3 & 5 & 1 & 3.0 & 4 & 4 & 2 & 3.3 \\
\hline 8 & 11.42 & 3 & 7 & 4 & 4.7 & 6 & 3 & 3 & 4.0 \\
\hline \multirow{2}{*}{\multicolumn{2}{|c|}{$\begin{array}{l}\text { Mean of absolute values: } \\
\text { " } \quad \text { " w/o points by wall: }\end{array}$}} & & & & 4.3 & & & & 3.6 \\
\hline & & & & & 3.2 & & & & 2.6 \\
\hline \multirow{2}{*}{\multicolumn{2}{|c|}{ Instuments Used: }} & & & & & & \multicolumn{2}{|r|}{ Grand mean ABS } & 4.0 \\
\hline & & & & & \multicolumn{2}{|l|}{ Cal. Due } & \multirow{2}{*}{\multicolumn{2}{|c|}{ " " w/o wall pts }} & 2.9 \\
\hline \multicolumn{2}{|c|}{ S-type pitot } & \multicolumn{3}{|c|}{ Dwyer 24-inch S-type Pitot\#10 } & \multicolumn{2}{|c|}{ Cert. of conformance } & & & \\
\hline \multicolumn{2}{|c|}{ Velocity sensor } & TSI Velocica & N\#T9535120 & & 10-Dec-13 & & & & \\
\hline \multicolumn{2}{|c|}{ Angle indicator } & Shop built & & & Cat. 3 & & & & \\
\hline \multirow{2}{*}{\multicolumn{2}{|c|}{ Manometer }} & Dwyer 400-5 & & & Cat. 3 & & & & \\
\hline & & & & tes: & & & & & \\
\hline
\end{tabular}

Note:

To assure similar hose connections between the manometer and pitot tube, rotating the pitot tube assembly clockwise drives the meniscus to the right (to higher pos. numbers).

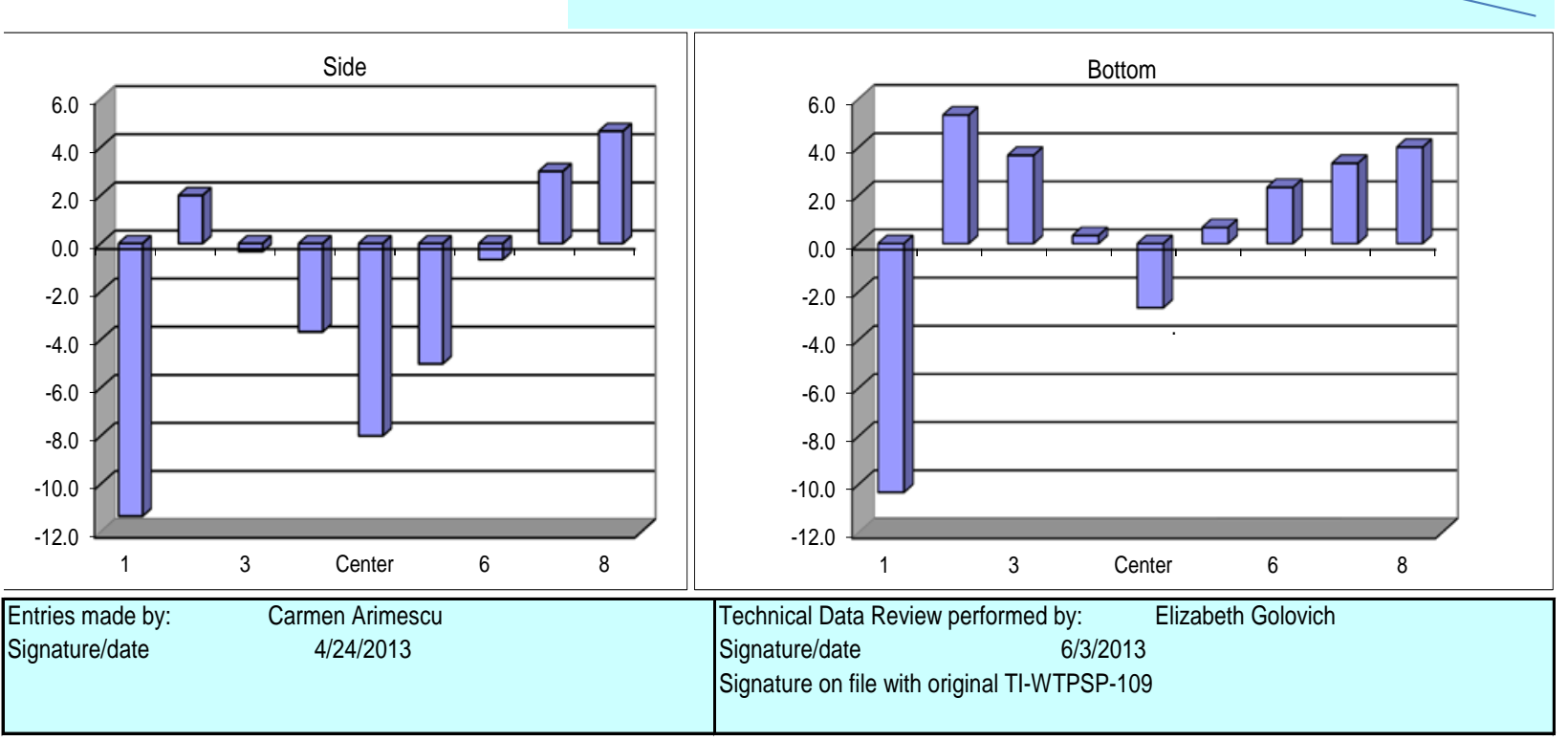




\section{FLOW ANGLE DATA FORM}

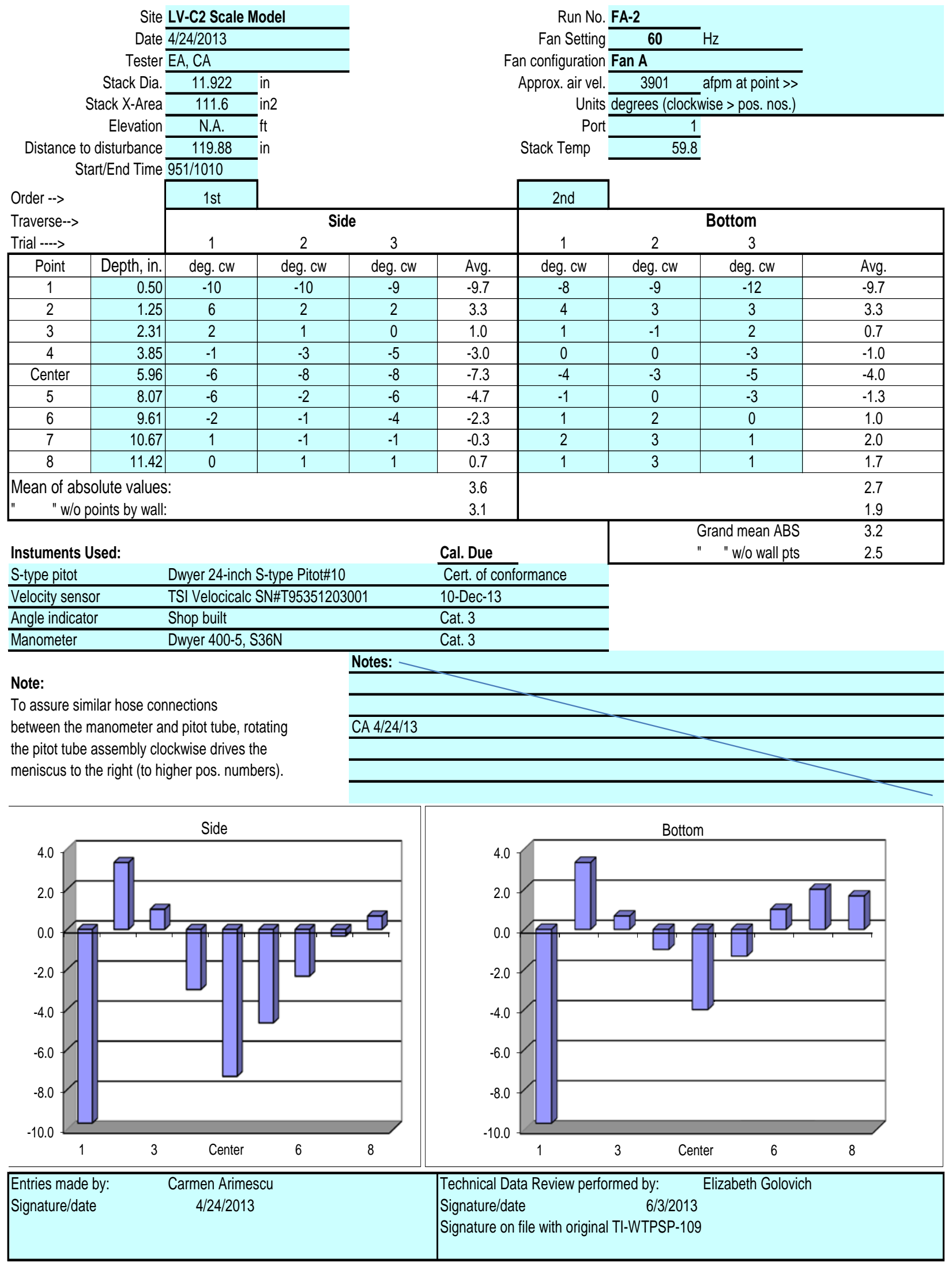




\section{FLOW ANGLE DATA FORM}

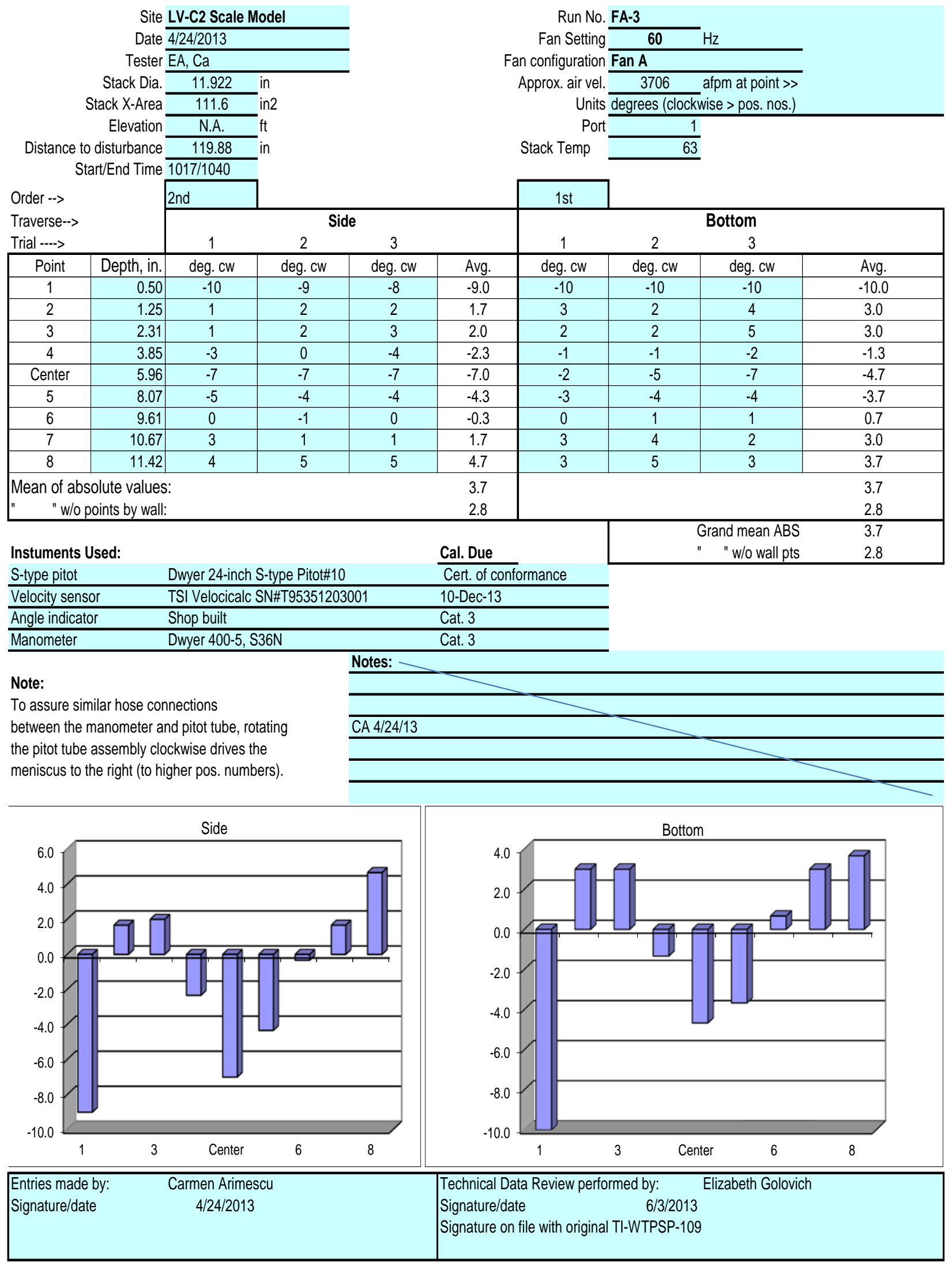




\section{FLOW ANGLE DATA FORM}

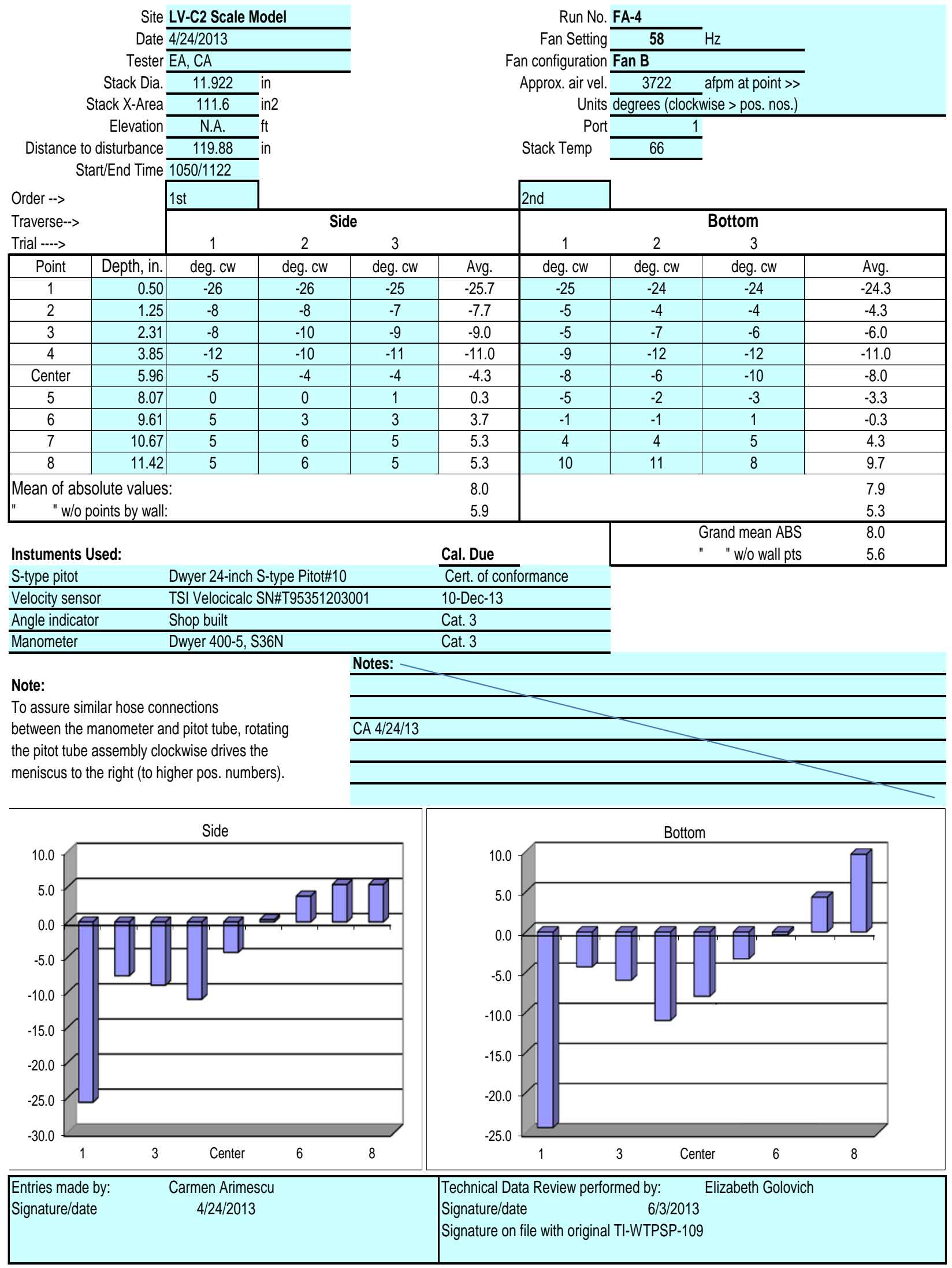




\section{FLOW ANGLE DATA FORM}

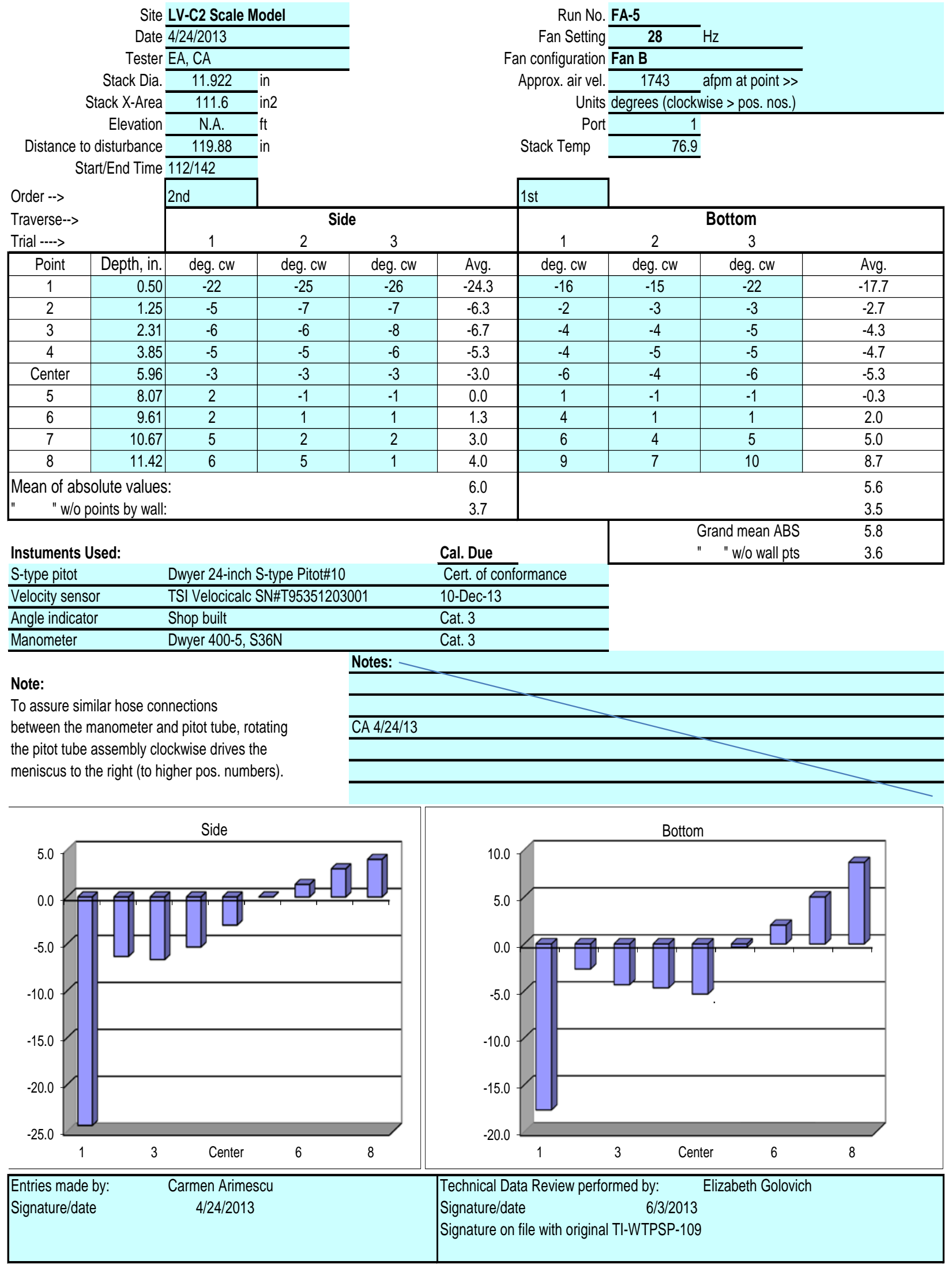




\section{FLOW ANGLE DATA FORM}

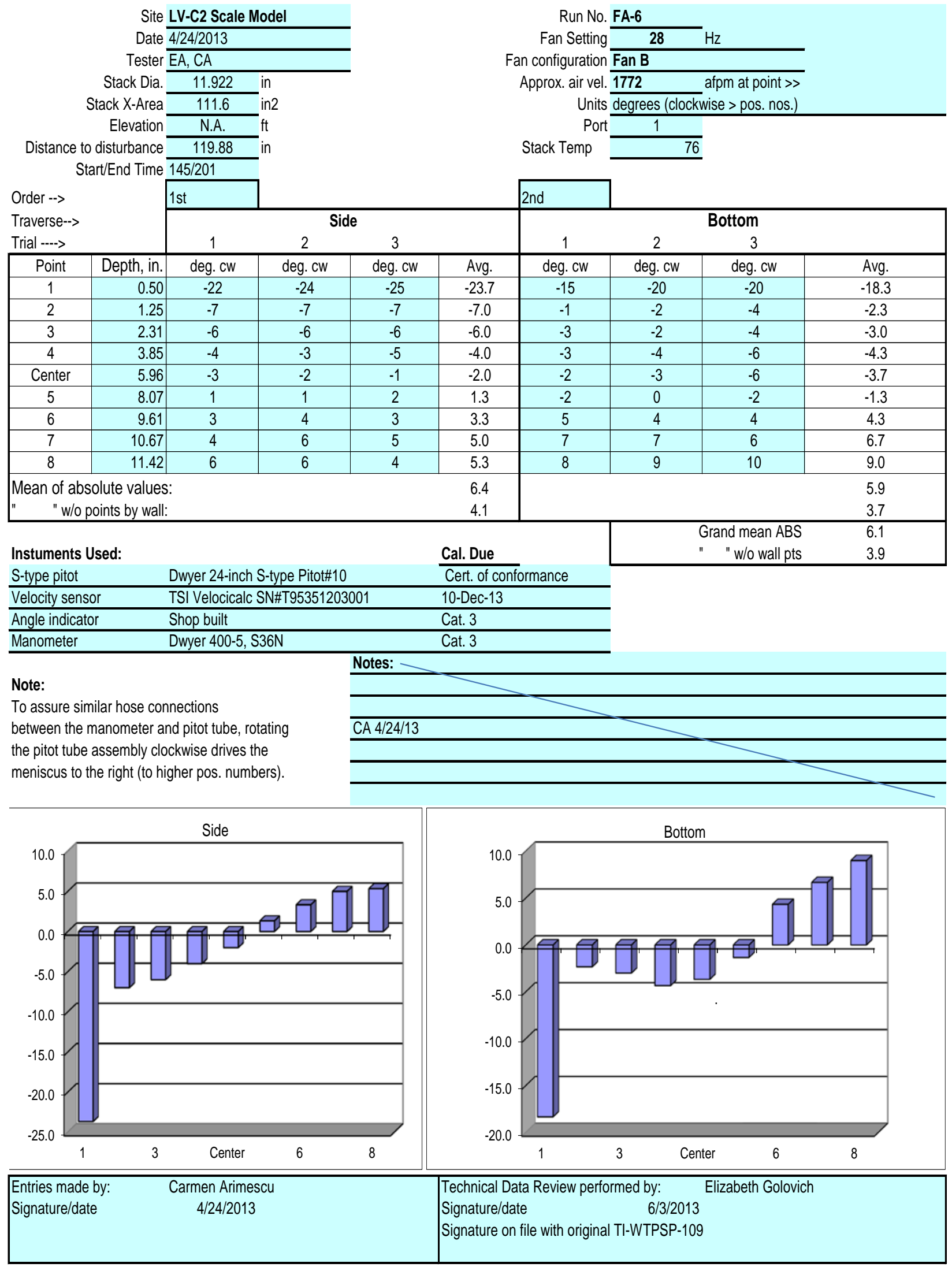




\section{FLOW ANGLE DATA FORM}

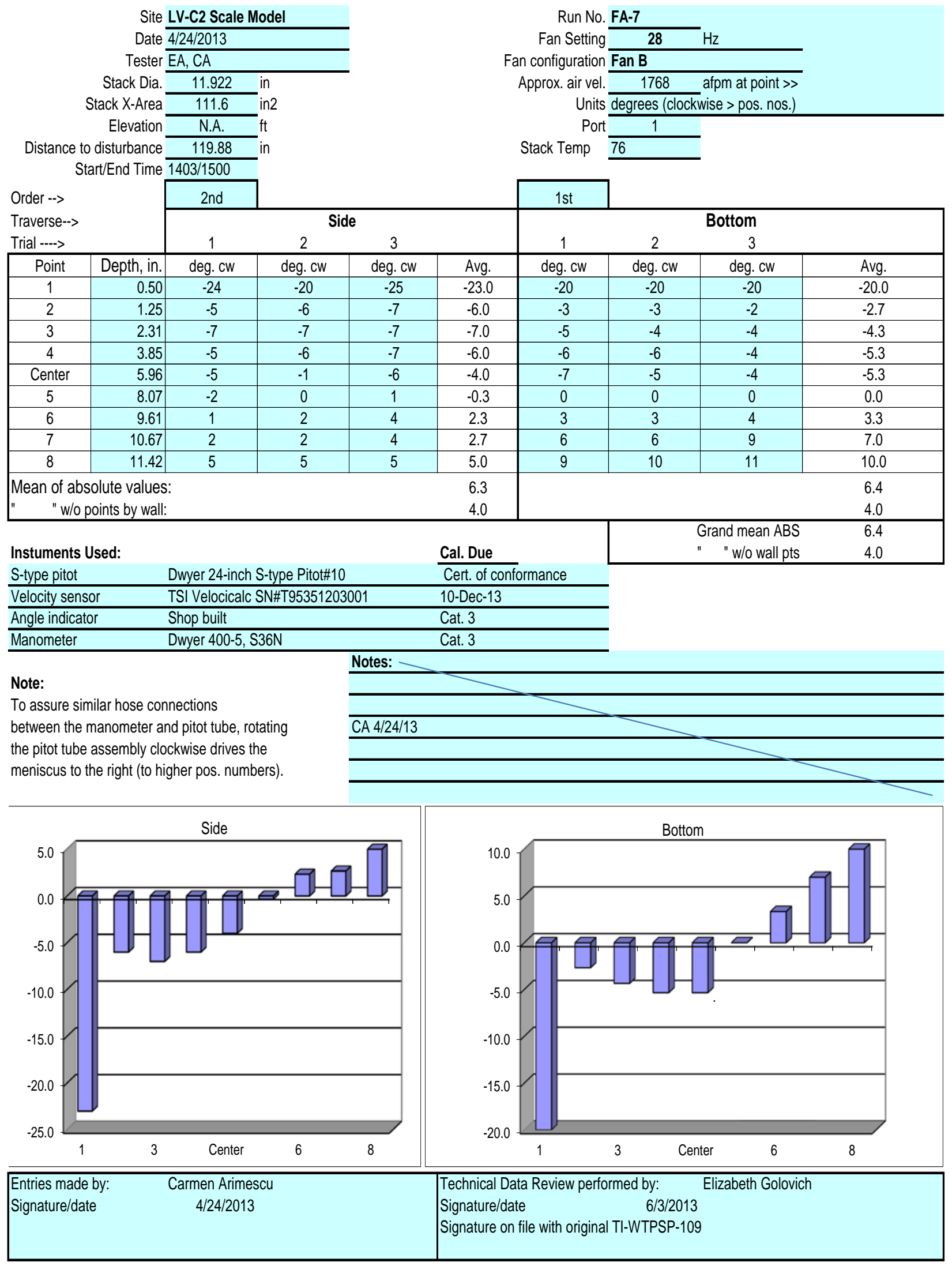




\section{FLOW ANGLE DATA FORM}

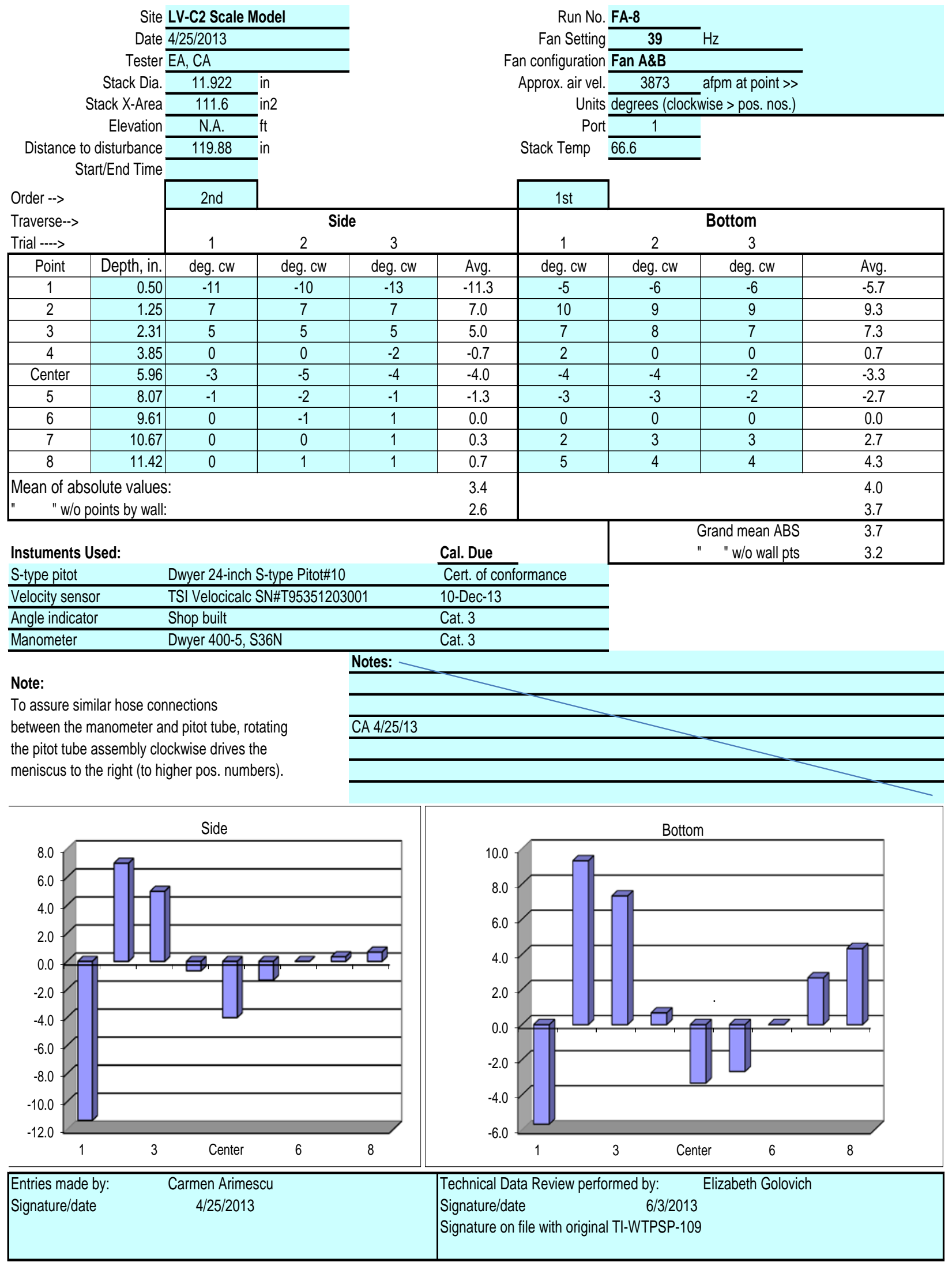




\section{FLOW ANGLE DATA FORM}

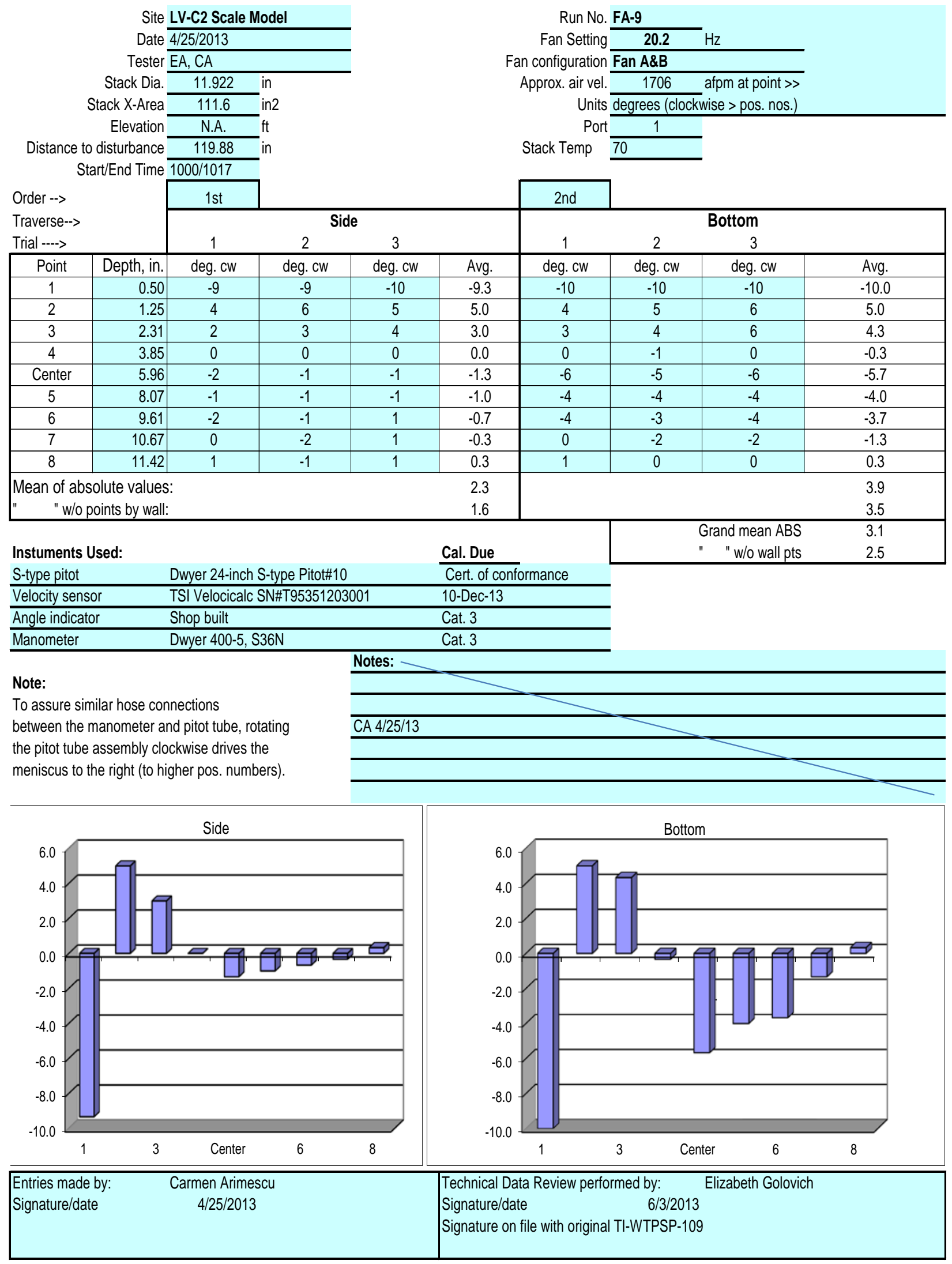




\section{FLOW ANGLE DATA FORM}

Site LV-C2 Scale Model

Date 4/25/2013

Tester EA, CA

Stack Dia. 11.922

Stack X-Area 111.6

Elevation N.A. $\mathrm{ft}$

Distance to disturbance 119.88 in

Start/End Time 1020/1051
Run No. FA-10

Fan Setting $30.1 \mathrm{~Hz}$

Fan configuration Fan A

Approx. air vel. 1850 afpm at point $>>$

Units degrees (clockwise $>$ pos. nos.)

Stack Temp

72.8

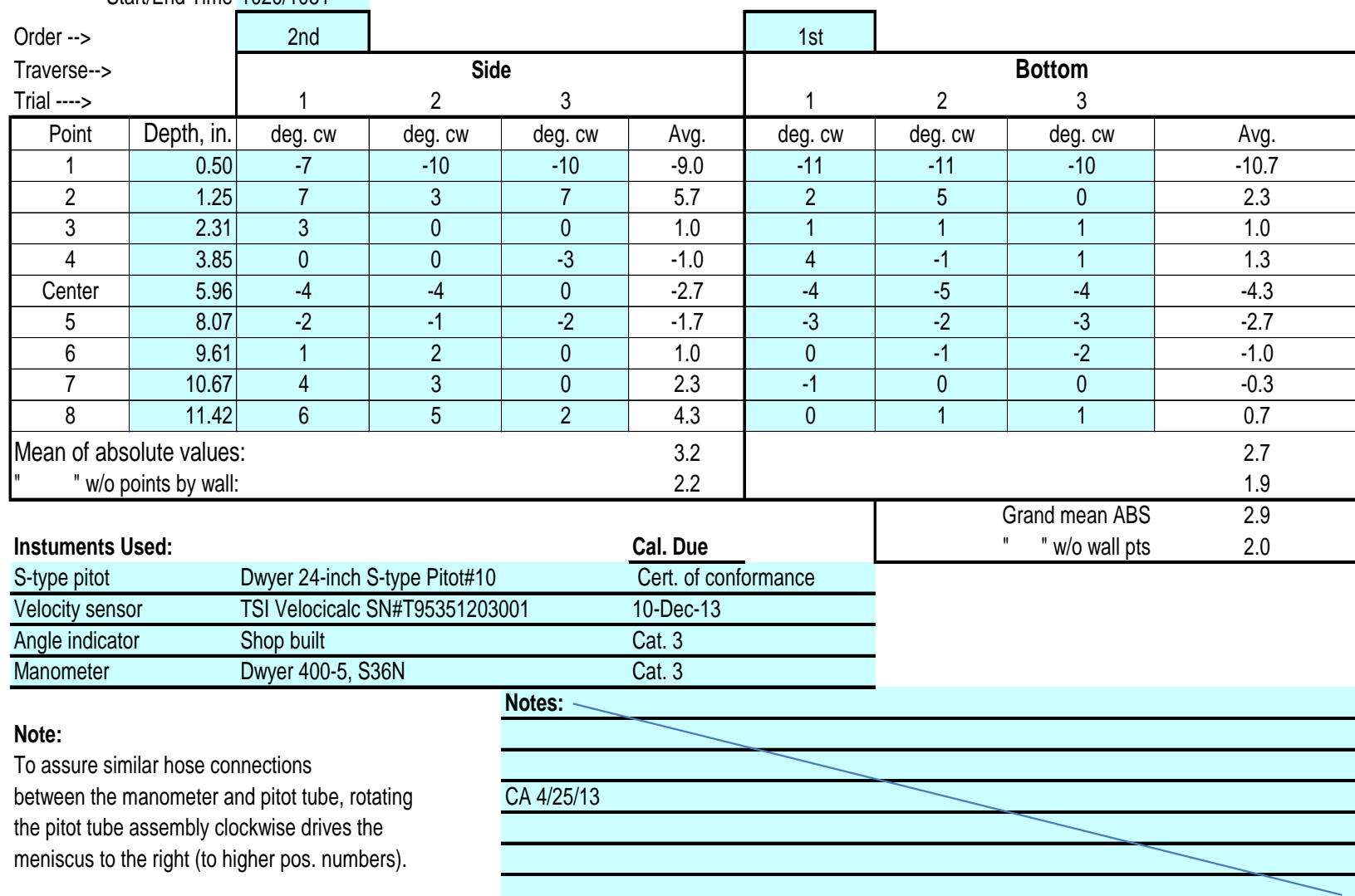

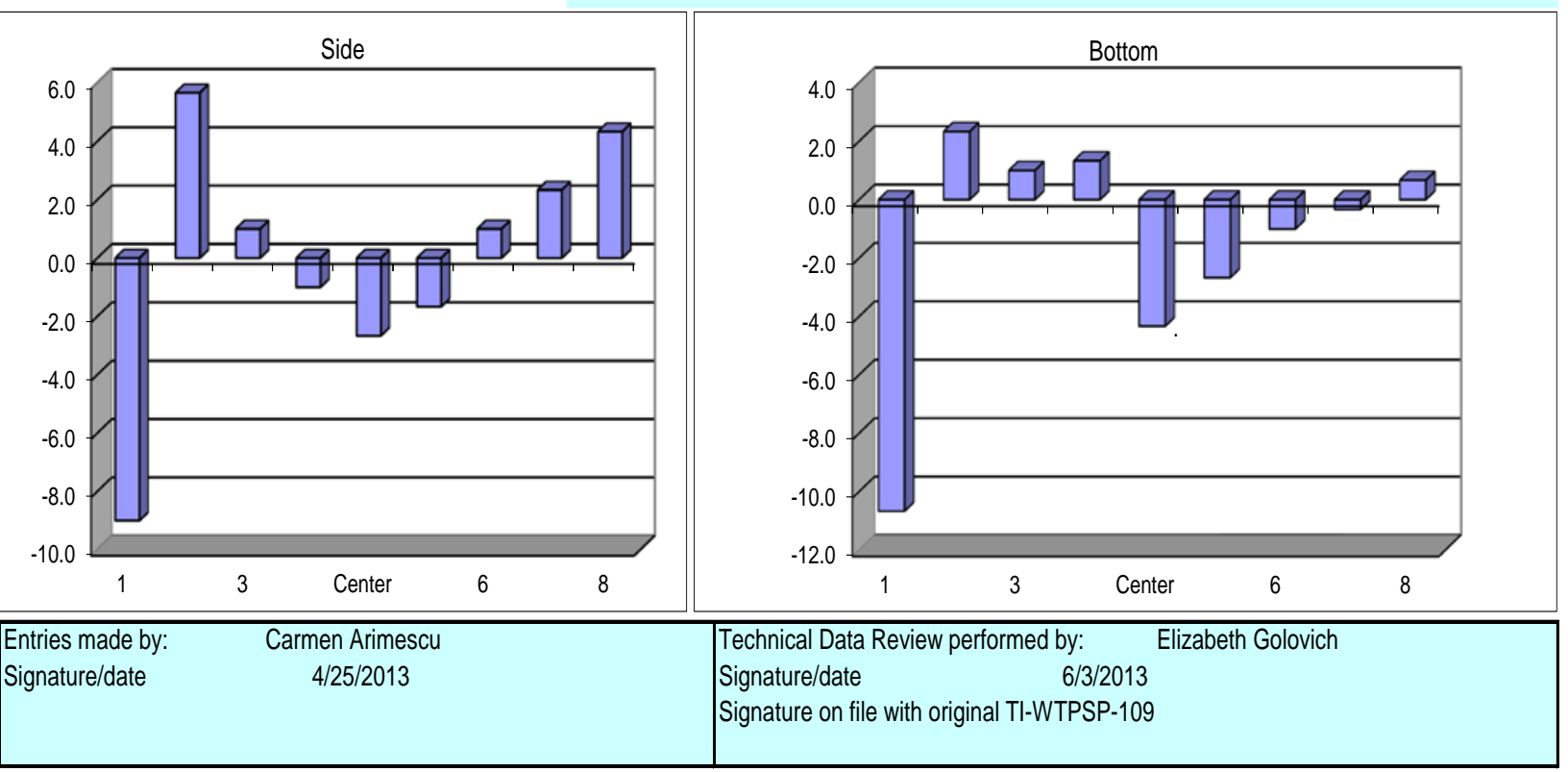




\section{B.5 LV-C2 Gas Tracer Calibration and Uniformity Data Sheets}

\section{GAS ANALYZER CALIBRATION}

\author{
Site LV-C2 Model \\ Date 5/17/2013 \\ Testers JEF, EA
}

Instrument
Serial No. $\frac{\text { B\&K Model } 1302}{1804888}$
Property No. WD54623

Setup: $6.3 \mathrm{ft} \quad$ B\&K sample inlet tube length

1011 mbar station pressure

74.3 deg F ambient temp analyzer corrects to $20 \mathrm{deg} C$ 29 percent $\mathrm{RH}$

Pre-Test background, ppb
Compensating for water vapor, monitoring task 2
$481,484,453,472,437$

$1.99 \mathrm{ppm}$

Cylinder SV17699

start $\mathrm{P}=1700 \mathrm{psi}$

end $P=1700$ psi

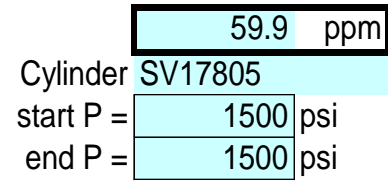

B\&K

Calibration

readings: (ppm)
B\&K

Calibration

readings: (ppm)

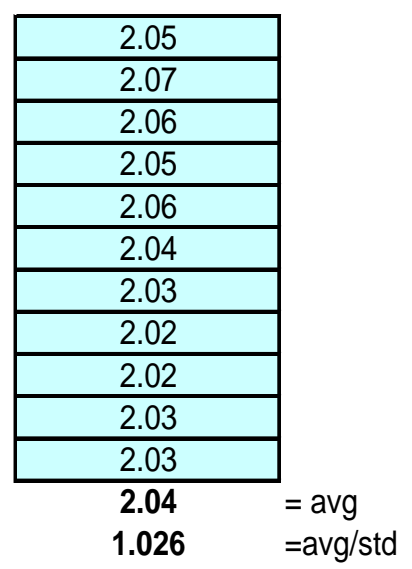

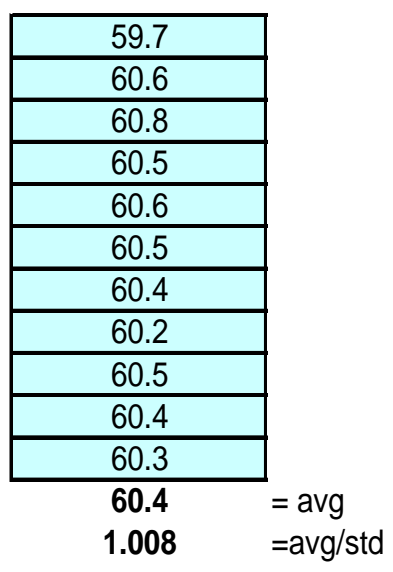

Expiration date:

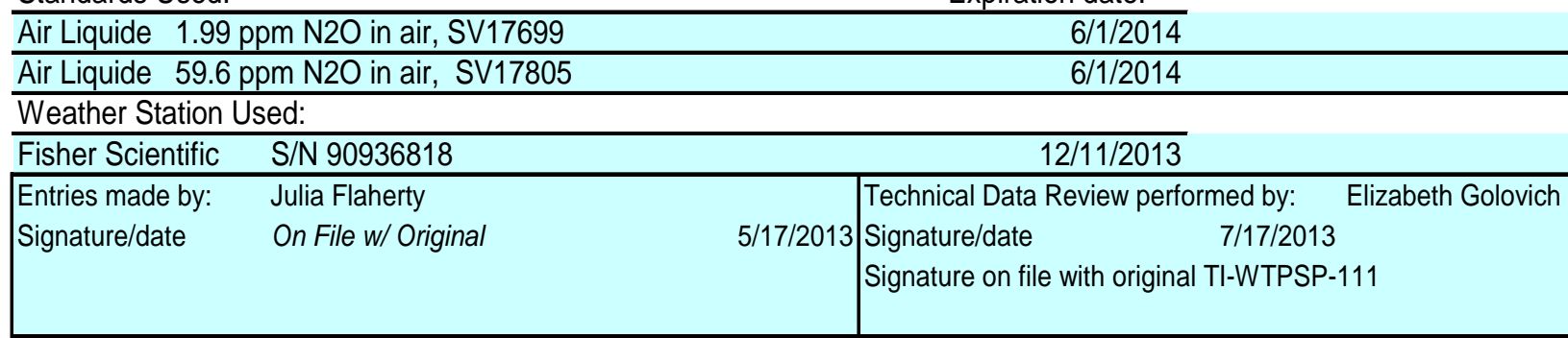




\section{GAS ANALYZER CALIBRATION}

\author{
Site LV-C2 Model \\ Date 5/28/2013 \\ Testers EA, CA
}

$\begin{aligned} & \text { Instrument } \text { B\&K Model } 1302 \\ & \text { Serial No. } \frac{1804888}{\text { WD54623 }} \\ & \text { Property No. }\end{aligned}$
Setup: $\quad 6.3 \mathrm{ft} \quad$ B\&K sample inlet tube length
1011 mbar station pressure
63.5 deg F ambient temp analyzer corrects to 20 deg C
41 percent $\mathrm{RH}$
Pre-Test background, ppb
Compensating for water vapor, monitoring task 2

$457,413,430,429,400$

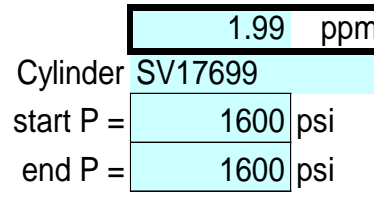

$B \& K$

Calibration

readings: (ppm)

\begin{tabular}{|c|}
\hline 2.11 \\
\hline 2.09 \\
\hline 2.10 \\
\hline 2.09 \\
\hline 2.08 \\
\hline 2.09 \\
\hline 2.07 \\
\hline 2.05 \\
\hline 2.07 \\
\hline 2.06 \\
\hline 2.06 \\
\hline 2.08 \\
\hline 1.045 \\
\hline
\end{tabular}

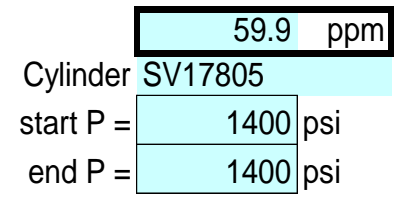

$B \& K$

Calibration

readings: (ppm)

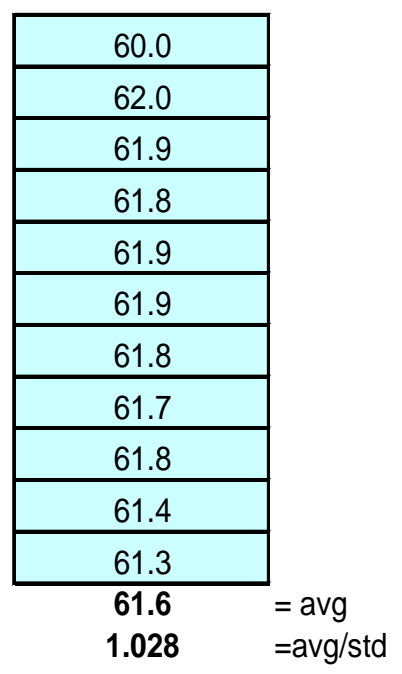

Standards Used:

Expiration date:

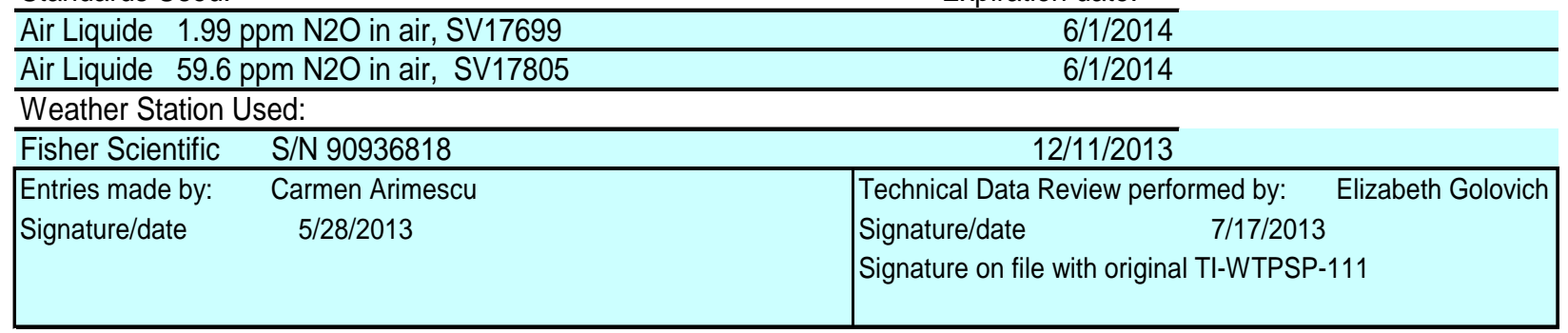




\section{GAS ANALYZER CALIBRATION}

\author{
Site LV-C2 Model \\ Date 6.3.2013 \\ Testers EA
}

\author{
Instrument B\&K Model 1302 \\ Serial No. 1804888 \\ Property No. WD54623
}
Setup: $\quad 6.3 \mathrm{ft} \quad$ B\&K sample inlet tube length
1014 mbar station pressure
66 deg F ambient temp analyzer corrects to $20 \mathrm{deg} C$
32 percent $\mathrm{RH}$
Pre-Test background, ppb
Compensating for water vapor, monitoring task 2

$498,469,473,425,421$

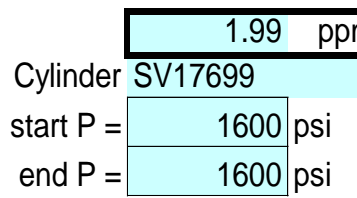

B\&K

readings: (ppm)

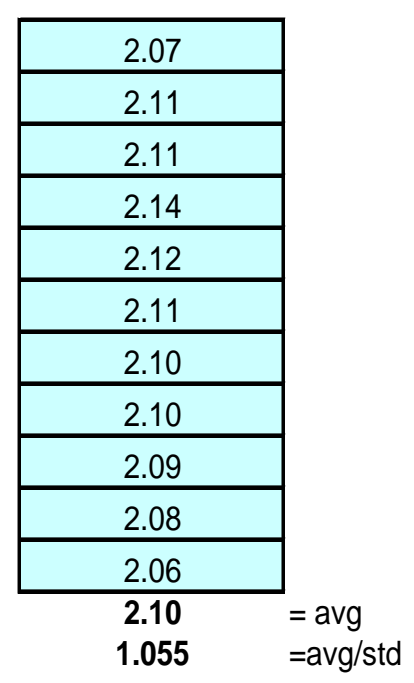

Calibration

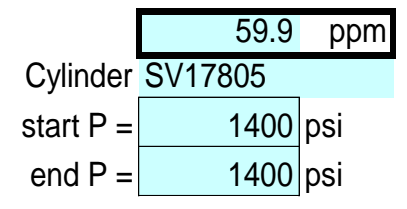

B\&K

Calibration

readings: $(\mathrm{ppm})$

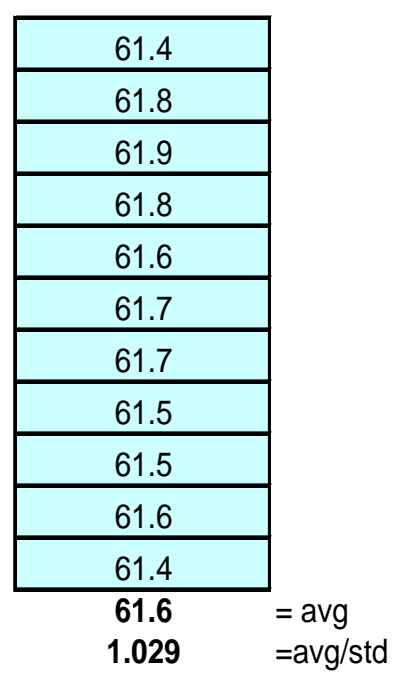

Expiration date:

Standards Used: $6 / 1 / 2014$

Air Liquide 1.99 ppm N2O in air, SV17699

$6 / 1 / 2014$

Air Liquide 59.6 ppm N2O in air, SV17805

Weather Station Used:

Fisher Scientific S/N 90936818

$12 / 11 / 2013$

Entries made by: Carmen Arimescu

Signature/date

$5 / 28 / 2013$
Technical Data Review performed by: Elizabeth Golovich Signature/date 7/17/2013

Signature on file with original TI-WTPSP-111 


\section{GAS ANALYZER CALIBRATION}

\author{
Site LV-C2 Model \\ Date 6/10/2013 \\ Testers EA, CA
}

$\begin{array}{rr}\text { Instrument } & \text { B\&K Model } 1302 \\ \text { Serial No. } & 1804888 \\ \text { Property No. }\end{array}$
Setup: $\quad 6.3 \mathrm{ft} \quad$ B\&K sample inlet tube length
1015 mbar station pressure
67.1 deg F ambient temp analyzer corrects to 20 deg C $32 \%$ percent $\mathrm{RH}$
Pre-Test background, ppb
Compensating for water vapor, monitoring task 2

$460,434,437,411,421$

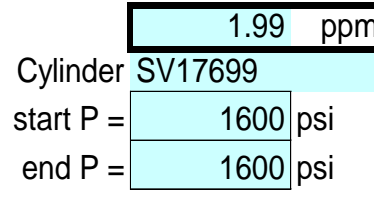

B\&K

Calibration

readings: (ppm)

\begin{tabular}{|c|}
\hline 2.02 \\
\hline 1.99 \\
\hline 1.98 \\
\hline 2.00 \\
\hline 2.00 \\
\hline 1.99 \\
\hline 1.98 \\
\hline 1.97 \\
\hline 1.98 \\
\hline 1.97 \\
\hline 1.97 \\
\hline 1.99 \\
\hline 0.998 \\
\hline
\end{tabular}

Standards Used:

Air Liquide 1.99 ppm N2O in air, SV17699

Air Liquide 59.6 ppm N2O in air, SV17805

Weather Station Used:

Fisher Scientific S/N 90936818

Entries made by: Carmen Arimescu

Signature/date

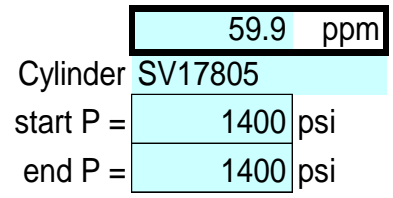

B\&K

Calibration

readings: (ppm)

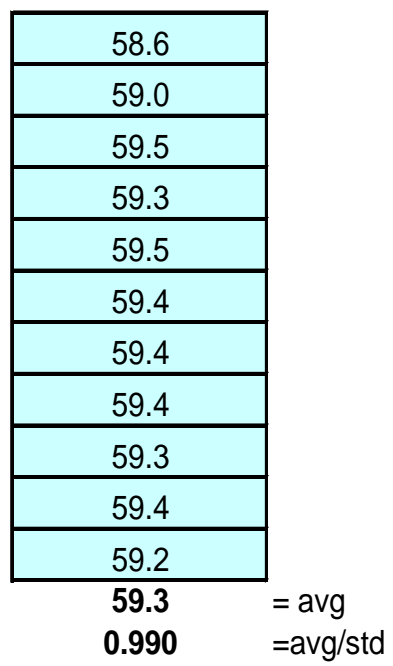

Expiration date:

$6 / 1 / 2014$

$6 / 1 / 2014$

$12 / 11 / 2013$

Technical Data Review performed by: Elizabeth Golovich

Signature/date 7/17/2013

Signature on file with original TI-WTPSP-111 
TRACER GAS TRAVERSE DATA FORM

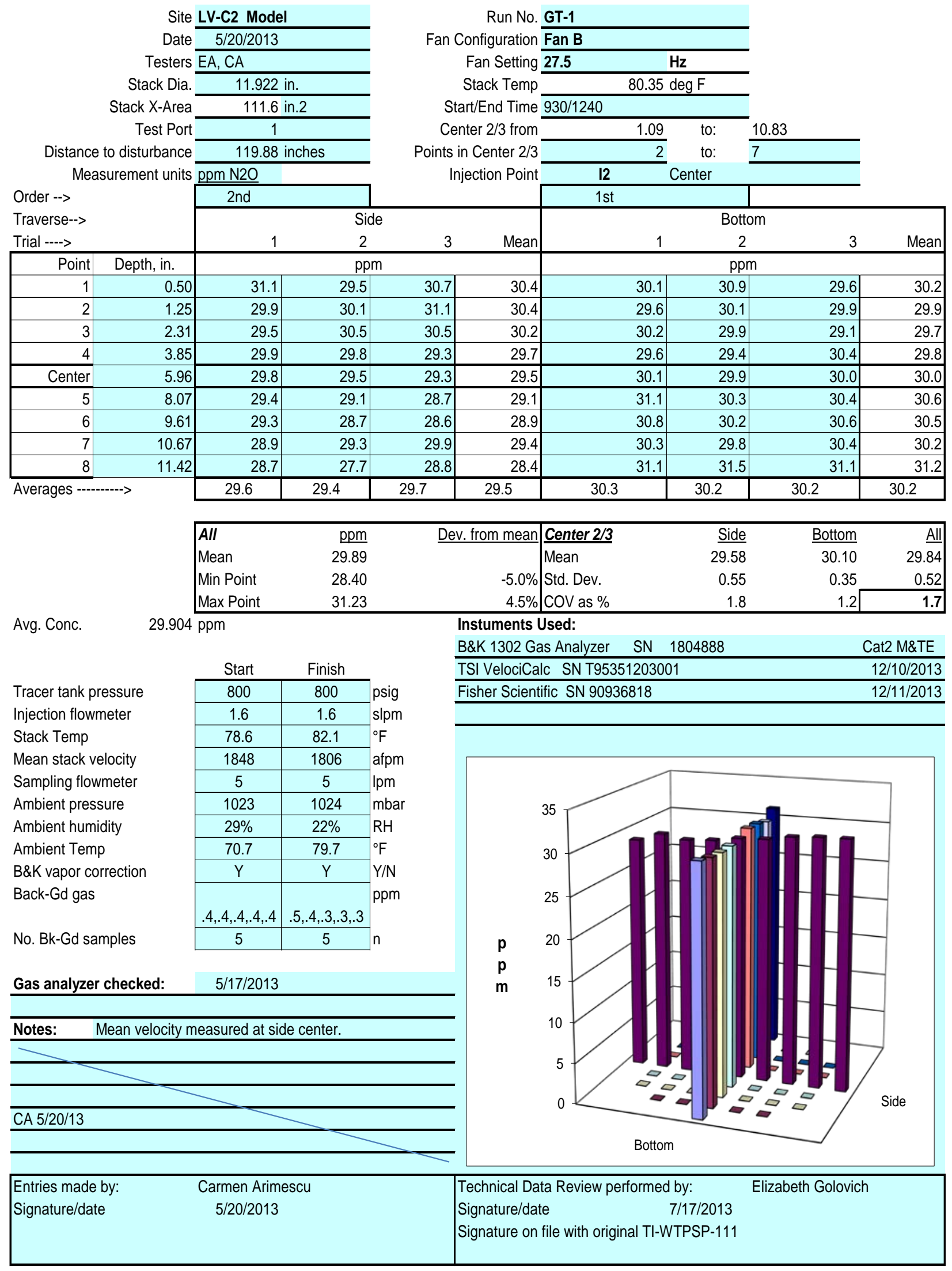


TRACER GAS TRAVERSE DATA FORM

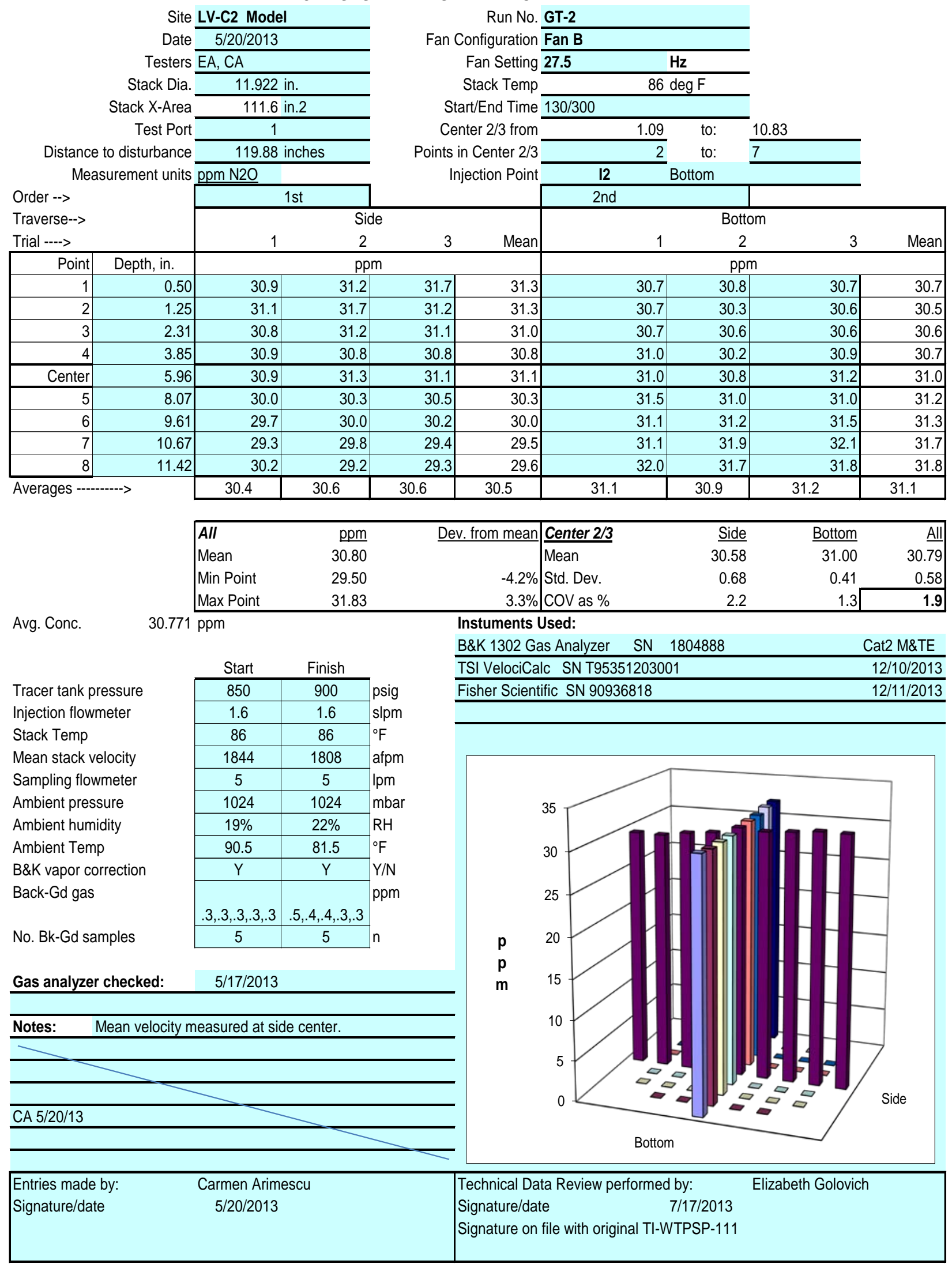


TRACER GAS TRAVERSE DATA FORM

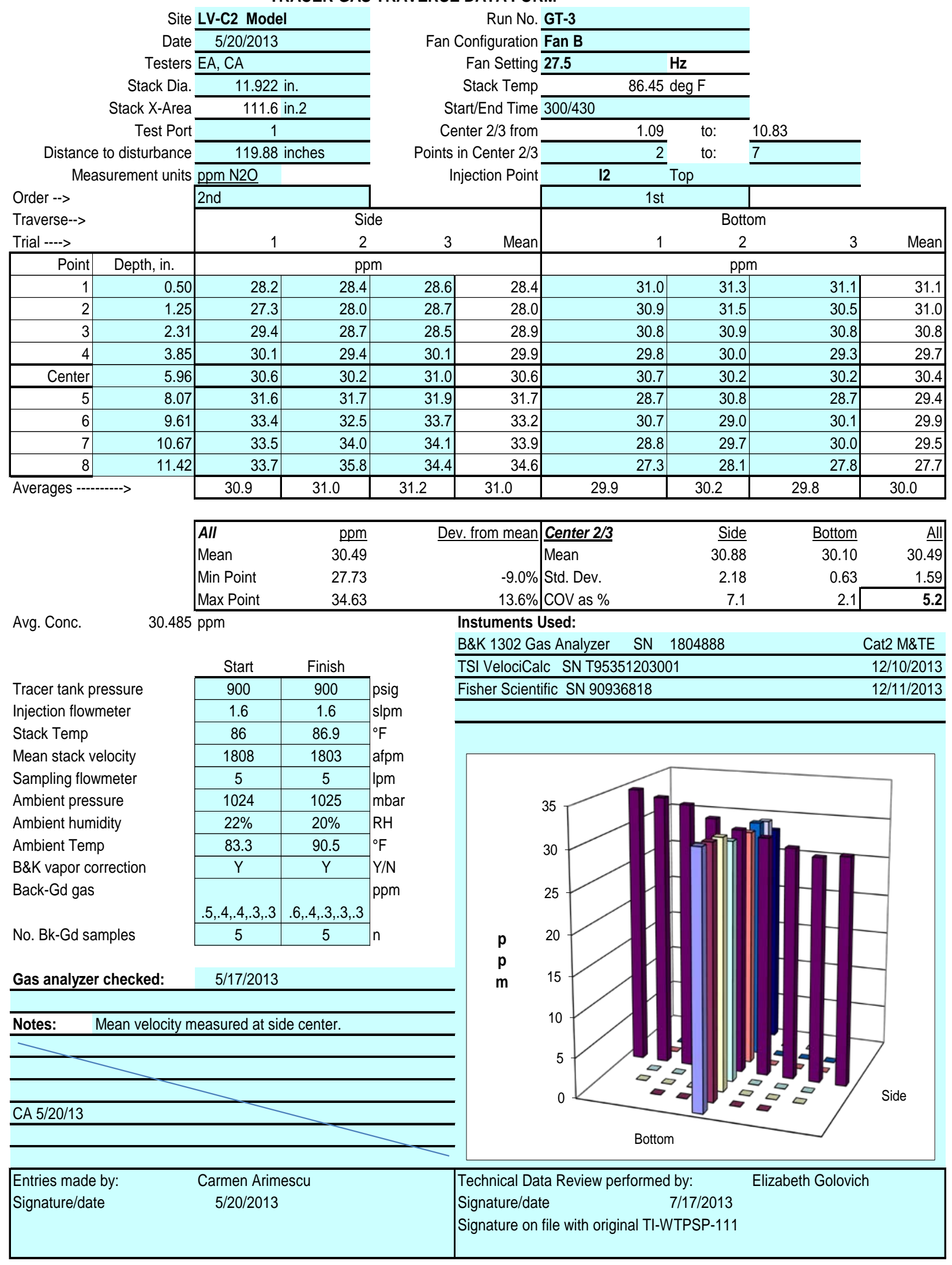


TRACER GAS TRAVERSE DATA FORM

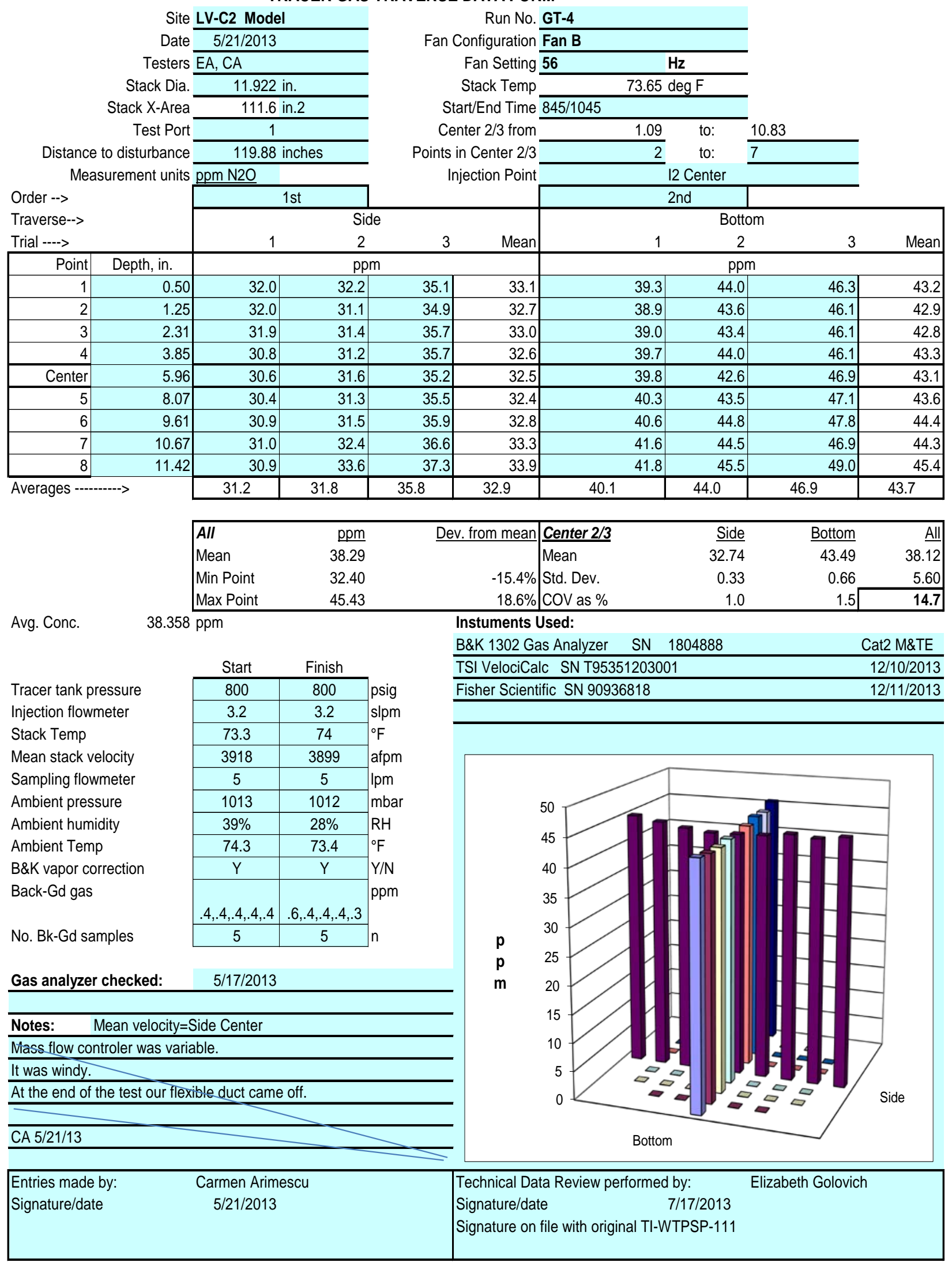


TRACER GAS TRAVERSE DATA FORM

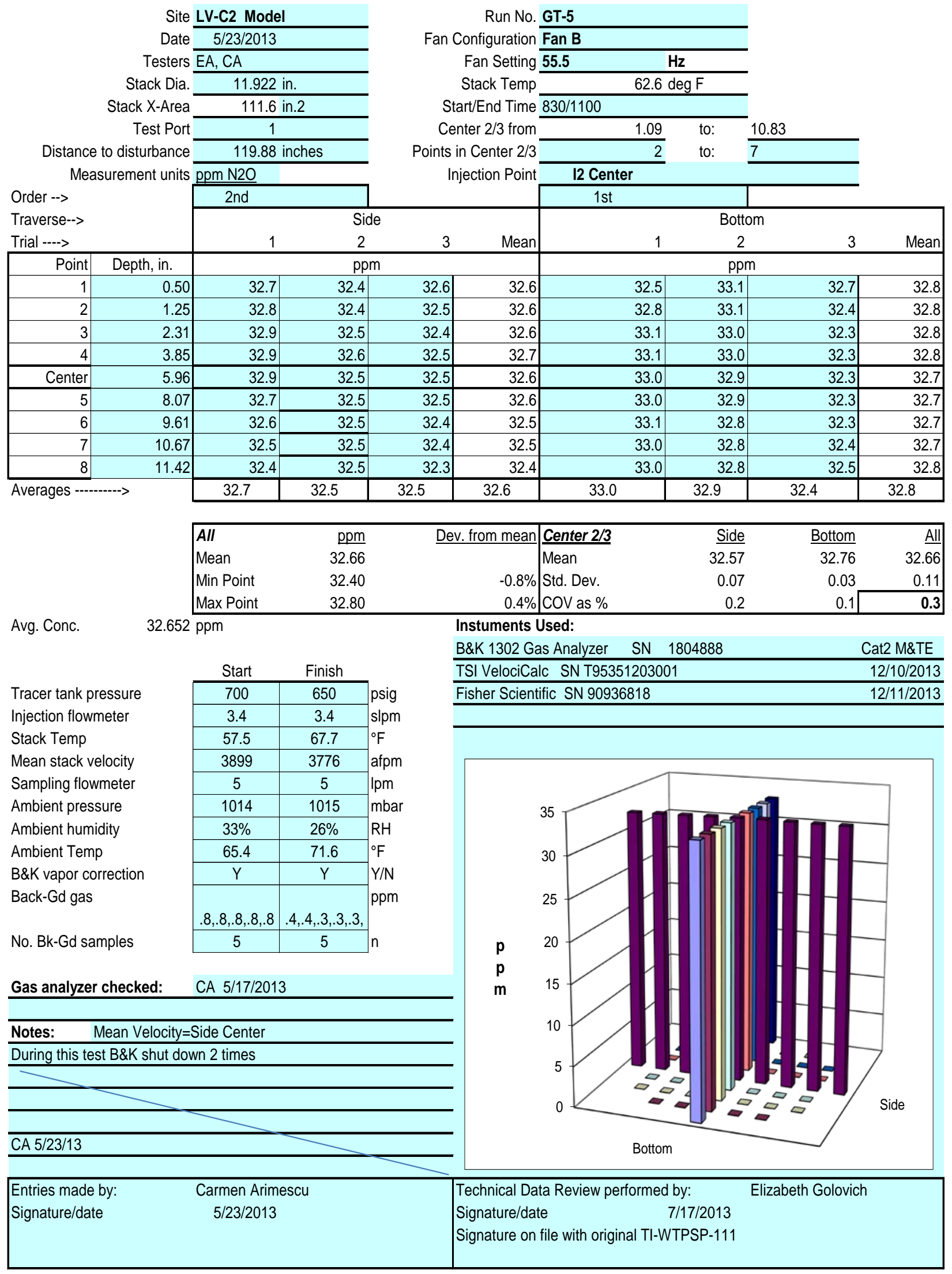


TRACER GAS TRAVERSE DATA FORM

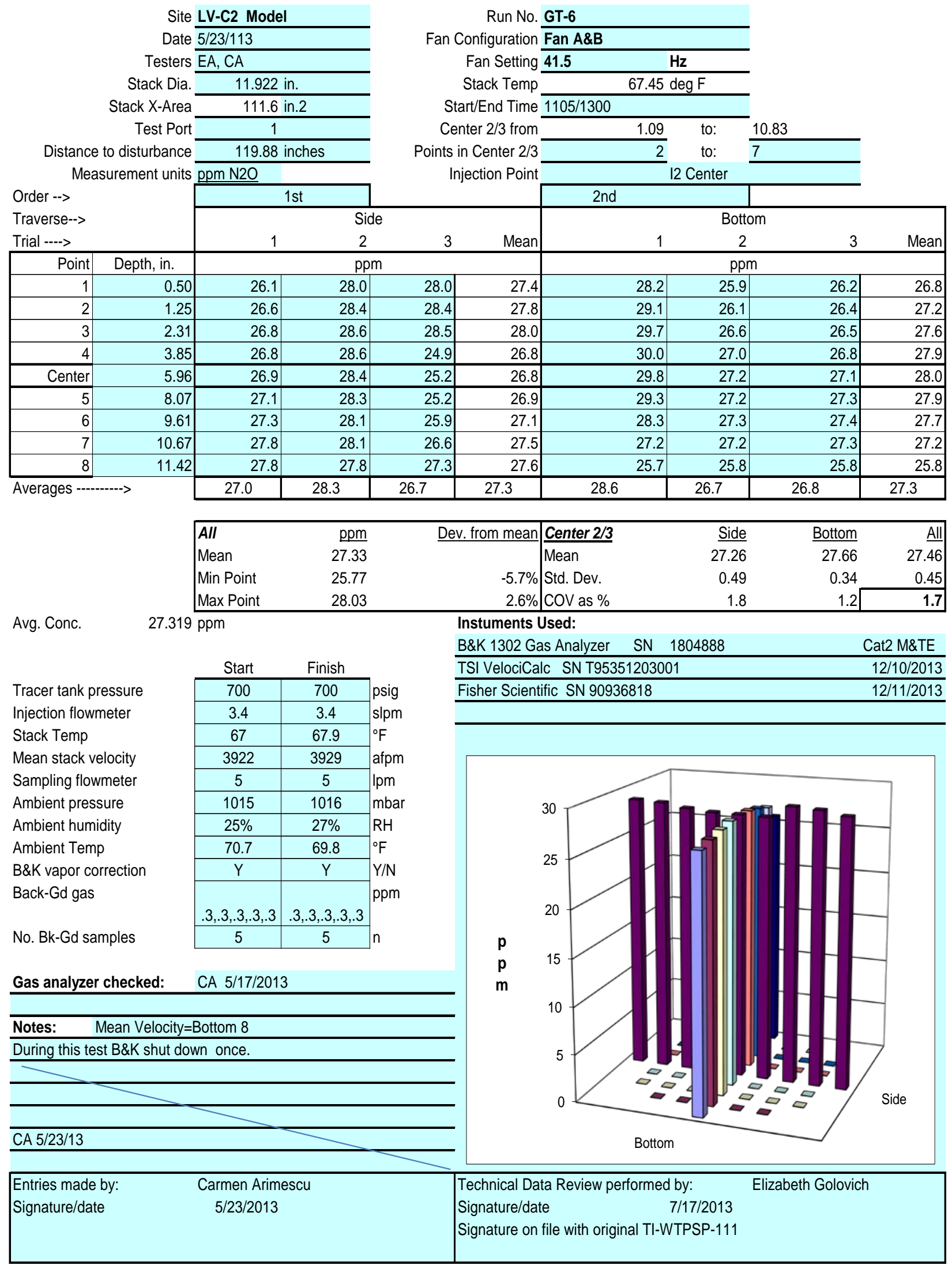


TRACER GAS TRAVERSE DATA FORM

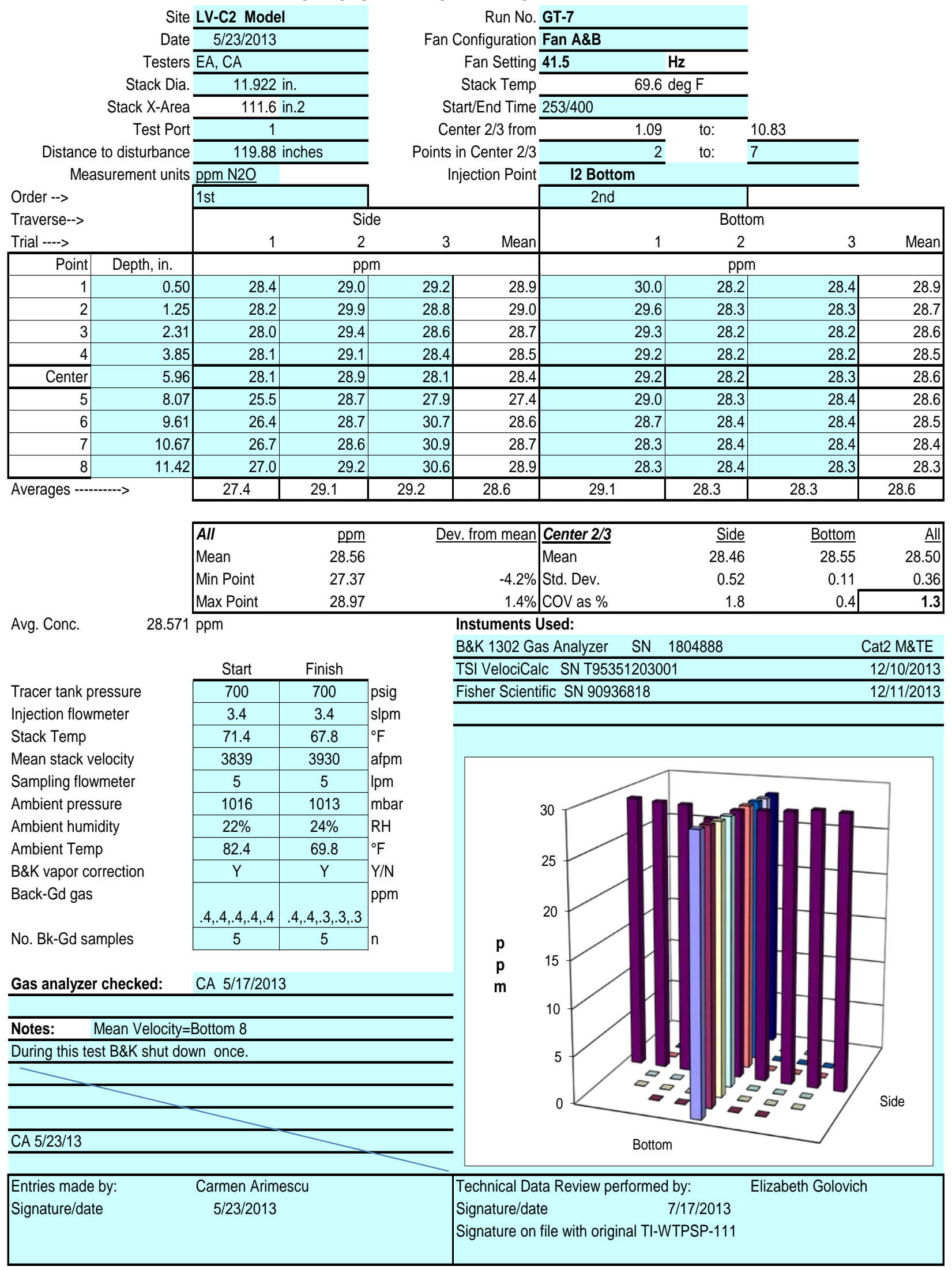


TRACER GAS TRAVERSE DATA FORM

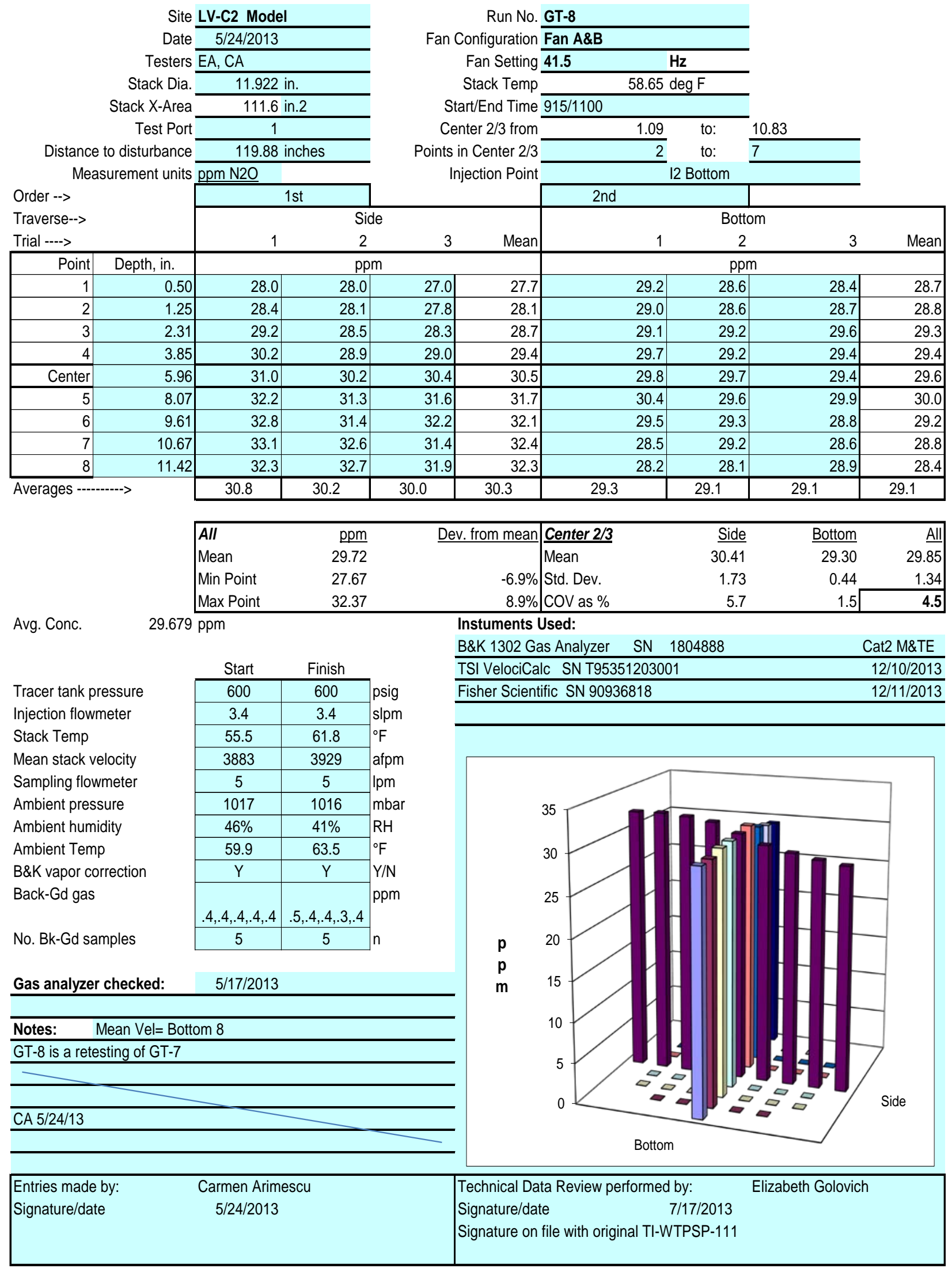


TRACER GAS TRAVERSE DATA FORM

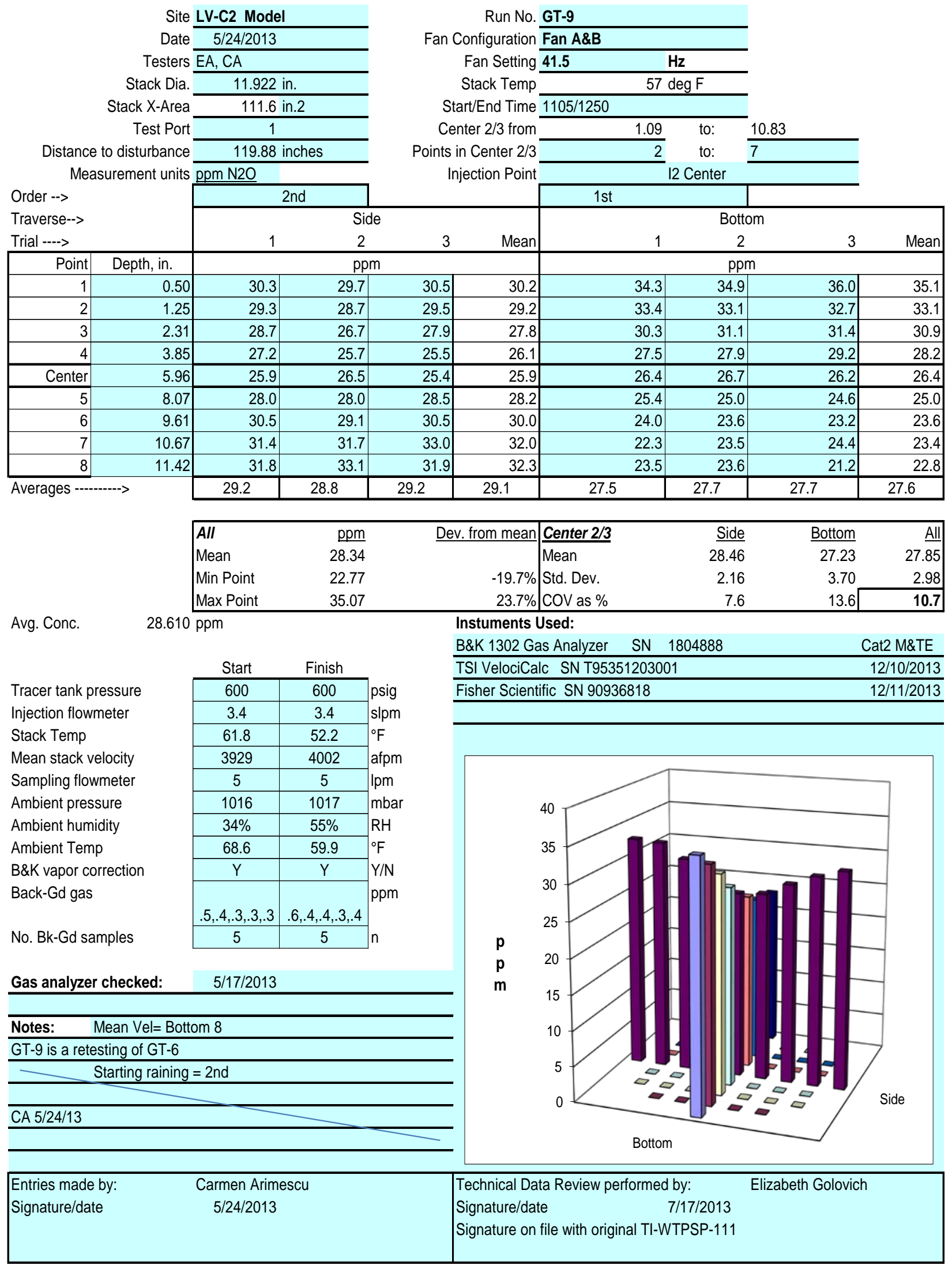


TRACER GAS TRAVERSE DATA FORM

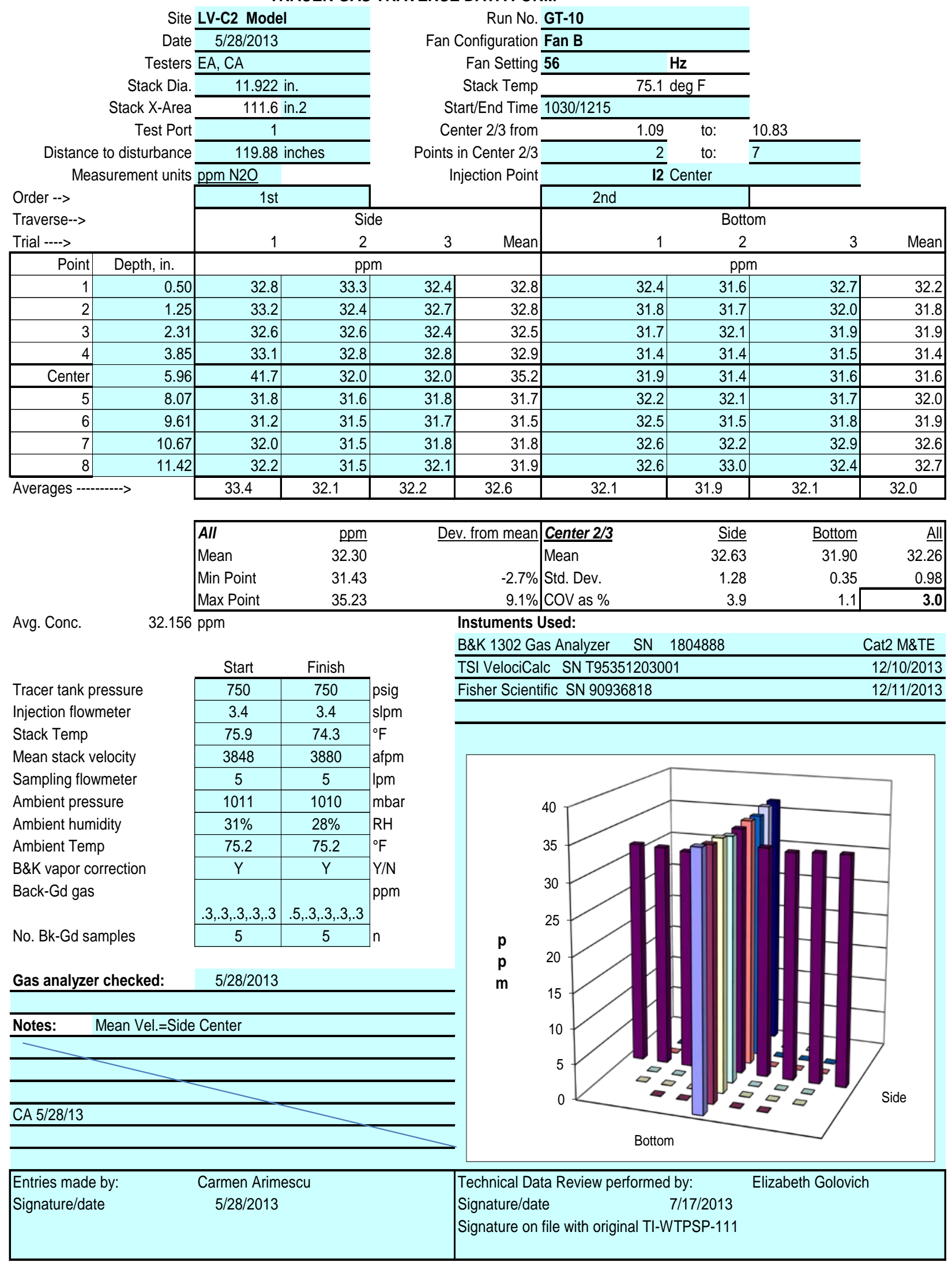


TRACER GAS TRAVERSE DATA FORM

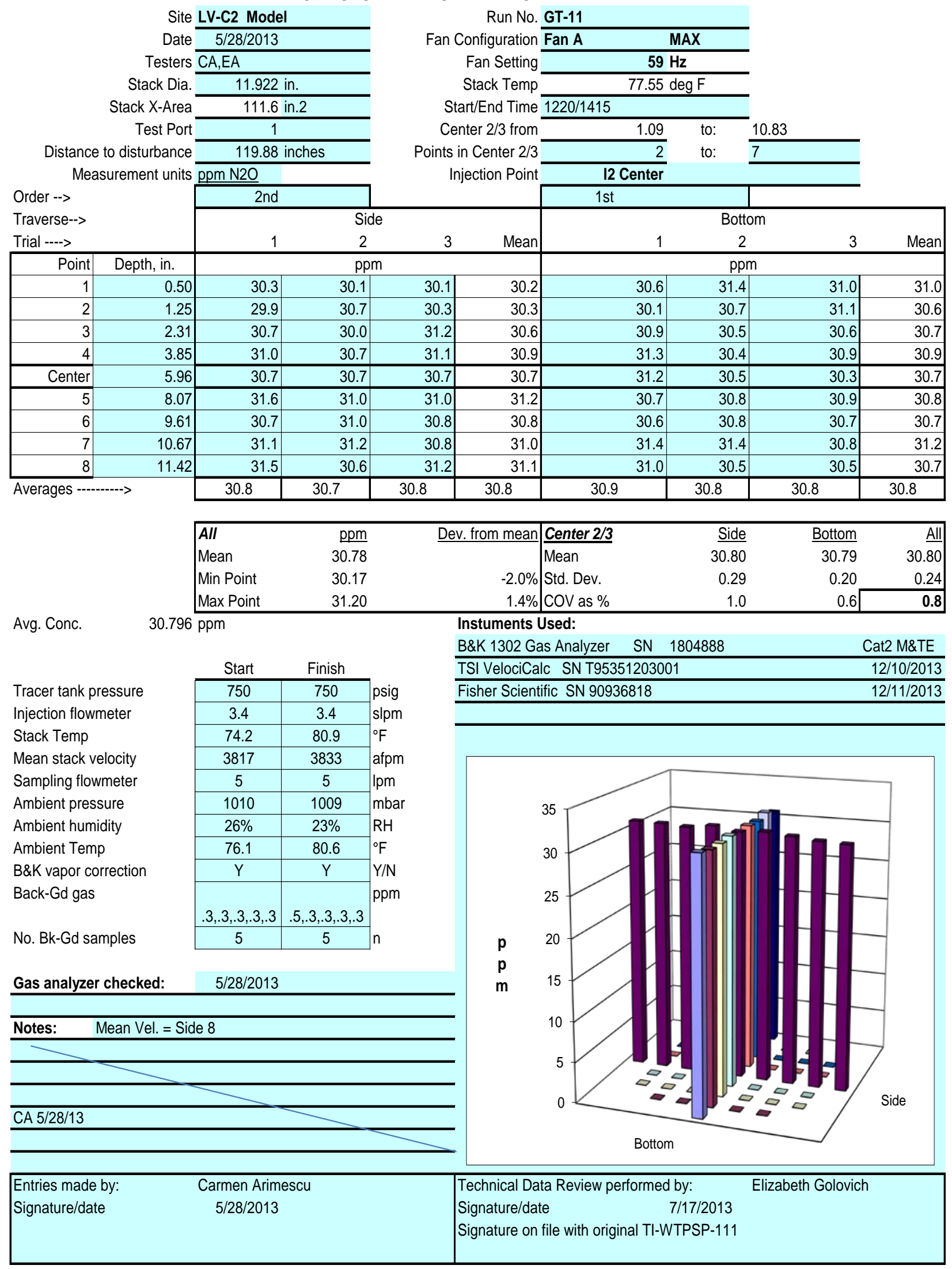




\section{TRACER GAS TRAVERSE DATA FORM}

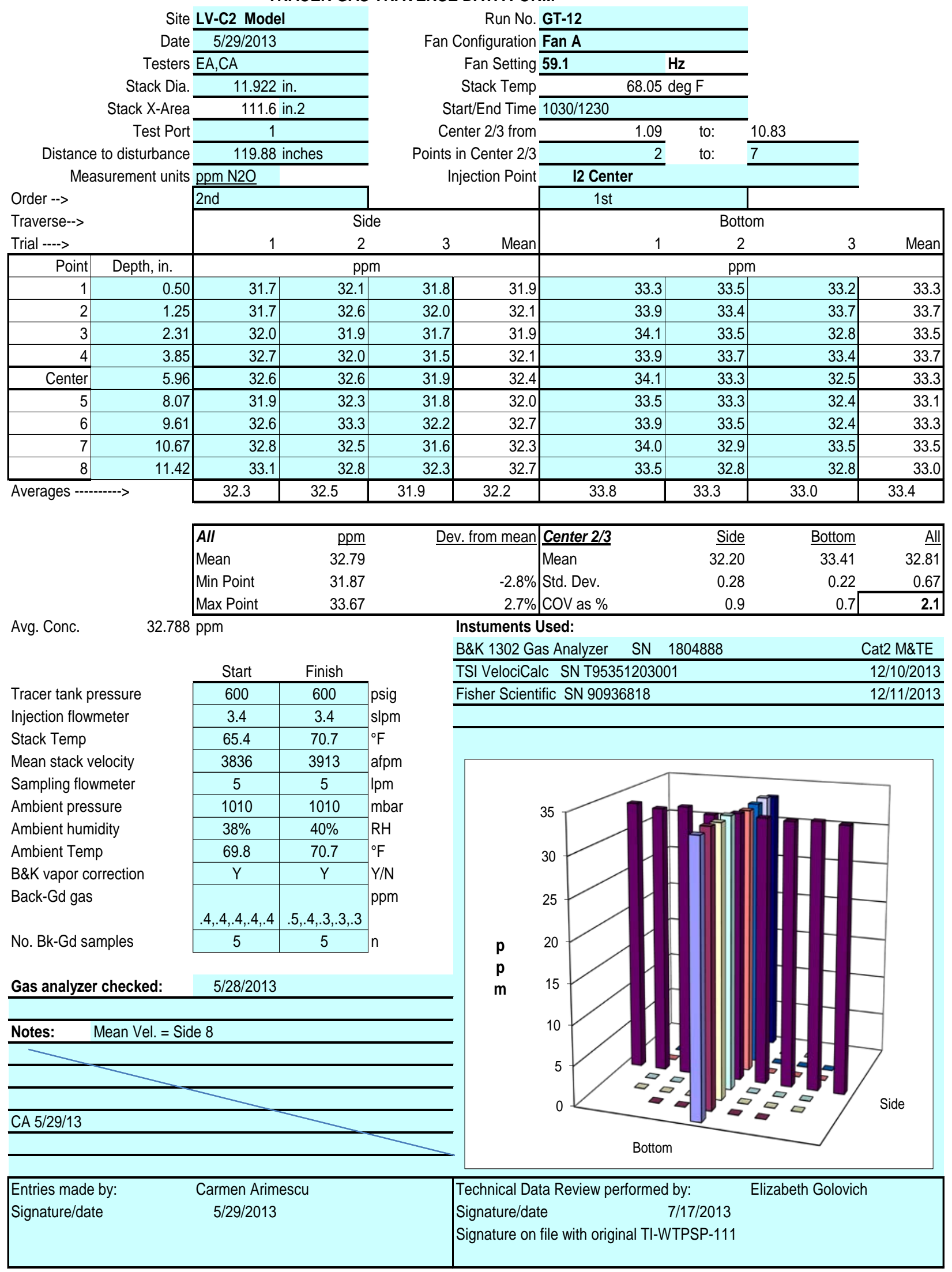


TRACER GAS TRAVERSE DATA FORM

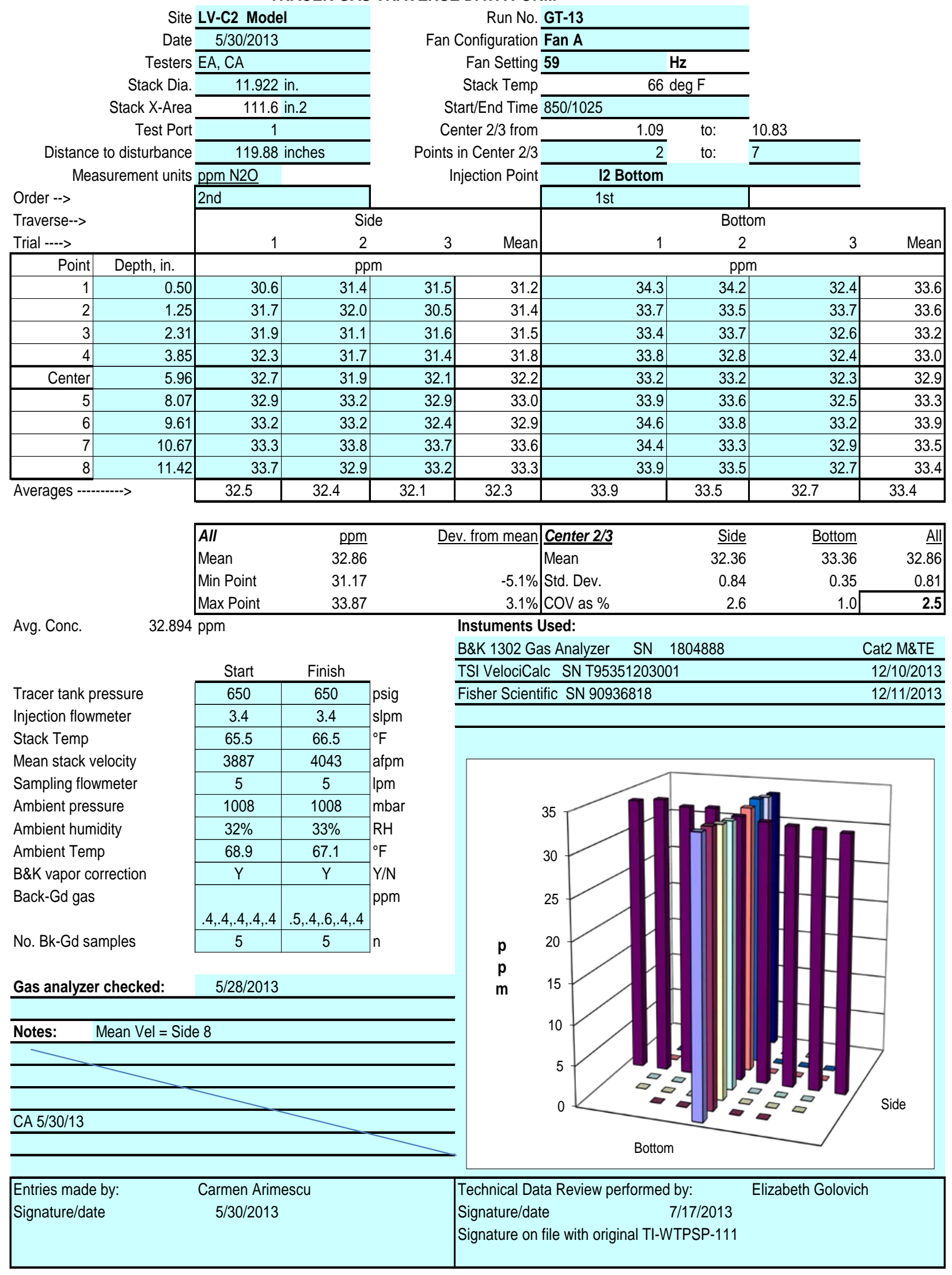


TRACER GAS TRAVERSE DATA FORM

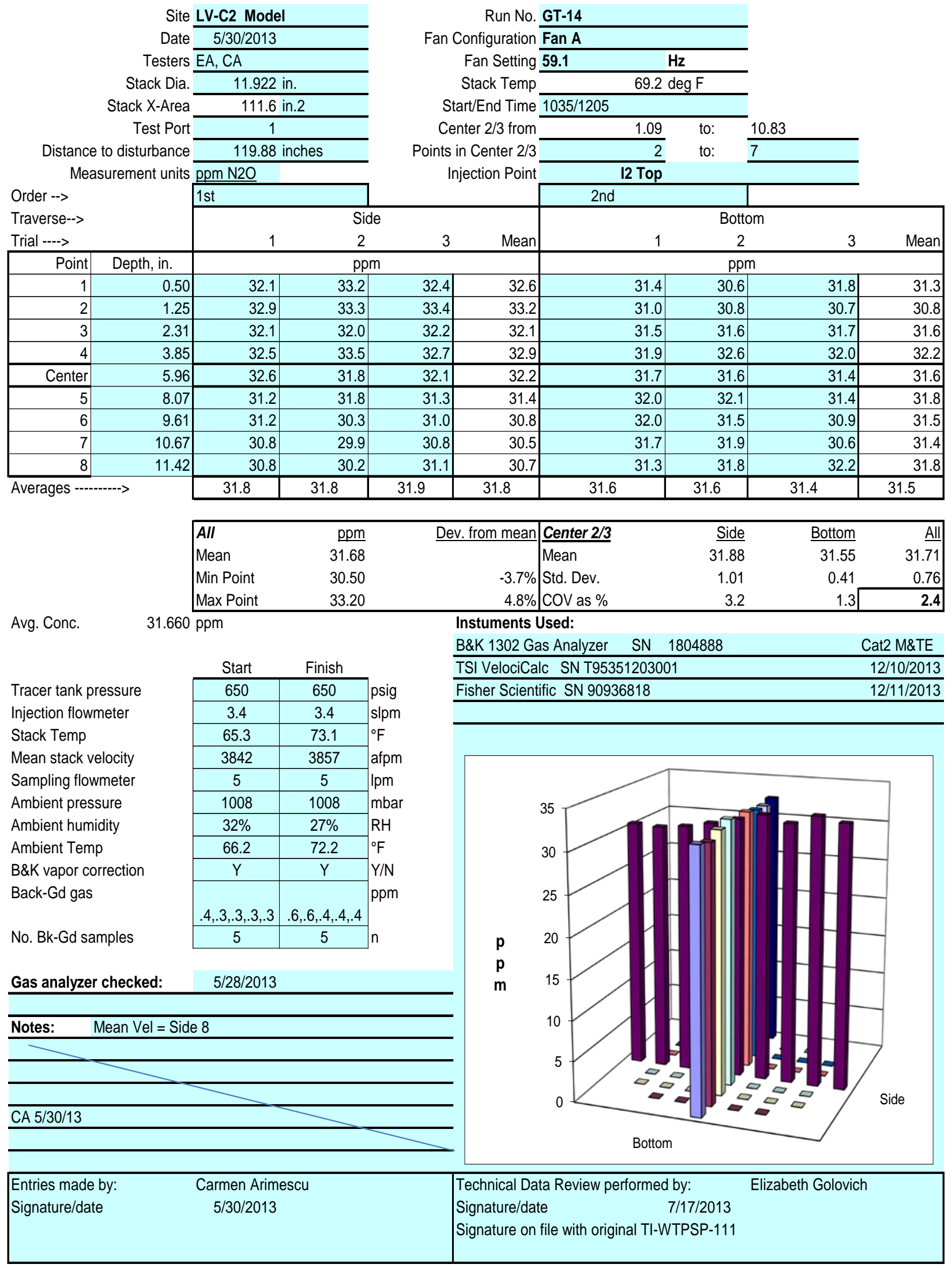


TRACER GAS TRAVERSE DATA FORM

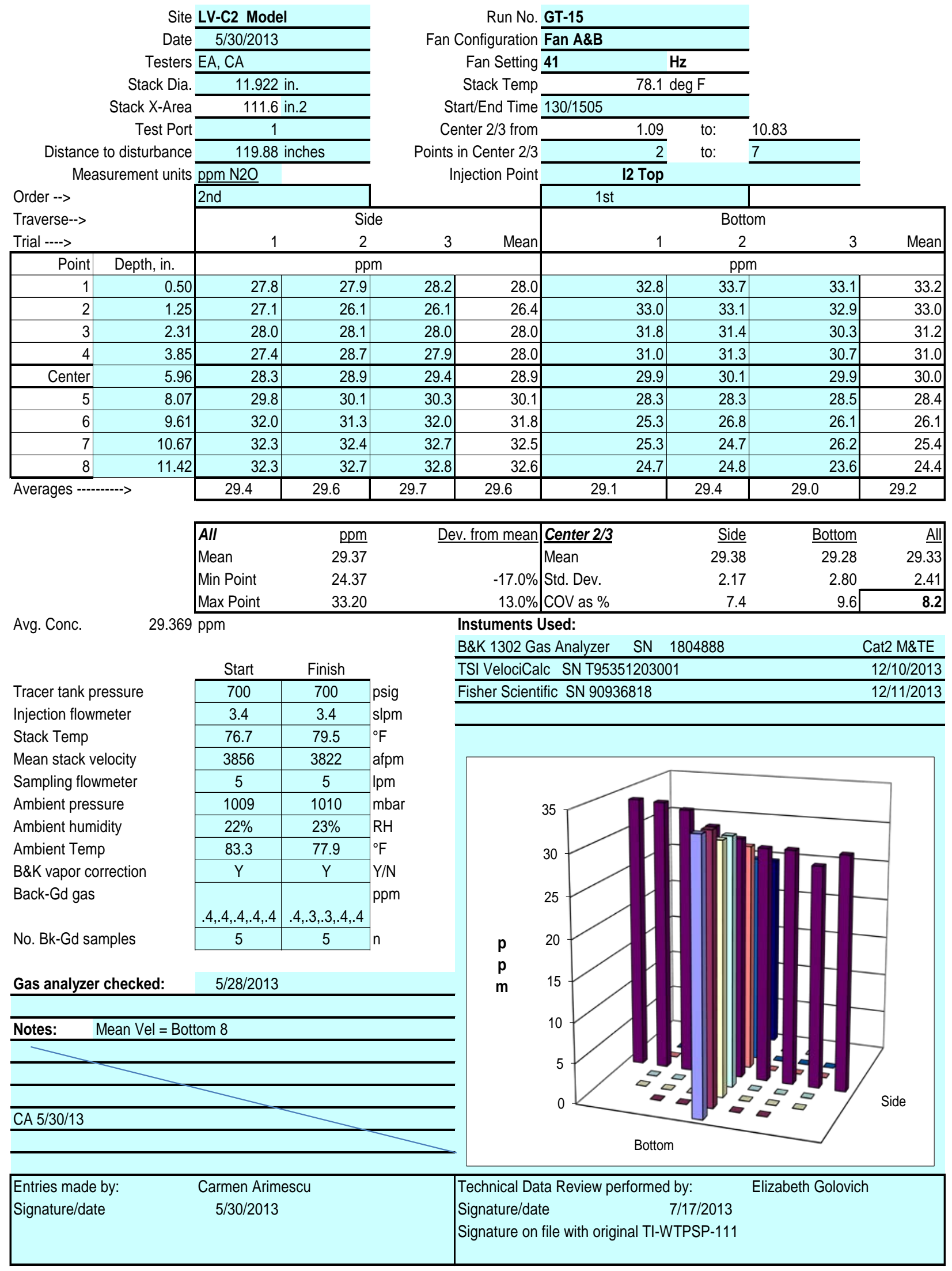


TRACER GAS TRAVERSE DATA FORM

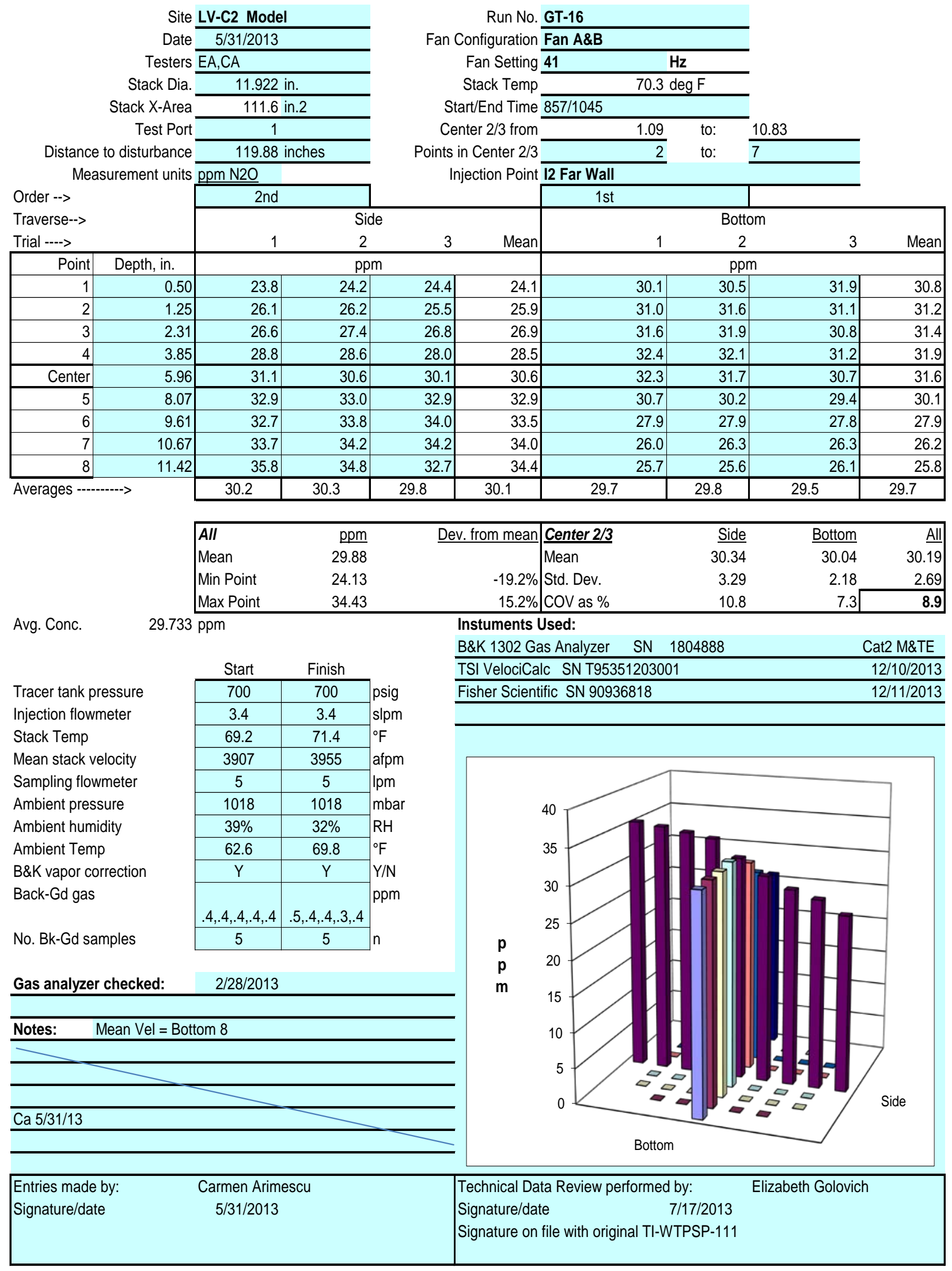


TRACER GAS TRAVERSE DATA FORM

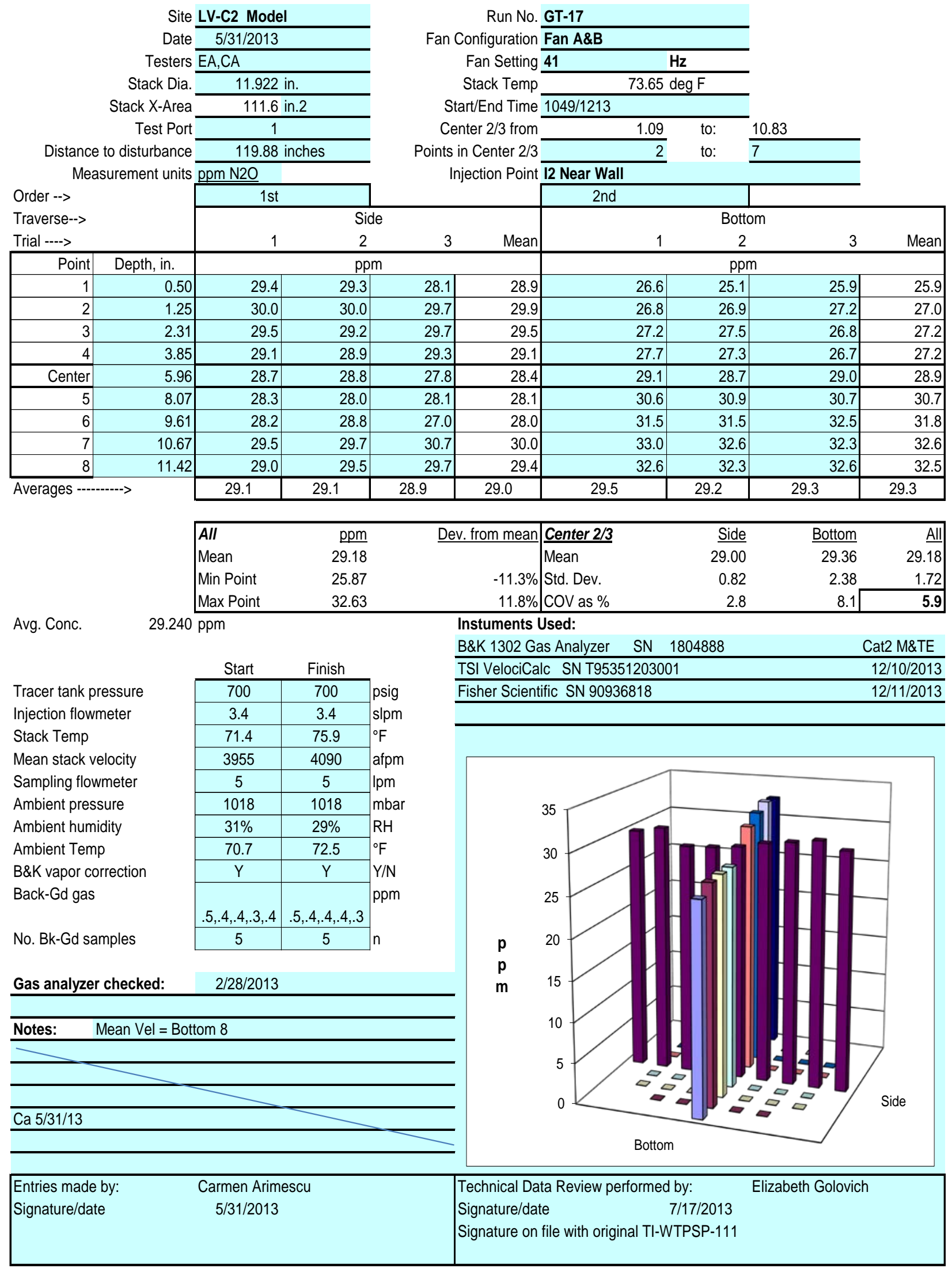


TRACER GAS TRAVERSE DATA FORM

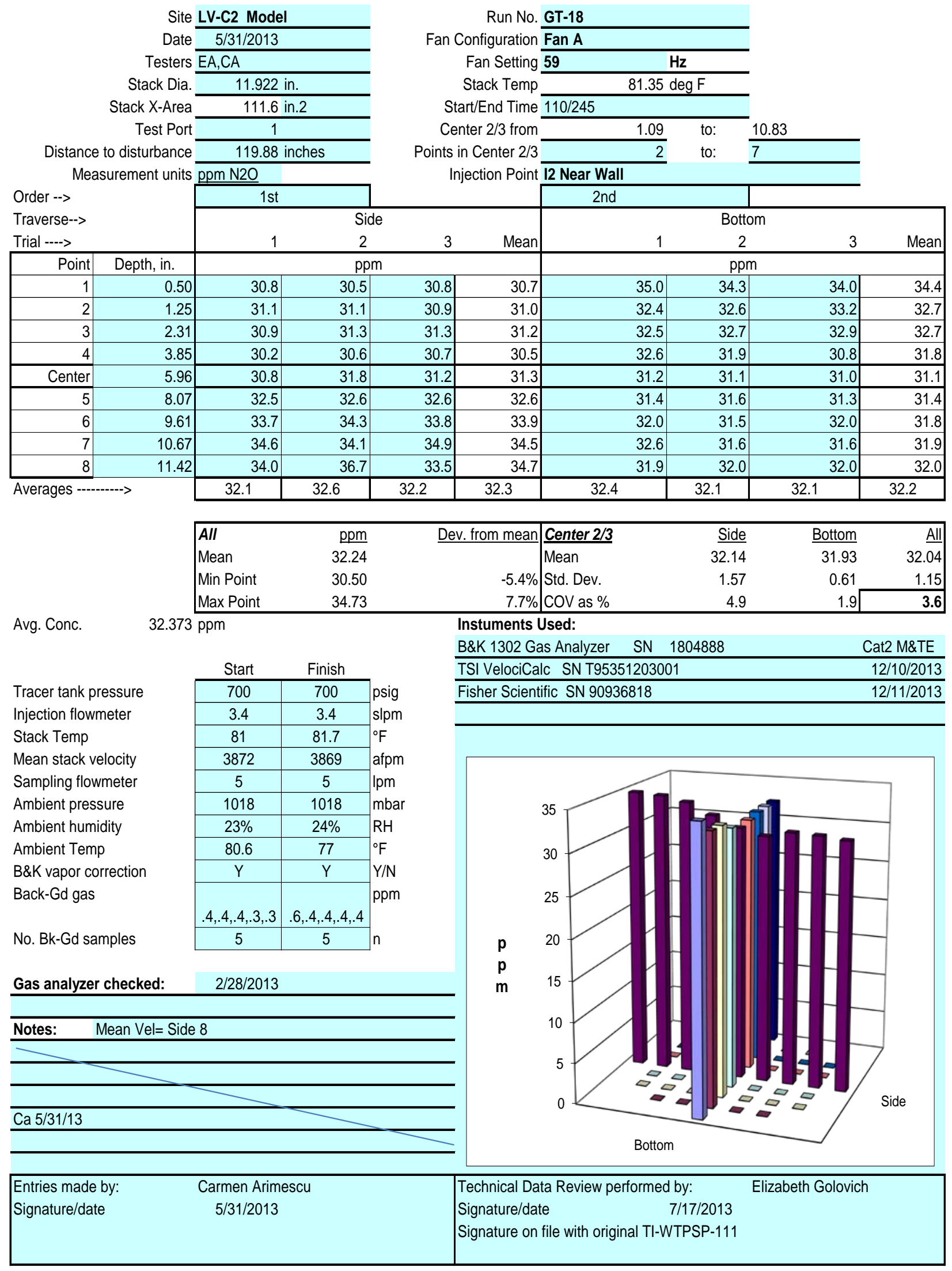


TRACER GAS TRAVERSE DATA FORM

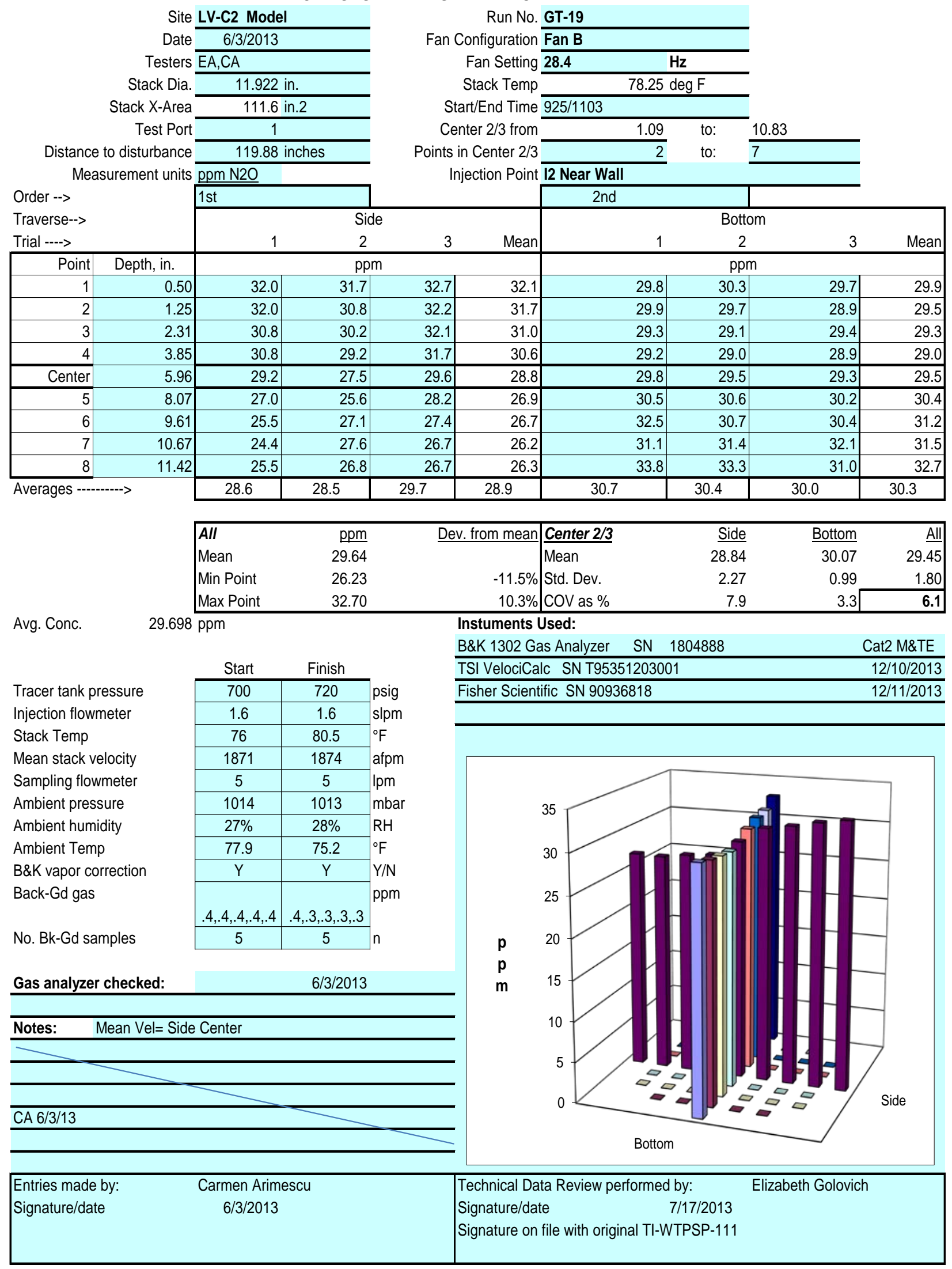


TRACER GAS TRAVERSE DATA FORM

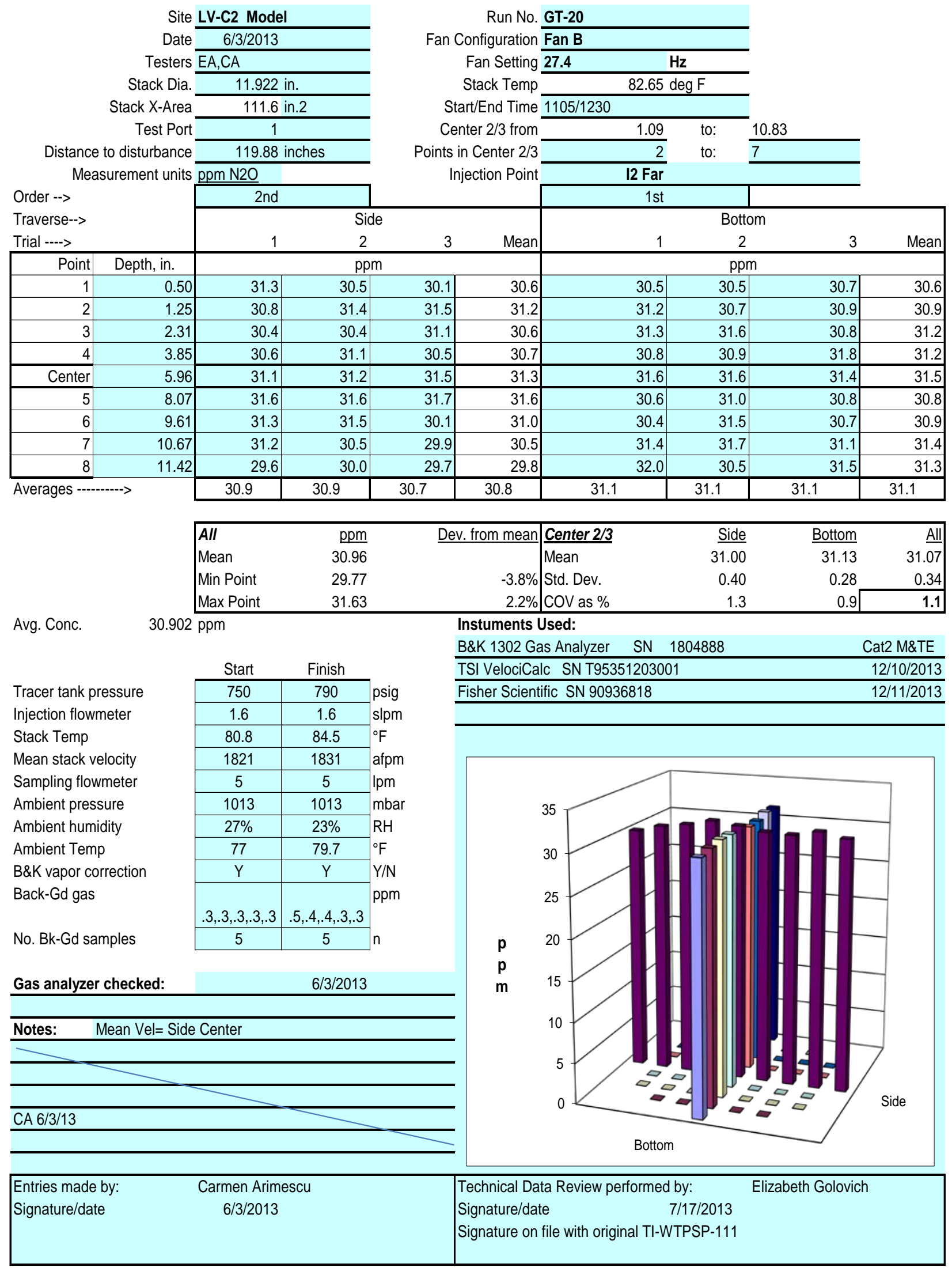


TRACER GAS TRAVERSE DATA FORM

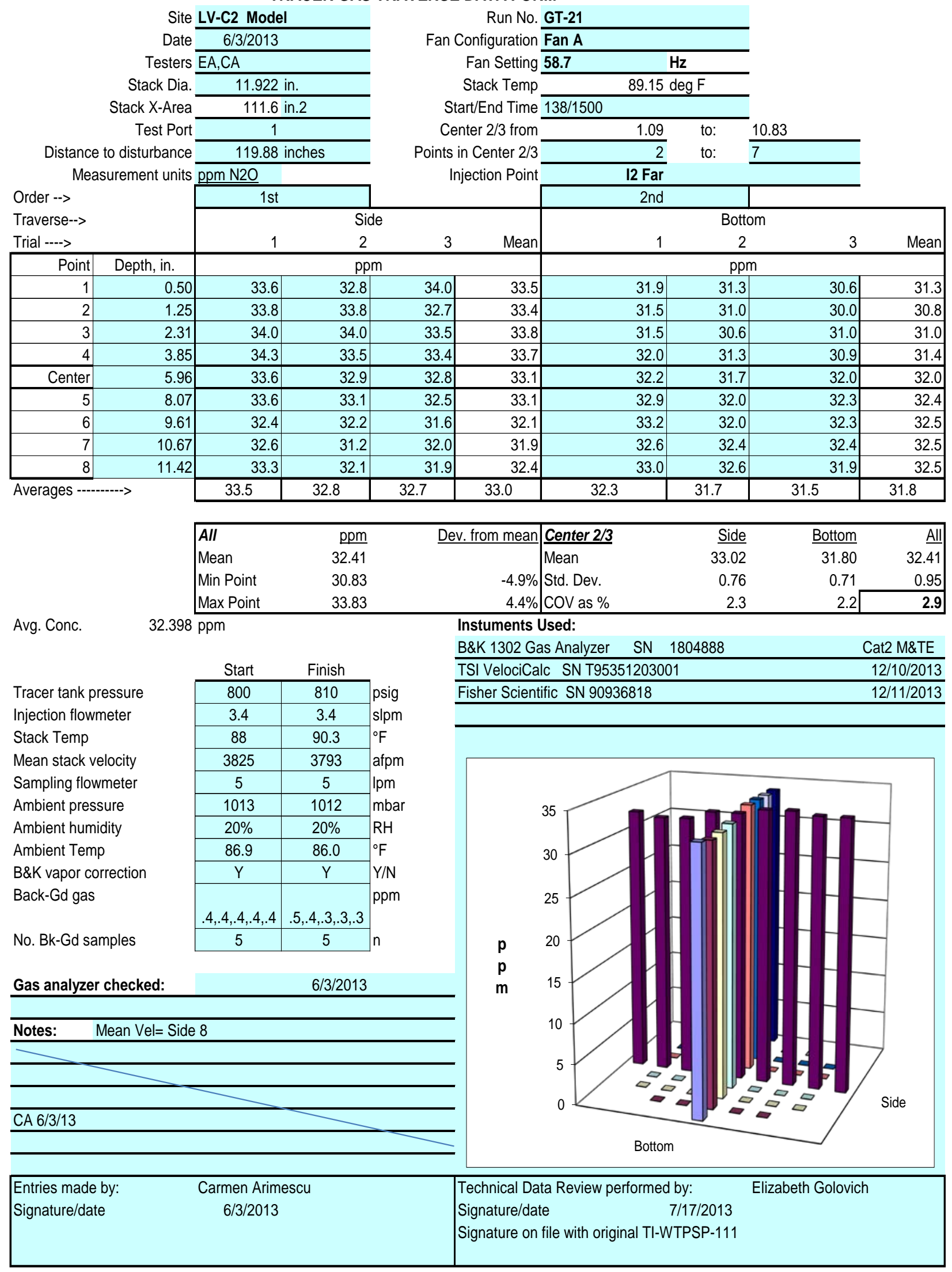


TRACER GAS TRAVERSE DATA FORM

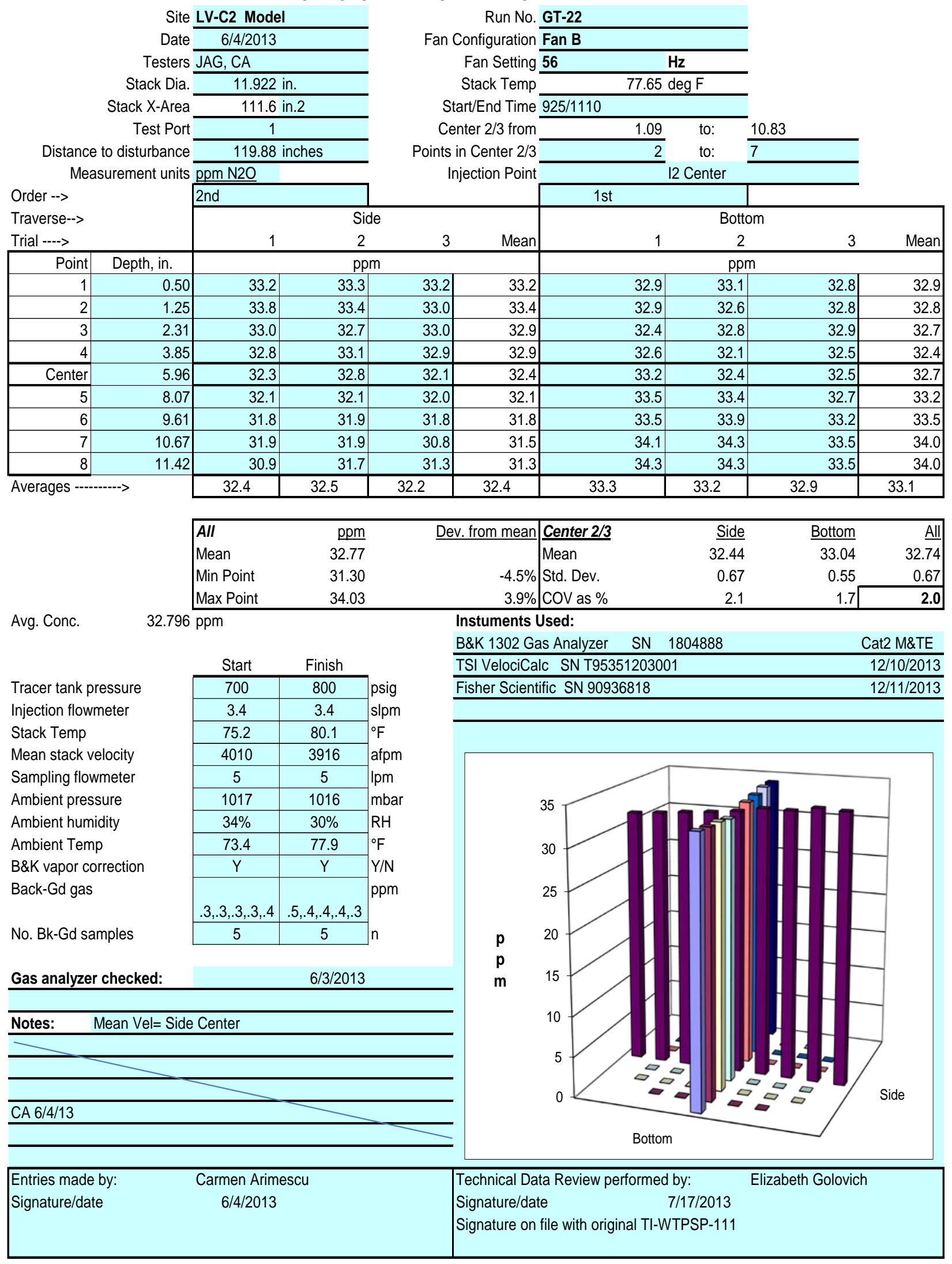


TRACER GAS TRAVERSE DATA FORM

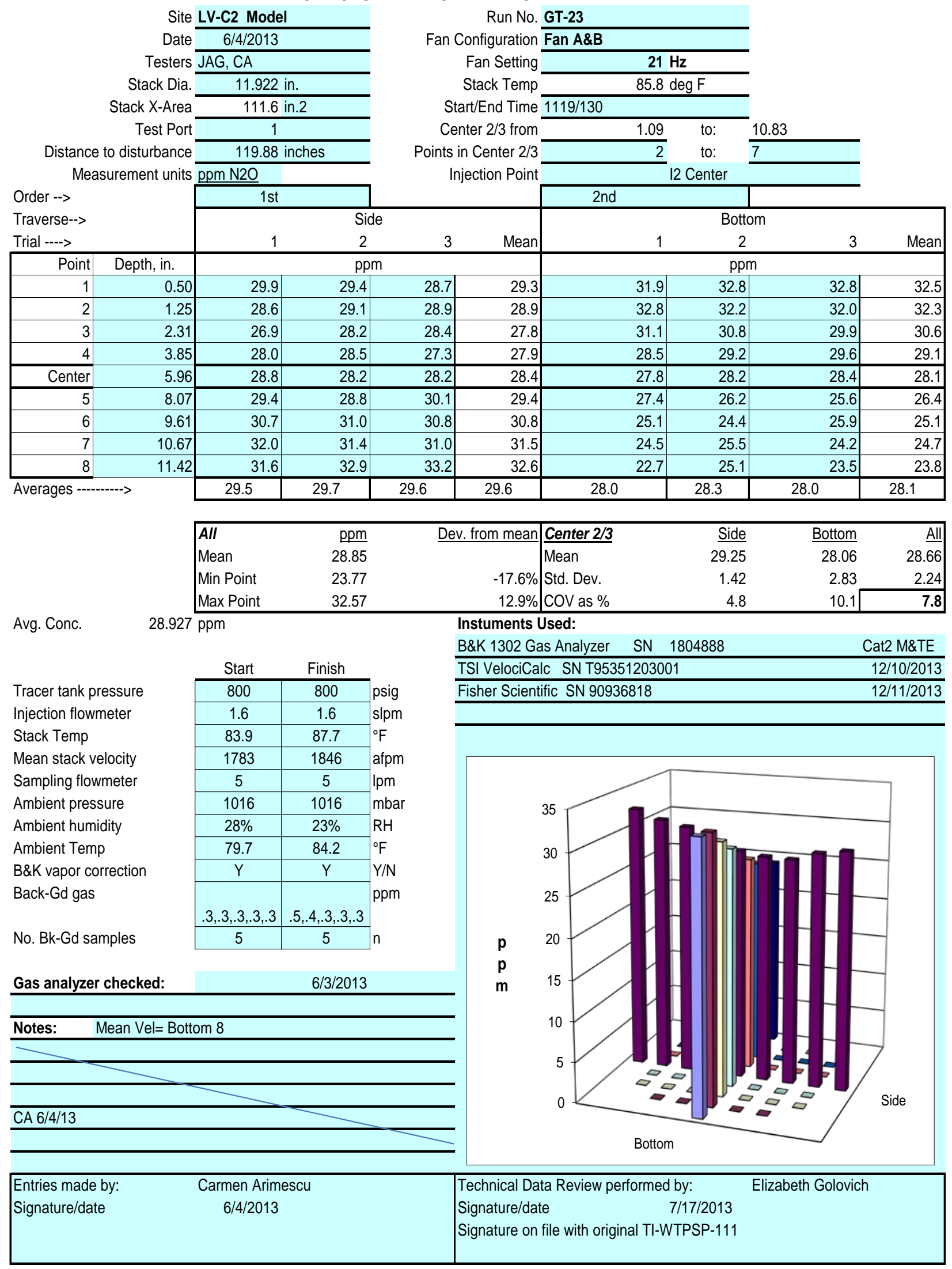


TRACER GAS TRAVERSE DATA FORM

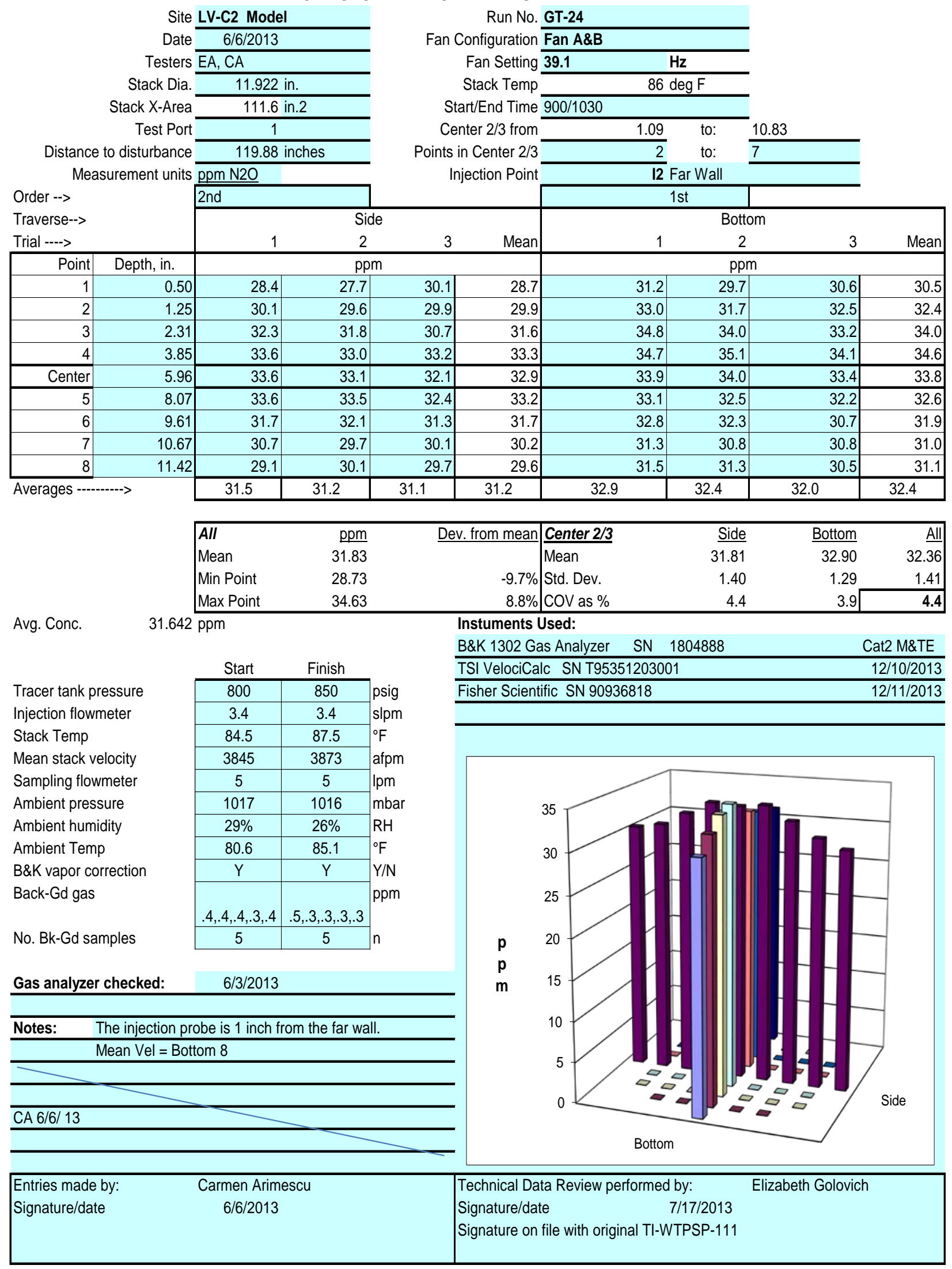


TRACER GAS TRAVERSE DATA FORM

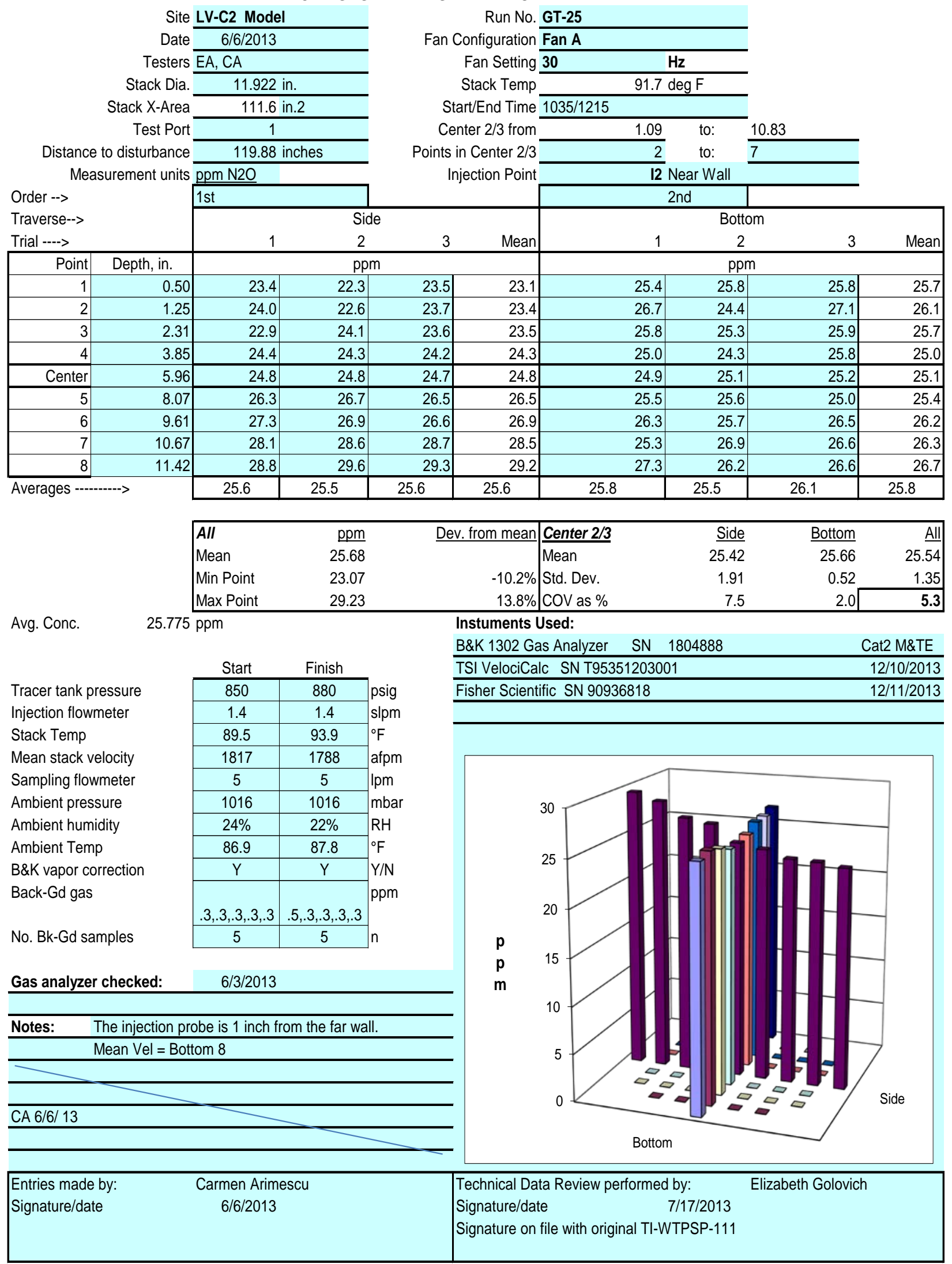




\section{B.6 LV-C2 Particle Tracer Uniformity Data Sheets}

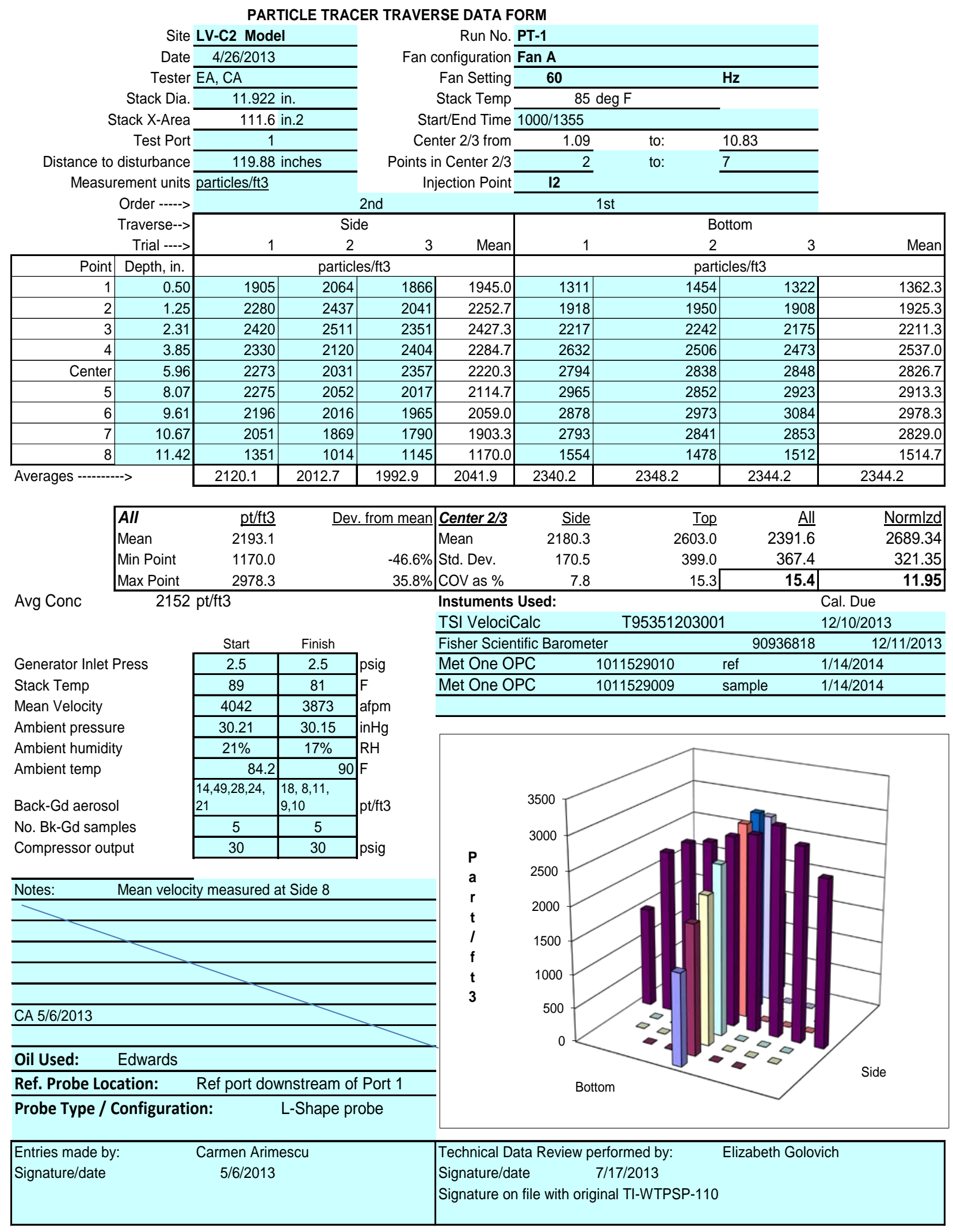




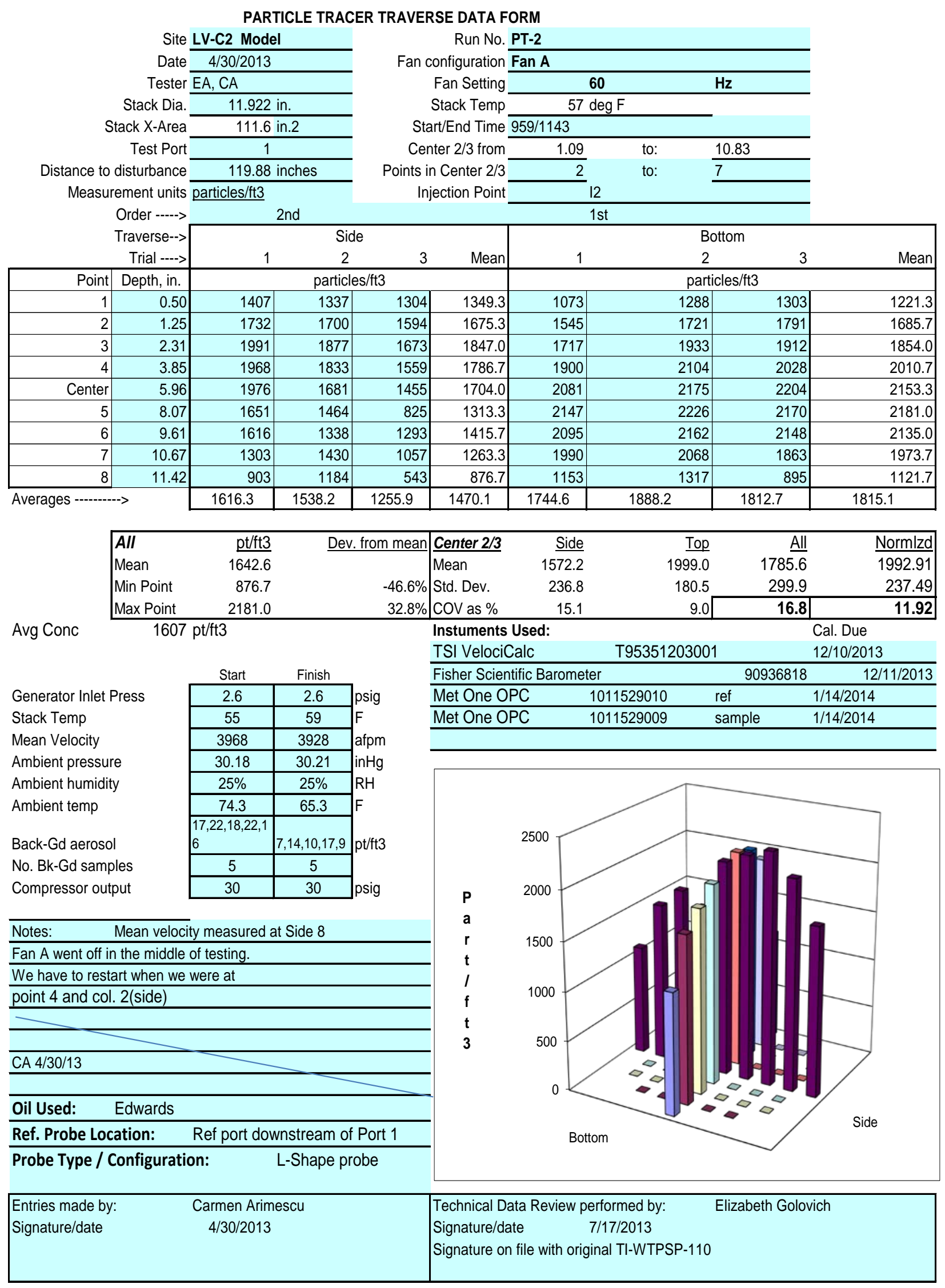




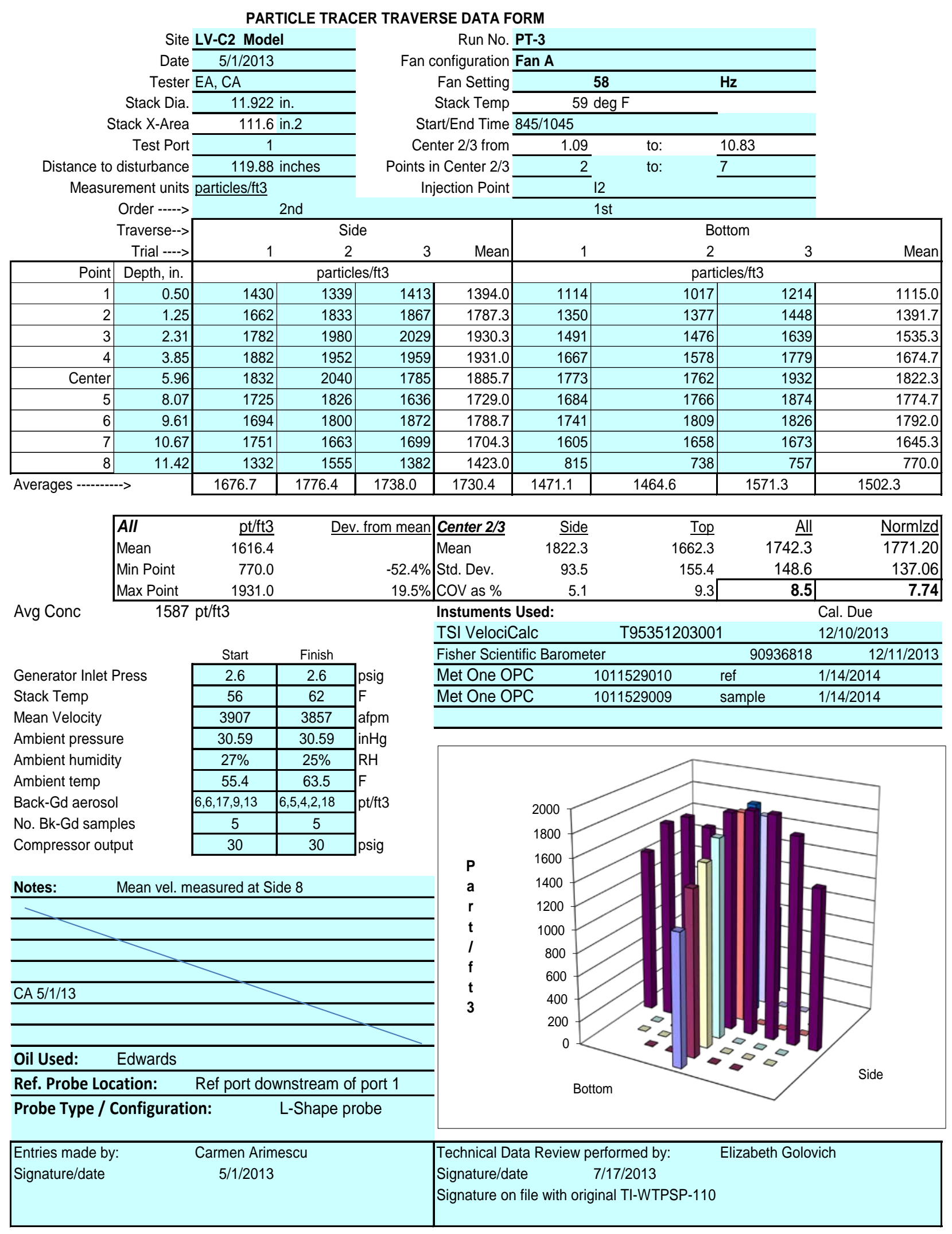




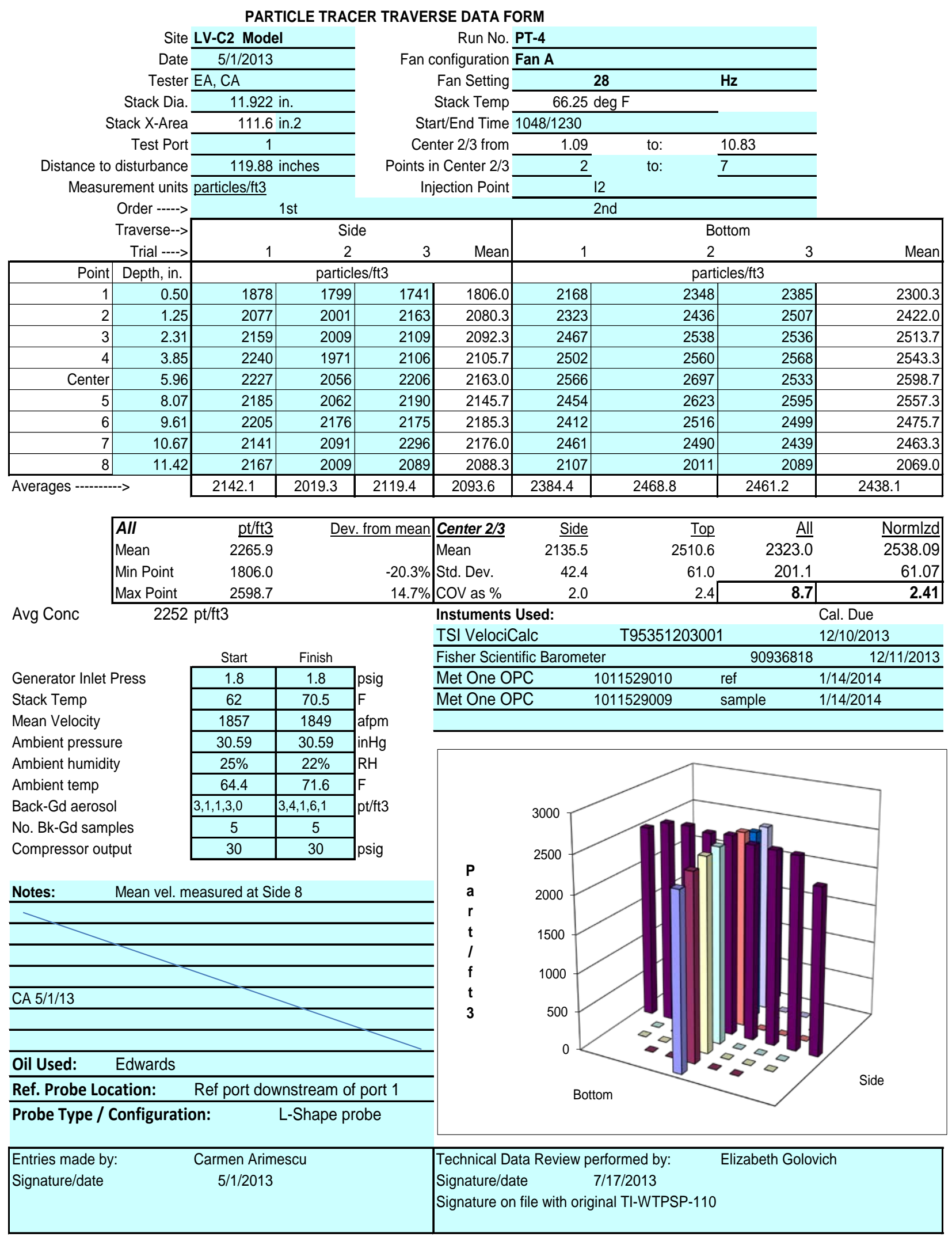




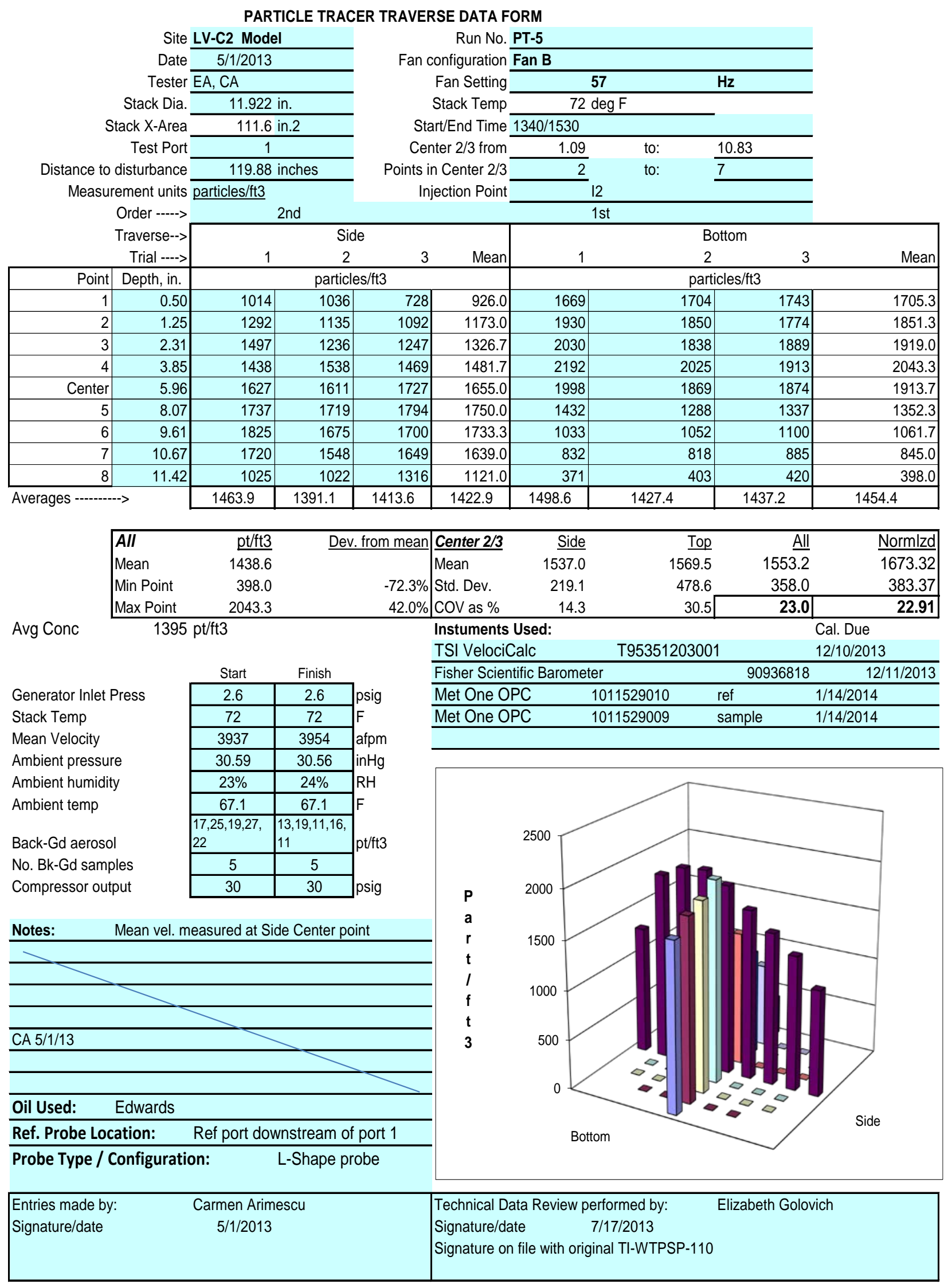




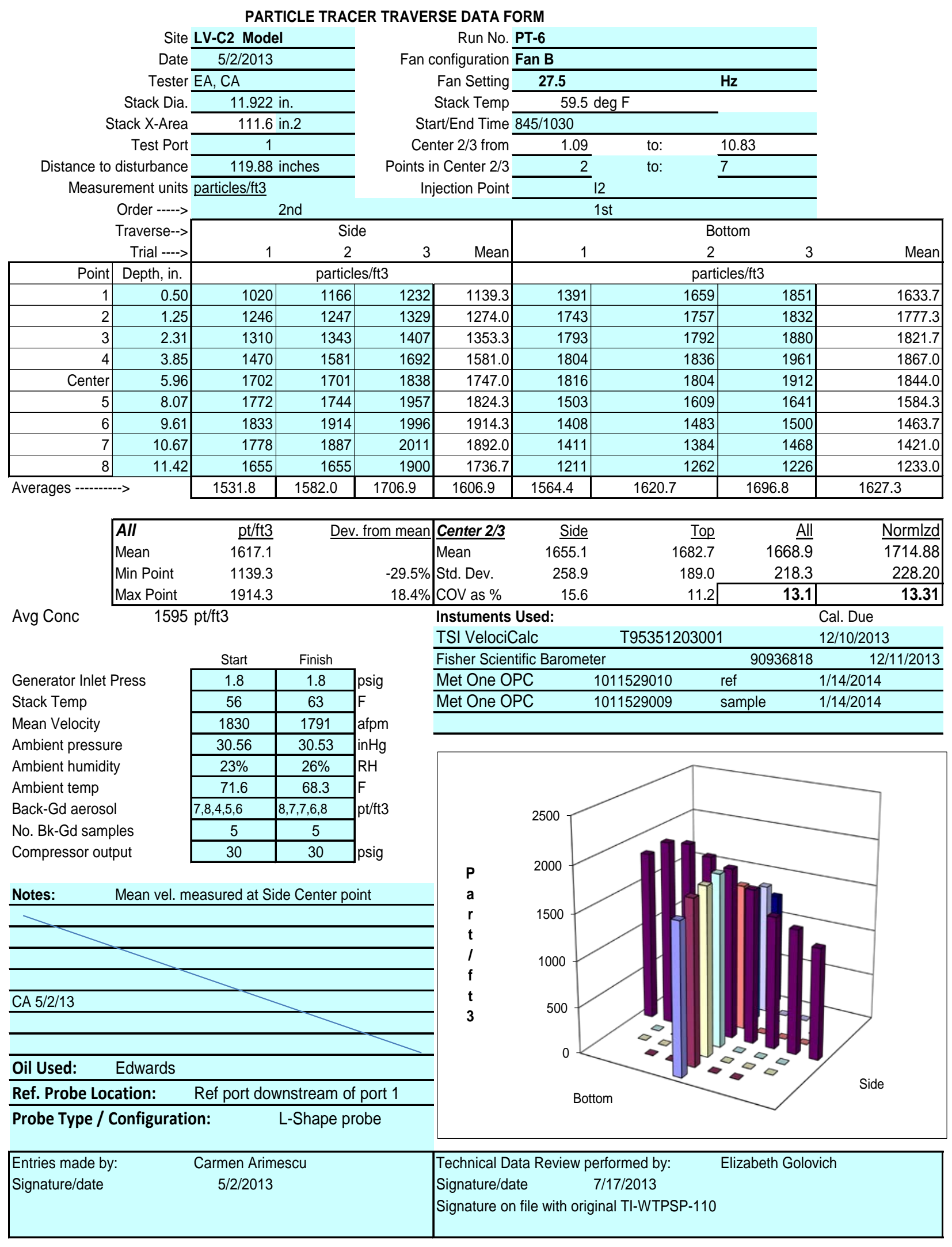




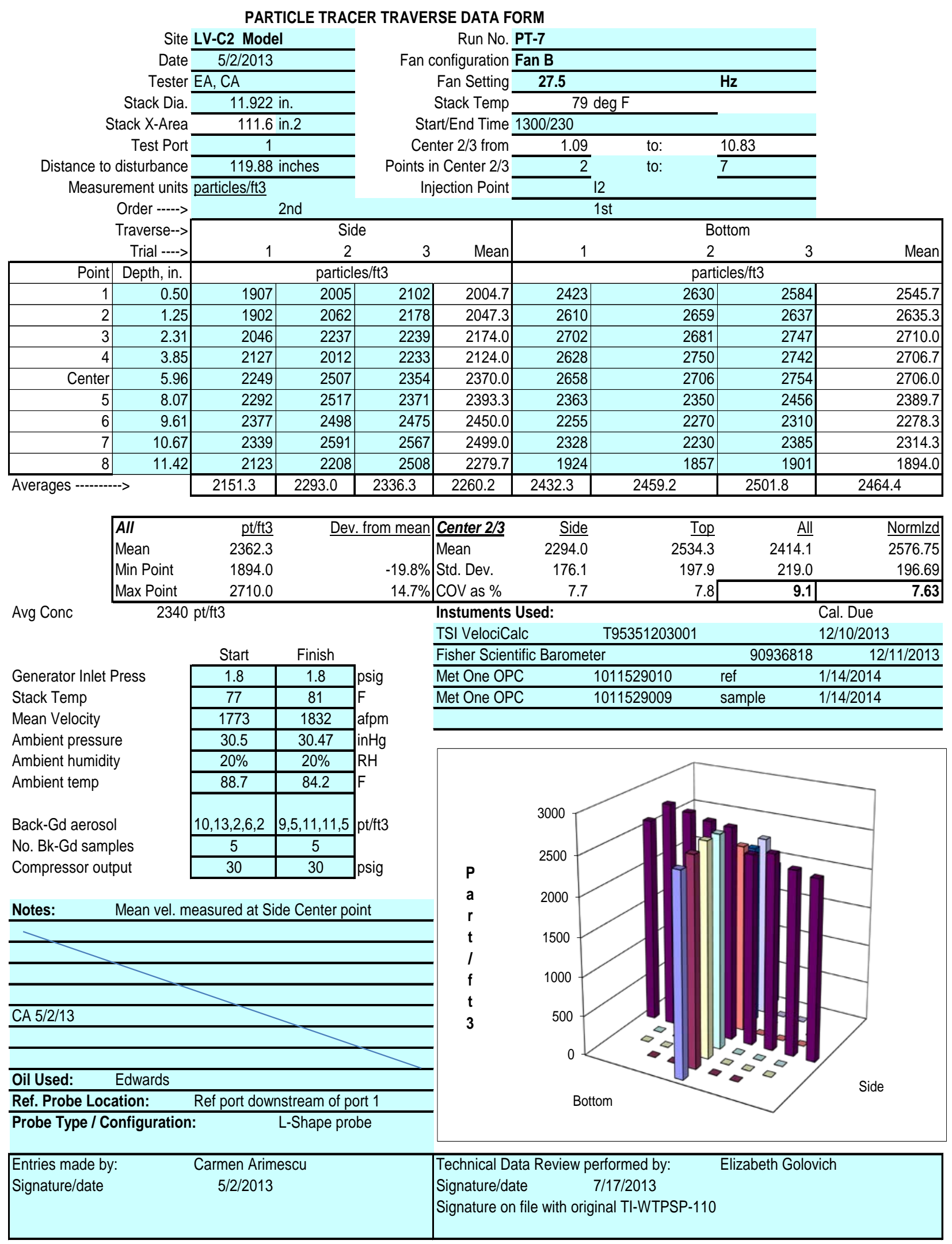




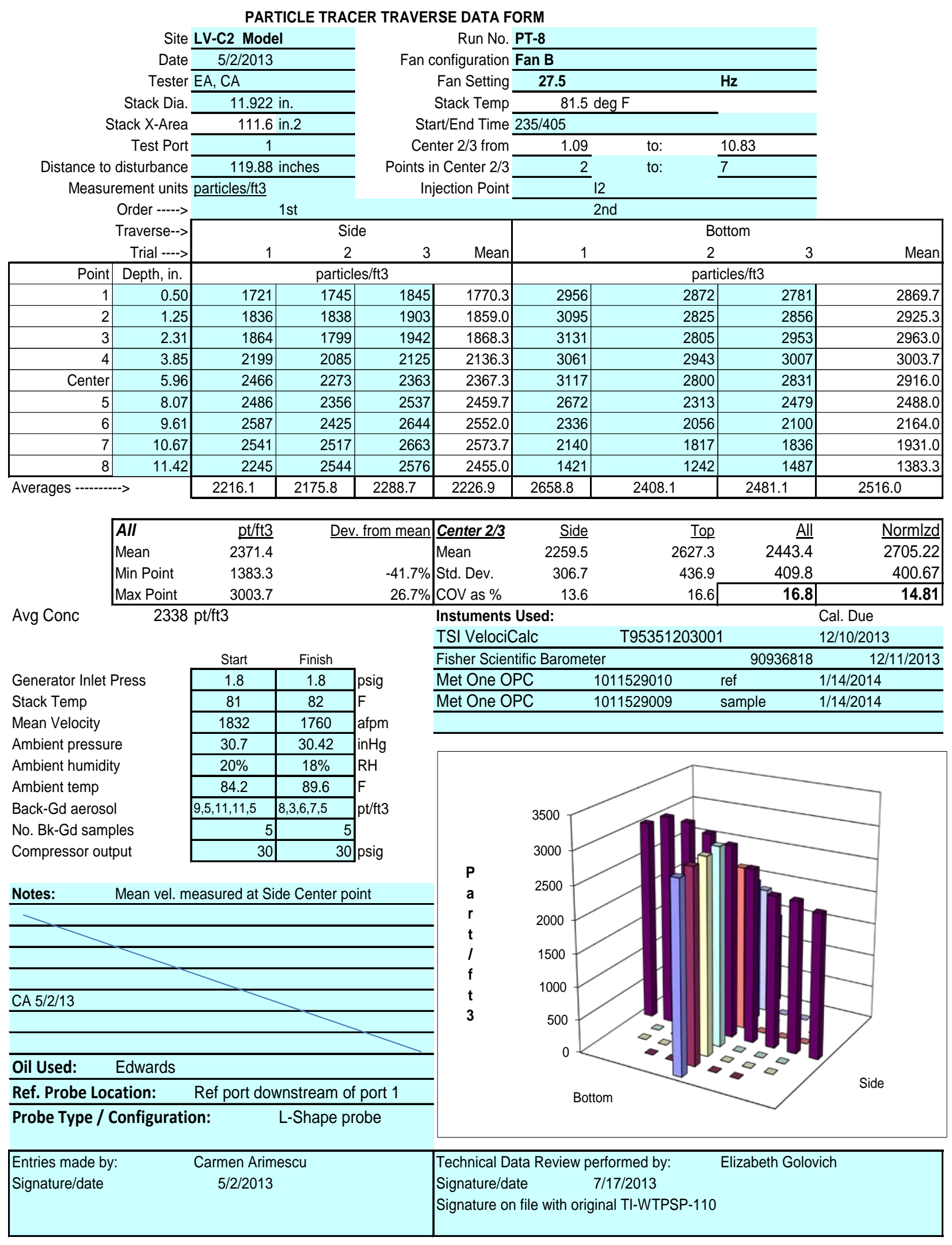




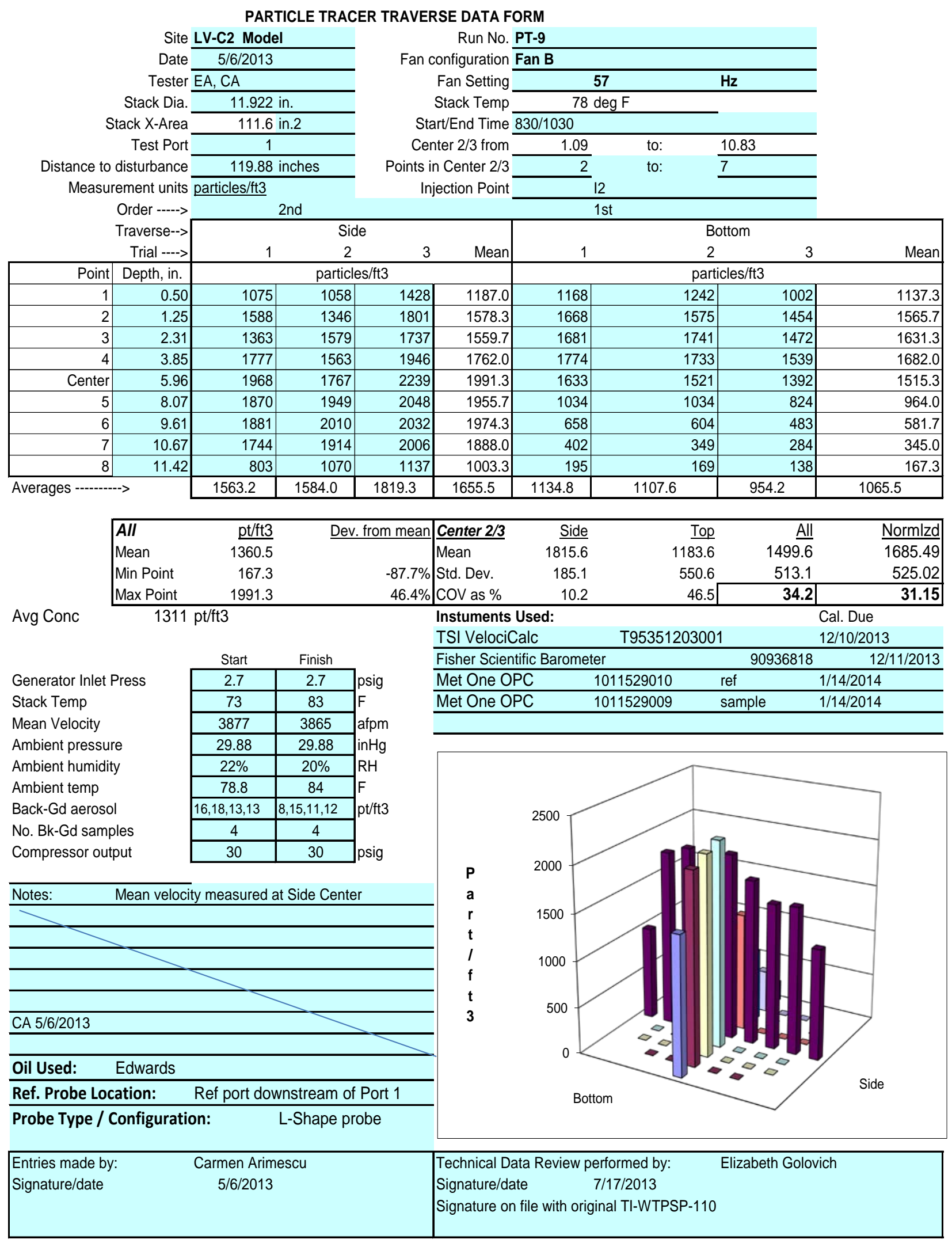




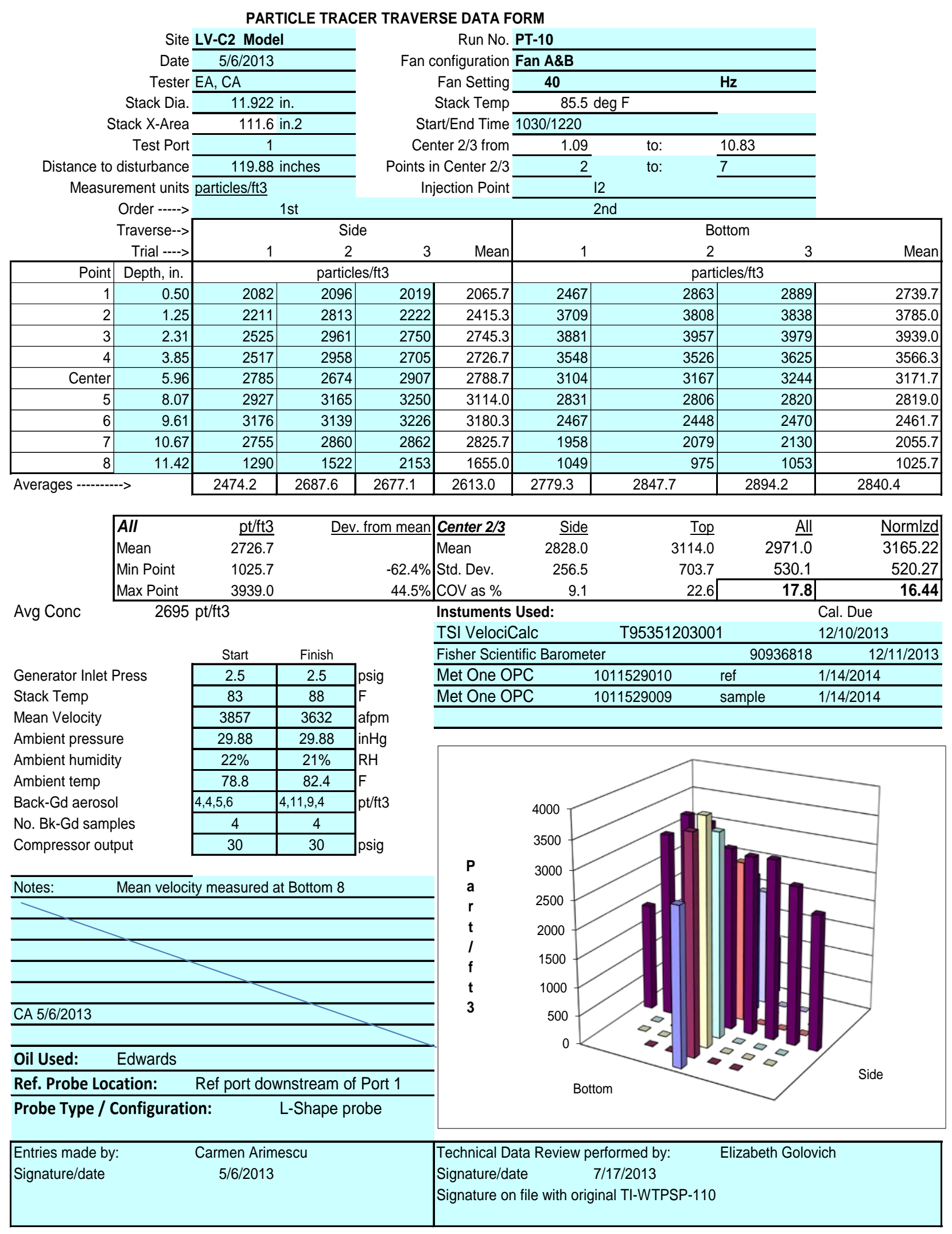




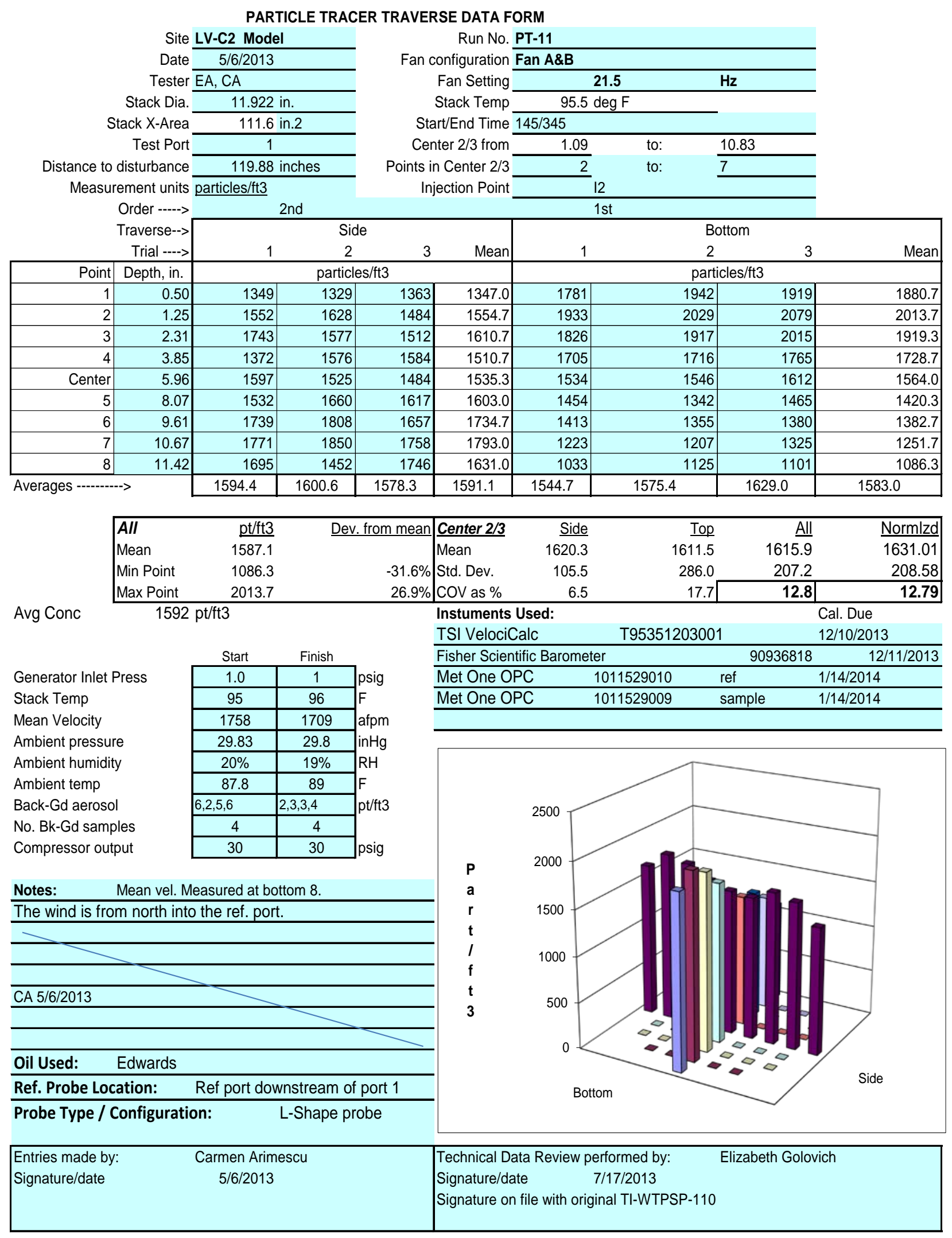




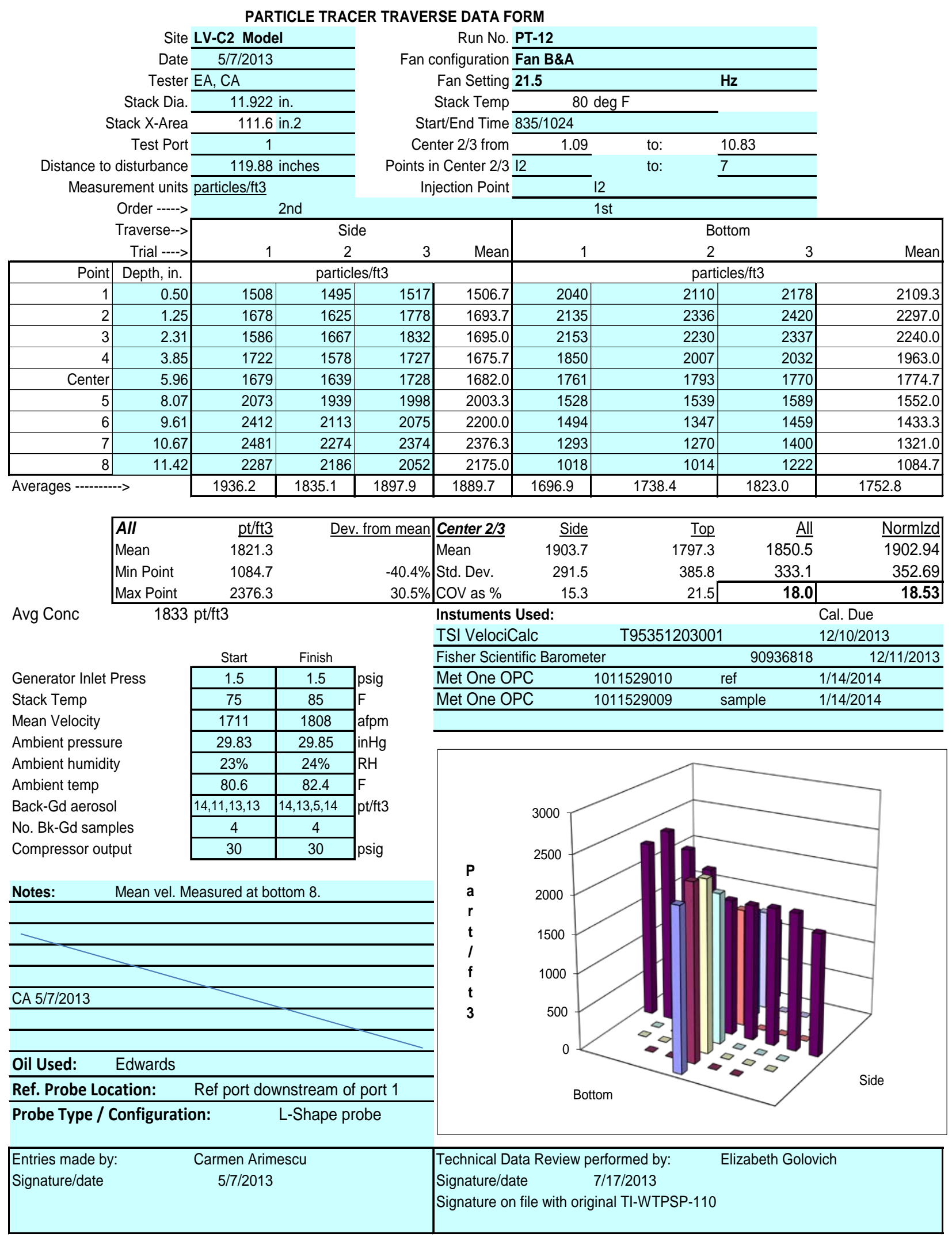




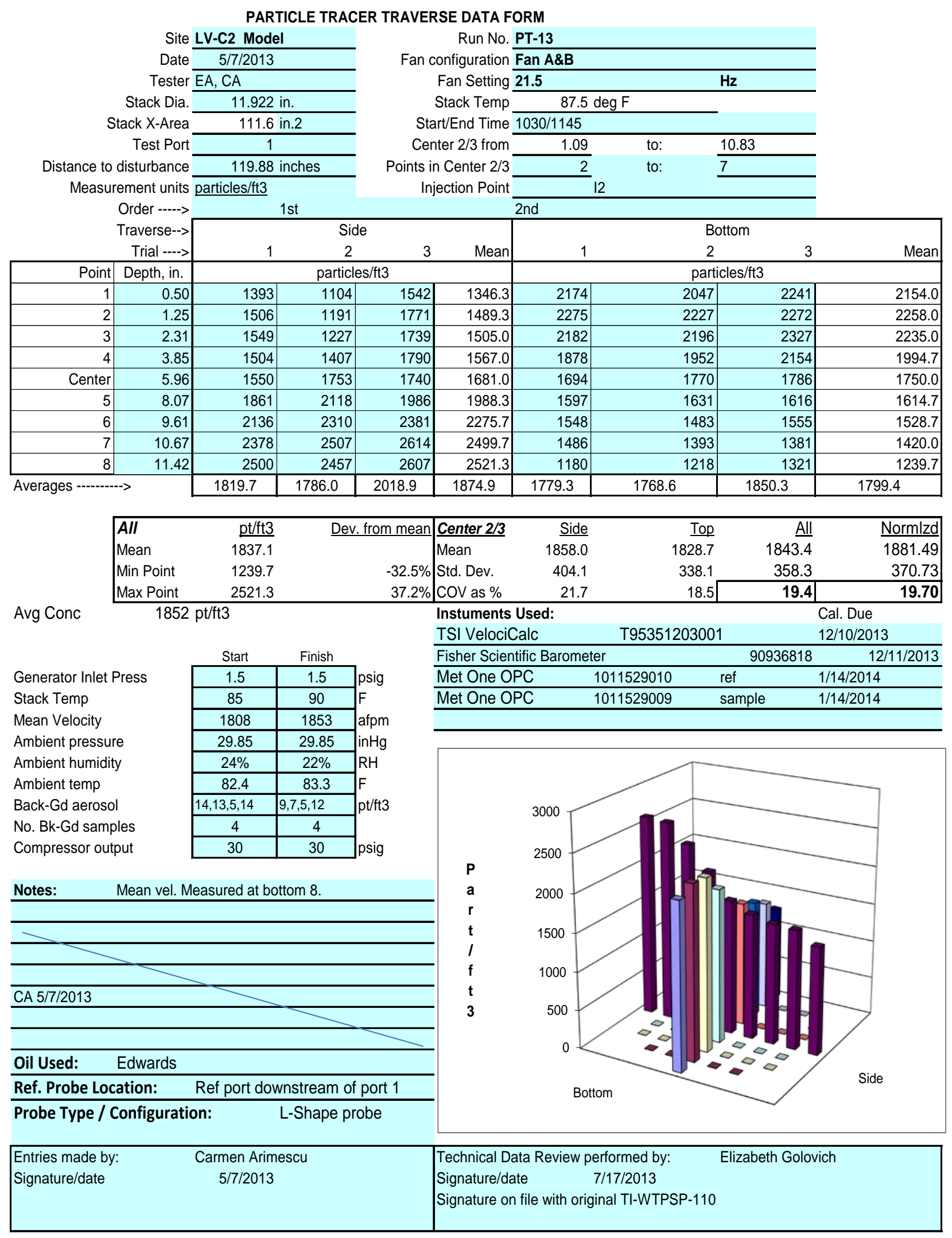




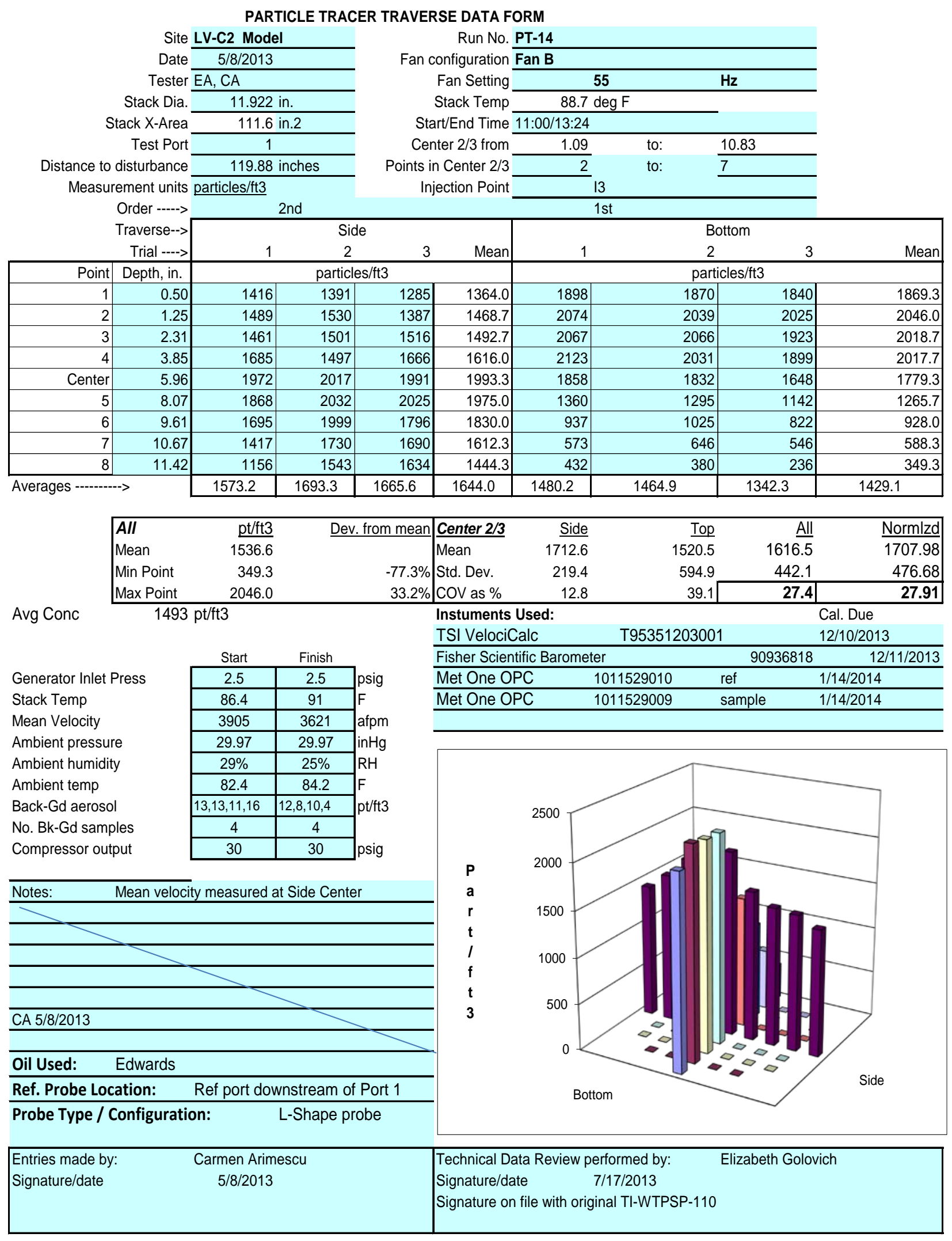




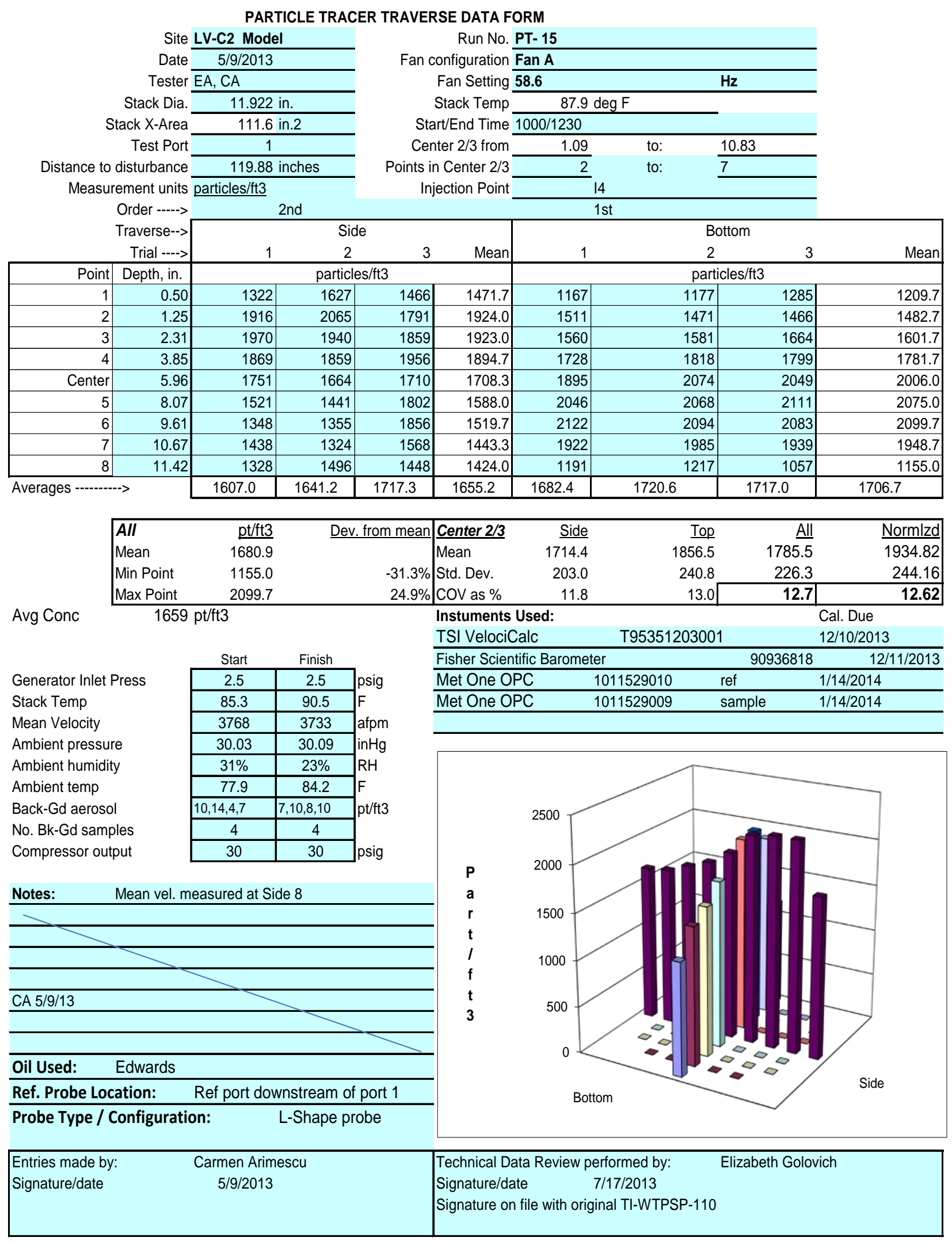




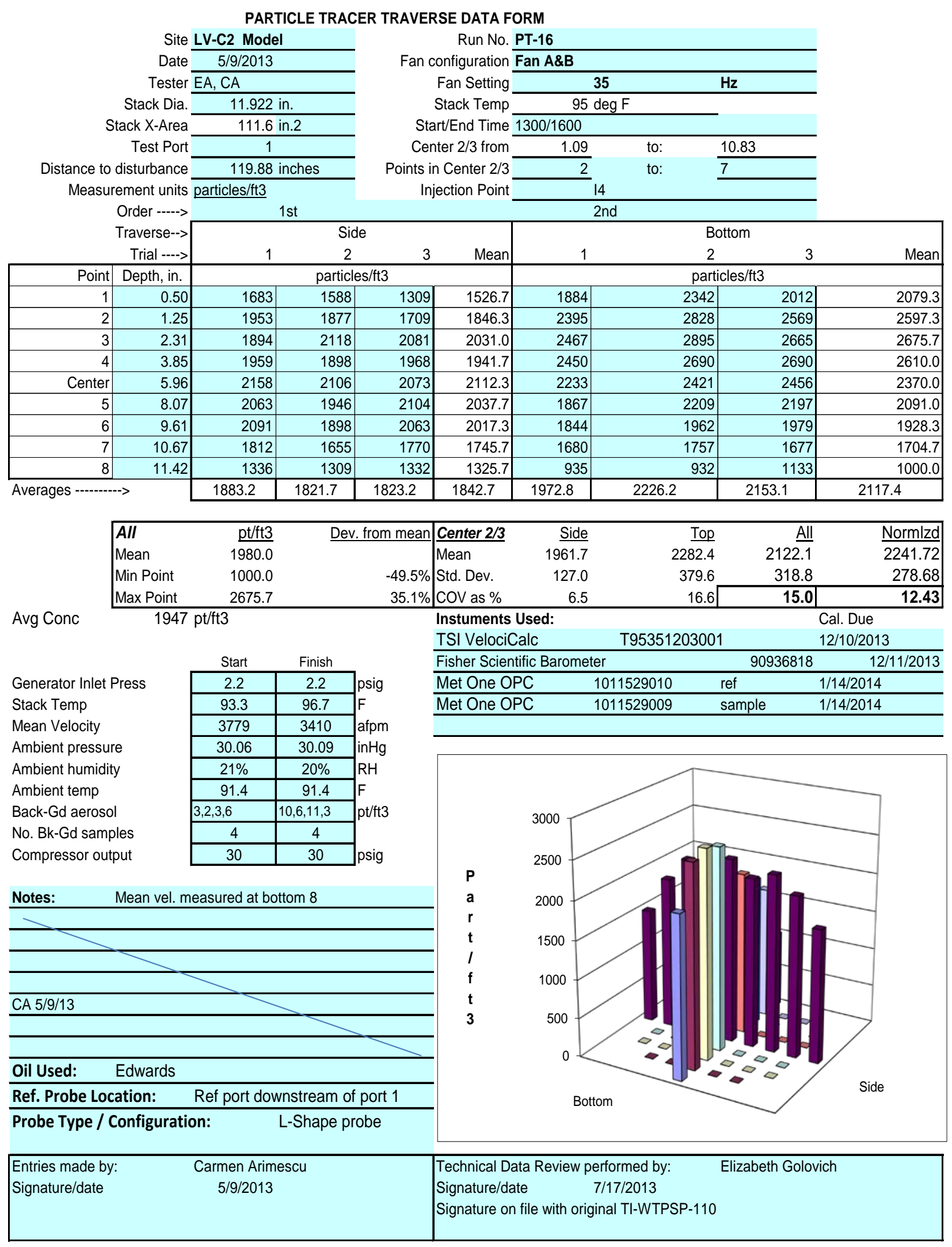




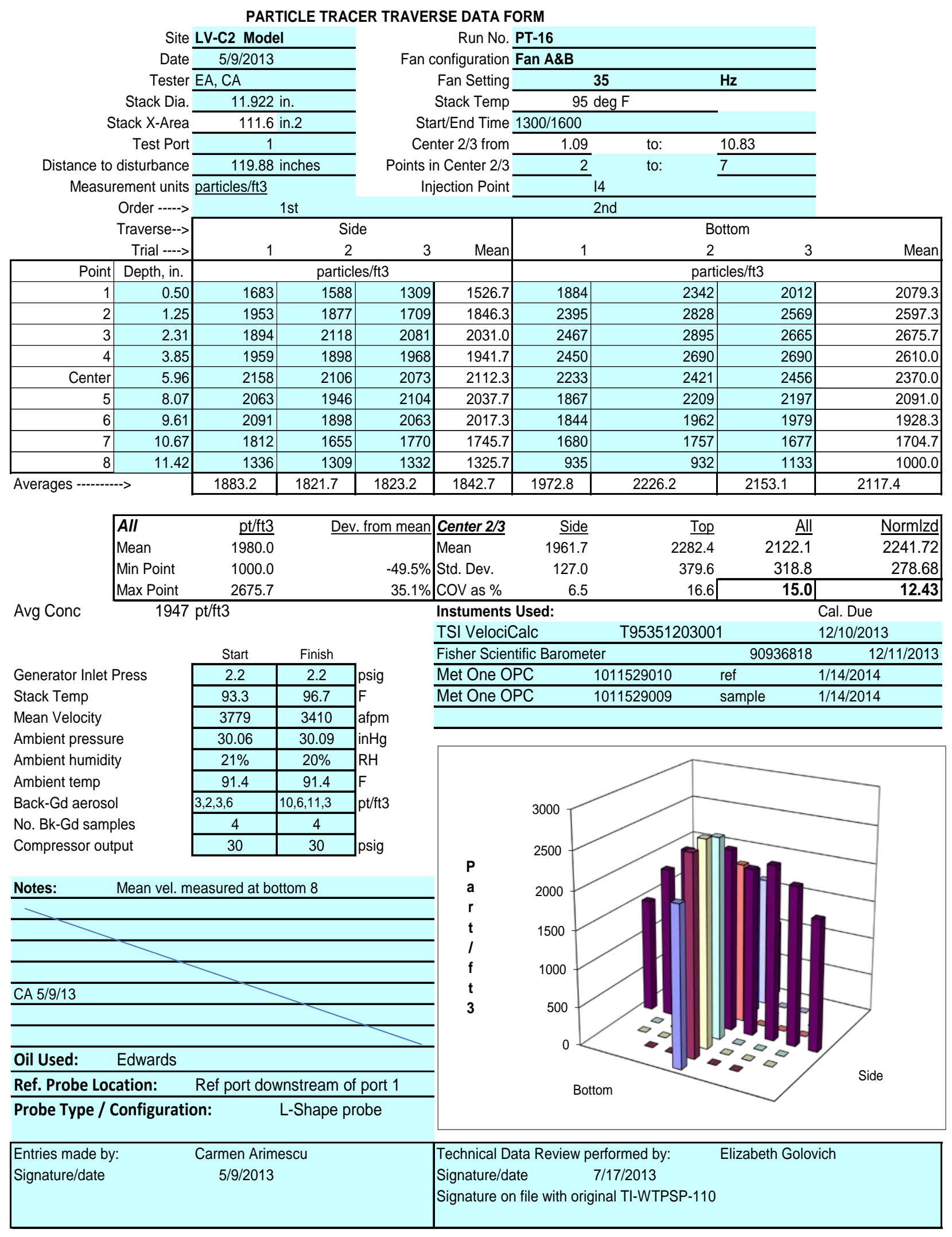




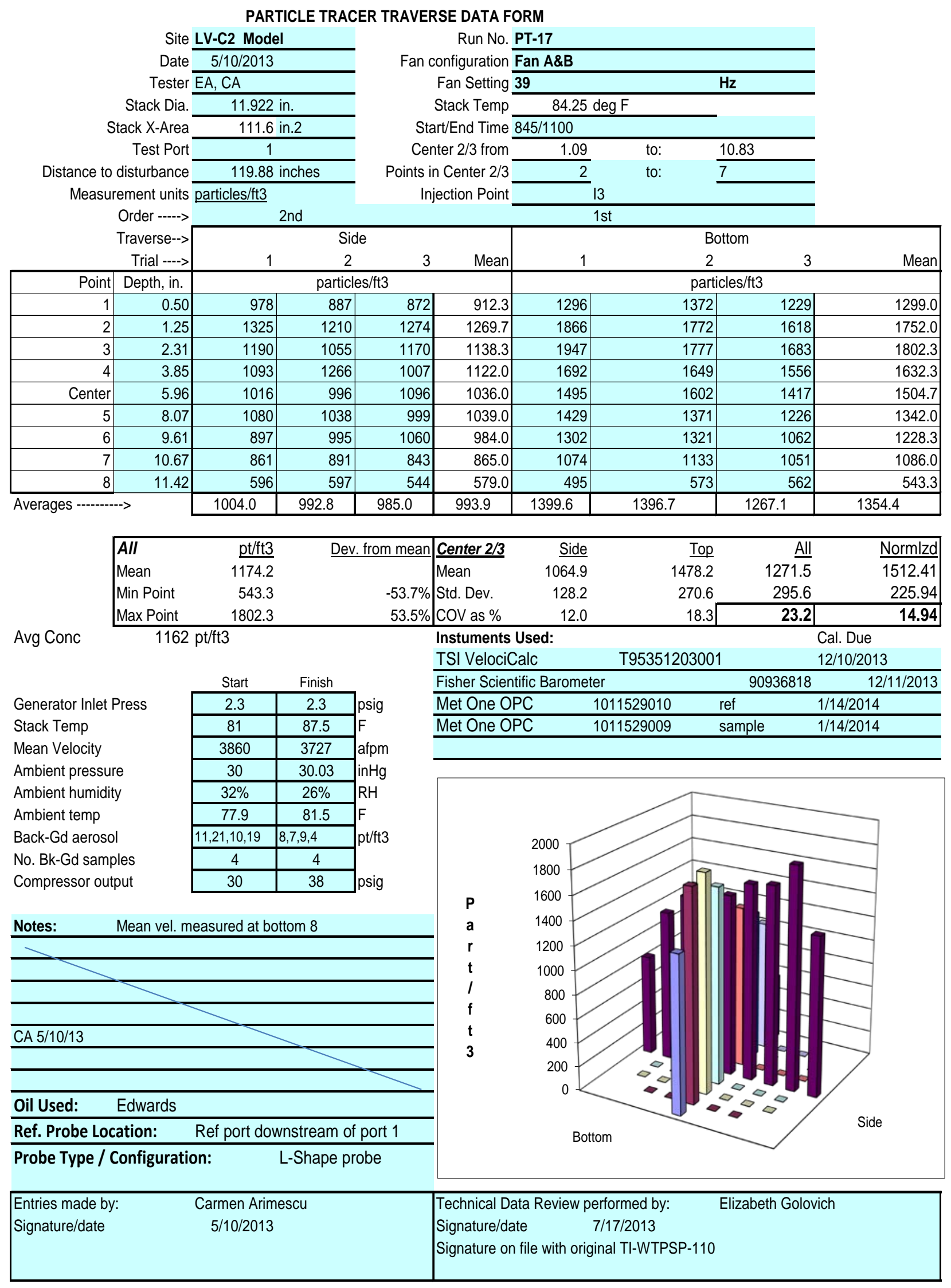




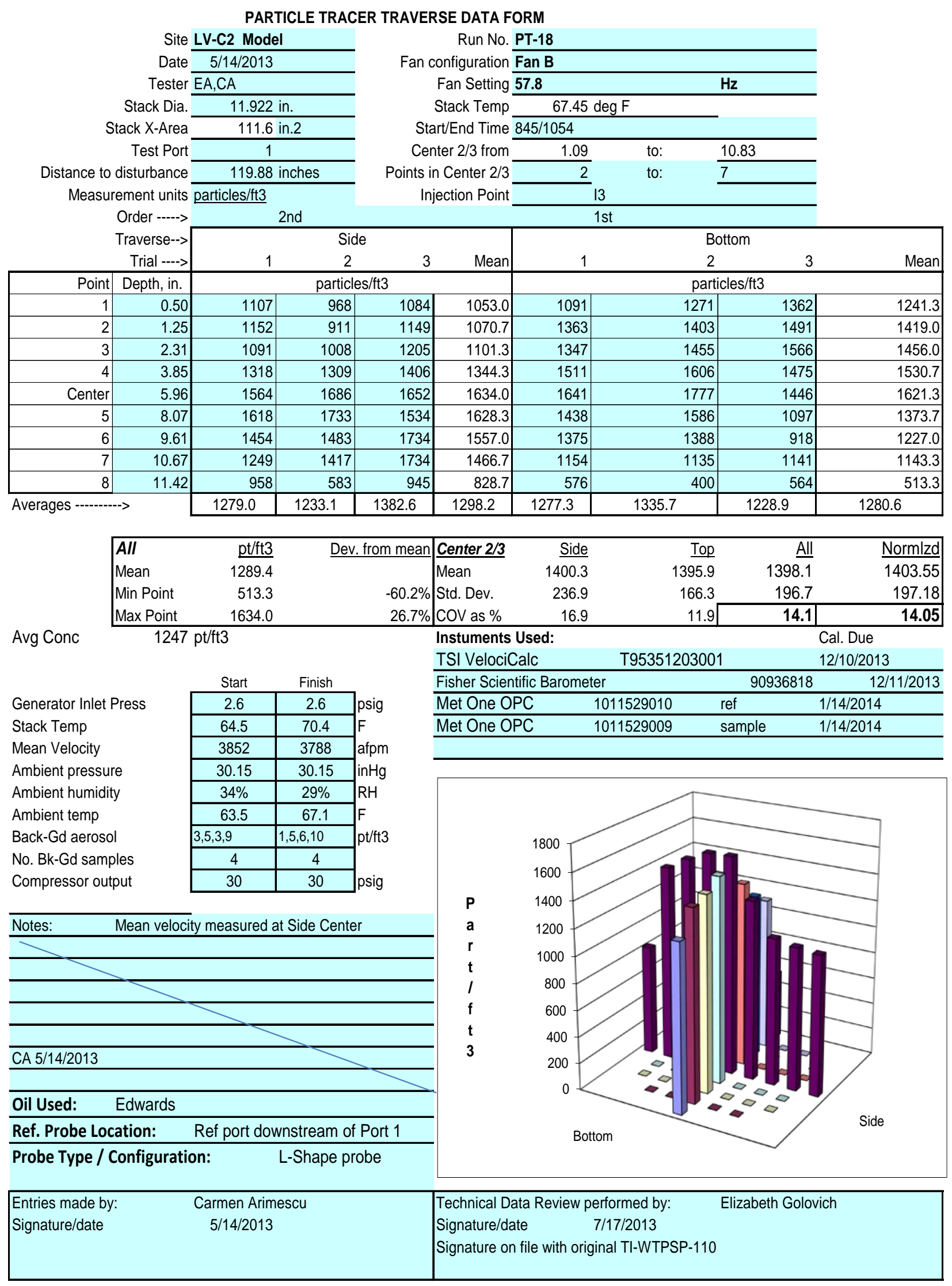




\section{PARTICLE TRACER TRAVERSE DATA FORM}

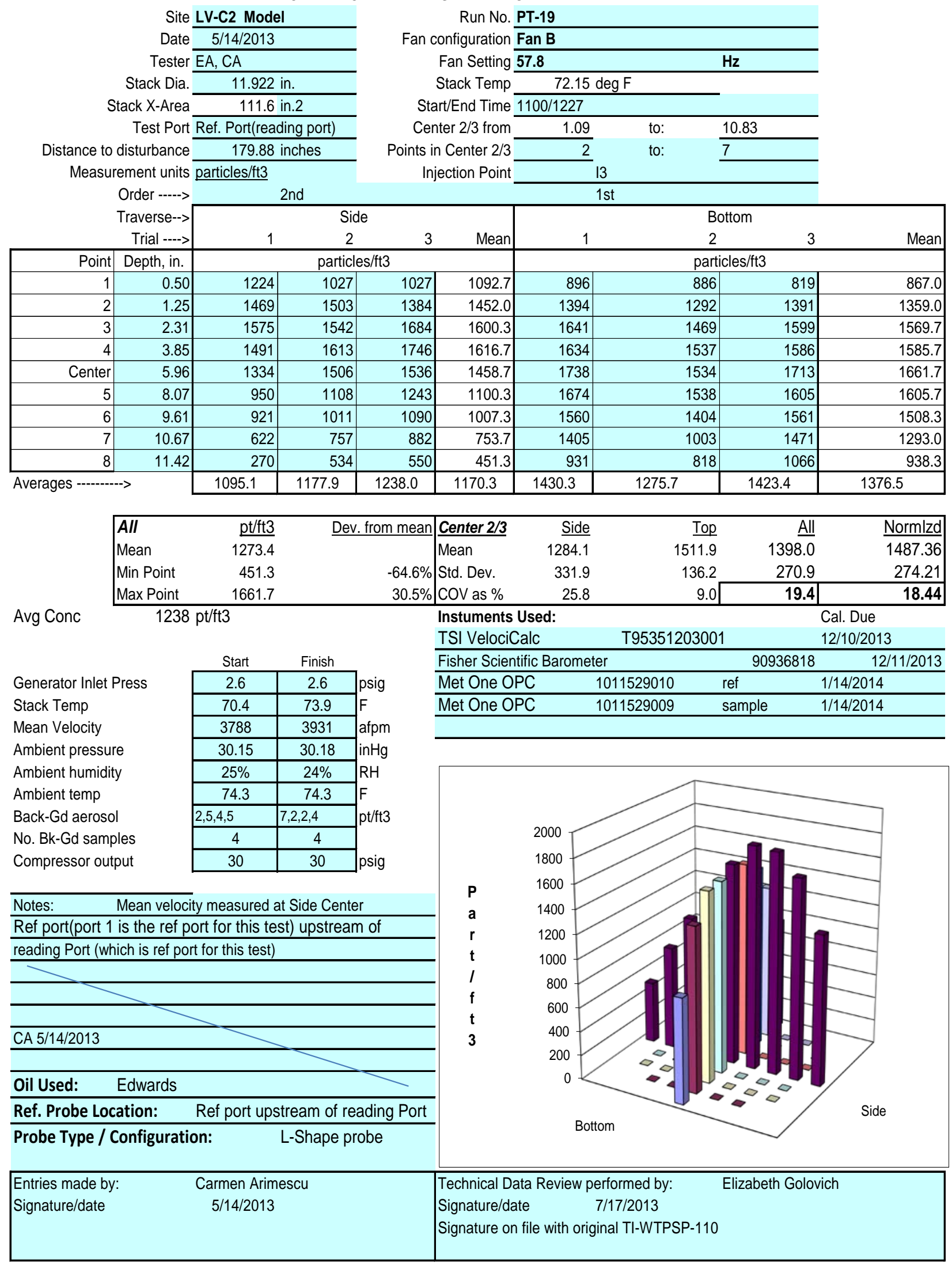




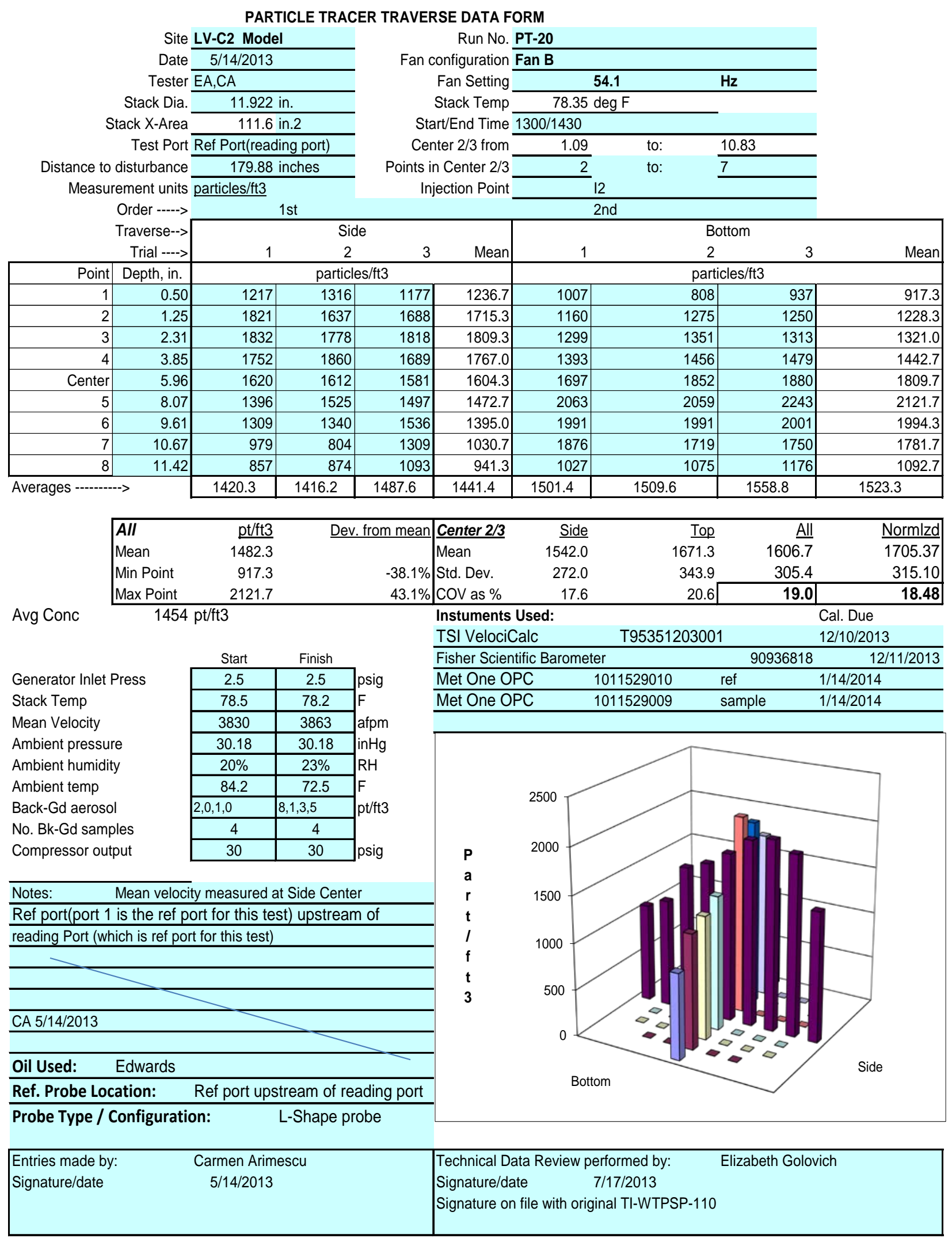




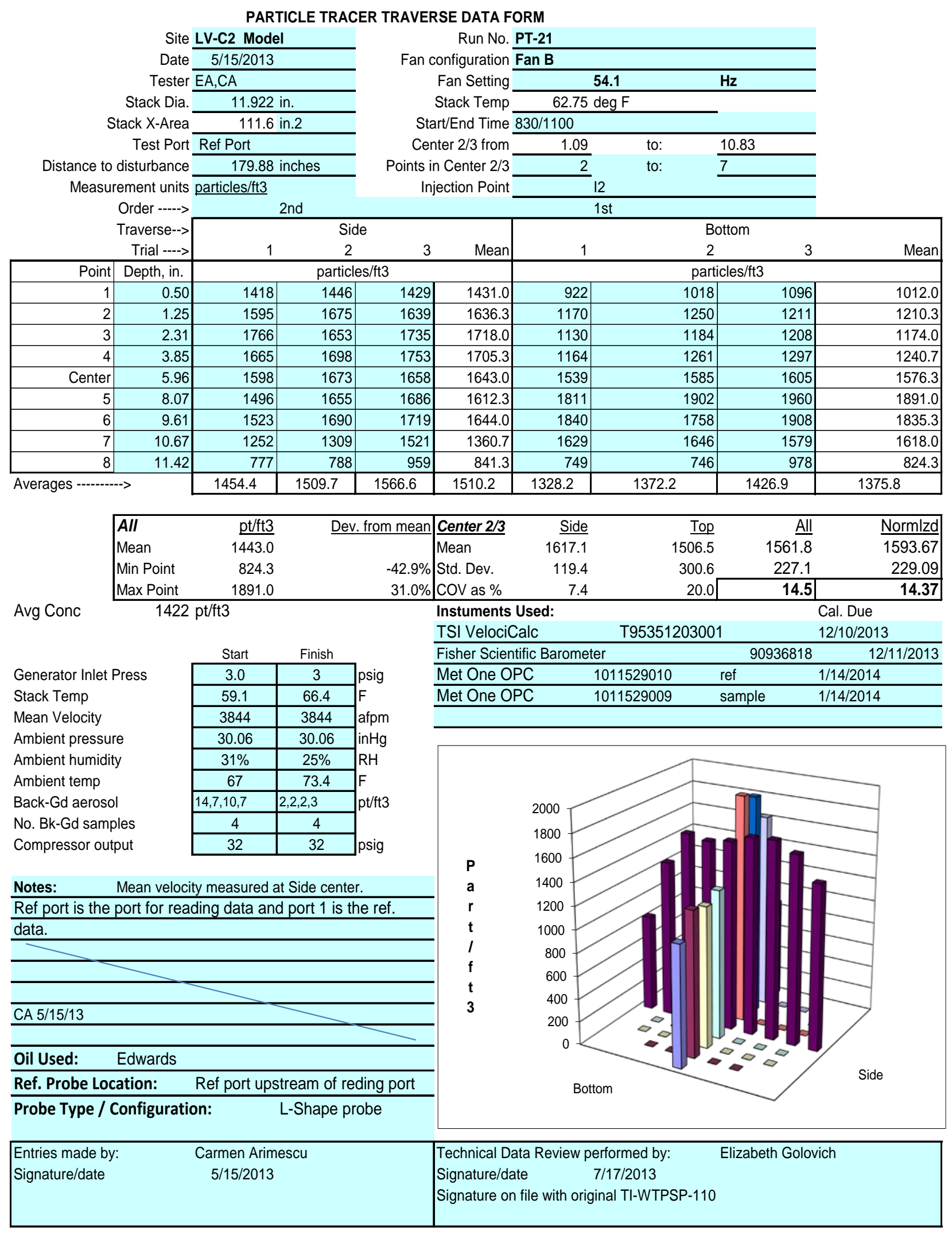




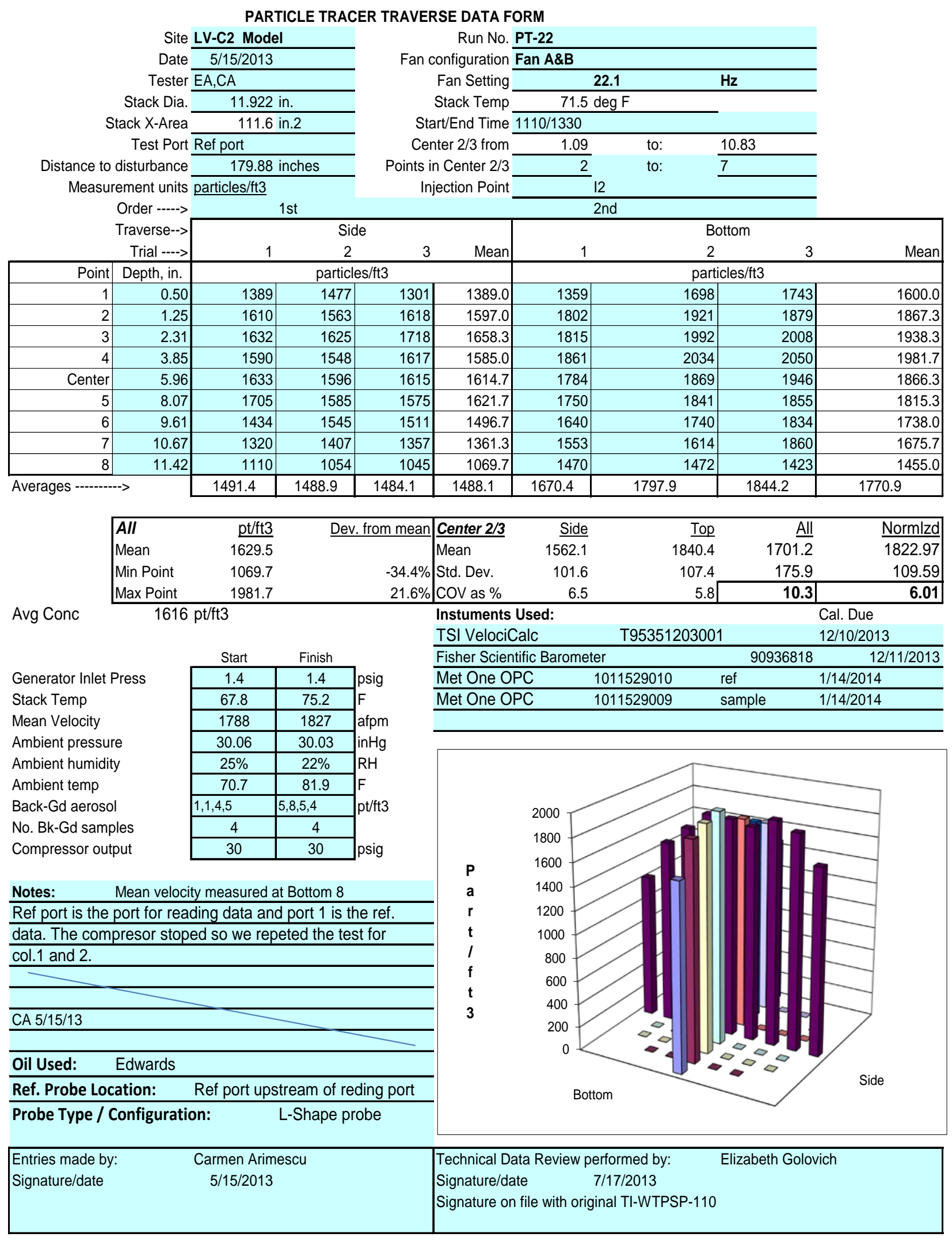




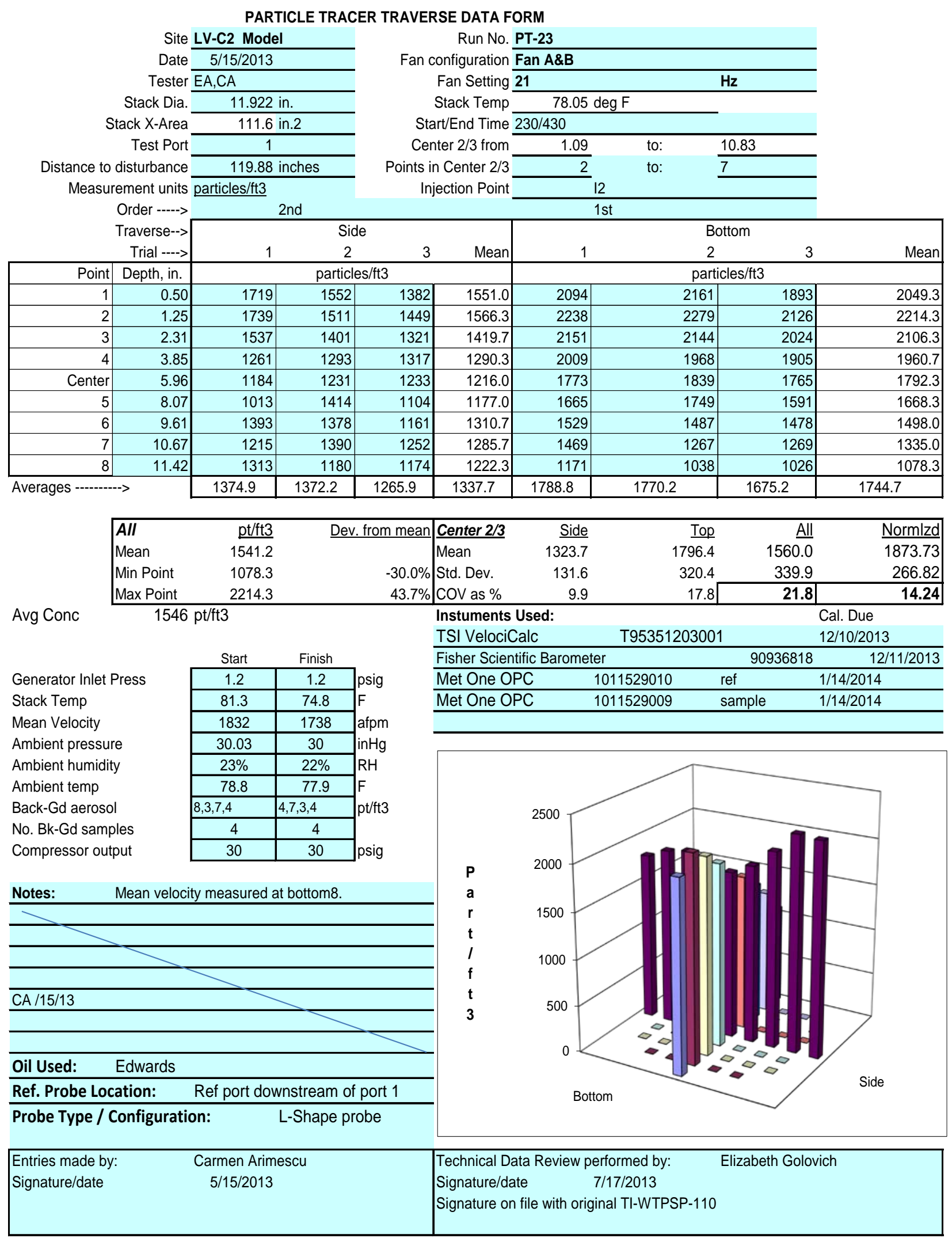




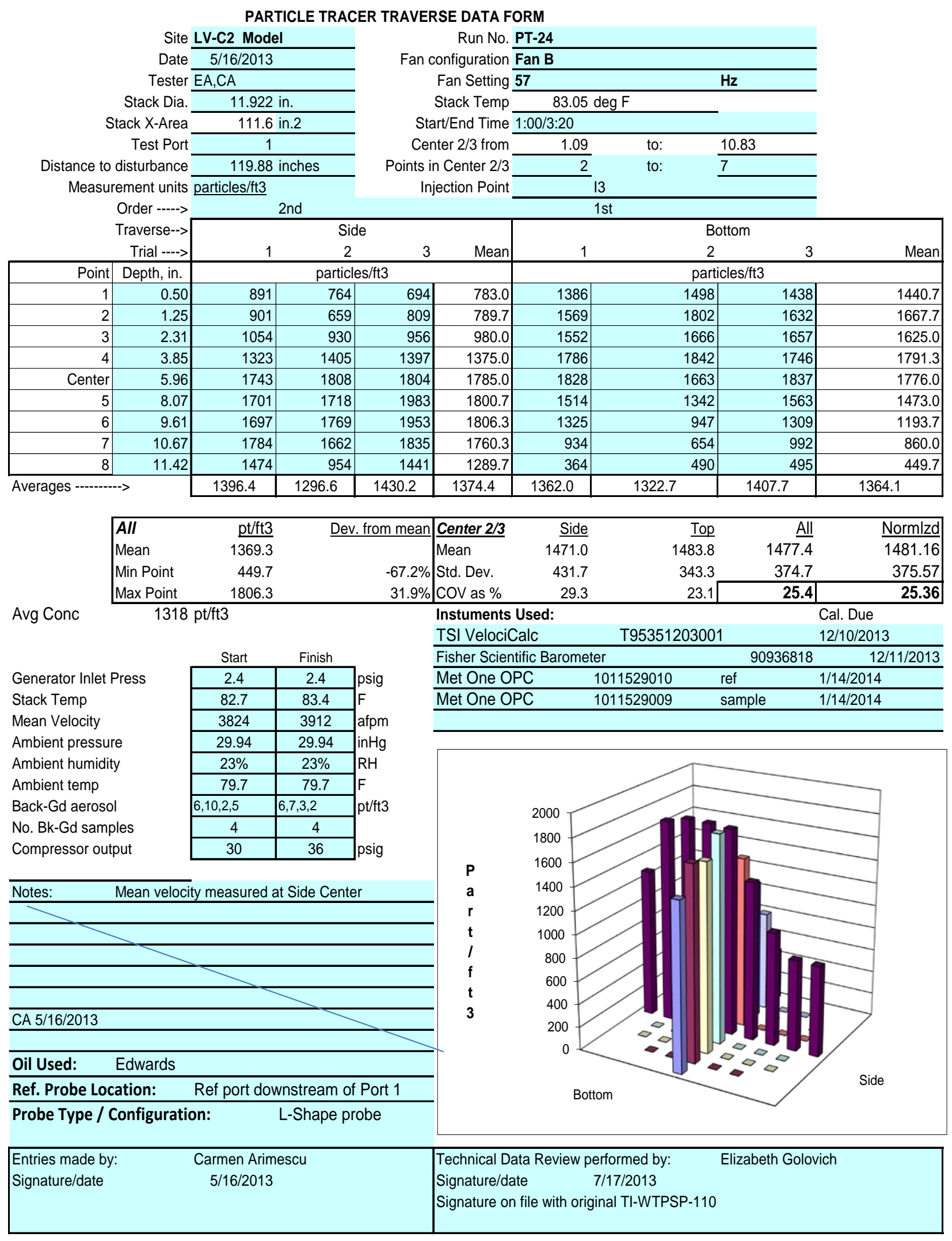



Appendix C

\section{LV-C2 Retest Data Sheets}





\section{C.1 LV-C2 Velocity Uniformity Data Sheets \\ VELOCITY TRAVERSE DATA FORM}

Site LV-C2 Remedial Scale Model

Date $1 / 9 / 15$

Testers CA, EA

Stack Dia.

Stack X-Area

Test Port

Distance to disturbance

Velocity units $\underline{\text { aft/min }}$
Run No. VT-1

Fan Configuration Fan B Max

Fan Setting 59

Stack Temp

Start/End Time 900/1014

Center $2 / 3$ from

Points in Center 2/3

Data Files: NA

Order -->

Traverse-->

Trial ---->

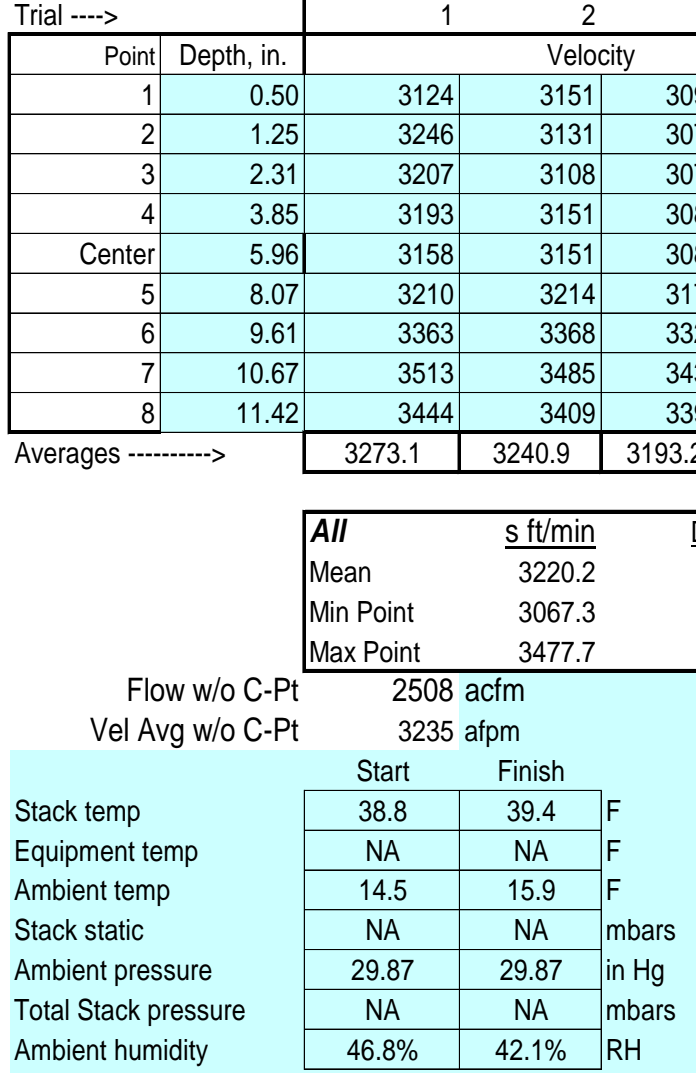

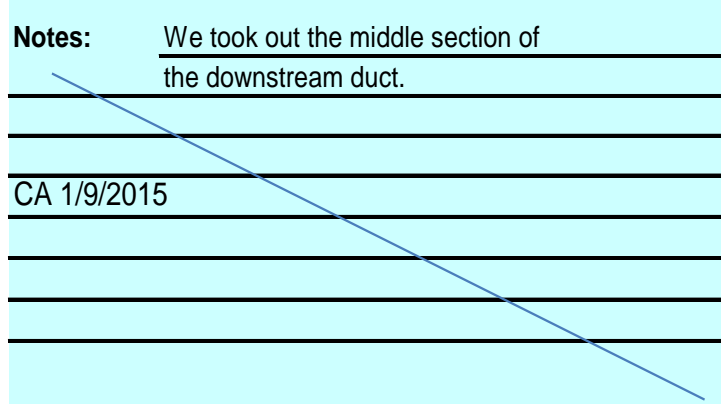

\begin{tabular}{r|l} 
Dev. from mean & Center $2 / 3$ \\
$-4.7 \%$ & Mean \\
$8.0 \%$ & Cov. Dev. \\
Cov $\%$
\end{tabular}

Instuments Used:

Fisher Scientific Barometer Hydro

Therm/Baro/Dew Point Pen 122277883

TSI VelociCalc SN T95351203001

\begin{tabular}{rrr} 
Side & Bottom & $\underline{\text { All }}$ \\
3225.7 & 3202.1 & 3213.9 \\
136.0 & 86.2 & 110.1 \\
4.2 & 2.7 & 3.4 \\
\hline
\end{tabular}

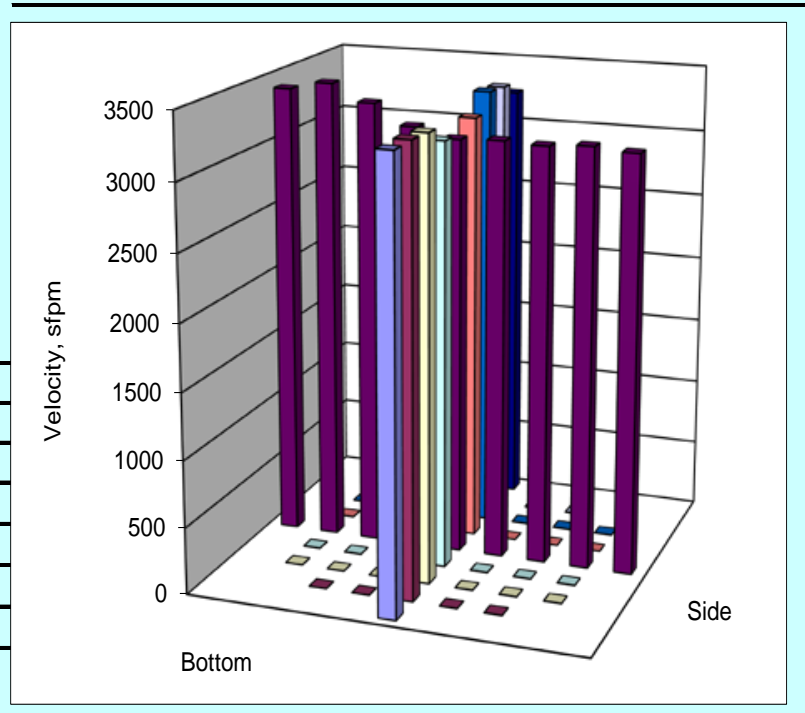

Entries made by:

Carmen Arimescu

$1 / 9 / 2015$

Technical Data Review performed by: John Glissmeyer

Signature/date

3/20/2015

Signature on file with original

Signature on file $n$ TI-WTPSP-136 


\section{VELOCITY TRAVERSE DATA FORM}

Site LV-C2 Remedial ScaleModel Date $1 / 9 / 15$

Testers CA,EA

Stack Dia.

Stack X-Area

Test Port

$\frac{\frac{C A, E A}{11.922 \text { in. }}}{\frac{111.6 \text { in. } 2}{1}}$

Distance to disturbance

Velocity units $\underline{\mathrm{ft} / \mathrm{min}}$

Run No. VT-2

Fan Configuration Fan B max

Fan Setting $\mathbf{5 9}$

Stack Temp

Start/End Time 1018/1046

Center $2 / 3$ from

Points in Center $2 / 3$

Data Files: NA

Order -->

2

Traverse-->

Trial ---->

\begin{tabular}{|r|r|}
\hline Point & Depth, in. \\
\hline 1 & 0.50 \\
\hline 2 & 1.25 \\
\hline 3 & 2.31 \\
\hline 4 & 3.85 \\
\hline Center & 5.96 \\
\hline 5 & 8.07 \\
\hline 6 & 9.61 \\
\hline 7 & 10.67 \\
\hline 8 & 11.42 \\
\hline Averages -------->
\end{tabular}

\begin{tabular}{|c|c|c|}
\hline & \multicolumn{2}{|c|}{ Side } \\
\hline 1 & 2 & \\
\hline & \multicolumn{2}{|c|}{ Velocity } \\
\hline 3005 & 2964 & 30 \\
\hline 2901 & 3005 & 30 \\
\hline 3008 & 2995 & 30 \\
\hline 3000 & 2989 & 30 \\
\hline 3040 & 3058 & 30 \\
\hline 3112 & 3125 & 31 \\
\hline 3309 & 3302 & 33 \\
\hline 3421 & 3430 & 35 \\
\hline 3352 & 3392 & 34 \\
\hline 3127.6 & 3140.0 & 3185.0 \\
\hline
\end{tabular}

1

Bottom

\begin{tabular}{llllll}
3 & Mean & 1 & 2 & 3 & Mean \\
\hline
\end{tabular}

\begin{tabular}{|r|r|r|r|} 
& \multicolumn{3}{|c|}{ Velocity } \\
\hline
\end{tabular}

\begin{tabular}{|r|r|r|r|r|r|}
\hline 000 & 2989.7 & 3190 & 3304 & 3165 & 3219.7 \\
\hline 006 & 2970.7 & 3249 & 3294 & 3294 & 3279.0 \\
\hline 092 & 3031.7 & 3209 & 3188 & 3244 & 3213.7 \\
\hline 057 & 3015.3 & 3095 & 3124 & 3096 & 3105.0 \\
\hline 3146 & 3051.0 & 3077 & 3026 & 3066 & 3056.3 \\
\hline 310 & 3307.0 & 3300 & 3263 & 3152 & 3238.3 \\
\hline 477 & 3457.7 & 3388 & 3236 & 3233 & 3285.7 \\
\hline 0 & 3407.0 & 3067 & 3409 & 3162 & 3212.7 \\
\hline
\end{tabular}

\begin{tabular}{|ll}
\hline All & $\underline{\mathrm{ft} / \mathrm{min}}$ \\
Mean & 3172.9 \\
Min Point & 2970.7 \\
Max Point & 3457.7 \\
\hline
\end{tabular}

Flow w/o C-Pt

$$
\text { Max Point }
$$

\section{Vel Avg w/o C-Pt}

\begin{tabular}{|c|c|}
\hline Start & Finish \\
\hline 39.4 & 39.6 \\
\hline NA & NA \\
\hline 15.9 & 15.1 \\
\hline NA & NA \\
\hline 29.87 & 29.86 \\
\hline NA & NA \\
\hline $42.1 \%$ & $43.8 \%$ \\
\hline
\end{tabular}

Stack temp

Equipment temp

Ambient temp

Stack static

Ambient pressure

Total Stack pressure

Ambient humidity

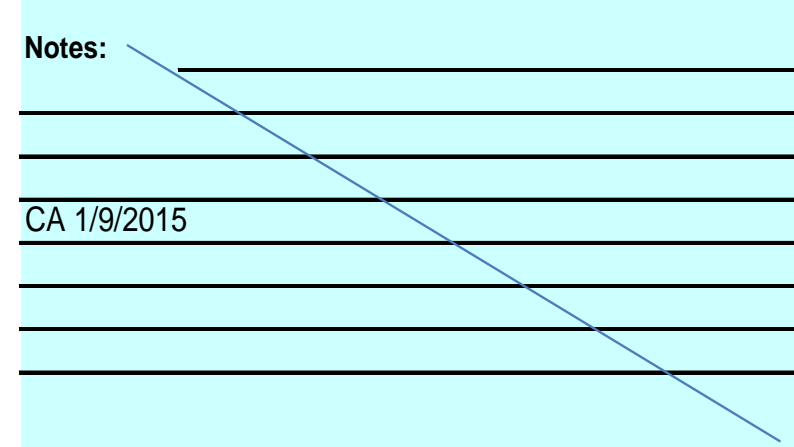

\begin{tabular}{r|l} 
Dev. from mean & Center 2/3 \\
\hline$-6.4 \%$ & Mean \\
$9.0 \%$ & Std. Dev. \\
COV as $\%$
\end{tabular}

\begin{tabular}{lr} 
Instuments Used: & \multicolumn{1}{c}{ Cal Due } \\
\hline Fisher Scientific Barometer Hydro & \\
Therm/Baro/Dew Point Pen 122277883 & 8/7/2015 \\
\hline TSI VelociCalc SN T95351203001 & 8/15/2015 \\
\hline
\end{tabular}

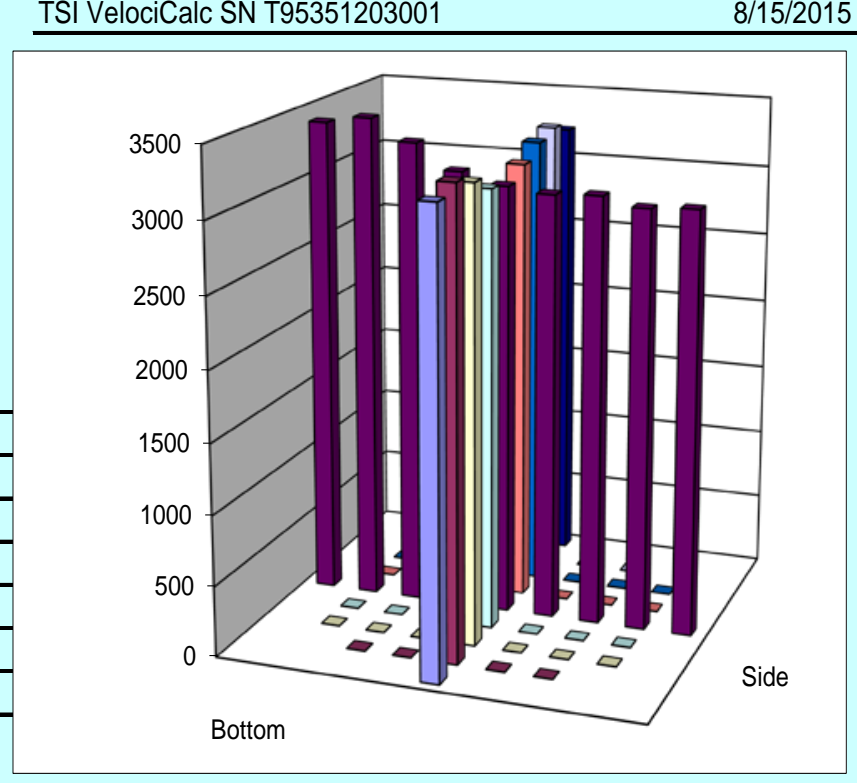

Entries made by:

Signature/date
Carmen Arimescu

$1 / 9 / 2015$

Signature on file with original
Technical Data Review performed by: John Glissmeyer Signature/date 3/20/2015

Signature on file n TI-WTPSP-136 


\section{VELOCITY TRAVERSE DATA FORM}

Site LV-C2 Remedial Scale Model Date $1 / 9 / 15$

Testers CA,EA

Stack Dia

Stack X-Area

Test Port

$\frac{11.922 \text { in. }}{\frac{111.6 \text { in. } 2}{1}}$

Distance to disturbance

Velocity units $\underline{\mathrm{ft} / \mathrm{min}}$

Run No. VT-3

Fan Configuration Fan B max

Fan Setting 59

Stack Temp

Start/End Time 1056/1120

Center $2 / 3$ from

Points in Center $2 / 3$

Data Files: $\overline{N A}$

Order -->

Traverse-->

Trial ---->

\begin{tabular}{|r|r|}
\hline Point & Depth, in. \\
\hline 1 & 0.50 \\
\hline 2 & 1.2 \\
\hline 3 & 2.3 \\
\hline 4 & 3.8 \\
\hline Center & 5.9 \\
\hline 5 & 8.07 \\
\hline 6 & 9.6 \\
\hline 7 & \multicolumn{2}{|c|}{10.6} \\
\hline 8 & 11.4 \\
\hline Averages -------->
\end{tabular}

1

1

2

\begin{tabular}{ll} 
& $\mathrm{Hz}$ \\
$39.6 \quad \operatorname{deg} \mathrm{F}$ \\
\hline
\end{tabular}

1.09 to:

2
10.83 7 2 Bottom

\begin{tabular}{lllllll}
2 & 3 & Mean & 1 & 2 & 3 & Mean \\
\hline
\end{tabular}

Velocity

\begin{tabular}{l|r|r|}
2884 & 2870 & 2910.7 \\
\hline
\end{tabular}

3126

Velocity

3092

\begin{tabular}{|r|r|}
\hline 967 & 2953 \\
\hline
\end{tabular}

2953 2950

\begin{tabular}{l|l|}
\hline .25 & 2967 \\
\hline 31 & 3002 \\
\hline
\end{tabular}

\begin{tabular}{l|l}
\hline 5.96 & 3061 \\
\hline & 3071
\end{tabular}

3061

\begin{tabular}{l|l|}
3000 & 2981 \\
\hline 3034 & 3043 \\
\hline
\end{tabular}

\begin{tabular}{l|l}
2956.7 \\
\hline 81 & 2994.3
\end{tabular}

\begin{tabular}{ll|l}
3091 & 3060 & 3074.0 \\
\hline
\end{tabular}

\begin{tabular}{ll|l}
3119 & 3144 & 3139.7 \\
\hline
\end{tabular}

\begin{tabular}{ll}
3156 & 3119 \\
\hline 3268 & 3285 \\
\hline
\end{tabular}

\begin{tabular}{|l|l|l|}
\hline 9.61 & 3268 & 3285 \\
\hline 0.67 & 3408 & 3414 \\
\hline .42 & 3404 & 3393 \\
\hline
\end{tabular}

\begin{tabular}{|l|l}
3285 & \\
\hline 3414 & \\
\hline 3393 &
\end{tabular}

3298

3283.7

\begin{tabular}{l|l}
3403 & 3408.3 \\
\hline
\end{tabular}

\begin{tabular}{|r|r|r|}
3393 & 3405 & 3400.7 \\
\hline 3130.3 & 3128.2 & 3134.9 \\
\hline
\end{tabular}

\begin{tabular}{|r|r|r|r|}
\hline 3198 & 3260 & 3212 & 3223.3 \\
\hline 3174 & 3208 & 3142 & 3174.7 \\
\hline 3133 & 3066 & 3070 & 3089.7 \\
\hline 32060 & 3070 & 3088 & 3072.7 \\
\hline 3274 & 3264 & 3306 & 3258.7 \\
\hline 3195 & 3307 & 3342 & 3307.7 \\
\hline 3080 & 3269 & 3316 & 3279.3 \\
\hline 3160.7 & 3219.7 & 3191.6 & 3166.3 \\
\hline
\end{tabular}

\begin{tabular}{|c|c|c|c|c|c|c|}
\hline All & $\mathrm{ft} / \mathrm{min}$ & Dev. from mean & Center $2 / 3$ & $\underline{\text { Side }}$ & Bottom & All \\
\hline Mean & 3162.8 & & Mean & 3129.0 & 3200.9 & 3164.9 \\
\hline Min Point & 2910.7 & $-8.0 \%$ & Std. Dev. & 163.2 & 92.1 & 132.7 \\
\hline Max Point & 3408.3 & $7.8 \%$ & cov as $\%$ & 5.2 & 2.9[ & 4.2 \\
\hline
\end{tabular}

Flow w/o C-Pt $2461 \mathrm{acfm}$ Vel Avg w/o C-Pt

3174 afpm

\begin{tabular}{|c|c|c|c|}
\hline \multirow{3}{*}{$\begin{array}{l}\text { Stack temp } \\
\text { Equipment temp }\end{array}$} & \multicolumn{2}{|r|}{ Finish } & \\
\hline & 39.6 & 39.5 & \\
\hline & NA & NA & \multirow{6}{*}{$\begin{array}{l}\mathrm{F} \\
\mathrm{C} \\
\mathrm{mbars} \\
\text { in Hg } \\
\text { mbars }\end{array}$} \\
\hline \multirow{5}{*}{$\begin{array}{l}\text { Ambient temp } \\
\text { Stack static } \\
\text { Ambient pressure } \\
\text { Total Stack pressure } \\
\text { Ambient humidity }\end{array}$} & 15.6 & 14.2 & \\
\hline & NA & NA & \\
\hline & 29.86 & 29.84 & \\
\hline & NA & NA & \\
\hline & $40.7 \%$ & $47.8 \%$ & \\
\hline
\end{tabular}

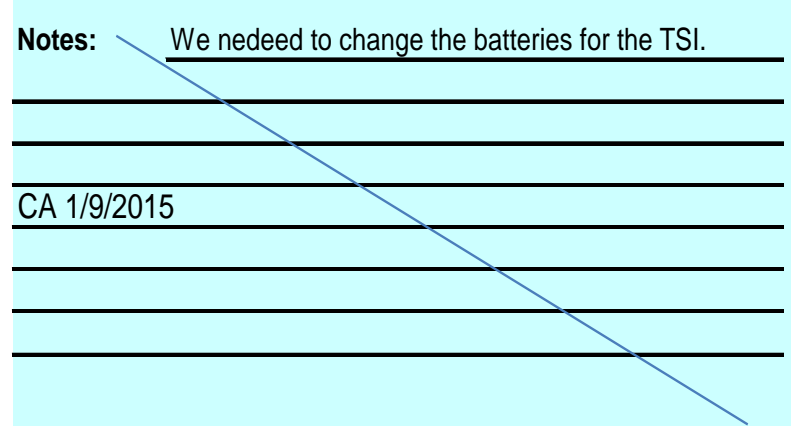

Entries made by: Signature/date

\section{Carmen Arimescu} $1 / 9 / 2015$

Signature on file with original

\begin{tabular}{lr} 
Instuments Used: & \multicolumn{1}{l}{ Cal Due } \\
\hline Fisher Scientific Barometer Hydro & \\
Therm/Baro/Dew Point Pen 122277883 & $8 / 7 / 2015$ \\
\hline TSI VelociCalc SN T95351203001 & 8/15/2015 \\
\hline
\end{tabular}

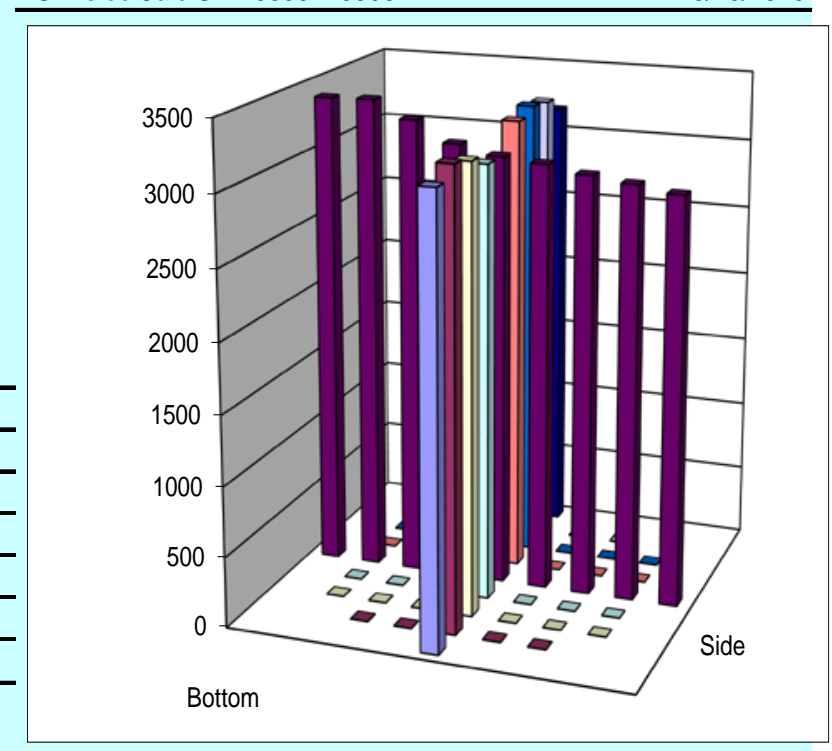

Technical Data Review performed by: John Glissmeyer Signature/date

Signature on file $n$ TI-WTPSP-136 


\section{VELOCITY TRAVERSE DATA FORM}

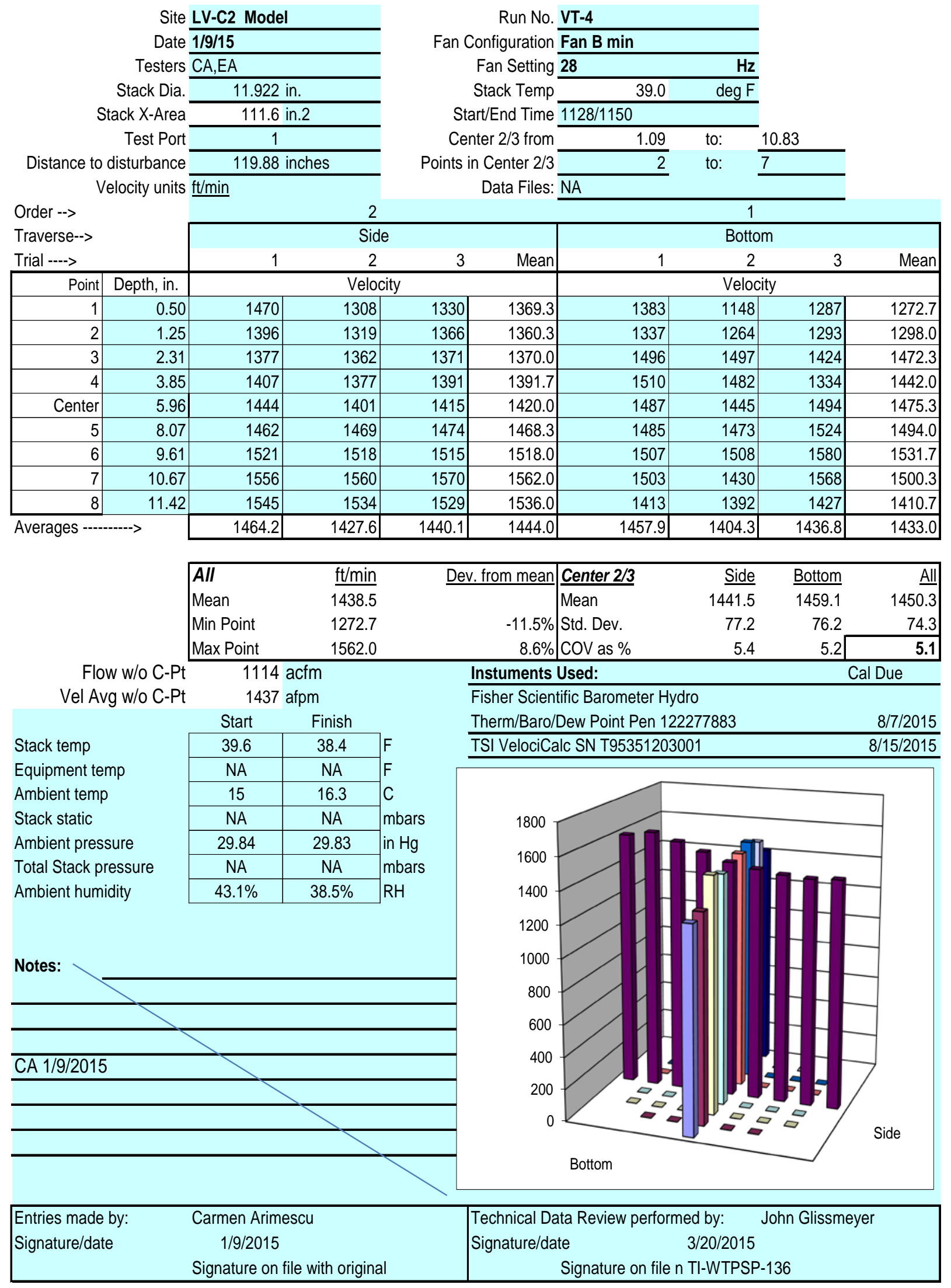




\section{VELOCITY TRAVERSE DATA FORM}

Site LV-C2 Remedial Scale Model Date 1/12/15

Testers CA, EA

Stack Dia.

Stack X-Area

Test Port

Distance to disturbance

Velocity units aft/min

119.88 inches

Run No. VT-5

Fan Configuration Fan B Normal

Fan Setting 45

Stack Temp

Start/End Time 900/930

Center $2 / 3$ from

Points in Center 2/3

Data Files: NA

Order -->

Traverse-->

Trial ---->

\begin{tabular}{|c|c|c|c|}
\hline \multicolumn{2}{|l|}{ Trial ----> } & 1 & \multirow{2}{*}{$\frac{2}{\text { Veloci }}$} \\
\hline Point & Depth, in. & & \\
\hline 1 & 0.50 & 2277 & 2349 \\
\hline 2 & 1.25 & 2528 & 2464 \\
\hline 3 & 2.31 & 2488 & 2509 \\
\hline 4 & 3.85 & 2560 & 2588 \\
\hline Center & 5.96 & 2536 & 2516 \\
\hline 5 & 8.07 & 2496 & 2956 \\
\hline 6 & 9.61 & 2650 & 2518 \\
\hline 7 & 10.67 & 2705 & 2730 \\
\hline 8 & 11.42 & 2686 & 2732 \\
\hline \multirow{5}{*}{\multicolumn{2}{|c|}{ Averages ---------> }} & 2547.3 & 2595.8 \\
\hline & & $A I I$ & $\mathrm{ft} / \mathrm{min}$ \\
\hline & & Mean & 2549.5 \\
\hline & & Min Point & 2335.7 \\
\hline & & Max Point & 2725.0 \\
\hline
\end{tabular}

Flow w/o C-Pt

$1982 \mathrm{acfm}$

Vel Avg w/o C-Pt

2556 afpm

\begin{tabular}{|c|c|}
\hline Start & Finish \\
\hline 40.5 & 40.7 \\
\hline NA & NA \\
\hline 18.1 & 16.2 \\
\hline NA & NA \\
\hline 29.95 & 29.97 \\
\hline NA & $\mathrm{NA}$ \\
\hline $35.7 \%$ & $43.8 \%$ \\
\hline
\end{tabular}

Stack temp

Equipment temp

Ambient temp

Stack static

Ambient pressure

Total Stack pressure

Ambient humidity

$35.7 \%$

2

\begin{tabular}{|r|r|r|r|r|}
\hline & \multicolumn{5}{|c|}{2} \\
Mean & 1 & \multicolumn{5}{|c|}{ Bottom } \\
\hline 2335.7 & 2540 & 2538 & 2434 & 2504.0 \\
\hline 2497.3 & 2575 & 2560 & 2617 & 2584.0 \\
\hline 2521.0 & 2543 & 2567 & 2520 & 2543.3 \\
\hline 2568.0 & 2467 & 2524 & 2437 & 2476.0 \\
\hline 2519.0 & 2471 & 2485 & 2464 & 2473.3 \\
\hline 2658.3 & 2557 & 2520 & 2619 & 2565.3 \\
\hline 2602.3 & 2594 & 2591 & 2665 & 2616.7 \\
\hline 2725.0 & 2551 & 2480 & 2572 & 2534.3 \\
\hline 2706.7 & 2444 & 2414 & 2526 & 2461.3 \\
\hline 2570.4 & 2526.9 & 2519.9 & 2539.3 & 2528.7 \\
\hline
\end{tabular}

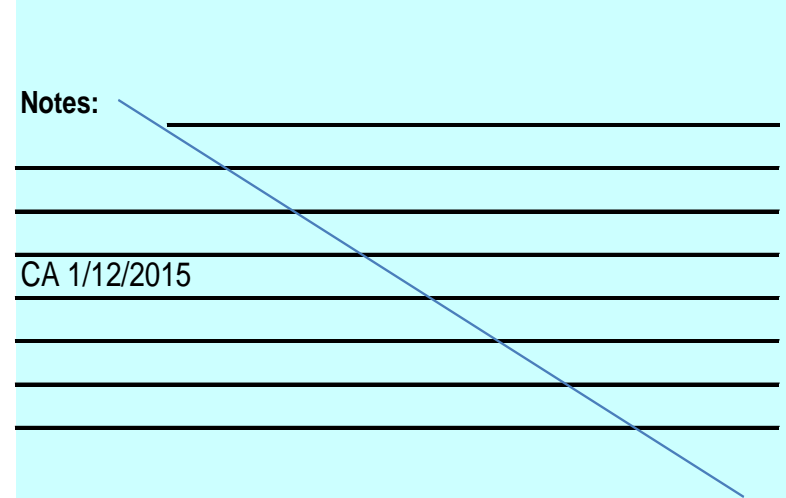

\section{Dev. from mean $\underline{\text { Center 2/3 }}$ \\ Mean \\ $-8.4 \%$ Std. Dev. \\ $6.9 \%$ COV as $\%$}

$40.6 \quad \operatorname{deg} \mathrm{F}$

1.09 to:

2 to: $\quad \underline{7}$

ean

Instuments Used:

\begin{tabular}{|c|c|c|}
\hline$\underline{\text { Side }}$ & Bottom & All \\
\hline 2584.4 & 2541.9 & 2563.1 \\
\hline 83.4 & 53.3 & 70.7 \\
\hline 3.2 & 2.1 & 2 \\
\hline
\end{tabular}

Fisher Scientific Barometer Hydro

Therm/Baro/Dew Point Pen 122277883

$8 / 7 / 2015$

TSI VelociCalc SN T95351203001 8/15/2015

Entries made by:

Signature/date
Carmen Arimescu
$1 / 12 / 2015$

Signature on file with original

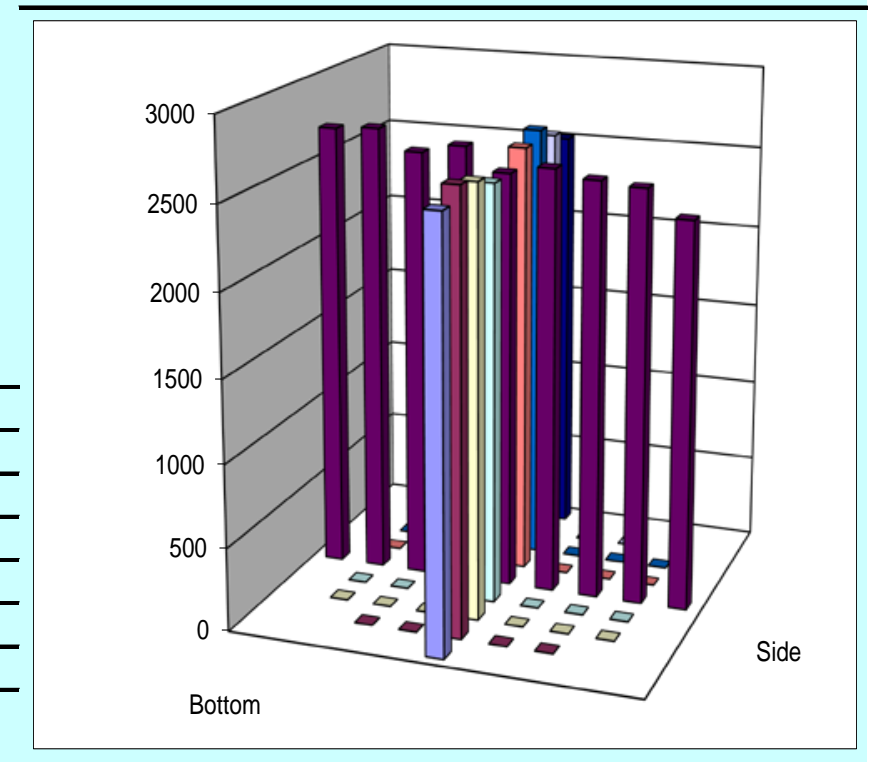
Technical Data Review performed by:
Signature/date
$3 / 20 / 2015$
Signature on file n TI-WTPSP-136 


\section{VELOCITY TRAVERSE DATA FORM}

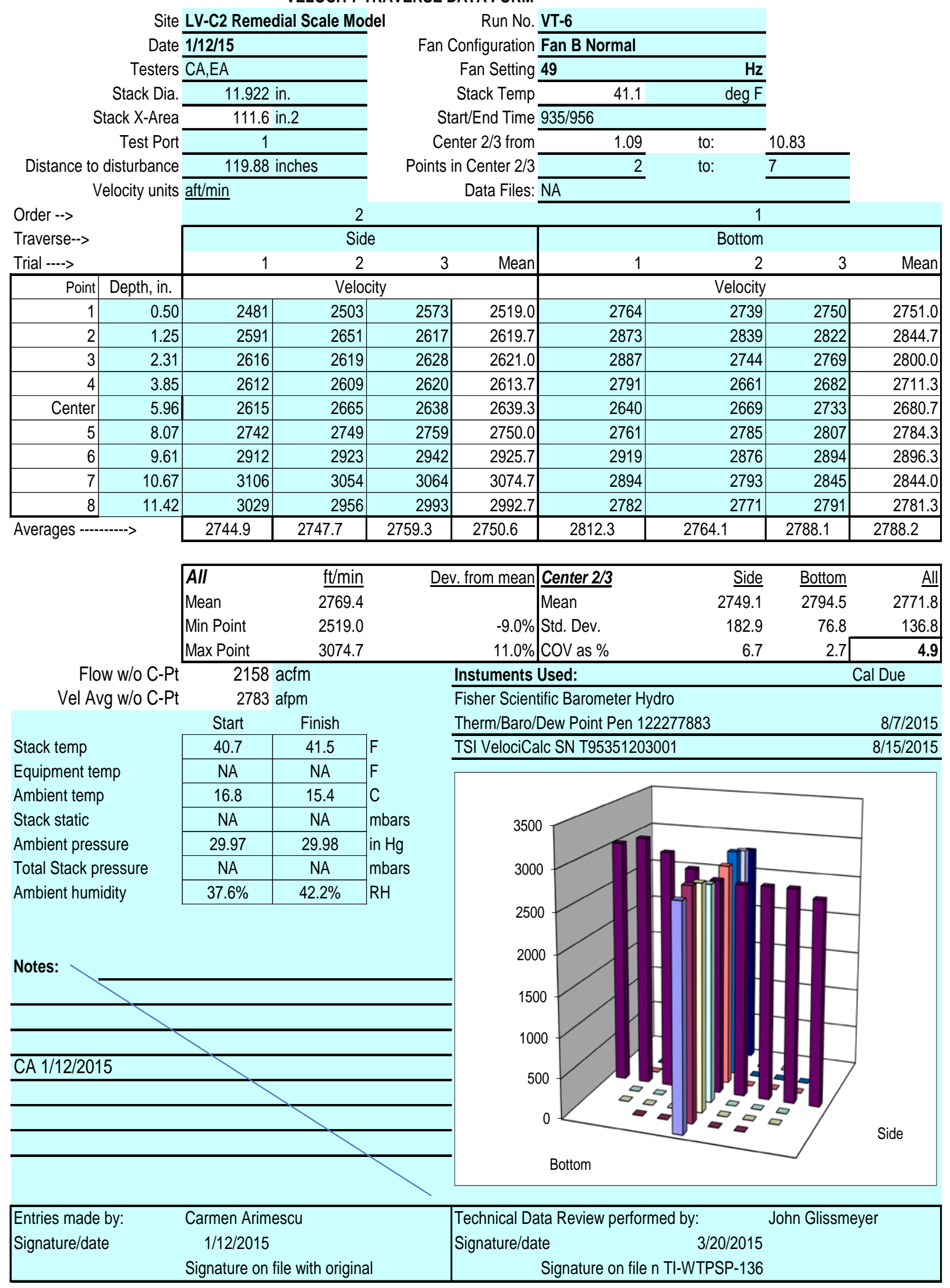




\section{VELOCITY TRAVERSE DATA FORM}

Site LV-C2 Remedial Scale Model Date 1/12/15

Testers CA, EA

Stack Dia Stack X-Area

Test Port

$\frac{11.922 \text { in. }}{\frac{111.6 \text { in. } 2}{1}}$

Distance to disturbance Velocity units aft/min
Run No. VT-7

Fan Configuration Fan B Normal

Fan Setting 42

Stack Temp

Start/End Time 1000/1021

Center 2/3 from

Points in Center 2/3

Data Files: NA

Order -->

Traverse-->

Trial ---->

\begin{tabular}{|c|c|c|c|}
\hline Trial ----> & & 1 & 2 \\
\hline Point & Depth, in. & & Velocity \\
\hline 1 & 0.50 & 2156 & 2144 \\
\hline 2 & 1.25 & 2215 & 2151 \\
\hline 3 & 2.31 & 2124 & 2161 \\
\hline 4 & 3.85 & 2218 & 2211 \\
\hline Center & 5.96 & 2246 & 2254 \\
\hline 5 & 8.07 & 2342 & 2382 \\
\hline 6 & 9.61 & 2491 & 2516 \\
\hline 7 & 10.67 & 2609 & 2578 \\
\hline 8 & 11.42 & 2512 & 2592 \\
\hline \multirow{5}{*}{\multicolumn{2}{|c|}{ Averages ----------> }} & 2323.7 & 2332.1 \\
\hline & & All & $\mathrm{ft} / \mathrm{min}$ \\
\hline & & Mean & 2331.8 \\
\hline & & Min Point & 2158.3 \\
\hline & & Max Point & 2587.0 \\
\hline
\end{tabular}

Flow w/o C-Pt

Max Point

2587.0

\section{Vel Avg w/o C-Pt}

\section{0 afpm}

\begin{tabular}{|c|c|l}
\multicolumn{1}{r|}{ Start } & \multicolumn{1}{c}{ Finish } & \\
\cline { 1 - 2 } 41.3 & 41.9 & $\mathrm{~F}$ \\
\cline { 1 - 2 } NA & NA & F \\
\hline 16.8 & 15.5 & C \\
\hline NA & NA & mbars \\
\cline { 1 - 2 } 29.98 & 29.98 & in Hg \\
\cline { 1 - 2 } NA & NA & mbars \\
\cline { 1 - 2 } $38.5 \%$ & $41.8 \%$ & RH \\
\hline
\end{tabular}

Stack temp

Equipment temp

Ambient temp

Stack static

Ambient pressure

Total Stack pressure

Ambient humidity

Notes:

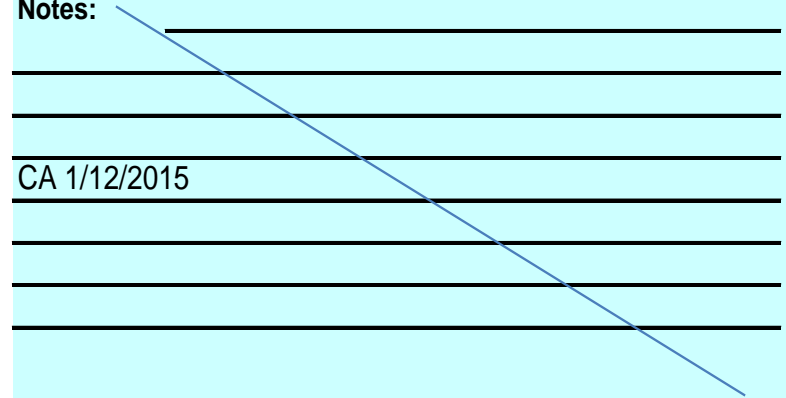

Entries made by:

Signature/date
Carmen Arimescu

$1 / 12 / 2015$

Signature on file with original

1

\begin{tabular}{rrrr}
\hline & 1.09 & to: & 10.83 \\
\hline NA & & to: & \\
\hline
\end{tabular}

\begin{tabular}{|r|r|r|r|r|r|}
\cline { 3 - 6 } \multicolumn{2}{r|}{} & \multicolumn{5}{|c|}{$\begin{array}{r}\text { Bottom } \\
3\end{array}$} & Mean & \multicolumn{4}{|c|}{ Velocity } \\
\hline 2175 & 2158.3 & 2334 & 2325 & 2293 & 2317.3 \\
\hline 2125 & 2163.7 & 2415 & 2374 & 2346 & 2378.3 \\
\hline 2214 & 2166.3 & 2324 & 2361 & 2323 & 2336.0 \\
\hline 2188 & 2205.7 & 2243 & 2286 & 2251 & 2260.0 \\
\hline 2218 & 2239.3 & 2242 & 2330 & 2291 & 2287.7 \\
\hline 2347 & 2357.0 & 2321 & 2387 & 2381 & 2363.0 \\
\hline 2457 & 2488.0 & 2402 & 2490 & 2405 & 2432.3 \\
\hline 2574 & 2587.0 & 2402 & 2394 & 2378 & 2391.3 \\
\hline 2497 & 2533.7 & 2320 & 2263 & 2337 & 2306.7 \\
\hline 2310.6 & 2322.1 & 2333.7 & 2356.7 & 2333.9 & 2341.4 \\
\hline
\end{tabular}

\section{Dev. from mean \\ Mean \\ $-7.4 \%$ Std. Dev. \\ $10.9 \%$ COV as $\%$}

Instuments Used:

\begin{tabular}{lr}
\hline Fisher Scientific Barometer Hydro & \multicolumn{1}{c}{ Cal Due } \\
Therm/Baro/Dew Point Pen 122277883 & \\
\hline TSI VelociCalc SN T95351203001 & 8/7/2015 \\
\hline
\end{tabular}

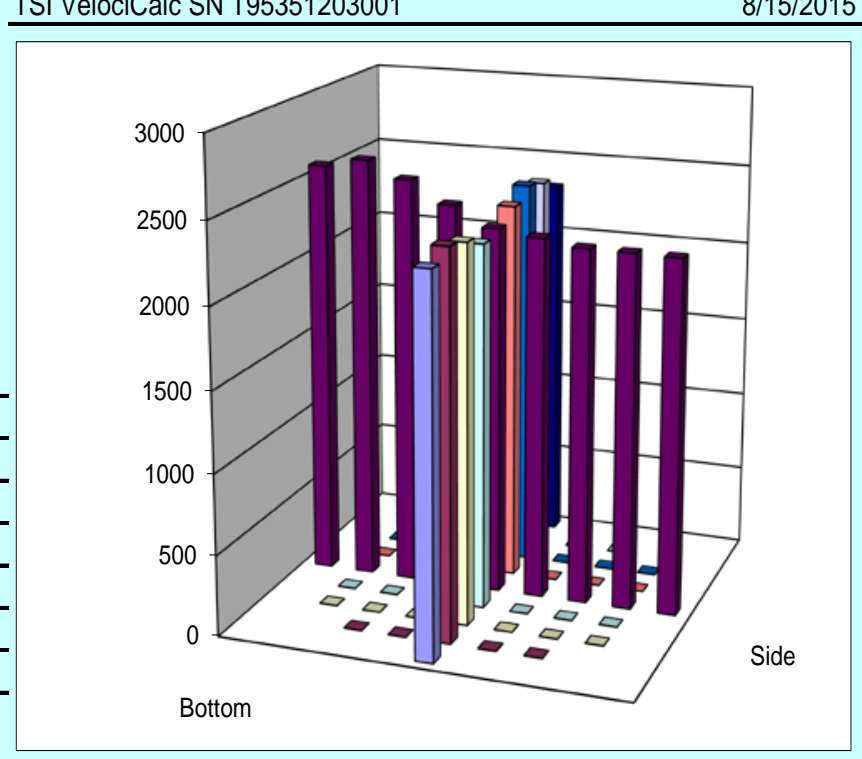

Technical Data Review performed by:

Signature/date

Signature on file $n$ TI-WTPSP-136
John Glissmeyer

3/20/2015

WTPSP-136 


\section{VELOCITY TRAVERSE DATA FORM}

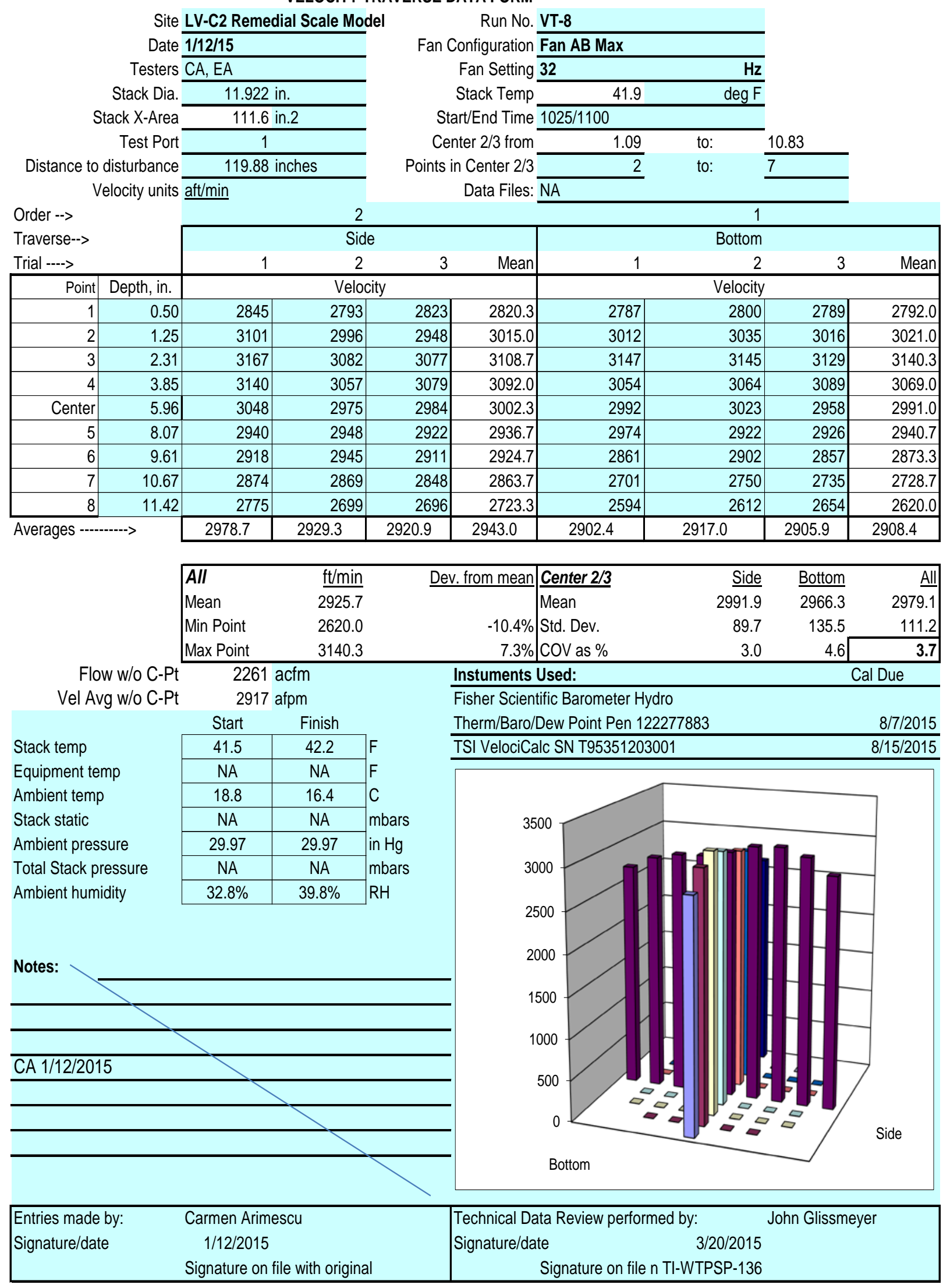




\section{VELOCITY TRAVERSE DATA FORM}

Site LV-C2 Remedial Scale Model Date 1/12/15

Testers CA, EA

Stack Dia.

Stack X-Area

Test Port

Distance to disturbance

Velocity units $\underline{\text { aft/min }}$

Run No. VT-9

Fan Configuration Fan AB Max

Fan Setting $\mathbf{3 2}$

Stack Temp

Start/End Time $1100 / 1120$

Center 2/3 from

Points in Center $2 / 3$

Data Files: $\mathrm{NA}$

Order -->

Traverse-->

Trial ---->

\begin{tabular}{|r|r|}
\hline Point & Depth, in. \\
\hline 1 & 0.50 \\
\hline 2 & 1.25 \\
\hline 3 & 2.31 \\
\hline 4 & 3.85 \\
\hline Center & 5.96 \\
\hline 5 & 8.07 \\
\hline 6 & 9.61 \\
\hline 7 & 10.67 \\
\hline 8 & 11.42 \\
\hline Averages -------->
\end{tabular}

1 1

\begin{tabular}{llll} 
& 1.09 & to: & 10.83 \\
\hline & 2 & to: & \\
\hline NA & & & \\
\hline
\end{tabular}

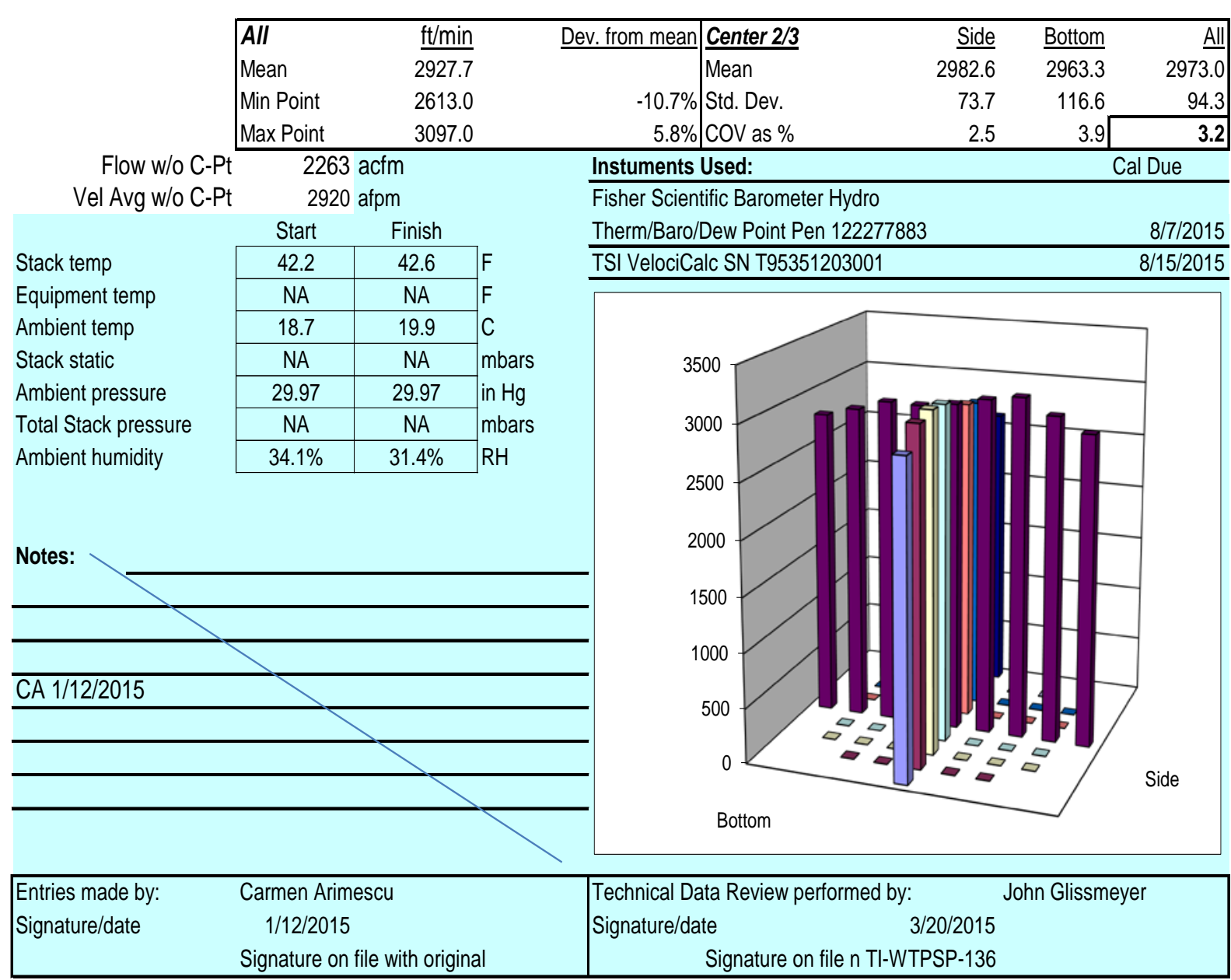




\section{VELOCITY TRAVERSE DATA FORM}

Site LV-C2 Remedial Scale Model Date 1/12/15

Testers CA, EA

Stack Dia.

Stack X-Area

Test Port

Distance to disturbance Velocity units aft/min

119.88 inches
Run No. VT-10

Fan Configuration Fan AB Max

Fan Setting 32

Stack Temp

Start/End Time 1125/1145

Center $2 / 3$ from Points in Center 2/3

Data Files: NA

Order -->

Traverse-->

Trial ---->

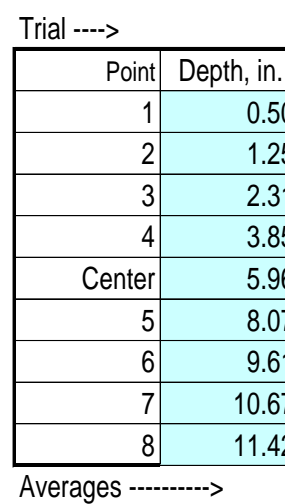

Da

\section{2}

Side

1

3

Bottom

Velocity

\begin{tabular}{l|l}
2775 & 2811 \\
2998 & 2952
\end{tabular}

\begin{tabular}{l|l|l|}
\hline & 2825 & 2803.7 \\
\hline
\end{tabular}

\begin{tabular}{l|r|r|}
\hline 952 & 2995 & 2981.7 \\
\hline
\end{tabular}

\begin{tabular}{l|l|l|}
\hline 095 & 3068 & 3078.7 \\
\hline
\end{tabular}

$3073 \quad 3095$

\begin{tabular}{l|l|}
3068 & 3078.7 \\
\hline 3046 & 3036.0 \\
\hline
\end{tabular}

\begin{tabular}{l|l|l|}
\hline 3047 & 3046 & 3036.0 \\
\hline 2972 & 3002 & 2986.0 \\
\hline
\end{tabular}

\begin{tabular}{r|r}
3015 & 3047 \\
\hline 2951 & 297 \\
\hline
\end{tabular}

\begin{tabular}{|l|l|}
\hline .01 & 2951 \\
\hline .67 & 29 \\
\hline .42 & 2710 \\
\hline
\end{tabular}

\begin{tabular}{l|l|l|l|}
2951 & 2969 & 2986 & 2968.7 \\
\hline 2963 & 2980 & 2957 & 2966.7 \\
\hline 2863 & 2909 & 2981 & 2917. \\
\hline
\end{tabular}

\begin{tabular}{l|l}
2710 & 2742 \\
\hline
\end{tabular}

\begin{tabular}{r|r}
2742 & 2705 \\
\hline
\end{tabular}

\begin{tabular}{l|l}
2705 & 2719 \\
\hline
\end{tabular}

\begin{tabular}{|lr}
\hline All & $\underline{\mathrm{ft} / \mathrm{min}}$ \\
Mean & 2916.0 \\
Min Point & 2617.3 \\
Max Point & 3116.0 \\
\hline
\end{tabular}

Flow w/o C-Pt Vel Avg w/o C-Pt $2908 \mathrm{afpm}$

\begin{tabular}{|c|c|}
\hline Start & Finish \\
\hline 42.6 & 43.2 \\
\hline NA & NA \\
\hline 18.7 & 17.1 \\
\hline$N A$ & NA \\
\hline 29.97 & 29.97 \\
\hline NA & NA \\
\hline $31.4 \%$ & $38.2 \%$ \\
\hline
\end{tabular}

\section{Notes:}

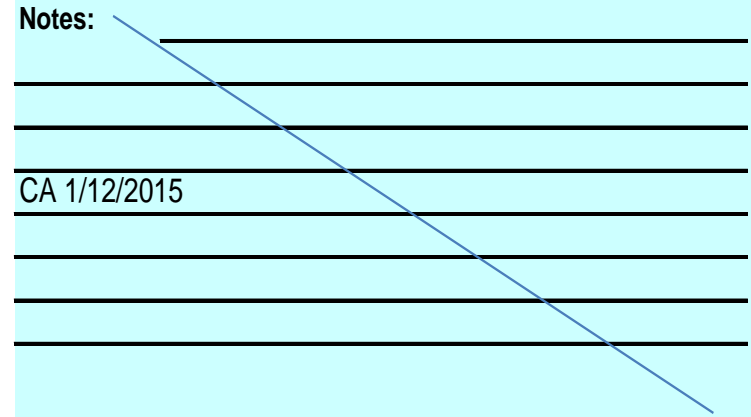

Entries made by: Signature/date

Carmen Arimescu
1/12/2015
Signature on file with original

\begin{tabular}{r|l} 
Dev. from mean & $\frac{\text { Center } 2 / 3}{\text { Mean }}$ \\
$-10.2 \%$ & Std. Dev. \\
$6.9 \%$ & COV as \% \\
\hline
\end{tabular}

Instuments Used:

Fisher Scientific Barometer Hydro

Therm/Baro/Dew Point Pen 122277883

TSI VelociCalc SN T95351203001

\begin{tabular}{rrr|} 
Side & Bottom & All \\
2990.8 & 2949.7 & 2970.2 \\
52.1 & 129.6 & 97.2 \\
1.7 & 4.4 & 3.3 \\
\hline
\end{tabular}

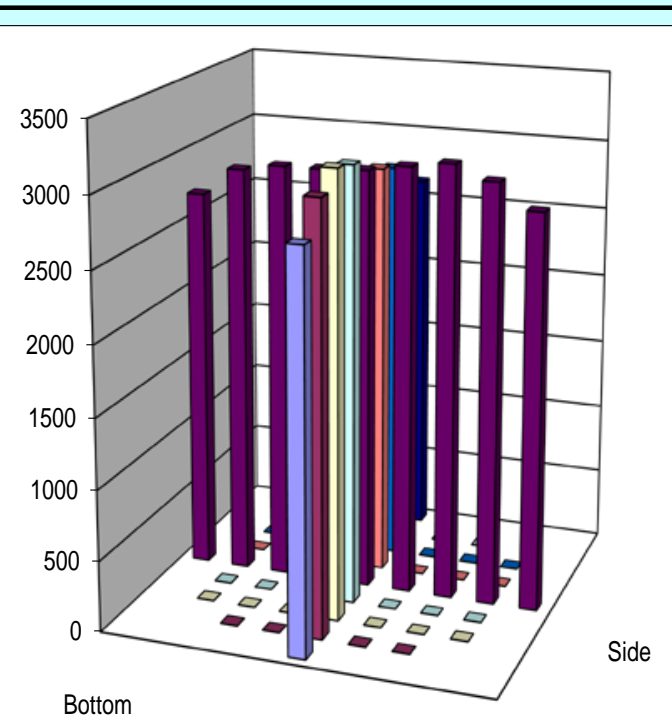

Technical Data Review performed by: John Glissmeyer Signature/date 3/20/2015

Signature on file n TI-WTPSP-136 


\section{VELOCITY TRAVERSE DATA FORM}

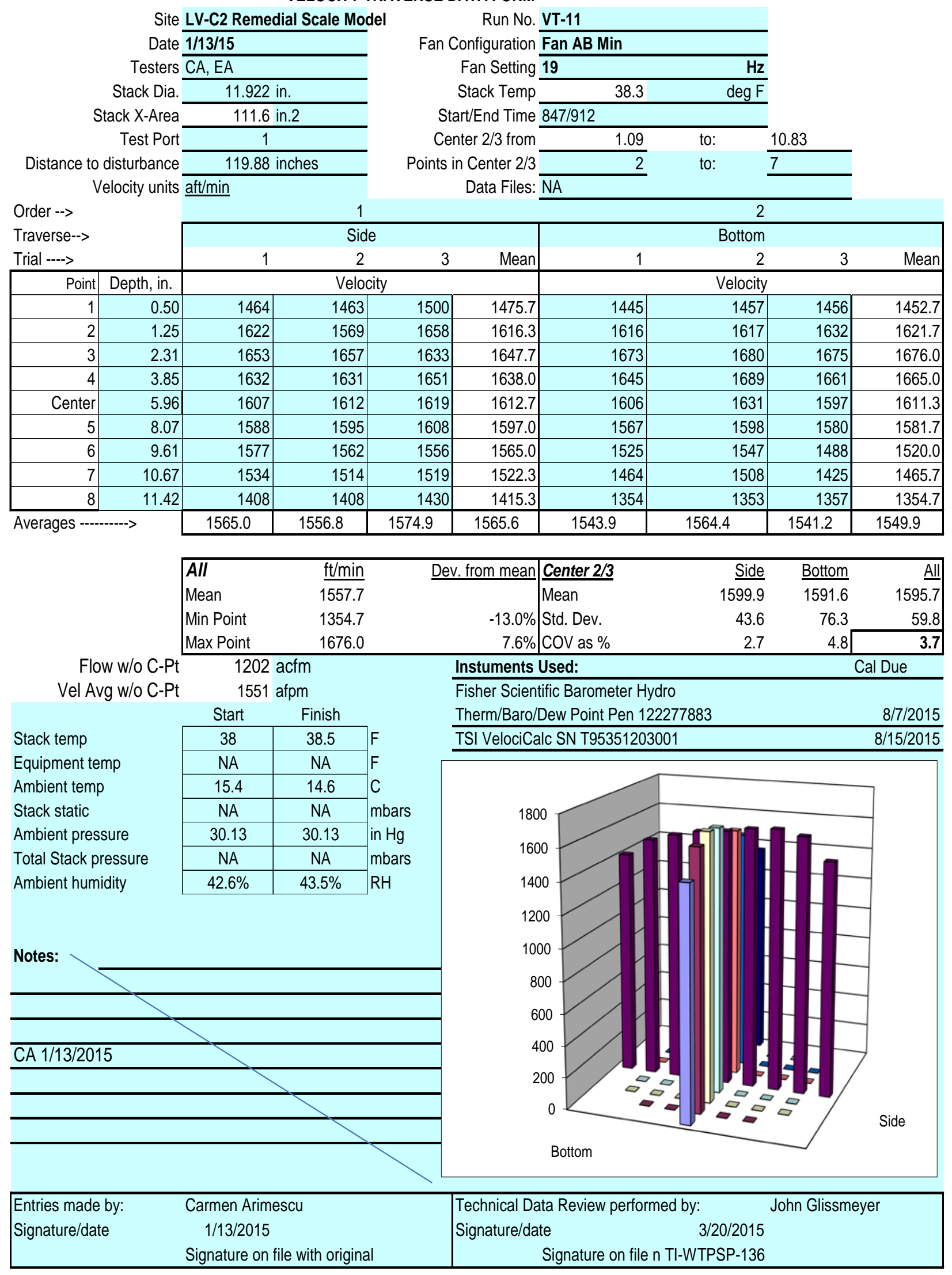




\section{VELOCITY TRAVERSE DATA FORM}

Site LV-C2 Remedial Scale Model Date $1 / 13 / 15$

Testers CA, EA

Stack Dia

Stack X-Area

Test Port

Distance to disturbance Velocity units aft/min

Run No. VT-12

Fan Configuration Fan A Max

Fan Setting $\mathbf{5 1 . 2}$

Stack Temp

Start/End Time 914/946

Center $2 / 3$ from

Points in Center 2/3

Data Files: NA

Order -->

Traverse-->

Trial ---->

1

2

\begin{tabular}{|c|c|c|c|c|c|c|c|c|c|}
\hline Trial ----> & & 1 & 2 & 3 & Mean & 1 & 2 & 3 & Mean \\
\hline Point & Depth, in. & \multicolumn{4}{|c|}{ Velocity } & \multicolumn{4}{|c|}{ Velocity } \\
\hline 1 & 0.50 & 2970 & 2913 & 2961 & 2948.0 & 2819 & 2841 & 2802 & 2820.7 \\
\hline 2 & 1.25 & 3117 & 3134 & 3059 & 3103.3 & 3080 & 3000 & 3020 & 3033.3 \\
\hline 3 & 2.31 & 3225 & 3238 & 3233 & 3232.0 & 3130 & 3113 & 3133 & 3125.3 \\
\hline 4 & 3.85 & 3243 & 3235 & 3224 & 3234.0 & 3143 & 3126 & 3136 & 3135.0 \\
\hline Center & 5.96 & 3158 & 3169 & 3156 & 3161.0 & 3212 & 3147 & 3114 & 3157.7 \\
\hline 5 & 8.07 & 3146 & 3128 & 3113 & 3129.0 & 3250 & 3186 & 3180 & 3205.3 \\
\hline 6 & 9.61 & 3101 & 3129 & 3140 & 3123.3 & 3232 & 3252 & 3203 & 3229.0 \\
\hline 7 & 10.67 & 3063 & 3069 & 3139 & 3090.3 & 3166 & 3318 & 3339 & 3274.3 \\
\hline 8 & 11.42 & 2934 & 3053 & 3023 & 3003.3 & 3155 & 3218 & 3064 & 3145.7 \\
\hline Averages --- & $-\cdots>$ & 3106.3 & 3118.7 & 3116.4 & 3113.8 & 3131.9 & 3133.4 & 3110.1 & 3125.1 \\
\hline
\end{tabular}

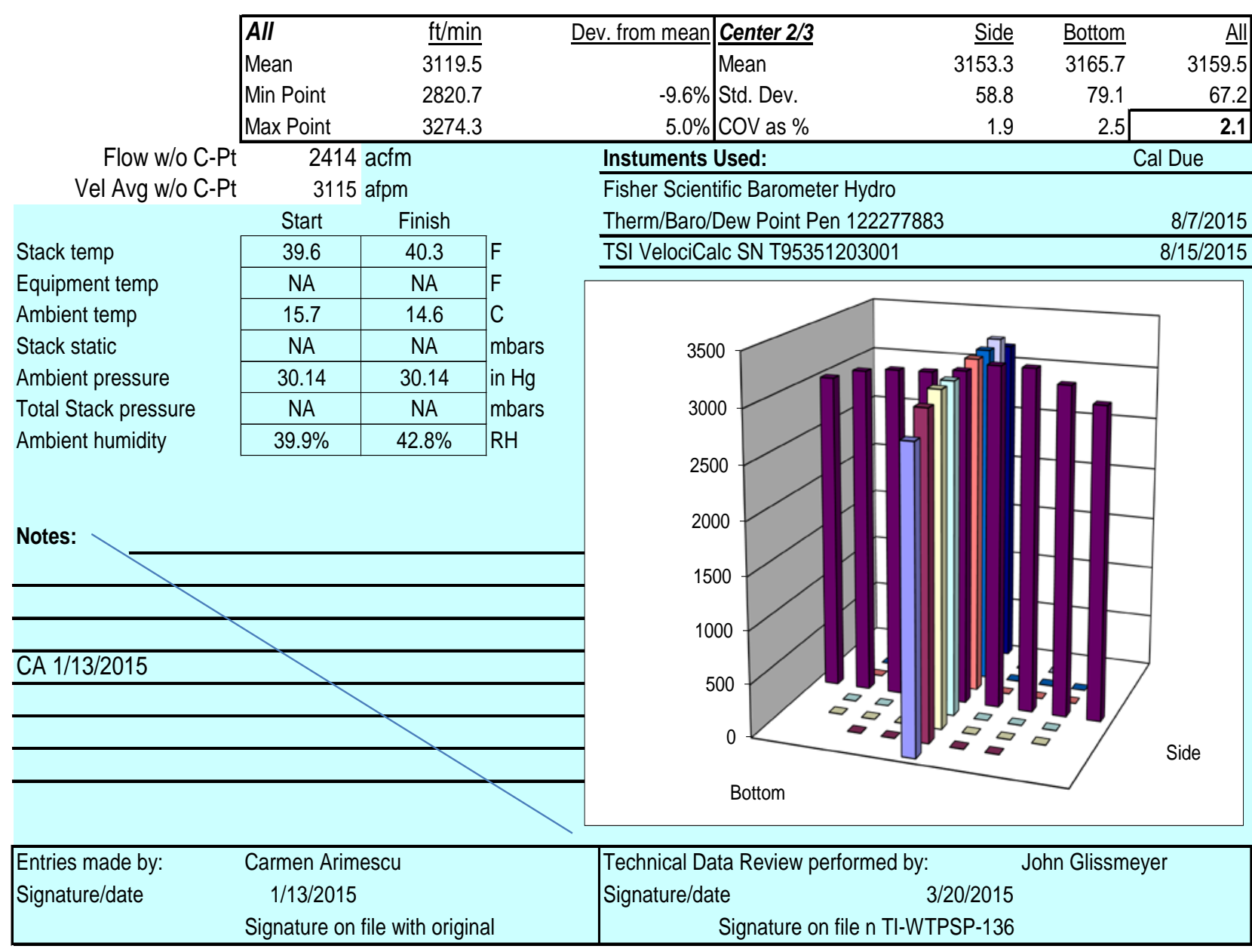




\section{VELOCITY TRAVERSE DATA FORM}

Site LV-C2 Remedial Scale Model Date 1/13/15

Testers CA, EA

Stack Dia.

Stack X-Area

Test Port

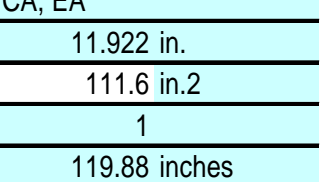

Distance to disturbance

Velocity units aft/min
Run No. VT-13

Fan Configuration Fan A Min

Fan Setting 27

Stack Temp

Start/End Time 1340 / 1402

Center $2 / 3$ from

Points in Center 2/3

Data Files: NA

Order -->

Traverse-->

Trial ---->

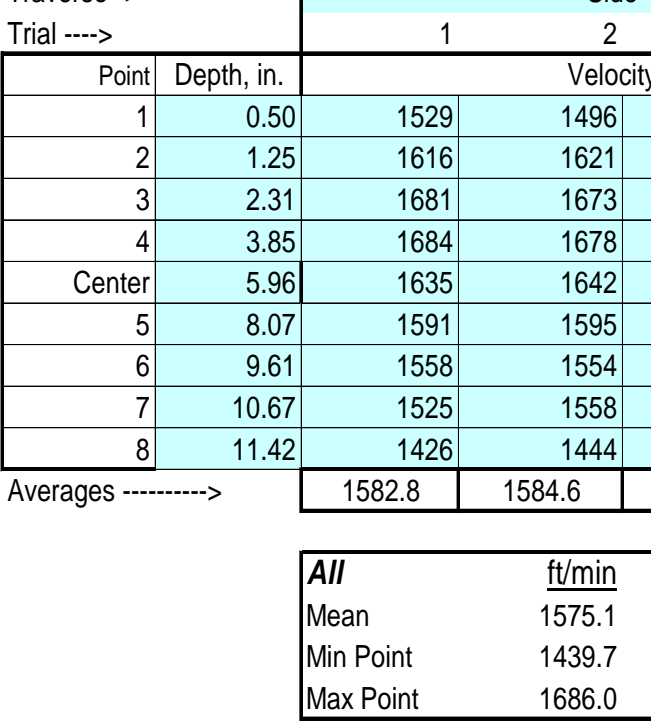

Flow w/o C-Pt 1217 acfm

Vel Avg w/o C-Pt

1570 afpm

\begin{tabular}{|c|c|}
\hline Start & Finish \\
\hline 40.3 & 40.9 \\
\hline NA & NA \\
\hline 14.4 & 15.7 \\
\hline$N A$ & NA \\
\hline 30.11 & 30.11 \\
\hline NA & NA \\
\hline $40.5 \%$ & $41.1 \%$ \\
\hline
\end{tabular}

Stack temp

Equipment temp

Ambient temp

Stack static

Ambient pressure

Total Stack pressure

Ambient humidity

Notes:

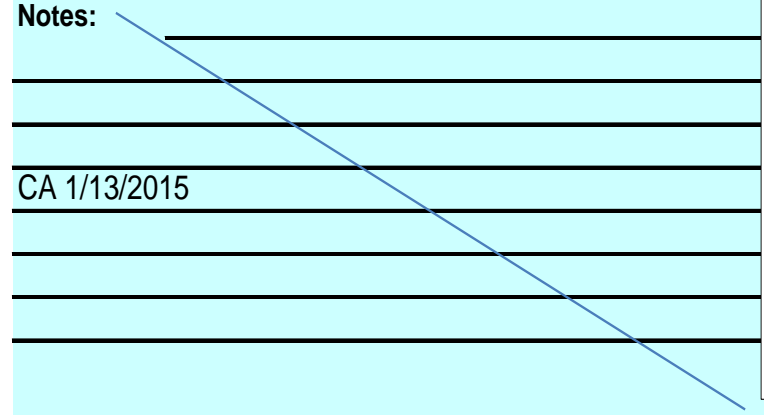

2

1

\begin{tabular}{|r|r|r|r|r|}
\hline & \multicolumn{5}{|c|}{$\begin{array}{r}\text { Bottom } \\
\text { Mean }\end{array}$} & \multicolumn{5}{|c|}{ Velocity } \\
\hline 1512.3 & 1459 & 1449 & 1423 & 1443.7 \\
\hline 1610.7 & 1553 & 1548 & 1535 & 1545.3 \\
\hline 1673.0 & 1586 & 1588 & 1597 & 1590.3 \\
\hline 1686.0 & 1618 & 1612 & 1613 & 1614.3 \\
\hline 1635.7 & 1602 & 1587 & 1623 & 1604.0 \\
\hline 1587.3 & 1615 & 1615 & 1620 & 1616.7 \\
\hline 1552.7 & 1626 & 1601 & 1613 & 1613.3 \\
\hline 1543.3 & 1573 & 1591 & 1573 & 1579.0 \\
\hline 1439.7 & 1510 & 1500 & 1506 & 1505.3 \\
\hline 1582.3 & 1571.3 & 1565.7 & 1567.0 & 1568.0 \\
\hline & & & & \\
\hline
\end{tabular}

\begin{tabular}{l|l}
149.6 & 1582.3 \\
\hline
\end{tabular}

\begin{tabular}{llll} 
& 1.09 & to: & 10.83 \\
\hline NA & 2 & to: & $\underline{7}$
\end{tabular}

\begin{tabular}{r|l} 
Dev. from mean & Center 2/3 \\
& Mean \\
$-8.6 \%$ & Std. Dev. \\
$7.0 \%$ & COV as \%
\end{tabular}

Instuments Used:

\begin{tabular}{rrrr|} 
Side & & Bottom & All \\
1612.7 & & 1594.7 & 1603.7 \\
55.7 & 25.8 & 42.7 \\
3.5 & 1.6 & 2.7 \\
\hline
\end{tabular}

Cal Due

\begin{tabular}{lr}
\hline Fisher Scientific Barometer Hydro & \\
Therm/Baro/Dew Point Pen 122277883 & 8/7/2015 \\
\hline TSI VelociCalc SN T95351203001 & 8/15/2015 \\
\hline
\end{tabular}

Entries made by:

Signature/date

\begin{abstract}
Carmen Arimescu
$1 / 13 / 2015$
\end{abstract}

Signature on file with original

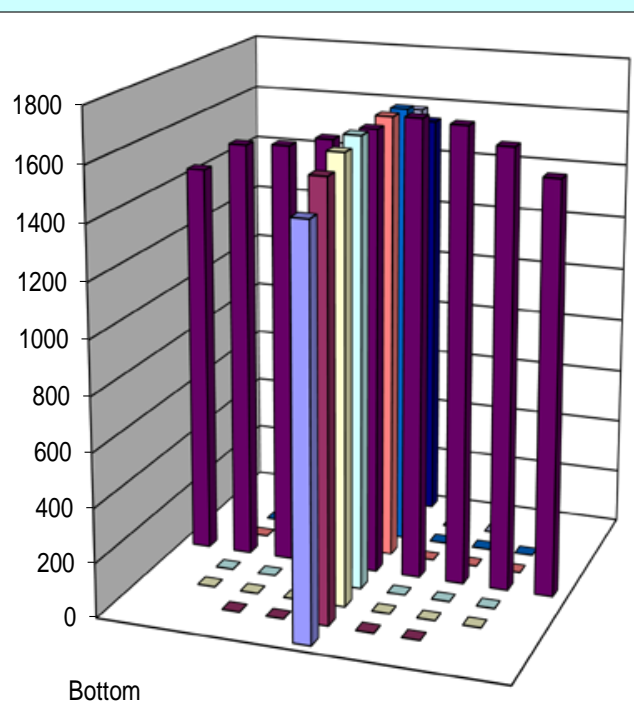

Side

Bottom
Technical Data Review performed by: Signature/date

Signature on file $n$ TI-WTPSP-136 


\section{VELOCITY TRAVERSE DATA FORM}

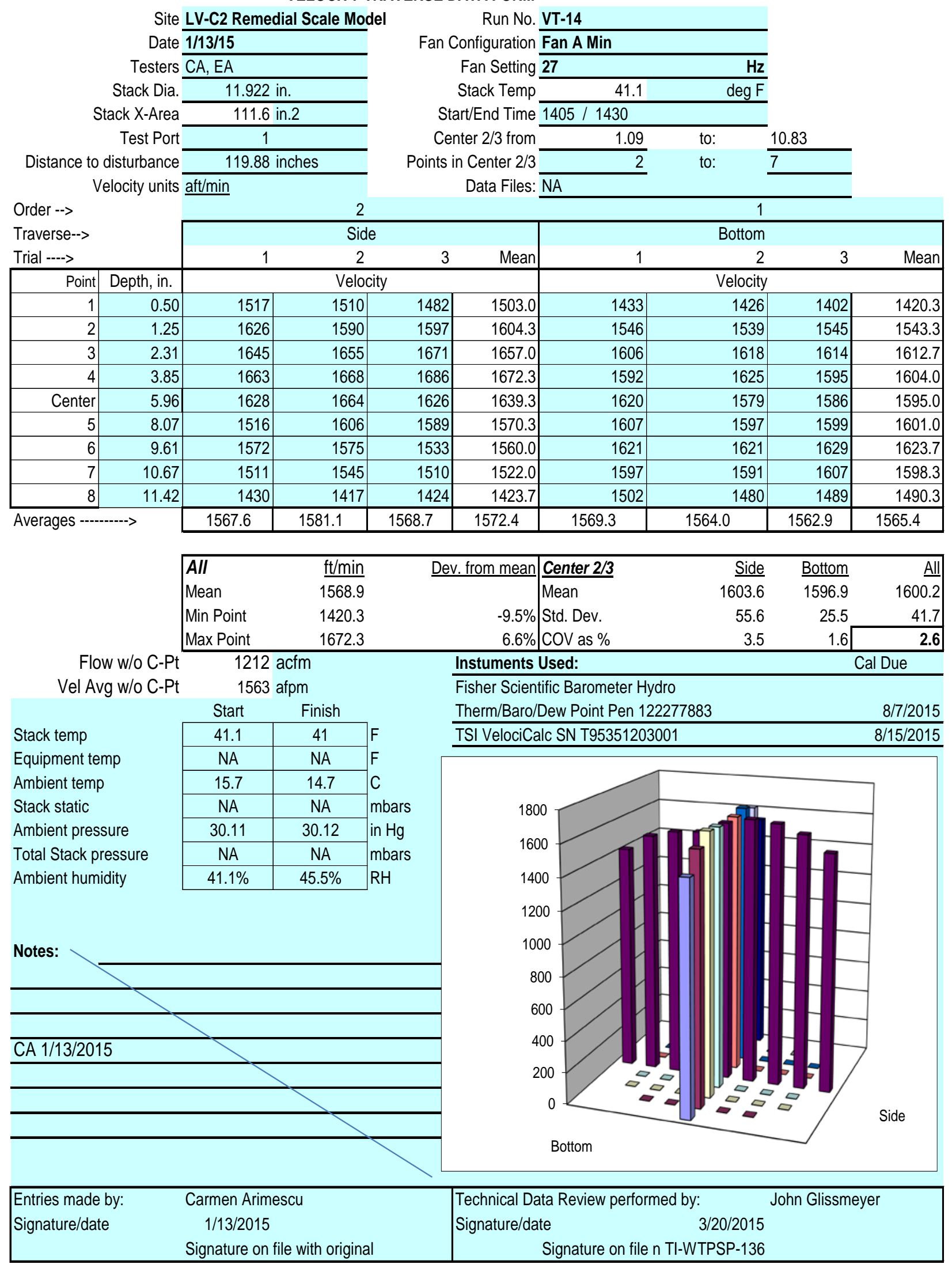




\section{VELOCITY TRAVERSE DATA FORM}

Site LV-C2 Remedial Scale Model Date 1/13/15

Testers CA, EA

Stack Dia.

Stack X-Area

Test Port

$\frac{11.922 \text { in. }}{111.6 \text { in. } 2}$

Distance to disturbance

Velocity units aft/min
Run No. VT-15

Fan Configuration Fan A Min

Fan Setting 27

Stack Temp

Start/End Time 1432 / 1454

Center 2/3 from

Points in Center 2/3

Data Files: NA

Order -->

Traverse-->

Trial ---->

\begin{tabular}{|c|c|c|c|}
\hline \multicolumn{2}{|l|}{ Trial ----> } & \multicolumn{2}{|c|}{1} \\
\hline Point & Depth, in. & & Velocit \\
\hline 1 & 0.50 & 1517 & 1524 \\
\hline 2 & 1.25 & 1590 & 1609 \\
\hline 3 & 2.31 & 1677 & 1645 \\
\hline 4 & 3.85 & 1683 & 1676 \\
\hline Center & 5.96 & 1650 & 1624 \\
\hline 5 & 8.07 & 1577 & 1573 \\
\hline 6 & 9.61 & 1575 & 1559 \\
\hline 7 & 10.67 & 1507 & 1522 \\
\hline 8 & 11.42 & 1397 & 1408 \\
\hline \multirow{5}{*}{\multicolumn{2}{|c|}{ Averages --------> }} & 1574.8 & 1571.1 \\
\hline & & All & $\underline{\mathrm{ft} / \mathrm{min}}$ \\
\hline & & Mean & 1570.4 \\
\hline & & Min Point & 1425.7 \\
\hline & & Max Point & 1674.3 \\
\hline
\end{tabular}

Flow w/o C-Pt $1214 \mathrm{acfm}$ Vel Avg w/o C-Pt $1565 \mathrm{afpm}$

\begin{tabular}{|c|c|l}
\multicolumn{1}{c}{ Start } & \multicolumn{1}{c}{ Finish } & \multicolumn{1}{c}{ F } \\
\hline 41 & 40.8 & F \\
\hline NA & NA & F \\
\hline 14.7 & 15.8 & C \\
\hline NA & NA & mbars \\
\hline 30.12 & 30.11 & in Hg \\
\hline NA & NA & mbars \\
\hline $45.8 \%$ & $41.8 \%$ & RH \\
\hline
\end{tabular}

Stack temp Equipment temp Ambient temp Stack static Ambient pressure Total Stack pressure Ambient humidity

Notes:

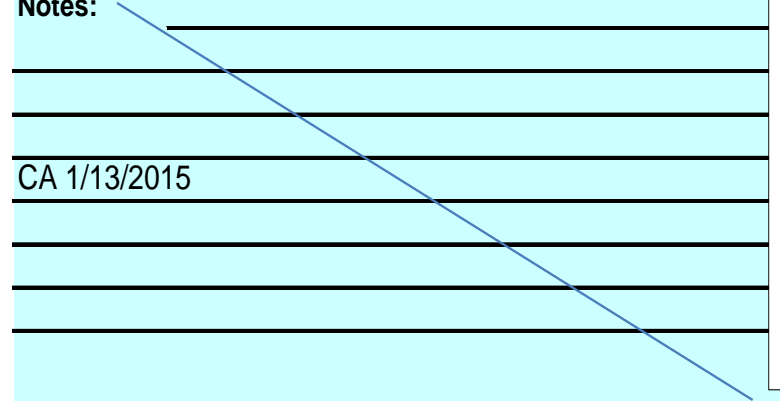

3

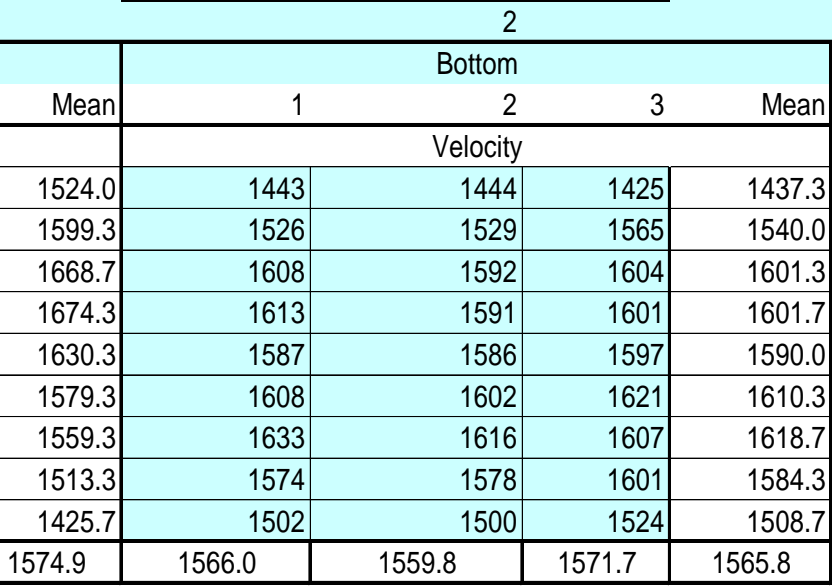

1578.9

\begin{tabular}{llll} 
& 1.09 & to: & 10.83 \\
\hline NA & 2 & to: & $\underline{7}$
\end{tabular}




\section{VELOCITY TRAVERSE DATA FORM}

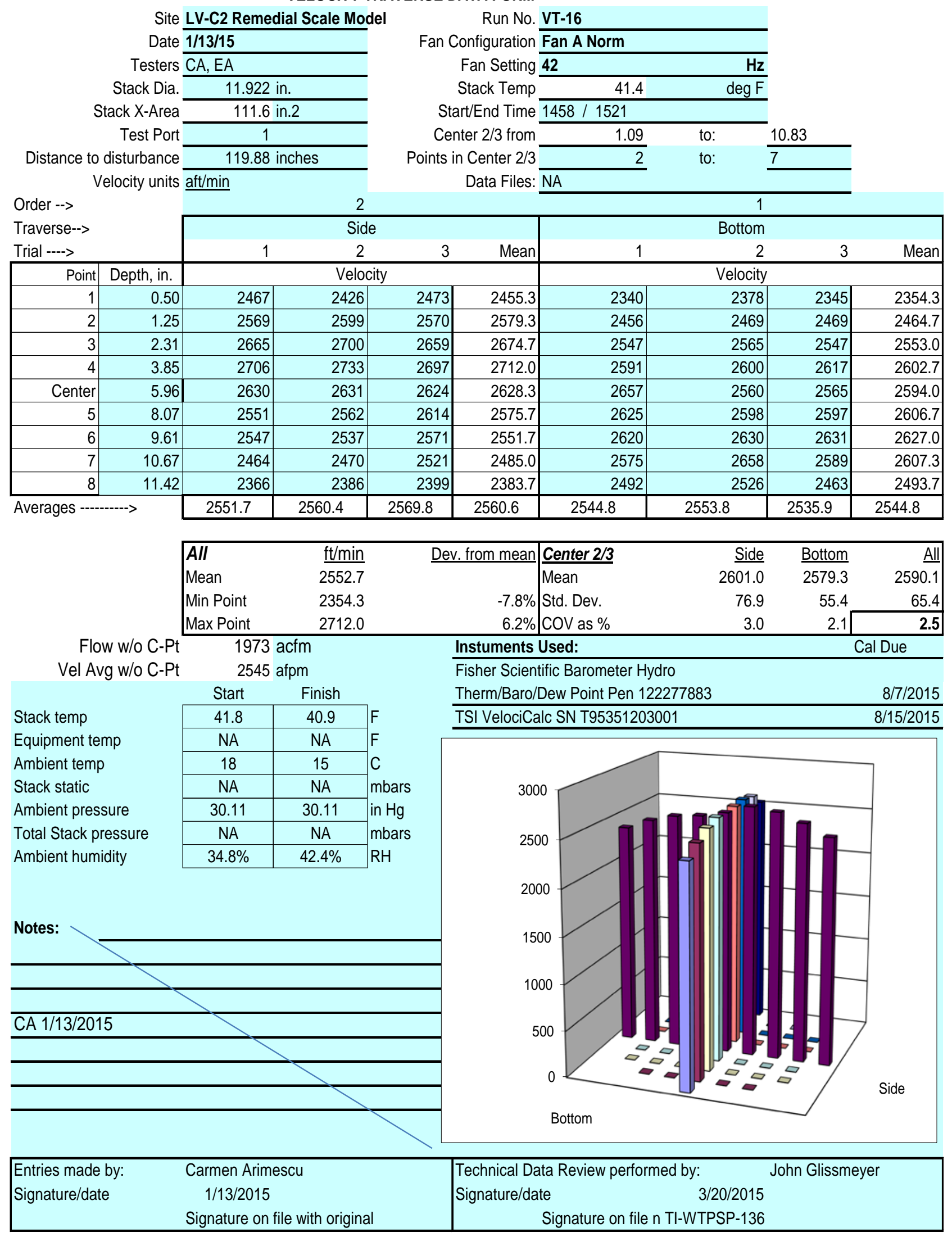




\section{C.2 LV-C2 Flow Angle Data Sheets}

\section{FLOW ANGLE DATA FORM}

Site LV-C2 -Remedial Scale Model

Date 1/14/2015

Tester CA, EA

Stack Dia. 11.92

Stack X-Area 111.6 in2

Elevation $\mathrm{N}$.A. $\mathrm{ft}$

ince to disturbance 119.88 in

Start/End Time 1100/1138

\author{
Run No. FA-1 \\ Fan Setting $\mathbf{5 1 . 2} \mathrm{Hz}$ \\ Fan configuration Fan A Max \\ Approx. air vel. 3266 afpm at point $>>$ \\ Units degrees (clockwise $>$ pos. nos.) \\ Port 1 \\ Stack Temp \\ $39.9 \mathrm{~F}$
}

Order -->

Traverse-->

Trial ---->

\begin{tabular}{|l|l|}
\hline 2 & \\
\hline \multicolumn{3}{|c|}{ Side } \\
1 & $2 \quad 3$ \\
\hline
\end{tabular}

\begin{tabular}{r|r}
$n y$ \\
\cline { 2 - 2 }
\end{tabular}

\begin{tabular}{|l|ll}
1 & \\
1 & 2 & \\
& $2^{\text {Bottom }}$
\end{tabular}

\begin{tabular}{|c|r|c|c|}
\hline Point & Depth, in. & deg. Cw & deg. \\
\hline 1 & 0.50 & 1 & \\
\hline 2 & 1.25 & 2 & \\
\hline 3 & 2.31 & 3 & \\
\hline 4 & 3.85 & -6 & \\
\hline Cente & 5.96 & -6 & \\
\hline 5 & 8.07 & -4 & \\
\hline 6 & 9.61 & -1 & \\
\hline 7 & 10.67 & 1 & \\
\hline 8 & 11.42 & 2 & \\
\hline
\end{tabular}

Mean of absolute values:

" w/o points by wall:

\begin{tabular}{|c|c|}
\hline deg. cudeg. \\
\hline 0 & 0 \\
\hline 3 & 3 \\
\hline 3 & 3 \\
\hline-6 & -6 \\
\hline-6 & -7 \\
\hline-3 & -4 \\
\hline-1 & -1 \\
\hline 2 & 2 \\
\hline 1 & 3 \\
\hline
\end{tabular}

\begin{tabular}{c|c}
\hline g. $\mathrm{cv}$ & Avg. \\
\hline 0 & 0.3 \\
\hline 3 & 2.7 \\
\hline 3 & 3.0 \\
\hline-6 & -6.0 \\
\hline-7 & -6.3 \\
\hline-4 & -3.7 \\
\hline-1 & -1.0 \\
\hline 2 & 1.7 \\
\hline 3 & 2.0 \\
\hline
\end{tabular}

\begin{tabular}{|l|l|}
\hline Avg. & \\
\hline 0.3 & \\
\hline 2.7 & \\
\hline 3.0 & \\
\hline-6.0 & \\
\hline-6.3 & \\
\hline-3.7 & \\
-1.0 & \\
1.7 & \\
\hline 2.0 & \\
3.0 & \\
\hline
\end{tabular}

\begin{tabular}{|c|c|}
\hline deg. Cw & de \\
\hline-5 & \\
\hline-1 & \\
\hline-1 & -14 \\
\hline-5 & \\
\hline-6 & \\
\hline-5 & \\
\hline-5 & \\
\hline-3 & \\
\hline-2 & \\
\hline
\end{tabular}

\begin{tabular}{c|c}
\hline deg. cw & deg. \\
\hline-1 & \\
-1 & \\
\hline-14 & -1 \\
\hline-9 & -8 \\
-8 & -7 \\
\hline-5 & -5 \\
-3 & -2 \\
-1 & -3 \\
\hline-1 & -1 \\
\hline
\end{tabular}
3

Instuments Used:

S-typ

Cal. Due

Dwyer 24-inch S-type Pitot\#10 Cert. of conformance

Velocity sensor TSI Velocicalc SN\#T95351203 15-Aug-15

Angle indicator Shop built $\quad$ Cat. 3

Manometer $\quad$ Dwyer 400-5, S36N $\quad$ MAN E Cat. 3

Notes Velocity and temp measured at center, side.

Note:

To assure similar hose connections between the manometer and pitot tube, rotating the pitot tube assembly clockwise drives the meniscus to the right (to higher pos. numbers)

$\mathrm{CA}$ $1 / 14 / 2015$
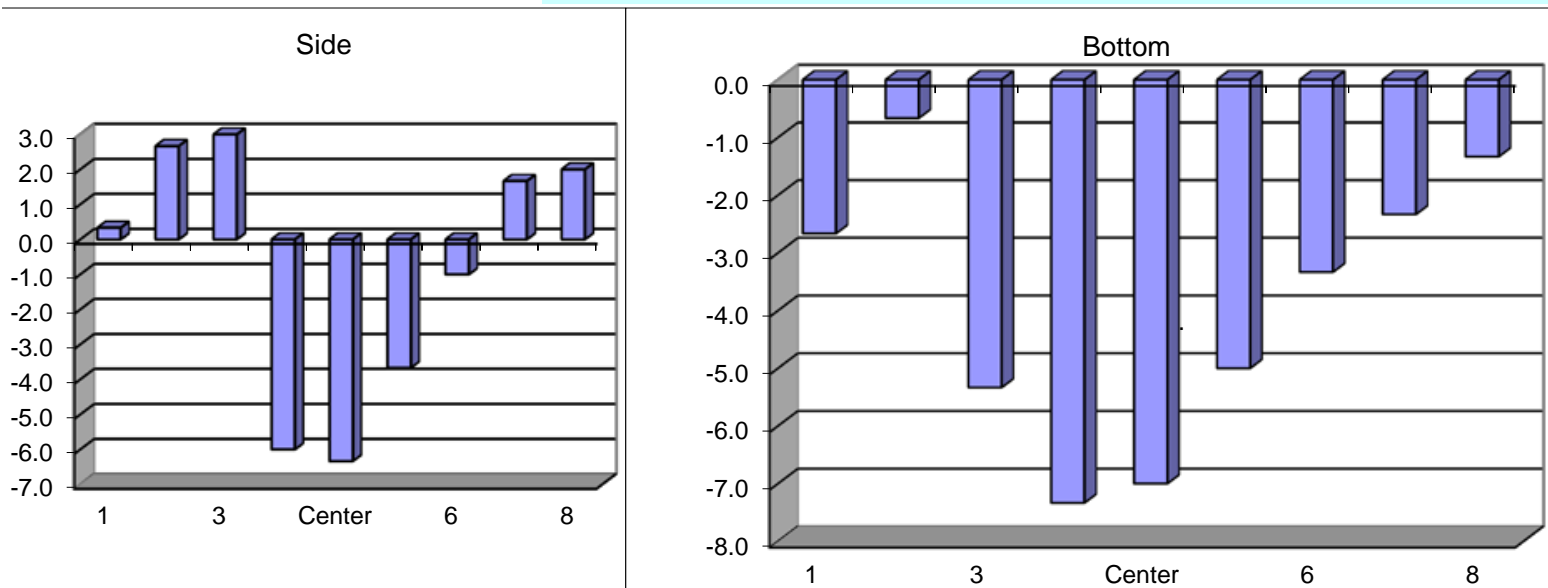

Entries made by: Carmen Arimescu Signature/date

$1 / 14 / 2015$

Signature on file with original
Technical Data Review performed by:

Signature/date

Signature on file in TI-WTPSP-135 


\section{FLOW ANGLE DATA FORM}

\begin{tabular}{|c|c|c|}
\hline \multirow{2}{*}{\multicolumn{3}{|c|}{$\begin{array}{l}\text { Date } \overline{1 / 14 / 2015} \\
\text { Tester }\end{array}$}} \\
\hline & & \\
\hline Stack Dia. & 11.922 & in \\
\hline Stack X-Area & 111.6 & in2 \\
\hline Elevation & N.A. & $\mathrm{ft}$ \\
\hline Distance to disturbance & 119.88 & in \\
\hline
\end{tabular}

Run No. FA-2

Fan Setting $51.2 \quad \mathrm{~Hz}$

Fan configuration Fan A Max

Approx. air vel. 3253 afpm at point $\gg$

Units degrees (clockwise > pos. nos.)

Port 1

Stack Temp $41.1 \mathrm{~F}$

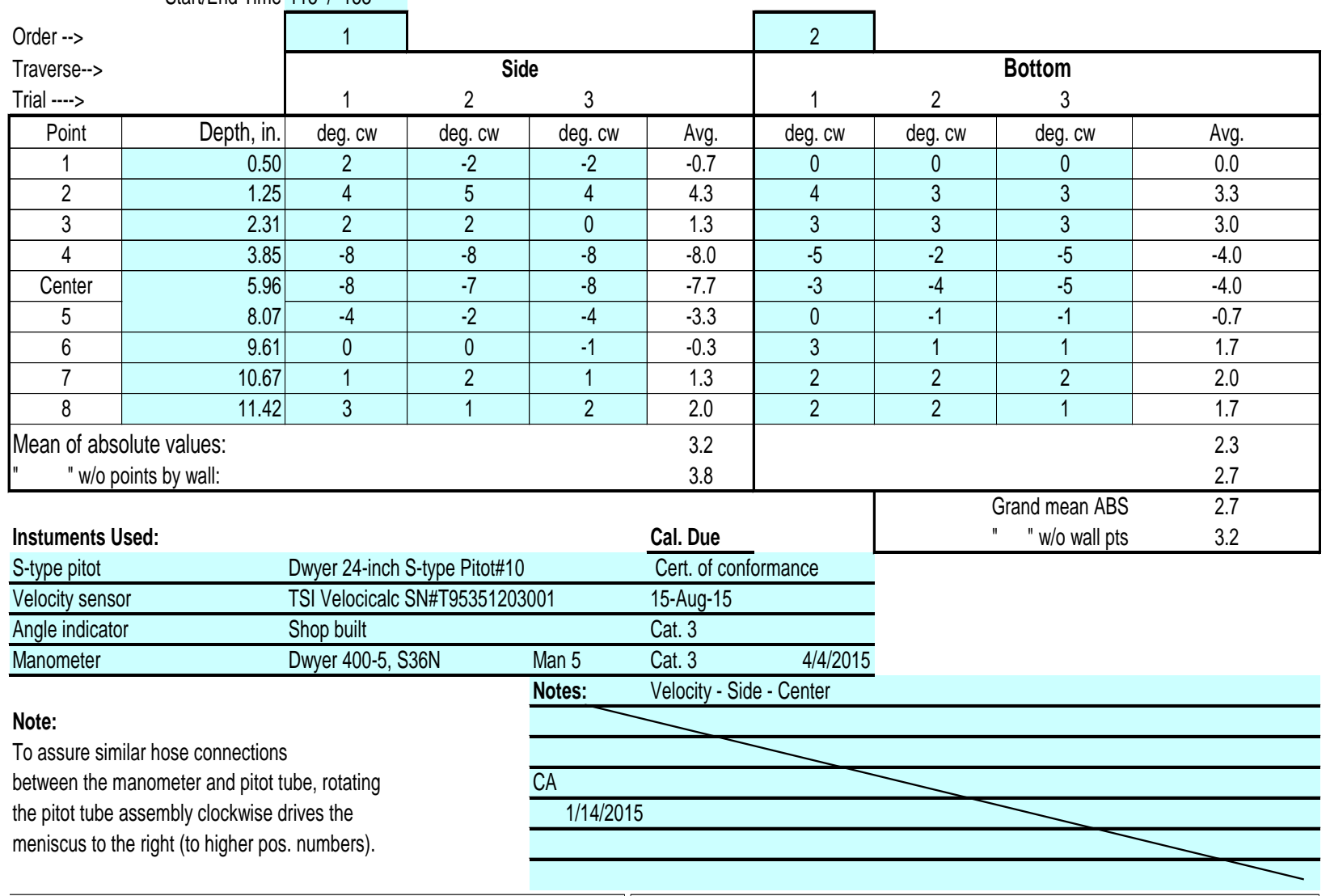

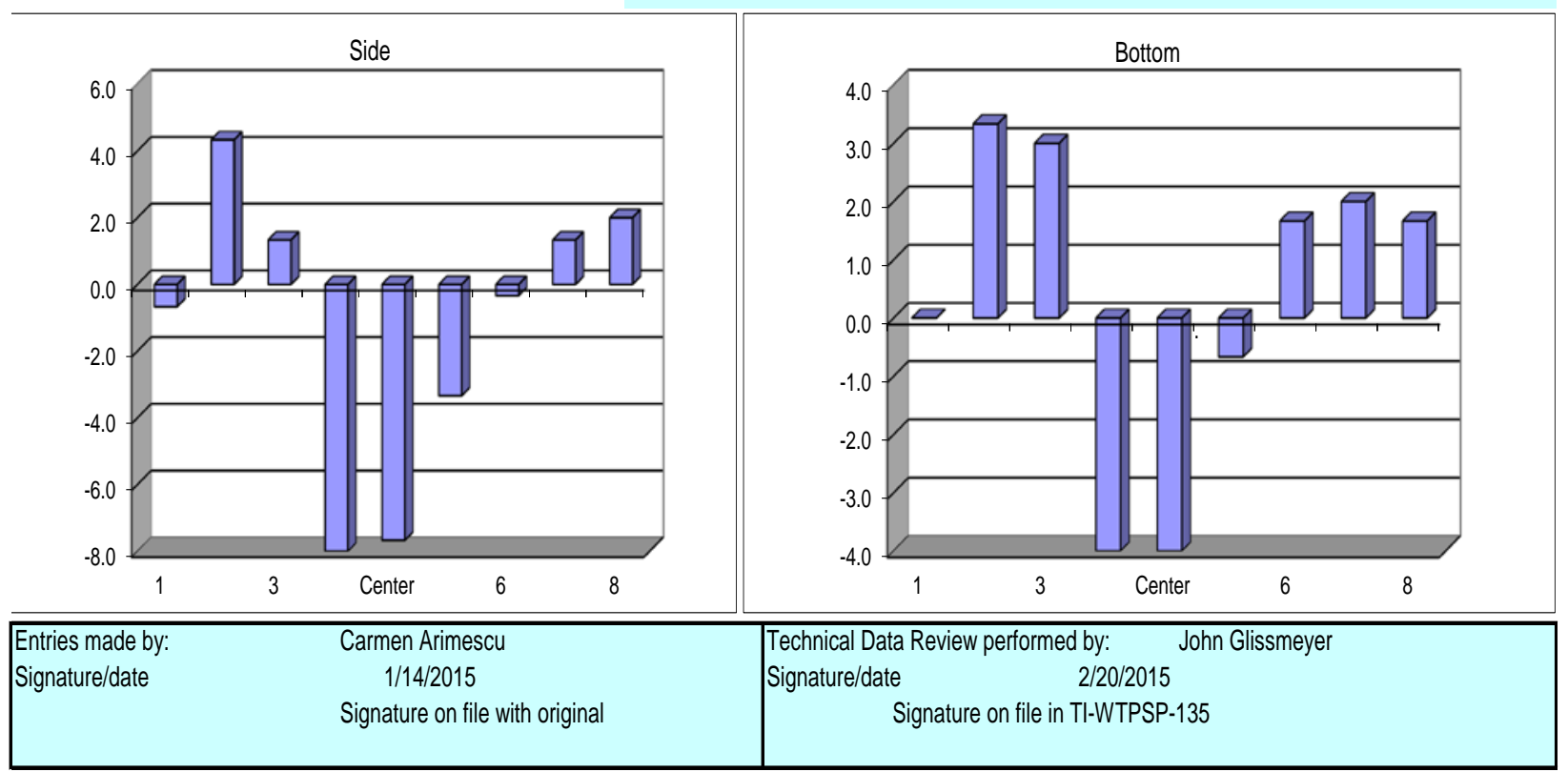




\section{ANGLE DATA FORM}

Site LV-C2 -Remedial Scale Model Date 1/14/2015

Tester CA, EA

Stack Dia. 11.922

Stack X-Area 111.6 in2

Elevation

111.6

$\mathrm{ft}$

Distance to disturbance 119.88 in

Start/End Time $200 / 220$

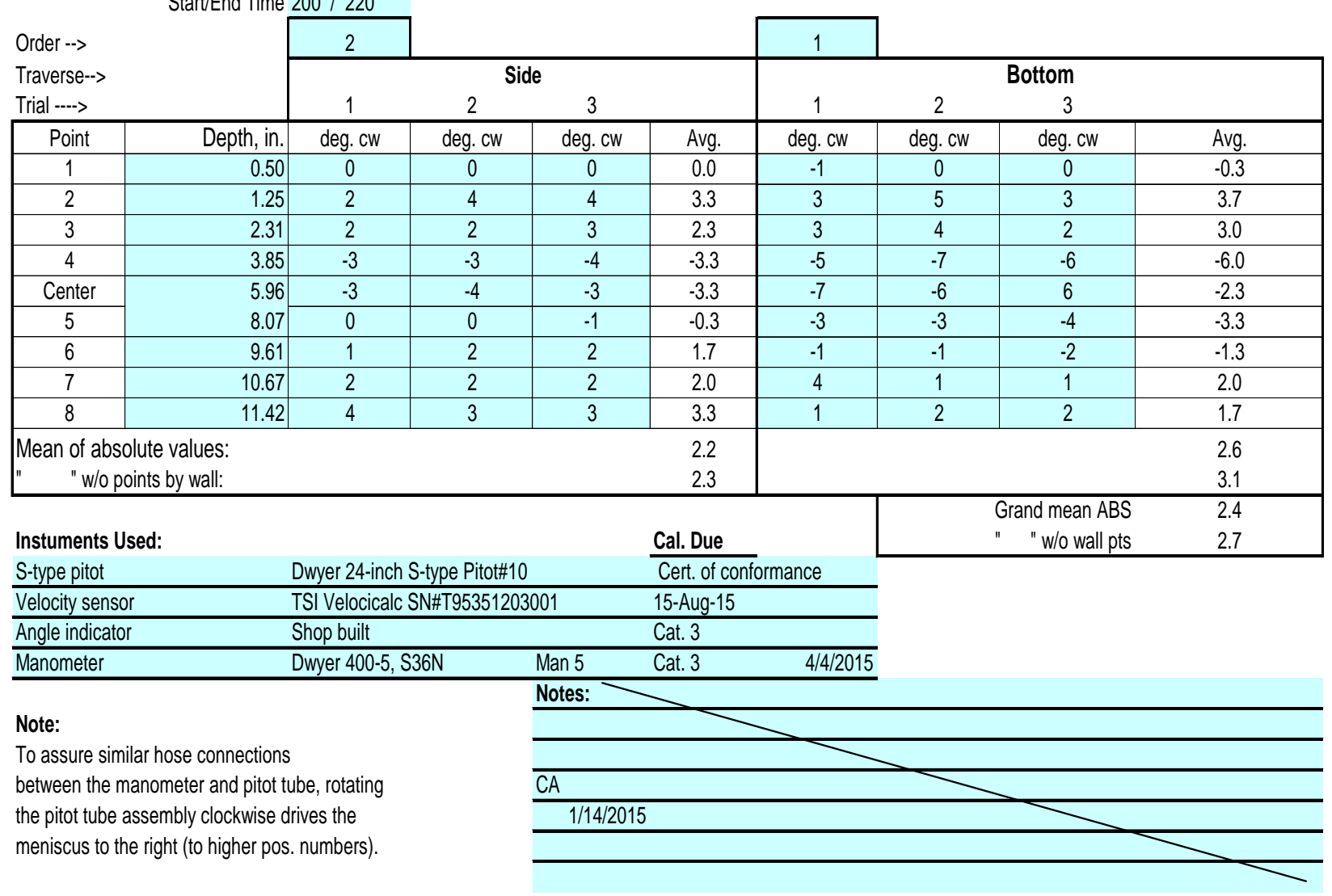
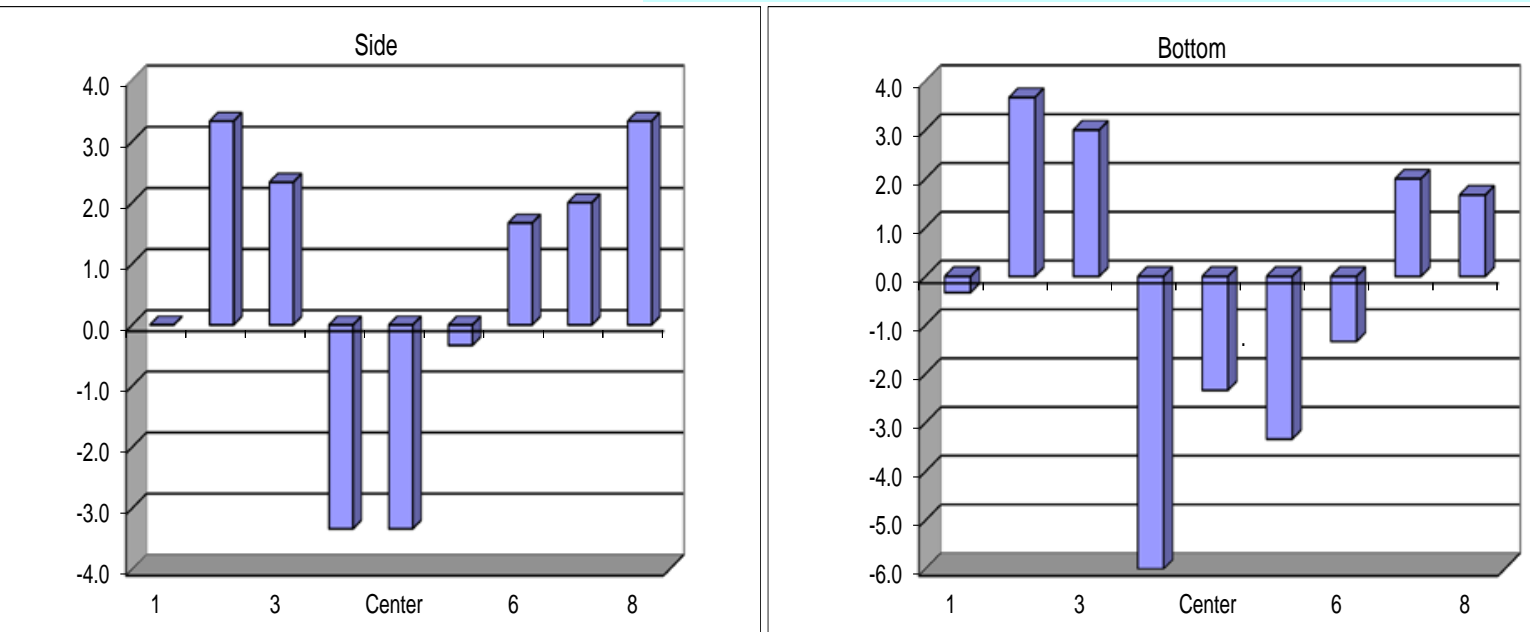

Technical Data Review performed by: John Glissmeyer Signature/date 2/20/2015

Signature on file in TI-WTPSP-135 


\section{ANGLE DATA FORM}

Site LV-C2 -Remedial Scale Model Date $1 / 15 / 2015$

Tester CA, EA

Stack Dia. 11.922

Stack X-Area 111.6 in2

Elevation

Distance to disturbance $\frac{N . A .}{119.88}$ in

Start/End Time $903 / 923$
Run No. FA-4

Fan Setting $42 \mathrm{~Hz}$

Fan configuration Fan A Norm

Approx. air vel. 2797 afpm at point $\gg$

Units degrees (clockwise > pos. nos.)

Stack Temp $\frac{1}{39.4} \mathrm{~F}$

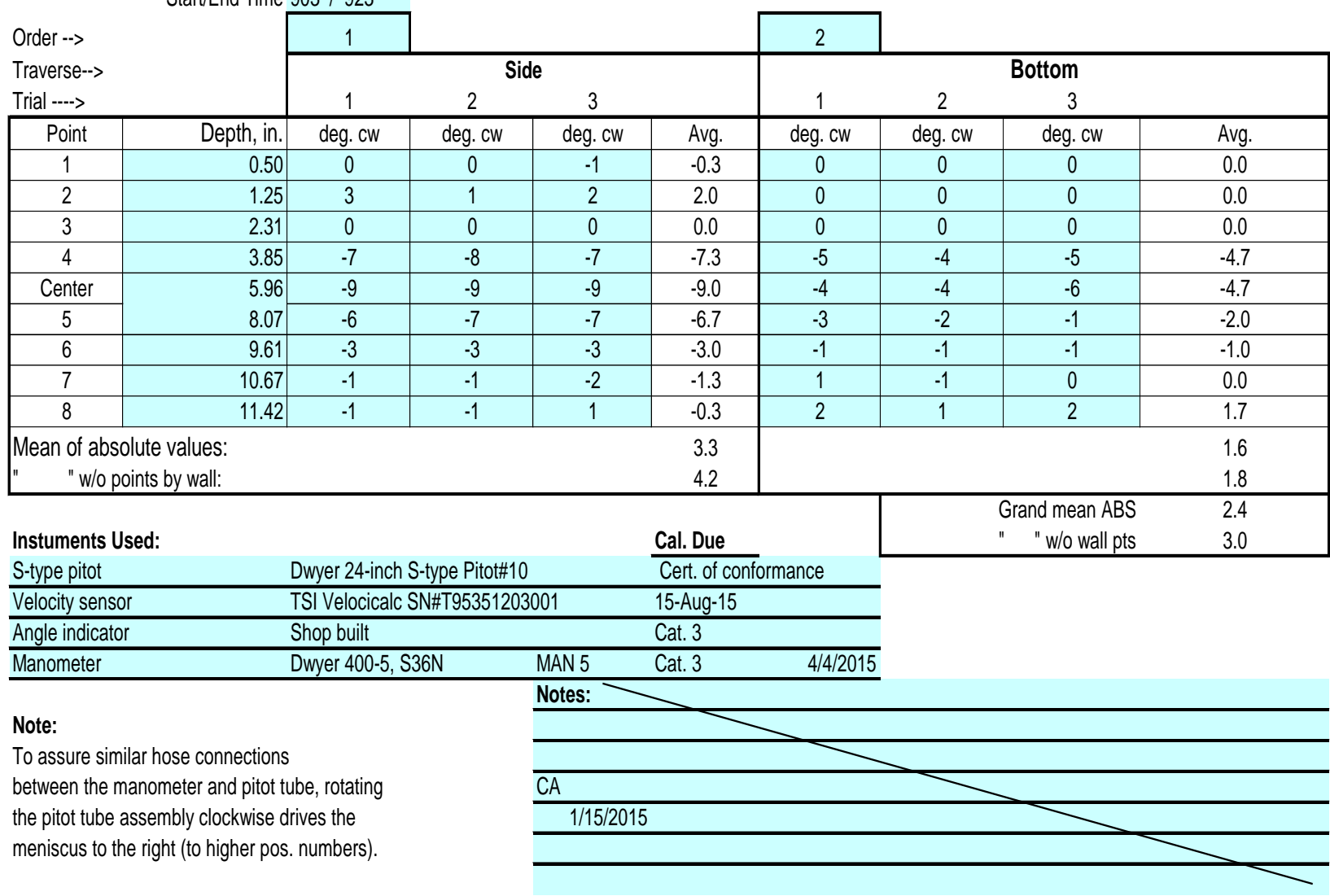

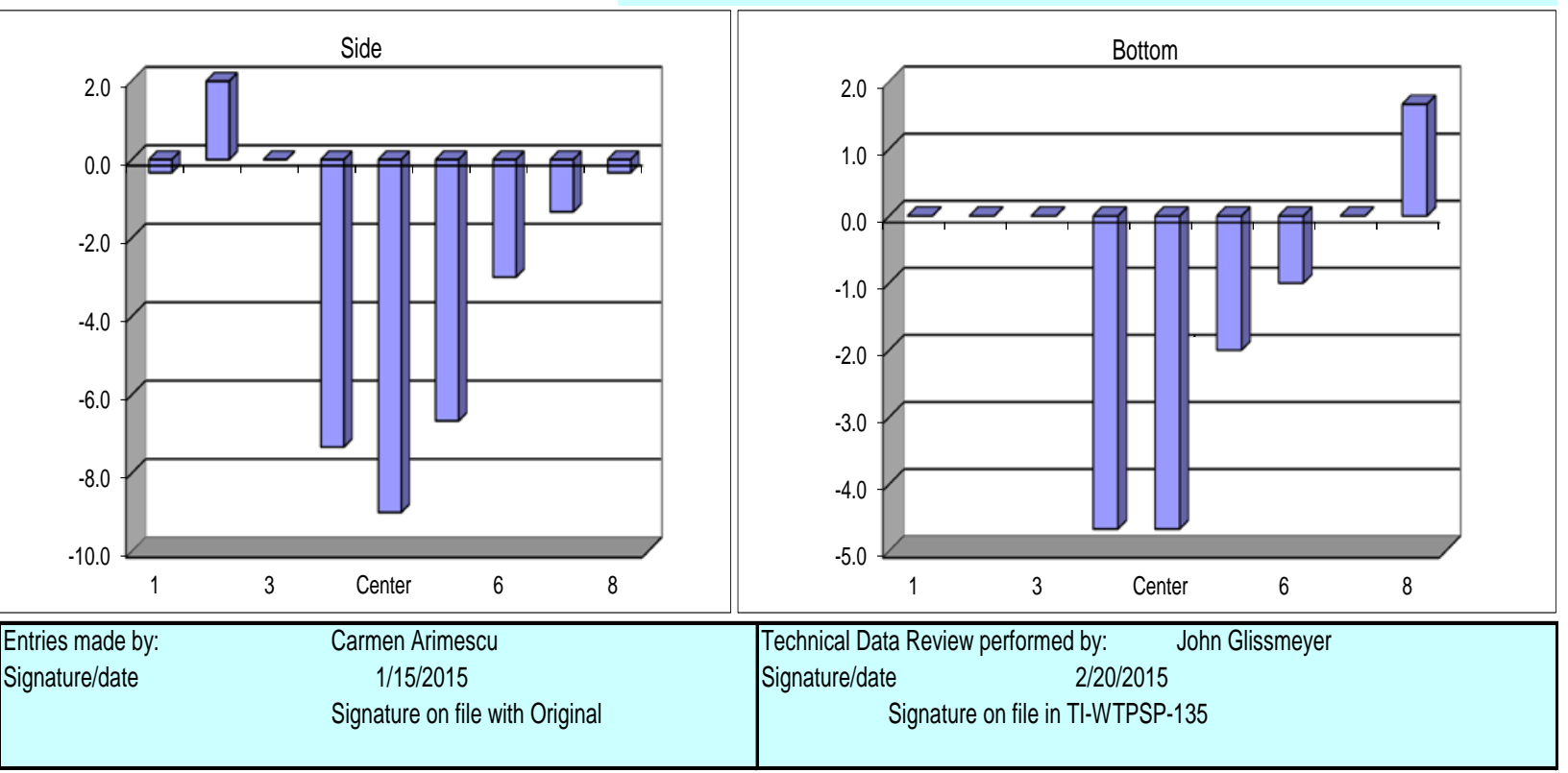




\section{ANGLE DATA FORM}

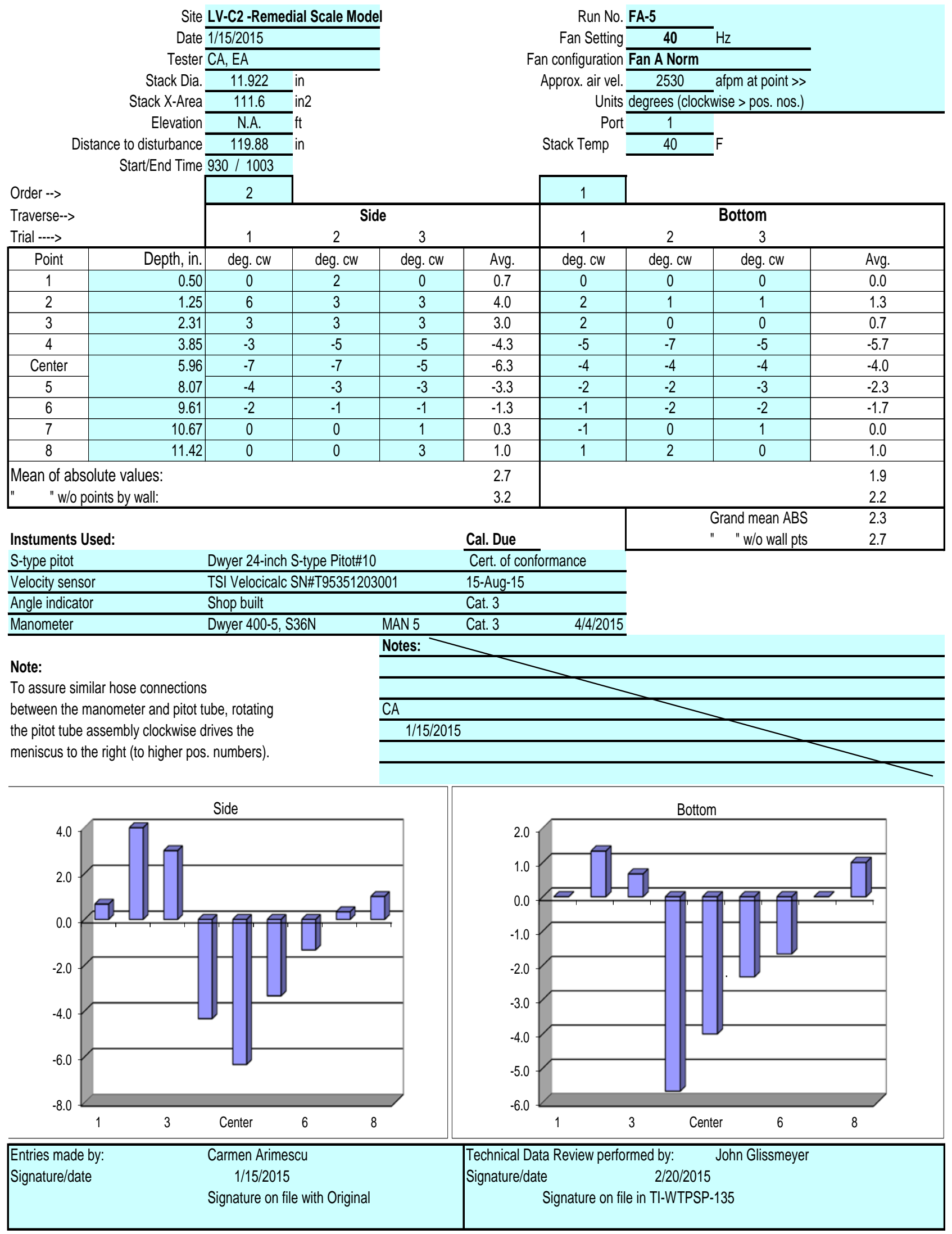




\section{ANGLE DATA FORM}

Site LV-C2 -Remedial Scale Model

Date 1/15/2015

Tester $\mathrm{CA}, \mathrm{EA}$

Stack Dia. 11.922

Stack X-Area 111.6 in2

Elevation N.A. $\mathrm{ft}$

Distance to disturbance $\frac{119.88}{10}$ in

Start/End Time 1010 / 1034

Order -->

Traverse-->

Trial -.-.>

$$
1
$$

r side

\begin{tabular}{|c|c|c|c|c|c|c|c|c|c|}
\hline Trial ----> & & 1 & 2 & 3 & & 1 & 2 & 0 & \\
\hline Point & Depth, in. & deg. Cw & deg. CW & deg. CW & Avg. & deg. CW & deg. CW & deg. CW & Avg. \\
\hline 1 & 0.50 & 0 & 0 & 0 & 0.0 & 0 & 0 & 0 & 0.0 \\
\hline 2 & 1.25 & 4 & 3 & 5 & 4.0 & 3 & 4 & 4 & 3.7 \\
\hline 3 & 2.31 & 2 & 2 & 2 & 2.0 & 3 & 0 & 0 & 1.0 \\
\hline 4 & 3.85 & -4 & -5 & -5 & -4.7 & -3 & -5 & -6 & -4.7 \\
\hline Center & 5.96 & -6 & -6 & -5 & -5.7 & -4 & -3 & -7 & -4.7 \\
\hline 5 & 8.07 & -4 & -4 & -3 & $\begin{array}{l}-3.7 \\
\end{array}$ & -2 & -3 & -4 & -3.0 \\
\hline 6 & 9.61 & 0 & -1 & -1 & -0.7 & 0 & 0 & -1 & -0.3 \\
\hline 7 & 10.67 & -1 & -1 & -2 & -1.3 & 1 & 2 & 0 & 1.0 \\
\hline 8 & 11.42 & 1 & -1 & 1 & 0.3 & 1 & 1 & 2 & 1.3 \\
\hline Mean of ab & ues: & & & & 2.5 & & & & 2.2 \\
\hline "w/o & & & & & 3.1 & & & & 2.6 \\
\hline & & & & & & & & Grand mean ABS & 2.3 \\
\hline Instuments & & & & & Cal. Due & & & " " w/o wall pts & 2.9 \\
\hline S-type pitot & & Dwyer 24-inc & type Pitot\#10 & & Cert. of $\mathrm{C}$ & nance & & & \\
\hline Velocity sen & & TSI Velocical & V\#T95351203 & & 15-Aug-15 & & & & \\
\hline Angle indica & & Shop built & & & Cat. 3 & & & & \\
\hline Manometer & & Dwyer 400-5, & & MAN 5 & Cat. 3 & $4 / 4 / 2015$ & & & \\
\hline & & & & Notes: & & & & & \\
\hline Note: & & & & & & & & & \\
\hline To assure si & connections & & & & & & & & \\
\hline between the & $r$ and pitot tu & ube, rotating & & $\overline{\mathrm{CA}}$ & & & & & \\
\hline the pitot tub & clockwise dr & rives the & & $1 / 15 / 20$ & & & & & \\
\hline meniscus to & higher pos. & numbers). & & & & & & & \\
\hline
\end{tabular}

Entries made by:




\section{ANGLE DATA FORM}

Site LV-C2 -Remedial Scale Model

Date 1/15/2015

Tester CA, EA

Stack Dia. 11.922

Stack X-Area 111.6 in2

Elevation N.A. $\mathrm{ft}$

Distance to disturbance $\frac{119.88}{10}$ in

Start/End Time 1047 / 1102
Run No. FA-7

Fan Setting $27 \quad \mathrm{~Hz}$

Fan configuration Fan A Min

Approx. air vel. 1647 afpm at point $\gg$

Units degrees (clockwise > pos. nos.)

Port 1

Stack Temp 41.5

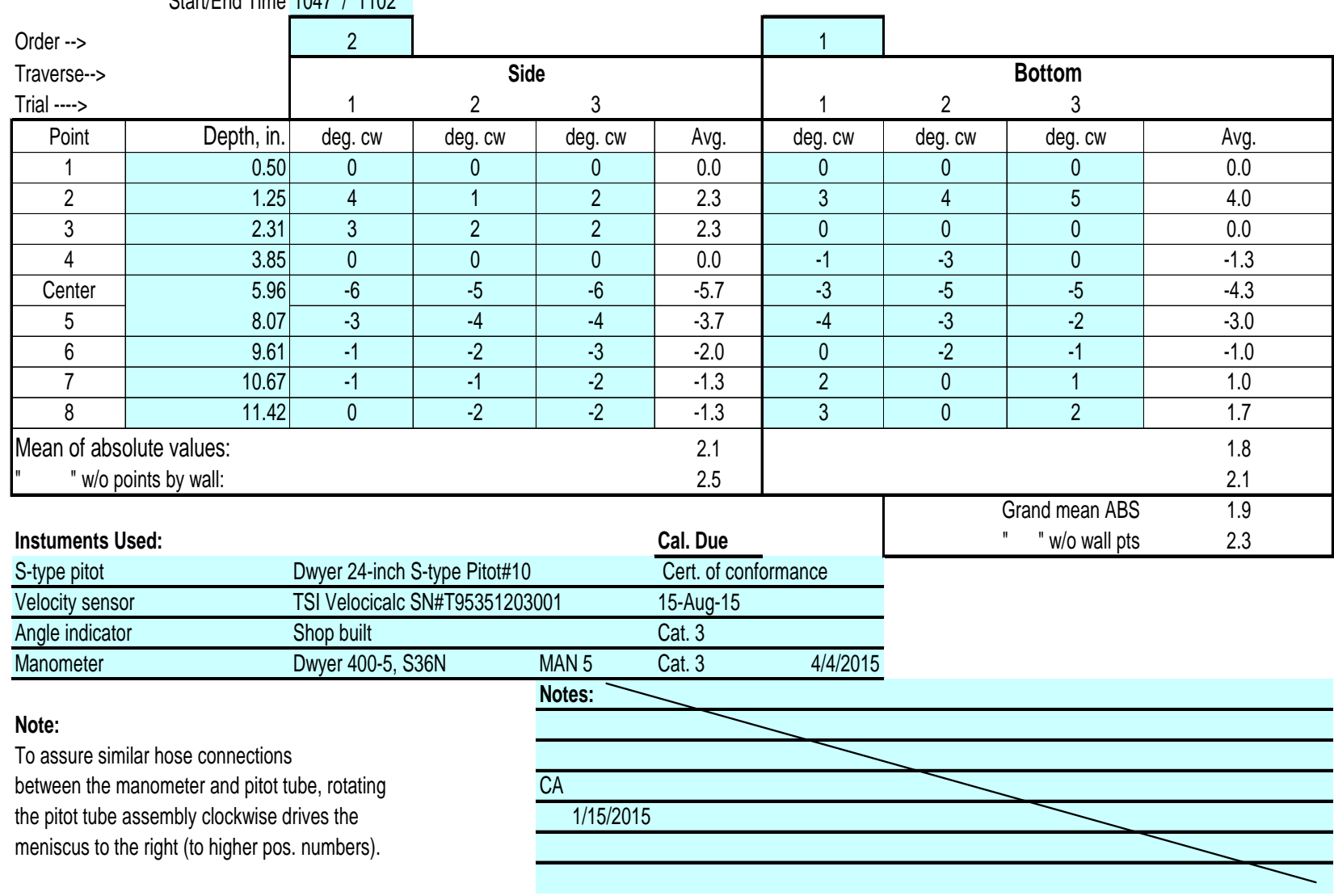

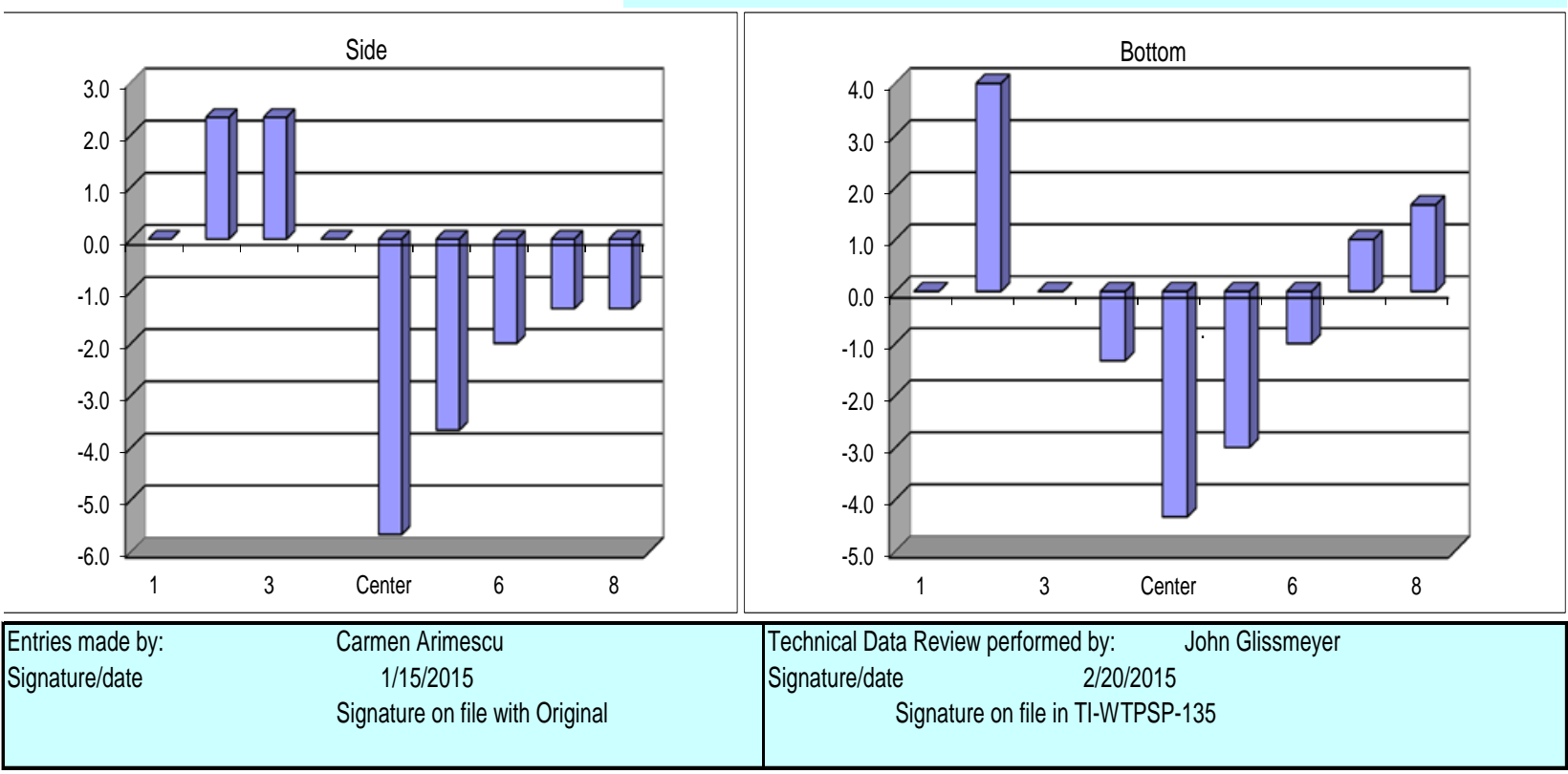




\section{ANGLE DATA FORM}

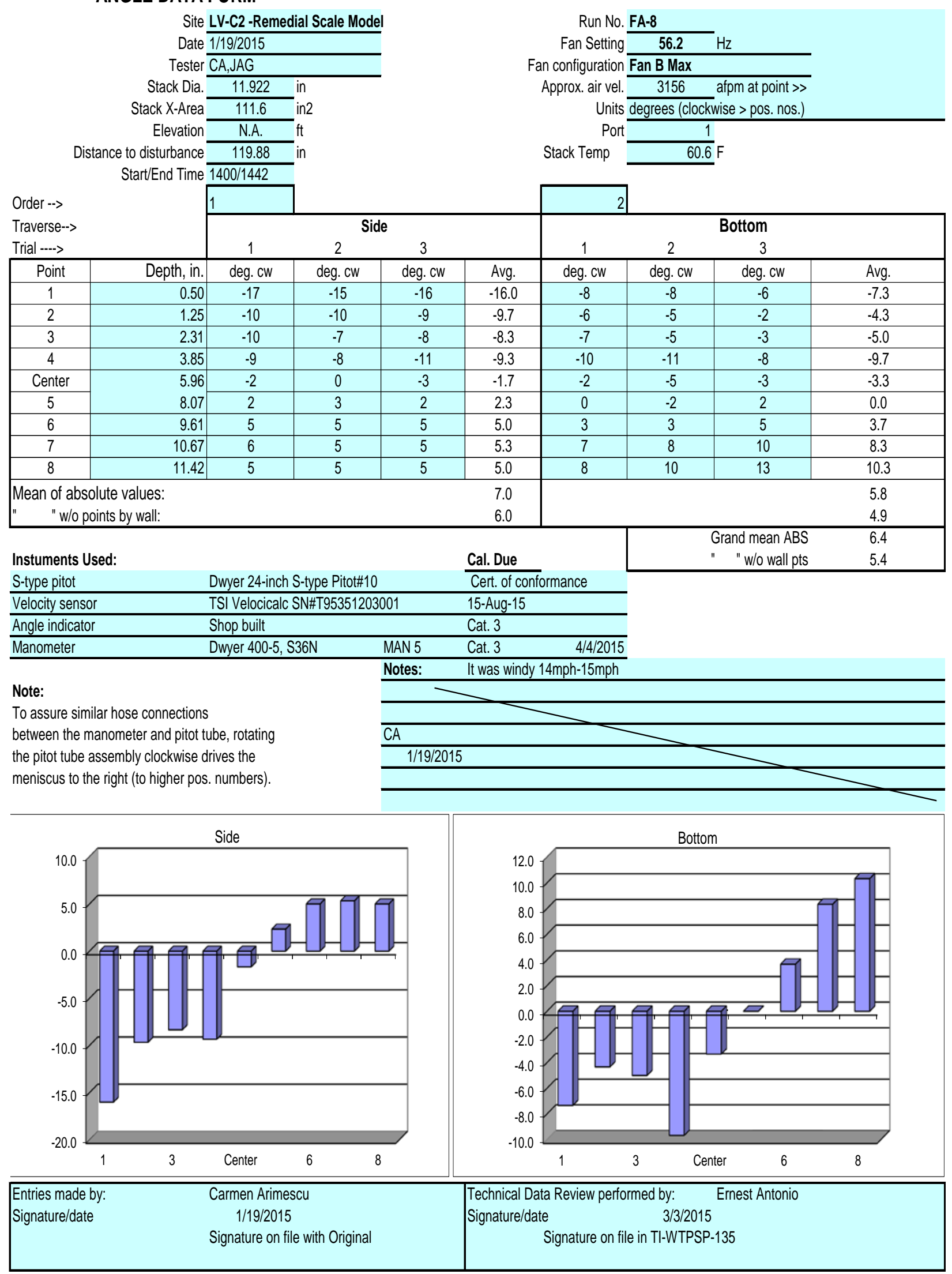


ANGLE DATA FORM

Site LV-C2 -Remedial Scale Model

Date 1/20/2015

Tester CA, EA

Stack Dia. 11.922

Stack X-Area 1116

Elevation N.A

Distance to disturbance 119.88 in

Start/End Time 930/1017
Run No. FA-9

Fan Setting $59 \quad \mathrm{~Hz}$

Fan configuration Fan B Max

Approx. air vel. 3177 afpm at point $\gg$

Units degrees (clockwise > pos. nos.)

Stack Temp

Port $\frac{1}{40.9} \mathrm{~F}$

Order $-->$

Traverse-->

2

Trial --.->

\begin{tabular}{|c|c|c|c|}
\hline \multicolumn{2}{|c|}{ Trial ----> } & \multicolumn{2}{|l|}{1} \\
\hline Point & Depth, in. & deg. CW & $\mathrm{deg}$ \\
\hline 1 & 0.50 & -10 & \\
\hline 2 & 1.25 & -6 & \\
\hline 3 & 2.31 & -4 & \\
\hline 4 & 3.85 & -7 & \\
\hline Center & 5.96 & -5 & \\
\hline 5 & 8.07 & 1 & \\
\hline 6 & 9.61 & 3 & \\
\hline 7 & 10.67 & 5 & \\
\hline 8 & 11.42 & 6 & \\
\hline
\end{tabular}

Mean of absolute values:

\begin{tabular}{c|r} 
& 1 \\
\hline Side & 1
\end{tabular}

$$
1
$$
23

deg. CW

\begin{tabular}{r|rrr}
\multicolumn{2}{|c|}{} & \multicolumn{3}{r}{ Bottom } \\
\hline
\end{tabular}

$$
\text { " " w/o points by wall: }
$$

Instuments Used:

S-type pitot

Velocity sensor

Angle indicator

Manometer

$+2$

$$
+1
$$

\begin{tabular}{|c|c|c|}
\hline 11 & -12 & -11.0 \\
\hline
\end{tabular}

\begin{tabular}{l|l|l|}
\hline-6 & -6 & -6.0 \\
\hline-4 & -3 & -3.7 \\
\hline-6 & -6 & -6.3 \\
\hline
\end{tabular}

Note:

To assure similar hose connections

\begin{tabular}{|c|c|}
\hline & Cal. Due \\
\hline Dwyer 24-inch S-type Pitot\#10 & Cert. of conformance \\
\hline TSI Velocicalc SN\#T95351203001 & 15-Aug-15 \\
\hline Shop built & Cat. 3 \\
\hline Dwyer 400-5, S36N & $4 / 4 / 2015$ \\
\hline
\end{tabular}
between the manometer and pitot tube, rotating the pitot tube assembly clockwise drives the meniscus to the right (to higher pos. numbers).

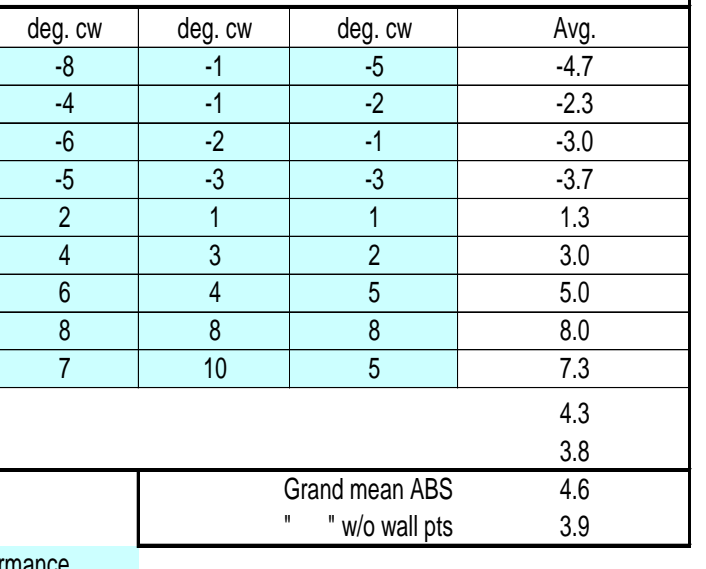
Notes:

This is a repeat of Fan B max ,FA-8, because the particle injection was on.

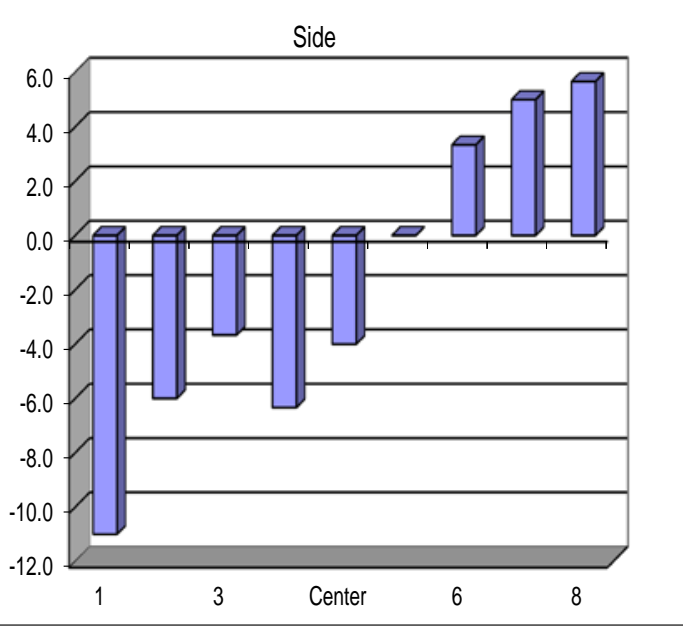

\begin{tabular}{|l|l|l|}
\hline $\begin{array}{l}\text { Entries made by: } \\
\text { Signature/date }\end{array}$ & $\begin{array}{l}\text { Carmen Arimescu } \\
1 / 20 / 2015 \\
\text { Signature on file with Original }\end{array}$ & $\begin{array}{l}\text { Signature/date } \\
\text { Signature on file in TI-WTPSP-135 }\end{array}$ \\
\hline
\end{tabular}




\section{ANGLE DATA FORM}

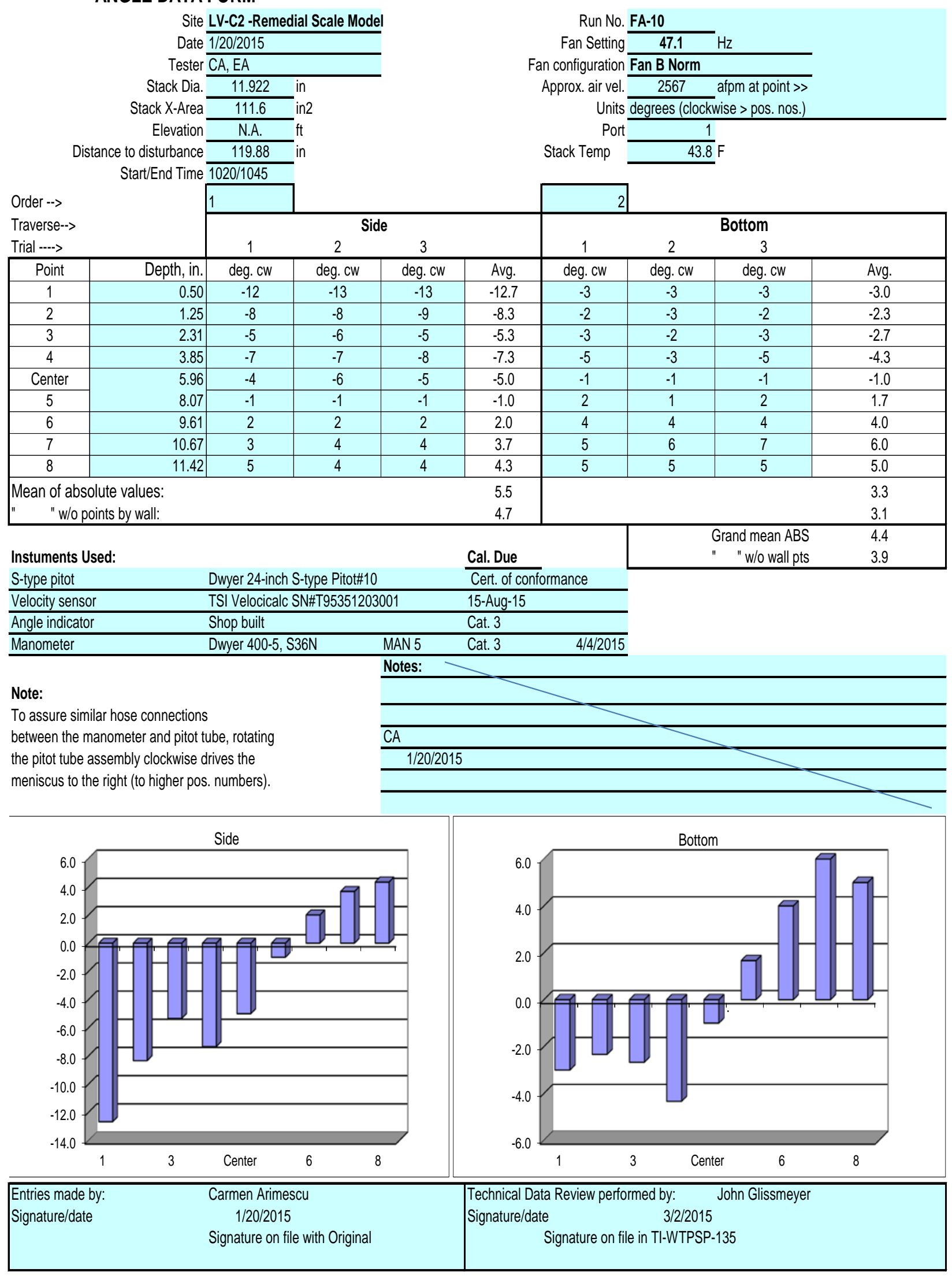


ANGLE DATA FORM

Site LV-C2 -Remedial Scale Model

Date $1 / 20 / 2015$

Tester CA, EA

Stack Dia. 11.922

Stack X-Area 111.6 in2

Elevation N.A. $\mathrm{ft}$

Distance to disturbance 119.88 in

Start/End Time 1050/1112
Run No. FA-11

Fan Setting $29.5 \mathrm{~Hz}$ Fan configuration Fan B Min

Approx. air vel. $1547 \quad$ afpm at point $\gg$

Units degrees (clockwise > pos. nos.)

Stack Temp $\frac{1}{46.4} \mathrm{~F}$

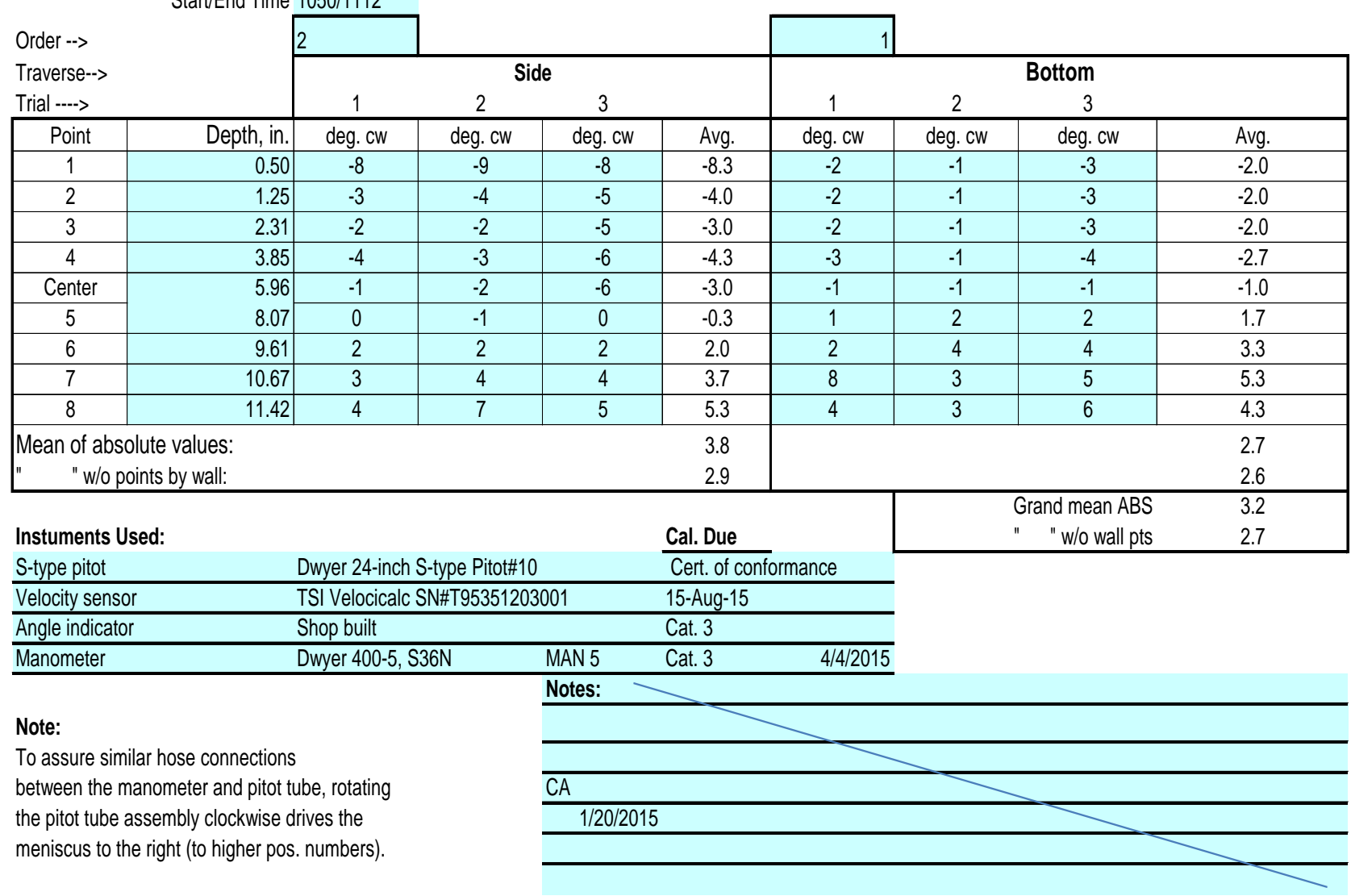

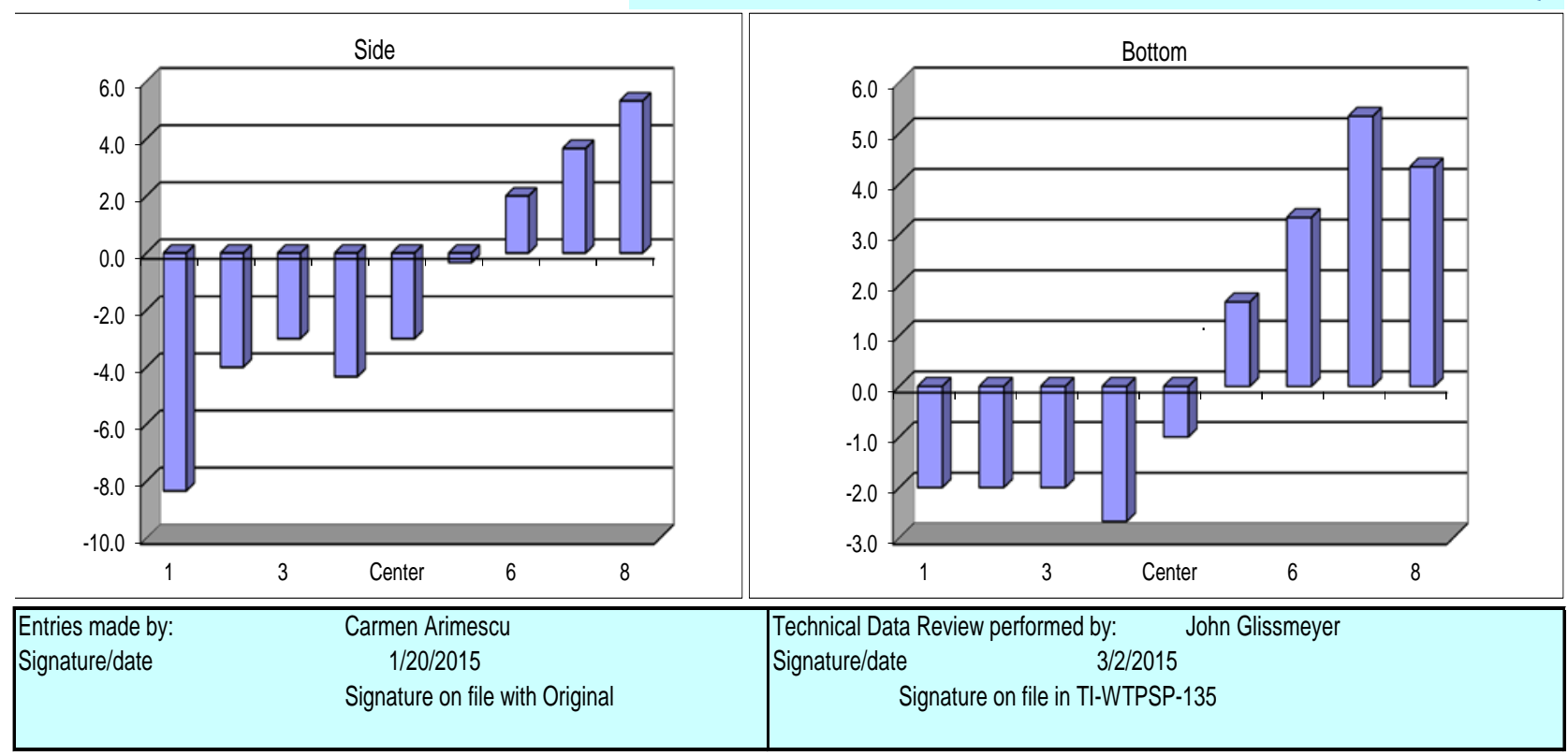




\section{ANGLE DATA FORM}

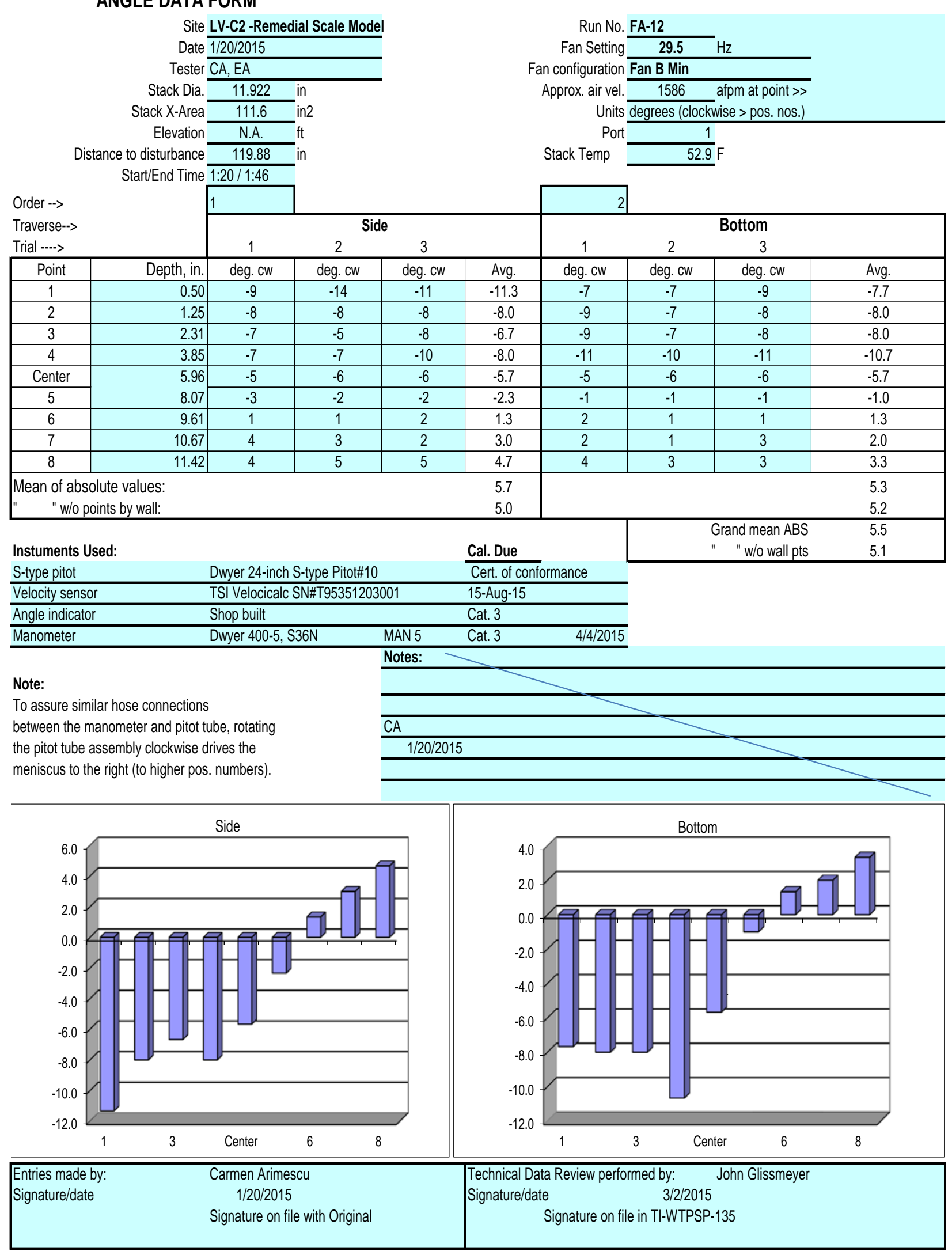




\section{ANGLE DATA FORM}

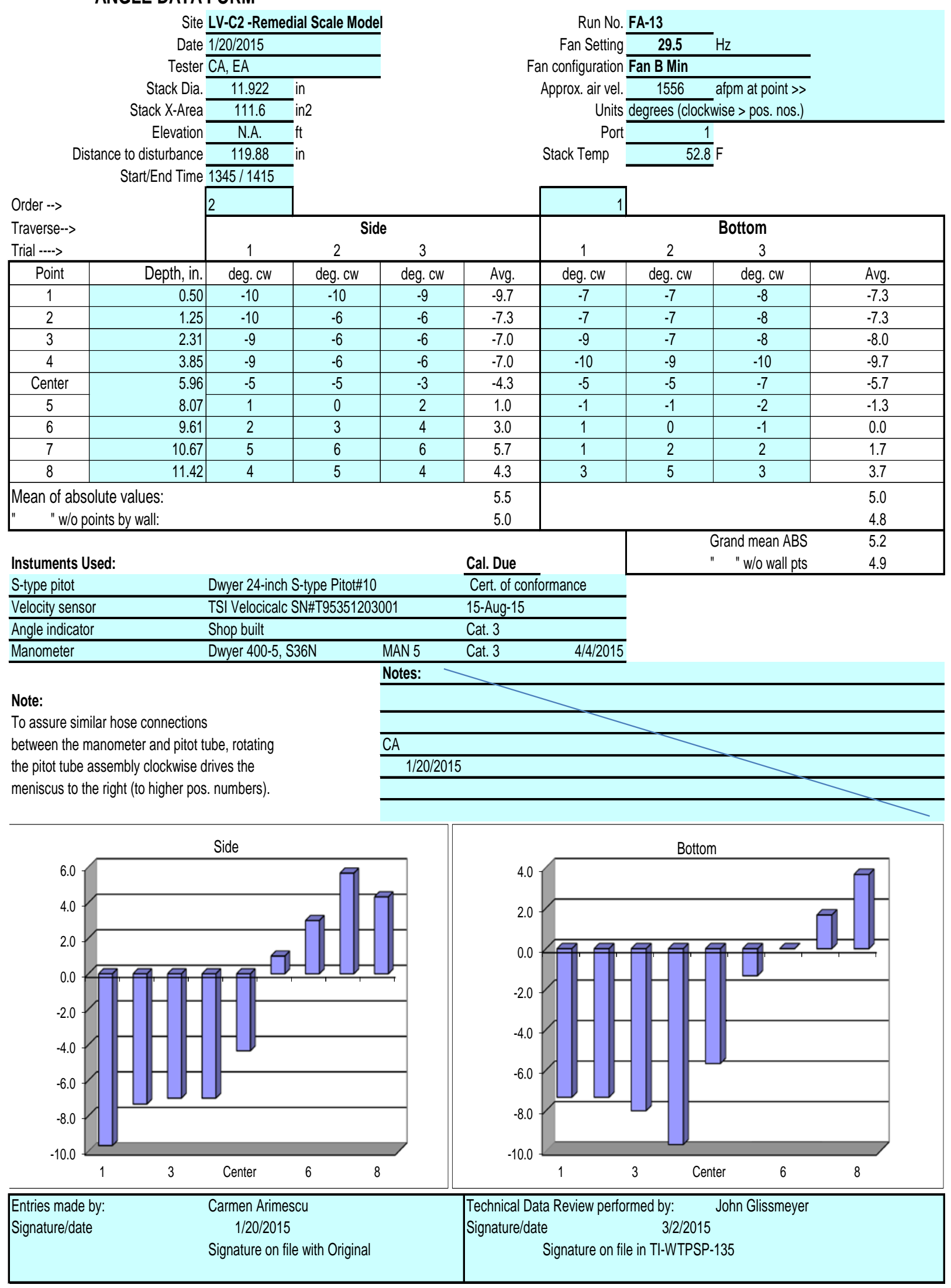




\section{ANGLE DATA FORM}

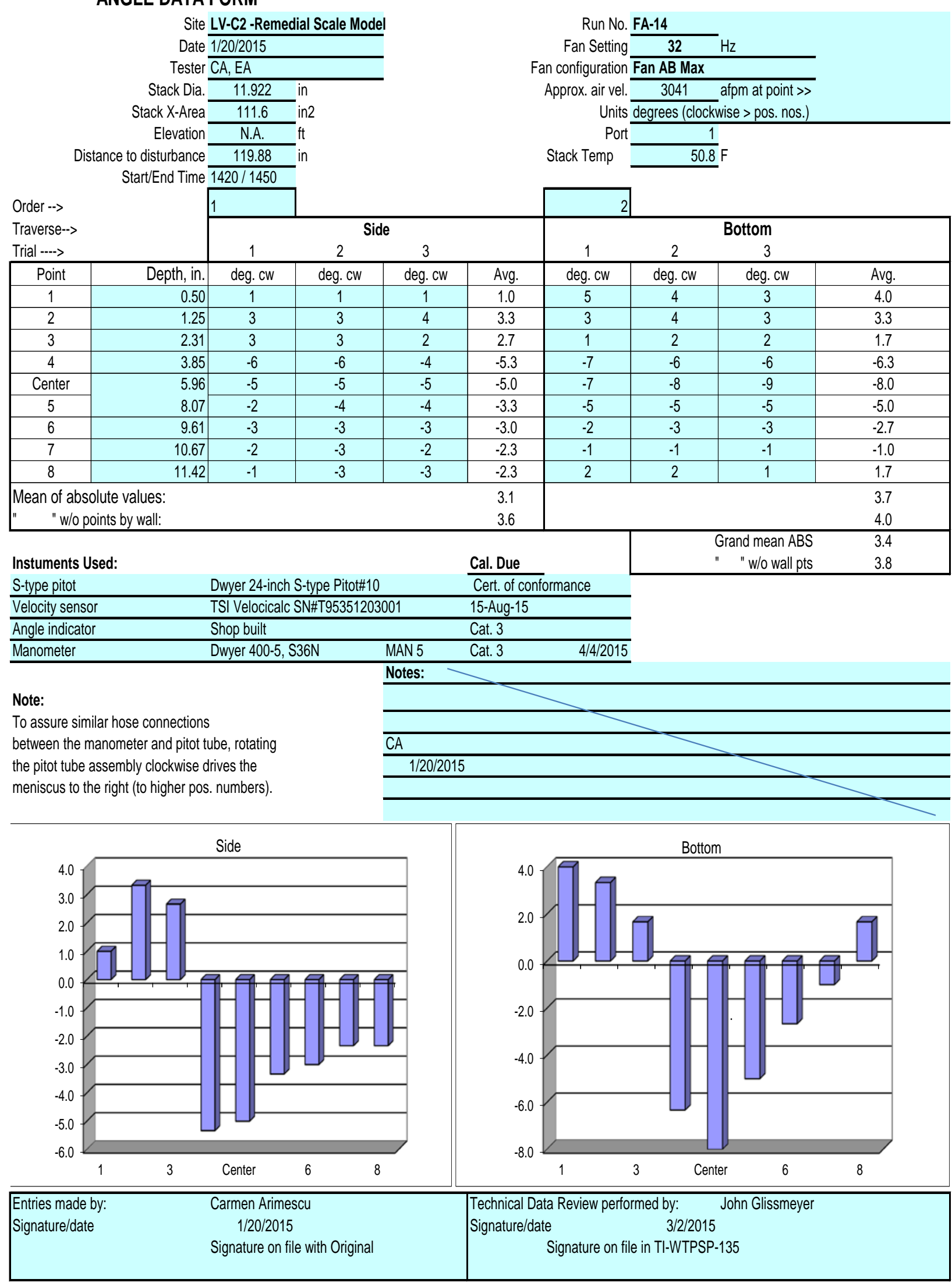




\section{ANGLE DATA FORM}

Site LV-C2 -Remedial Scale Model

Date 1/21/2015

Tester CA, EA

Stack Dia. 11.922

Stack X-Area

Elevation

$\frac{11.922}{111.6}$ in

Start/End Time 920/953
Run No. FA-15

Fan Setting $\frac{18}{\mathrm{~Hz}}$ Fan configuration Fan AB Min

Approx. air vel. 1582 afpm at point $\gg$ Units degrees (clockwise > pos. nos.)

Stack Temp

Order -->

Traverse-->

Trial -..->

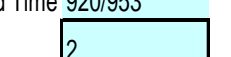

\begin{tabular}{|c|c|c|c|c|}
\hline Order --> & & 2 & & \\
\hline Traverse---> & & & & \\
\hline Trial --.-> & & 1 & 2 & \\
\hline Point & Depth, in. & deg. cw & deg. Cw & \\
\hline 1 & 0.50 & 1 & 3 & \\
\hline 2 & 1.25 & 4 & 4 & \\
\hline 3 & 2.31 & 4 & 4 & \\
\hline 4 & 3.85 & 2 & 1 & \\
\hline Center & 5.96 & -2 & -2 & \\
\hline 5 & 8.07 & -1 & -2 & \\
\hline 6 & 9.61 & -2 & -2 & \\
\hline 7 & 10.67 & 0 & -2 & \\
\hline 8 & 11.42 & -1 & -1 & \\
\hline
\end{tabular}

Mean of absolute values:

"w/o points by wall:

\section{Instuments Used:}

S-type pitot

Velocity sensor

Angle indicator

Manometer

\section{Note:}

To assure similar hose connections between the manometer and pitot tube, rotating the pitot tube assembly clockwise drives the meniscus to the right (to higher pos. numbers).
Cal. Due Dwyer 24-inch S-type Pitot\#10 TSI Velocicalc SN\#T95351203001 Cert. of conformance 15-Aug-15

Shop built $\quad$ Cat. 3

Dwyer 400-5, S36N

\begin{tabular}{lll} 
MAN 5 & Cat. 3 & $4 / 4 / 2015$ \\
\hline Notes: &
\end{tabular}

\section{1}

1 Bottom

\begin{tabular}{c|c|c|c|c|c}
3 & \multicolumn{2}{|c}{1} & \multicolumn{2}{c}{3} \\
\hline deg. CW & Avg. & deg. CW & deg. CW & deg. CW & Avg. \\
\hline 3 & 23 & 4 & 3 & 3 & 3.3
\end{tabular}

\begin{tabular}{|c|c|c|c|c|c|}
\hline 3 & 2.3 & 4 & 3 & 3 & 3.3 \\
\hline 3 & 3.7 & 4 & 5 & 4 & 4.3 \\
\hline 3 & 3.7 & 3 & 3 & 2 & 2.7 \\
\hline 0 & 1.0 & -3 & -2 & -3 & -2.7 \\
\hline-3 & -2.3 & -6 & -8 & -7 & -7.0 \\
\hline-3 & -2.0 & -6 & -4 & -4 & -4.7 \\
\hline-1 & -1.7 & -4 & -4 & -2 & -3.3 \\
\hline-2 & -1.3 & 0 & -1 & 0 & -0.3 \\
\hline-3 & -1.7 & 0 & -1 & 0 & -0.3 \\
\hline \multirow{2}{*}{\multicolumn{2}{|c|}{$\begin{array}{l}2.2 \\
2.2\end{array}$}} & & & & 3.2 \\
\hline & & & & & 3.6 \\
\hline \multirow{2}{*}{\multicolumn{2}{|c|}{ Cal. Due }} & & \multirow{2}{*}{\multicolumn{2}{|c|}{$\begin{array}{l}\text { Grand mean ABS } \\
" \quad \text { " w/o wall pts }\end{array}$}} & 2.7 \\
\hline & & & & & 2.9 \\
\hline
\end{tabular}

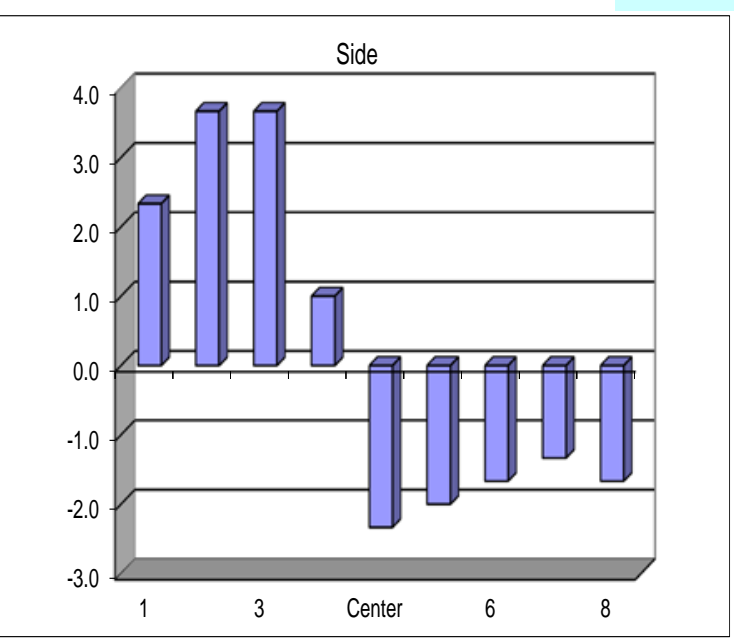

\begin{tabular}{|lc|}
\hline Entries made by: & Carmen Arimescu \\
Signature/date & $1 / 21 / 2015$ \\
& Signature on file with Original \\
\hline
\end{tabular}

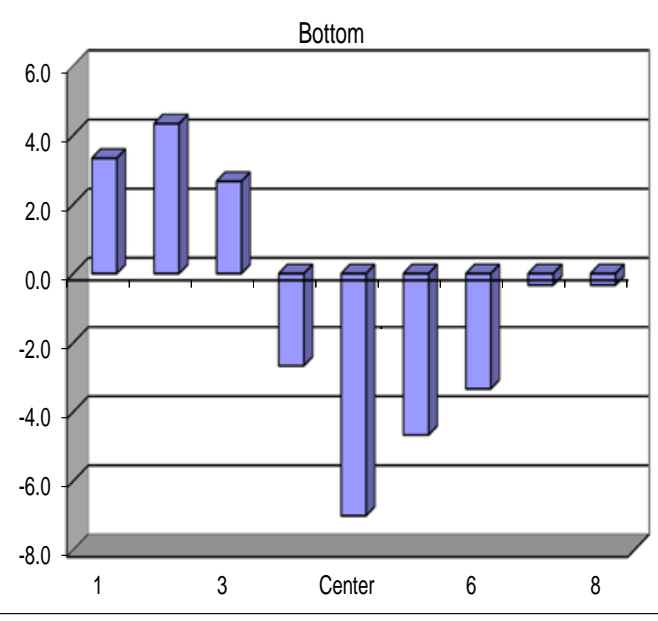

Technical Data Review performed by: John Glissmeyer

Signature/date 3/2/2015

Signature on file in TI-WTPSP-135 


\section{ANGLE DATA FORM}

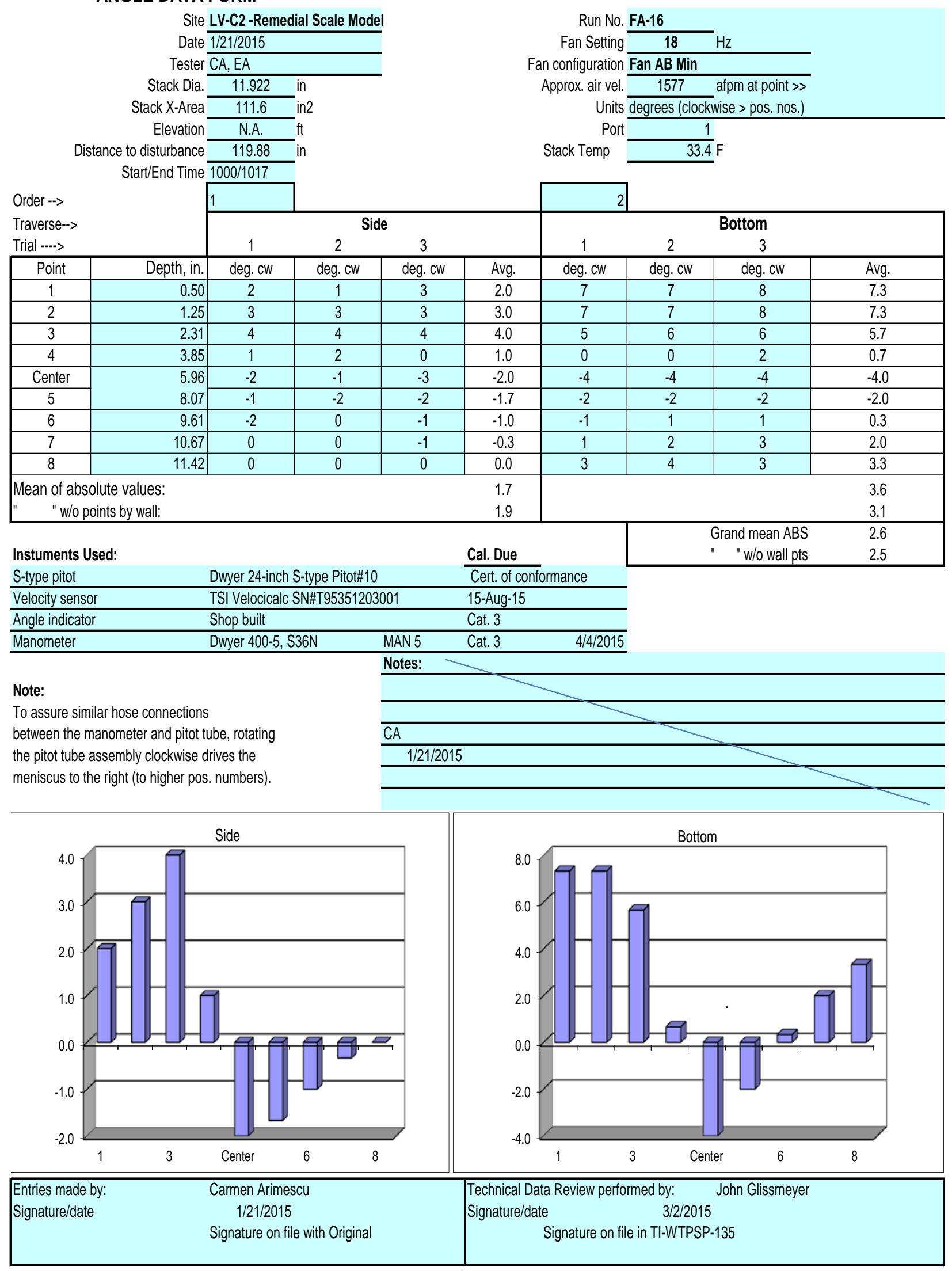




\section{FLOW ANGLE DATA FORM}

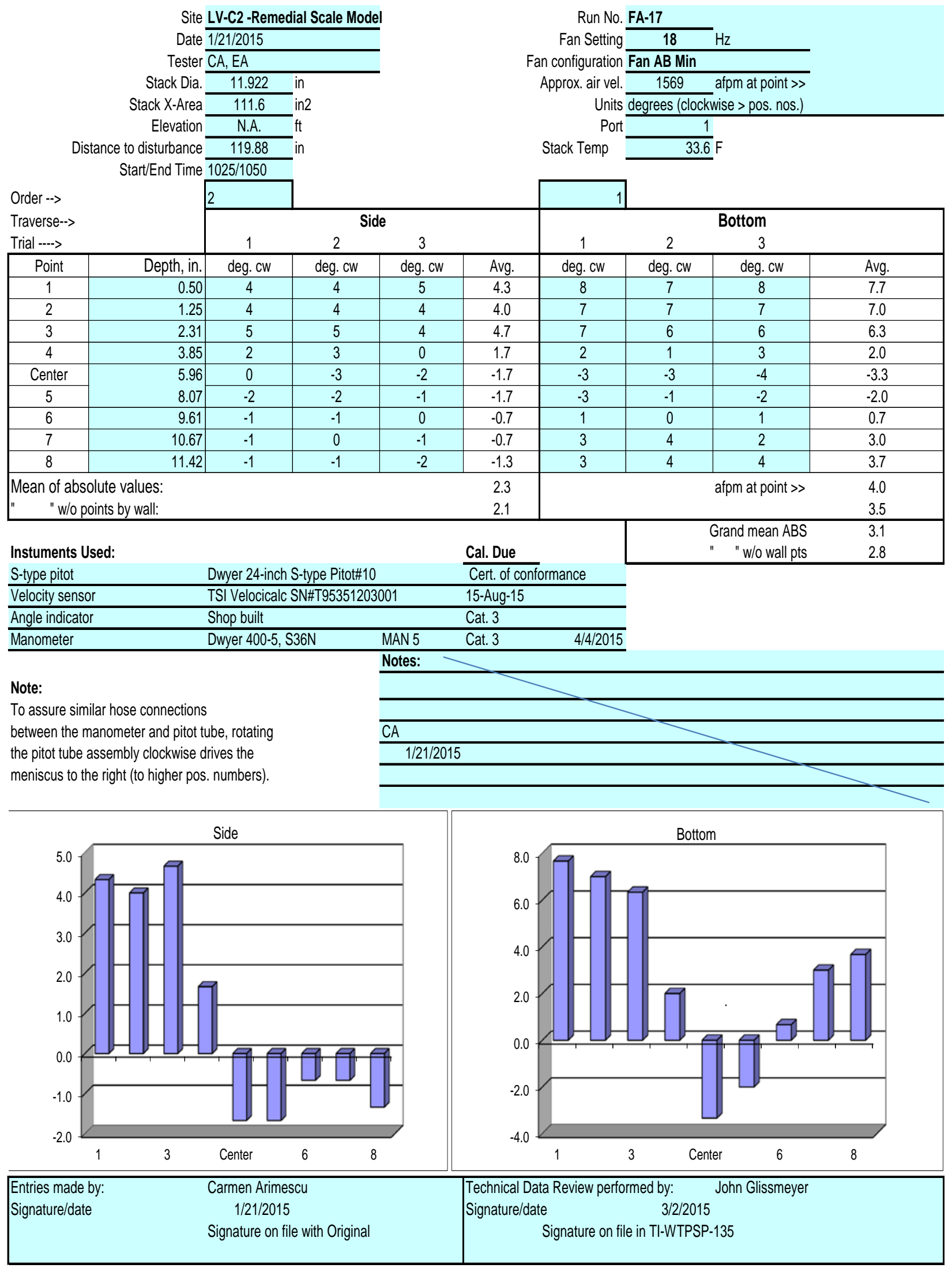




\section{C.3 LV-C2 Gas Tracer Calibration and Uniformity Data Sheets GAS ANALYZER CALIBRATION}

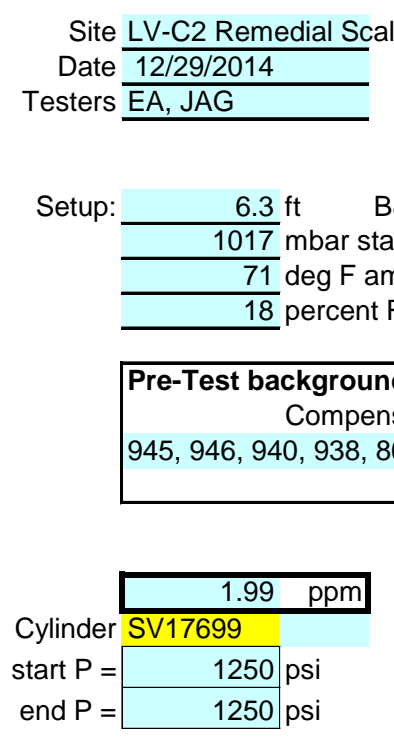

B\&K

Calibration readings:

(ppm)

\begin{tabular}{|c|}
\hline 2.14 \\
\hline 2.12 \\
\hline 2.11 \\
\hline 2.14 \\
\hline 2.12 \\
\hline 2.12 \\
\hline 2.09 \\
\hline 2.11 \\
\hline 2.10 \\
\hline 2.10 \\
\hline 2.07 \\
\hline 2.11 \\
1.061 \\
\end{tabular}

Instrument B\&K Model 1302

Serial No. 1804888

Property No. WD54623

Standards Used: $\quad$ Do Not Use Per NCR OTS-02787

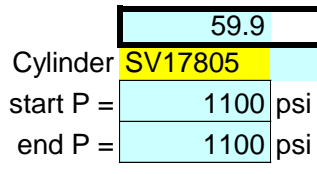

B\&K

Calibration

readings: $(\mathrm{ppm})$

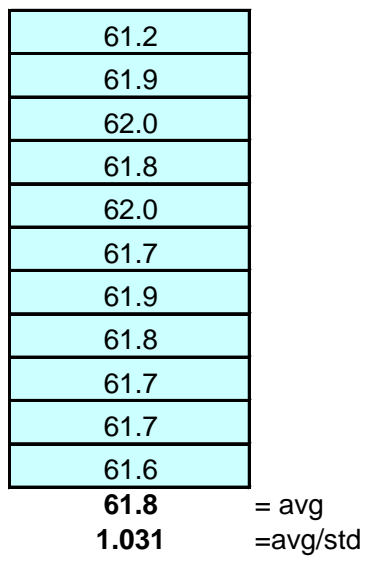

Expiration date:

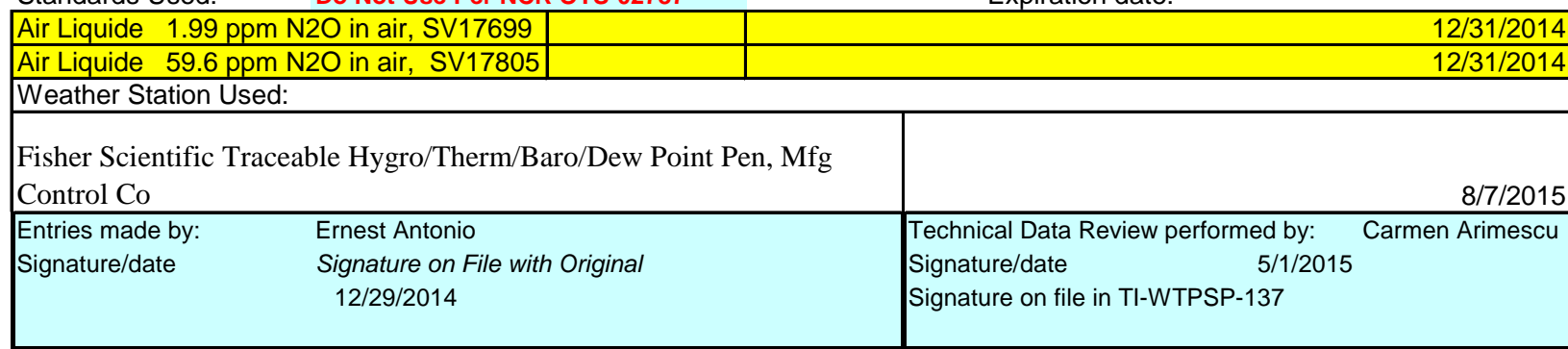




\section{GAS ANALYZER CALIBRATION}

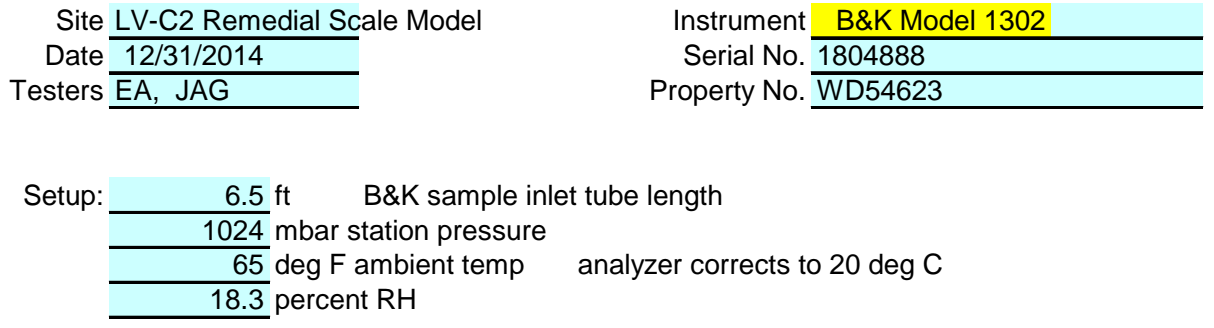
Pre-Test background, ppm
Compensating for water vapor, monitoring task 2
$0.4,0.4, .5, .6, .5, .6, .6, .6, .5, .6$

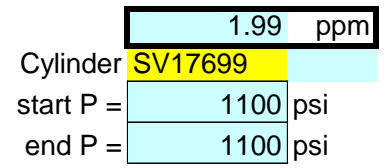

$B \& K$

Calibration readings:

(ppm)

\begin{tabular}{|c|}
\hline 2.04 \\
\hline 2.05 \\
\hline 2.05 \\
\hline 2.06 \\
\hline 2.05 \\
\hline 2.04 \\
\hline 2.05 \\
\hline 2.04 \\
\hline 2.03 \\
\hline 2.05 \\
\hline 2.04 \\
\hline 2.05 \\
\hline 1.028
\end{tabular}

Standards Used: Do Not Use Per NCR OTS-02787

\begin{tabular}{r|rr|} 
& 59.9 & $\mathrm{ppm}$ \\
Cylinder & SV17805 \\
Start $\mathrm{P}$ & $=1050 \mathrm{psi}$ \\
end $\mathrm{P}$ & $=1030 \mathrm{psi}$
\end{tabular}

B\&K

Calibration readings: (ppm)

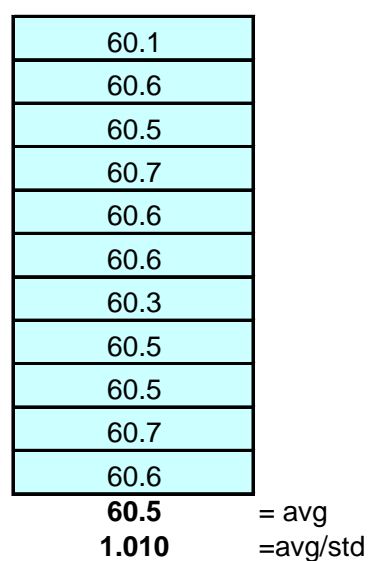

Expiration date:

Air Liquide 59.6 ppm N2O in air, Weather Station Used:

Fisher Scientific Traceable Hygro/Therm/Baro/Dew Point Pen, Mfg Control Co

Entries made by:

Ernest Antonio

Signature on file with original

$12 / 31 / 2014$ 


\section{GAS ANALYZER CALIBRATION}

Site LV-C2 Remedial Scale Model Date 2/23/2015

Testers CA,EA
Instrument B\&K Model 1302

Serial No. 1804888

Property No. WD54623

\author{
Pre-Test background, ppb \\ Compensating for water vapor, monitoring task 2 \\ $674,624,656,627,629,639,614,617,602,622$
}

analyzer corrects to 20 deg C

66.2 deg F ambient temp

$1.983 \mathrm{ppm}$

Cylinder FF17099

start $\mathrm{P}=1920$ psi

end $P=1920$ psi

\section{Cylinder FF17089}

start $\mathrm{P}=$

end $\mathrm{P}=$
$59.72 \mathrm{ppm}$

B\&K

Calibration

readings: $(\mathrm{ppm})$
Calibration readings:

(ppm)

\begin{tabular}{|c|}
\hline 2.10 \\
\hline 2.11 \\
\hline 2.12 \\
\hline 2.09 \\
\hline 2.06 \\
\hline 2.11 \\
\hline 2.10 \\
\hline 2.09 \\
\hline 2.07 \\
\hline 2.08 \\
\hline 2.09 \\
\hline 2.09 \\
\hline 1.055 \\
\hline
\end{tabular}

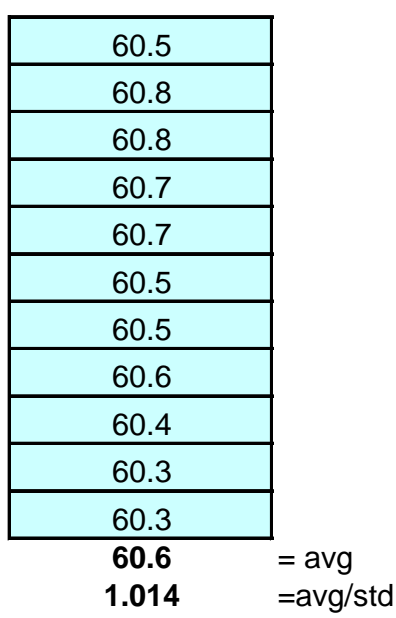

Expiration date:

Airgas 1.98 ppm, FF 17099

Airgas 59.72 ppm, FF 17089

Weather Station Used:

Fisher Scientific Traceable Hygro/Therm/Baro/Dew Point Pen, Mfg Control Co

Entries made by: $\quad$ Carmen Arimescu 2/23/2015

Signature/date Signature on file with original
$8 / 7 / 2015$

Technical Data Review performed by: Signature/date

John Glissmeyer $5 / 26 / 2015$

Signature on file in TI-WTPSP-137 


\section{GAS ANALYZER CALIBRATION}

Site LV-C2 Remedial Scale Model

Date 3/9/2015

Testers CA, EA
Instrument B\&K Model 1302

Serial No. 1804888

Property No. WD54623

Setup: $6.4 \mathrm{ft} \quad$ B\&K sample inlet tube length 1003 mbar station pressure 18.4 deg $\mathrm{C}$ ambient temp analyzer corrects to 20 deg $\mathrm{C}$ 33.3 percent $\mathrm{RH}$

Pre-Test background, ppb

Compensating for water vapor, monitoring task 2

$691,715,734,673,727,717,733,766,837,829$

$\begin{array}{rrr} & 1.983 \\ \text { Cylinder } & \text { FF17099 } \\ \text { start } P= & 1950 \mathrm{psi} \\ \text { end } \mathrm{P}= & 1930 \mathrm{psi}\end{array}$

B\&K

Calibration readings:

(ppm)

\begin{tabular}{|c|}
\hline 2.09 \\
\hline 2.08 \\
\hline 2.09 \\
\hline 2.09 \\
\hline 2.08 \\
\hline 2.08 \\
\hline 2.08 \\
\hline 2.06 \\
\hline 2.07 \\
\hline 2.06 \\
\hline 2.06 \\
\hline 2.08 \\
\hline 1.047 \\
\hline
\end{tabular}

B\&K

Calibration readings: $(\mathrm{ppm})$

\begin{tabular}{|c|}
\hline 59.8 \\
\hline 61.8 \\
\hline 61.8 \\
\hline 61.6 \\
\hline 61.4 \\
\hline 61.4 \\
\hline 61.4 \\
\hline 61.4 \\
\hline 61.3 \\
\hline 61.1 \\
\hline 61.1 \\
\hline 61.3 \\
\hline 1.026 \\
\hline
\end{tabular}

Expiration date:

Airgas 1.98 ppm, FF 17099

Airgas 59.72 ppm, FF 17089

Cylinder FF17089

start $\mathrm{P}=$

end $P=$

\begin{aligned} 1900 & psi \\ \hline 1900 & psi \end{aligned}

$9.72 \mathrm{ppm}$

1900 psi Weather Station Used:

Fisher Scientific Traceable Hygro/Therm/Baro/Dew Point Pen, Mfg Control Co

Entries made by:

Signature/date

Carmen Arimescu 3/9/2015

Signature on file with original
Technical Data Review performed by: Signature/date John Glissmeyer $5 / 28 / 2015$

Signature on file in TI-WTPSP-137 


\section{GAS ANALYZER CALIBRATION}

Site LV-C2 Remedial Scale Model Date 3/16/2015 Testers CA, EA
Instrument B\&K Model 1302

Serial No. 1804888

Property No. WD54623

Setup: $6.4 \mathrm{ft} \quad$ B\&K sample inlet tube length 1009 mbar station pressure 19.3 deg $\mathrm{C}$ ambient temp analyzer corrects to 20 deg $\mathrm{C}$ 32.1 percent $\mathrm{RH}$

Pre-Test background, ppb

Compensating for water vapor, monitoring task 2

$714,730,712,703,679,607,593,609,599,594$

$\begin{array}{rrr} & 1.983 \\ \text { Cylinder } & \text { FF17099 } \\ \text { start } P= & 1910 \\ \text { end } P= & 1910 \mathrm{psi}\end{array}$

B\&K

Calibration readings:

(ppm)

\begin{tabular}{|c|}
\hline 2.09 \\
\hline 2.09 \\
\hline 2.07 \\
\hline 2.05 \\
\hline 2.06 \\
\hline 2.06 \\
\hline 2.07 \\
\hline 2.05 \\
\hline 2.05 \\
\hline 2.06 \\
\hline 2.04 \\
\hline 2.06 \\
\hline 1.041 \\
\hline
\end{tabular}

B\&K

Calibration readings: $(\mathrm{ppm})$

\begin{tabular}{|c|}
\hline 60.4 \\
\hline 61.6 \\
\hline 61.3 \\
\hline 61.6 \\
\hline 61.5 \\
\hline 61.3 \\
\hline 61.1 \\
\hline 61.2 \\
\hline 61.2 \\
\hline 61.2 \\
\hline 61.3 \\
\hline 61.2 \\
\hline 1.026 \\
\hline
\end{tabular}

Expiration date:

Airgas 1.98 ppm, FF 17099

Airgas 59.72 ppm, FF 17089

Cylinder FF17089

start $\mathrm{P}=$

end $\mathrm{P}=$

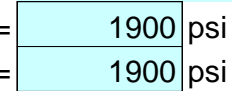

$9.72 \mathrm{ppm}$

1900 psi Weather Station Used:

Fisher Scientific Traceable Hygro/Therm/Baro/Dew Point Pen, Mfg Control Co

Entries made by:

Carmen Arimescu 3/16/2015

Signature on file with original

Technical Data Review performed by: Signature/date 


\section{GAS ANALYZER CALIBRATION}

Site LV-C2 Remedial Scale Model Date 3/17/2015 Testers CA, EA
Instrument B\&K Model 1302

Serial No. 1804888

Property No. WD54623

Setup: $6.4 \mathrm{ft} \quad$ B\&K sample inlet tube length 1004 mbar station pressure 17.2 deg $\mathrm{C}$ ambient temp analyzer corrects to 20 deg $\mathrm{C}$ 50.1 percent $\mathrm{RH}$

Pre-Test background, ppb

Compensating for water vapor, monitoring task 2

$556,542,543,524,520,527,529,518,512,504$

\begin{tabular}{r|r|} 
& 1.983 \\
Cylinder FF17099
\end{tabular}

B\&K

Calibration readings:

(ppm)

\begin{tabular}{|c|}
\hline 2.01 \\
\hline 1.99 \\
\hline 2.00 \\
\hline 2.01 \\
\hline 1.98 \\
\hline 1.98 \\
\hline 1.97 \\
\hline 1.98 \\
\hline 2.01 \\
\hline 1.97 \\
\hline 2.00 \\
\hline 1.99 \\
\hline 1.004 \\
\hline
\end{tabular}

$59.72 \mathrm{ppm}$ Cylinder FF17089 start $P=1850$ psi end $P=1800$ psi
B\&K

Calibration readings: $(\mathrm{ppm})$

Standards Used:

Airgas 1.98 ppm, FF 17099

Airgas 59.72 ppm, FF 17089

\begin{tabular}{|c|}
\hline 59.3 \\
\hline 59.7 \\
\hline 59.7 \\
\hline 59.8 \\
\hline 59.7 \\
\hline 59.6 \\
\hline 59.7 \\
\hline 59.7 \\
\hline 59.7 \\
\hline 59.5 \\
\hline 59.6 \\
\hline 59.6 \\
\hline 0.999 \\
\hline
\end{tabular}

Weather Station Used:

Fisher Scientific Traceable Hygro/Therm/Baro/Dew Point Pen, Mfg Control Co

Entries made by: Signature/date

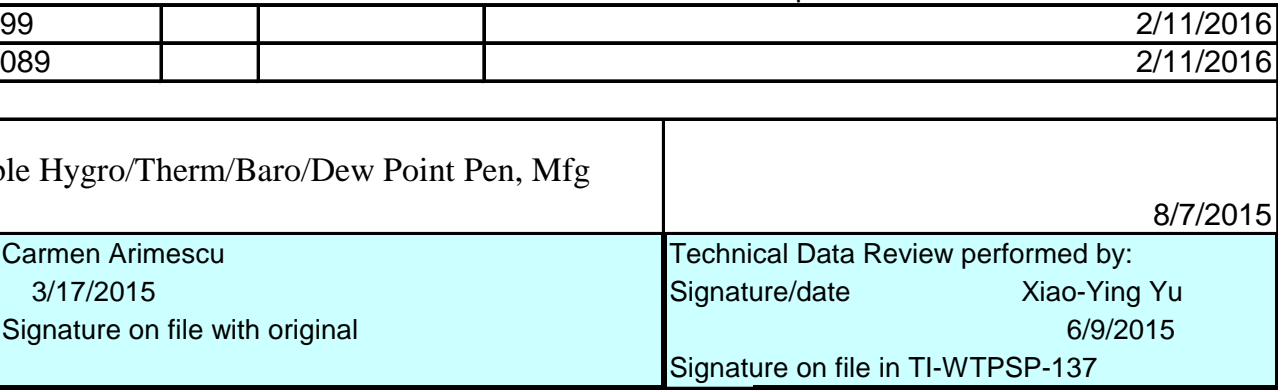

Expiration date: 


\section{GAS ANALYZER CALIBRATION}

\author{
Site LV-C2 Remedial Scale Model \\ Date 5/18/2015 \\ Testers CA, EA
}

Instrument B\&K Model 1302

Serial No. 1804888

Property No. WD54623

Setup: $6.4 \mathrm{ft} \quad$ B\&K sample inlet tube length

1003 mbar station pressure 20.2 deg $C$ ambient temp analyzer corrects to 20 deg C 36.3 percent $\mathrm{RH}$

$\begin{gathered}\text { Pre-Test background, ppb } \\ \text { Compensating for water vapor, monitoring task } 2 \\ 660,640,643,634,611,622,587,587,603,553\end{gathered}$

\begin{tabular}{rr|r|}
\cline { 2 - 2 } & 1.983 \\
Cylinder FF17099 & F \\
start $P=$ & 1900 & psi \\
end $P=$ & 1900 & psi
\end{tabular}

$B \& K$

Calibration readings:

(ppm)

\begin{tabular}{|c|}
\hline 2.05 \\
\hline 2.06 \\
\hline 2.06 \\
\hline 2.06 \\
\hline 2.06 \\
\hline 2.05 \\
\hline 2.05 \\
\hline 2,05 \\
\hline 2.03 \\
\hline 2.03 \\
\hline 2.02 \\
\hline 2.05 \\
\hline 1.032 \\
\hline
\end{tabular}

Standards Used:

Airgas 1.98 ppm, FF 17099

Airgas 59.72 ppm, FF 17089

Weather Station Used:

Fisher Scientific Traceable Hygro/Therm/Baro/Dew Point Pen, Mfg Control Co Entries made by: Signature/date

Carmen Arimescu
$5 / 18 / 2015$
Signature on file with original

$59.72 \mathrm{ppm}$

Cylinder FF17089

$\begin{aligned} \text { start } P= & 1800 \text { psi } \\ \text { end } P & =1800 \text { psi }\end{aligned}$

B\&K

Calibration readings: (ppm)

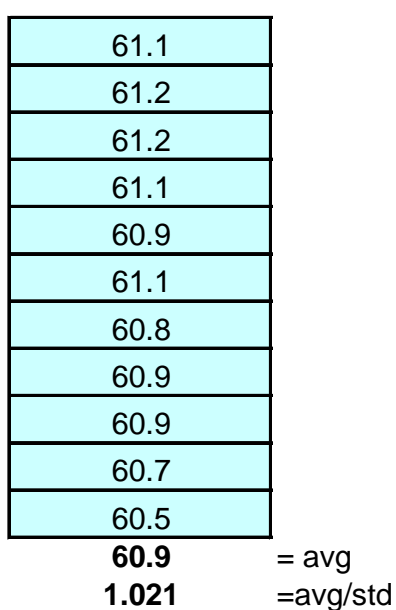

Expiration date: 
GAS ANALYZER CALIBRATION

\begin{aligned} & Site LV-C2 Remedial Scale Model \\ & Date 5/19/2015 \\ & Testers \\ & \cline { 2 - 2 }\end{aligned}

Instrument B\&K Model 1302

Serial No. 1804888

Property No. WD54623

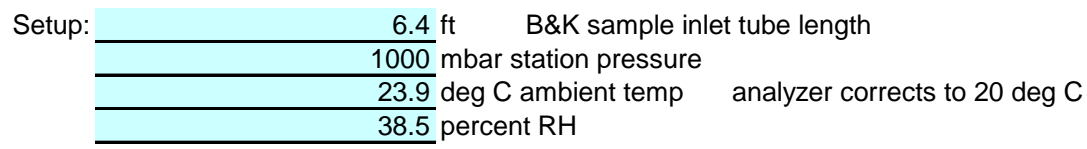

Pre-Test background, ppb

Compensating for water vapor, monitoring task 2

$510,505,488,497,488,469,466,464,484,470$

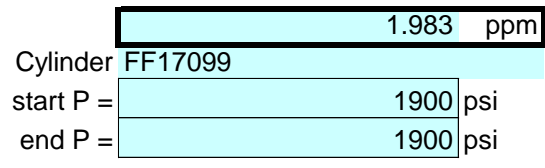

\begin{tabular}{rlr|} 
& $59.72 \mathrm{ppm}$ \\
Cylinder FF17089 \\
start $\mathrm{P}=$ \\
end $\mathrm{P}=$ & $1800 \mathrm{psi}$ \\
1750 & $\mathrm{psi}$
\end{tabular}

B\&K

Calibration readings:

(ppm)

\begin{tabular}{|c|}
\hline 1.92 \\
\hline 1.93 \\
\hline 1.93 \\
\hline 1.96 \\
\hline 1.94 \\
\hline 1.94 \\
\hline 1.96 \\
\hline 1.94 \\
\hline 1.93 \\
\hline 1.91 \\
\hline 1.94 \\
\hline 1.94 \\
\hline 0.976 \\
\hline
\end{tabular}

B\&K

Calibration

readings: (ppm)

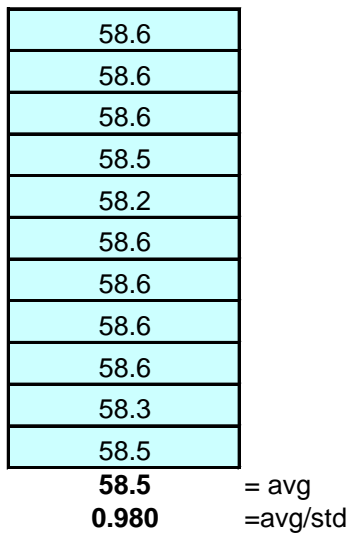

Expiration date:

Standards Used:

Airgas 1.98 ppm, FF 17099

Airgas 59.72 ppm, FF 17089

$2 / 11 / 2016$ $2 / 11 / 2016$ Weather Station Used:

Fisher Scientific Traceable Hygro/Therm/Baro/Dew Point Pen, Mfg Control Co Entries made by: Carmen Arimescu $5 / 19 / 2015$

Signature on file with original 
TRACER GAS TRAVERSE DATA FORM

Site LV-C2_Rem Scale Model

Date 12/30/2014

Testers EA, YFS

Stack Dia. 11.922 in.

Stack X-Area 111.6 in.2

Test Port 1

Distance to disturbance

Measurement units ppm N2O

1

Order -->

Traverse-->

Trial ---->

$1 \mathrm{st}$

\section{.}

Run No. GT-1

Fan Configuration
Fan Setting $\mathbf{5 9}$

Stack Temp

Start/End Time $1000 / 1210$

Center $2 / 3$ from

Points in Center 2/3

Injection Point I 3 Center

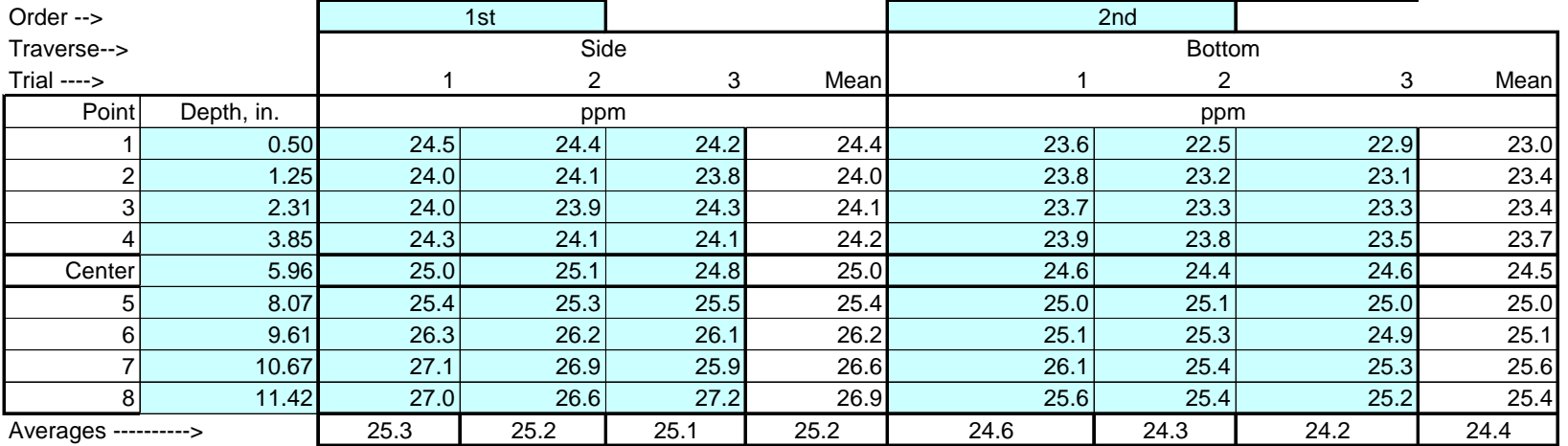

Avg. Conc.

\begin{tabular}{|lr}
\hline All & ppm \\
Mean & 24.77 \\
Min Point & 23.00 \\
Max Point & 26.93 \\
\hline
\end{tabular}

$24.775 \mathrm{ppm}$

Tracer tank pressure Injection flowmeter

Stack Temp

Mean stack velocity

Sampling flowmeter

Ambient pressure

Ambient humidity

Ambient Temp

B\&K vapor correction

Back-Gd gas

No. Bk-Gd samples

\begin{tabular}{|c|c|}
\hline Start & Finish \\
\hline 390 & 390 \\
\hline 1.6 & 1.6 \\
\hline 55.8 & 58.4 \\
\hline 3129 & 3253 \\
\hline 10 & 10 \\
\hline 30.5 & 30.48 \\
\hline $16.2 \%$ & $13.9 \%$ \\
\hline 9.4 & 12.2 \\
\hline $\mathrm{Y}$ & $Y$ \\
\hline $\begin{array}{c}.538, .594, \\
.577 \\
\end{array}$ & $\begin{array}{c}.7, .5, .4, .4 \\
.4\end{array}$ \\
\hline 5 & 5 \\
\hline
\end{tabular}

Gas analyzer checked:

$12 / 29 / 2014$

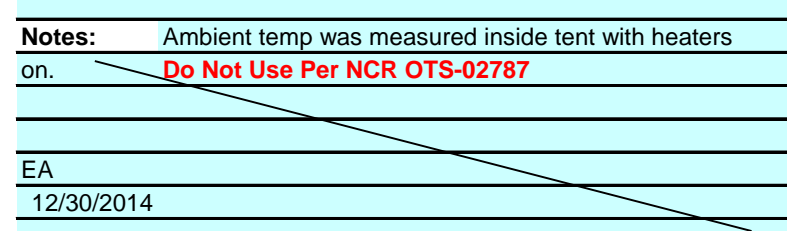

Entries made by:

Signature/date

Ernest Antonio

Signature on file with original

$12 / 30 / 2014$

\begin{tabular}{|c|c|c|c|c|}
\hline Dev. from mean & Center $2 / 3$ & Side & Bottom & All \\
\hline & Mean & 25.06 & 24.40 & 24.73 \\
\hline$-7.2 \%$ & Std. Dev. & 1.07 & 0.89 & 1.01 \\
\hline $8.7 \%$ & cov as $\%$ & 4.3 & 3.7 & 4.1 \\
\hline
\end{tabular}

Instuments Used:

B\&K 1302 Gas Analyzer SN

1804888 Cat2 M\&TE

TSI Velocicalc SN\#T95351203001 $8 / 15 / 2015$ 122277883 $8 / 7 / 2015$

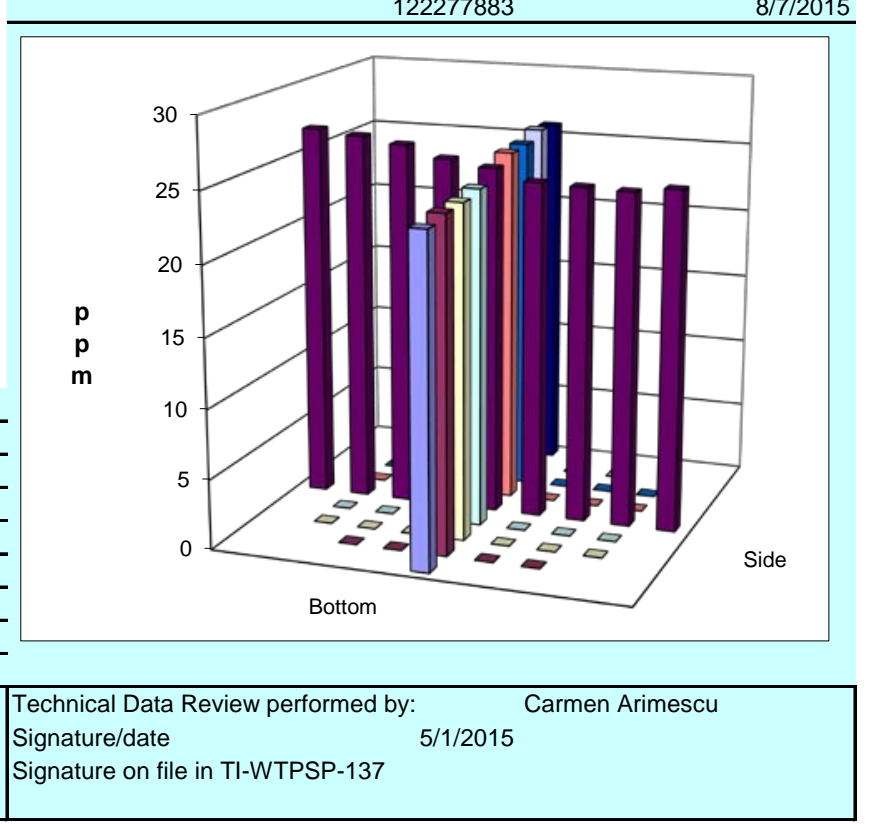

Fisher Scientific Barometer Hydro/Therm/Baro/Dew Point Pen 
TRACER GAS TRAVERSE DATA FORM

Site LV-C2_Rem Scale Model

Date 12/30/2014

Testers EA, JAG

Stack Dia. 11.922 in

Stack X-Area 111.6 in. 2

Test Port 1

Distance to disturbance

Measurement units ppm N2O

Order -->

Traverse-->

Trial -.-->

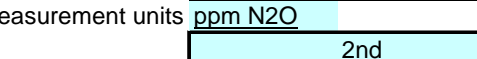

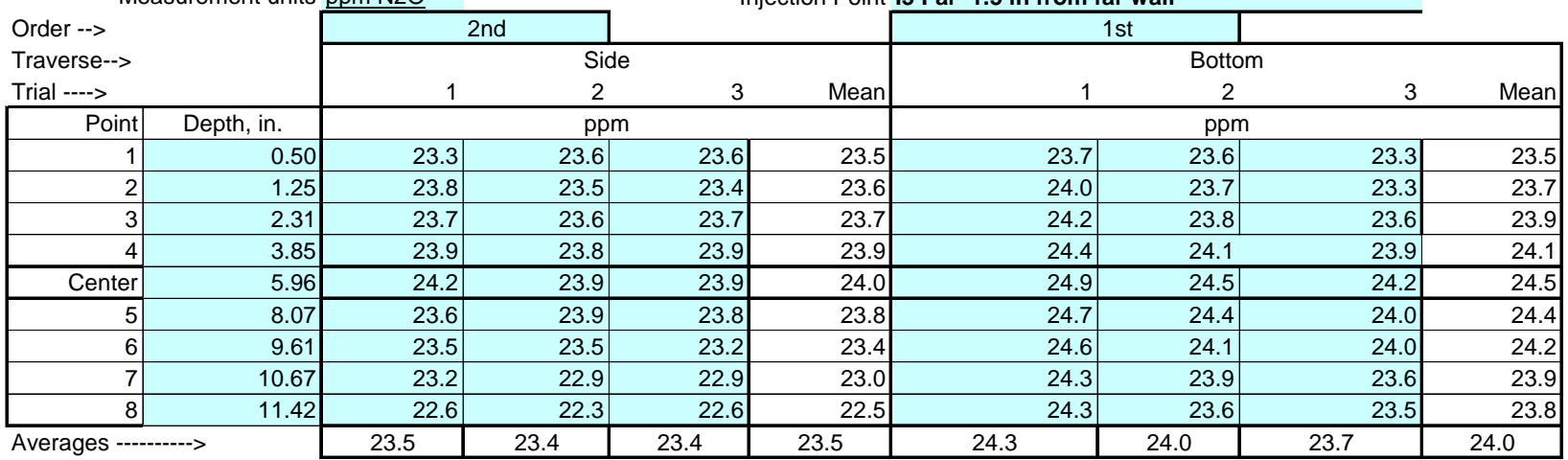

Avg. Conc.

$23.675 \mathrm{ppm}$

\begin{tabular}{|lr}
\hline All & ppm \\
Mean & 23.74 \\
Min Point & 22.50 \\
Max Point & 24.53 \\
\hline
\end{tabular}

Tracer tank pressure Injection flowmeter

Stack Temp

Mean stack velocity

Sampling flowmeter

Ambient pressure

Ambient humidity

Ambient Temp

B\&K vapor correction

Back-Gd gas

No. Bk-Gd samples

\begin{tabular}{|c|c|}
\hline Start & Finish \\
\hline 450 & 450 \\
\hline 1.6 & 1.6 \\
\hline 56.8 & 56.8 \\
\hline 3121 & 3089 \\
\hline 10 & 10 \\
\hline 1031 & 1031 \\
\hline $15 \%$ & $15 \%$ \\
\hline 12 & 12.7 \\
\hline$Y$ & $\mathrm{Y}$ \\
\hline $\begin{array}{c}0.5, .5, .5 \\
.5, .5\end{array}$ & $\begin{array}{c}.6, .4, .4, .4 \\
.4\end{array}$ \\
\hline 5 & 5 \\
\hline
\end{tabular}

Gas analyzer checked:

$12 / 29 / 2014$

Notes: Duct heaters ON. Tent heaters ON. Ambient Conditions taken inside tent.

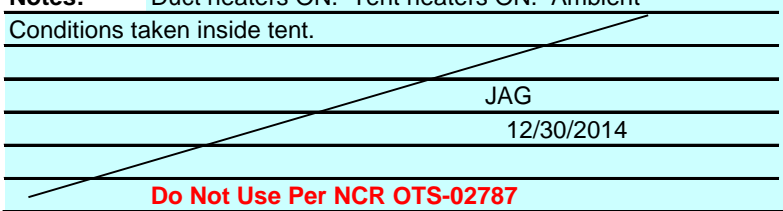

Entries made by: $\quad$ Ernest Antonio

Signature/date Signature on file with original

$12 / 30 / 2014$
Run No. GT-2

Fan Configuration B Max

Fan Setting $\mathbf{5 9}$

Stack Temp

Start/End Time $1415 / 1600$

Center $2 / 3$ from

Points in Center 2/3

Injection Point 13 Far 1.5 in from far wall

\begin{tabular}{r|l} 
Dev. from mean & Center $2 / 3$ \\
$-5.2 \%$ & Mean \\
$3.3 \%$ & COV as \% \\
\hline
\end{tabular}

Side
23.61
0.33
1.4

\begin{tabular}{rr|} 
Bottom & All \\
\hline 24.10 & 23.86 \\
0.30 & 0.40 \\
& 1.3 \\
\hline
\end{tabular}

Instuments Used:

B\&K 1302 Gas Analyzer SN

1804888 Cat2 M\&TE

TSI Velocicalc SN\#T95351203001 $8 / 15 / 2015$

Fisher Scientific Barometer Hydro/Therm/Baro/Dew Point Pen 122277883 $8 / 7 / 2015$

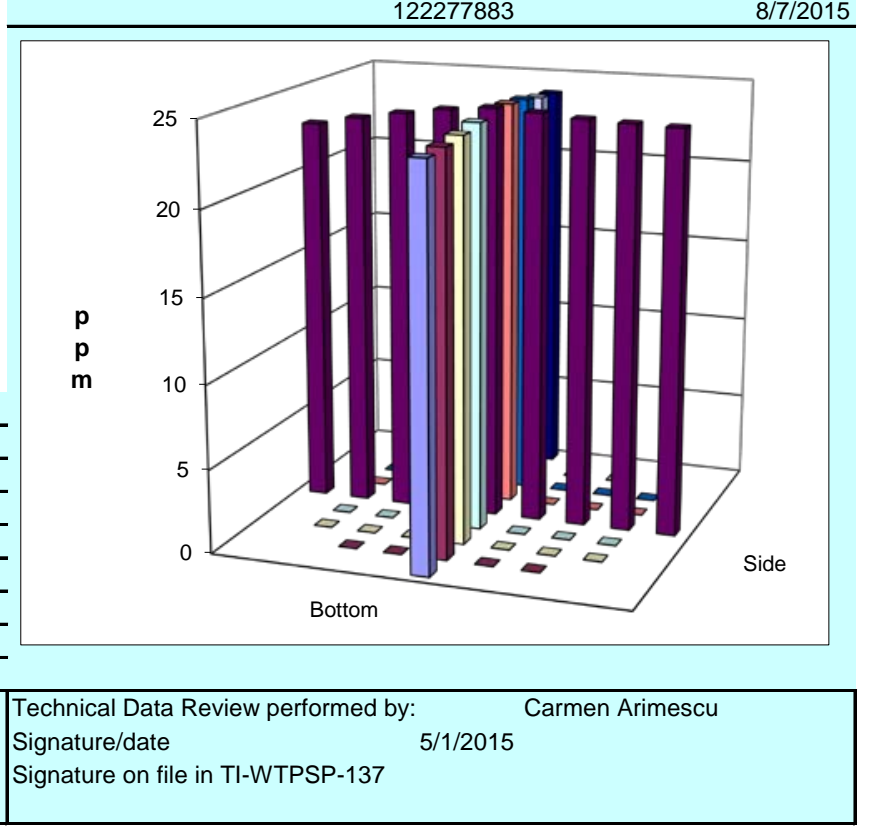


TRACER GAS TRAVERSE DATA FORM

Date 12/31/2014

Testers EA, YFS

Stack Dia. 11.922 in.

Stack X-Area 111.6 in.2

Test Port 1

Distance to disturbance

Measurement units ppm N2O

Order -->

Traverse-->

Trial -.-->

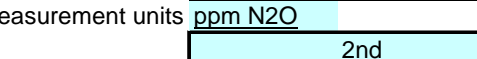

\begin{tabular}{|c|c|c|c|c|c|c|c|c|c|}
\hline \multirow{4}{*}{\multicolumn{2}{|c|}{$\begin{array}{l}\text { Order --> } \\
\text { Traverse--> } \\
\text { Trial ----> }\end{array}$}} & $\mathrm{m} \mathrm{IN}$ & & \multicolumn{5}{|c|}{ 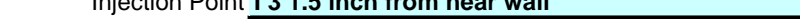 } & \multirow{4}{*}{ Mean } \\
\hline & & \multicolumn{2}{|c|}{ 2nd } & & & \multicolumn{2}{|c|}{$1 \mathrm{st}$} & & \\
\hline & & \multicolumn{4}{|c|}{ Side } & \multicolumn{3}{|c|}{ Bottom } & \\
\hline & & 1 & 2 & 3 & Mean & 1 & 2 & 3 & \\
\hline Point & Depth, in. & \multicolumn{4}{|c|}{ ppm } & \multicolumn{4}{|c|}{ ppm } \\
\hline 1 & 0.50 & 26.3 & 25.9 & 26.1 & 26.1 & 26.0 & 26.1 & 26.3 & 26.1 \\
\hline 2 & 1.25 & 26.2 & 26.0 & 25.7 & 26.0 & 26.1 & 26.0 & 26.5 & 26.2 \\
\hline 3 & 2.31 & 25.6 & 25.2 & 24.9 & 25.2 & 26.1 & 25.9 & 26.0 & 26.0 \\
\hline 4 & 3.85 & 25.3 & 24.7 & 25.1 & 25.0 & 25.8 & 25.5 & 25.7 & 25.7 \\
\hline Center & 5.96 & 24.8 & 24.5 & 24.7 & 24.7 & 24.8 & 25.0 & 25.0 & 24.9 \\
\hline 5 & 8.07 & 24.2 & 24.3 & 24.1 & 24.2 & 24.3 & 24.4 & 24.2 & 24.3 \\
\hline 6 & 9.61 & 24.2 & 24.3 & 24.3 & 24.3 & 24.2 & 23.7 & 23.9 & 23.9 \\
\hline 7 & 10.67 & 24.5 & 24.1 & 24.0 & 24.2 & 24.2 & 24.1 & 23.6 & 24.0 \\
\hline 8 & 11.42 & 25.3 & 23.9 & 24.1 & 24.4 & 23.9 & 24.0 & 23.8 & 23.9 \\
\hline \multicolumn{2}{|c|}{ Averages ---------> } & 25.2 & 24.8 & 24.8 & 24.9 & 25.0 & 25.0 & 25.0 & 25.0 \\
\hline
\end{tabular}

Avg. Conc.

$24.971 \mathrm{ppm}$

Tracer tank pressure Injection flowmeter

Stack Temp

Mean stack velocity

Sampling flowmeter

Ambient pressure

Ambient humidity

Ambient Temp

B\&K vapor correction

Back-Gd gas

No. Bk-Gd samples

Gas analyzer checked:

\begin{tabular}{|c|c|}
\hline Start & Finish \\
\hline 300 & 310 \\
\hline 1.6 & 1.6 \\
\hline 42.6 & 54.1 \\
\hline 3130 & 3160 \\
\hline 10 & 10 \\
\hline 1029 & 1028.00 \\
\hline $28.3 \%$ & $21.8 \%$ \\
\hline 4.6 & 11 \\
\hline $\mathrm{Y}$ & $\bar{Y}$ \\
\hline $\begin{array}{c}.6, .6, .6, .6 \\
.6\end{array}$ & $\begin{array}{c}.7, .5, .5, .5 \\
.5\end{array}$ \\
\hline 5 & 5 \\
\hline
\end{tabular}

$12 / 29 / 2014$

Notes: $\quad$ Temperature outside tent in the teens to low 20s. Do Not Use Per NCR OTS-02787

\begin{tabular}{|c|c|}
\hline EA & 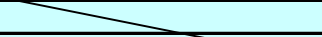 \\
\hline $12 / 31 / 2014$ & \\
\hline $\begin{array}{l}\text { Entries made by: } \\
\text { Signature/date }\end{array}$ & $\begin{array}{l}\text { Ernest Antonio } \\
\text { Signature on file with original } \\
12 / 31 / 2014\end{array}$ \\
\hline
\end{tabular}

Site LV-C2_Rem Scale Model

Run No. GT-3

Fan Configuration B Max

Fan Setting $\mathbf{5 9}$

Stack Temp

Start/End Time $0915 / 1050$

Center $2 / 3$ from

Points in Center 2/3

31.5 inch from near wall

$\frac{1.09}{2}$ to: $\frac{10.83}{7}$

7

\begin{tabular}{|lr}
\hline All & ppm \\
Mean & 24.95 \\
Min Point & 23.90 \\
Max Point & 26.20 \\
\hline
\end{tabular}

\begin{tabular}{r|l} 
Dev. from mean & Center $2 / 3$ \\
$-4.2 \%$ & Mean \\
$5.0 \%$ & Std. Dev. \\
Cov as \%
\end{tabular}

Side

24.80

0.66

2.7

\begin{tabular}{rr|}
\hline Bottom & All \\
\hline 25.00 & 24.90 \\
0.96 & 0.80 \\
3.9 & $\mathbf{3 . 2}$ \\
\hline
\end{tabular}

Instuments Used:

B\&K 1302 Gas Analyzer SN

1804888 Cat2 M\&TE

TSI Velocicalc SN\#T95351203001 $8 / 15 / 2015$

Fisher Scientific Barometer Hydro/Therm/Baro/Dew Point Pen 122277883 $8 / 7 / 2015$

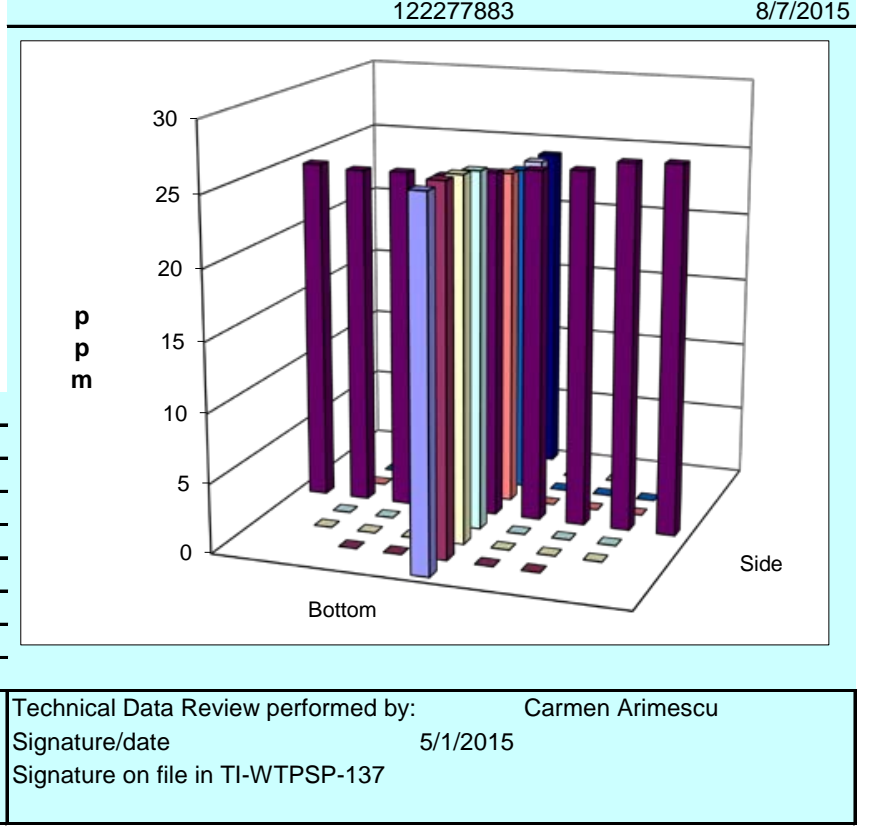




\begin{tabular}{|c|c|c|c|c|c|c|c|c|c|}
\hline & & & RACER GAS & TRAVERSE & DATA FOR & & & & \\
\hline & Site & LV-C2_Rem & Scale Model & & Run No. & GT-4 & & & \\
\hline & Date & $12 / 31 / 2014$ & & Fan $C$ & Configuration & B Max & & & \\
\hline & Testers & JAG, EA & & & Fan Setting & 59 & & & \\
\hline & Stack Dia. & 11.922 & & & Stack Temp & 57.75 & & & \\
\hline & Stack X-Area & 111.6 & in. 2 & & tart/End Time & $1405 / 1535$ & & & \\
\hline & Test Port & 1 & & & enter $2 / 3$ from & 1.09 & to: & 10.83 & \\
\hline Distanc & to disturbance & 119.88 & inches & Points & in Center 2/3. & 2 & to: & 7 & \\
\hline & surement units & ppm N2O & & & njection Point & 13 Top & & & \\
\hline Order --> & & & 2nd & & & & & & \\
\hline Traverse--> & & & Sid & de & & & Bottor & & \\
\hline Trial ----> & & 1 & 2 & 3 & Mean & 1 & 2 & 3 & Mean \\
\hline Point & Depth, in. & & $\mathrm{ppr}$ & $\mathrm{m}$ & & & $\mathrm{ppm}$ & & \\
\hline 1 & 0.50 & 24.3 & 24.1 & 23.8 & 24.1 & 26.0 & 25.5 & 25.2 & 25.6 \\
\hline 2 & 1.25 & 24.5 & 24.1 & 24.0 & 24.2 & 25.8 & 25.2 & 25.4 & 25.5 \\
\hline 3 & 2.31 & 24.3 & 23.9 & 23.8 & 24.0 & 25.8 & 25.2 & 25.1 & 25.4 \\
\hline 4 & 3.85 & 24.2 & 24.0 & 24.0 & 24.1 & 25.4 & 25.0 & 24.9 & 25.1 \\
\hline Center & 5.96 & 24.0 & 24.0 & 23.8 & 23.9 & 25.3 & 24.7 & 24.6 & 24.9 \\
\hline 5 & 8.07 & 24.1 & 23.9 & 24.0 & 24.0 & 25.0 & 24.8 & 24.4 & 24.7 \\
\hline 6 & 9.61 & 24.6 & 24.1 & 24.4 & 24.4 & 25.4 & 24.9 & 24.6 & 25.0 \\
\hline 7 & 10.67 & 24.6 & 24.6 & 24.5 & 24.6 & 25.1 & 24.9 & 24.3 & 24.8 \\
\hline 8 & 11.42 & 24.9 & 24.6 & 24.6 & 24.7 & 25.1 & 24.7 & 24.5 & 24.8 \\
\hline Averages ----- & $-\cdots$ & 24.4 & 24.1 & 24.1 & 24.2 & 25.4 & 25.0 & 24.8 & 25.1 \\
\hline & & All & $\mathrm{ppm}$ & & v. from mean & Center 2/3 & Side & Bottom & All \\
\hline & & Mean & 24.64 & & & Mean & 24.16 & 25.04 & 24.60 \\
\hline & & Min Point & 23.93 & & $-2.9 \%$ & Std. Dev. & 0.23 & 0.29 & 0.52 \\
\hline & & Max Point & 25.57 & & $3.8 \%$ & cov as $\%$ & 1.0 & 1.1[ & 2.1 \\
\hline Avg. Conc. & 24.669 & $\mathrm{ppm}$ & & & Instuments L & Used: & & & \\
\hline & & & & & B\&K $1302 \mathrm{Ga}$ & as Analyzer & & $1804888 \mathrm{C}$ & at2 M\&TE \\
\hline & & Start & Finish & & TSI Velocicalc & Ic SN\#T95351203001 & & & $8 / 15 / 2015$ \\
\hline Tracer tank pr & essure & 400 & 400 & psig & Fisher Scienti & tific Barometer Hydro & erm/Baro/D & Dew Point Pen & \\
\hline Injection flown & neter & 1.6 & 1.6 & slpm & & & 22277883 & & $8 / 7 / 2015$ \\
\hline Stack Temp & & 58.8 & 56.7 & ${ }^{\circ} \mathrm{F}$ & & & & & \\
\hline Mean stack ve & locity & 3131 & 3100 & afpm & & & & & \\
\hline Sampling flow & meter & 10 & 10 & Ipm & & 30 & & & \\
\hline Ambient press & & 1025 & 1024 & mbar & & & & & \\
\hline Ambient humi & & $20 \%$ & $15 \%$ & $\mathrm{RH}$ & & 25 & & & \\
\hline Ambient Temr & & 12 & 17.3 & ${ }^{\circ} \mathrm{C}$ & & & & & \\
\hline B\&K vapor co & rection & $\mathrm{Y}$ & $\mathrm{Y}$ & $\mathrm{Y} / \mathrm{N}$ & & & & & \\
\hline Back-Gd gas & & $\begin{array}{c}.5, .5, .5, .5 \\
.5\end{array}$ & $\begin{array}{c}.5, .4, .4, .4 \\
.4\end{array}$ & ppm & p & 20 & & & \\
\hline No. Bk-Gd sar & nples & 5 & 5 & $n$ & & 15 & & & \\
\hline Gas analyzer & checked: & $12 / 29 / 2014$ & & & 1 & 10 & & & \\
\hline Notes: & eplaced injectio & on probe with o & ne with $27 / 8 "$ & ' hook. & & & & & \\
\hline Do Not Use P & er NCR OTS-02 & & 2 & & & & & & \\
\hline & & & JAG & & & & & & Side \\
\hline & $\simeq$ & & $12 / 31 / 2014$ & & & Bottom & & & \\
\hline 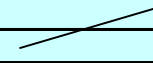 & & & & & & & & & \\
\hline Entries made & & J. Glissmeyer & & & Technical Dat & ta Review performed & & Carmen Arimescu & \\
\hline Signature/date & & $\begin{array}{l}12 / 31 / 2014 \\
\text { Signature on } f\end{array}$ & file with origina & & Signature/dat & $\begin{array}{l}\text { te } \\
\text { |Signature on file in } T\end{array}$ & $\begin{array}{l}\text { 5/1/2015 } \\
\text { WTPSP-137 }\end{array}$ & 37 & \\
\hline
\end{tabular}


TRACER GAS TRAVERSE DATA FORM

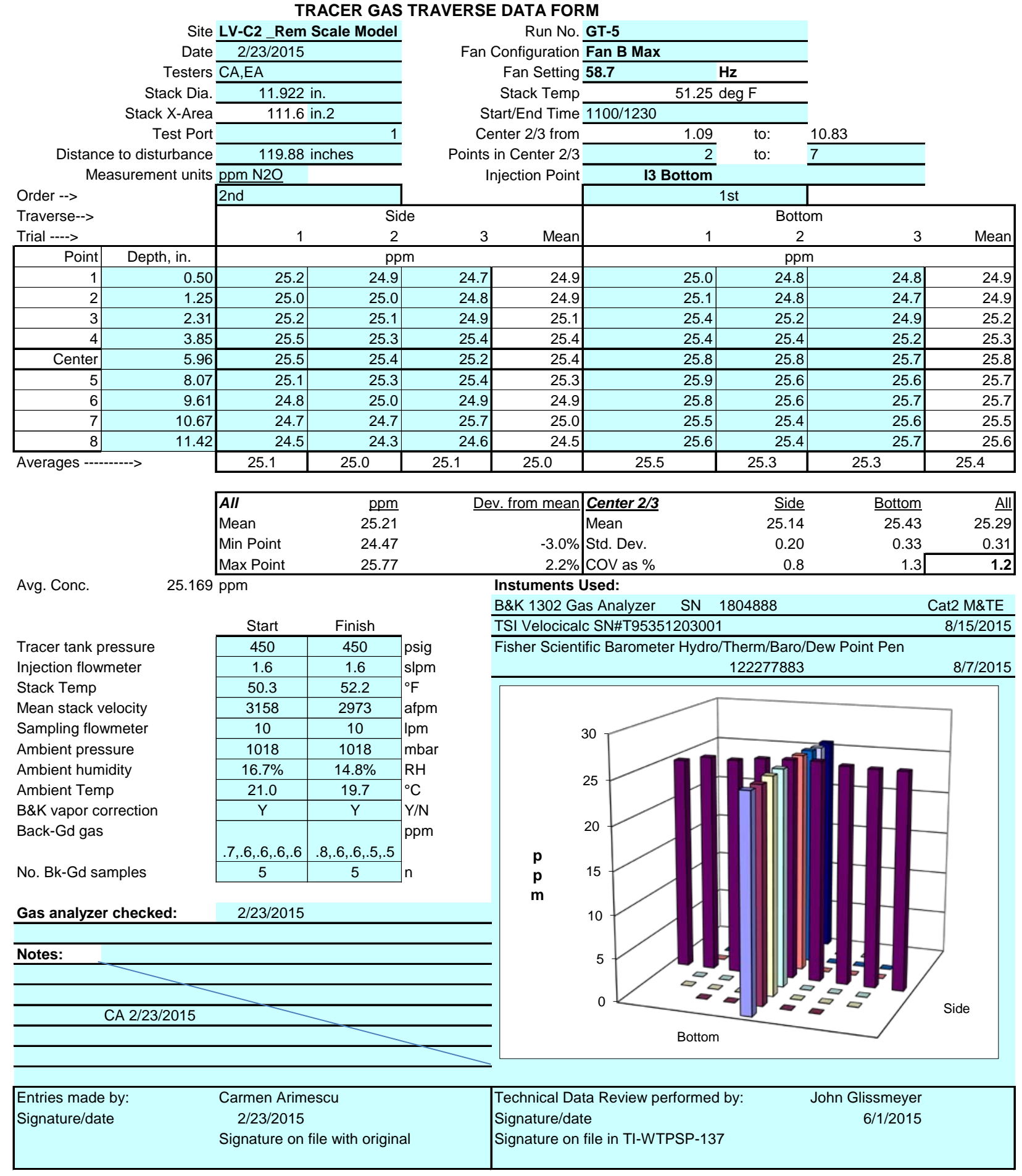


TRACER GAS TRAVERSE DATA FORM

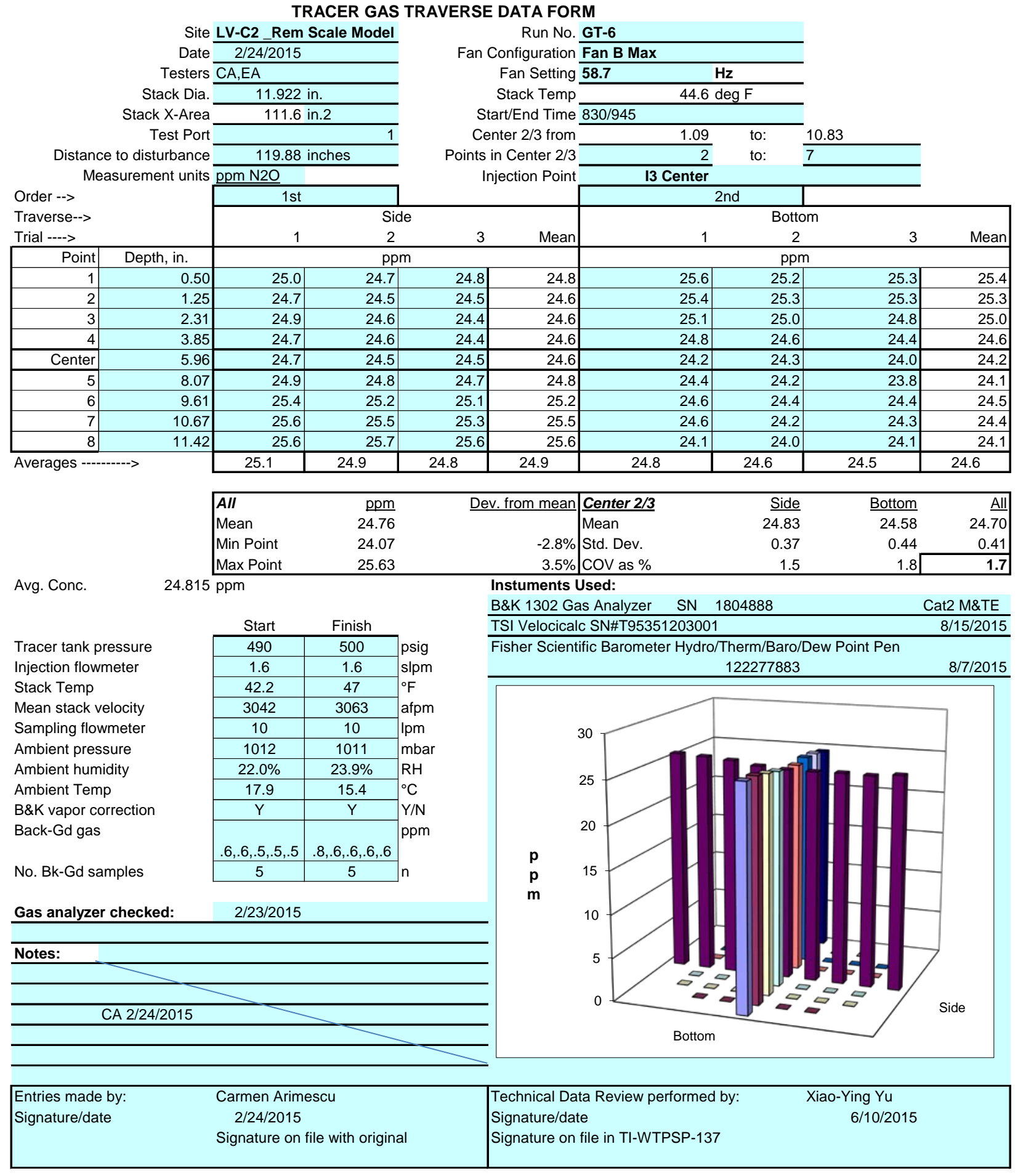




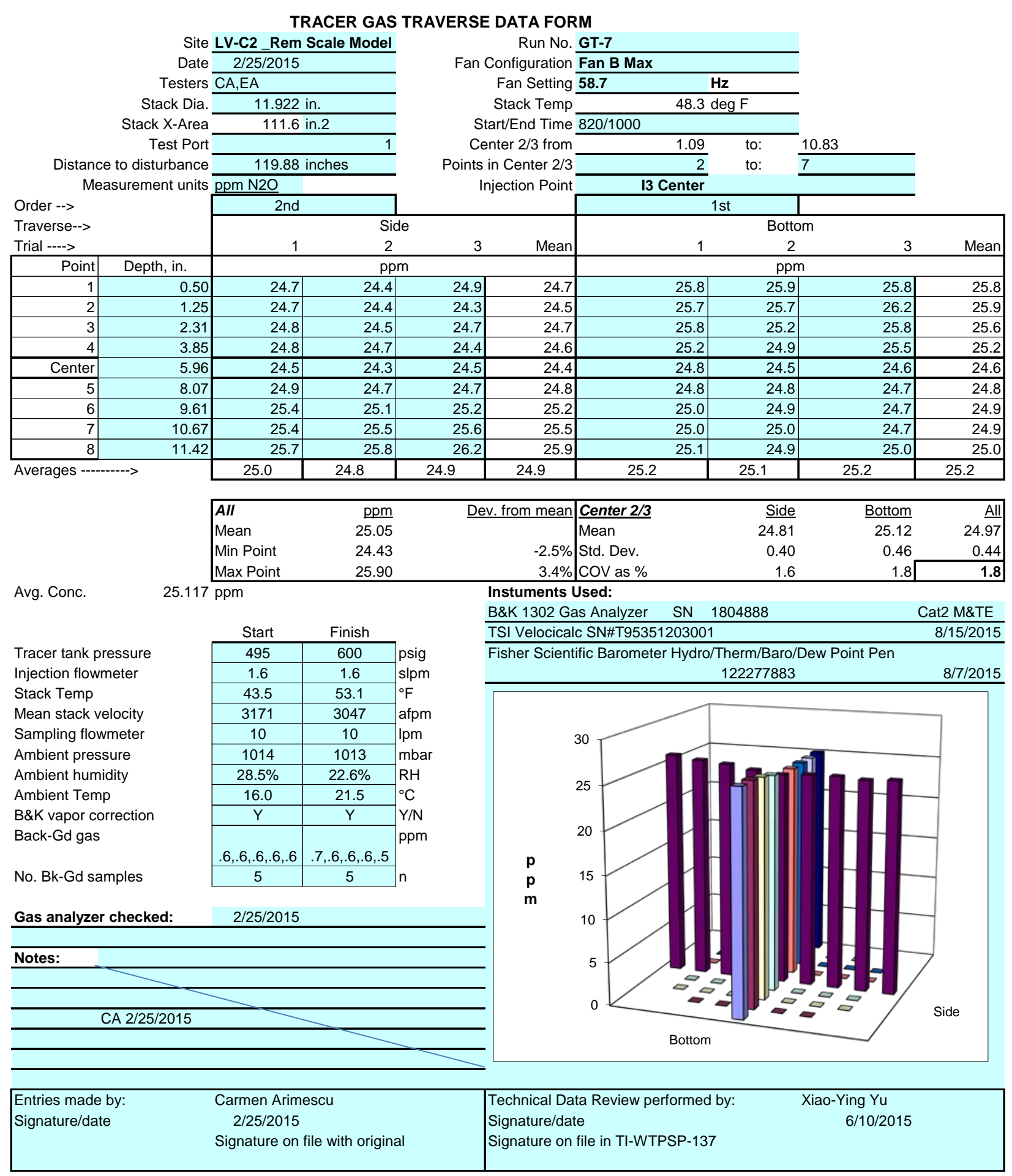




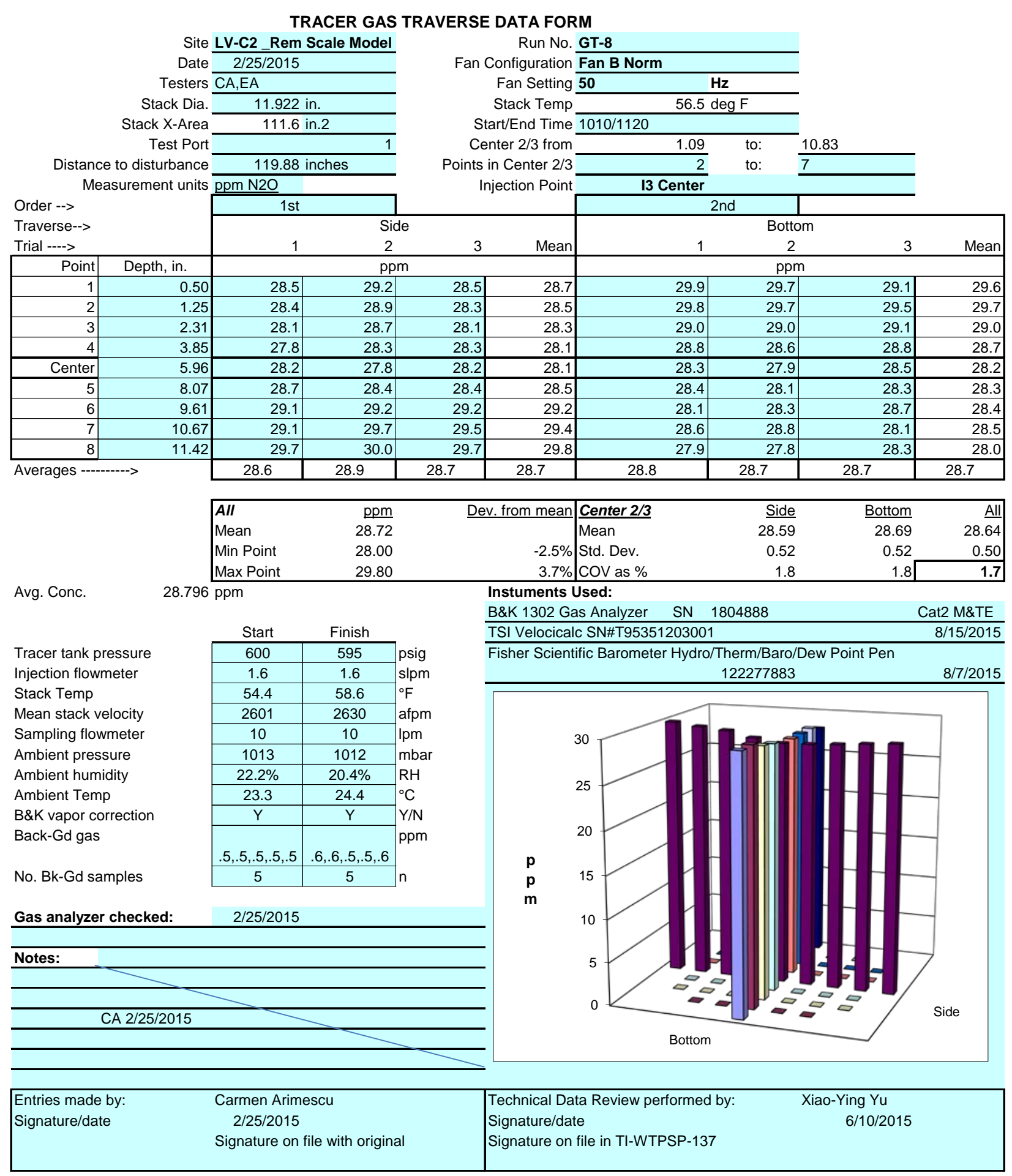




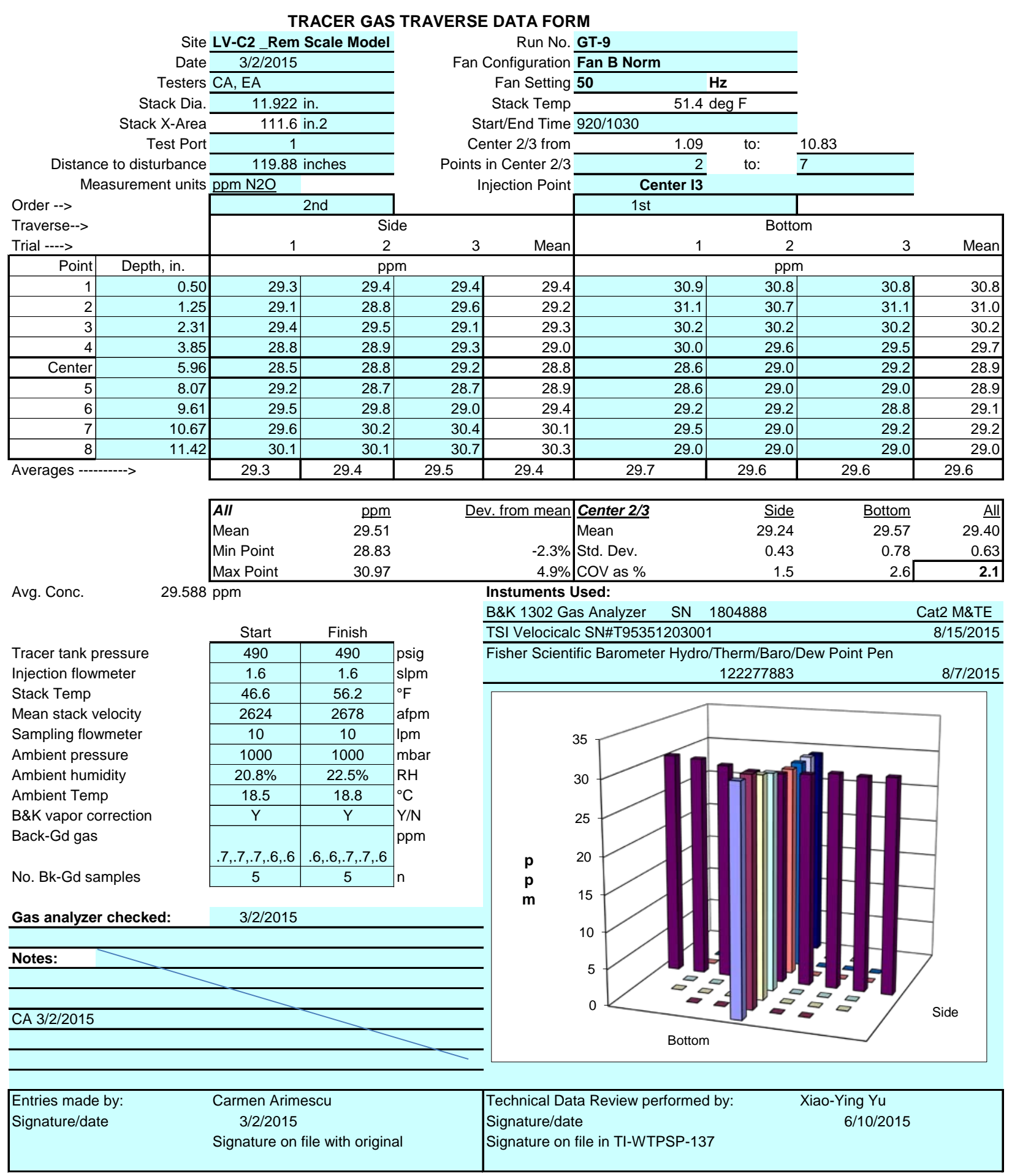


TRACER GAS TRAVERSE DATA FORM

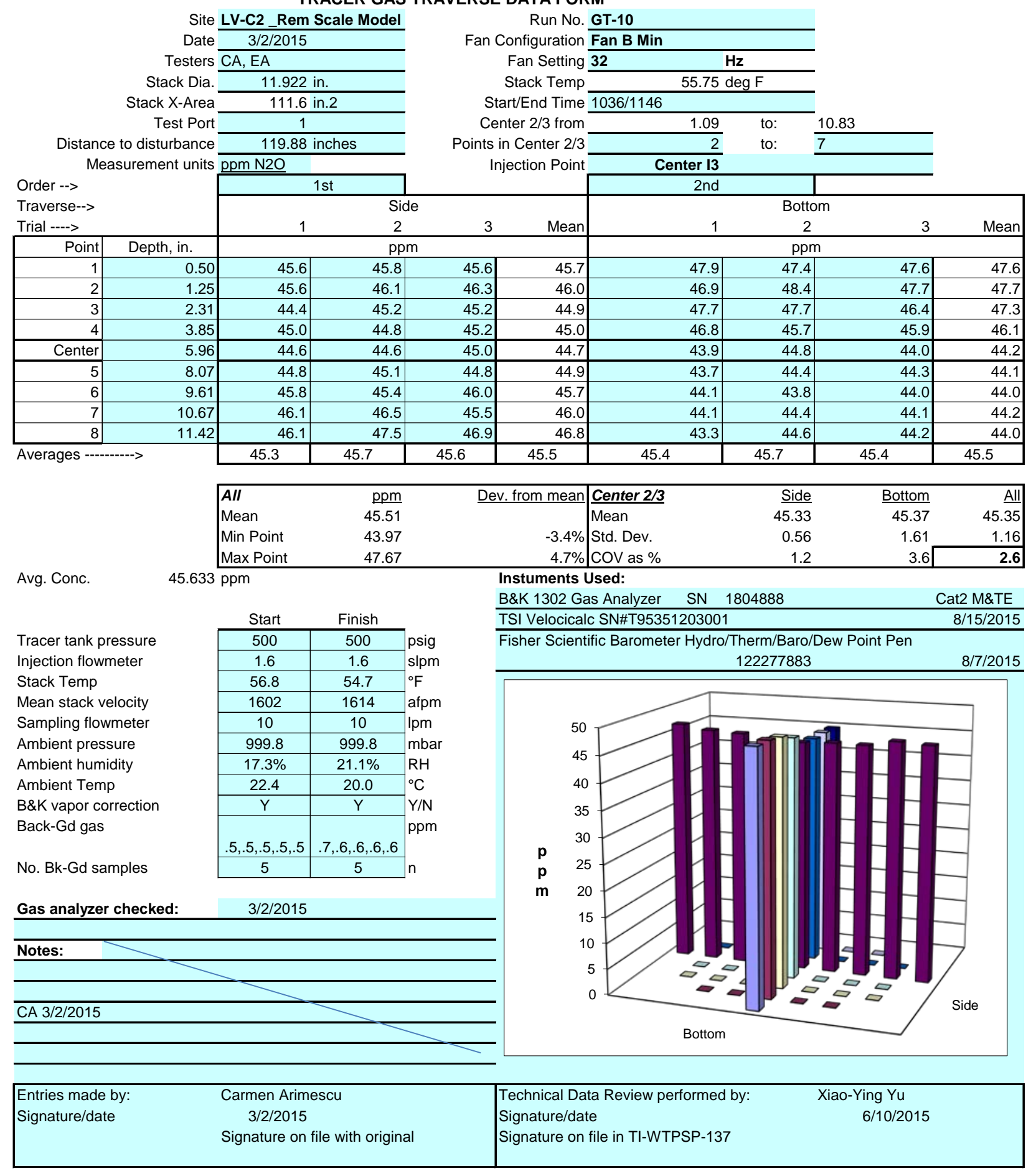




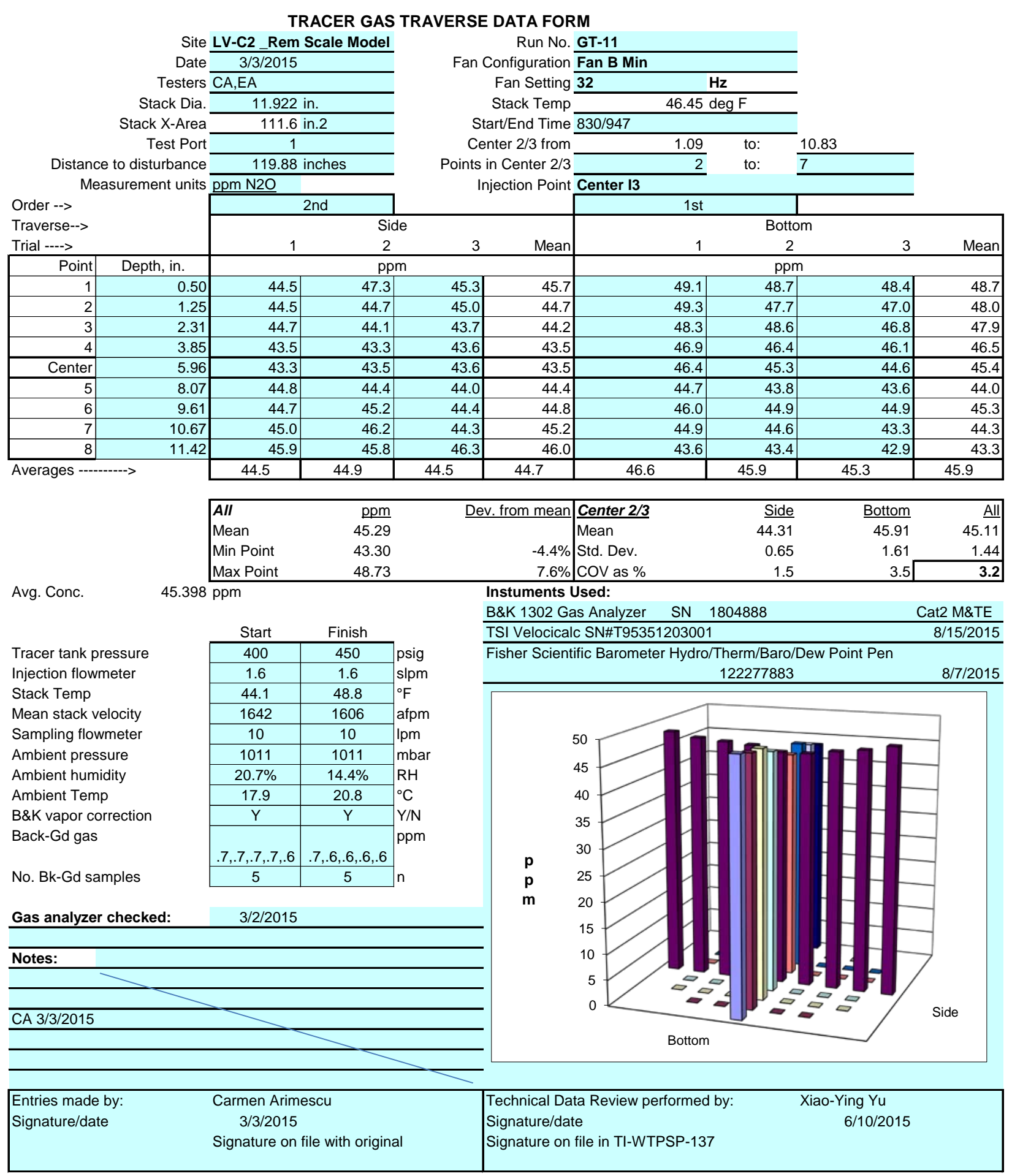


TRACER GAS TRAVERSE DATA FORM

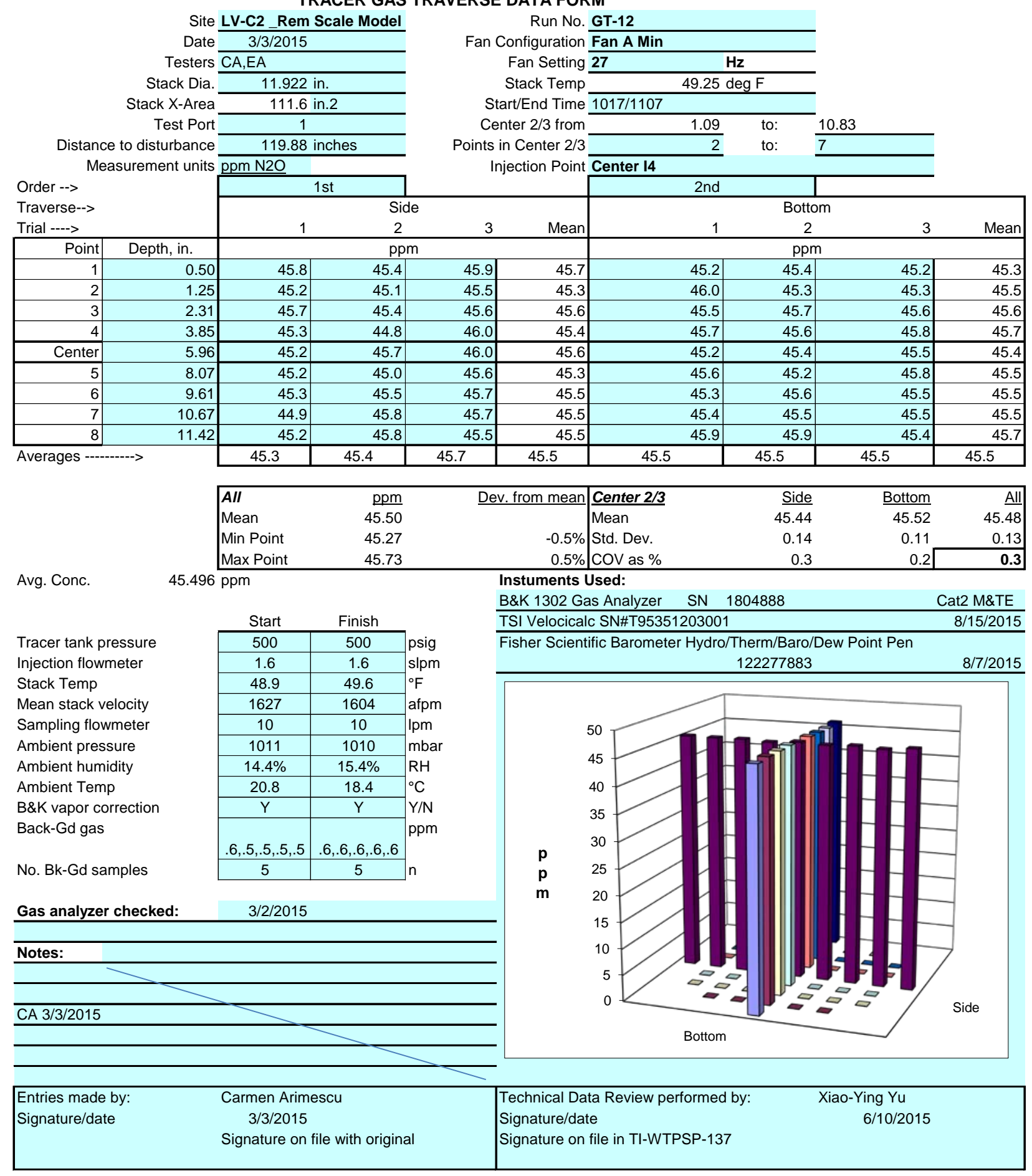


TRACER GAS TRAVERSE DATA FORM

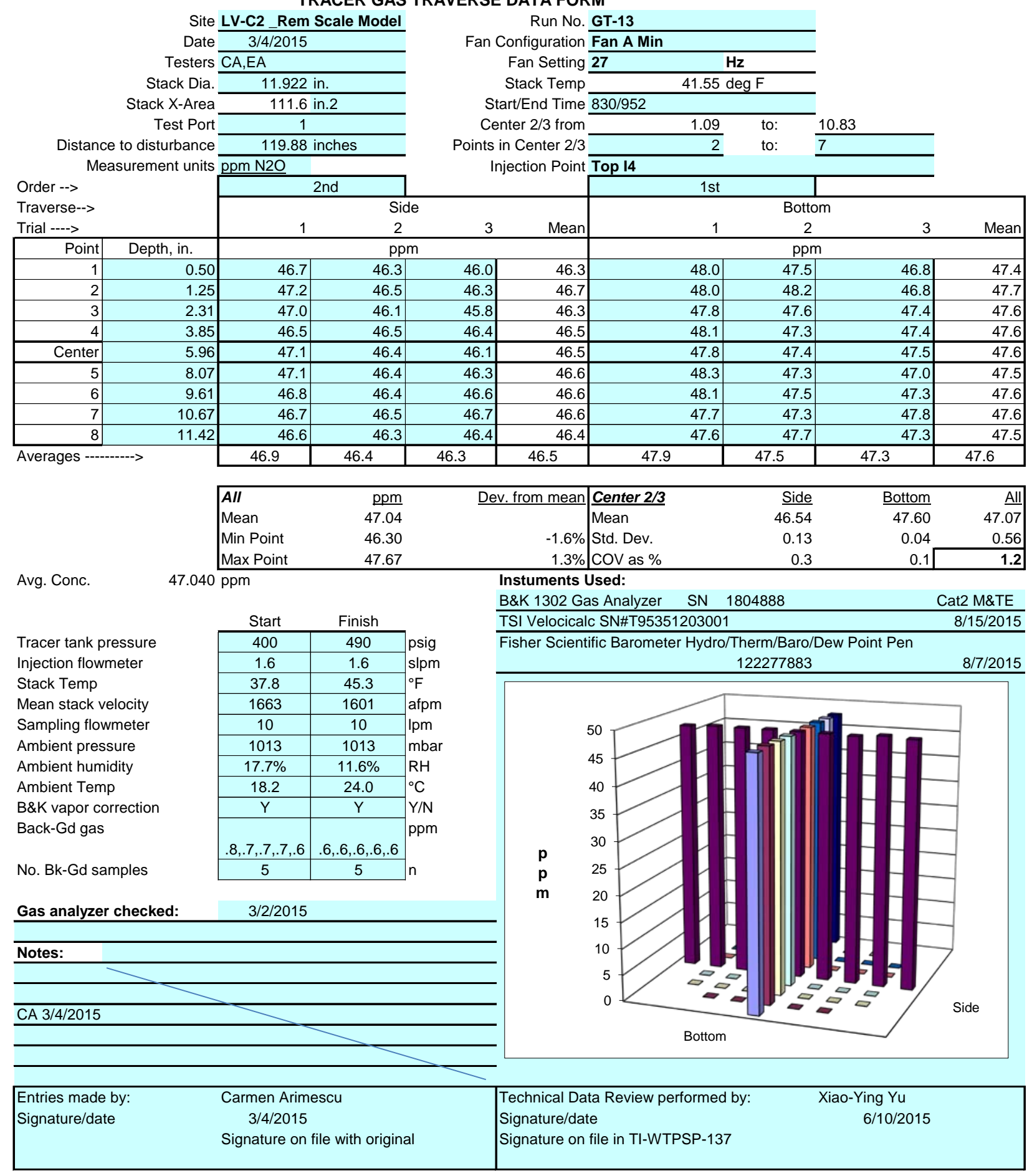


TRACER GAS TRAVERSE DATA FORM

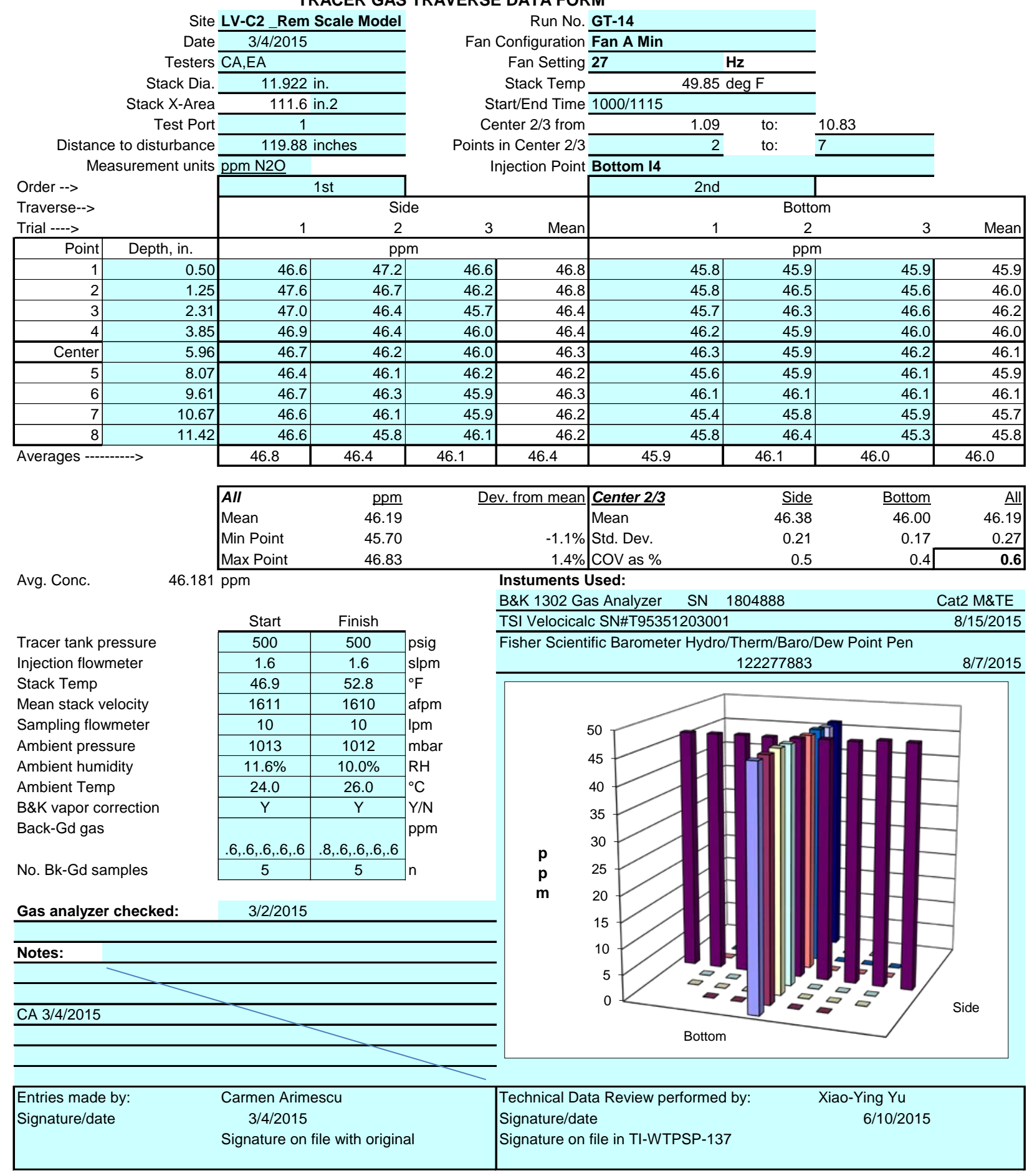




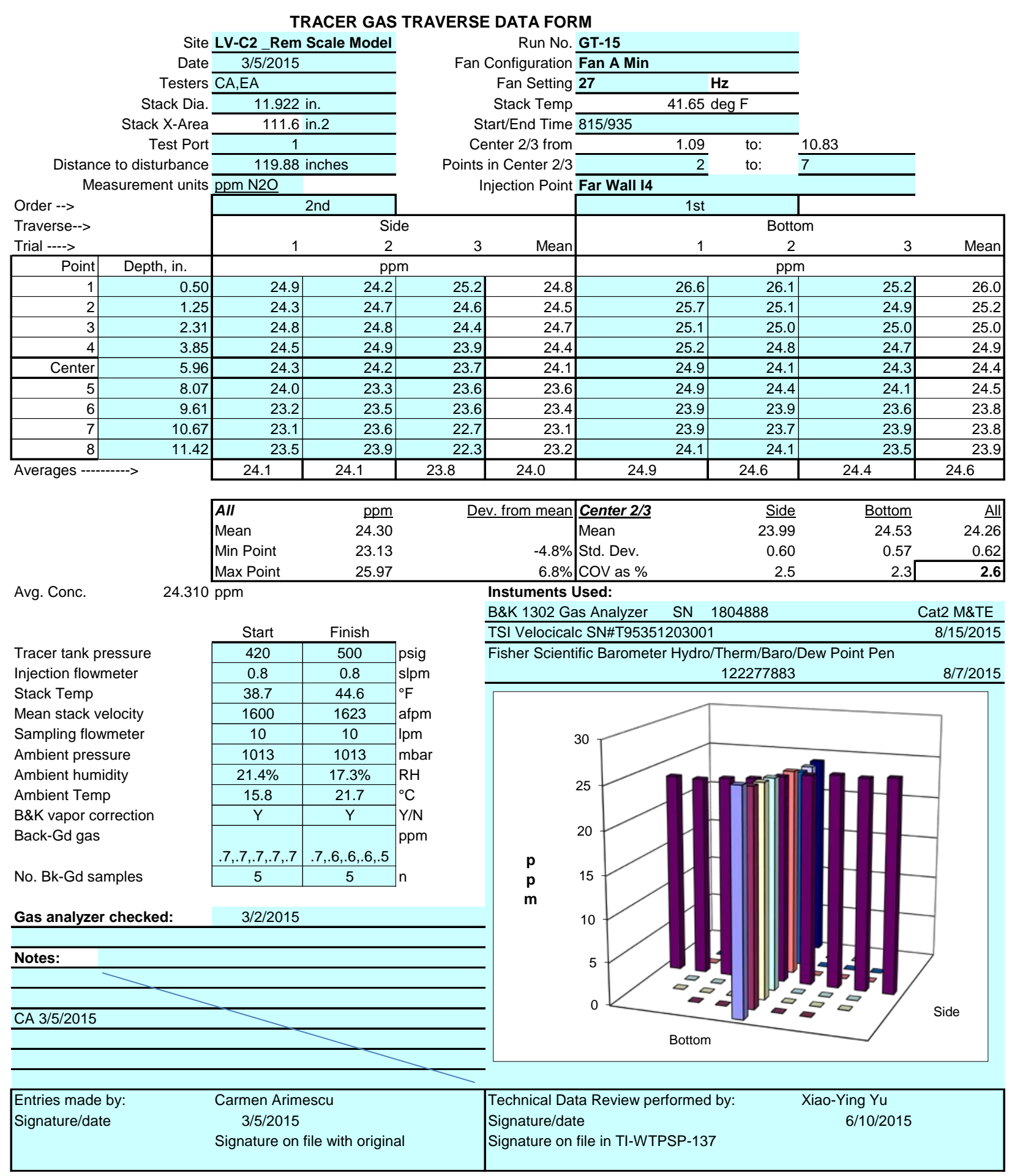


TRACER GAS TRAVERSE DATA FORM

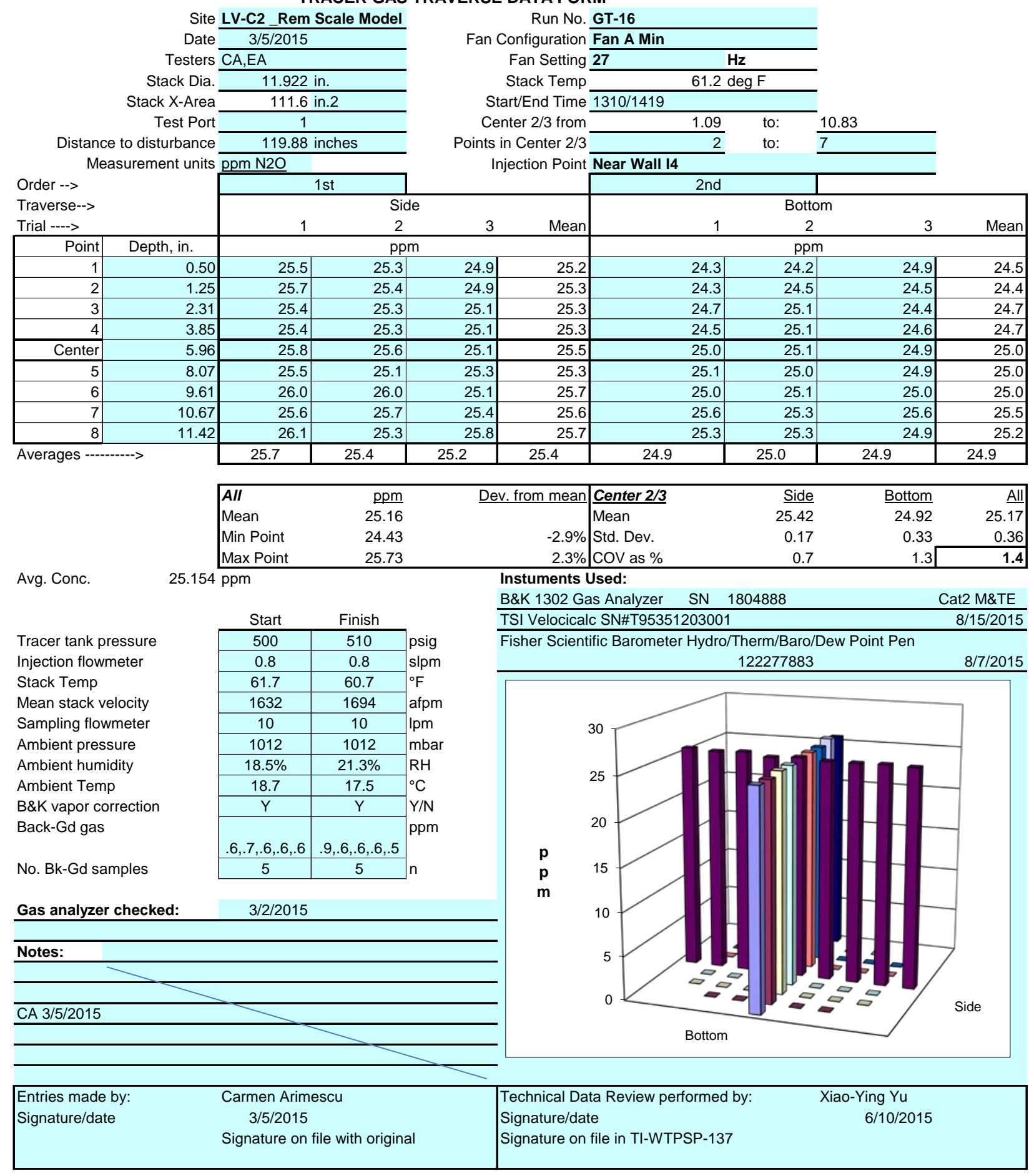




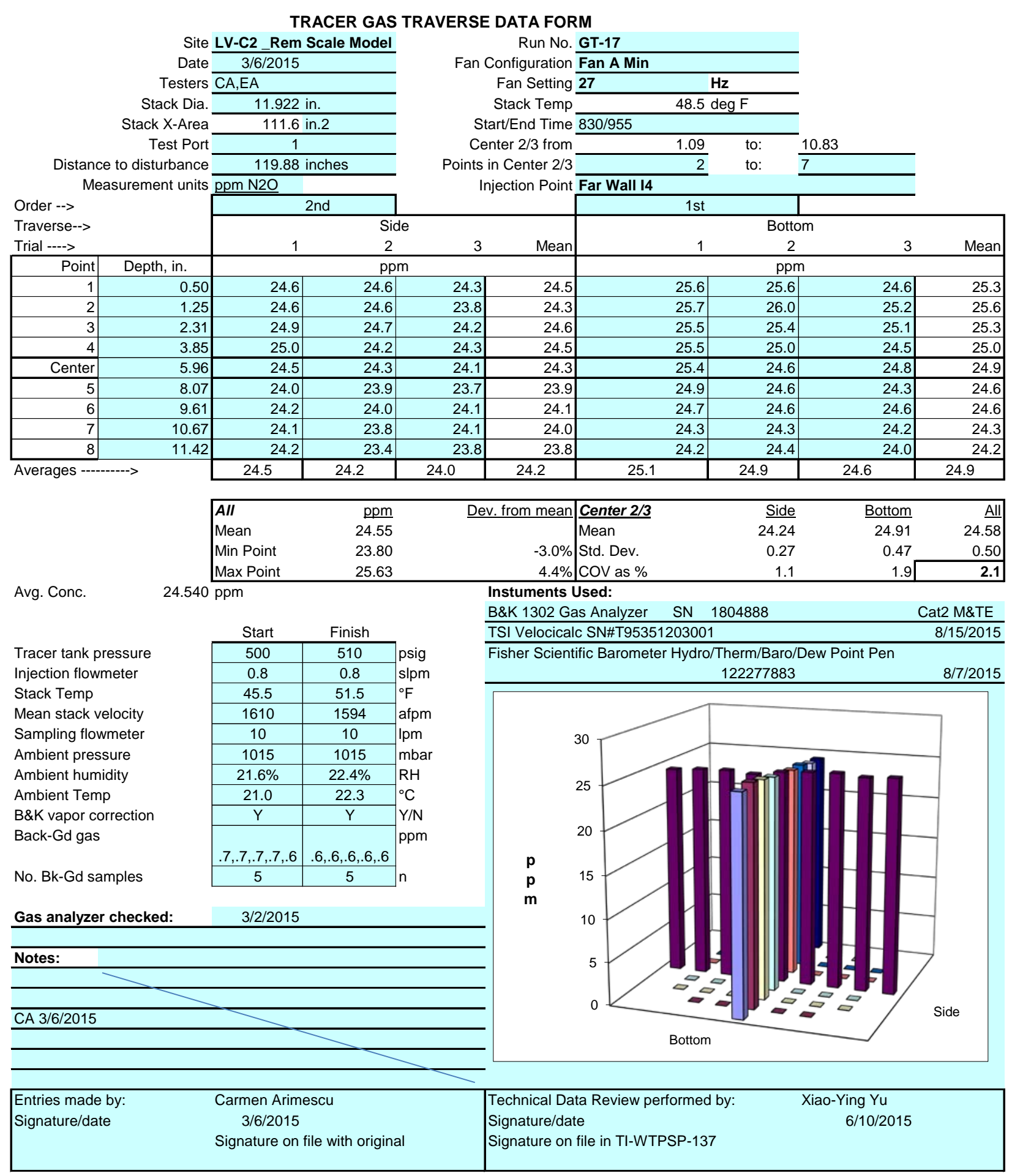


TRACER GAS TRAVERSE DATA FORM

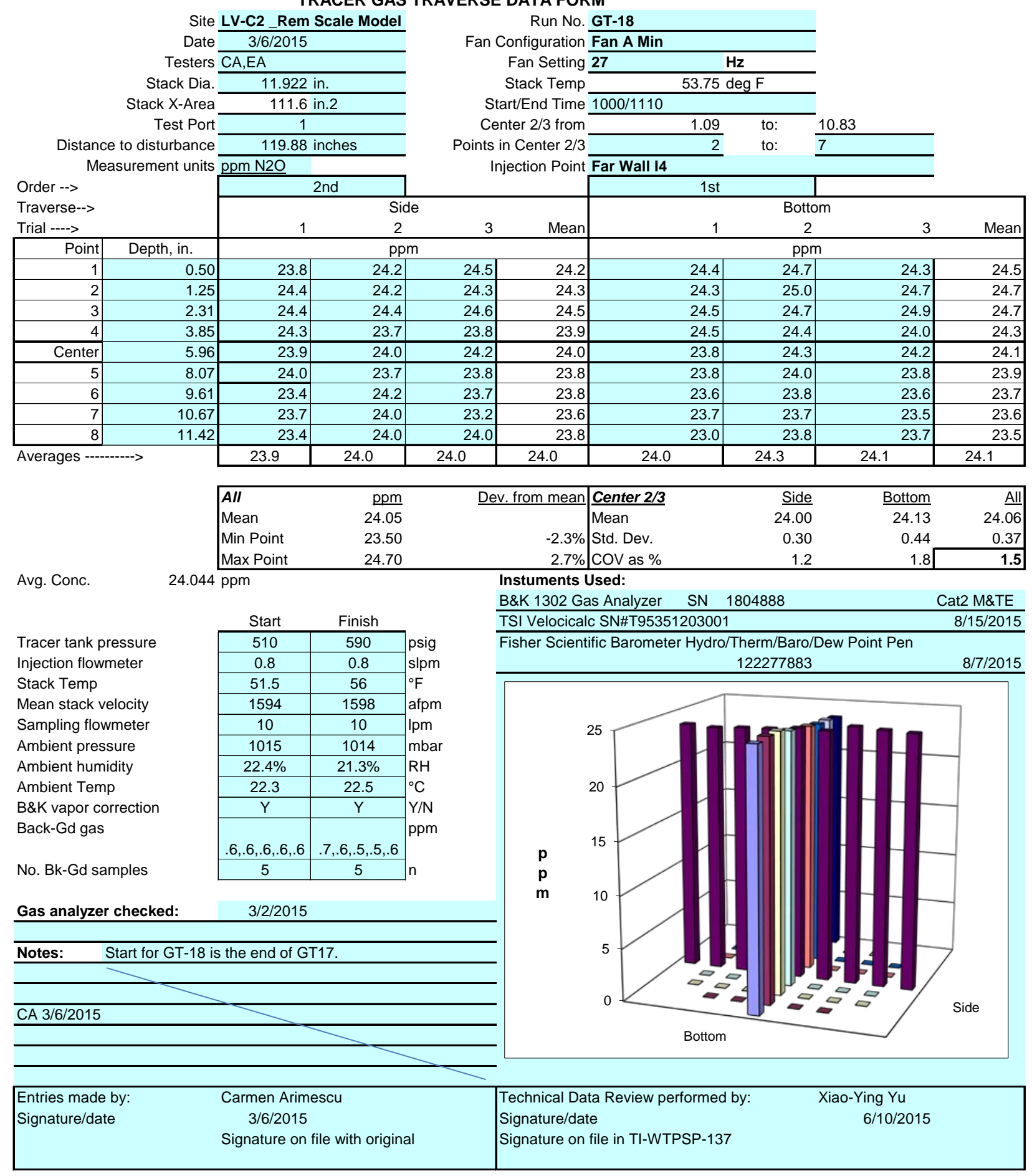




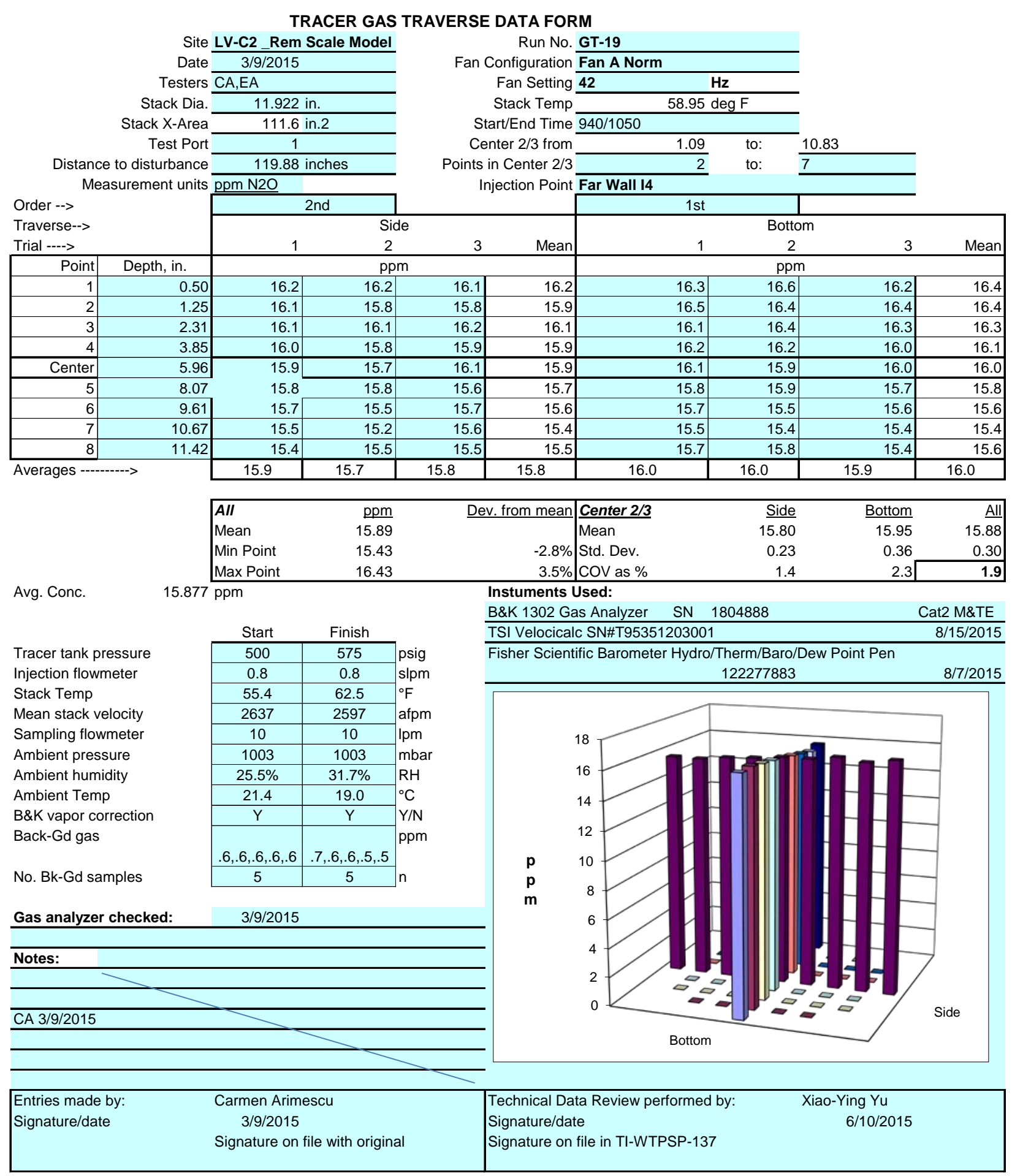




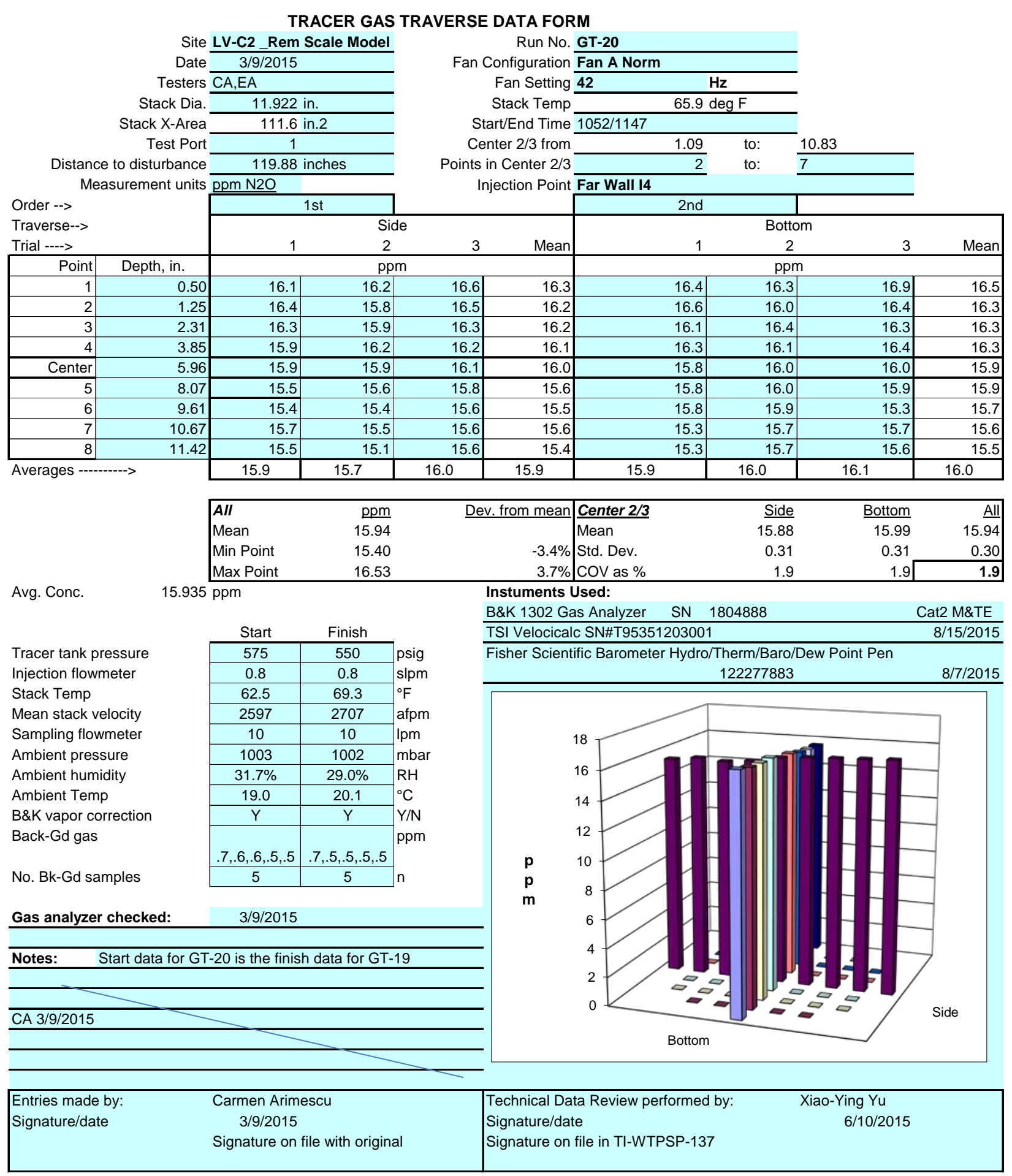


TRACER GAS TRAVERSE DATA FORM

Site LV-C2_Rem Scale Model

Date 3/10/2015

Testers CA,EA

Stack Dia. 11.922 in.

Stack X-Area 111.6 in.2

Test Port 1

Distance to disturbance

Measurement units ppm N2O

Order -->

Traverse-->

Trial ---->

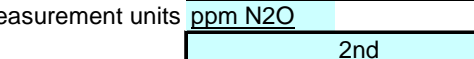

\begin{tabular}{|c|c|c|c|c|c|c|c|c|c|}
\hline \multirow{2}{*}{\multicolumn{2}{|c|}{ Trial ----> }} & & \\
\hline & & 1 & 2 & 3 & Mean & 1 & 2 & 3 & Mean \\
\hline Point & Depth, in. & \multicolumn{4}{|c|}{ ppm } & \multicolumn{4}{|c|}{ ppm } \\
\hline 1 & 0.50 & 28.5 & 28.3 & 28.8 & 28.5 & 29.0 & 28.9 & 28.8 & 28.9 \\
\hline 2 & 1.25 & 28.8 & 27.6 & 28.4 & 28.3 & 29.4 & 28.6 & 28.5 & 28.8 \\
\hline 3 & 2.31 & 28.2 & 28.3 & 28.2 & 28.2 & 29.2 & 28.3 & 28.4 & 28.6 \\
\hline 4 & 3.85 & 27.6 & 28.1 & 27.7 & 27.8 & 28.8 & 28.4 & 28.3 & 28.5 \\
\hline Center & 5.96 & 27.7 & 27.7 & 27.8 & 27.7 & 28.3 & 28.2 & 27.6 & 28.0 \\
\hline 5 & 8.07 & 27.3 & 27.0 & 27.5 & 27.3 & 28.0 & 27.5 & 27.7 & 27.7 \\
\hline 6 & 9.61 & 27.0 & 27.0 & 27.6 & 27.2 & 27.7 & 27.2 & 27.9 & 27.6 \\
\hline 7 & 10.67 & 26.4 & 26.4 & 26.5 & 26.4 & 27.2 & 27.3 & 27.4 & 27.3 \\
\hline 8 & 11.42 & 27.6 & 26.2 & 26.2 & 26.7 & 27.2 & 27.3 & 27.0 & 27.2 \\
\hline Averages ---- & $-\cdots$ & 27.7 & 27.4 & 27.6 & 27.6 & 28.3 & 28.0 & 28.0 & 28.1 \\
\hline
\end{tabular}

Avg. Conc.

$27.817 \mathrm{ppm}$

\begin{tabular}{|lr}
\hline All & ppm \\
Mean & 27.82 \\
Min Point & 26.43 \\
Max Point & 28.90 \\
\hline
\end{tabular}

Tracer tank pressure Injection flowmeter

Stack Temp

Mean stack velocity

Sampling flowmeter

Ambient pressure

Ambient humidity

Ambient Temp

B\&K vapor correction

Back-Gd gas

No. Bk-Gd samples

\begin{tabular}{|c|c|c|}
\hline Start & Finish & \multirow{3}{*}{$\begin{array}{l}\text { psic } \\
\text { slpr }\end{array}$} \\
\hline 500 & 500 & \\
\hline 1.6 & 1.6 & \\
\hline 66.5 & 70.7 & \\
\hline 3246 & 3109 & \\
\hline 10 & 10 & \\
\hline 998.9 & 997.8 & \\
\hline $27.7 \%$ & $26.5 \%$ & \\
\hline 18.7 & 20.8 & \\
\hline$Y$ & $\bar{Y}$ & \\
\hline $.6, .6, .6, .6, .6$ & $.6, .6, .6, .5, .6$ & \\
\hline 5 & 5 & \\
\hline
\end{tabular}

Gas analyzer checked:

$3 / 9 / 2015$

\section{Notes:}

CA 3/10/2015

Entries made by:

Signature/date
Carmen Arimescu

3/10/2015

Signature on file with original
Run No. GT-21

Fan Configuration Fan A Max

Fan Setting $\mathbf{5 0}$

Stack Temp

Start/End Time 1200/121

Center $2 / 3$ from

Points in Center 2/3

Injection Point Far Wall I4

$\mathrm{Hz}$

$68.6 \operatorname{deg} F$

$\begin{aligned} 1.09 & \text { to: } \\ 2 & \text { to: }\end{aligned}$

\section{4}

\begin{tabular}{l|l} 
1st & \\
\hline
\end{tabular}


TRACER GAS TRAVERSE DATA FORM

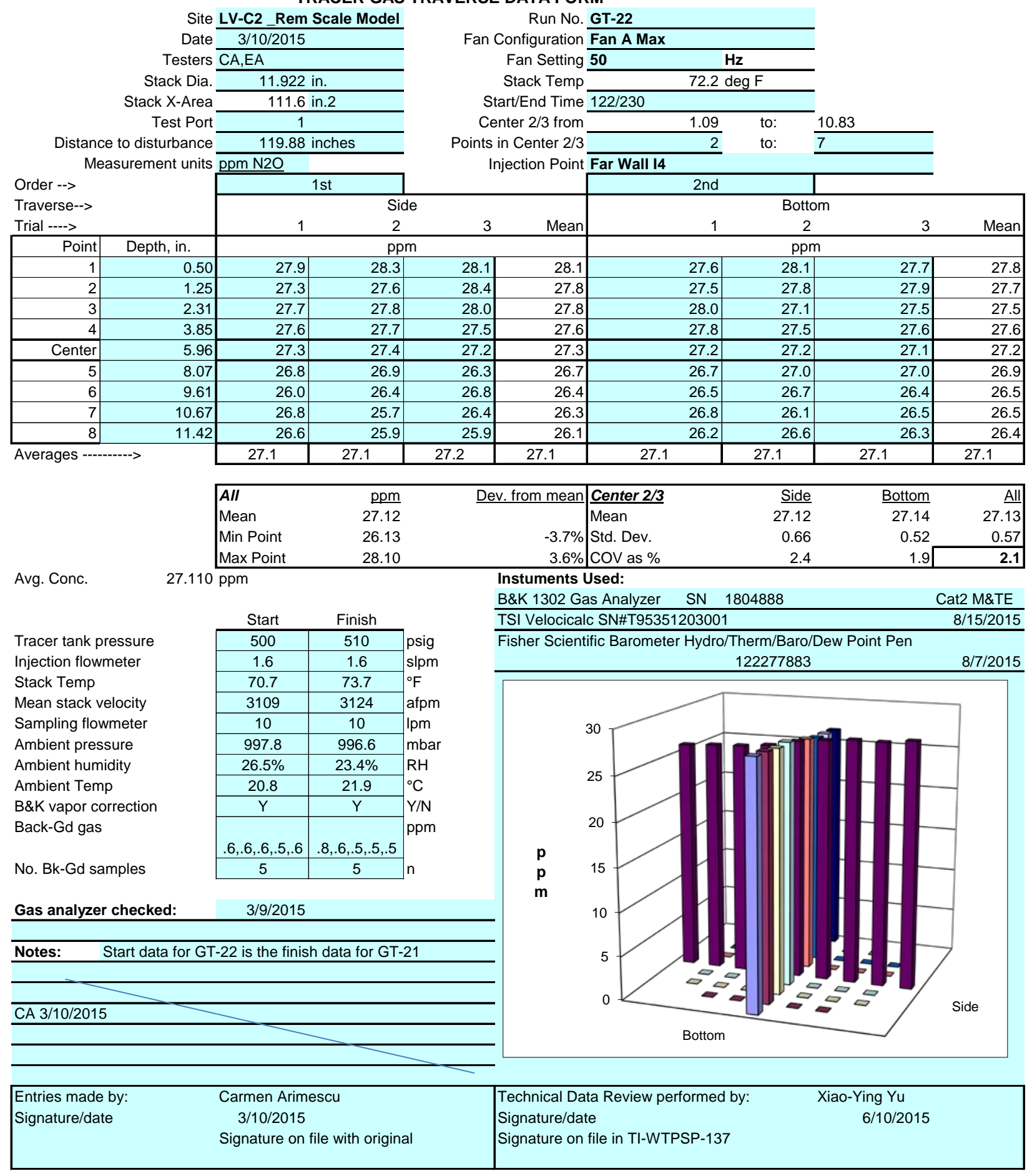




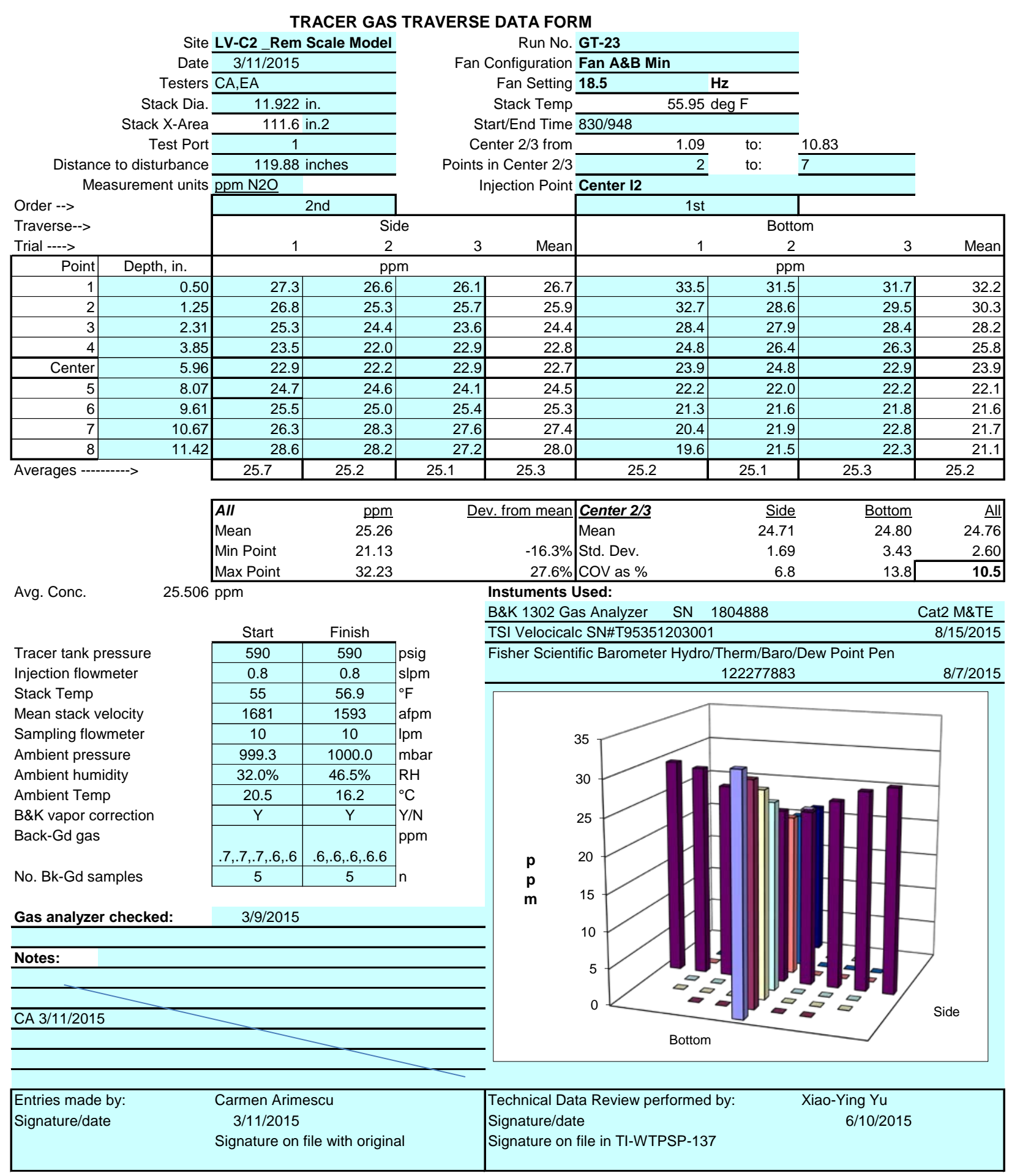


TRACER GAS TRAVERSE DATA FORM

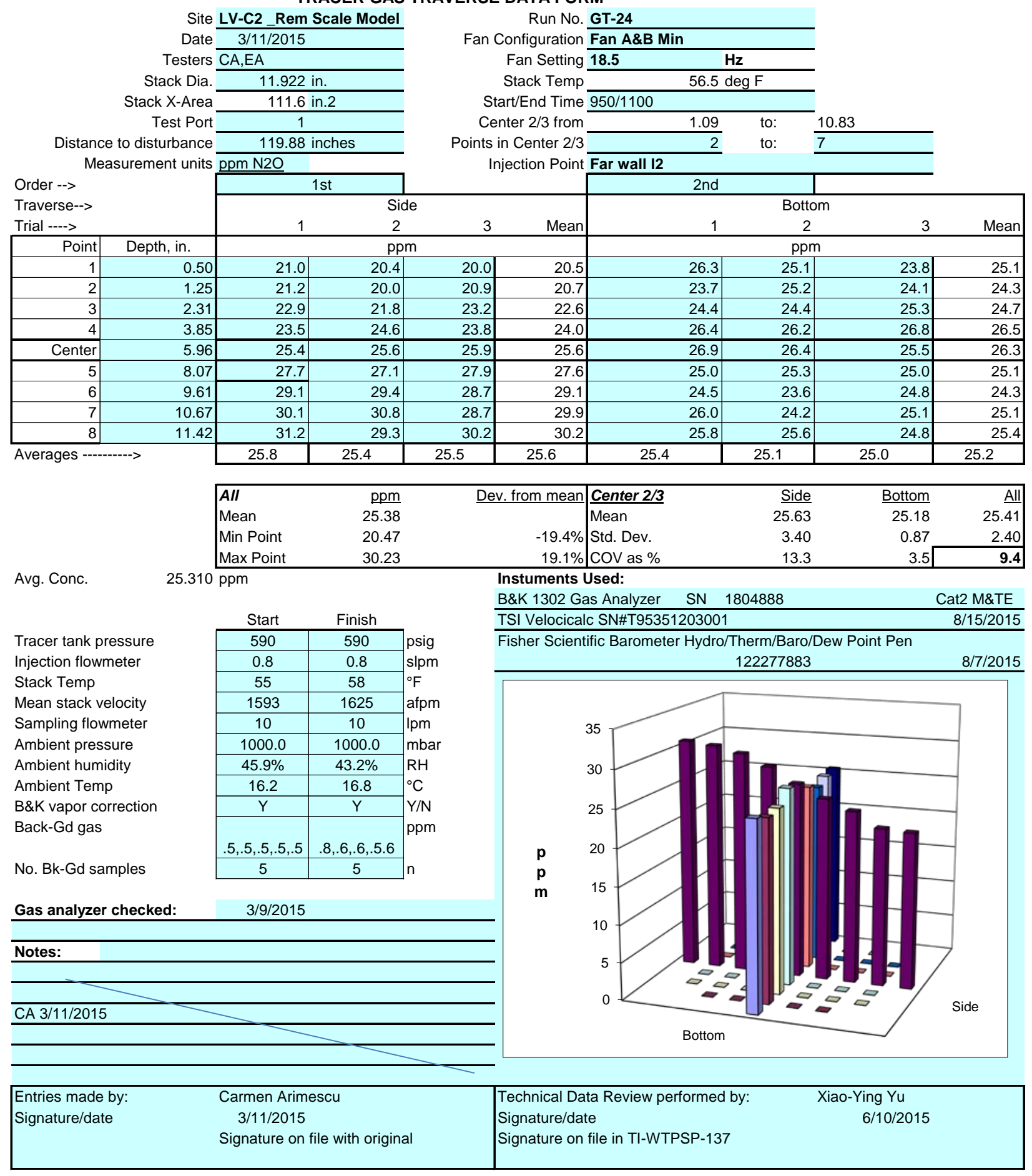


TRACER GAS TRAVERSE DATA FORM

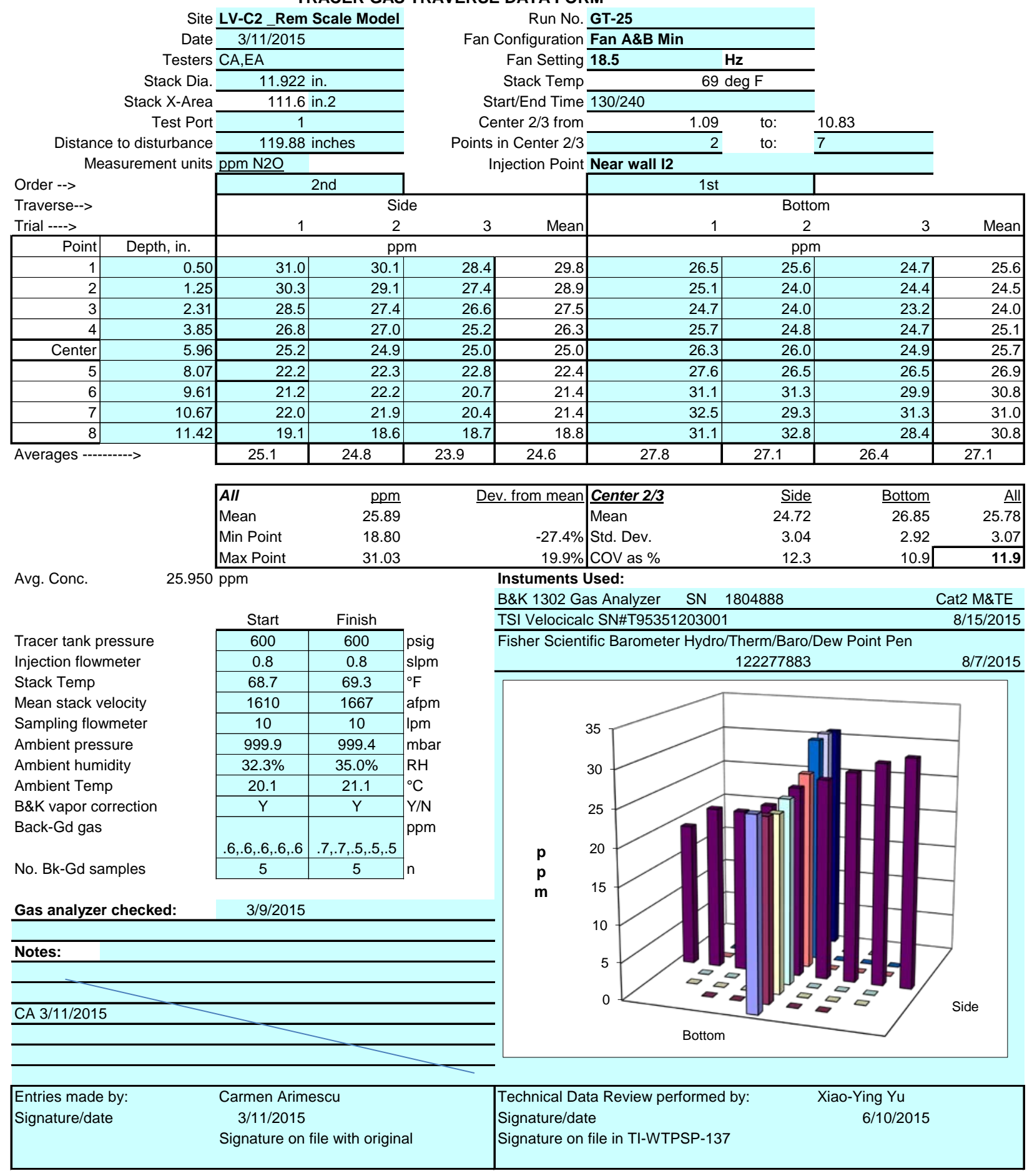


TRACER GAS TRAVERSE DATA FORM

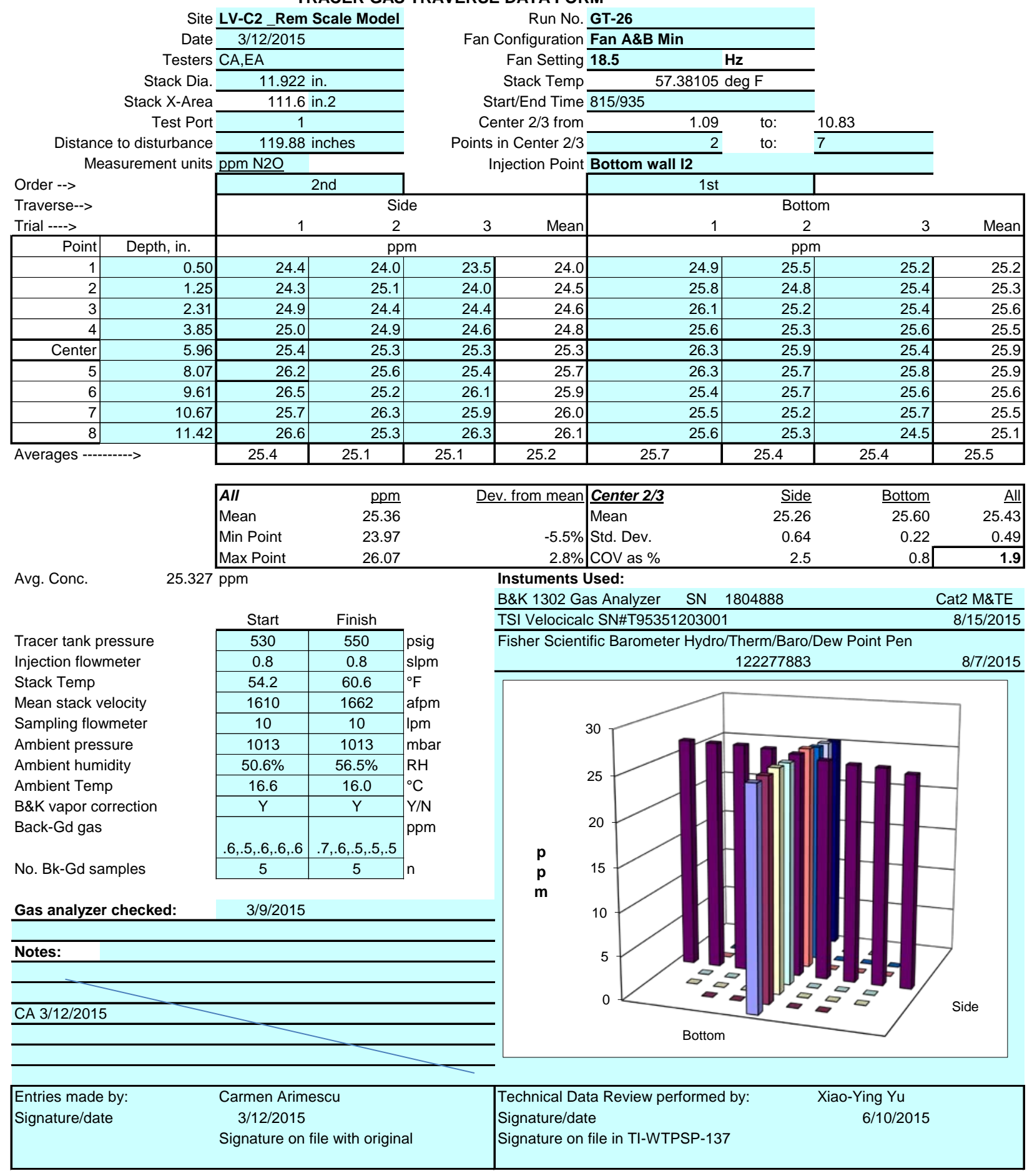




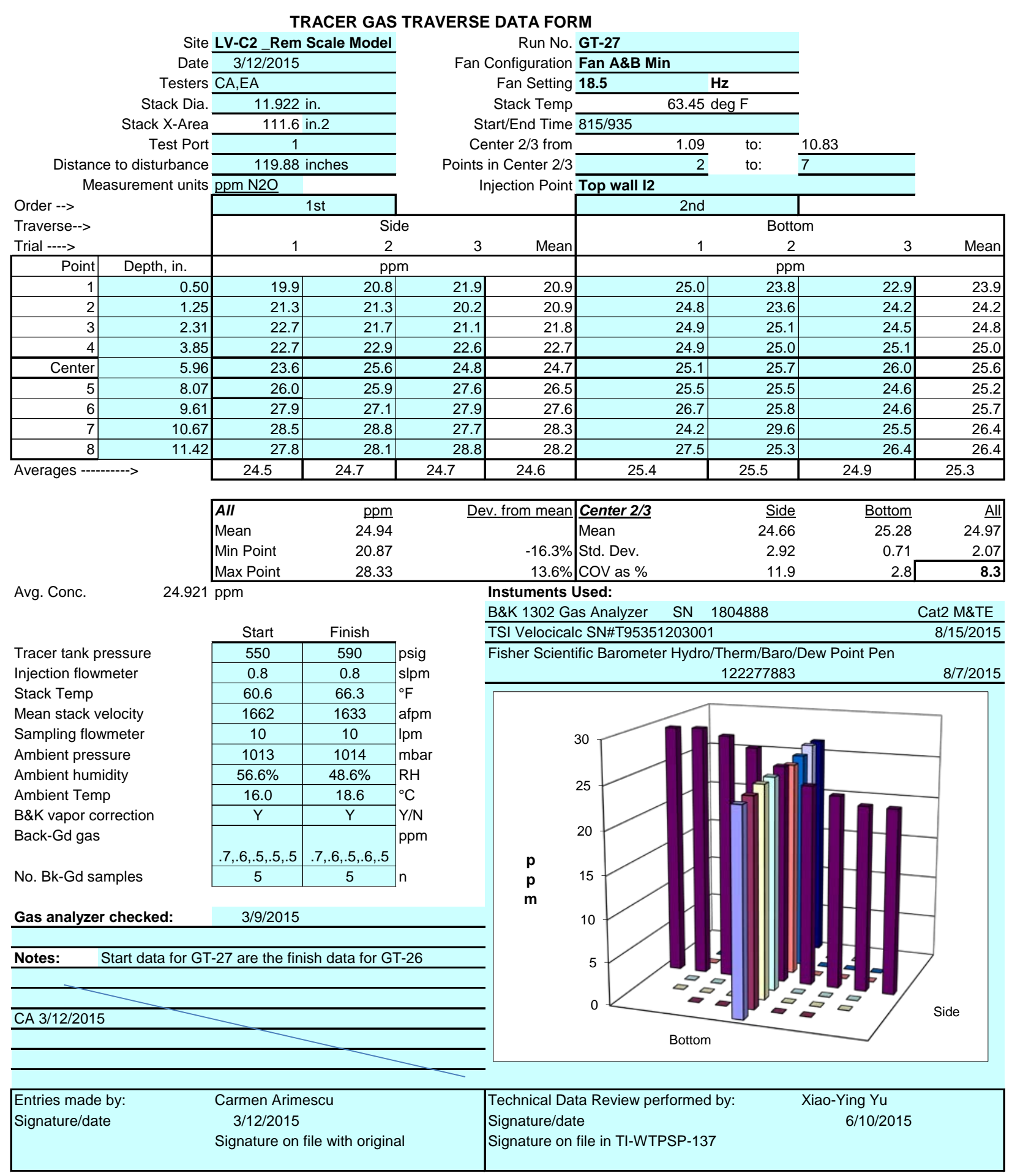


TRACER GAS TRAVERSE DATA FORM

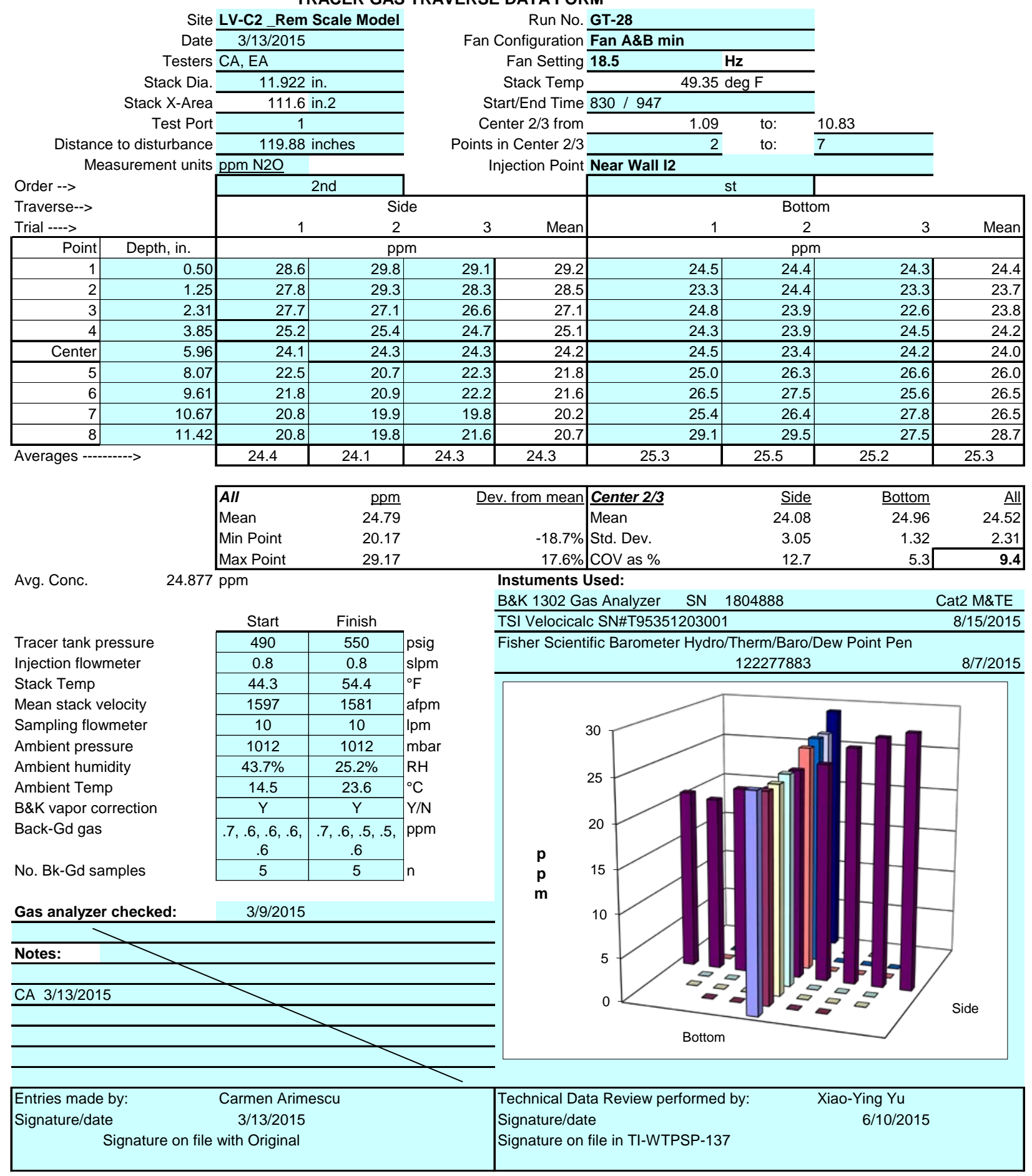


TRACER GAS TRAVERSE DATA FORM

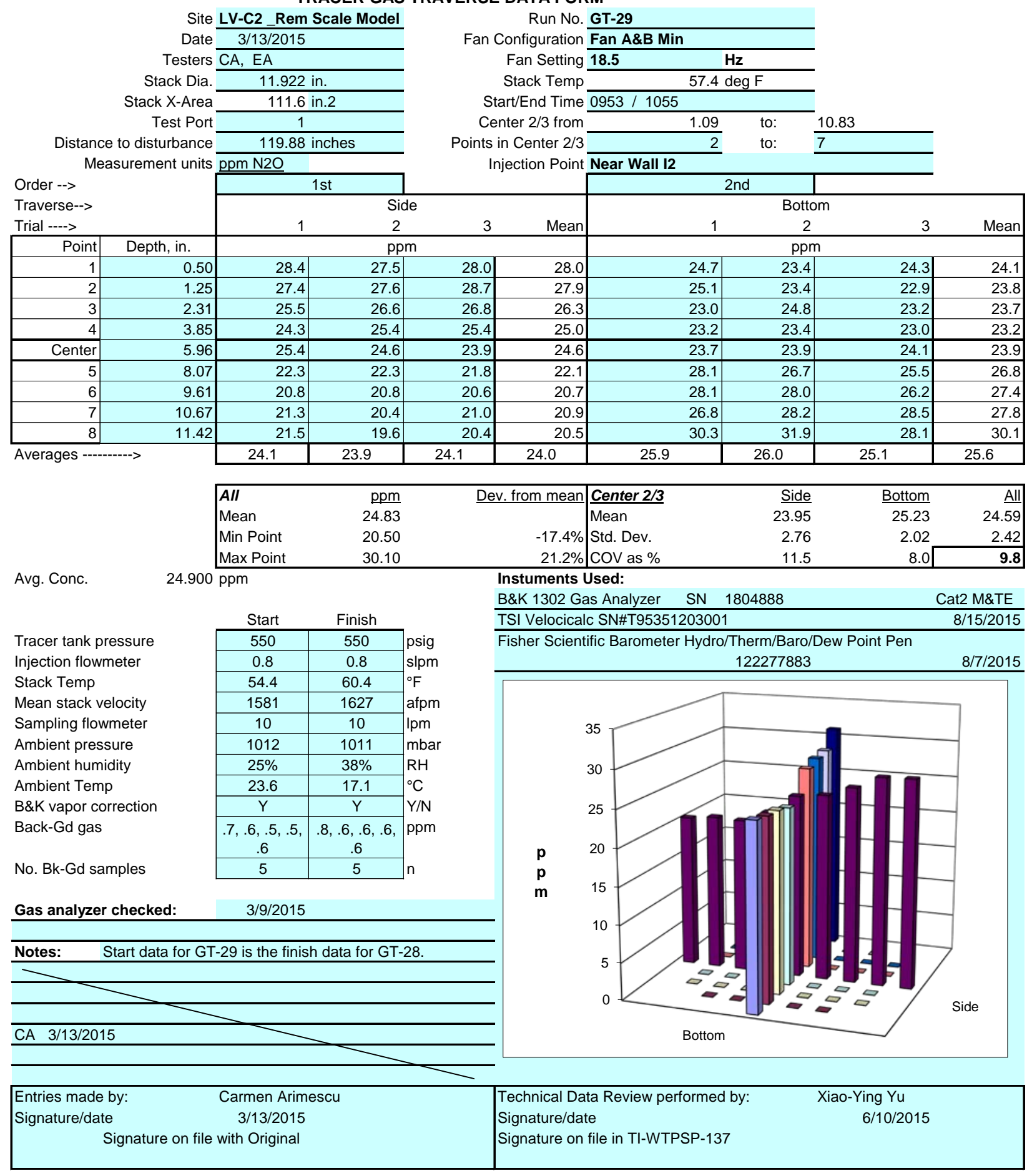


TRACER GAS TRAVERSE DATA FORM

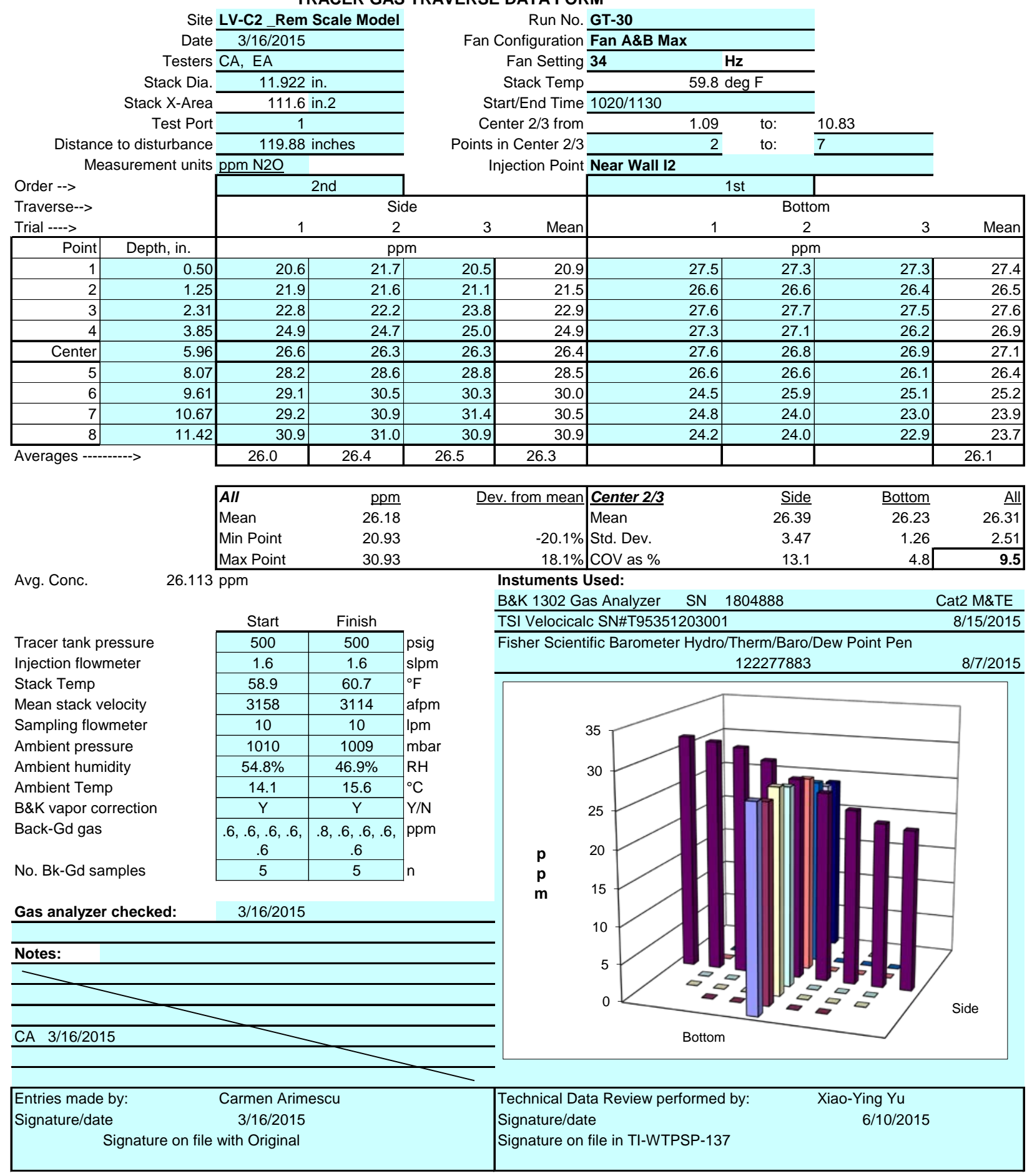


TRACER GAS TRAVERSE DATA FORM

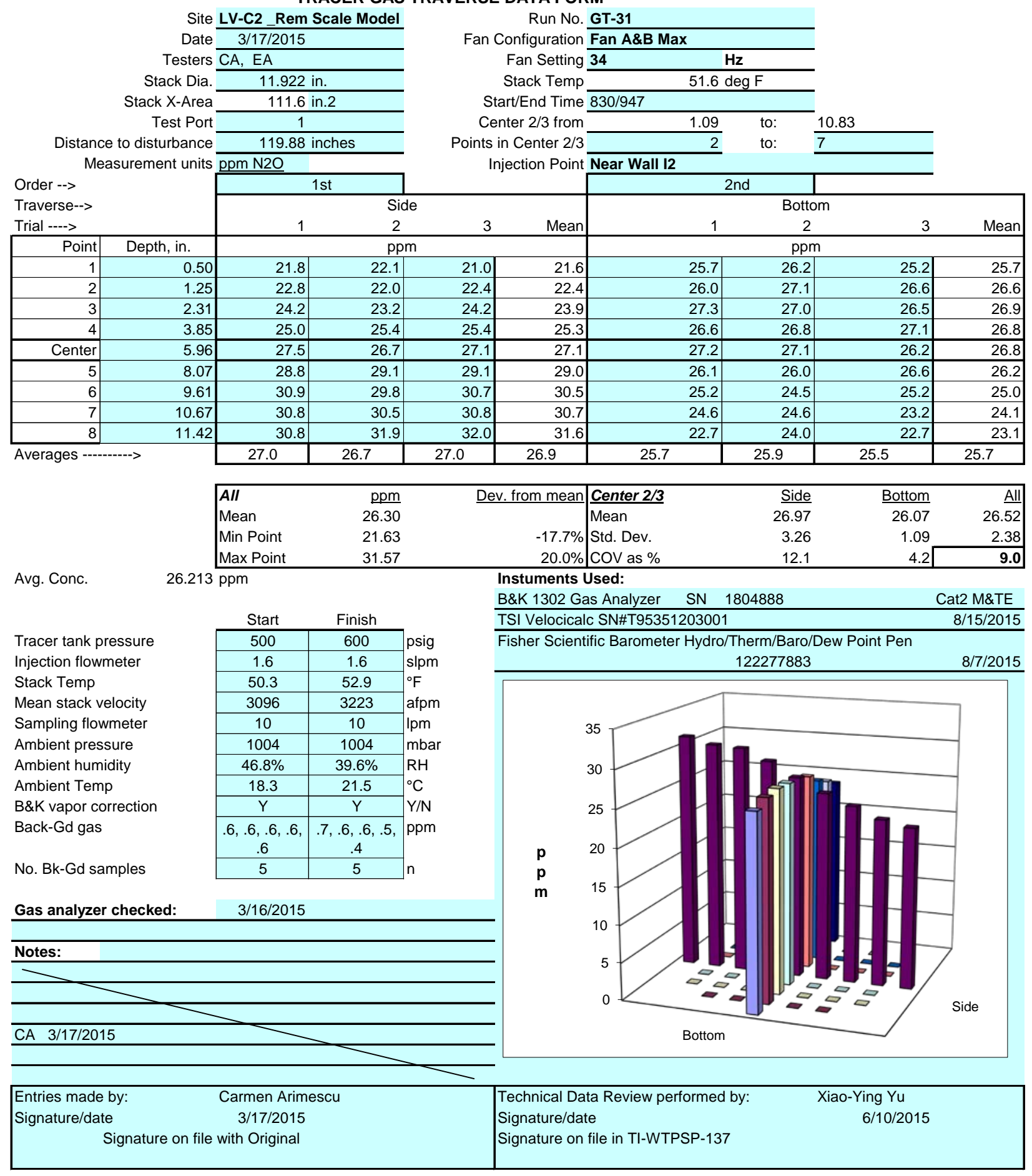


TRACER GAS TRAVERSE DATA FORM

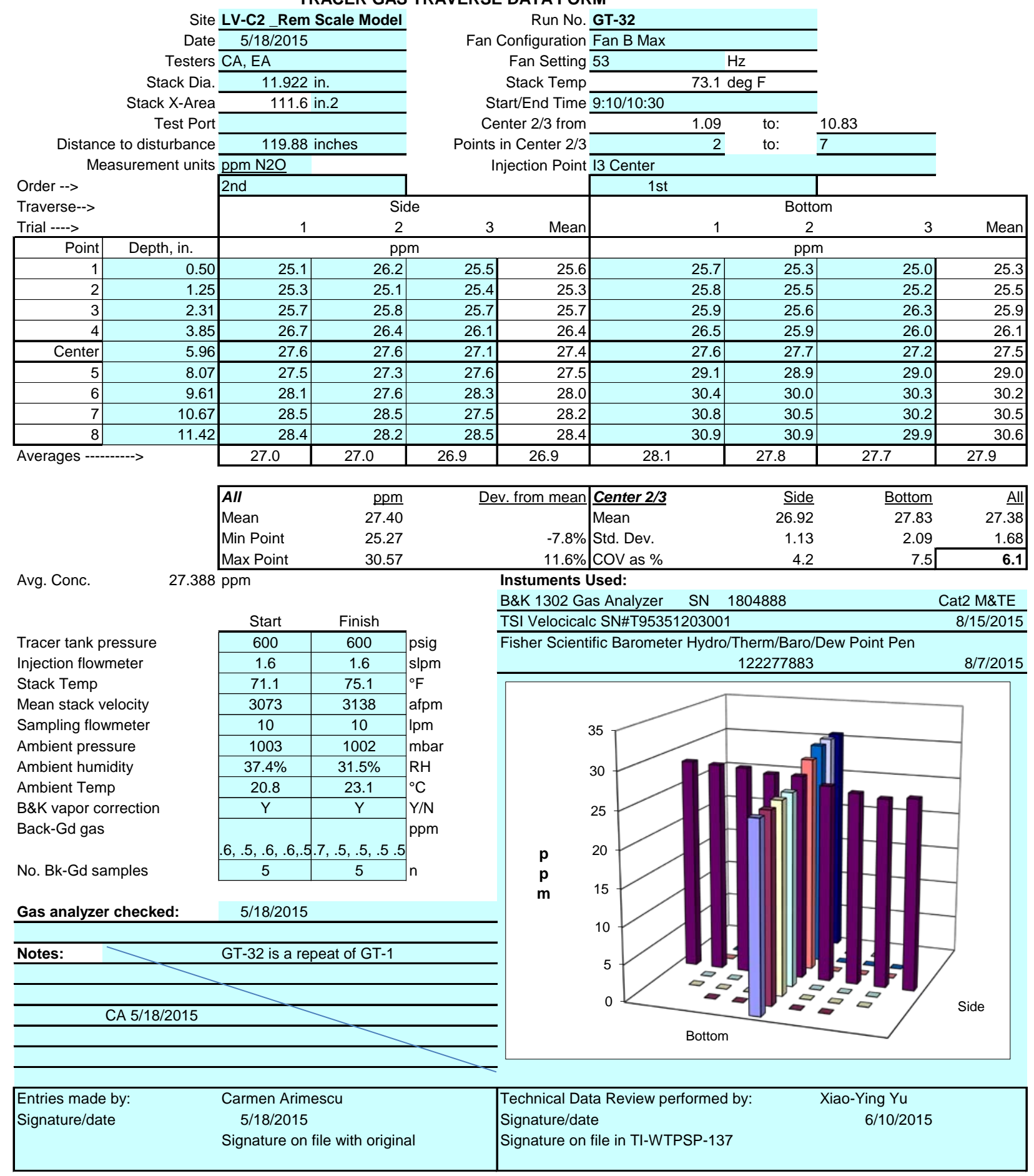




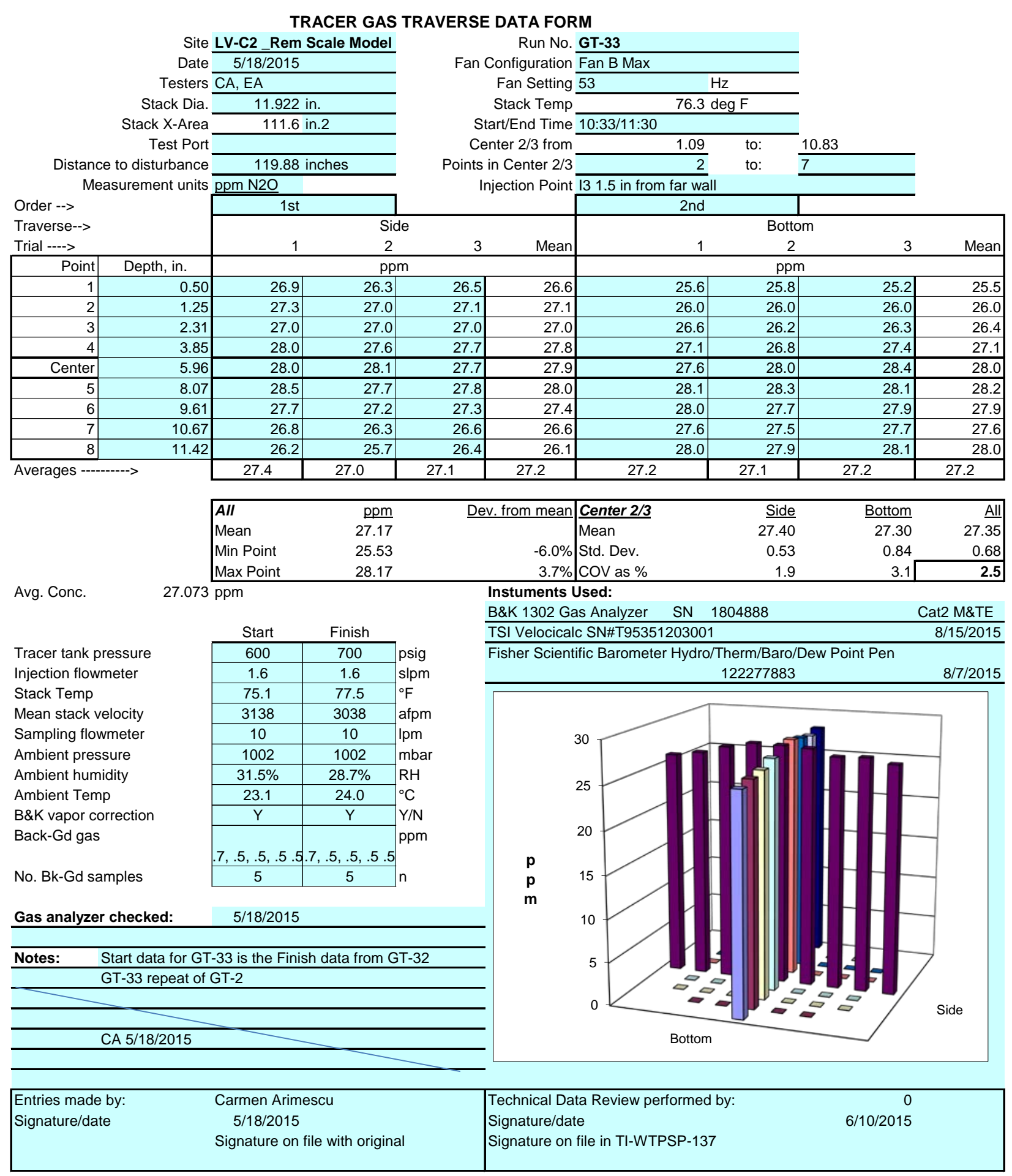




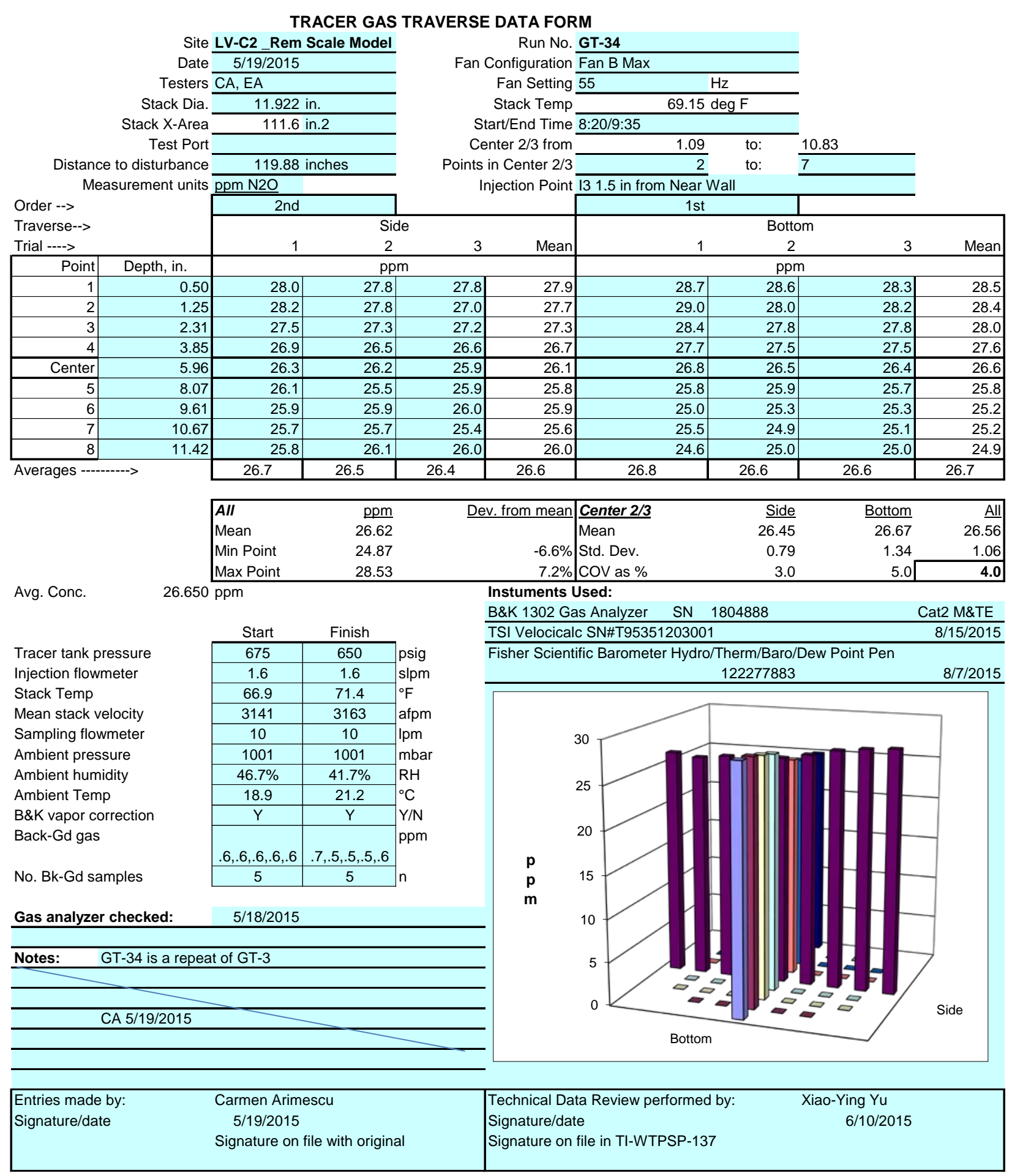




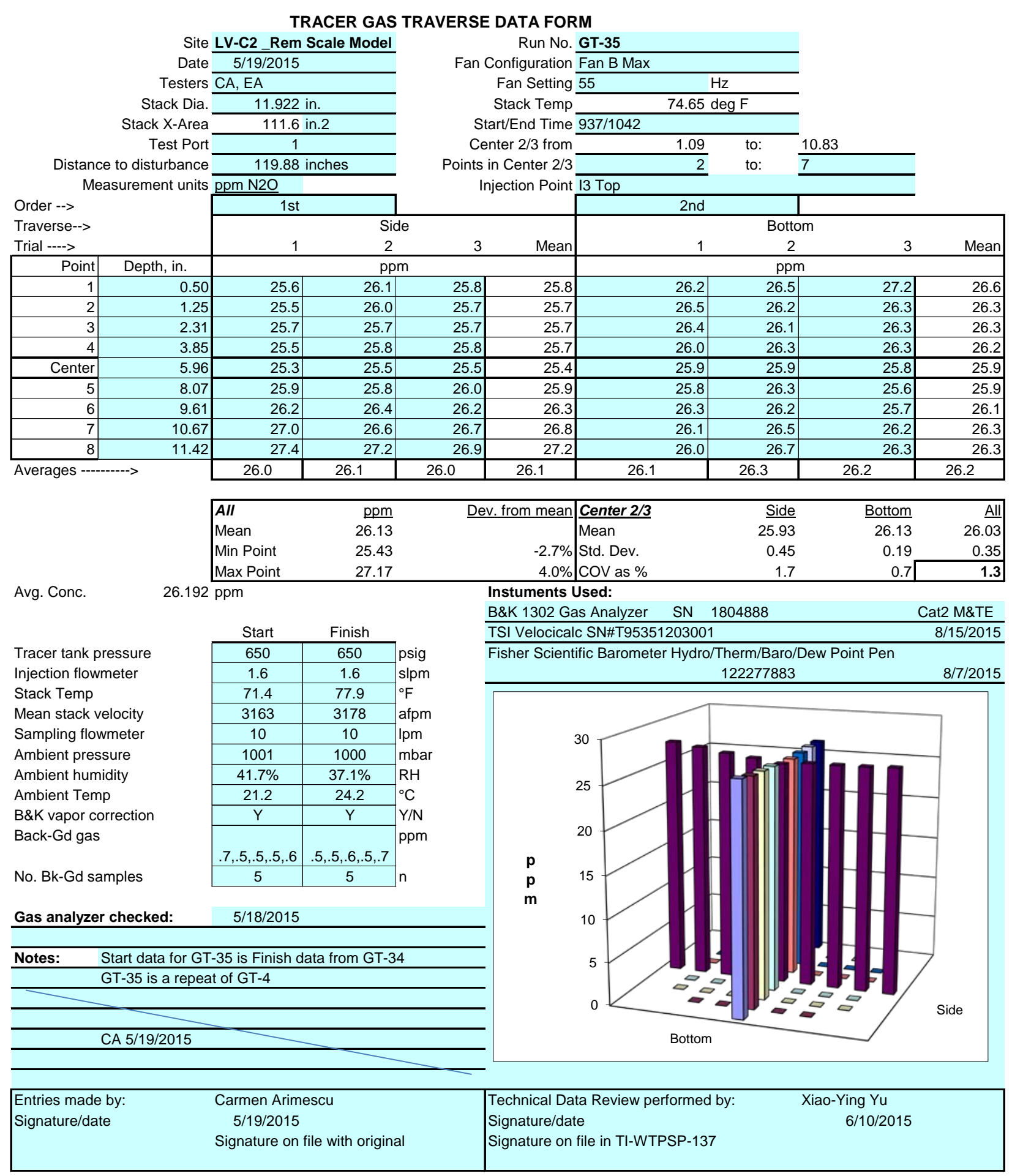




\section{C.4 LV-C2 Particle Tracer Uniformity Data Sheets}

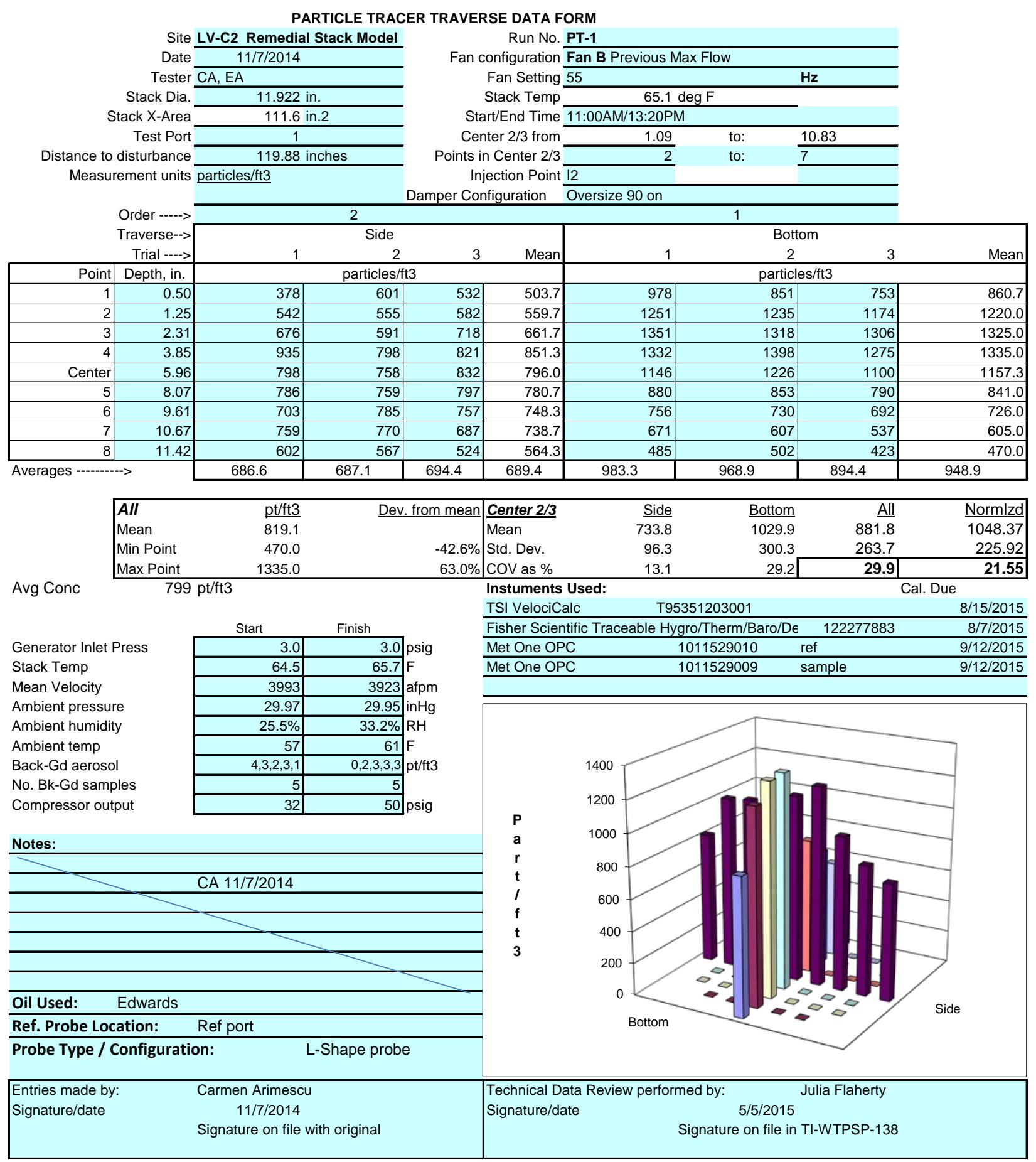




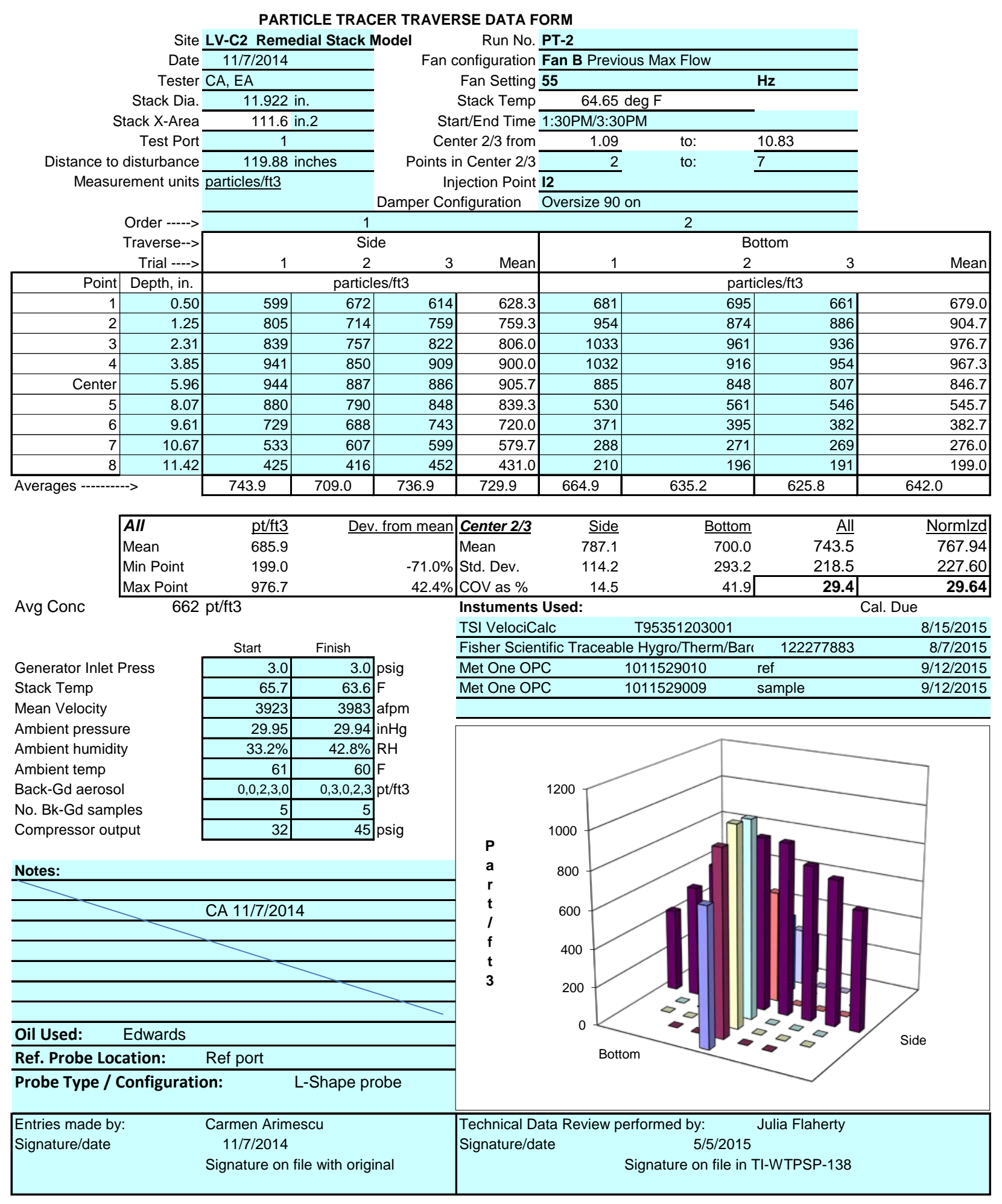




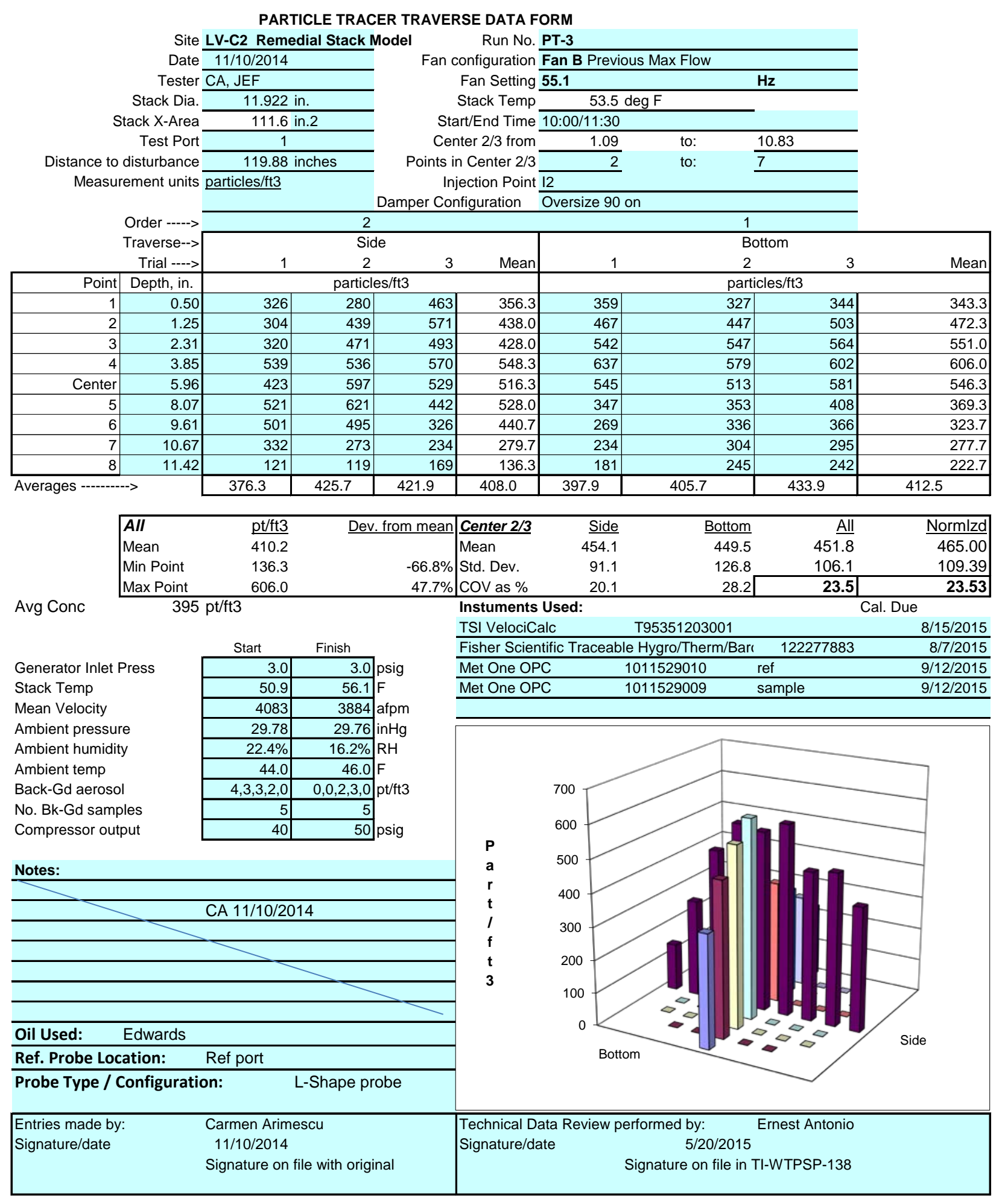




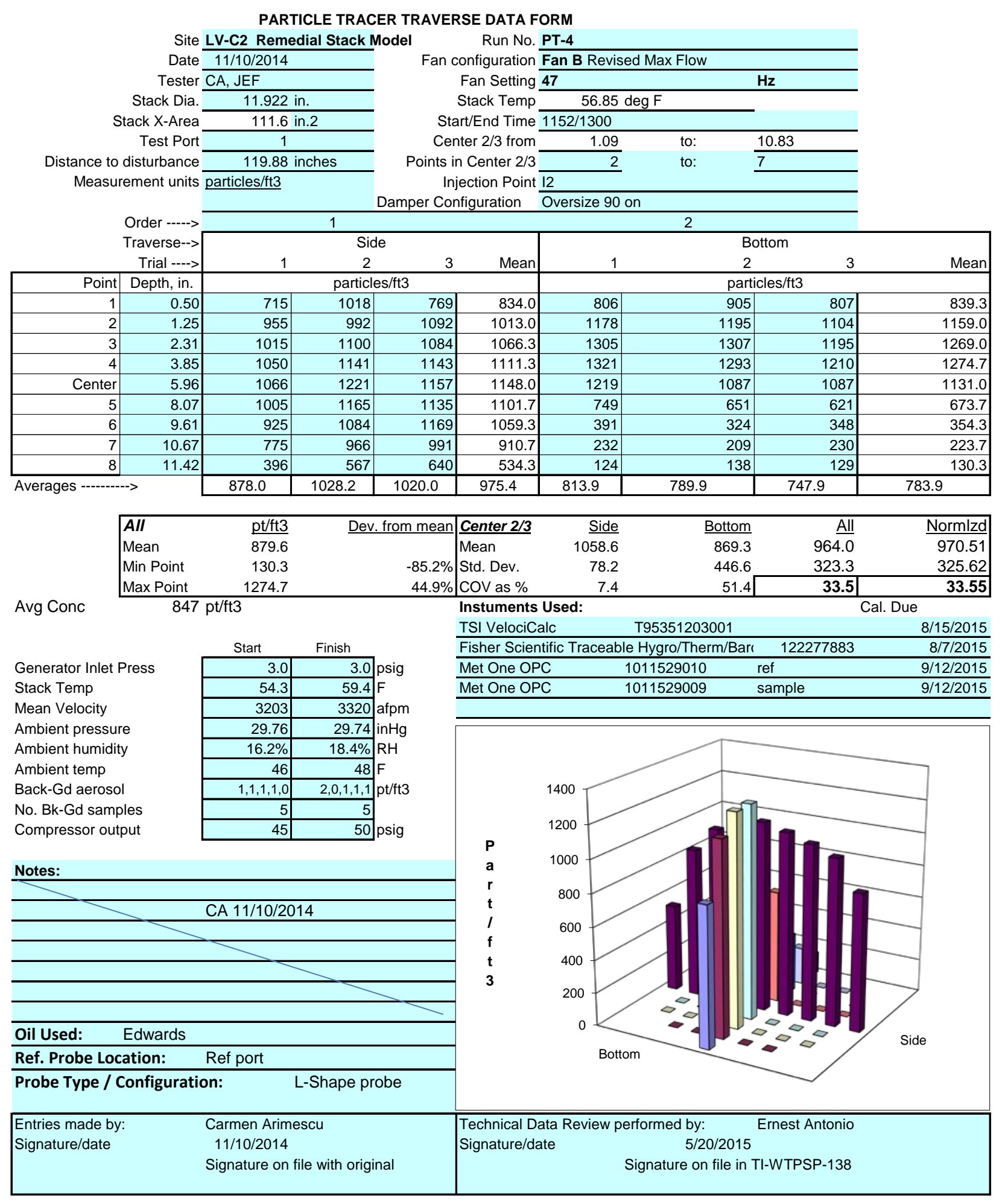




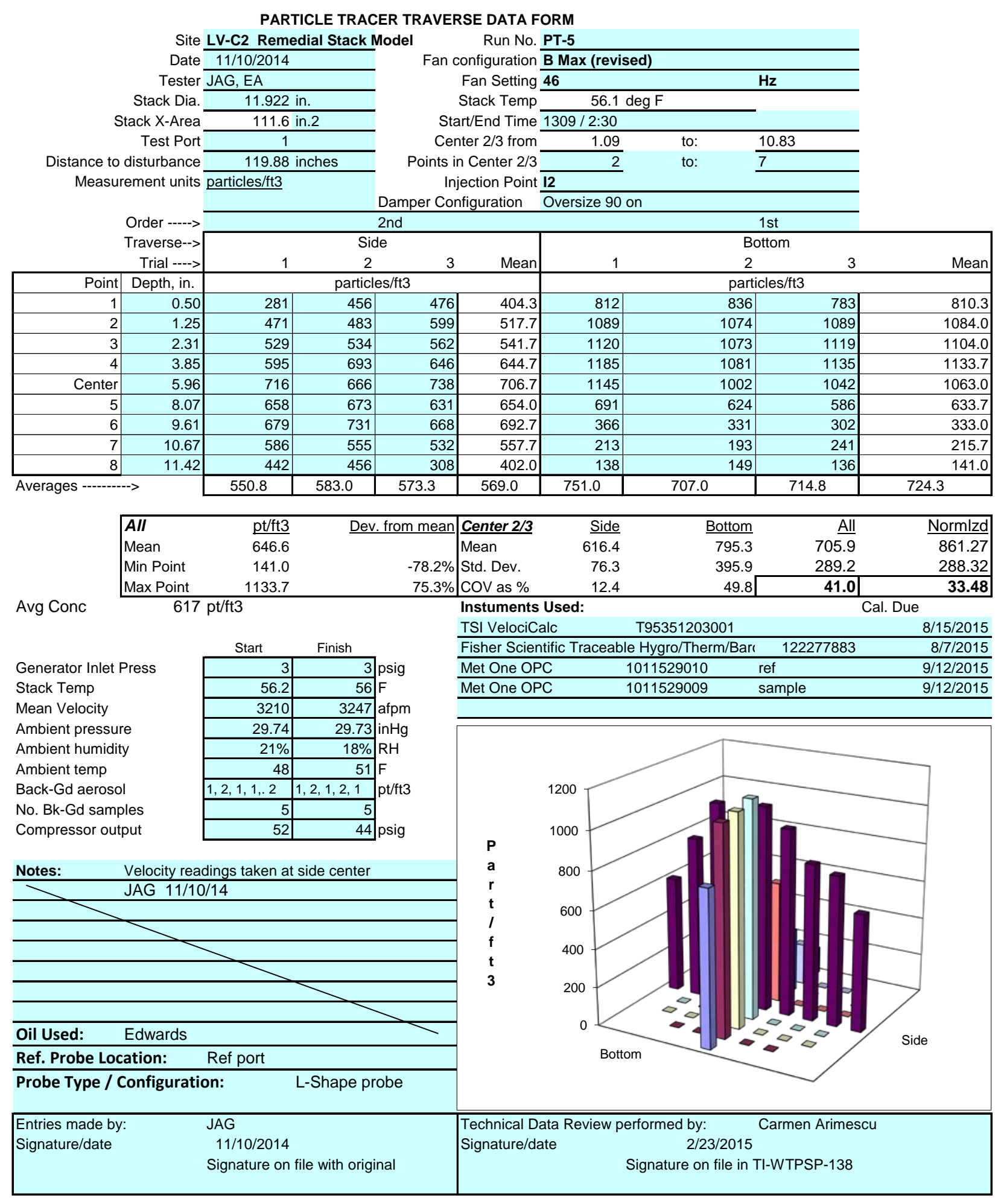




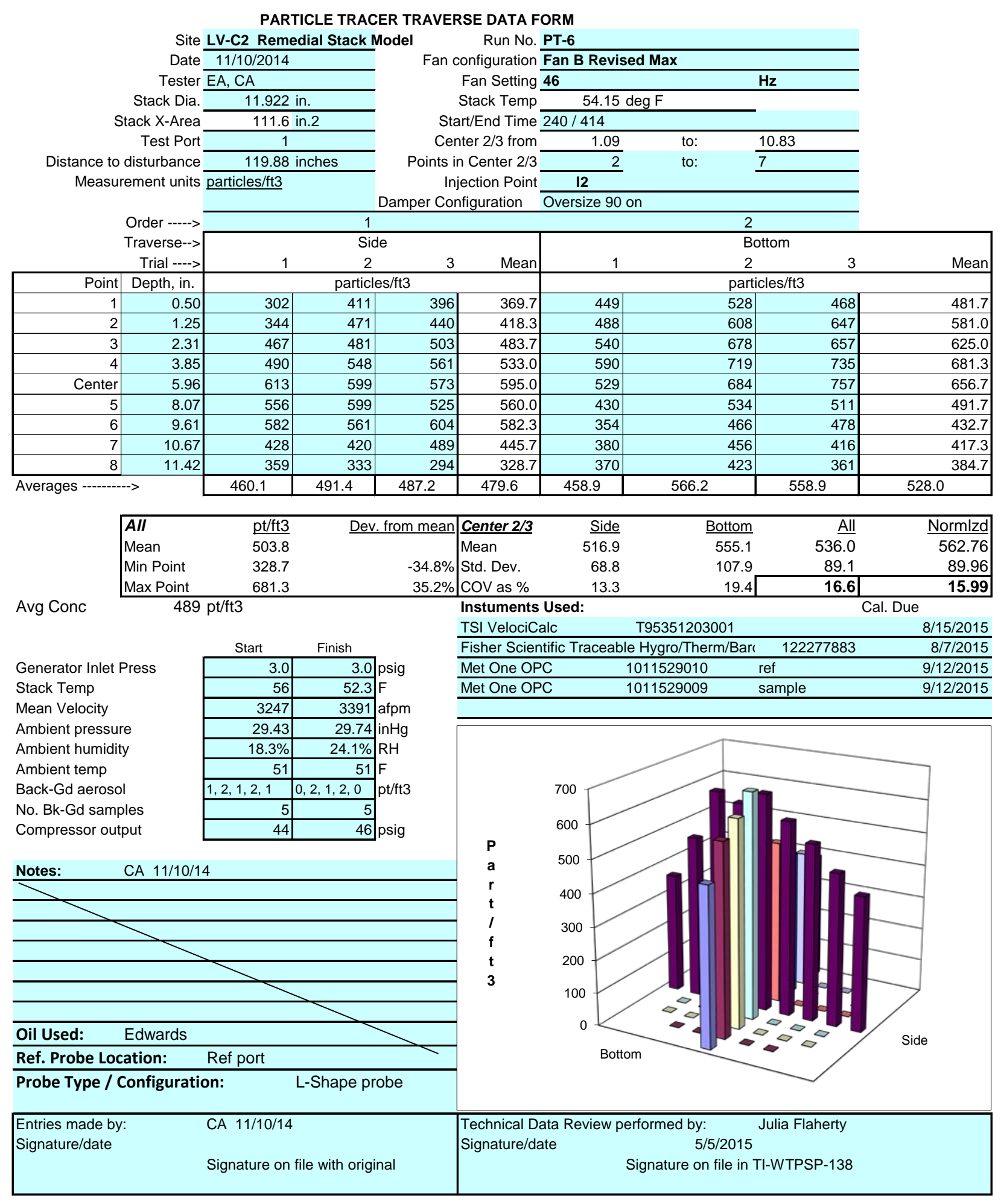




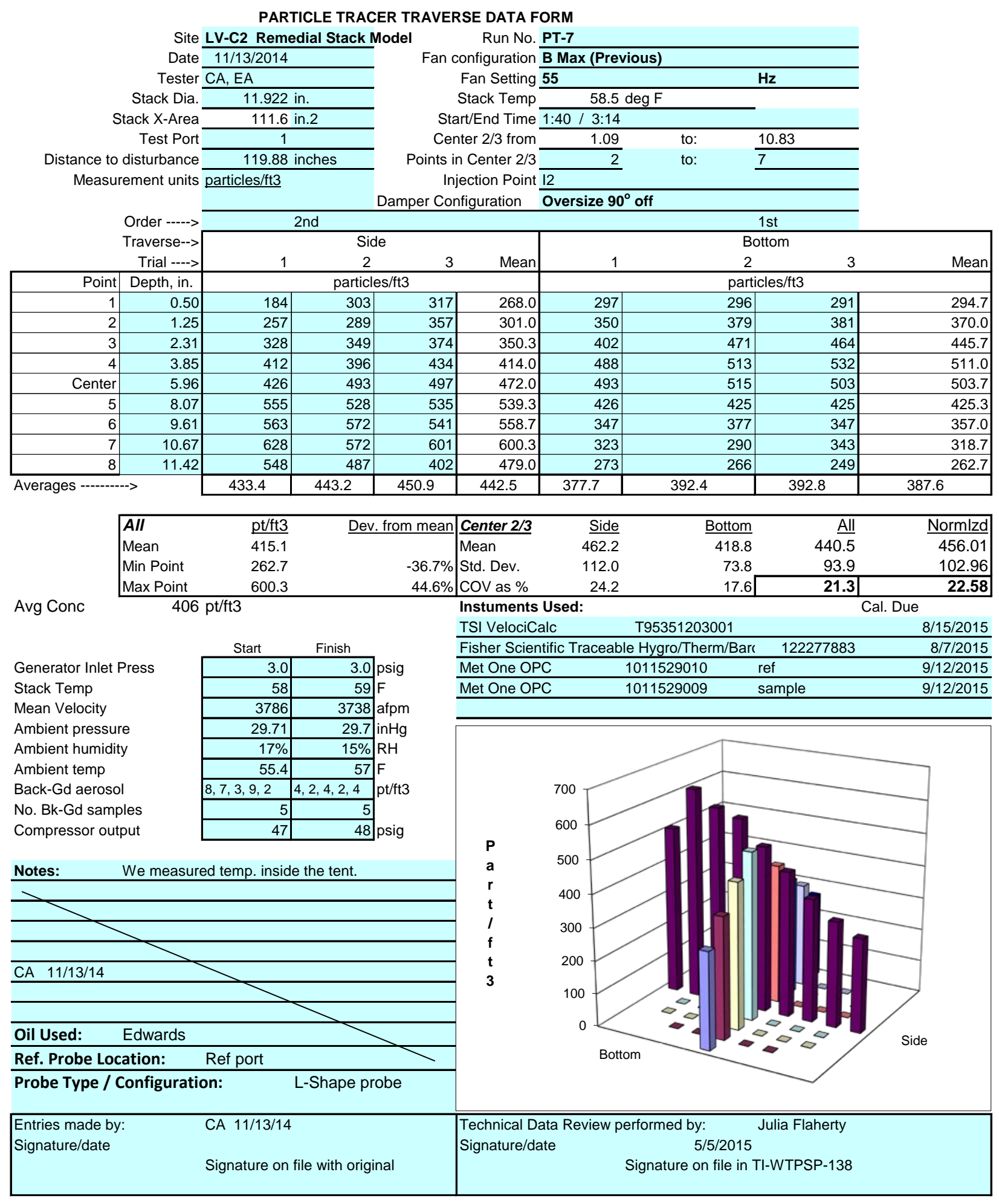




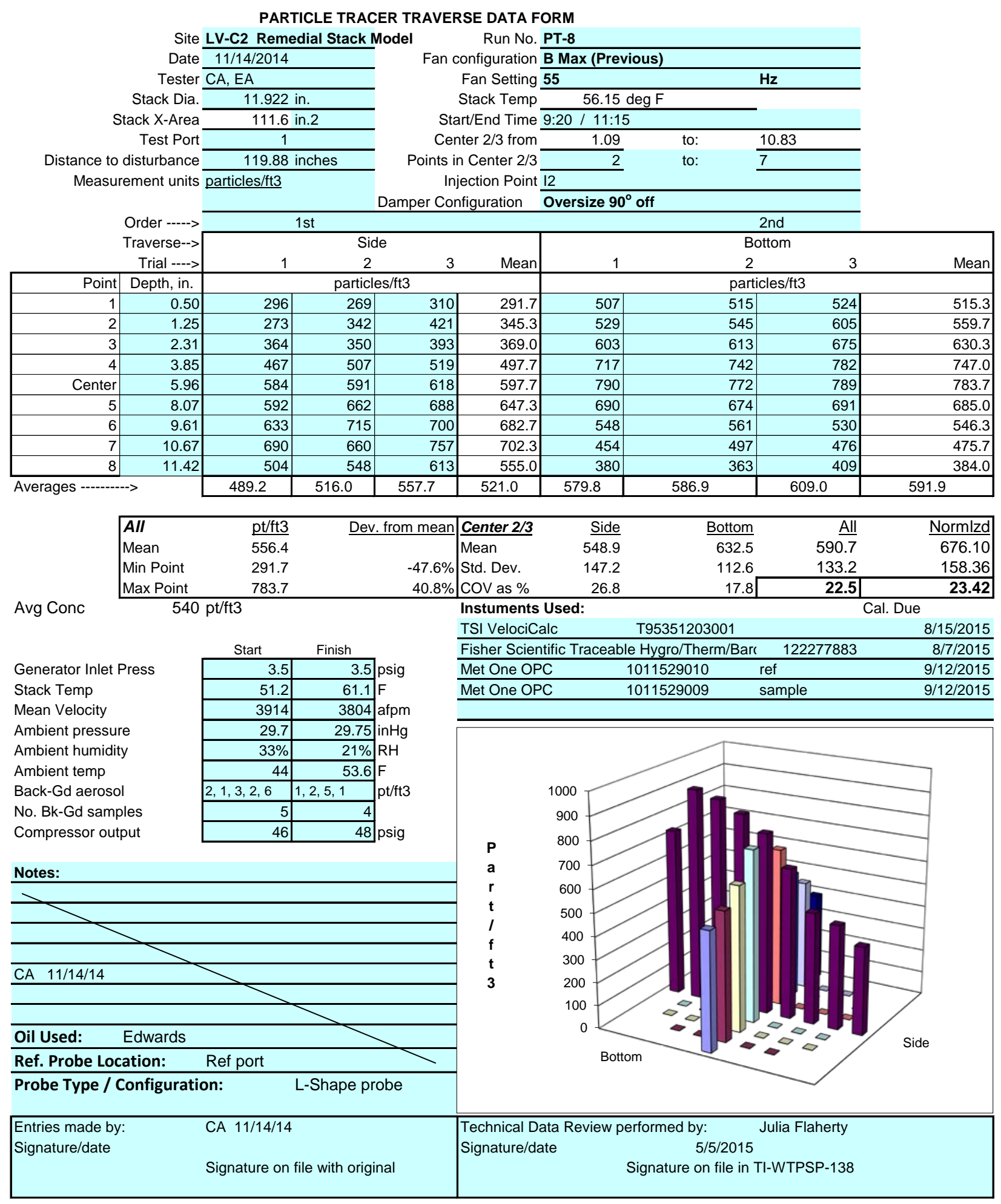




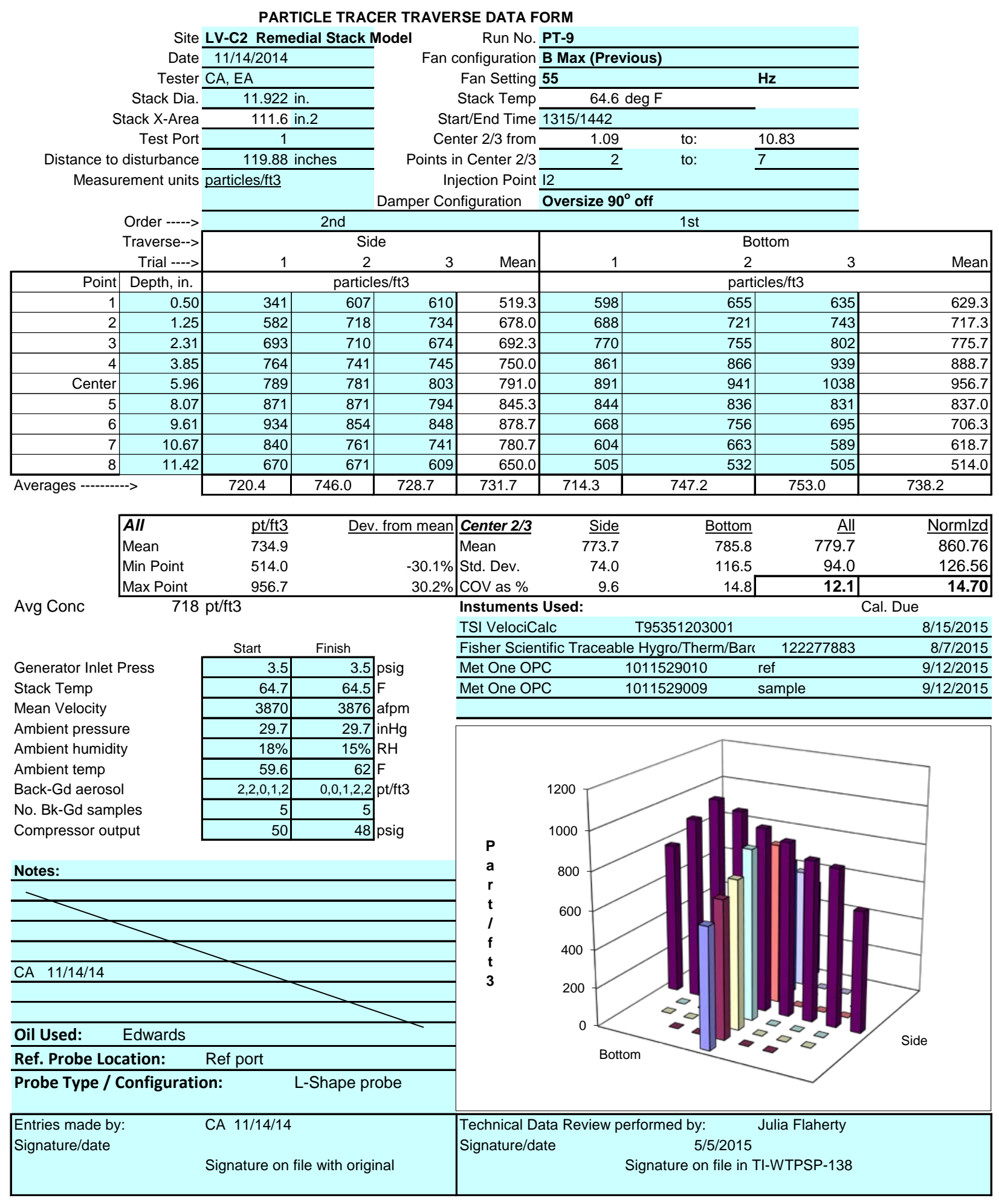




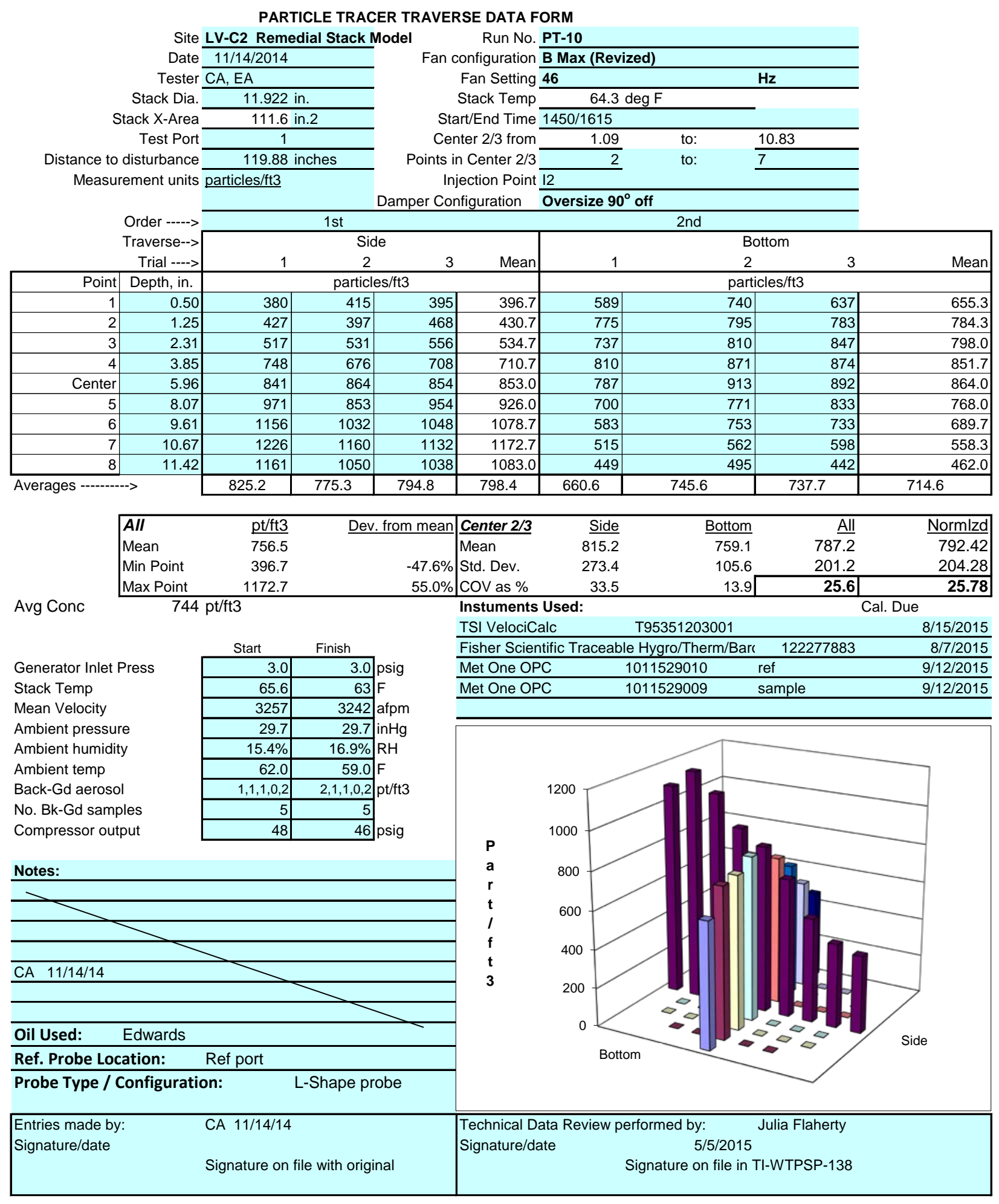




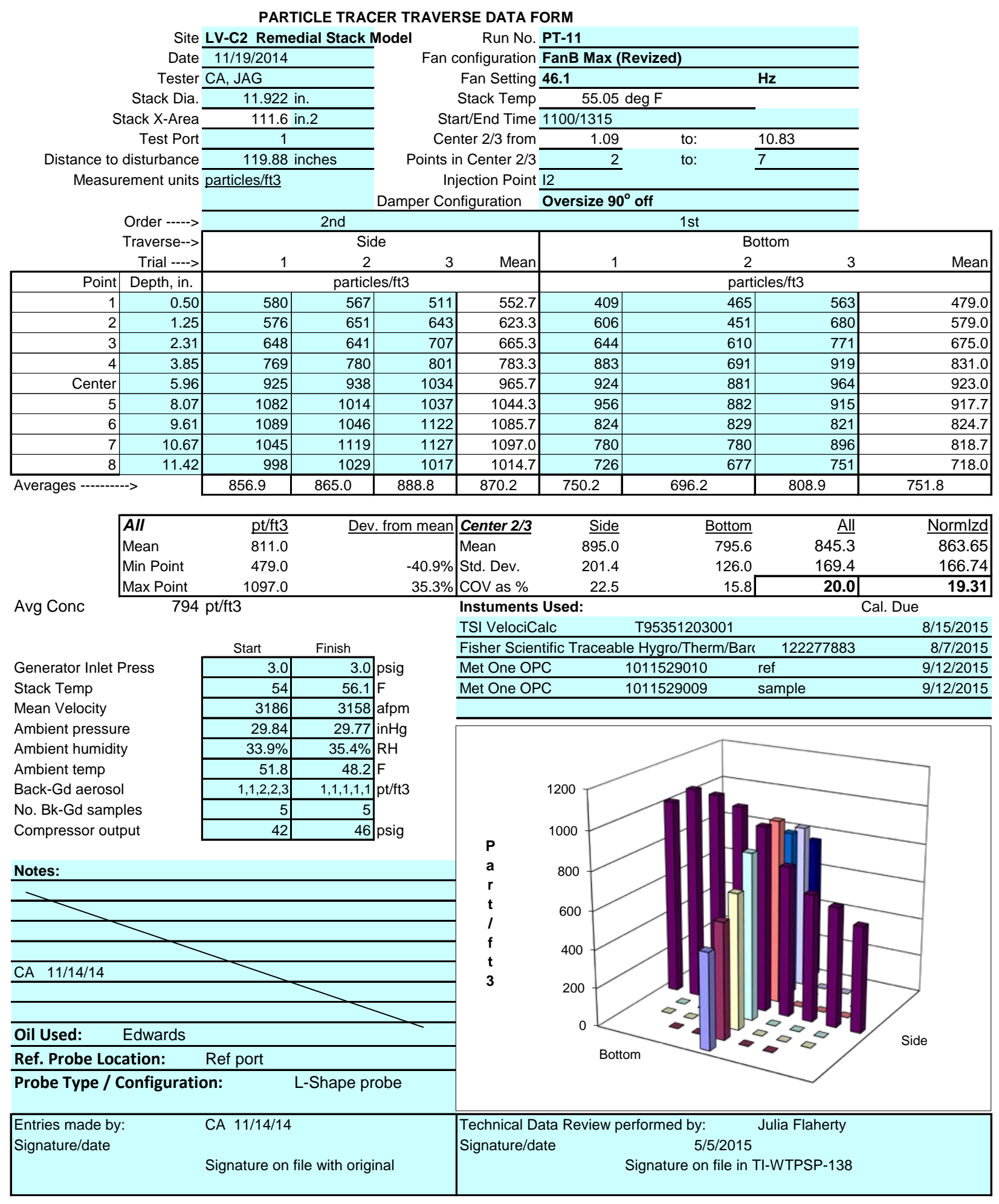




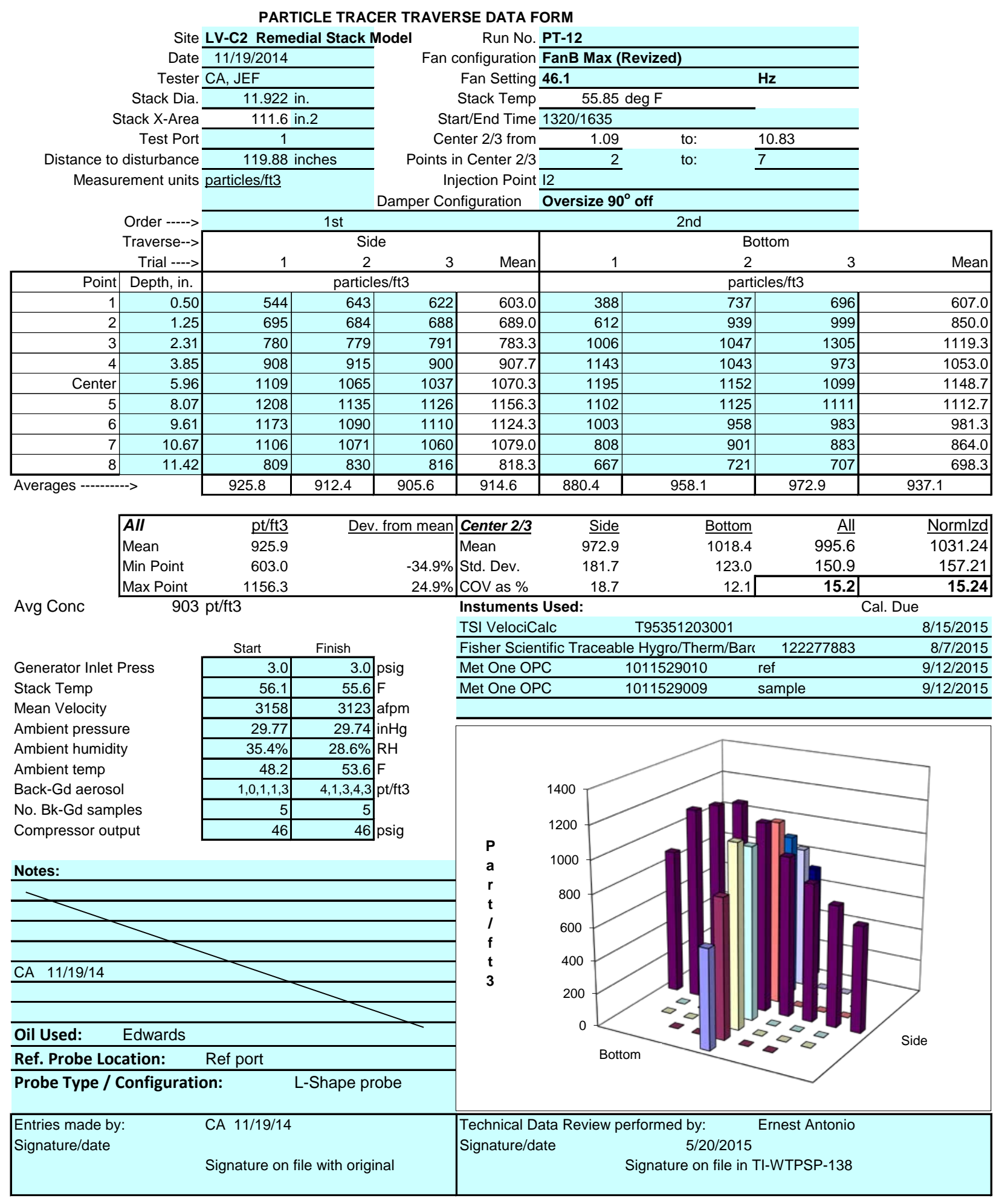




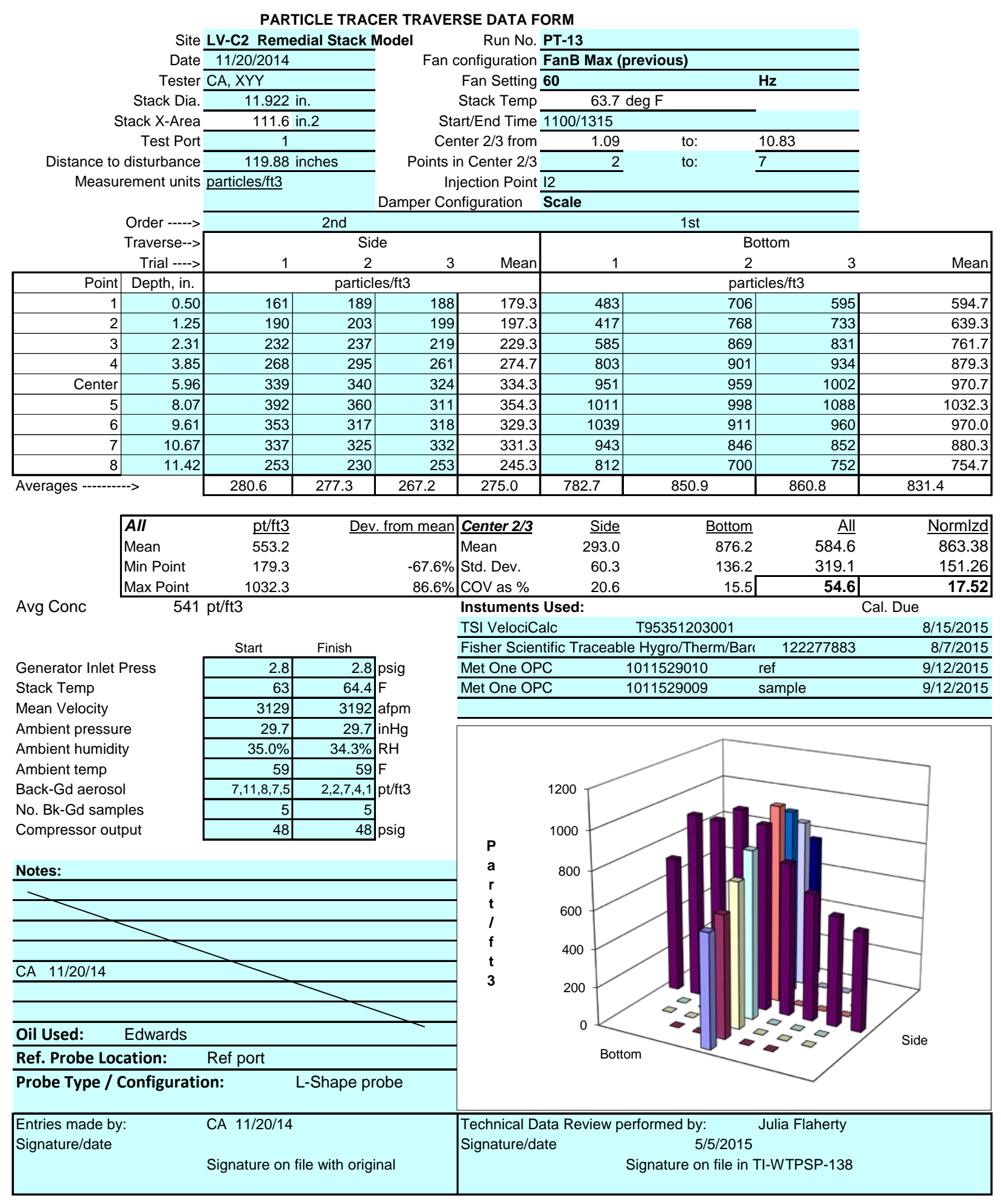




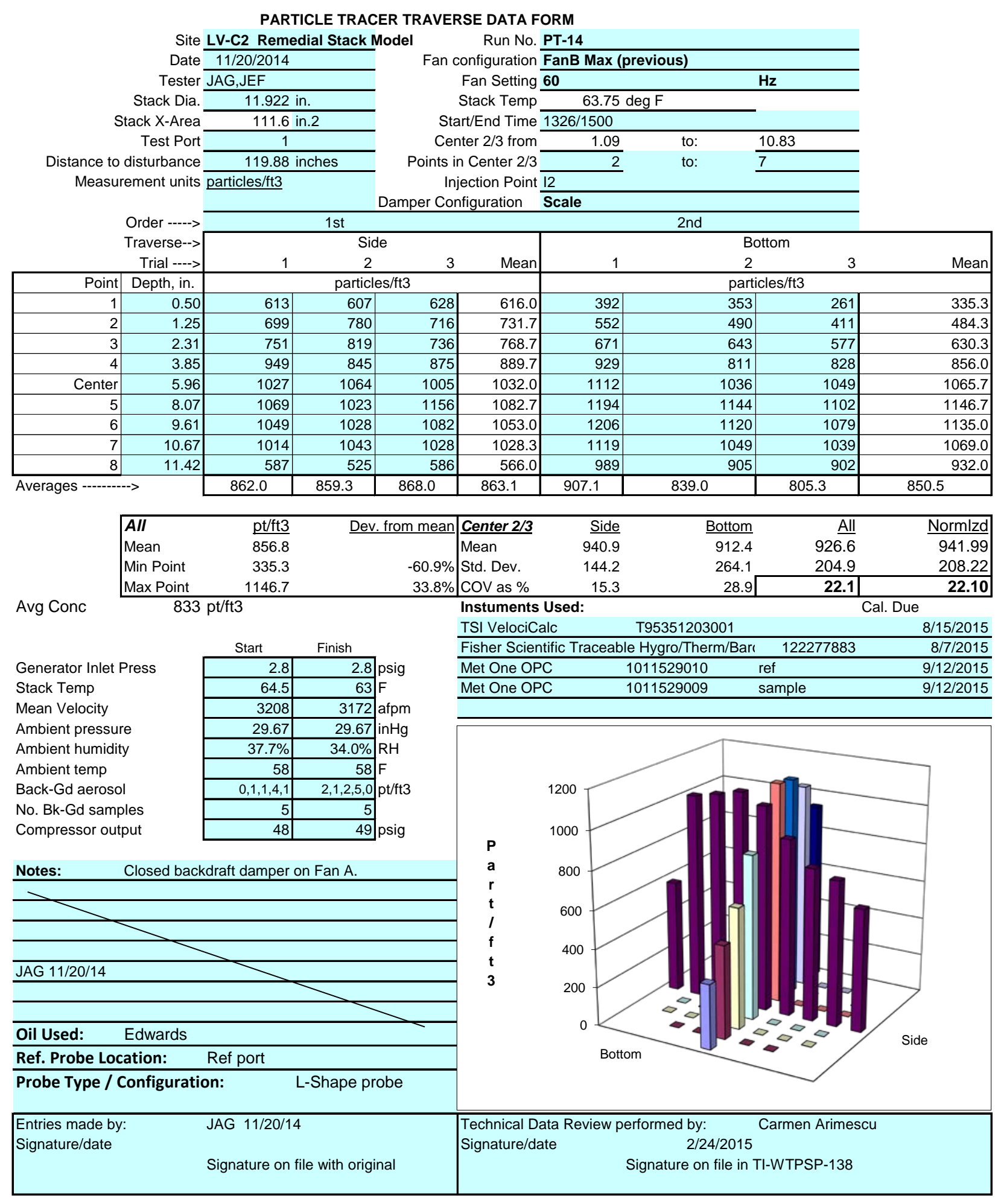




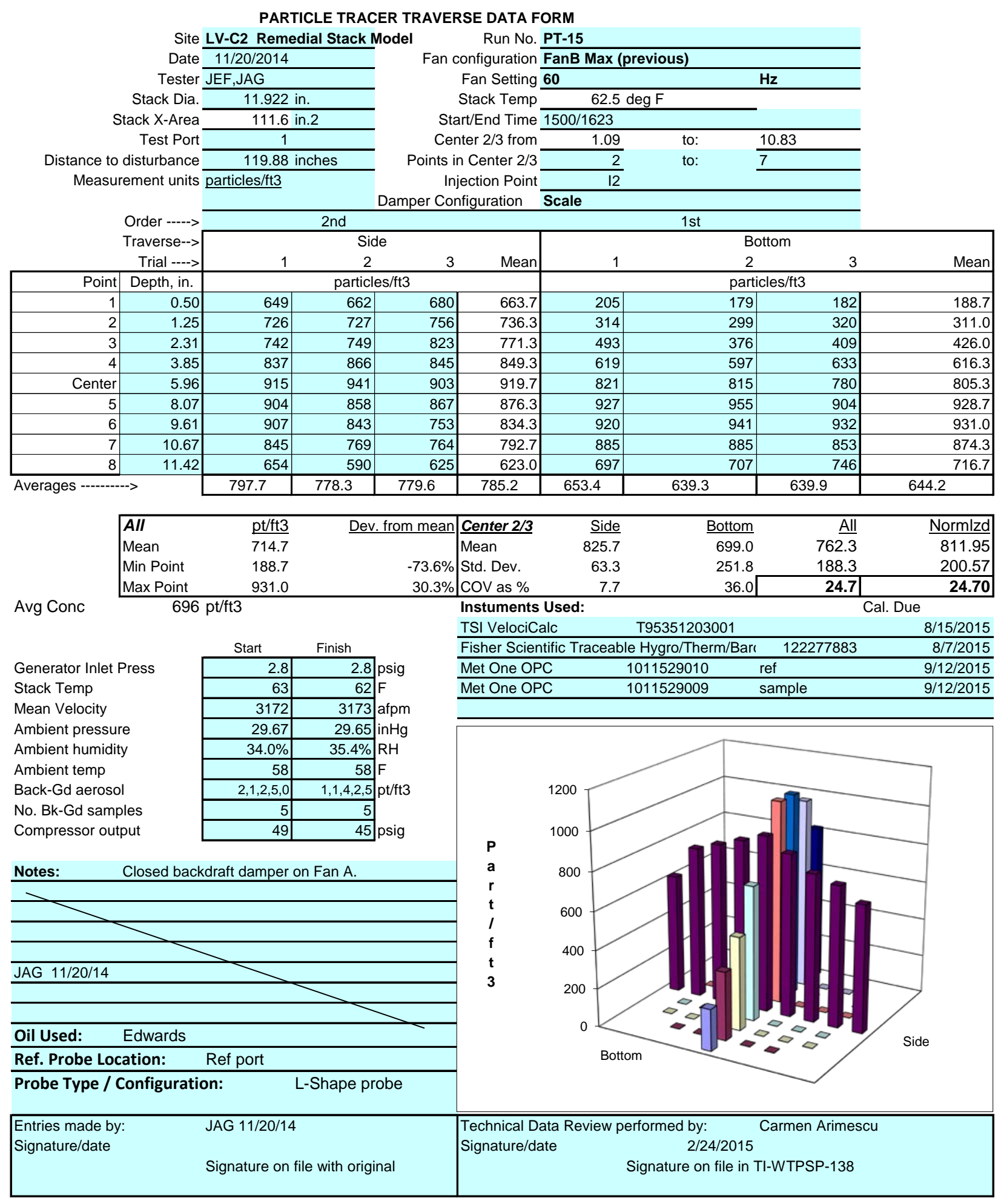




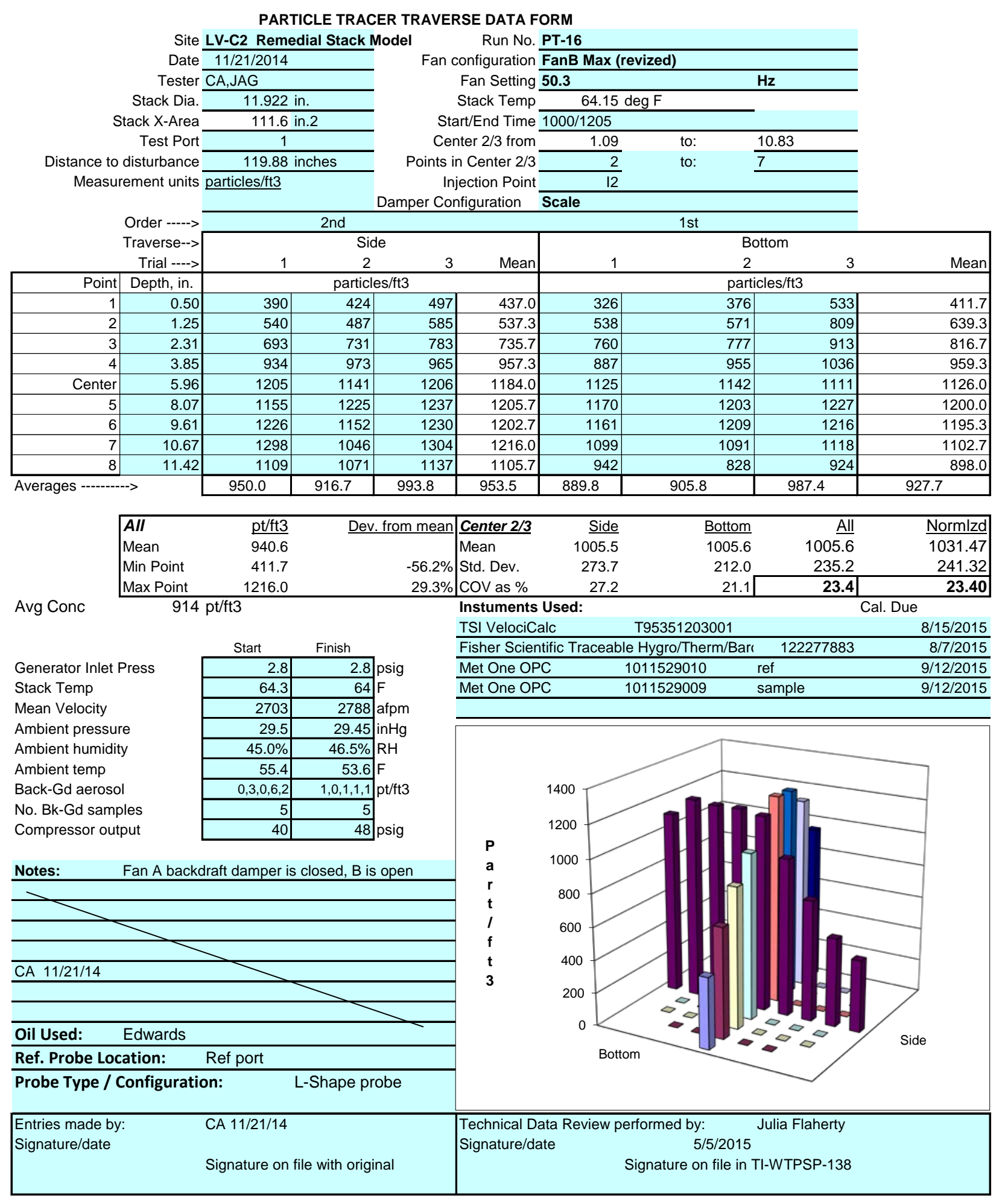




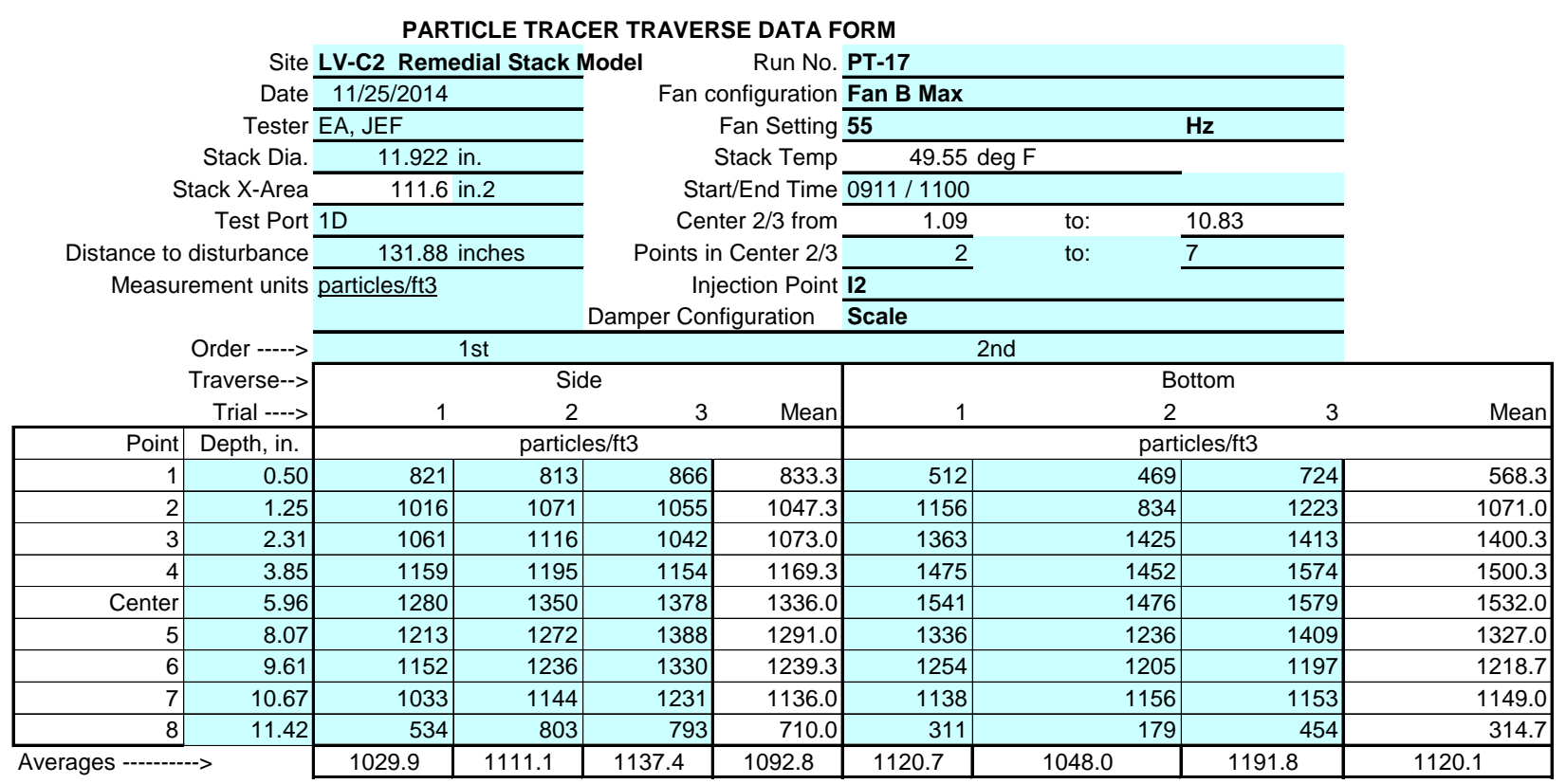

\begin{tabular}{|c|c|c|c|c|c|c|c|}
\hline All & $\mathrm{pt} / \mathrm{ft} 3$ & Dev. from mean & Center 2/3 & $\underline{\text { Side }}$ & Bottom & All & Normlzd \\
\hline Mean & 1106.5 & & Mean & $11 \overline{84.6}$ & $\overline{1314.0}$ & 1249.3 & 1336.20 \\
\hline Min Point & 314.7 & $-71.6 \%$ & Std. Dev. & 108.9 & 175.7 & 155.7 & 148.23 \\
\hline Max Point & 1532.0 & $38.5 \%$ & cov as $\%$ & 9.2 & 13.4 & 12.5 & 11.09 \\
\hline
\end{tabular}

Avg Conc $1066 \mathrm{pt} / \mathrm{ft} 3$

Generator Inlet Press

Stack Temp

Mean Velocity

Ambient pressure

Ambient humidity

Ambient temp

Back-Gd aerosol

No. Bk-Gd samples

Compressor output

\begin{tabular}{|c|c|}
\hline Start & Finish \\
\hline 2.8 & 2.8 \\
\hline 49.7 & 49. \\
\hline 3069 & 2945 \\
\hline 29.72 & 29.76 \\
\hline $47 \%$ & $40 \%$ \\
\hline 15.5 & 19.5 \\
\hline $3,1,3,6,1$ & $0,3,1,1,4$ \\
\hline 5 & 5 \\
\hline 28 & \\
\hline
\end{tabular}

Notes: $\quad$ Ambient temp measured inside tent. Fan B damper open $70^{\circ}$, Fan A damper closed.

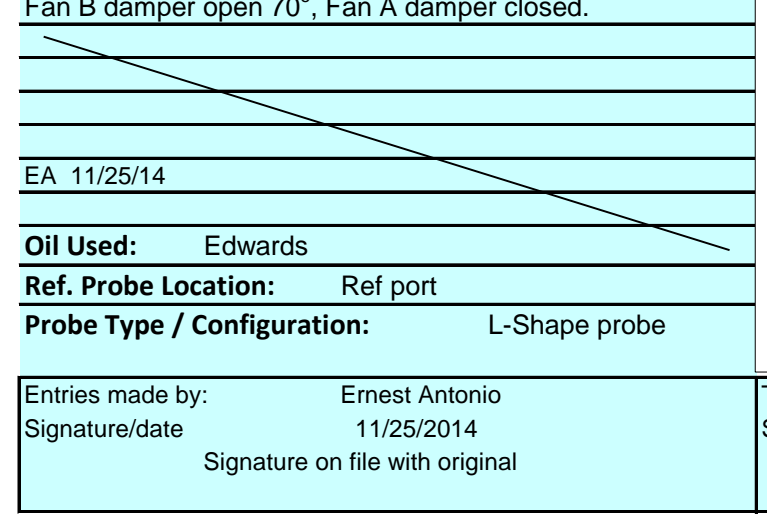

Instuments Used:

Cal. Due

\begin{tabular}{llr} 
TSI VelociCalc & T95351203001 & 8/15/2015 \\
\hline
\end{tabular} Fisher Scientific Traceable Hygro/Therm/Barc $122277883 \quad 8 / 7 / 2015$ \begin{tabular}{llll}
\hline Met One OPC & 1011529010 & ref & $9 / 12 / 2015$ \\
\hline
\end{tabular} \begin{tabular}{llll}
\hline Met One OPC & 1011529009 & sample & 9/12/2015
\end{tabular} N/A

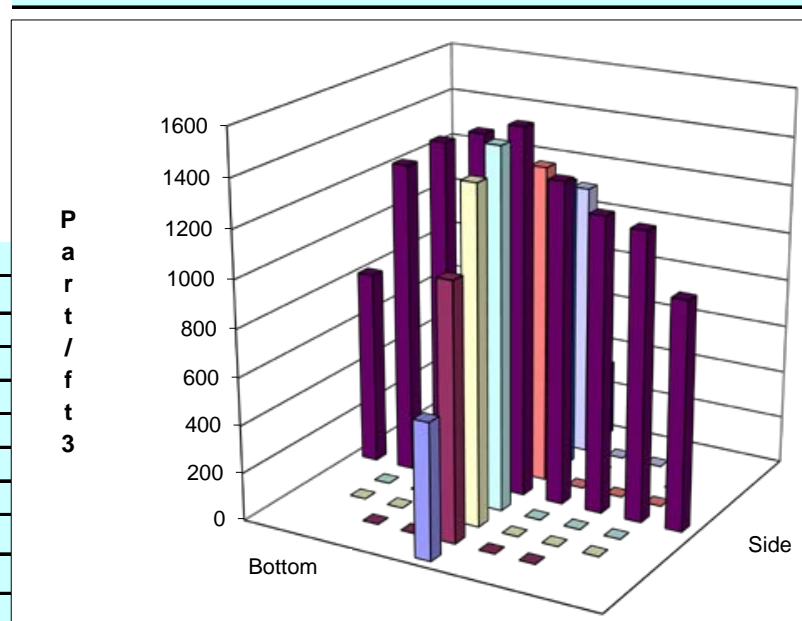

Technical Data Review performed by:

2/24/2015

Signature/date

Signature on file in TI-WTPSP-138 


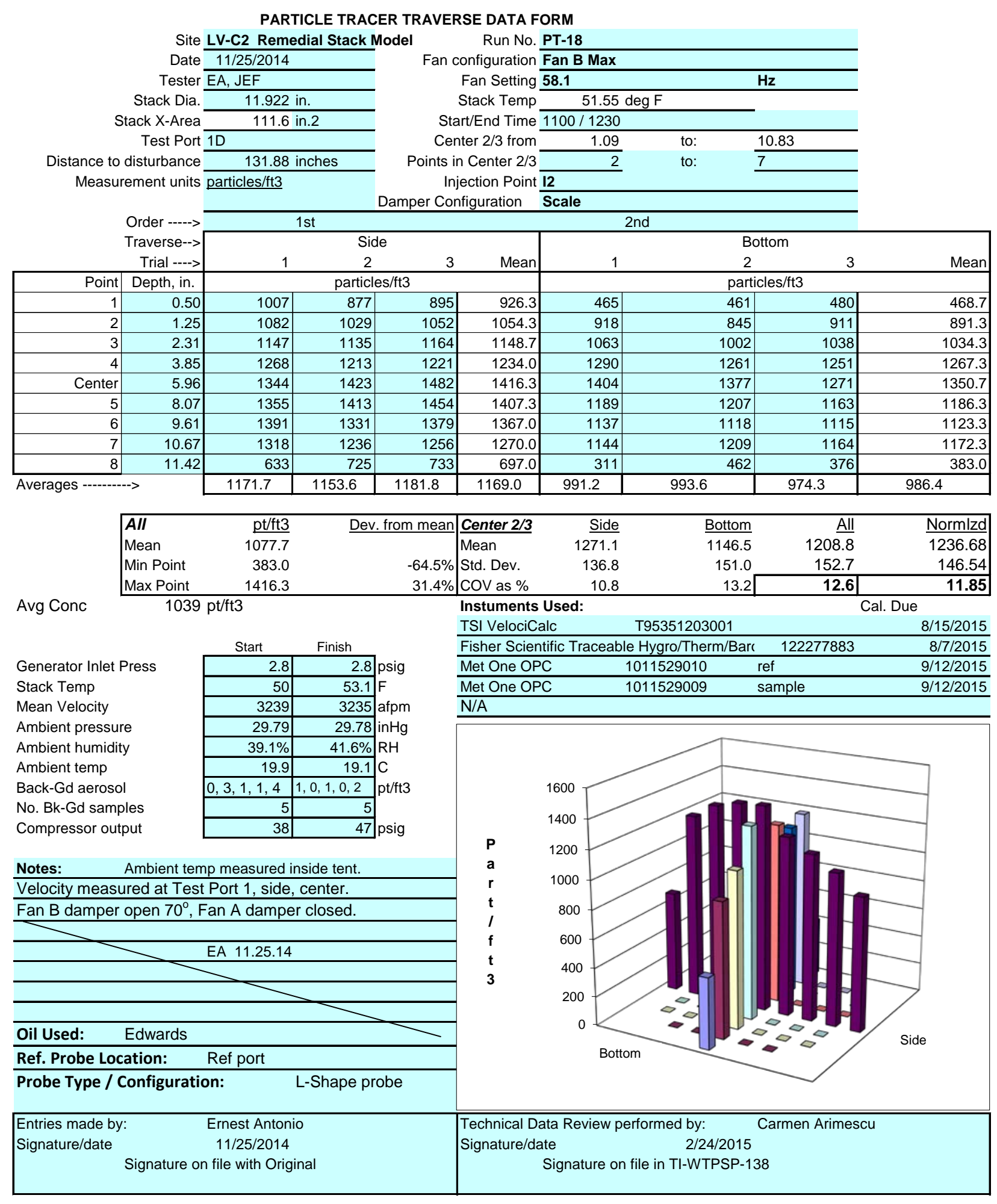




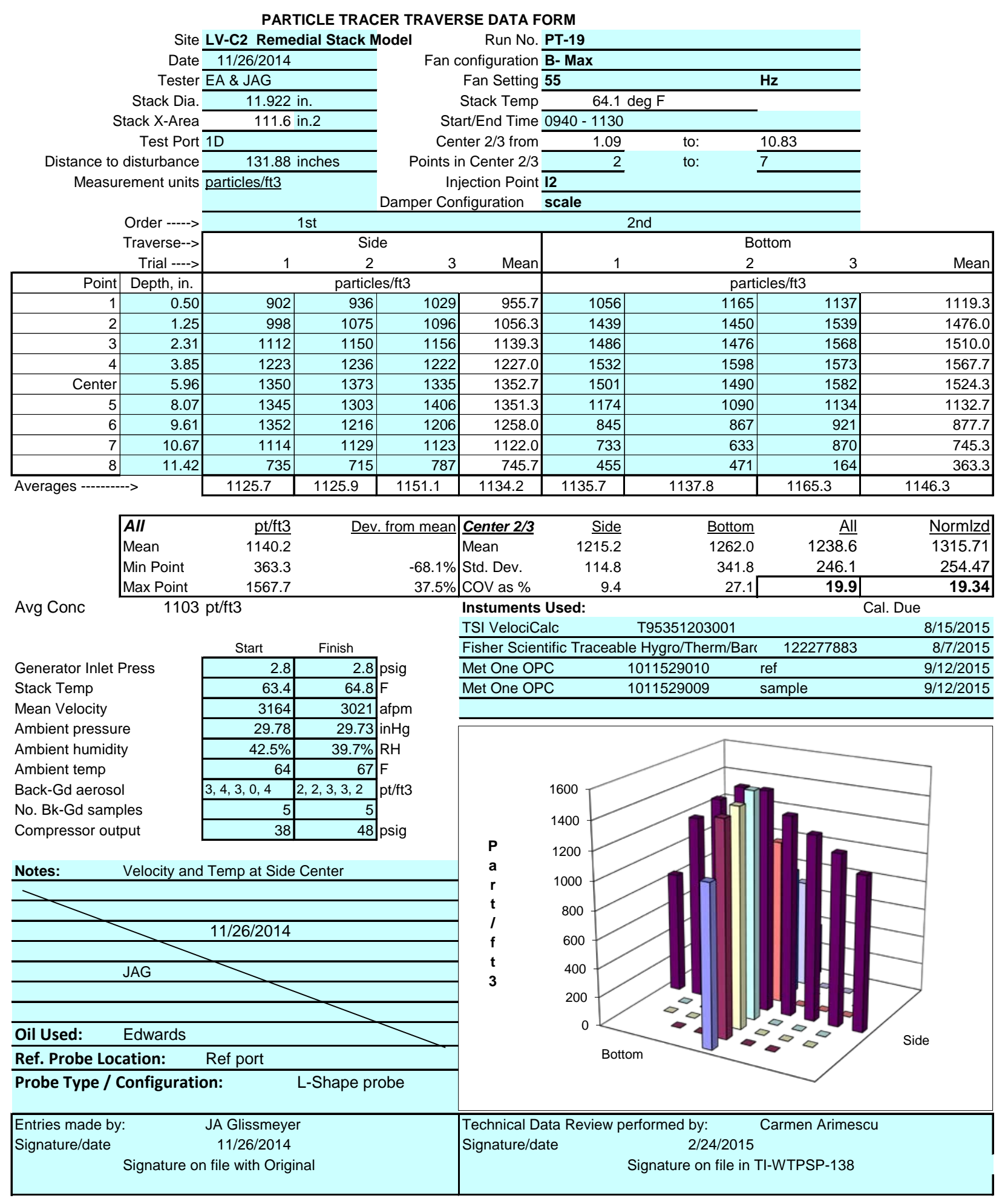




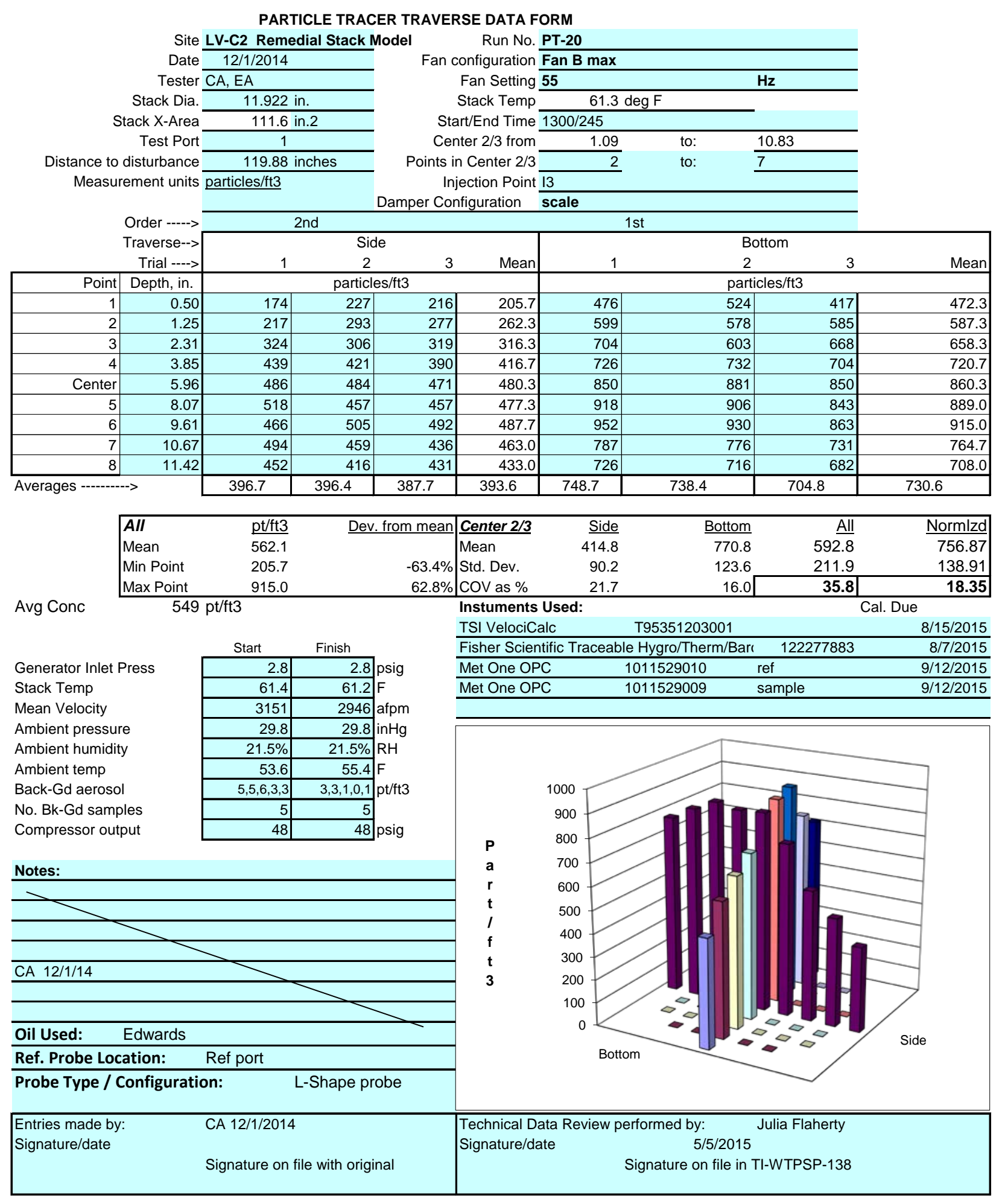




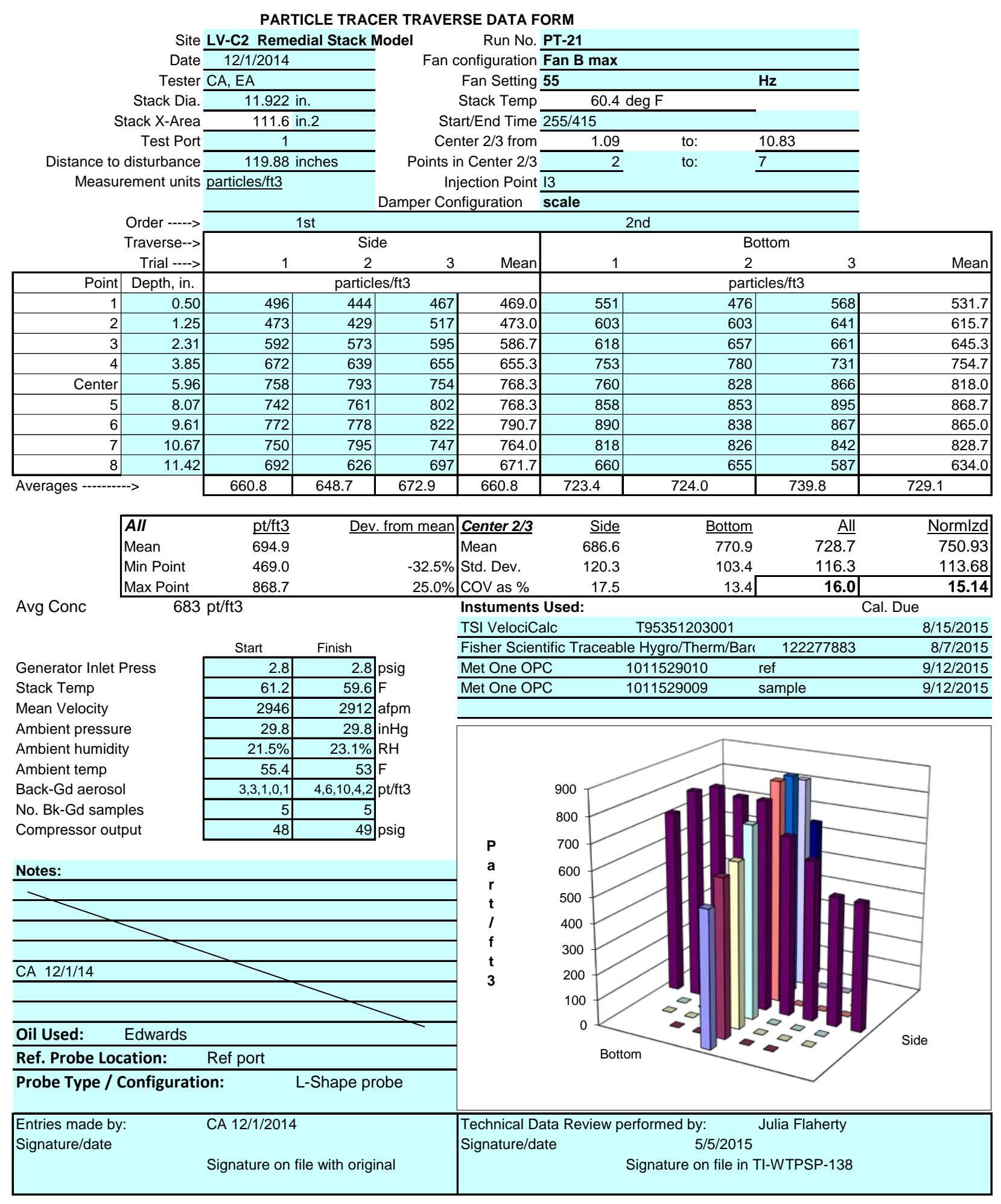




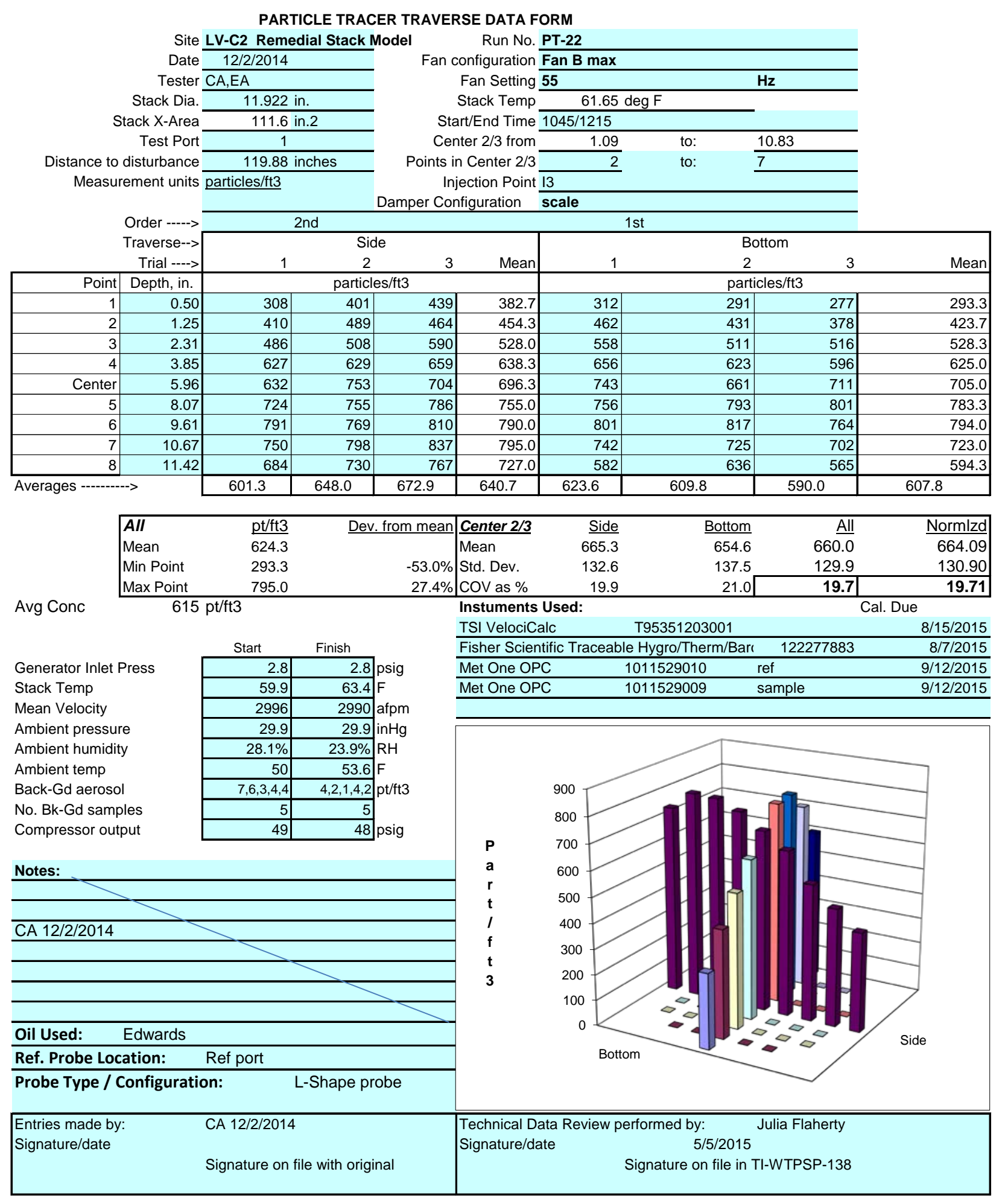




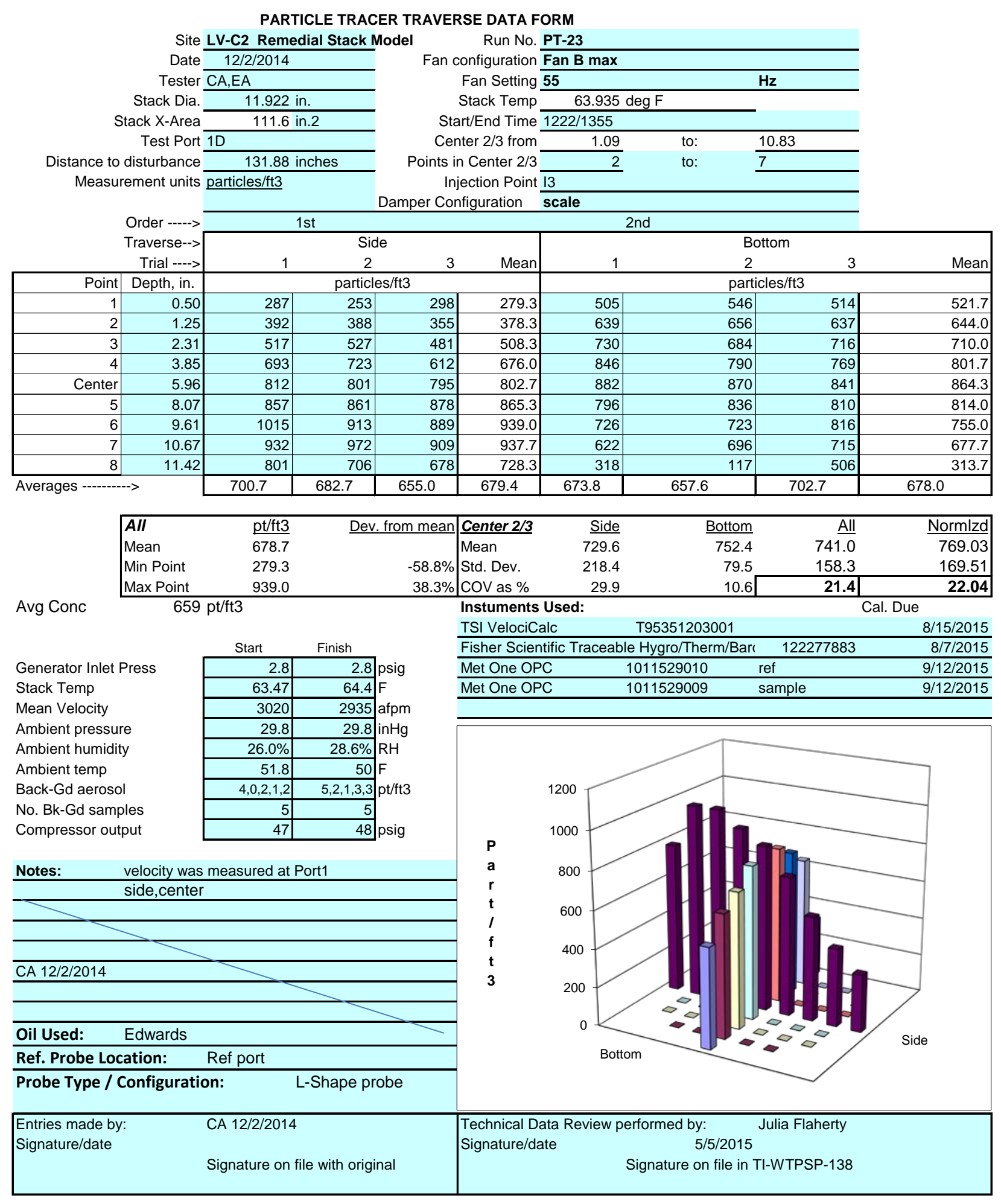




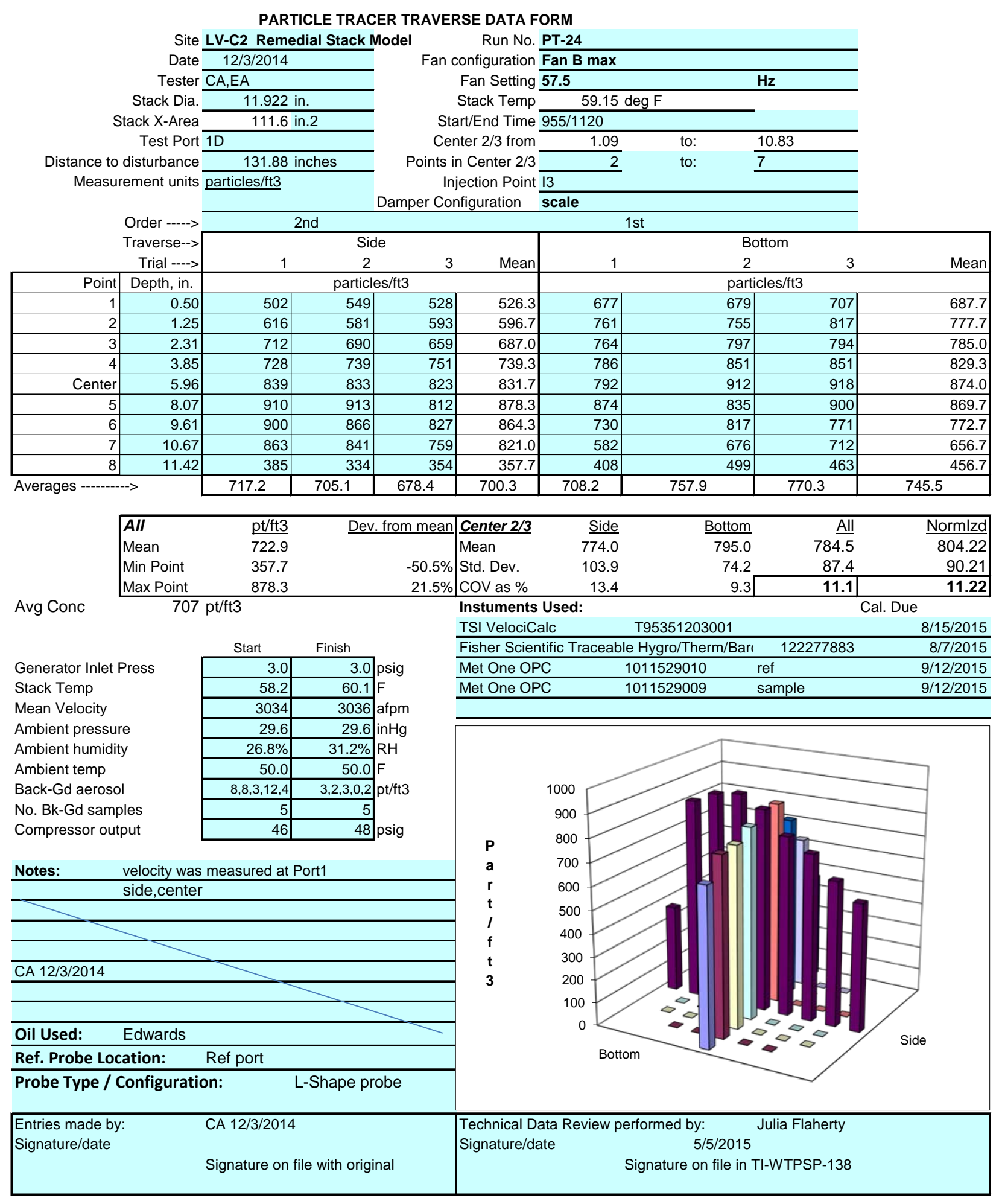




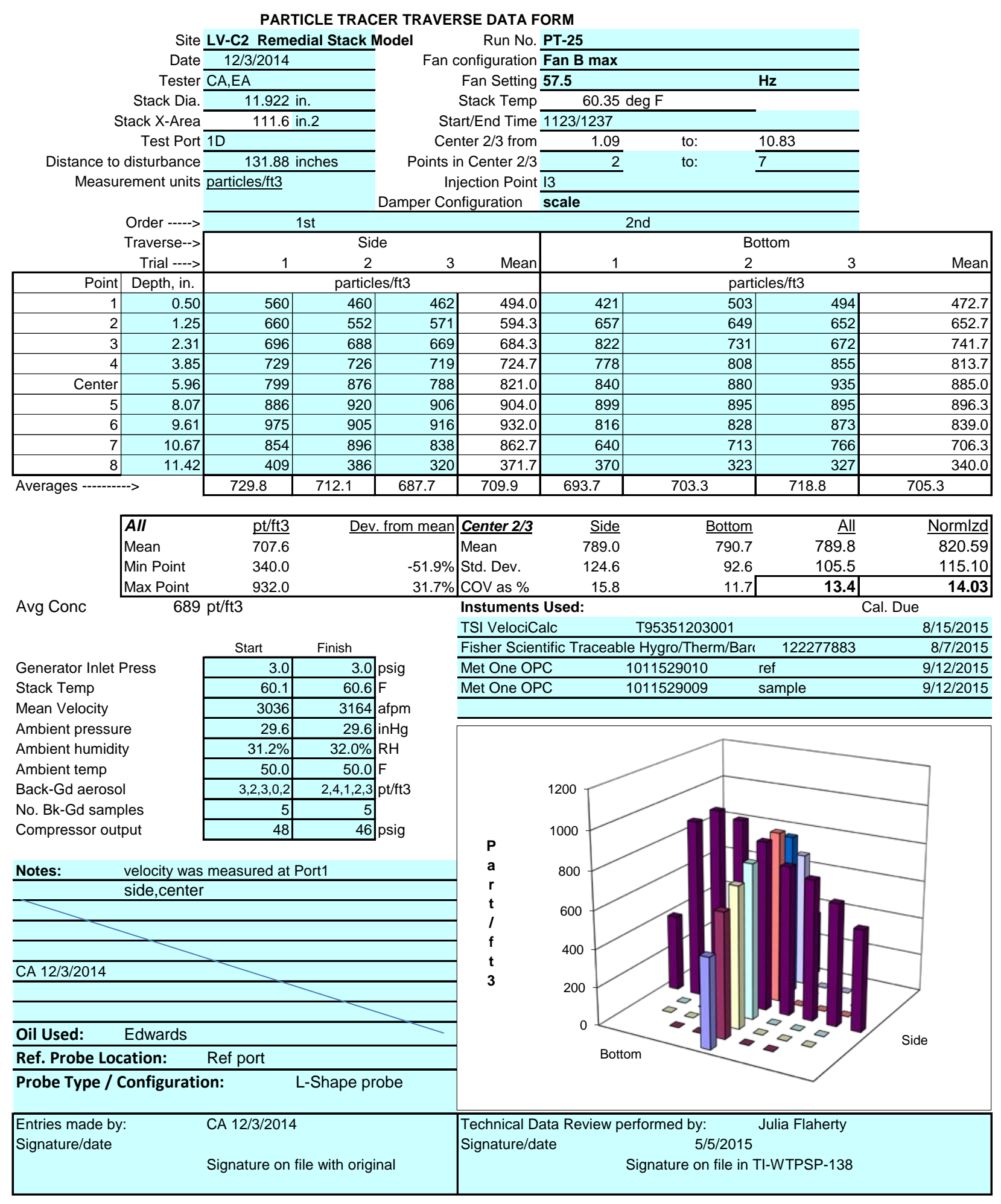




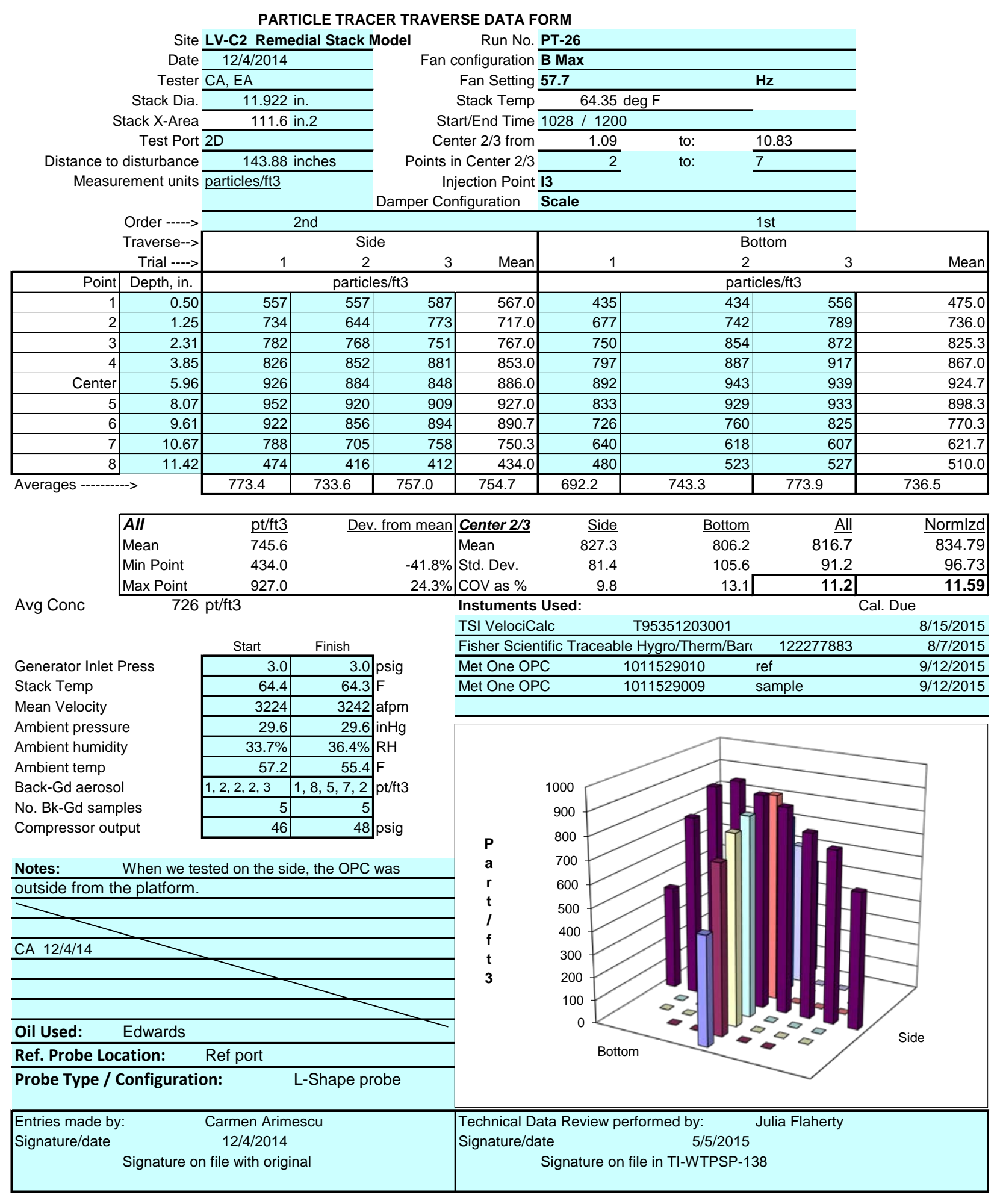




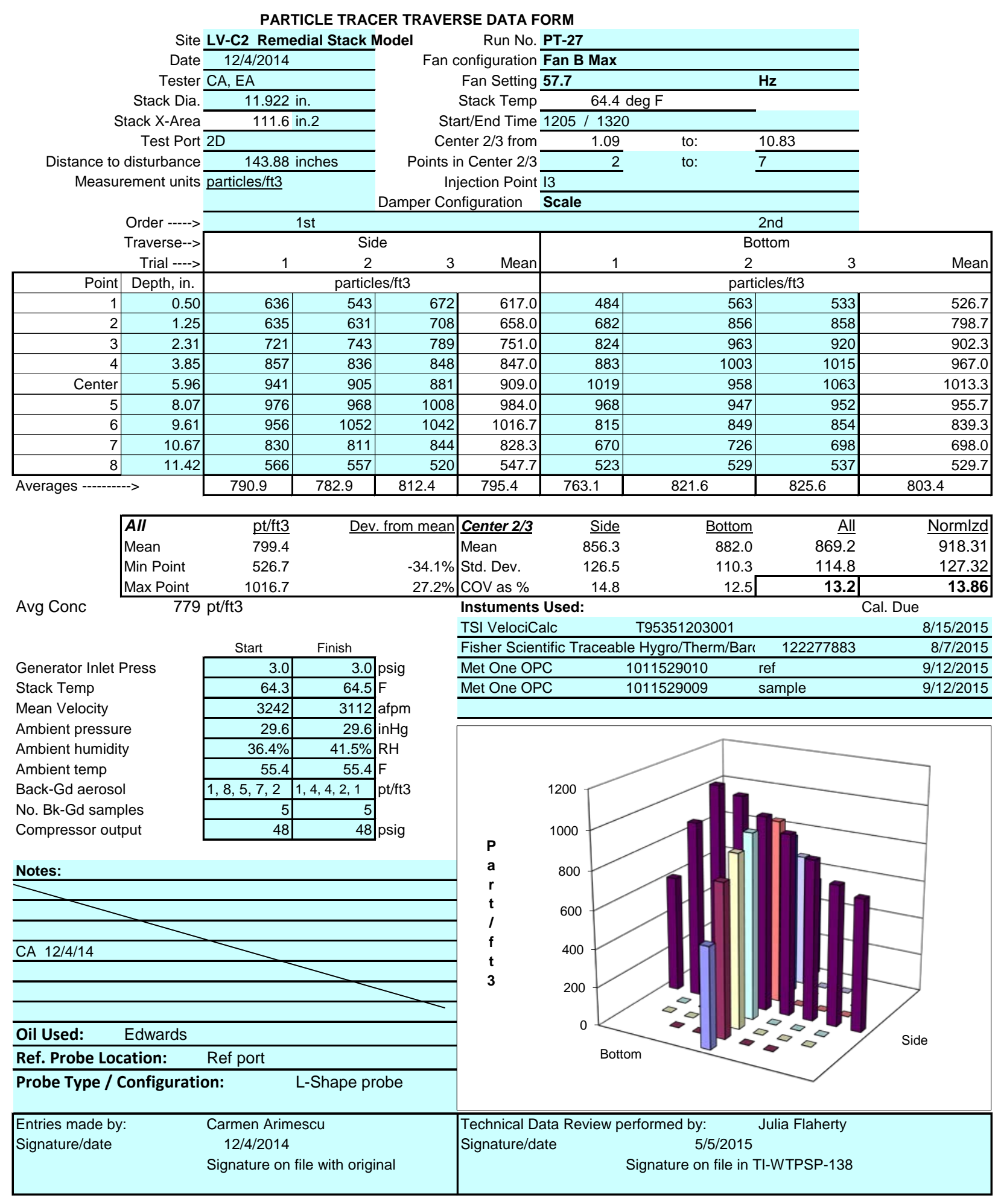




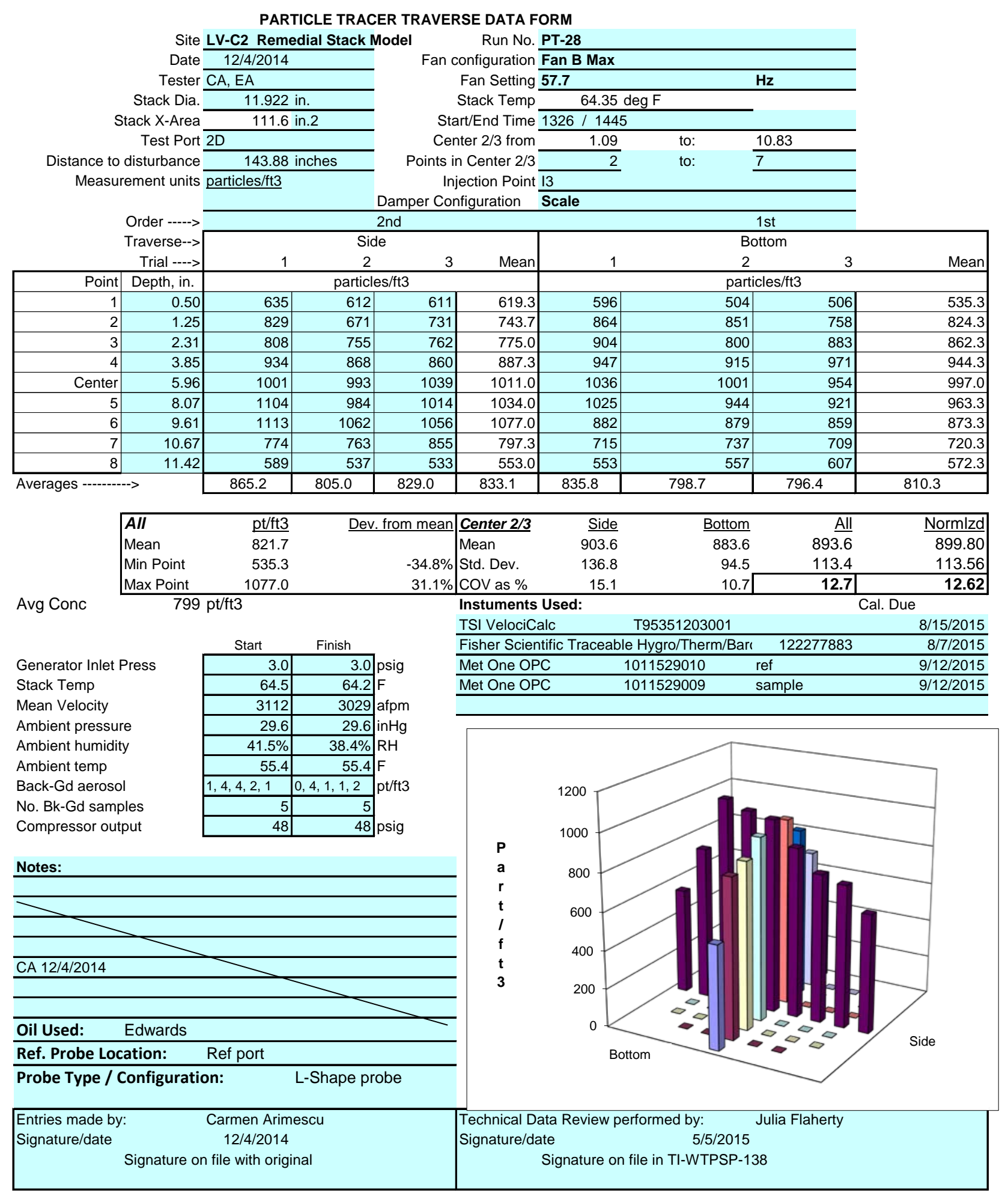




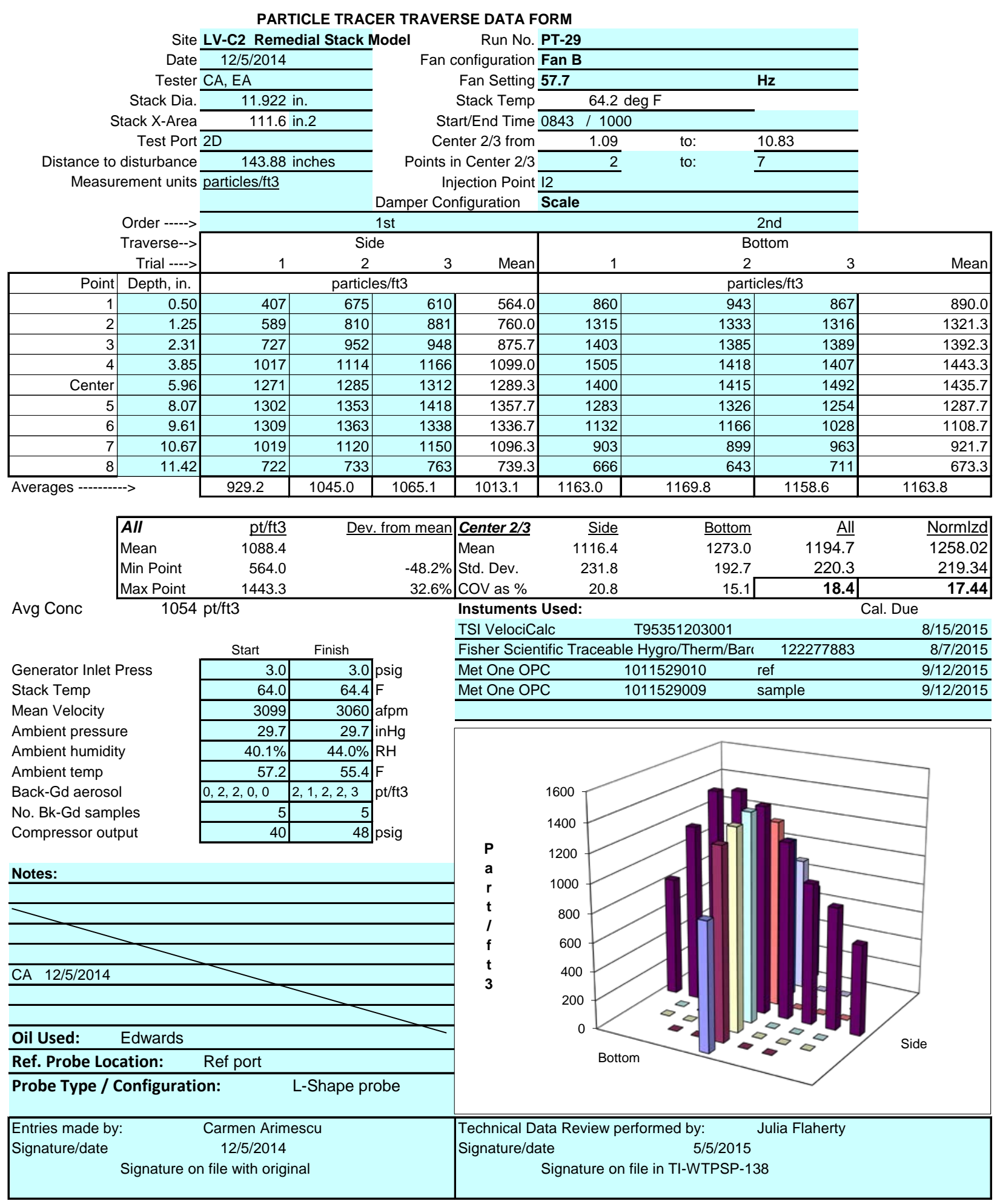




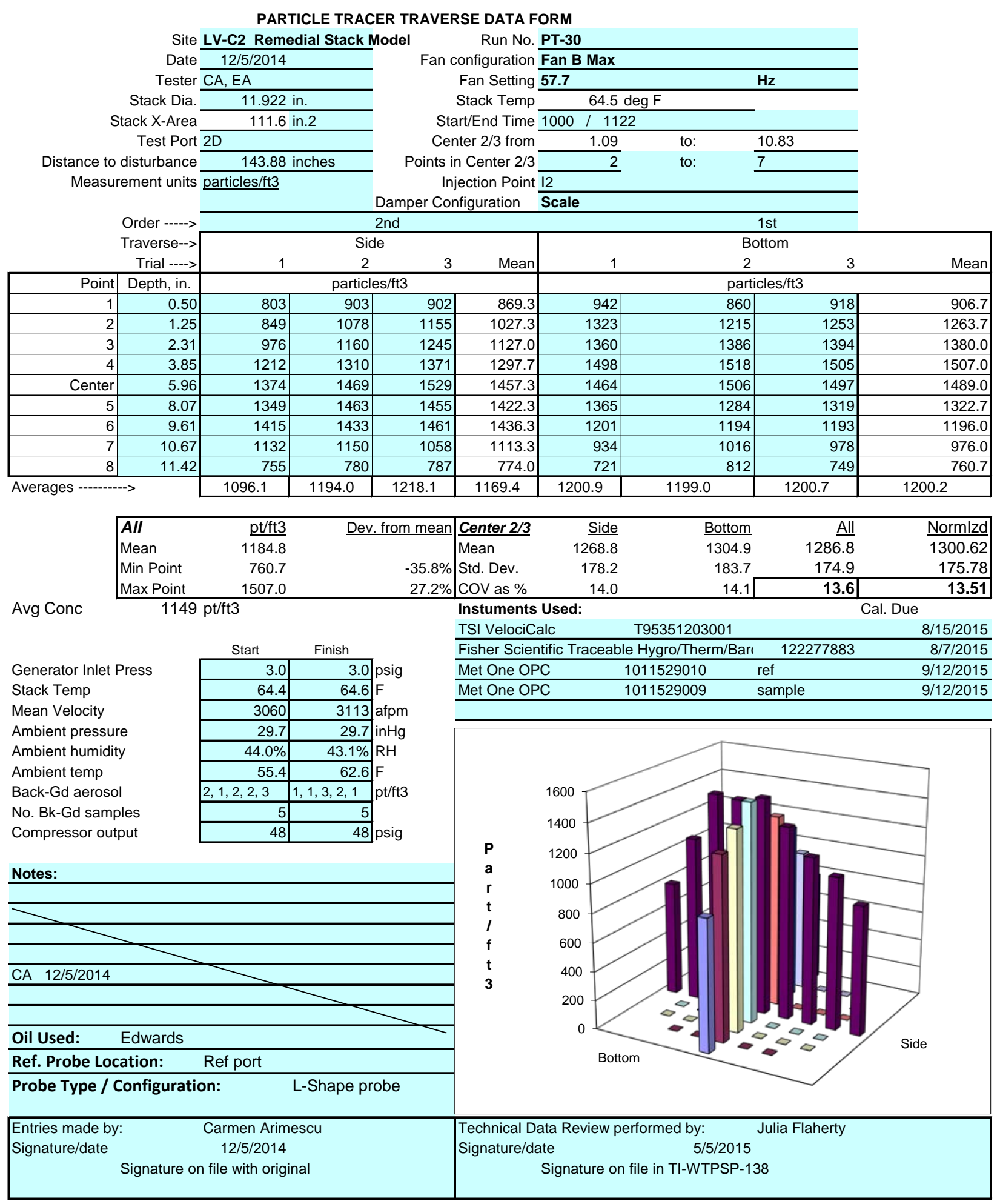




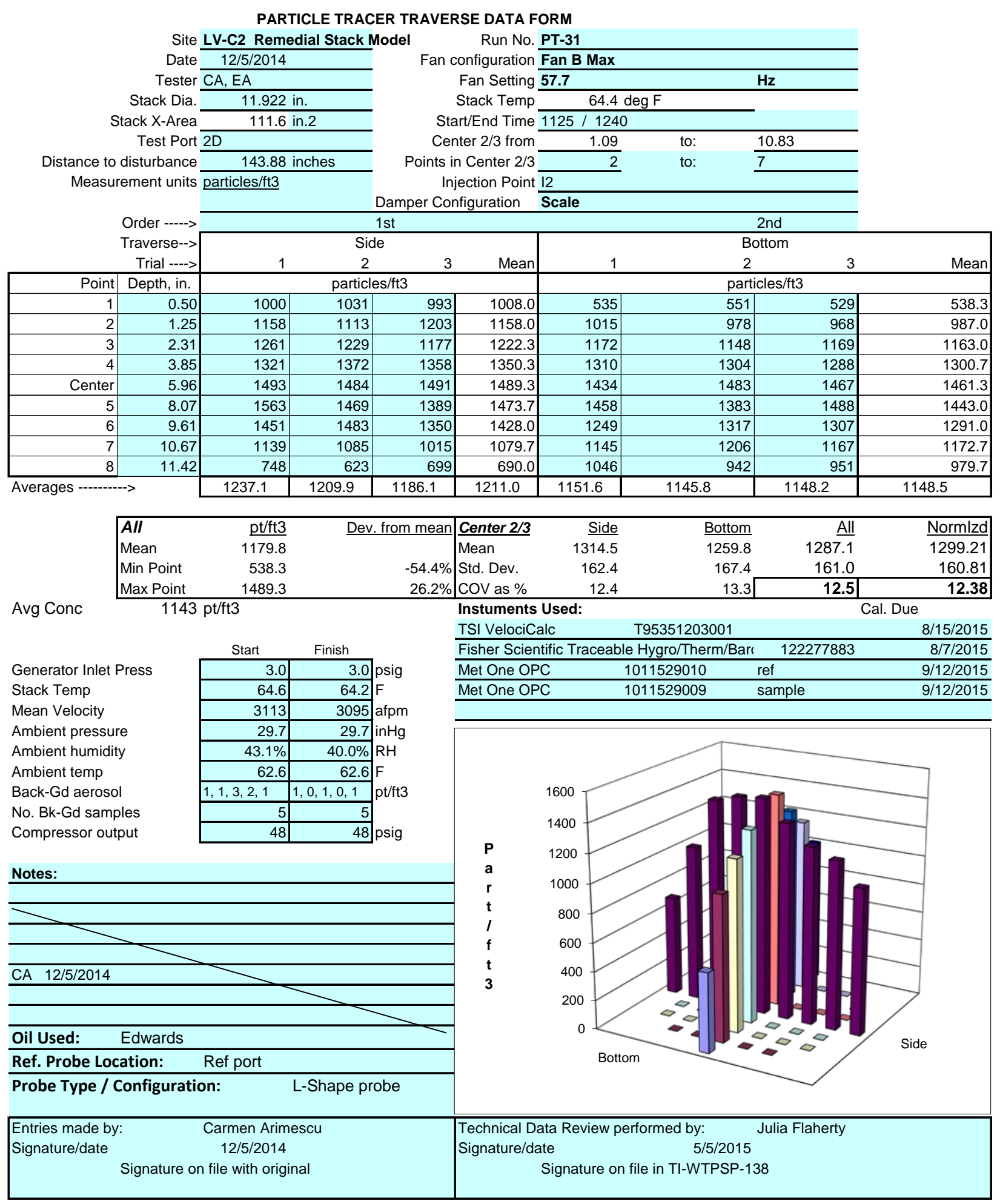




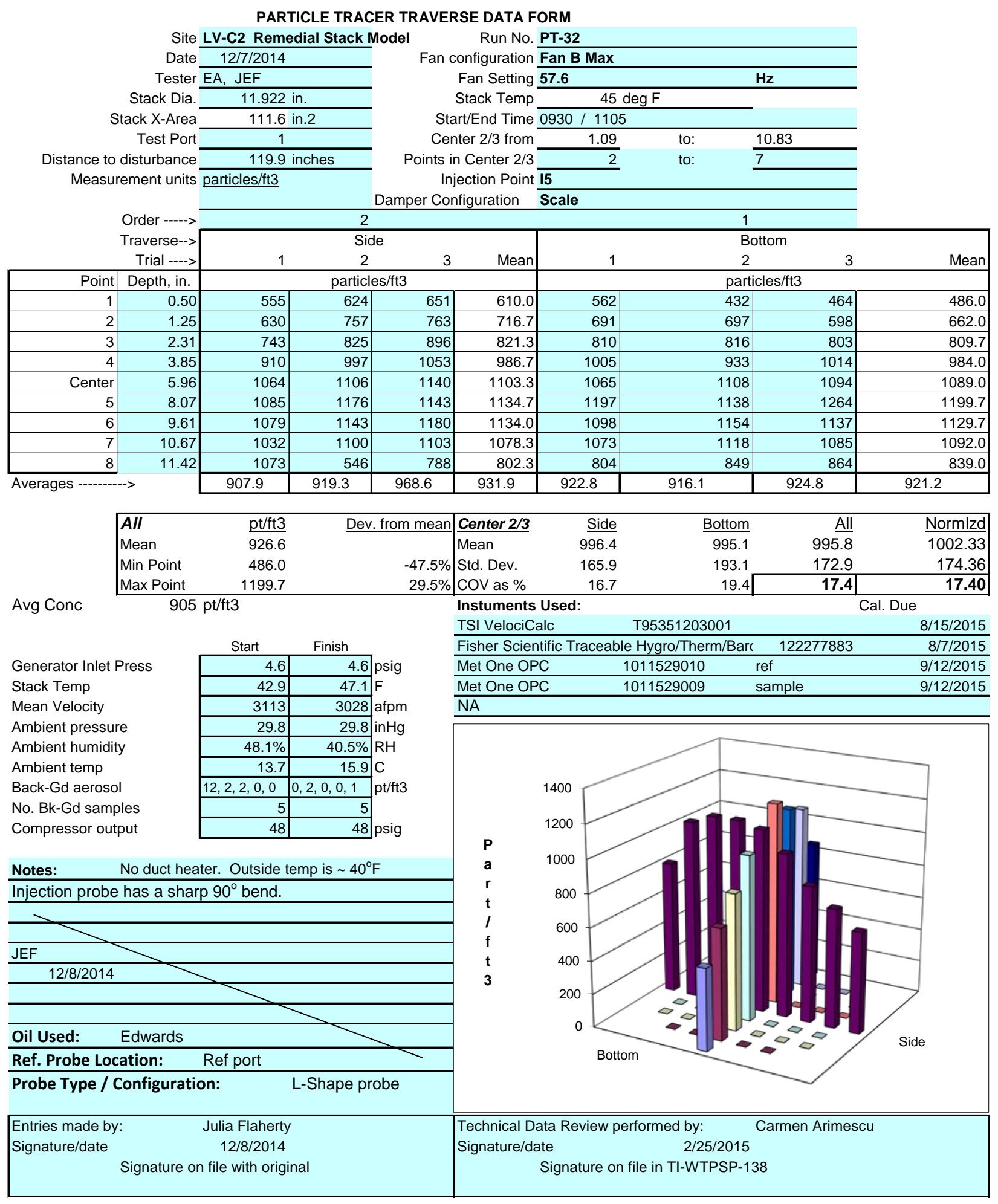




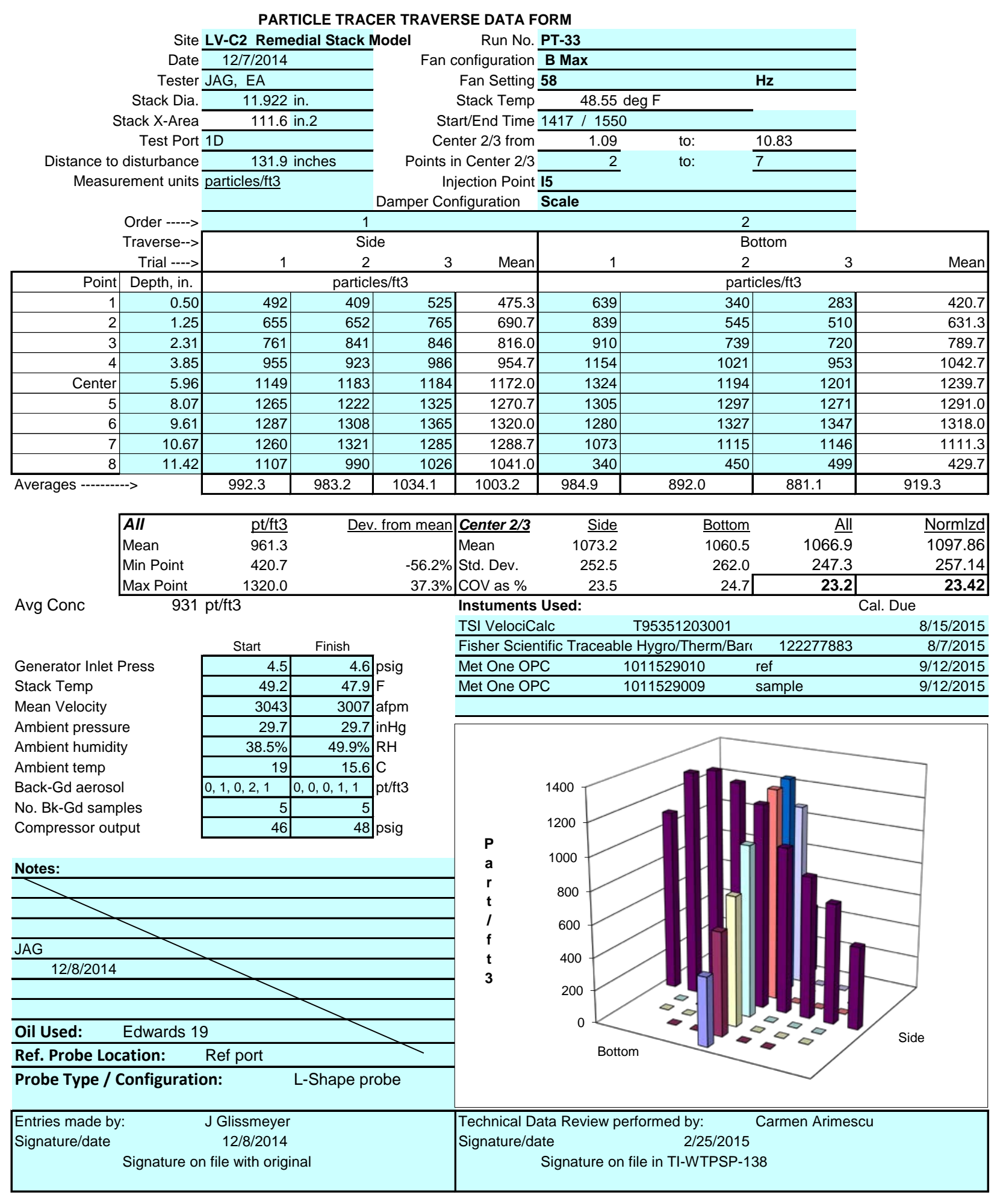




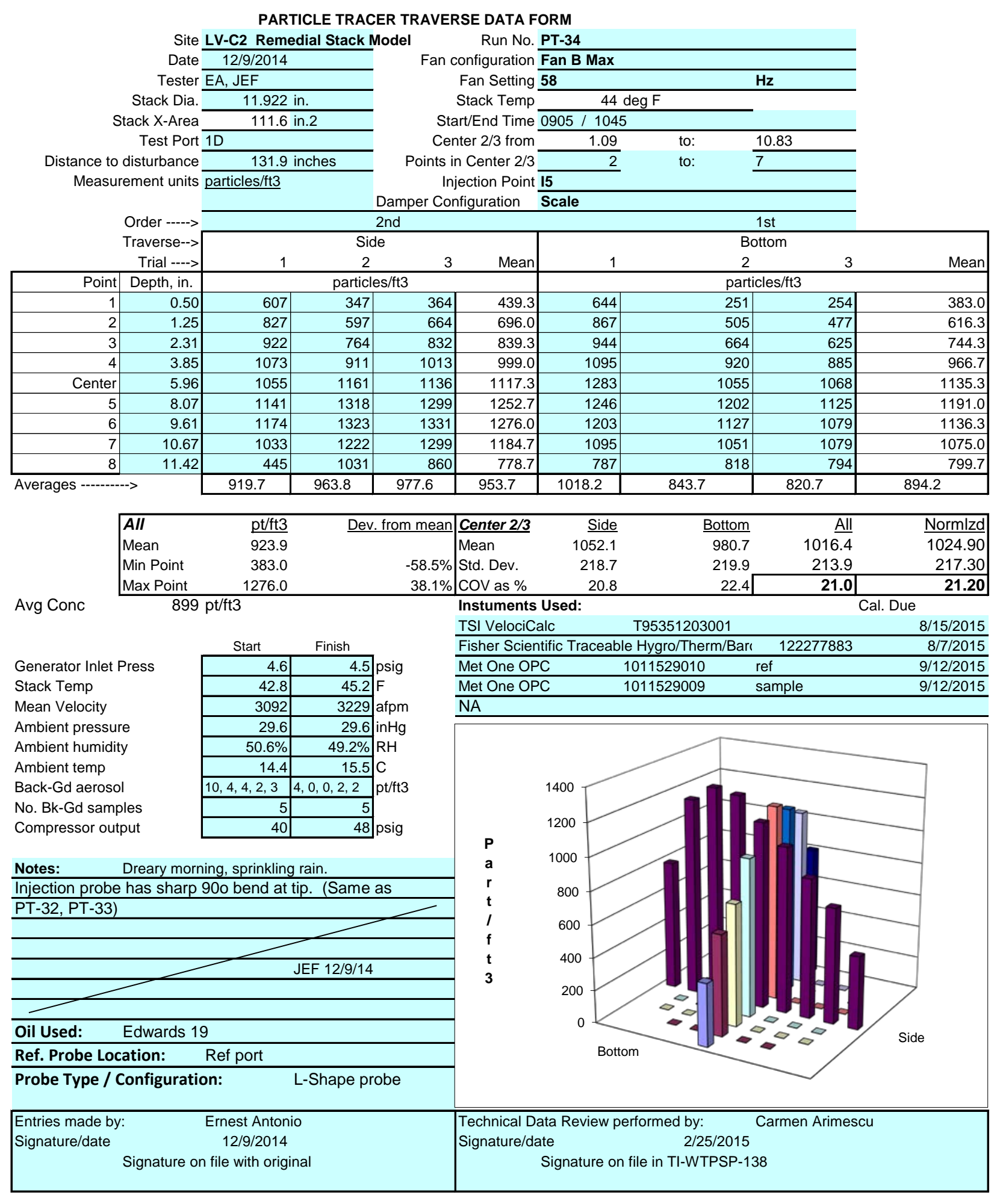




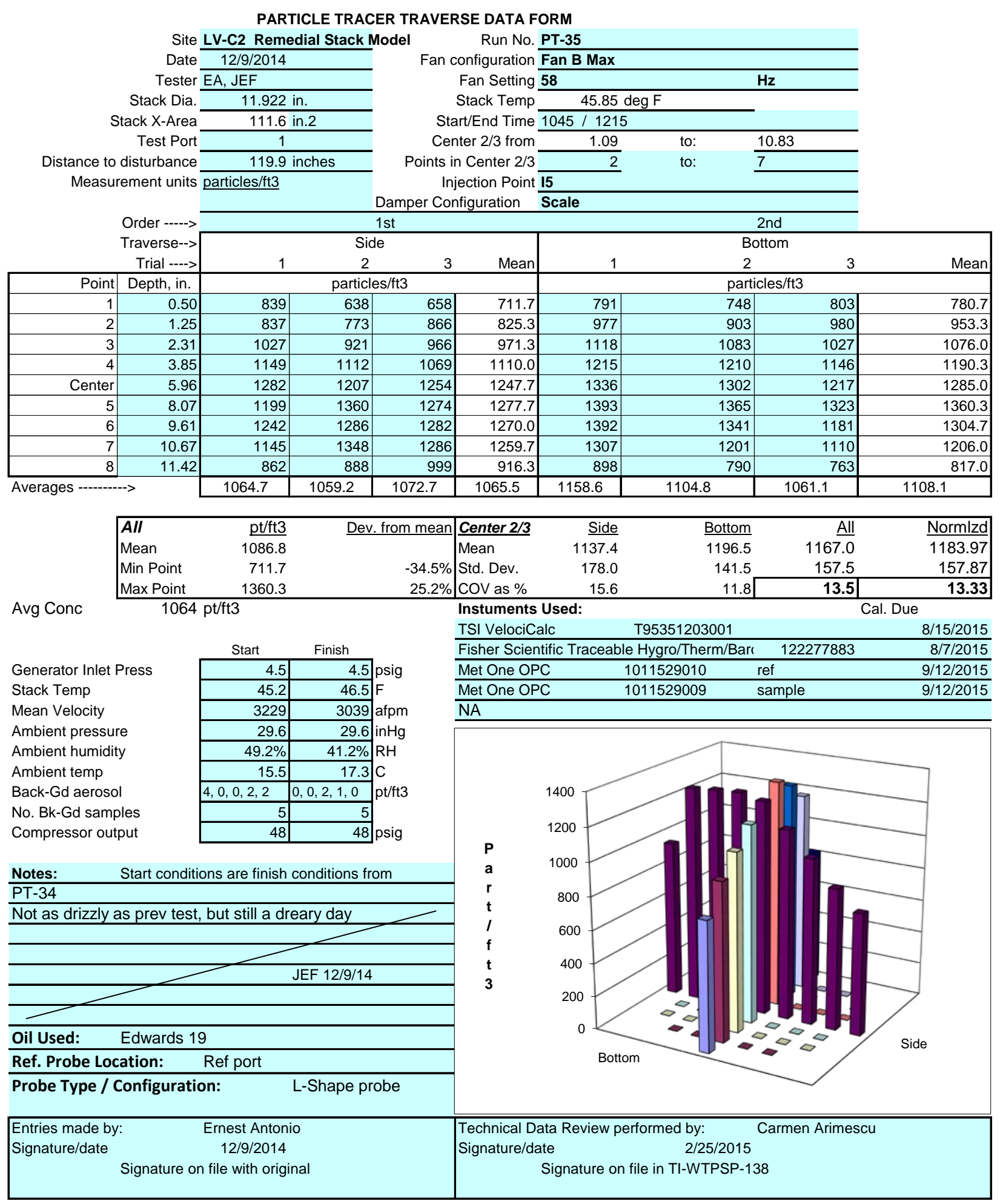


PARTICLE TRACER TRAVERSE DATA FORM

Site LV-C2 Remedial Stack Model

Date 12/10/2014

Tester JAG, EA

Stack Dia

Stack X-Area

Test Port 1D

11.922 in.

111.6 in. 2

Distance to disturbance

131.9 inches

Measurement units particles/ft3

Run No. PT-36

Fan configuration $\mathbf{B}$ Max

Fan Setting $\mathbf{5 8}$

Stack Temp

Start/End Time $0930 /$

Center $2 / 3$ from

Points in Center $2 / 3$

Injection Point $\mathbf{1 5}$

Damper Configuration Scale

\begin{tabular}{|c|c|c|c|c|c|c|c|c|c|}
\hline & \multirow{4}{*}{$\begin{array}{r}\text { Order -----> } \\
\text { Traverse--> } \\
\text { Trial ----> }\end{array}$} & \multicolumn{7}{|c|}{ Damper Configuration Scale } & \\
\hline & & \multicolumn{4}{|c|}{ 2nd } & & \multicolumn{3}{|c|}{$1 \mathrm{st}$} \\
\hline & & \multicolumn{4}{|c|}{ Side } & \multicolumn{4}{|c|}{ Bottom } \\
\hline & & 1 & 2 & 3 & Mean & 1 & 2 & 3 & Mean \\
\hline Point & Depth, in. & \multicolumn{4}{|c|}{ particles/ft3 } & \multicolumn{4}{|c|}{ particles/ft3 } \\
\hline 1 & 0.50 & 628 & 658 & 567 & 617.7 & 137 & 306 & 259 & 234.0 \\
\hline 2 & 1.25 & 742 & 726 & 719 & 729.0 & 503 & 574 & 510 & 529.0 \\
\hline 3 & 2.31 & 816 & 819 & 780 & 805.0 & 991 & 740 & 695 & 808.7 \\
\hline 4 & 3.85 & 898 & 877 & 834 & 869.7 & 1066 & 969 & 906 & 980.3 \\
\hline Center & 5.96 & 925 & 939 & 870 & 911.3 & 1198 & 1080 & 1061 & 1113.0 \\
\hline 5 & 8.07 & 954 & 909 & 815 & 892.7 & 1181 & 1157 & 1154 & 1164.0 \\
\hline 6 & 9.61 & 881 & 790 & 772 & 814.3 & 1059 & 1099 & 1071 & 1076.3 \\
\hline 7 & 10.67 & 805 & 730 & 621 & 718.7 & 942 & 949 & 973 & 954.7 \\
\hline 8 & 11.42 & 468 & 447 & 408 & 441.0 & 781 & 740 & 649 & 723.3 \\
\hline \multicolumn{2}{|c|}{ Averages ---------> } & 790.8 & 766.1 & 709.6 & 755.5 & 873.1 & 846.0 & 808.7 & 842.6 \\
\hline
\end{tabular}

Avg Conc \begin{tabular}{lrr|}
\hline All & $\underline{\mathrm{pt} / \mathrm{ft} 3}$ & Dev. from mean \\
Mean & 799.0 & \\
Min Point & 234.0 & $-70.7 \%$ \\
Max Point & 1164.0 & $45.7 \%$ \\
\hline \multicolumn{2}{c}{$772 \mathrm{pt} / \mathrm{ft} 3$} &
\end{tabular}

\begin{tabular}{|c|c|}
\hline Center $2 / 3$ & Side \\
\hline Mean & 820.1 \\
\hline Std. Dev. & 76.3 \\
\hline COV as \% & 9.3 \\
\hline
\end{tabular}

\begin{tabular}{|c|c|c|}
\hline Bottom & All & Normlzd \\
\hline 946.6 & 883.3 & 974.07 \\
\hline 218.5 & 170.4 & 163.86 \\
\hline 23.1 & 19.3 & 16.82 \\
\hline
\end{tabular}

Instuments Used:

\begin{tabular}{lrr} 
TSI VelociCalc & T95351203001 & 8/15/2015 \\
\hline
\end{tabular}

Generator Inlet Press

Stack Temp

Mean Velocity

Ambient pressure

Ambient humidity

Ambient temp

Back-Gd aerosol

No. Bk-Gd samples

Compressor output

\begin{tabular}{|c|c|c|}
\hline Start & Finish & \\
\hline 4.5 & 4.5 & 5 psig \\
\hline 43.7 & 45.1 & 1 1 $F$ \\
\hline 3050 & 3088 & 8 afpm \\
\hline 29.3 & 29.24 & 4 inHg \\
\hline $47 \%$ & $43 \%$ & $\mathrm{RH}$ \\
\hline 15.8 & 17.5 & $5] \mathrm{C}$ \\
\hline $2,1,3,0,1$ & $3,0,0,1,1$ & $1 \mathrm{pt} / \mathrm{ft} 3$ \\
\hline 5 & 5 & 5 \\
\hline 50 & 50 & 0 psig \\
\hline
\end{tabular}

Notes:

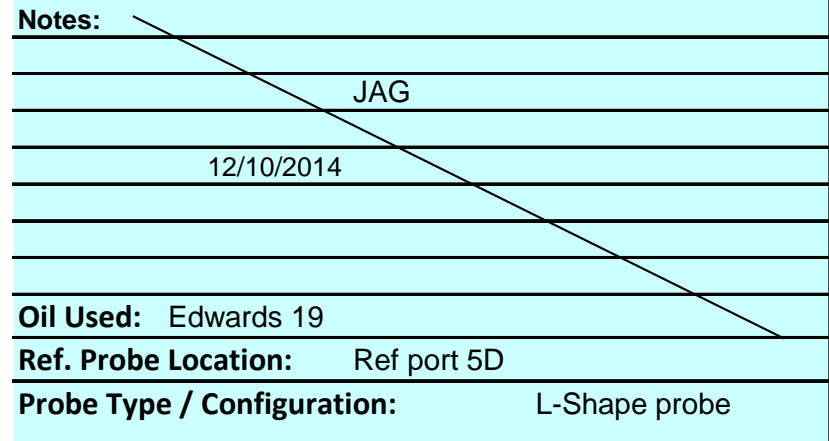

\begin{tabular}{lr}
\hline Fisher Scientific Traceable Hygro/Therm/E 122277883 & 8/7/2015 \\
\hline
\end{tabular}

\begin{tabular}{llll}
\hline Met One OPC & 1011529010 & ref & $9 / 12 / 2015$ \\
\hline Met One OPC & 1011529009 & sample & $9 / 12 / 2015$ \\
\hline
\end{tabular}

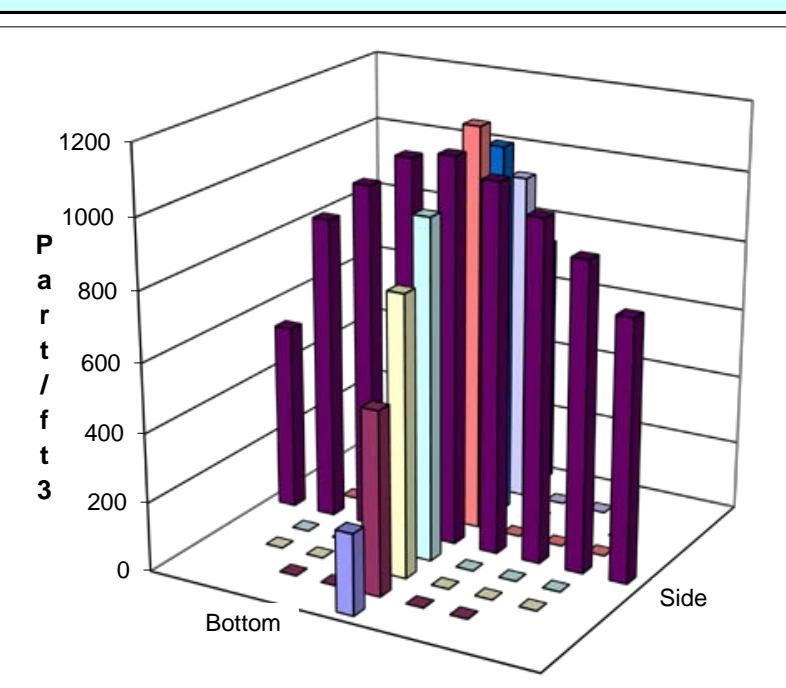

\begin{tabular}{lr}
\hline Entries made by: & J Glissmeyer \\
Signature/date & $12 / 10 / 2014$
\end{tabular}

Signature on file with original

Technical Data Review performed by: Carmen Arimescu

Signature/date 2/25/2015

Signature on file in TI-WTPSP-138 


\section{PARTICLE TRACER TRAVERSE DATA FORM}

\section{Site LV-C2 Remedial Stack Model Run No. PT-37}

Date 12/10/2014

Tester EA, JAG

Stack Dia.

Stack X-Area

Test Port

Distance to disturbance

Measurement units particles/ft3
11.922 in

111.6 in. 2

119.9 inches

(

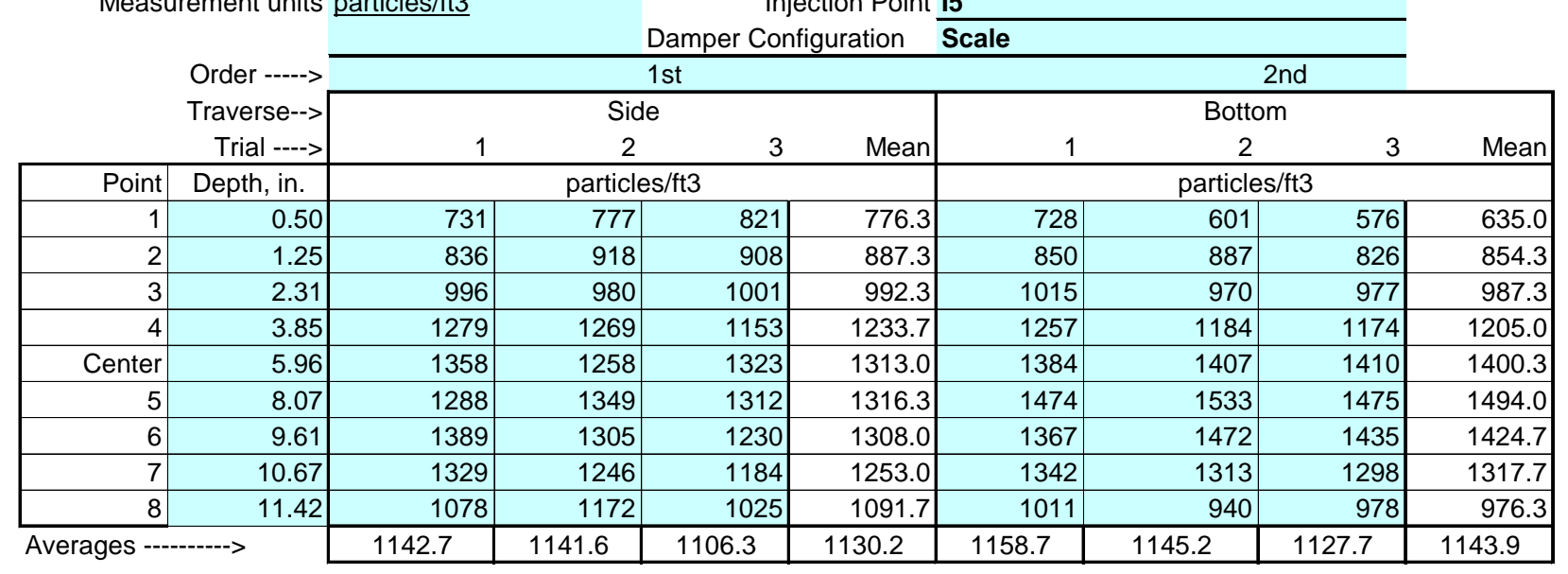

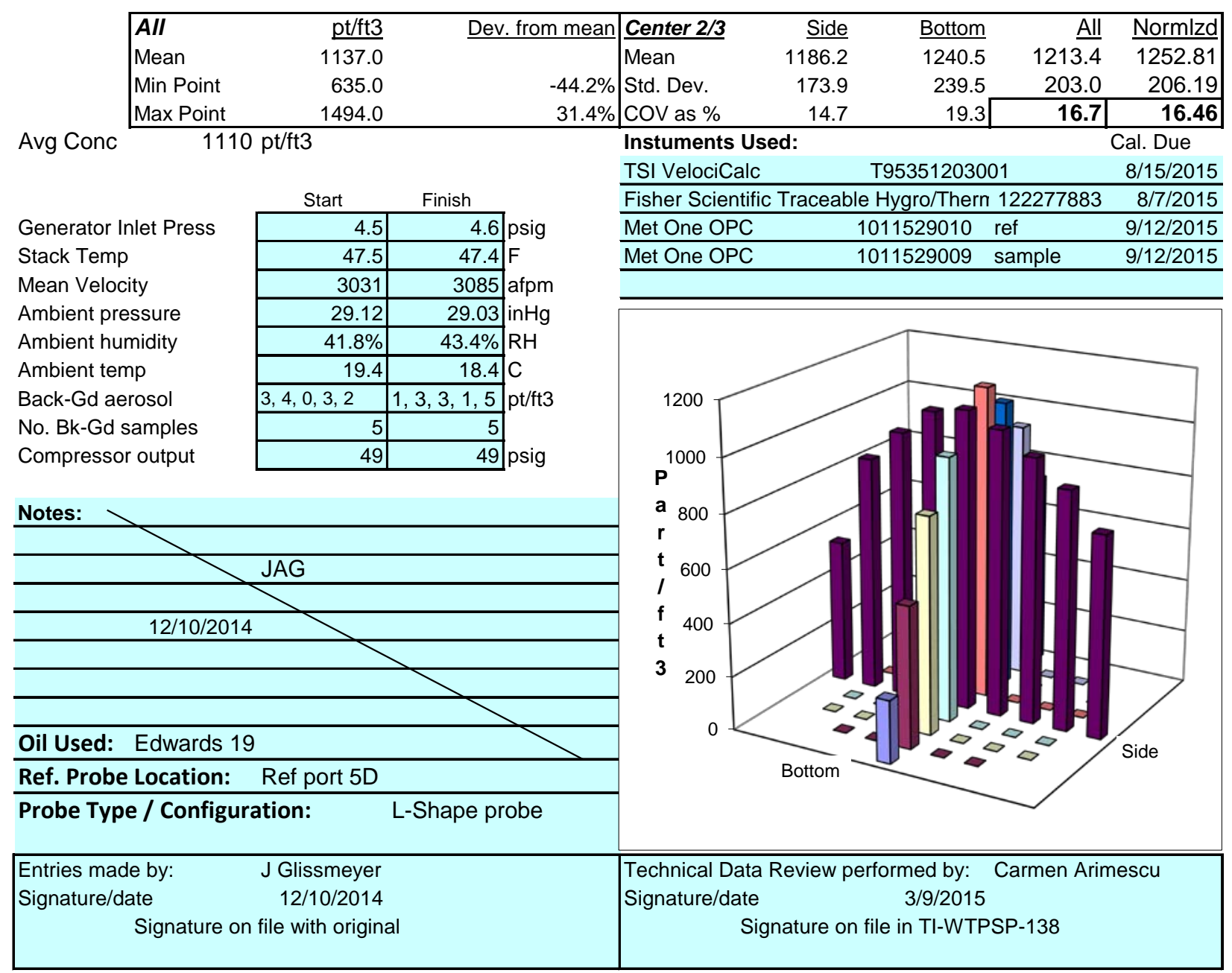




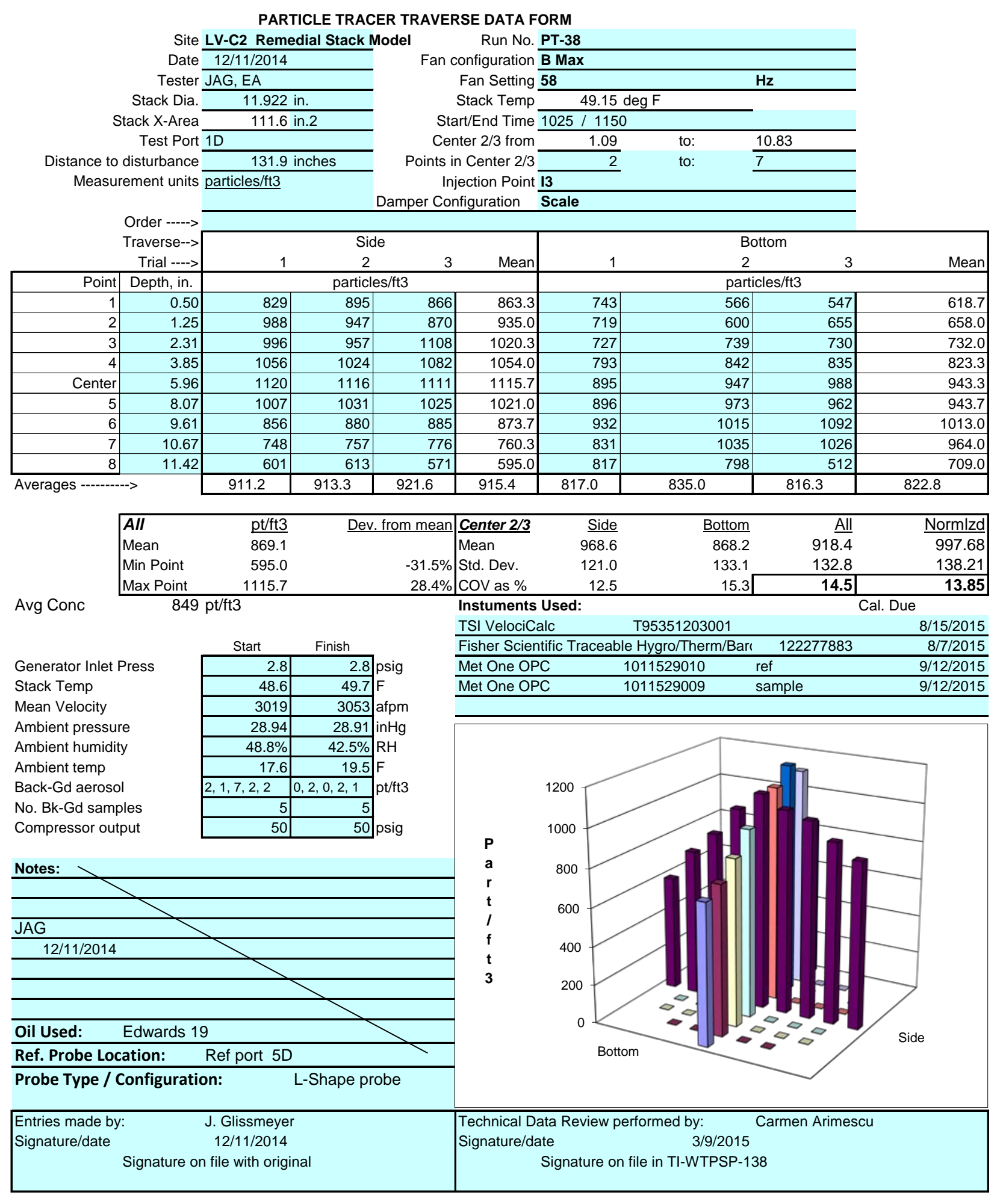




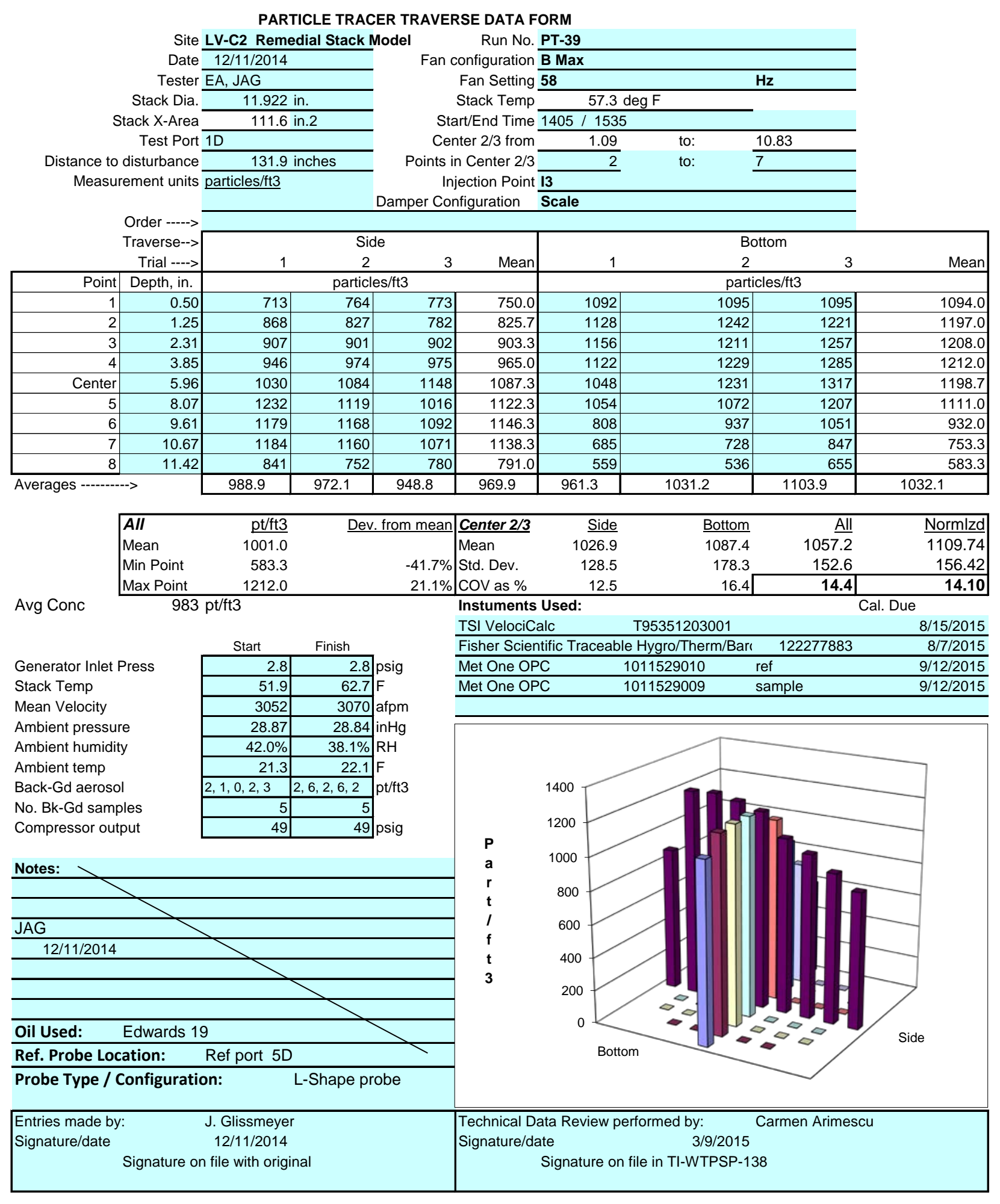




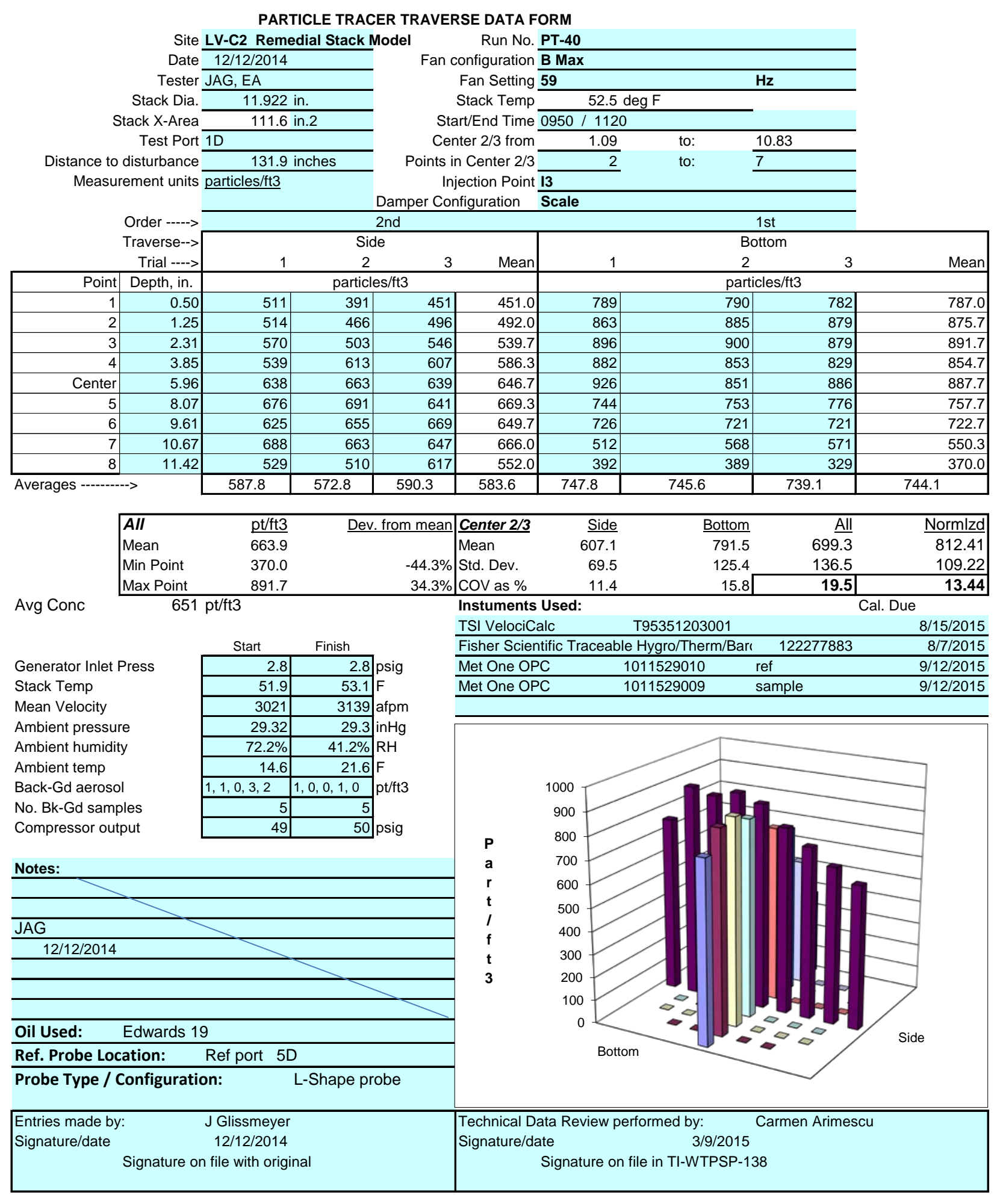




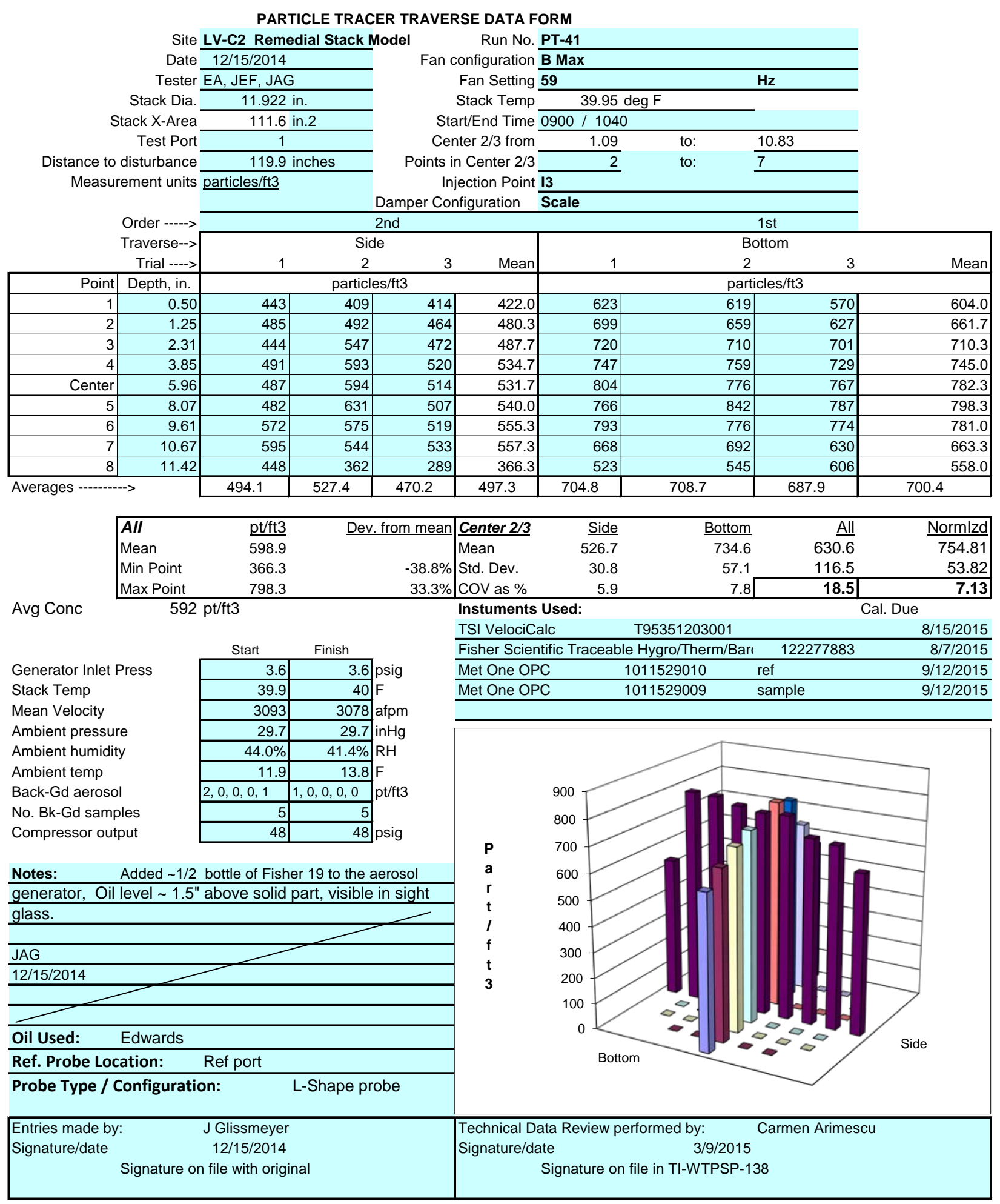




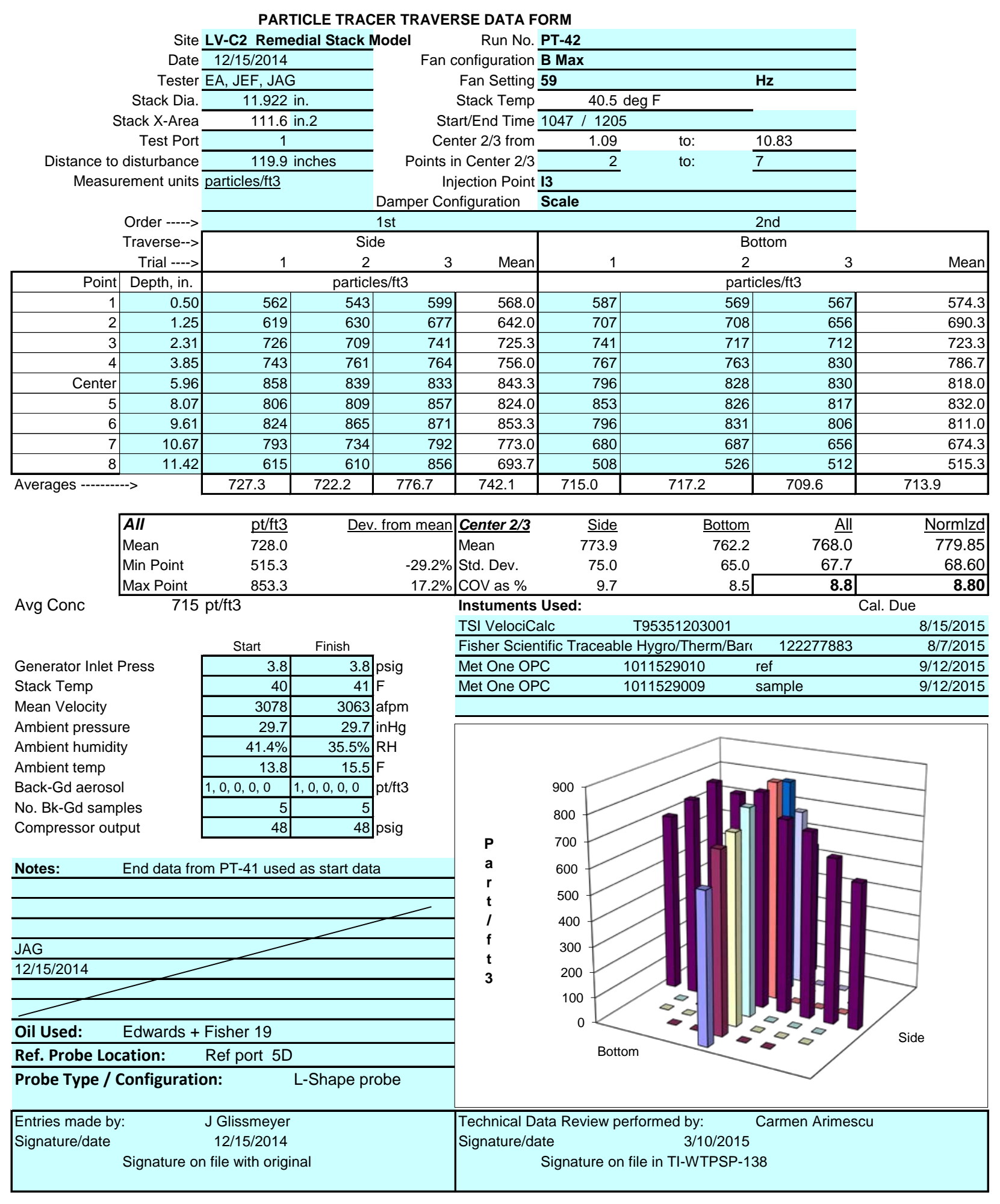




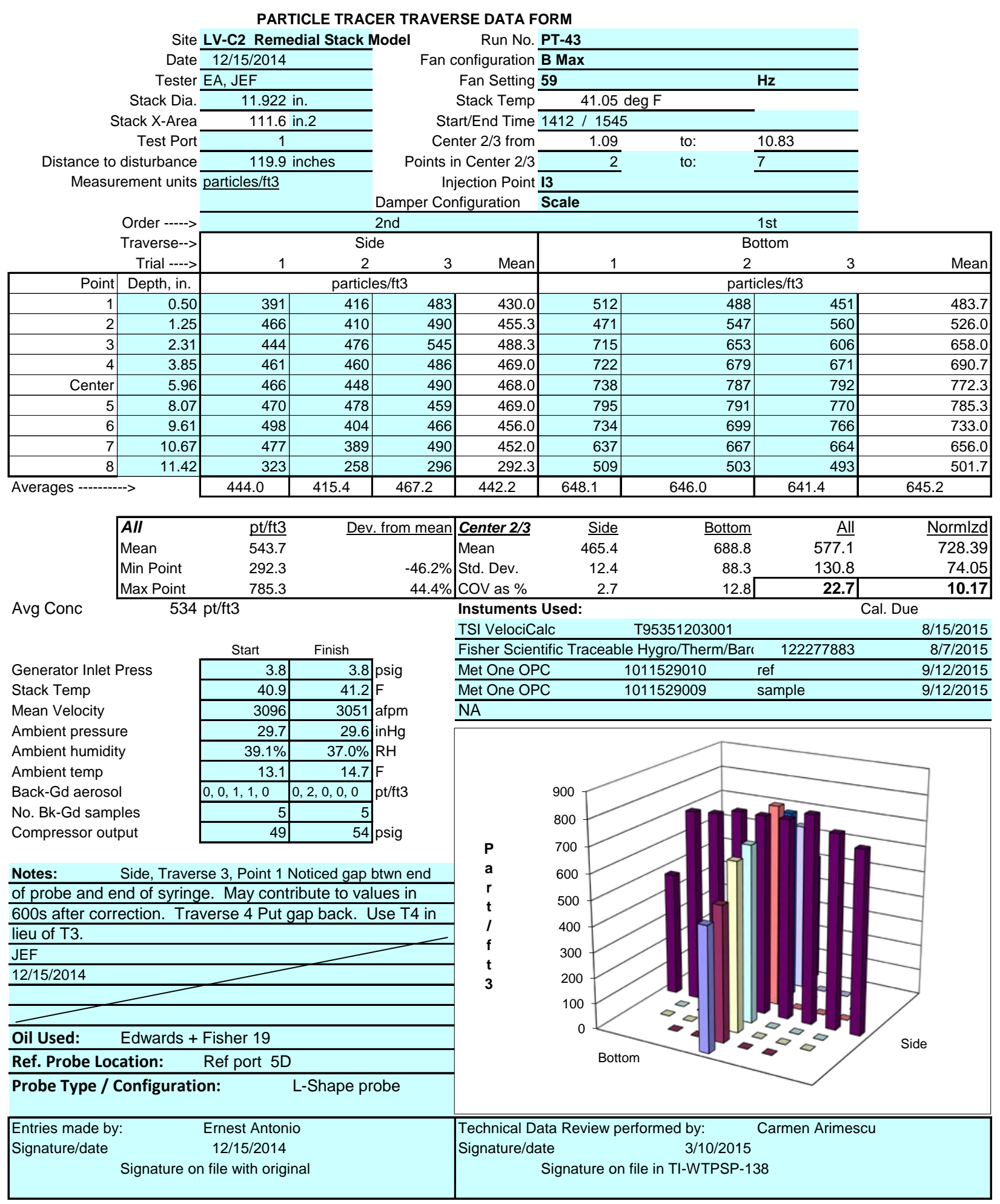




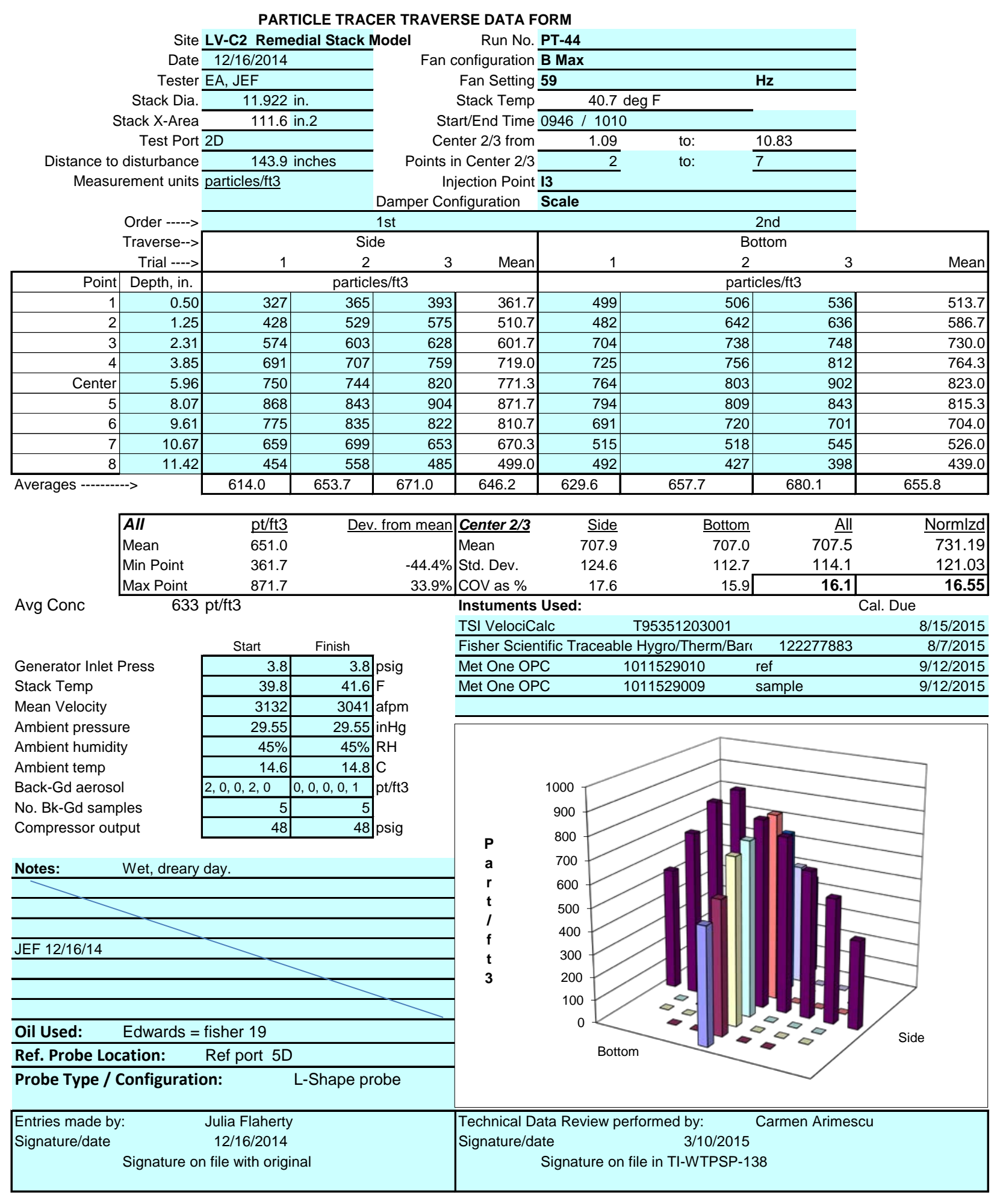




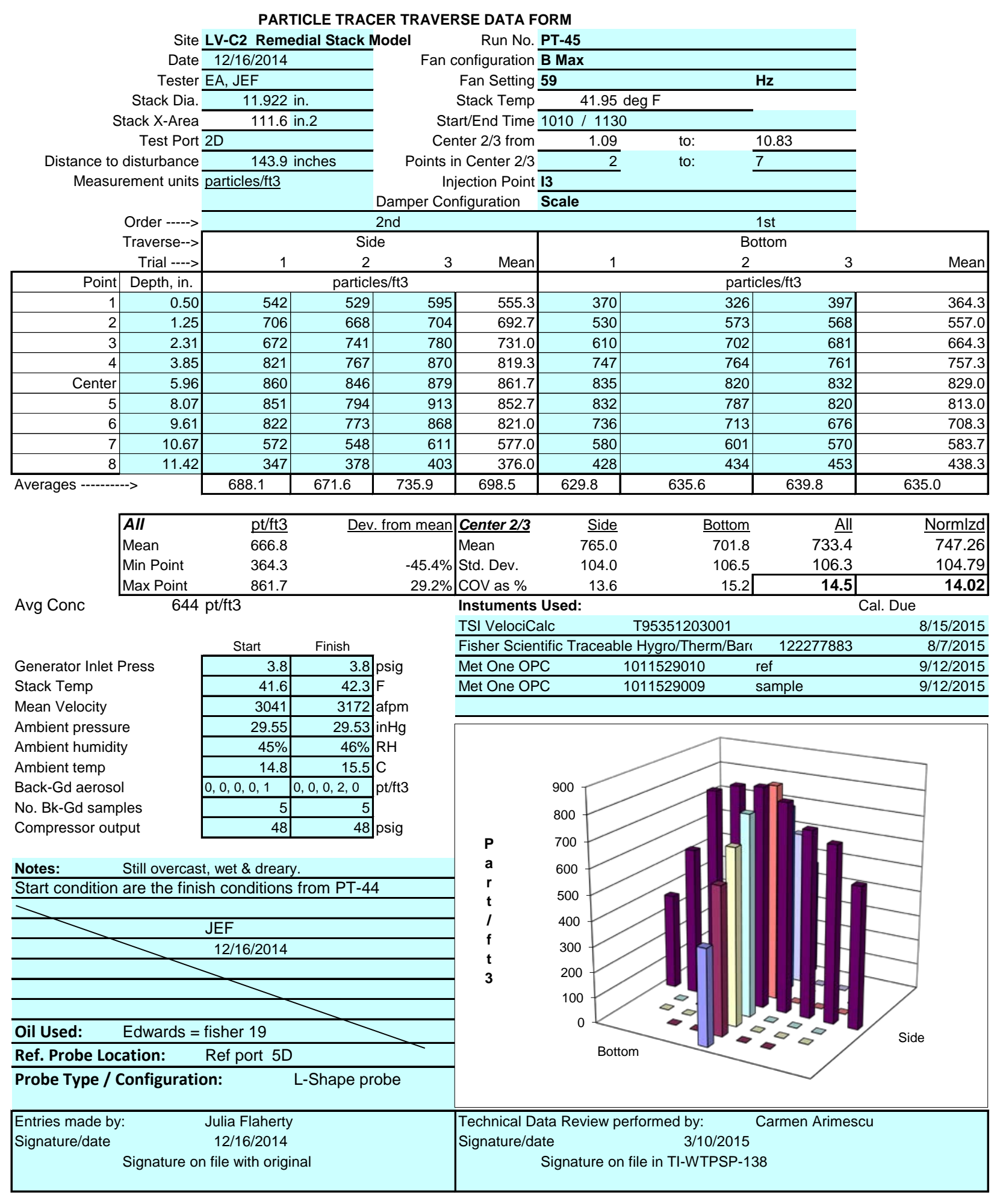




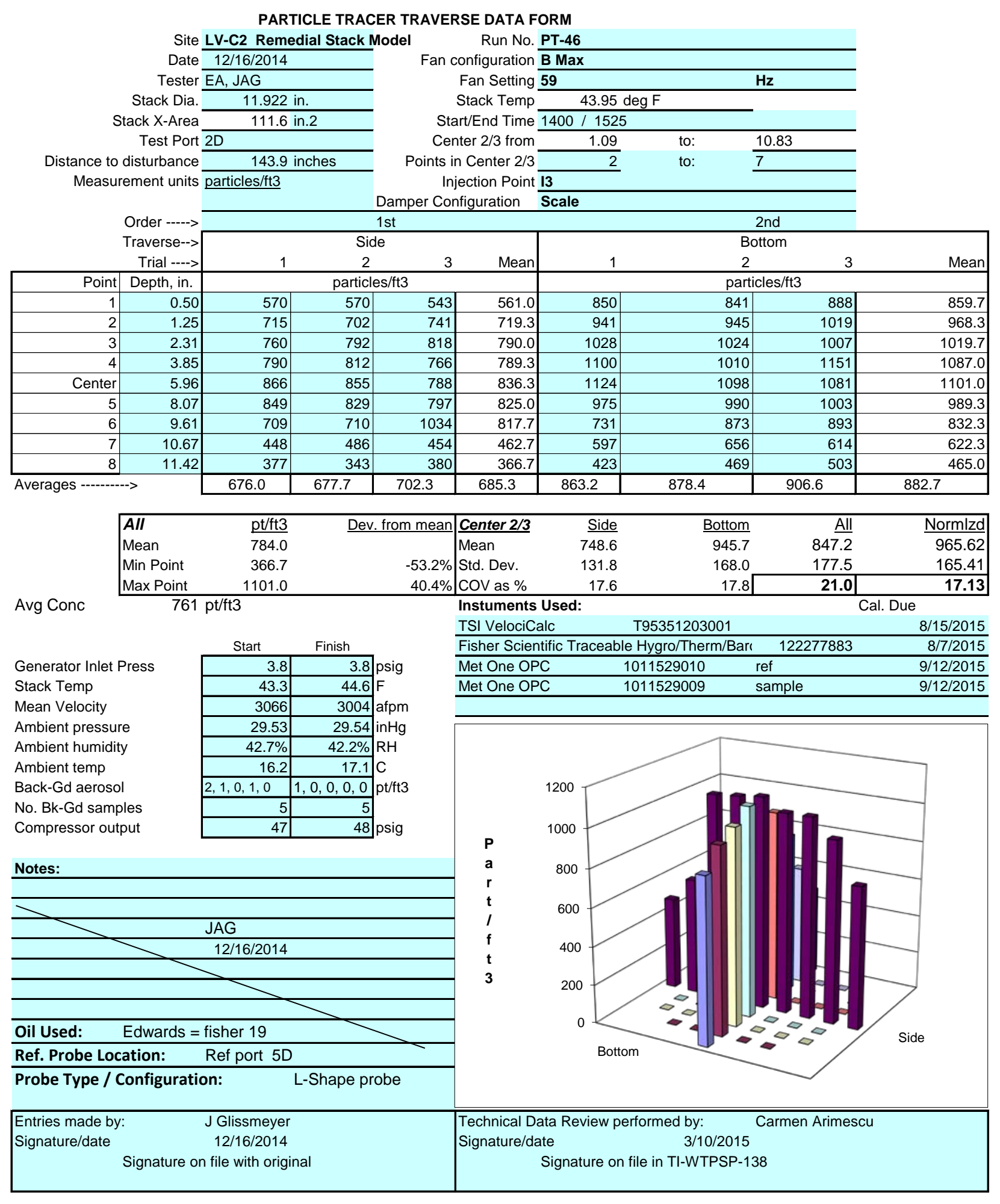




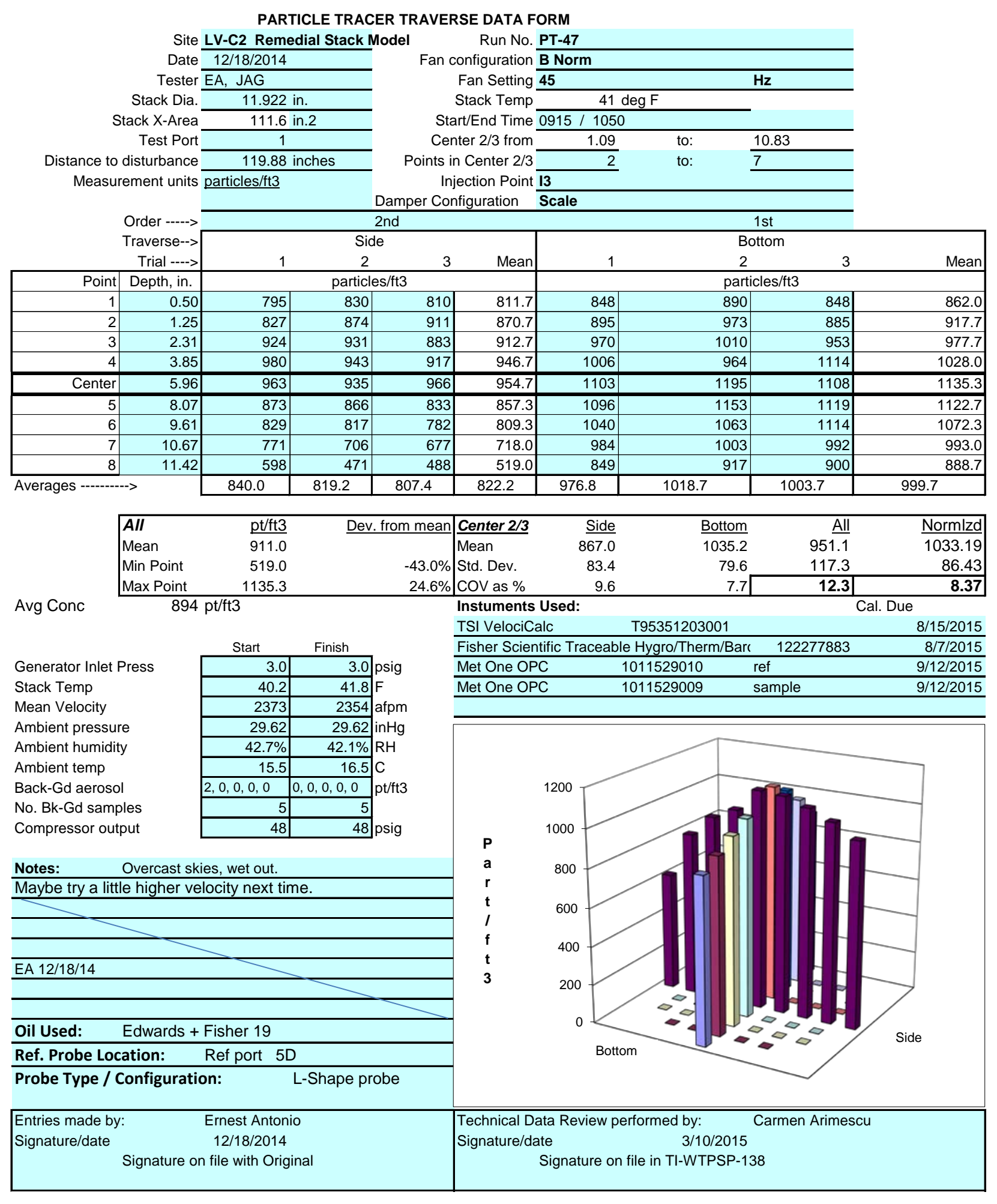




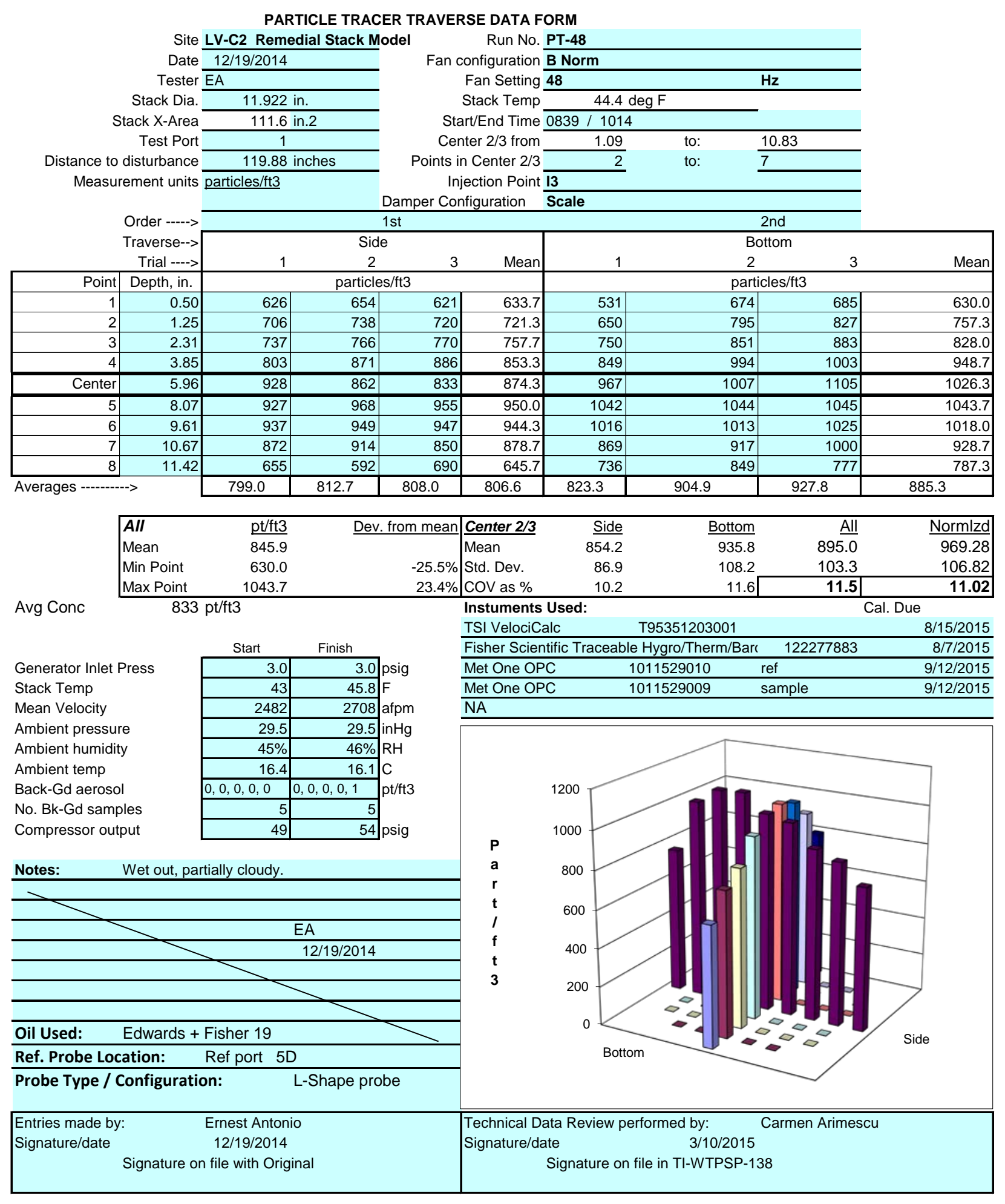




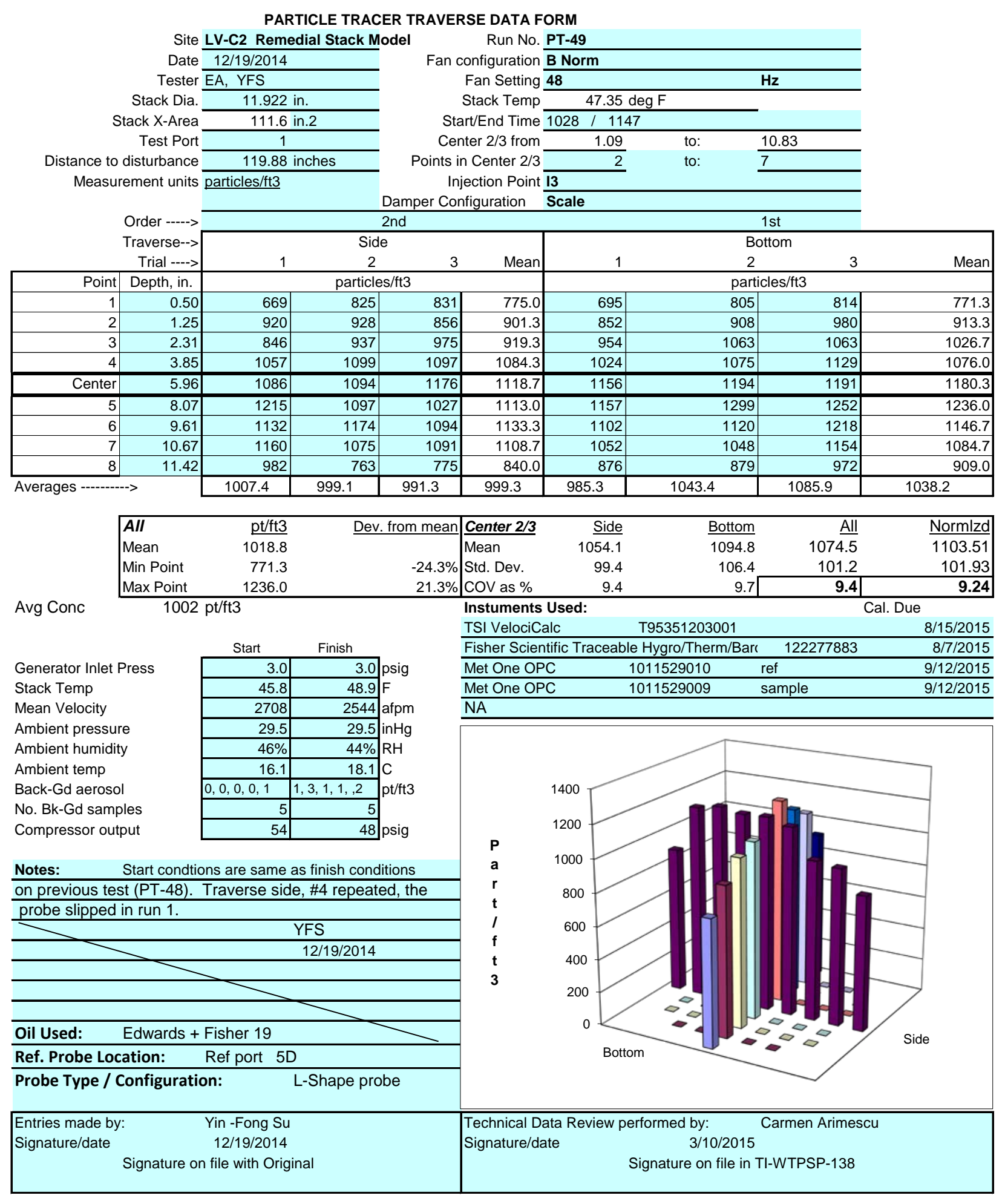




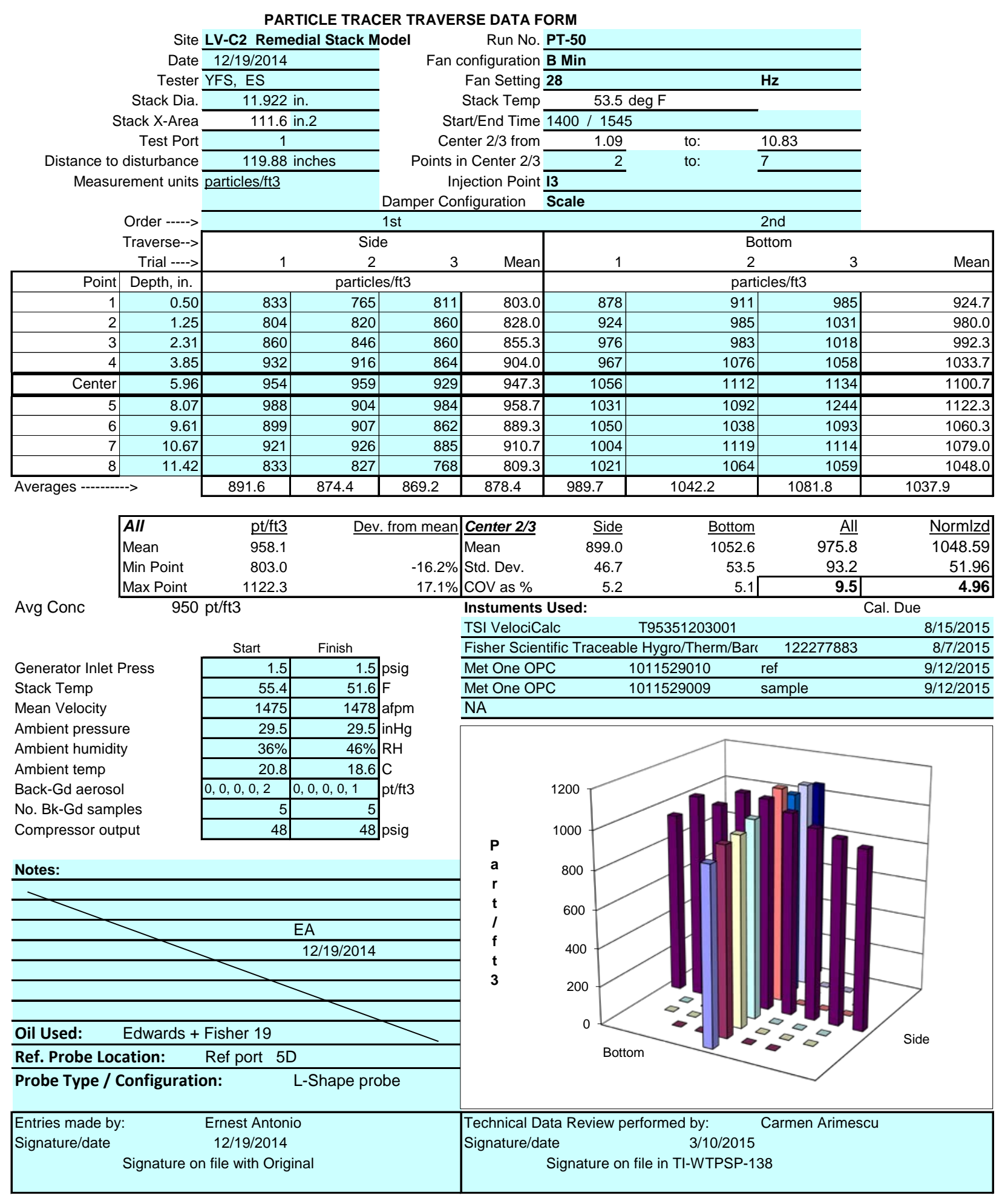




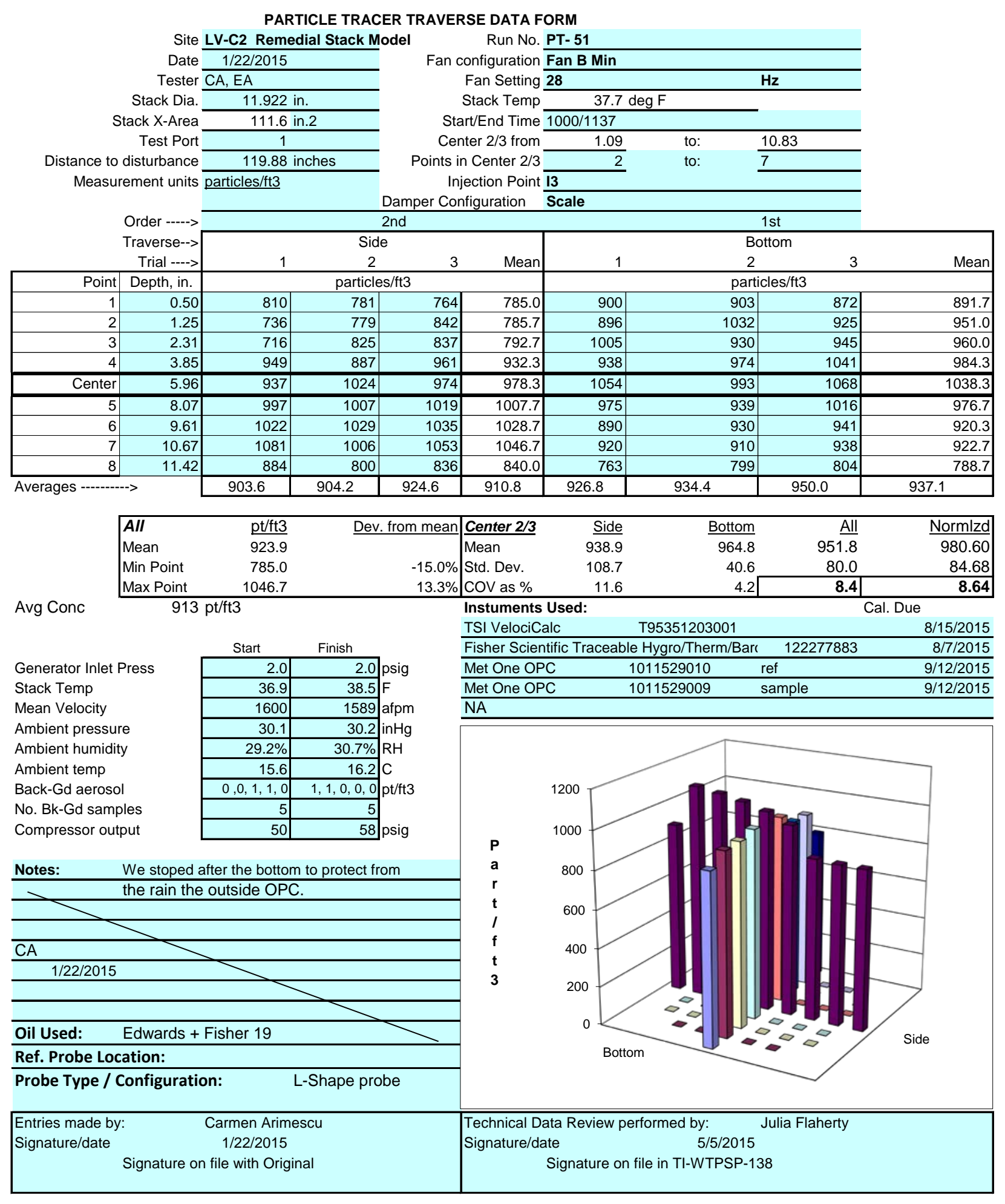




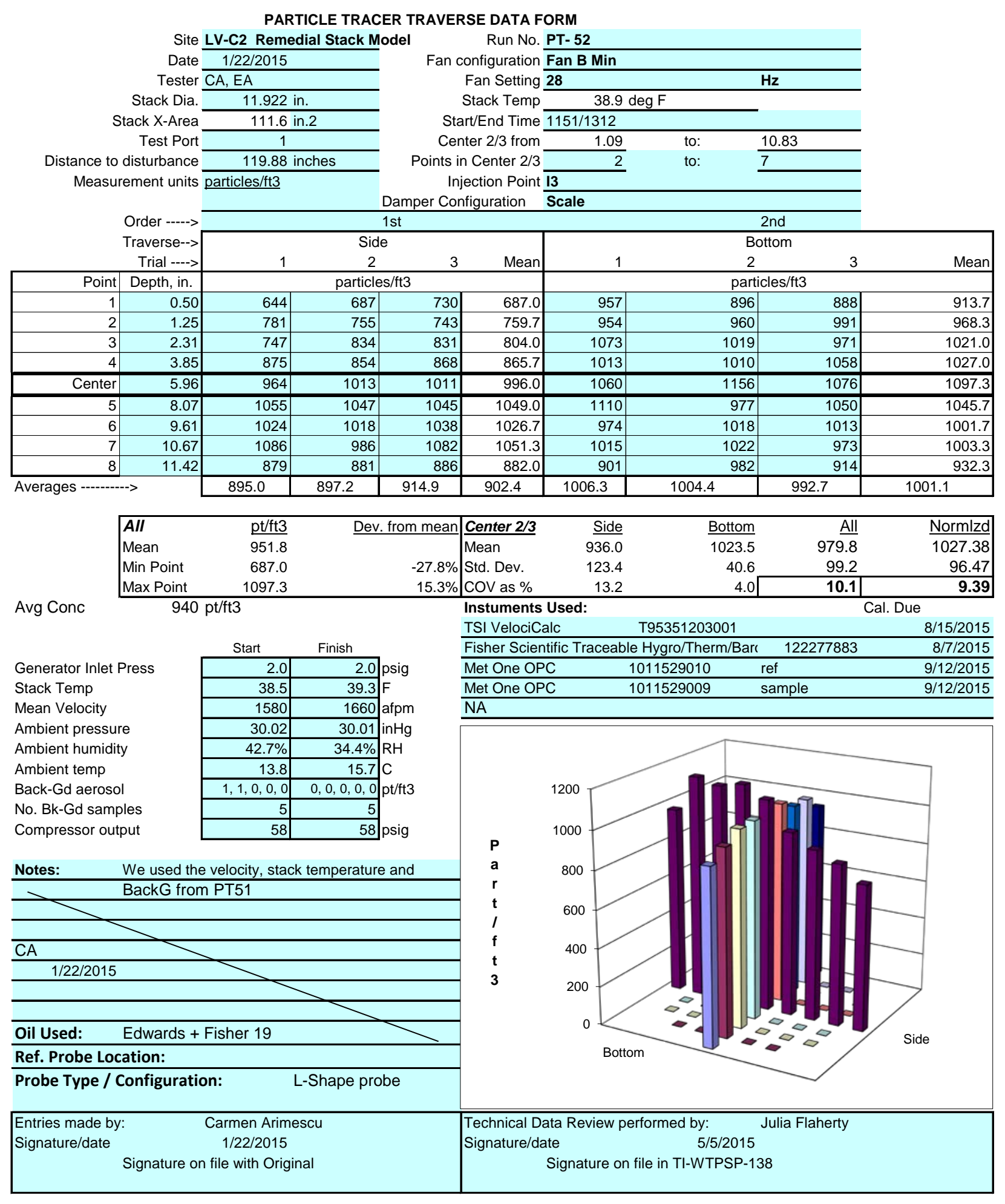




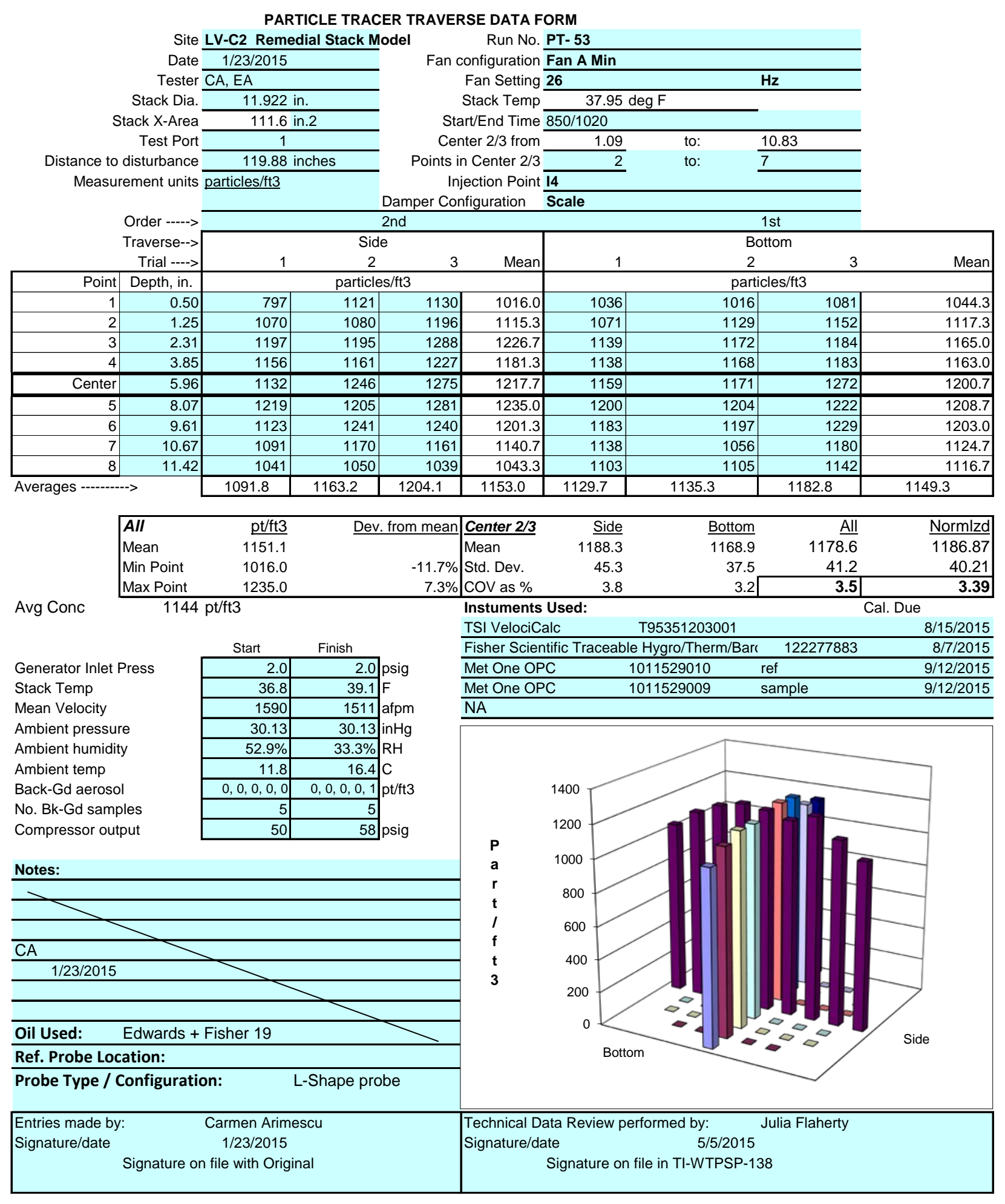




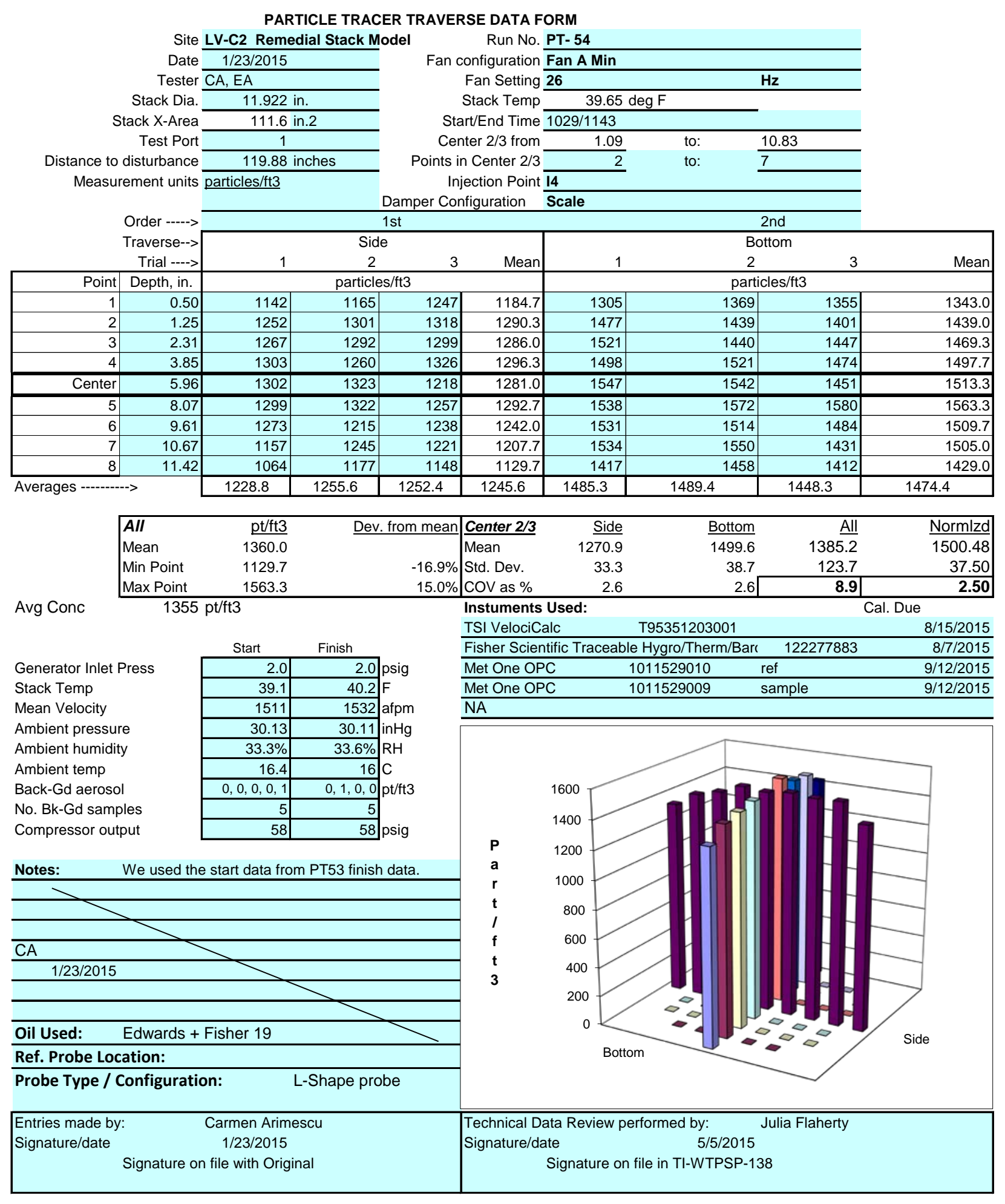




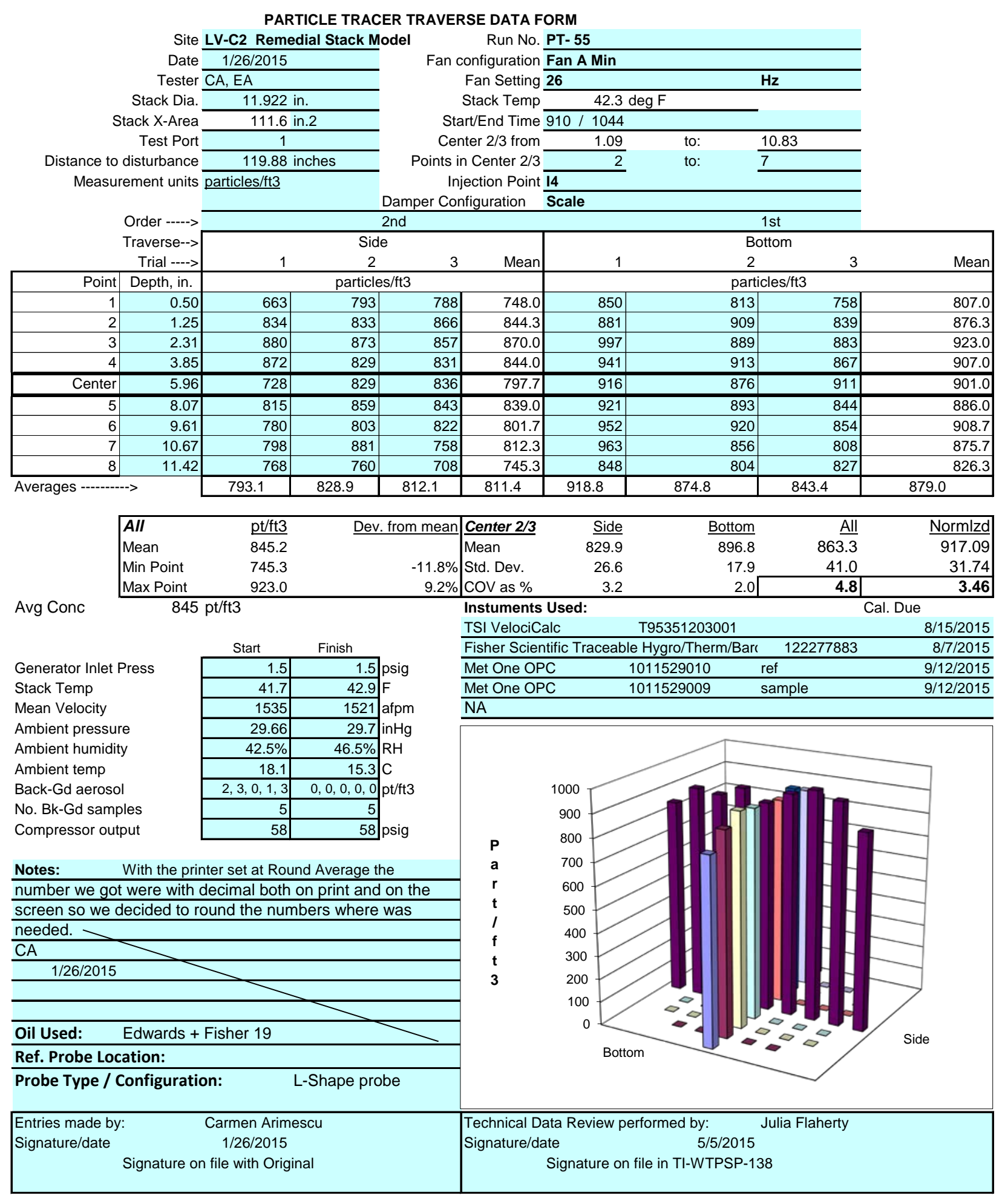




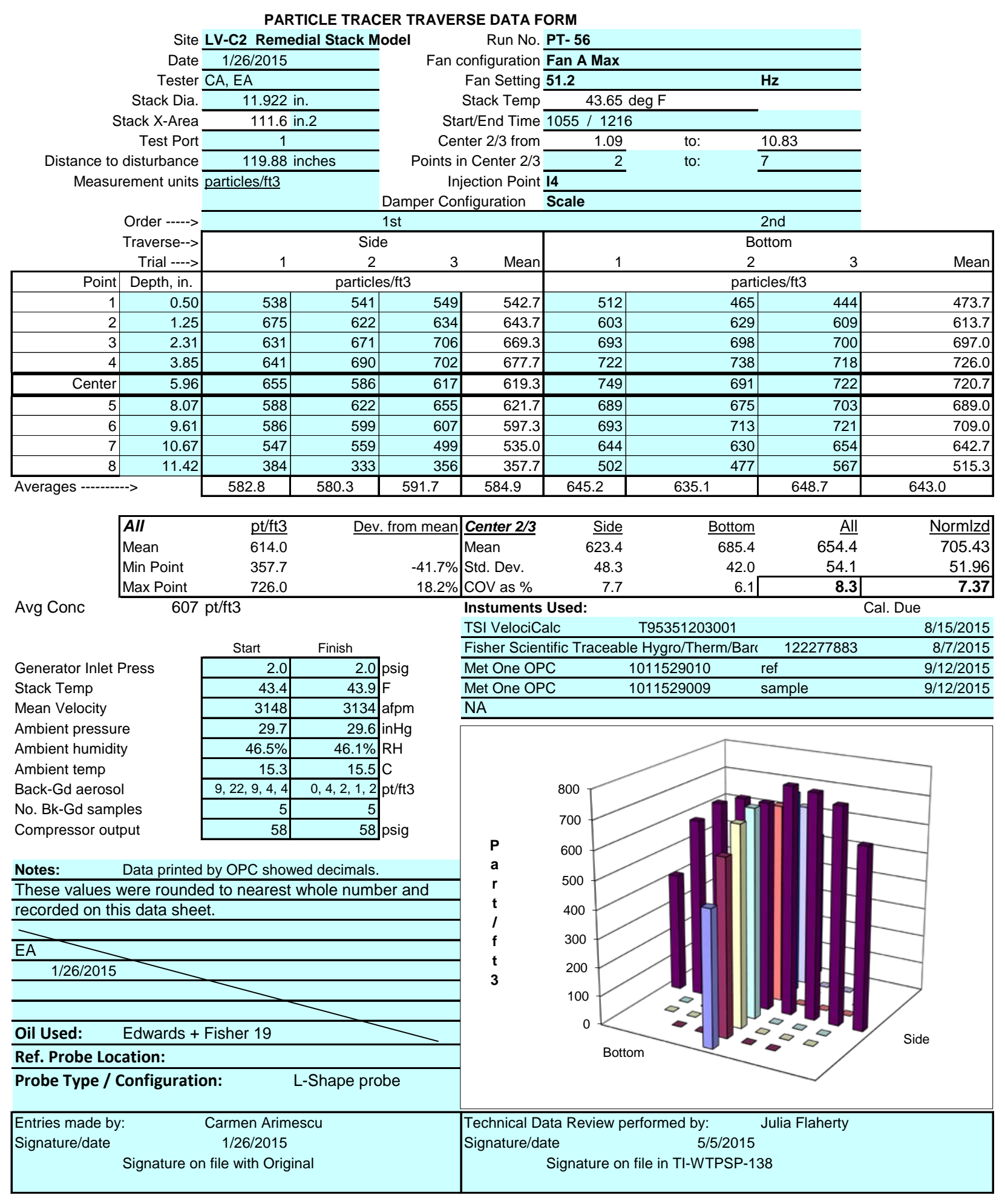




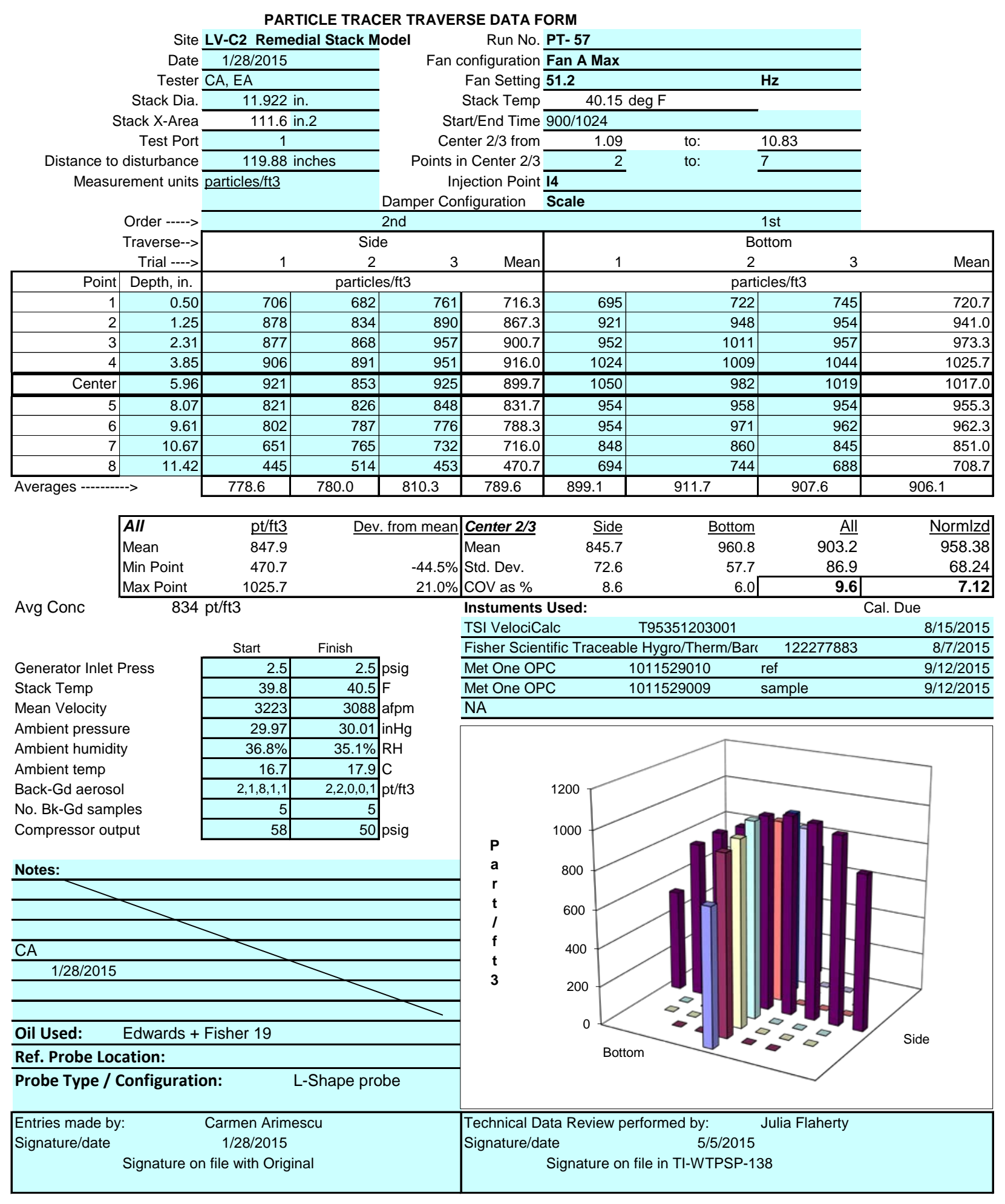




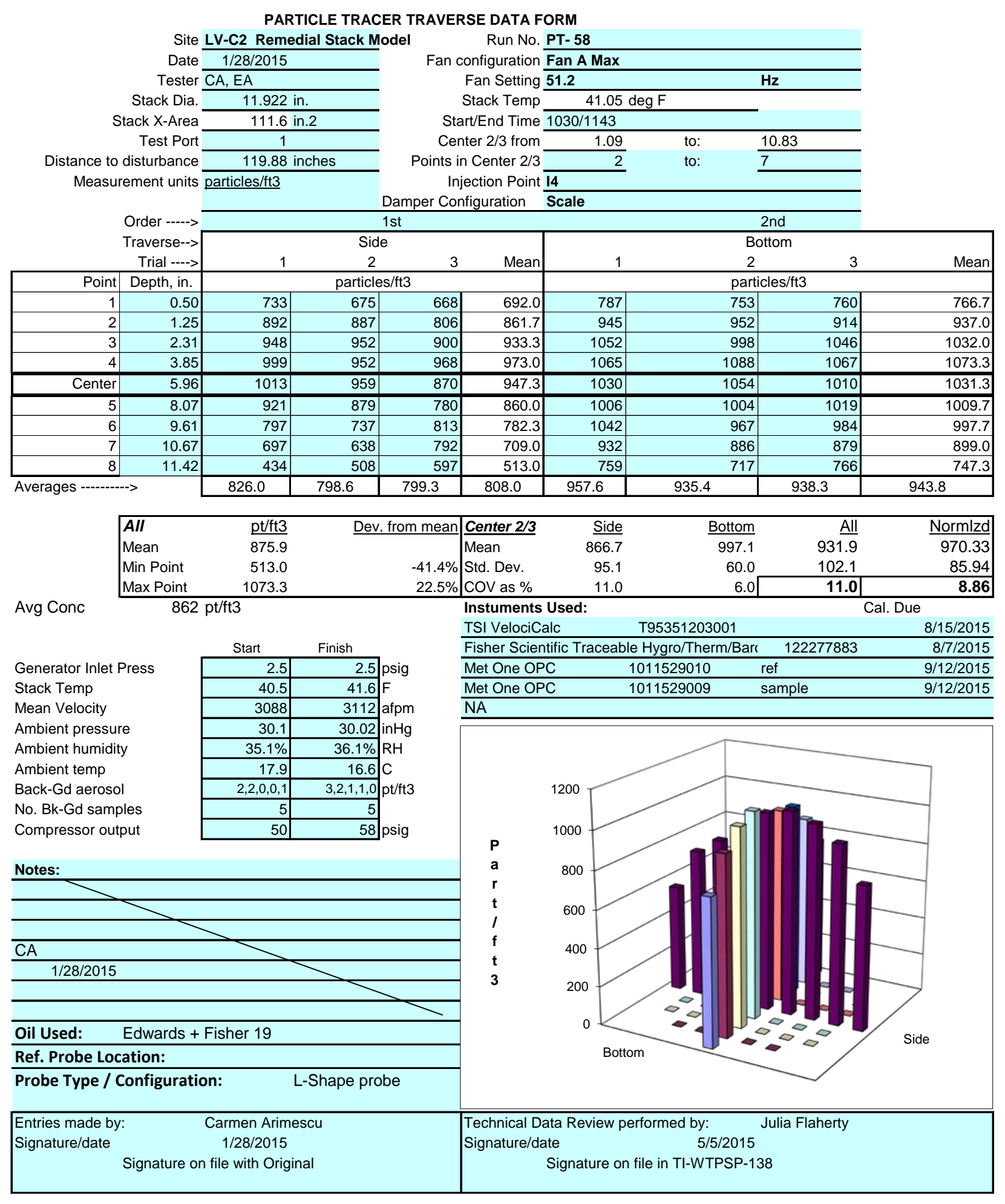


PARTICLE TRACER TRAVERSE DATA FORM

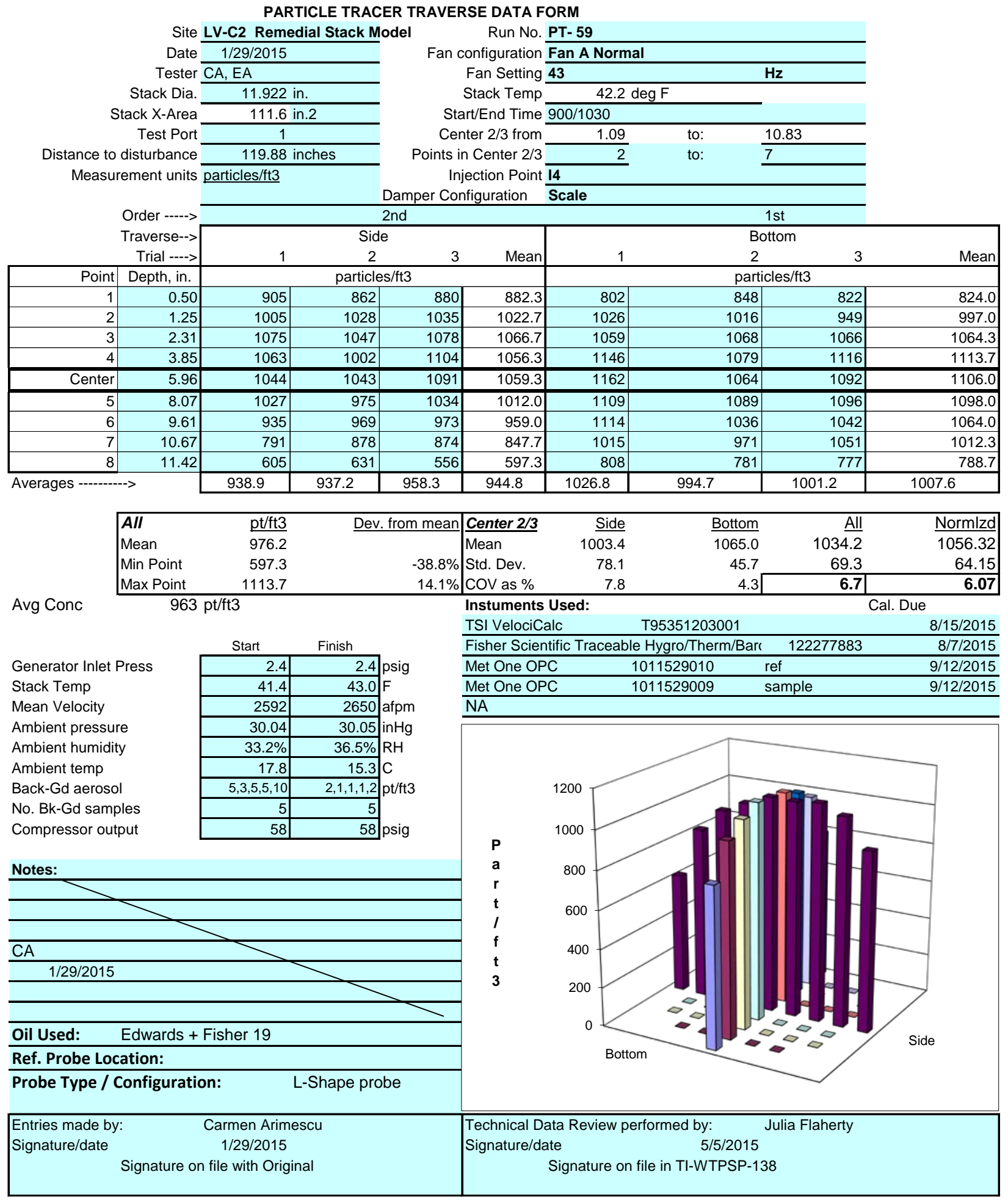




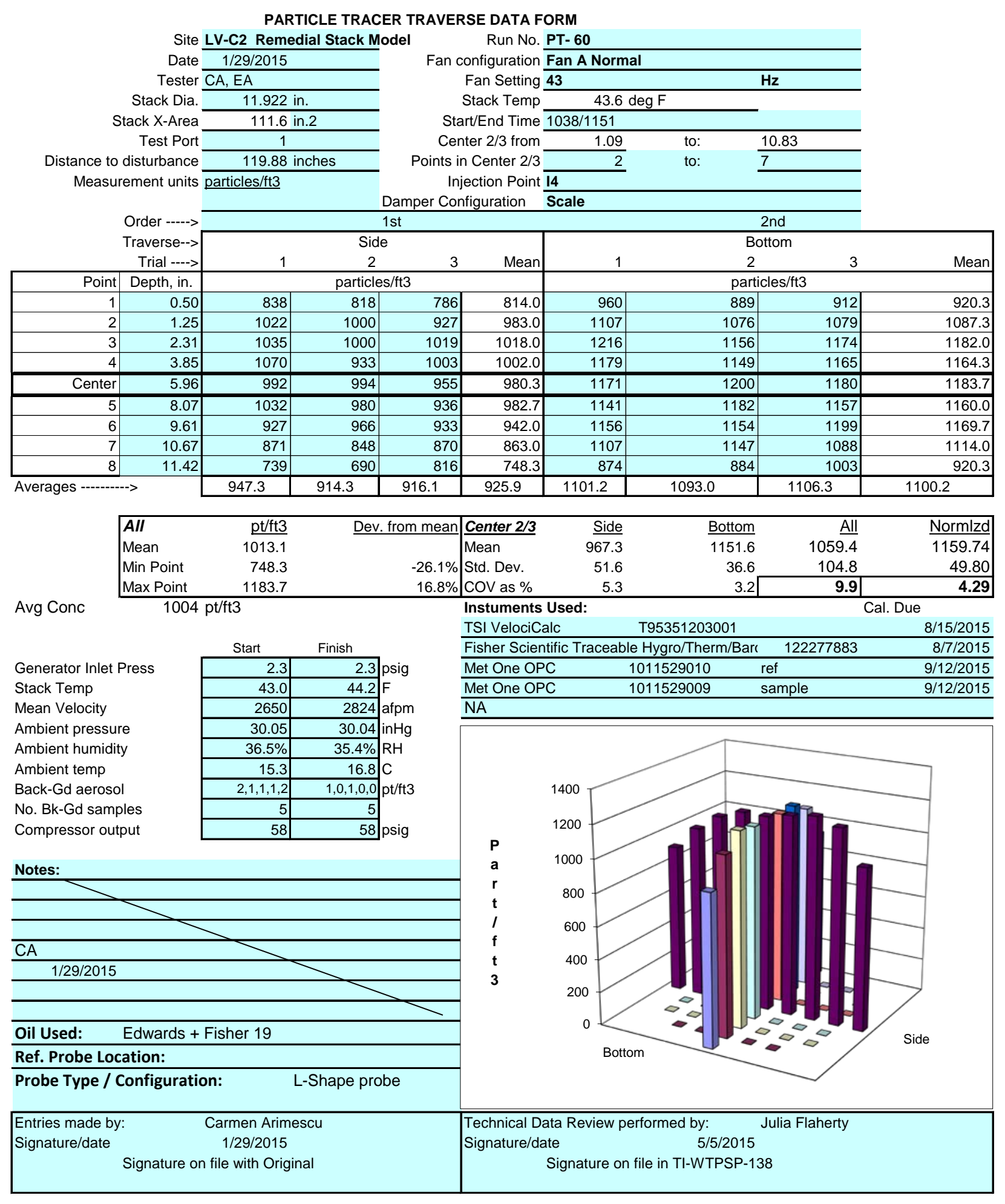


PARTICLE TRACER TRAVERSE DATA FORM

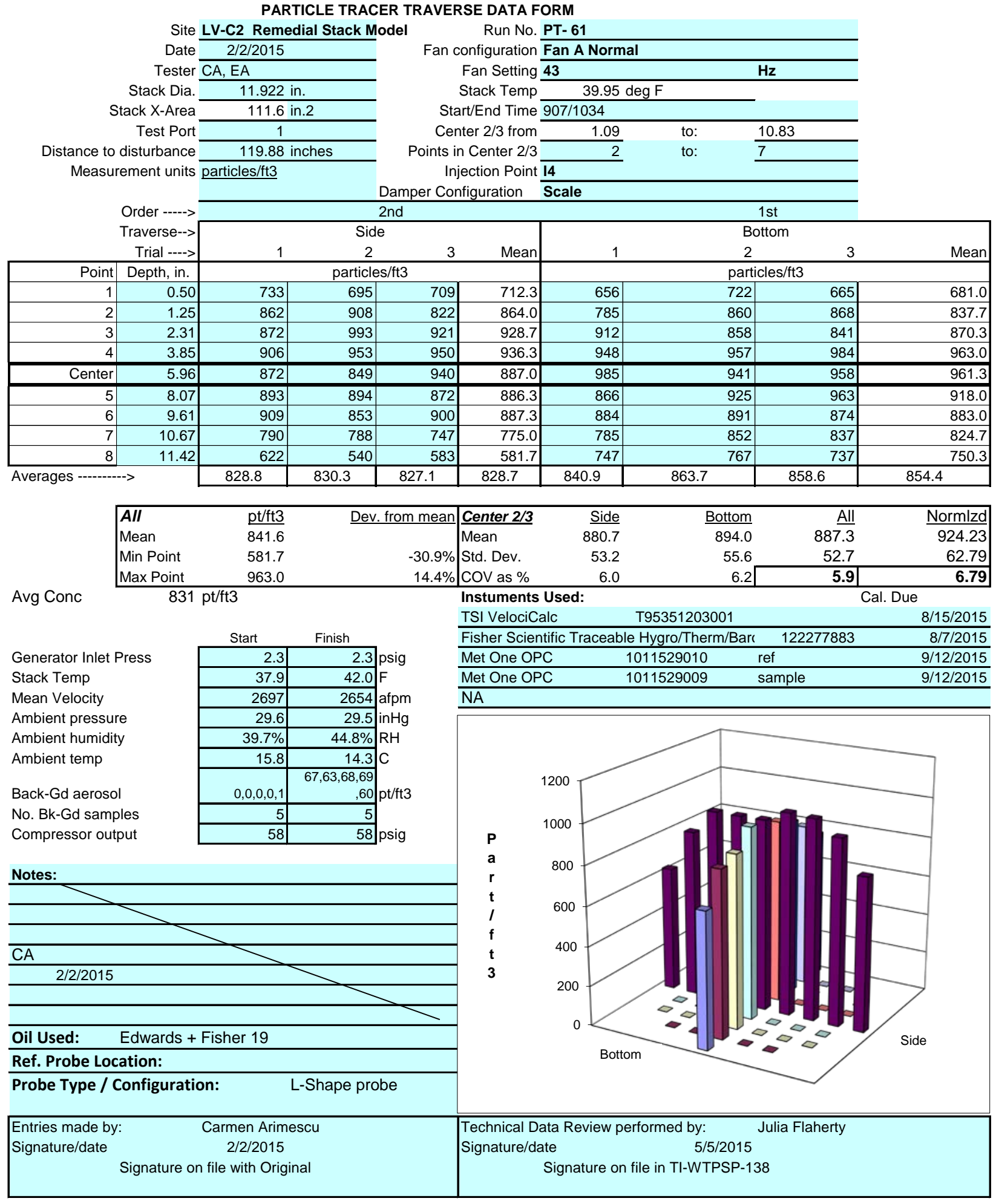




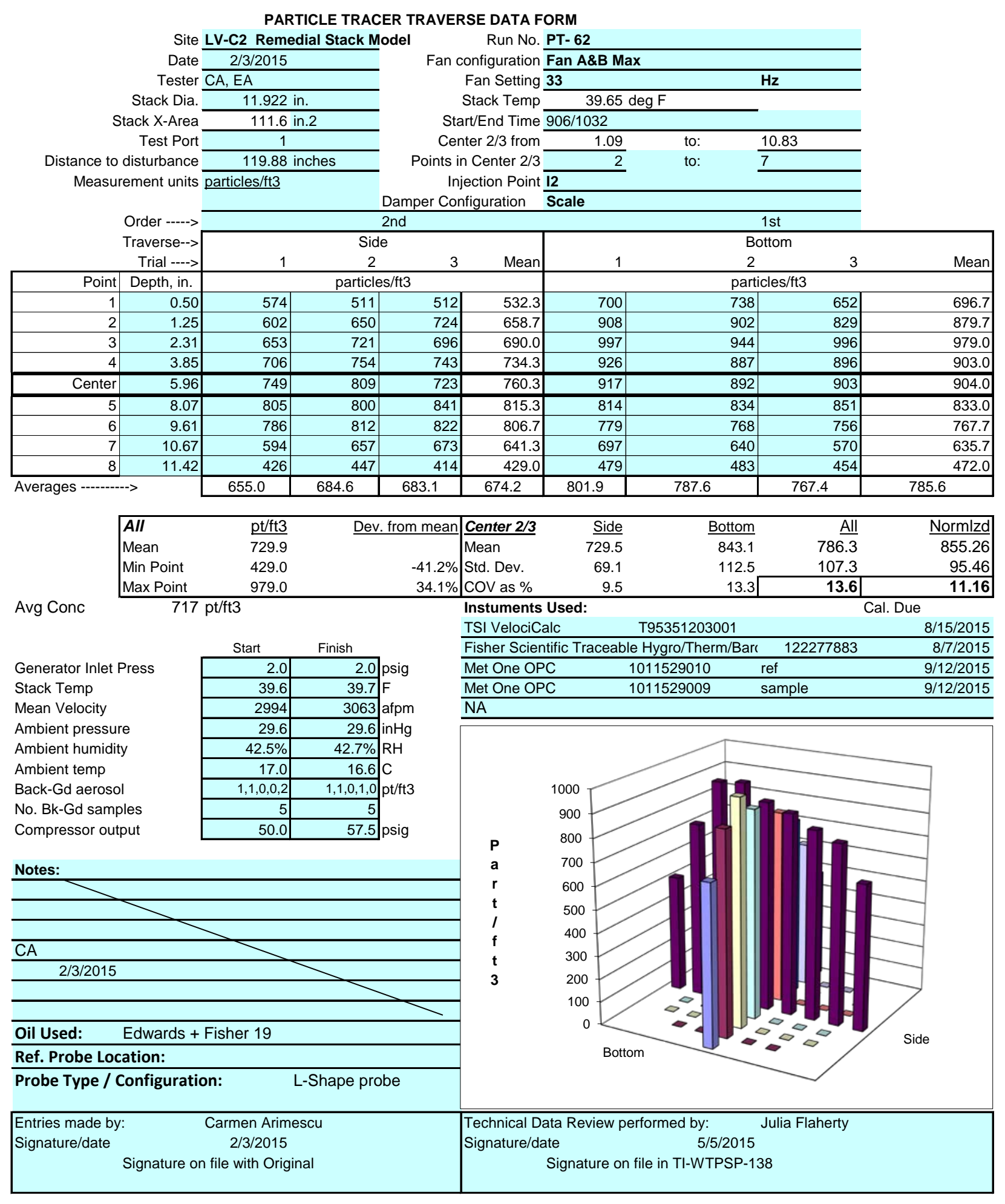




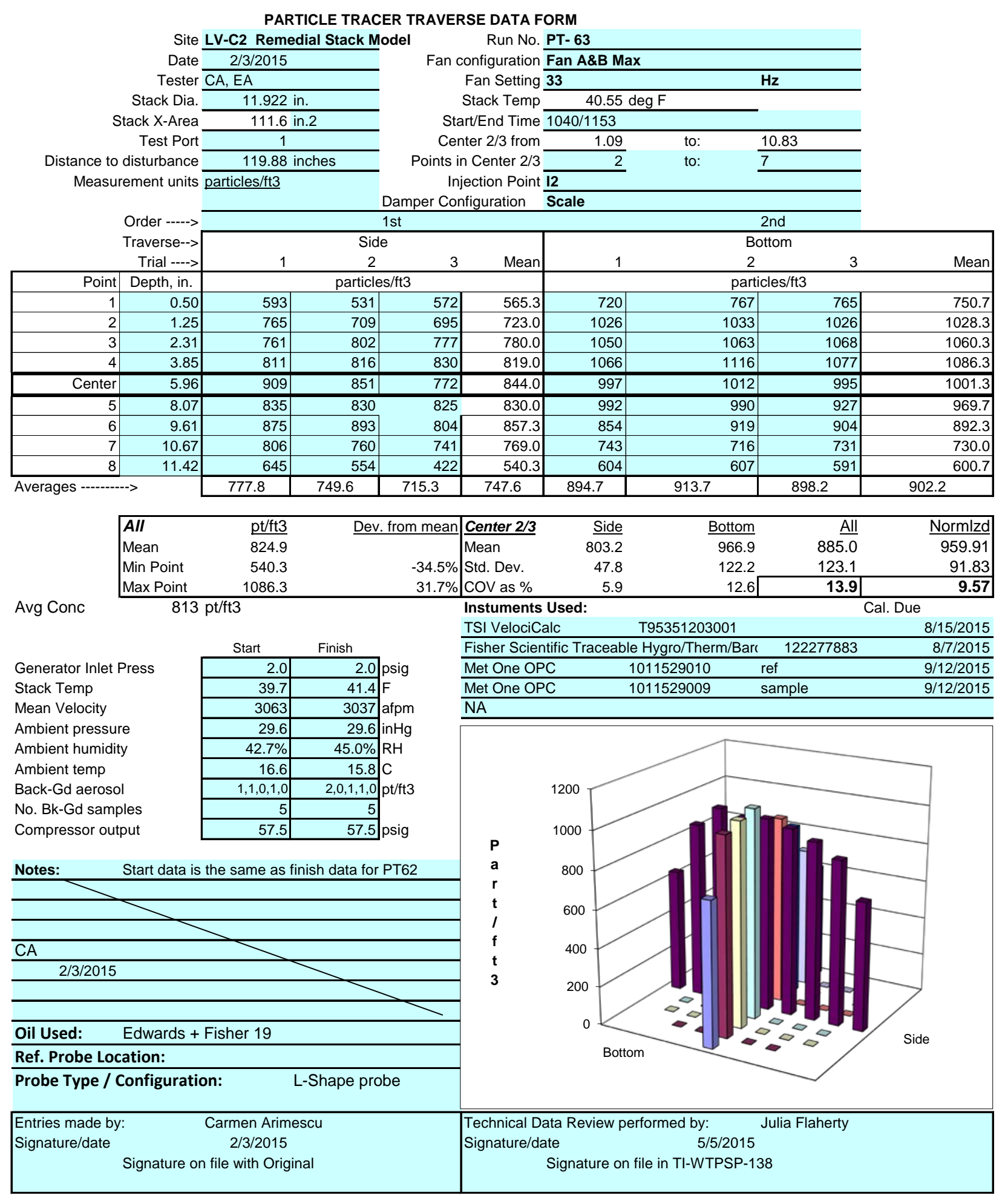




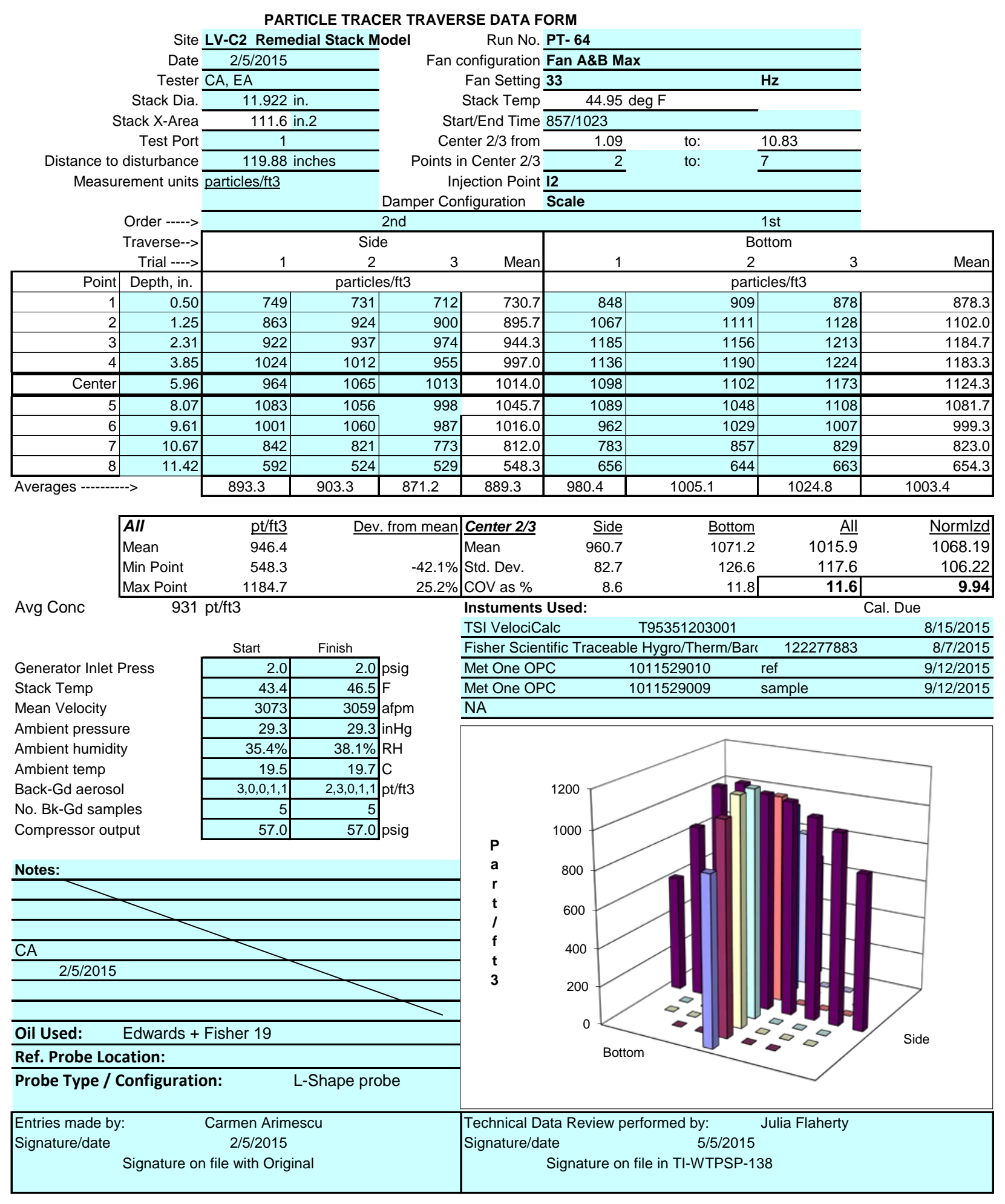


PARTICLE TRACER TRAVERSE DATA FORM

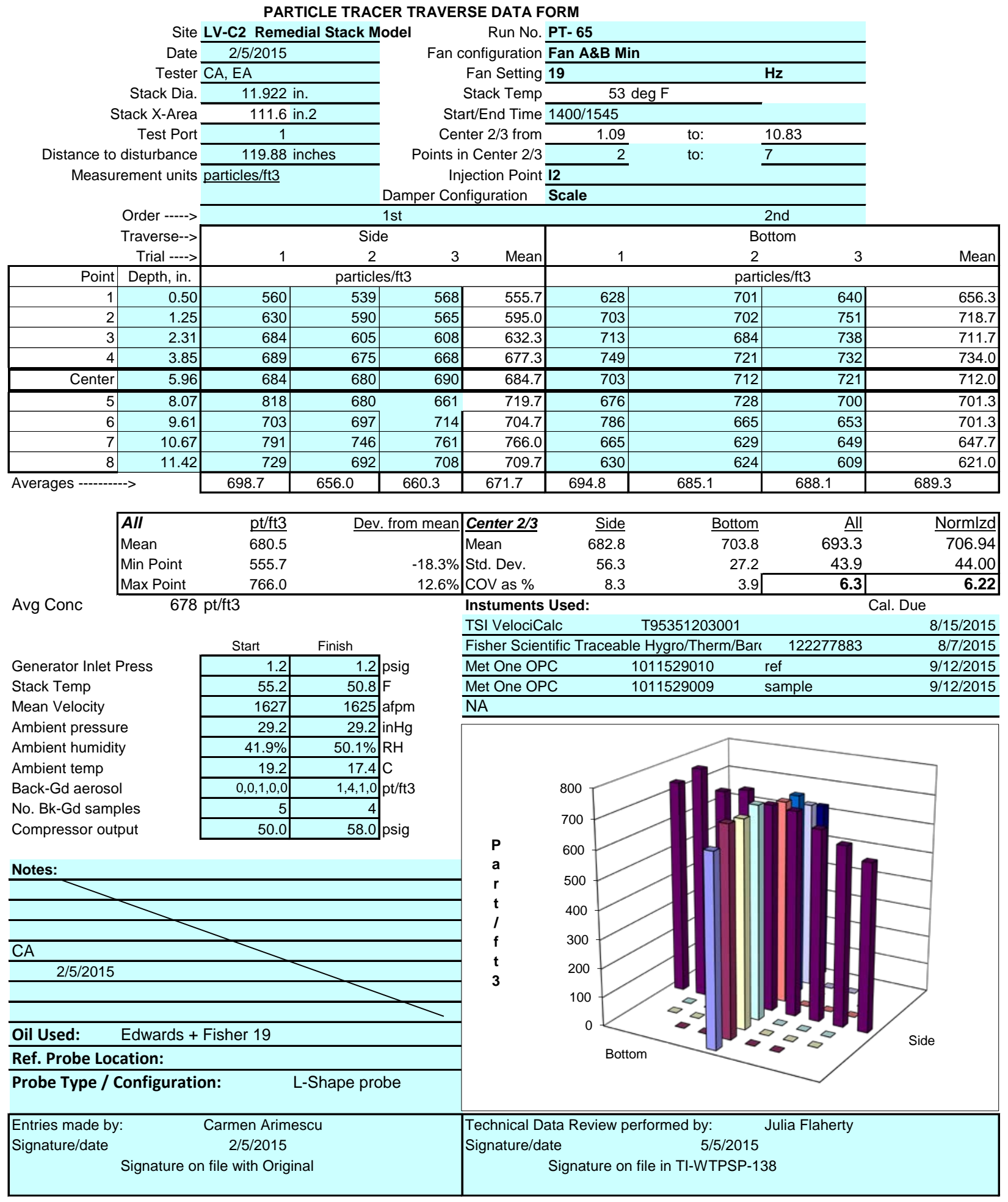


PARTICLE TRACER TRAVERSE DATA FORM

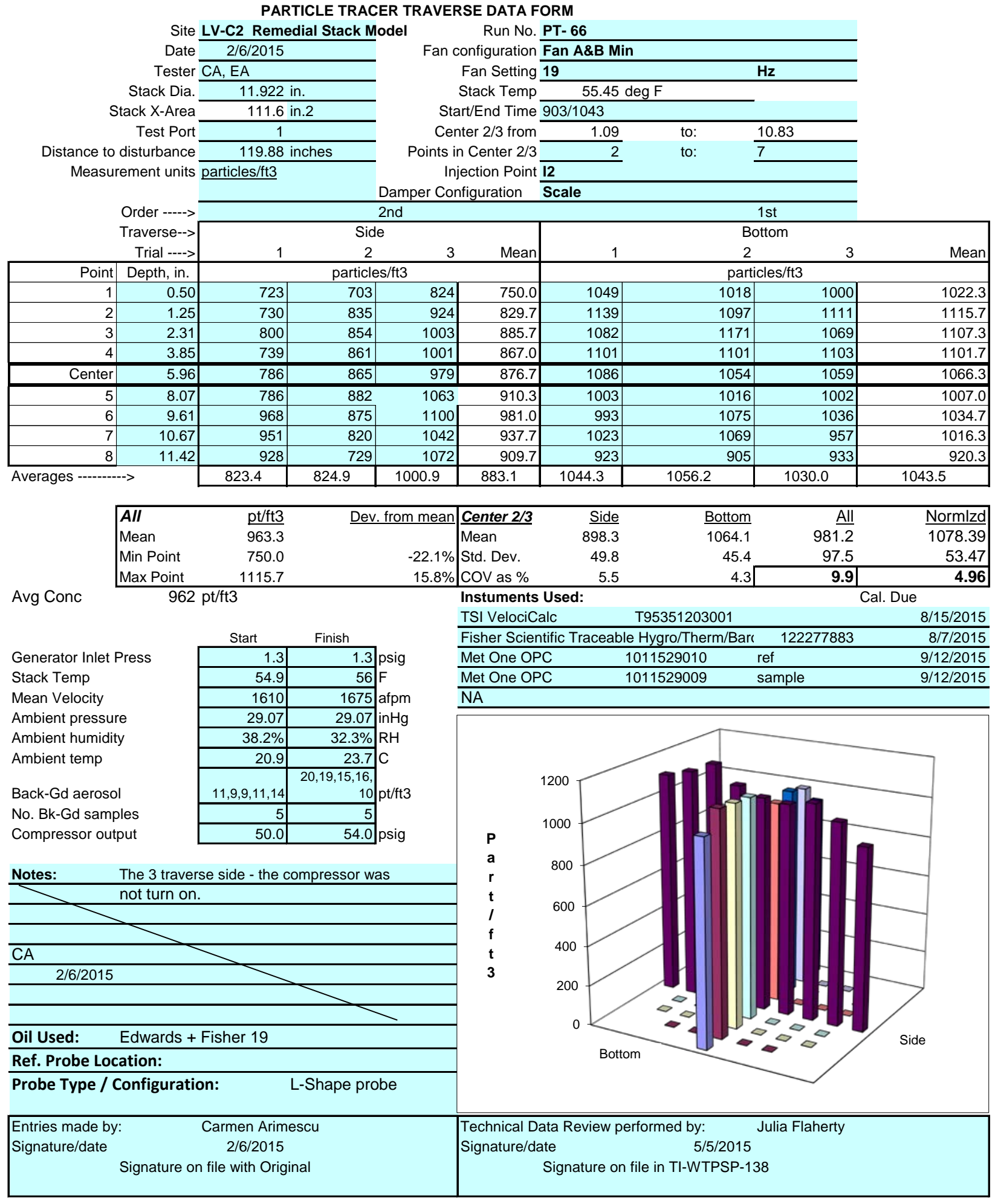


PARTICLE TRACER TRAVERSE DATA FORM

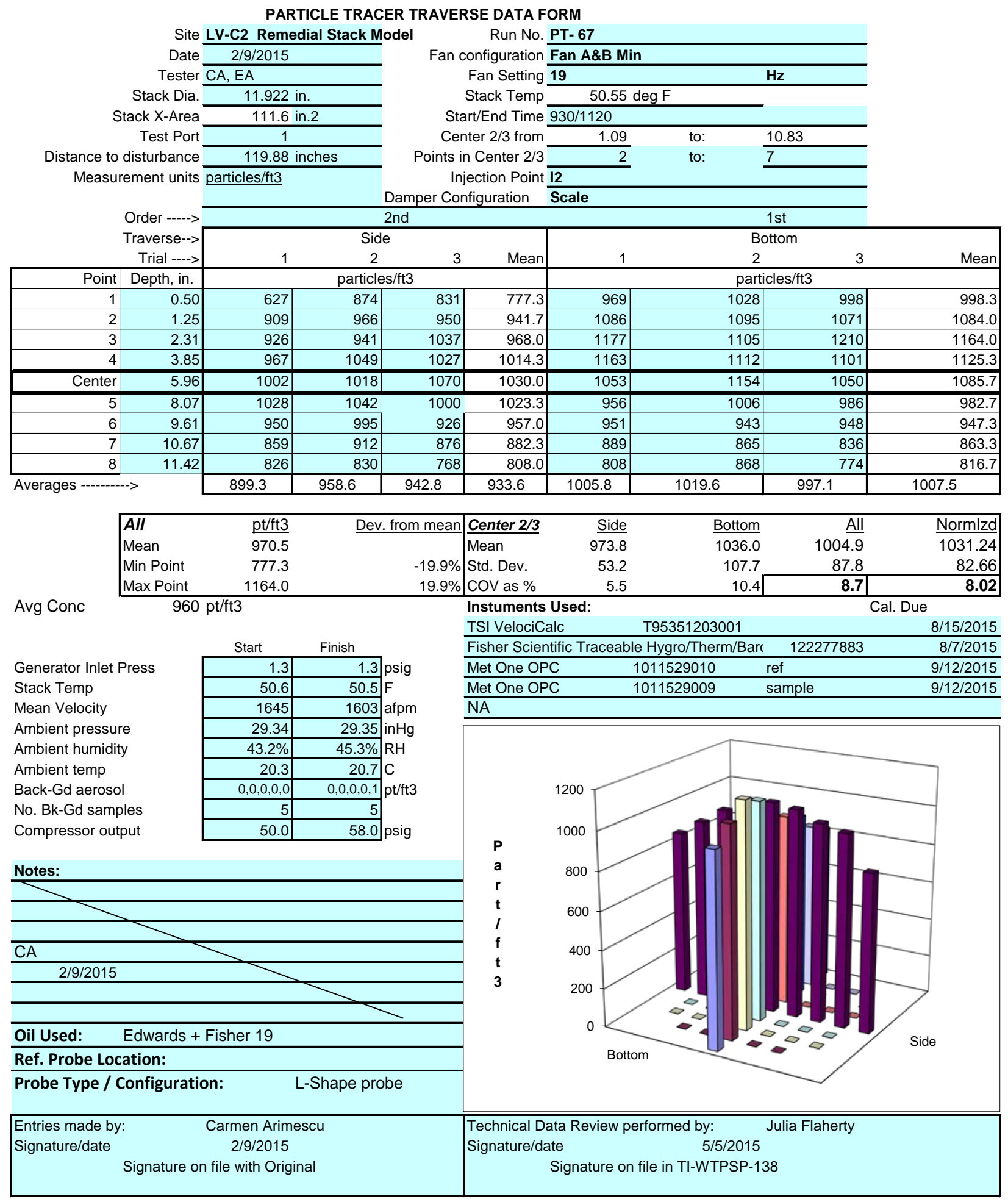




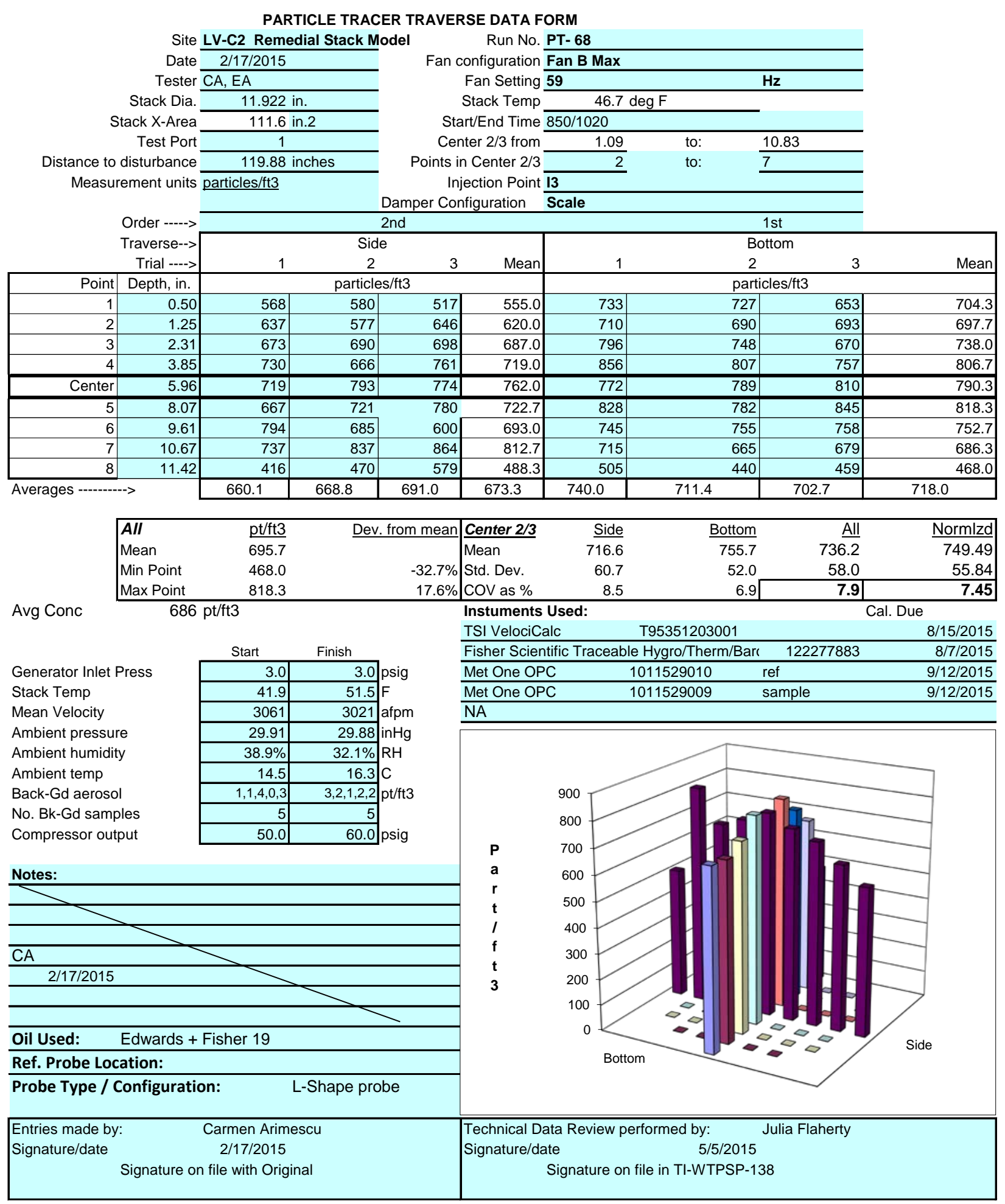




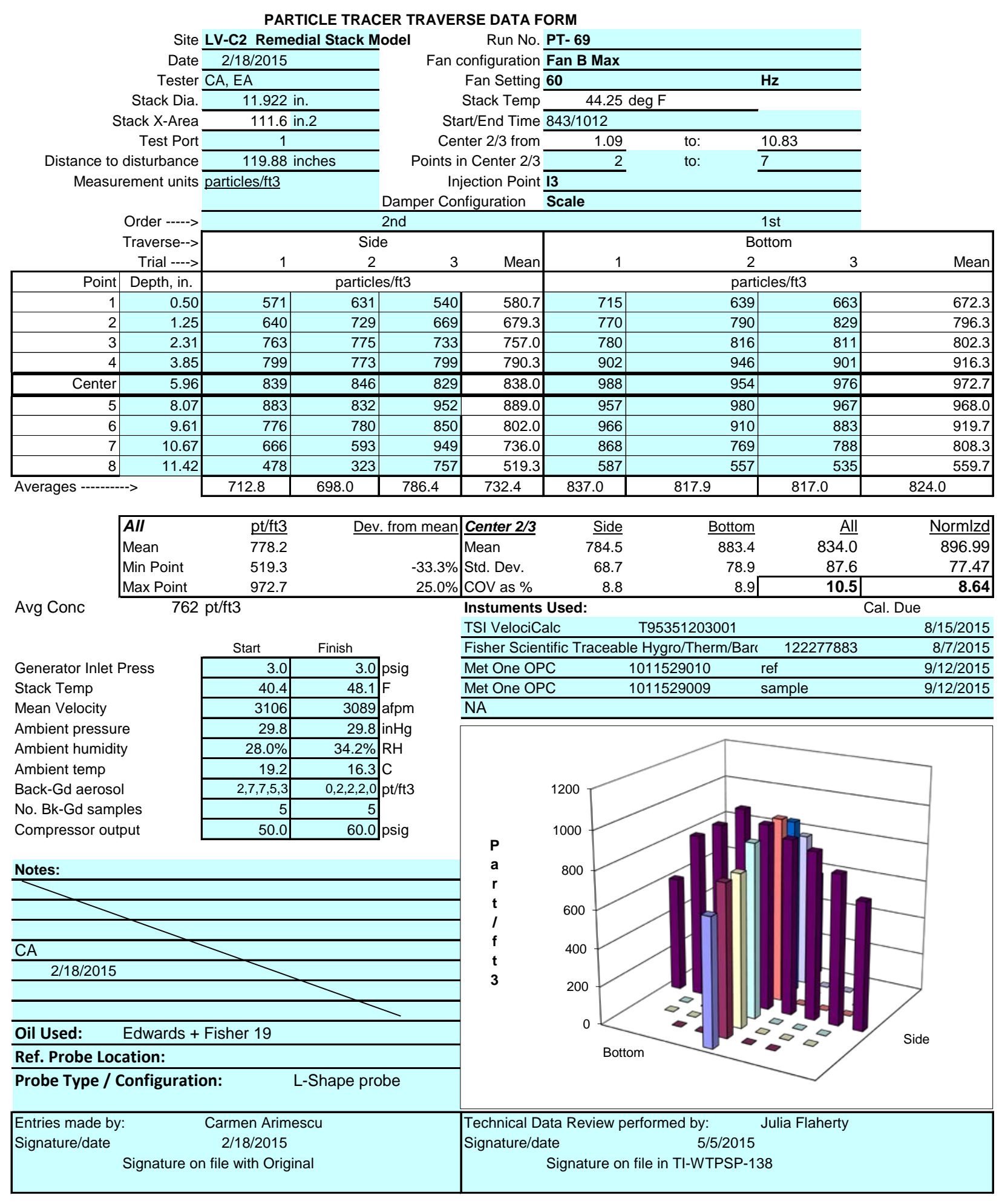




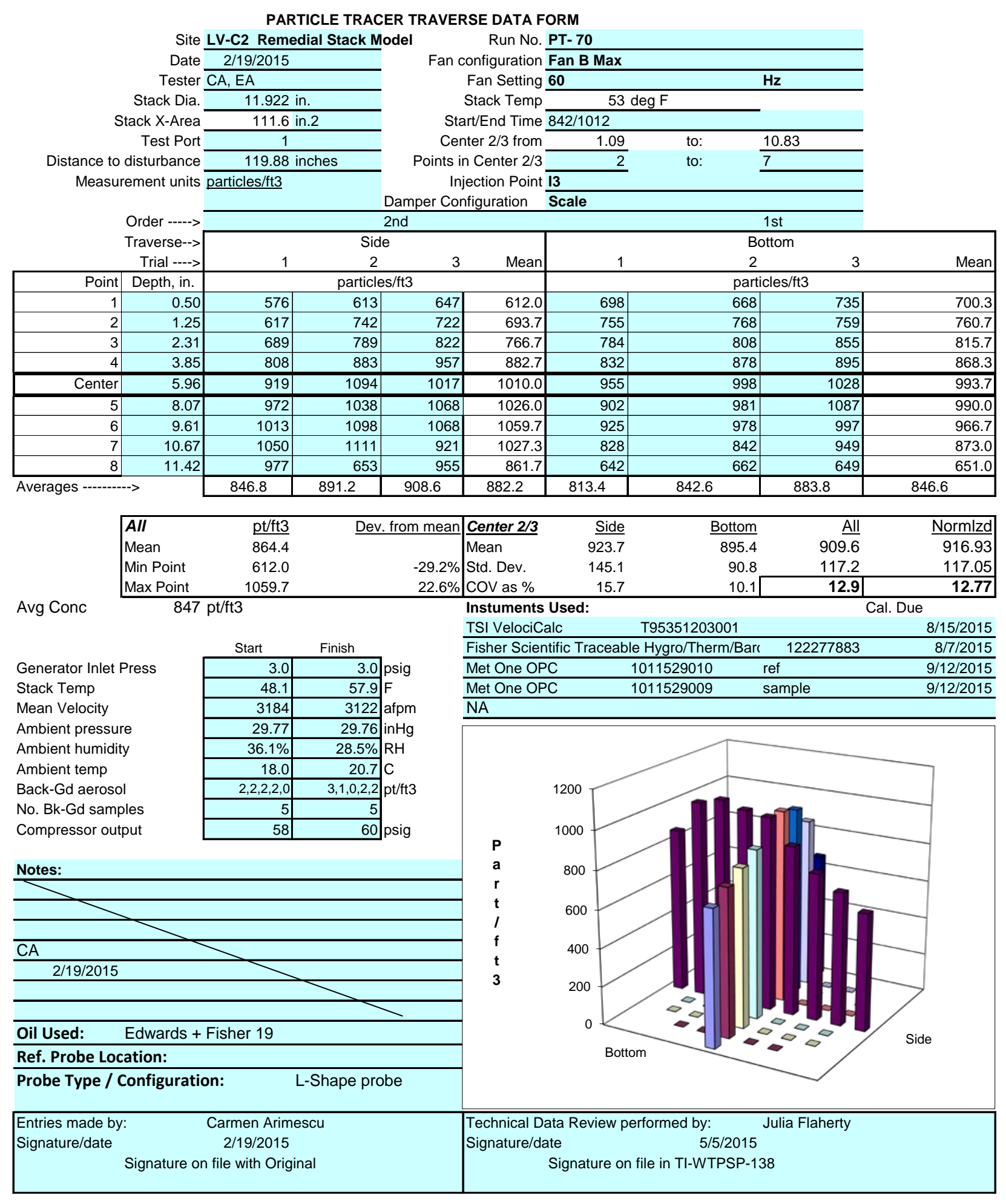




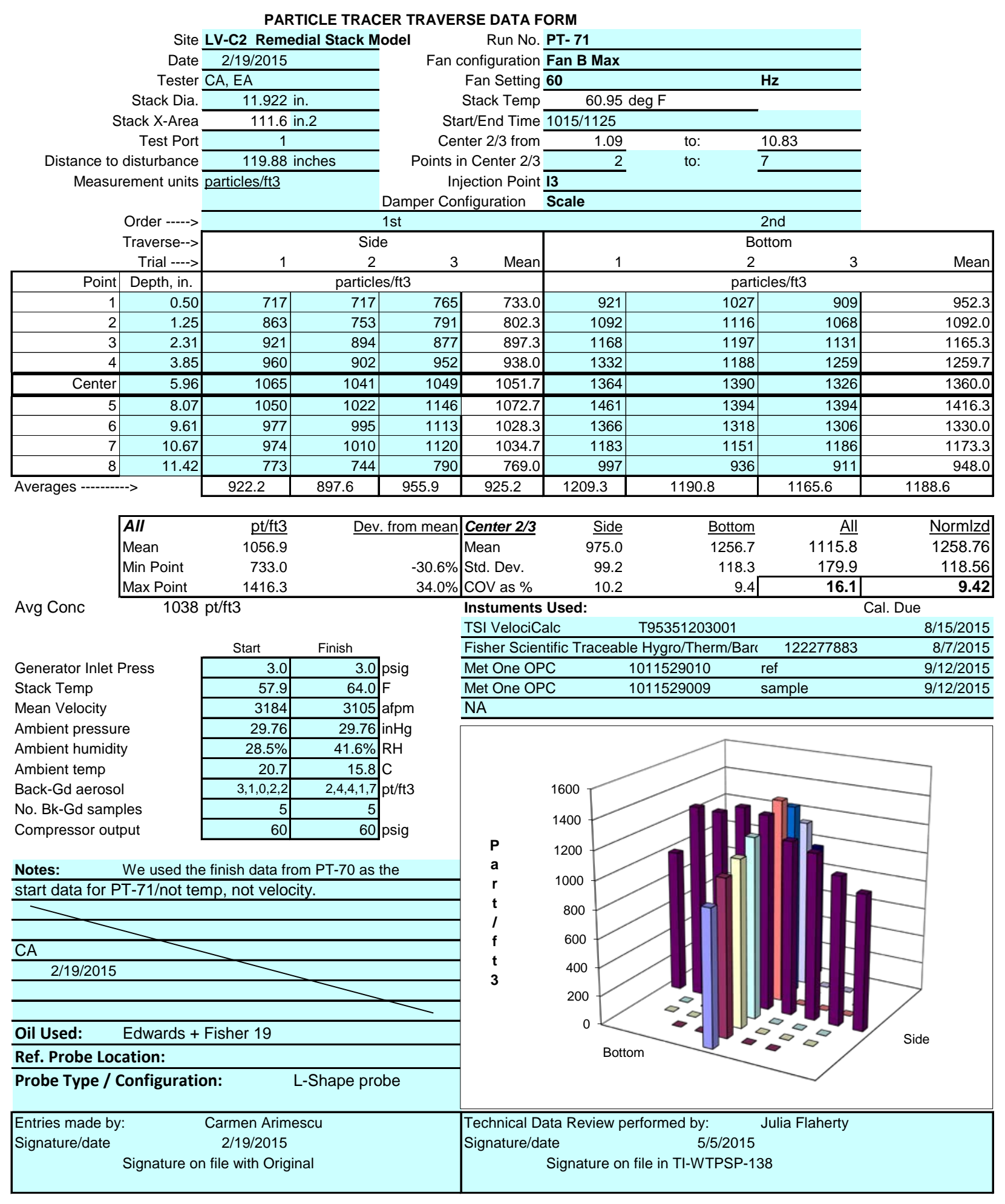



PNNL-24467

WTP-RPT-236, Rev. 0

\section{Distribution}

No. of

Copies

ONSITE*

3 Bechtel National, Inc.

FW Damerow

PA Douglass

WTP Docs
No. of

Copies

$7 \quad$ Pacific Northwest National Laboratory

EJ Antonio

K6-28

C Arimescu

K3-53

JM Barnett

JE Flaherty

JA Glissmeyer

RA Peterson

Information Release

Project File (1)
J2-25

K9-30

K3-54

P7 -22

K3-52

K3-52

*All distribution will be made electronically.

Distr. 1 


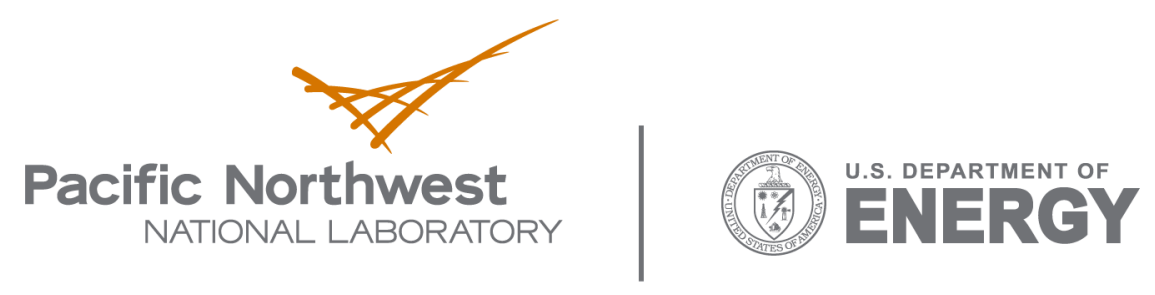

902 Battelle Boulevard

P.O. Box 999

Richland, WA 99352

1-888-375-PNNL (7665)

www.pnl.gov 